\title{
Characterizations of concretes with alkali-activated binder and correlating their properties from micro- to specimen level
}

Arkamitra Kar

West Virginia University

Follow this and additional works at: https://researchrepository.wvu.edu/etd

\section{Recommended Citation}

Kar, Arkamitra, "Characterizations of concretes with alkali-activated binder and correlating their properties from micro- to specimen level" (2013). Graduate Theses, Dissertations, and Problem Reports. 165.

https://researchrepository.wvu.edu/etd/165

This Dissertation is protected by copyright and/or related rights. It has been brought to you by the The Research Repository @ WVU with permission from the rights-holder(s). You are free to use this Dissertation in any way that is permitted by the copyright and related rights legislation that applies to your use. For other uses you must obtain permission from the rights-holder(s) directly, unless additional rights are indicated by a Creative Commons license in the record and/ or on the work itself. This Dissertation has been accepted for inclusion in WVU Graduate Theses, Dissertations, and Problem Reports collection by an authorized administrator of The Research Repository @ WVU.

For more information, please contact researchrepository@mail.wvu.edu. 
CHARACTERIZATIONS OF CONCRETES WITH ALKALI-

ACTIVATED BINDER AND CORRELATING THEIR

PROPERTIES FROM MICRO- TO SPECIMEN LEVEL

\author{
Arkamitra Kar \\ Dissertation submitted \\ to the Benjamin M. Statler College of Engineering and Mineral \\ Resources \\ at West Virginia University
}

in partial fulfillment of the requirements for the degree of

Doctor of Philosophy in

Civil Engineering

Udaya B. Halabe, Ph. D., Chair

Indrajit Ray, Ph.D.

Ben Dawson-Andoh, Ph. D.

Avinash Unnikrishnan, Ph.D.

John Zaniewski, Ph. D.

Roger Chen, Ph. D.

Department of Civil and Environmental Engineering

Morgantown, West Virginia

2013

Keywords: Alkali-activated binder, characterization, nondestructive evaluations, optimization, modeling 


\title{
ABSTRACT
}

\section{CHARACTERIZATIONS OF CONCRETES WITH ALKALI-ACTIVATED BINDER AND CORRELATING THEIR PROPERTIES FROM MICRO- TO SPECIMEN LEVEL}

\author{
Arkamitra Kar
}

The manufacturing of portland cement (PC), the main binder of concrete, generates large amount of $\mathrm{CO}_{2}$ (a greenhouse gas), cement kiln dust (solid waste), and consumes significant amount of heat energy. Alkali-activated binder ( $A A B$ ) is increasingly being considered as an environmentally friendly or green alternative to PC. The AAB is produced by alkali activation of aluminosilicate compounds as precursors with or without calcium ions in them in the temperature range of $60^{\circ} \mathrm{C}$ to $90^{\circ} \mathrm{C}$. Since most of the precursors are waste or by-products, the $A A B$ is regarded as sustainable and green construction material with great potential for its use in civil infrastructures. Previous researches on $A A B$ concretes primarily focused on development of materials using limited number of aluminosilicates or calcium-based compounds, and corresponding qualitative evaluations of their microstructural properties and strengths. However, no systematic studies have been conducted on characterizing a wide range of concretes with $A A B$ comprising various proportions of fly ash and slag cured at relatively lower temperature, followed by correlating their properties from micro to specimen level. This research conducts an extensive study to develop and evaluate 30 different $A A B$ mixtures containing fly ash and/or slag activated by sodium hydroxide and sodium silicate and correlates their properties from micro to specimen level using volume stoichiometry and optimizations. The test results showed that Ms modulus (precursor-activator ratio) of 1.4 provided the best compressive strengths when cured for 24 hours at temperatures of $23^{\circ} \mathrm{C}, 40^{\circ} \mathrm{C}$ and $60^{\circ} \mathrm{C}$. The compressive strength of $A A B$ concrete was in the range of 20.9 to $85.0 \mathrm{MPa}$ (3030 to $12,330 \mathrm{psi}$ ). Full replacement of fly ash by slag improved the strength by $126 \%$ on an average. Investigations of the $A A B$ microstructure through XRD, FTIR, SEM/EDS, and isothermal calorimetry showed sodium aluminosilicate hydrate gel to be the primary strength contributing phase. Reaction rates increased with the slag content due to formation of additional calcium silicate hydrate (CSH) in the $A A B$ paste matrix. Evaluation of specimen level properties such as compressive strength, splitting tensile strength, flexural strength, dynamic modulus of elasticity, and their correlations confirmed these findings. The results also show that the ultrasonic pulse velocity technique can be effectively used to estimate dynamic modulus of elasticity, compressive strength, and stress level of concrete with AAB for wide range of mixes, curing temperature, and ages. Finally, based on a detailed stoichiometric approach and optimization, the present study proposed a nonlinear regression model to correlate the microstructural characteristics with specimen level properties to predict compressive strength as a function of the ultrasonic pulse velocity and the volume fractions of sodium aluminosilicate gel $\left(v_{f, A A B}\right)$ and calcium silicate hydrate $\left(v_{f, C S H(S)}\right)$. Out of 18 possible model forms, the model with the least mean square error (0.053) was selected as the final prediction model that closely agreed with the experimental data with $\mathrm{R}^{2}$ value of 0.89 . The findings of this study can be highly beneficial for promoting the use of $A A B$ in concrete structures. 


\section{Acknowledgements}

I wish to express my sincere gratitude towards Dr. Udaya Halabe for agreeing to serve as the chairperson of my Ph.D. committee and for his relentless support during one of the toughest phases of my career. I would also like to thank him for letting me use his laboratory facilities, for providing me with his guidance on nondestructive testing techniques and also for helping me with other technical aspects related to my work. I am extremely grateful to him for providing me the opportunity to work with him.

My sincere appreciation and respect goes to Dr. Indrajit Ray, who provided me with the topic of research and invaluable guidance and supervision throughout my research work. His extensive knowledge in the field of concrete science and technology was of utmost help throughout my project. By virtue of his extreme encouragement, suggestions and advice he made my task a lot simpler. I was very fortunate to have worked with Dr. Ray on this topic.

I would like to express my sincere thanks to Dr. Avinash Unnikrishnan who agreed to be present as a member of my committee and provided me with lot of technical inputs, especially the statistical analysis and optimization. I would also like to thank him for all the moral support he provided to me and helped to overcome lot of difficulties.

I would also like to thank Dr. Ben Dawson-Andoh for agreeing to be part of my Ph. D. committee and sharing his expertise on characterizations and also allowing me to use his laboratory facilities.

I convey my sincere thanks to Dr. John Zaniewski for kindly agreeing to be on my Ph. D. committee. I would also like to thank Dr. Roger Chen for being on my Ph. D. committee.

I would also like to thank Dr. Julio F. Davalos for encouraging me to proceed with my doctoral studies.

I hugely appreciate the help of Dr. Kolin Brown and Dr. Marcela Redigolo of the WV SRF. I would also like to thank my friends Saurabh Chaudhuri, Pallavi Anipindi, Savan Suri, Sai Praneeth Gunturu and Siddhita Aparaj for their immense assistance with my experiments. I would like to thank Dr. Mohinder Seehra and his students, Vivek Singh and Sai Kishore for helping me with the XRD studies. No word of gratitude is enough for Sriparna Ghosh because of her relentless support in the concrete lab as well as my personal life.

I gratefully acknowledge WV-EPSCOR/WVHEPC and West Virginia Department of Transportation - Division of Highways for their financial support. I also acknowledge Arrow Concrete Company, PQ Corporation and ASCE for generously supporting the present work.

I would especially like to thank Mohna Banerjee, Soumya Gujjar, John Wattick, Manish Roy, Subhadeep Ghosh, and Kedar V Panday for their sustained moral support throughout my stay in WVU. I would like to thank Anasua Guha Ray, Probal Som, and Debraj Goswami for all their support

I would like to acknowledge the contributions of my mother and grandmother, without whose support this work could not have been accomplished. 


\section{TABLE OF CONTENTS}

Pg. No.

Abstract

Acknowledgement

TABLE OF CONTENTS

iv

List of Tables

ix

List of Figures

xii

\section{CHAPTER 1 INTRODUCTION}

1.1 Background 1

1.2 Motivation 2

1.3 Goals 3

1.4 Research Objectives 4

1.4.1 Characterization at microstructural level 4

1.4.2 Characterization at Specimen Level: Both Destructive and Nondestructive Testing 5

1.4.3 Statistical tools to correlate microlevel to specimen level properties

\section{CHAPTER 2 LITERATURE REVIEW 6}

2.1 History of Concrete with Alkali Activated Binders 6

2.2 Terminology and Chemistry of Geopolymer (or AAB) 8

2.3 Applications of Geopolymers (or AAB) 13

2.4 Current Trend of Research on Geopolymer (or AAB) 16

2.5 Fly Ash Based Geopolymer (or AAB) - A Brief Overview 18

2.5.1 Microstructure of fly ash AAB 19

2.5.1.1 General characterization of $A A B$ gels $\quad 19$

2.5.1.2 Role of silicon in N-A-S-H gel structure 21

2.5.1.3 Role of aluminum in $N$ - $A$-S- $H$ gel 21

2.5.1.4 Role of sodium in $N-A-S-H$ gel structure 22 
2.6 Microanalysis Techniques $\quad 22$

2.6.1 X-ray diffraction (XRD) 22

2.6.2 XRD of fly ash-based AAB 23

2.6.3 SEM/EDS 25

2.6.3.1 SEM results from previous research 26

2.6.3.2 EDS results from previous research 28

2.7 Fourier Transform Infra-Red (FTIR) spectroscopy 29

2.8 Nondestructive Characterization of Cement Using Ultrasound Techniques 33

2.9 Correlation between Microscale and Mechanical Characteristics at Specimen Level Using Nondestructive Characterizations 35

2.10 Brief Overview of $\mathrm{R} \quad 37$

2.11 Summary from Literature Review and Limitations of Existing Research 38

\section{CHAPTER 3 MATERIALS AND MIX PROPORTIONS 40}

3.1 Materials 40

3.1.1 Coarse aggregate $\quad 40$

3.1.2 Fine aggregate 41

3.1.3 Fly ash 42

3.1.4 Slag 42

3.1.5 Sodium hydroxide $[\mathrm{NaOH}]$

3.1.6 Sodium silicate $\left[\mathrm{Na}_{2} \mathrm{O} .2 \mathrm{SiO}_{2}\right]$

3.1.7 Mixing water 44

3.1.8 High range water reducing admixture (HRWRA) 44

3.2 Selection Criteria for Mix Proportions 44

3.3 Mixing Procedure 51

3.3.1 Preparation of dry mix 52

3.3.2 Preparation of liquid mix 53

3.3.3 Combination of solid and liquid mix 53

3.4 Curing Procedure $\quad 54$ 
3.5 Sample Calculations for the Mix Design

3.6 Calculation for Additional Water to Achieve

Desired Workability

56

3.7 Calculation for Effective Molarity of $\mathrm{NaOH}$ in the Mix

57

\section{CHAPTER 4 CHARACTERIZATION OF HARDENED ALKALI ACTIVATED BINDER PASTE AT MICROSTRUCTURAL LEVEL}

$4.1 \times R D$

4.2 FTIR Results 61

4.3 SEM/EDS 65

4.3.1 Polishing/Sample preparation for SEM/EDS 66

4.3.2 Sputtering the samples before SEM/EDS 68

4.3.3 SEM results 69

4.4 EDS Results 73

4.5 Analysis of Microscale Test Results Using Volume Stoichiometry and Optimization 79

4.5.1 Chemical reactions during alkali activation of fly ash 80

4.5.2 Reaction mechanism of alkali activation of slag 81

4.6 Estimation of Quantities of the Products of

Alkali Activation of Fly Ash and Hydration of Slag 83

4.6.1 Estimation of polymer product due to alkali activation of fly ash

4.6.2 Estimation of polymer product and $\mathrm{CSH}(\mathrm{S})$ for P\% fly ash combined with Q\% slag

4.7 Degree of Reaction at Different Ages 86

4.8 Isothermal Calorimetry 90 
4.9 Optimization Using GAMS

4.10 Comparison of Experimental and Predicted Data for Reacted AAB Paste Product and $\mathrm{CSH}(\mathrm{S})$ Using Results from Optimization

4.11 Variation of Reacted AAB Paste Product and $\mathrm{CSH}(\mathrm{S})$ and the Total Hydrated Paste Volumes with Time for Different Combinations of Fly Ash and Slag at Different Temperatures

\section{CHAPTER 5 PROPERTIES OF CONCRETE WITH} ALKALI ACTIVATED BINDER AT SPECIMEN LEVEL: DESTRUCTIVE TESTS

5.1 Test for Compressive Strength 103

5.1.1 Effect of age on strength of concrete 109

5.1.2 Effect of slag addition on compressive strength 113 of $A A B$ concrete

5.3 Effect of Slag Addition on Splitting Tensile Strength 120

5.4 Relation between Splitting Tensile Strength and Compressive Strength

5.5 Modulus of Rupture $\quad 122$

5.6 Effect of Slag Addition on Flexural Strength 126

5.7 Relation between Flexural Strength and 128

CHAPTER 6 PROPERTIES OF CONCRETE WITH ALKALI ACTIVATED BINDER AT SPECIMEN LEVEL: NONDESTRUCTIVE CHARACTERIZATIONS

6.1 Ultrasonic Pulse Velocity Measurements

6.2 Dynamic Modulus of Elasticity 
6.4 Variation of Compressive Strength with UPV

6.5 Effect of Gradually Increasing Applied

Compressive Stress on UPV

6.6 Density of Concrete with AAB 167

6.7 Comparison between Concrete with AAB and PC Concrete 167

\section{CHAPTER 7 CORRELATION BETWEEN} MICROSTRUCTURAL PROPERTIES AND SPECIMEN LEVEL PROPERTIES OF CONCRETE WITH ALKALI ACTIVATED BINDER

7.1 Basis of Model Development

7.2 Formulation of Proposed Regression Model 171

7.3 Selection of Suitable Model 173

7.4 Significance of Independent Variables $\quad 174$

7.5 Test for Accuracy of the Proposed Model 176

\section{CHAPTER 8 SUMMARY AND CONCLUSIONS}

8.1 Conclusions from the Present Study

8.1.1 Characterization of alkali activated concrete at microstructural level

8.1.2 Properties of alkali activated concrete at specimen level: destructive tests

8.1.3 Properties of alkali activated concrete at specimen level: nondestructive characterizations

8.1.4 Correlation between microstructural properties and specimen level properties of alkali activated concrete

8.2 Flow Chart for Compressive Strength Prediction of Concrete with $A A B$ and Summary of Parameters and Number of Samples/Specimens for Various Experiments in the Study 
8.3 Practical Applications of the Present Study 185

8.4 Recommendations for Future Work 186

$\begin{array}{ll}\text { References } & 188\end{array}$

$\begin{array}{ll}\text { APPENDIX } & 201\end{array}$ 


\section{List of Tables}

Pg. No.

Table 2.1 Applications of Geopolymeric Materials Based on Si:Al Atomic

Ratio (Wallah and Rangan, 2006)

Table 2.2 IR Characteristic Bands of AAB Chemical units/bonds

30

Table 2.3 IR Characteristic Bands of Chemical Units/bonds in Portland Cement Concrete Surface Treated by Chemical Reagents

(Chollet and Horgnies, 2011)

Table 3.1 Properties of Coarse Aggregates

Table 3.2 Sieve Analysis Result

Table 3.3 Properties of Fine Aggregate

Table 3.4a Sieve Analysis of Sand

Table 3.4b Mineral Composition of Sand

Table 3.5 Basic Properties of Fly ash and Slag

Table 3.6 3-day Compressive Strength Test Results for Initial FA 100 Mixtures

Table 3.7 7-day Compressive Strength Test Results for Initial FA 100 Mixtures

Table 3.8 28-day Compressive Strength Test Results for Initial FA 100 Mixtures

Table 3.9 3-day Compressive Strength Test Results for Initial AAB Hardened Pastes with FA and Different Percentages of SG

Table 3.10 7-day Compressive Strength Test Results for Initial AAB Hardened Pastes with FA and Different Percentages of SG 
Table 3.12 Final Concrete Mix Proportions for Alkali-activated Fly ash and/or Slag (Ms modulus $=1.4$ )

Table 4.1 Characteristic Si-O-Si peak (Shift w.r.t. $1043 \mathrm{~cm}^{-1}$ ) for the Different AAB Mixtures at 28-day Age

Table 4.3 Comparison between Fly ash Degrees of Reaction from Present Study and External Data

Table 4.4 Degree of Reaction (Average Value and Range) of Alkali-activated Slag at Different Temperatures

Table 4.5 Comparison between Predicted and Experimental Values of Volume Fraction of $A A B$

Table 4.6 Comparison between Predicted and Experimental Values of Volume Fraction of $\mathrm{CSH}(\mathrm{S})$

Table 4.7 Volume Fractions of Reacted Phases of AAB $\left(v_{f, A A B}+v_{f, C S H(S)}\right)$ at Different Ages for all Mixture Proportions Cured at Different Temperatures

Table 5.1 Compressive Strength Results at Different Ages for all AAB Cylinders Cured at Different Temperatures

Table 5.2 Ratios of 7-day and 90-day Compressive Strengths of AAB w.r.t their 28-day Compressive Strength Values for all Mixes at Different Curing Temperatures

Table 5.3 Splitting Tensile Strength Results at Different Ages for all AAB Cylinders Cured at Different Temperatures

Table 5.4 Flexural Strength Results at 28 Days for all AAB Cylinders Cured at Different Temperatures 


\section{List of Figures}

Fig. 2.1 Structure of polysialates (Wallah and Rangan 2006) 9

Fig. 2.2 Conceptual modeling of polymerization (Provis et al., 2005) 12

Fig. 2.3 Structural model proposed for CSH gel in PC (Taylor, 1990) 19

Fig. 2.4 Two-dimensional representation of the structural model proposed for N-A-S-H gel (Provis and Van Deventer 2009 based on data from Criado 2007)

Fig. 2.5 XRD diffractograms of geopolymers derived from flyash and solid silicate material: GP - geothermal silica, LC - low carbon rice hull ash, HC - high carbon rice hull ash. Reference samples: LIQ - silicate solution; AA - alkali activation only. GFA - unreacted flyash; S - hydroxy sodalite; Q - quartz; M - Mullite (Kamhangrittirong et al., 2007).

Fig. 2.6 XRD Analysis of geopolymer concrete (GPC) and Portland Cement (OPC) [Kupwade-Patil and Allouche (2011)]

Fig. 2.7 SEM images: (a) original fly ash; (b) fly ash activated with $8 \mathrm{M} \mathrm{NaOH}$ for 20 hours at $85^{\circ} \mathrm{C}$ (showing reaction details for small spheres); (c) fly ash activated with sodium silicate (Provis and Van Deventer 2009 with data from Fernandez-Jimenez 2005d).

Fig. 2.8 SEM micrographs of the hardened alkali activated fly ash samples (Muzek et al. 2012)

Fig. 2.9 SEM micrographs and EDS analysis of the hardened alkali activated fly ash samples (Muzek et al. 2012)

Fig. 2.10 A multiple reflection ATR system

(http://www.utsc.utoronto.ca/ traceslab/ATR_FTIR.pdf)

Fig. 2.11 Experimental setup for ultrasonic measurements (Smith et al. 2002).

Fig. 2.12 (a) Mechanical strength versus $Q^{4}(2 A I)+Q^{4}(3 A I) / Q^{4}(4 A l)$ ratios deduced by NMR spectroscopy for three fly ashes with different reactive alumina content $(P \approx 18.0 \% ; L \approx 22.5 \% ; M \approx 12.6 \%$ ); (b) Schematic description of mechanical properties evolution with reaction time as function of chemical composition of gel (Fernandez-Jimenez and Palomo, 2003).

Fig. 3.1 Mixing the aggregates and the precursor in dry state

Fig. 3.2 Alkaline activating agents: (a) Sodium hydroxide powder and (b) Sodium silicate solution

Fig. 4.1 Typical XRD pattern of 28-day FA 100 AAB specimen at curing temperature of $40^{\circ} \mathrm{C}$. ( $\mathrm{S}=$ hydroxy sodalite, $\mathrm{M}=$ Mullite, $\mathrm{Q}=\mathrm{Quartz}, \mathrm{An}=$ Analcime) 
Fig. 4.2 XRD results for six different mixture proportions and each sample being tested at 28 -day age - (1) FA 100 cured at $23^{\circ} \mathrm{C}$, (2) FA 100 cured at $40^{\circ} \mathrm{C}$, (3) FA 100 cured at $60^{\circ} \mathrm{C}$, (4) FA 50 SG 50 cured at $40^{\circ} \mathrm{C}$, (v) SG 100 cured at $40^{\circ} \mathrm{C}$, and (6) FA 100 preblended with $\mathrm{NaOH}$ for 7 days and cured at $40^{\circ} \mathrm{C}$. ( $\mathrm{S}=$ hydroxy sodalite, $\mathrm{M}=$ Mullite, $\mathrm{Q}=\mathrm{Quartz}, \mathrm{An}=$ Analcime, $\mathrm{CSH}=$ Calcium silicate hydrate due to slag, $\mathrm{CSH}(\mathrm{S})$ ).

Fig. 4.3 (a) Placing a powder sample onto the Universal diamond ATR top-plate; (b) Applying pressure to a solid sample on the Universal diamond ATR top-plate.

Fig. 4.4 Comparing FTIR absorbance spectra of fly ash powder and $100 \%$ fly ash based $A A B$.

Fig. 4.5 Comparing FTIR absorbance spectra of FA 100, FA 50 SG 50, and SG 100 AAB samples.

Fig. 4.6 Field Emission Scanning Electron Microscope (FE-SEM), JSM-7600F (accompanied by an EDS analyzer), supplied by JEOL Limited

Fig. 4.7 Denton Vacuum Desk V Sputtering equipment

Fig. 4.8 Example SEM images of 28-days old FA 100 AAB paste specimens at two different magnifications - 2500x and 5000x: (a) and (b) $23^{\circ} \mathrm{C}$, (c) and (d) $40^{\circ} \mathrm{C}$, and (e) and (f) $60^{\circ} \mathrm{C}$. Five different points were scanned at nine different locations on each specimen at each magnification to obtain a total of 90 data points in each case.

Fig. 4.9 Example SEM images of 28-days old $A A B$ paste specimens cured at $40^{\circ} \mathrm{C}$ and at two different magnifications - 2500x and 5000x: (a) and (b) FA 85 SG 15; (c) and (d) FA 50 SG 50, and (e) and (f) SG 100. Five different points were scanned at nine different locations on each specimen at each magnification to obtain a total of 90 data points in each case.

Fig. 4.10 (a) and (b) Example SEM images of 28-days old paste of FA 100 p30 AAB mix cured at $60^{\circ} \mathrm{C}$ specimens at two different magnifications - 2500x and 5000x. Five different points were scanned at nine different locations on each specimen at each magnification to obtain a total of 90 data points in each case.

Fig. 4.11 Example EDS images of 28-days old AAB paste specimens cured at $40^{\circ} \mathrm{C}$ : (a) FA 100 and (b) FA 50 SG 50. Five different points were scanned at nine different locations on each specimen at each of two different magnifications to obtain a total of 90 data points in each case.

Fig. 4.12 3D plots of $\mathrm{Na} / \mathrm{Al}, \mathrm{Si} / \mathrm{Al}$ and $\mathrm{Ca} / \mathrm{Si}$ atomic ratios for a typical 7-day old FA $100 \mathrm{AAB}$ paste at three different curing temperatures: (a) $23^{\circ} \mathrm{C}$, (b) $40^{\circ} \mathrm{C}$, and (c) $60^{\circ} \mathrm{C}$.

Fig. 4.13 Typical 3D plots of $\mathrm{Na} / \mathrm{Al}, \mathrm{Si} / \mathrm{Al}$ and $\mathrm{Ca} / \mathrm{Si}$ atomic ratios for (a) FA 50 SG 50 and (b) SG 100 AAB pastes at curing temperature of $23^{\circ} \mathrm{C}$. 
Fig. 4.14 Correlation between values of degree of reaction of fly ash

from present study and those from existing literature.

Fig. 4.15 Degree of slag hydration at different curing

temperatures (Fernandez-Jimenez and Puertas, 1997).

90

Fig. 4.16 Test setup for the isothermal calorimetry test using

the TAM-Air instrument.

91

Fig. 4.17 Example of isotherms for FA 100 at different curing temperatures

92

Fig. 4.18 Correlation between predicted and experimental values of $v_{f, A A B}$

96

Fig. 4.19 Correlation between predicted and experimental values of $v_{f, C S H(S)}$

98

Fig. 4.20 Volume fraction of $A A B+C S H(S)$ pastes for FA 100 at

different temperatures

100

Fig. 4.21 Volume fraction of $A A B+C S H(S)$ pastes for $S G 100$ at different temperatures

101

Fig. 4.22 Volume fractions of $A A B$ paste, $C S H(S)$ and total $A A B+C S H(S)$

for FA 50 SG 50 at $23^{\circ} \mathrm{C}$

101

Fig. 4.23 Volume fractions of $A A B$ paste, $C S H(S)$ and total $A A B+C S H(S)$

for FA 50 SG 50 at $40^{\circ} \mathrm{C}$

102

Fig. 4.24 Volume fractions of $A A B$ paste, $C S H(S)$ and total $A A B+C S H(S)$

for FA 50 SG 50 at $60^{\circ} \mathrm{C}$

102

Fig. 5.1 Setup for testing of compressive strength according to

ASTM C39/C39M - 12a

105

Fig. 5.2a Compressive strength data at $23^{\circ} \mathrm{C}$ for all mixes at different ages (bar chart)

107

Fig. 5.2b Compressive strength data at $23^{\circ} \mathrm{C}$ for all mixes at different ages

Fig. 5.3a Compressive strength data at $40^{\circ} \mathrm{C}$ for all mixes at different ages(bar chart)

Fig. 5.3b Compressive strength data at $40^{\circ} \mathrm{C}$ for all mixes at different ages

108

Fig. 5.4a Compressive strength data at $60^{\circ} \mathrm{C}$ for all mixes at different ages(bar chart)

Fig. 5.4b Compressive strength data at $60^{\circ} \mathrm{C}$ for all mixes at different ages

Fig. 5.5 Compressive strength data at 7-day age for all mixes cured at different temperatures 
Fig. 5.6 Compressive strength data at 28-day age for all mixes cured at different temperatures

Fig. 5.7 Compressive strength data at 90-day age for all mixes cured at different temperatures

Fig. 5.8 Effect of slag addition on compressive strength of $A A B$ at different temperatures: (a) $23^{\circ} \mathrm{C}$, (b) $40^{\circ} \mathrm{C}$, and (c) $60^{\circ} \mathrm{C}$.

Fig. 5.9a Mean Tensile strength data at $23^{\circ} \mathrm{C}$ for all mixes at different ages(bar chart)

Fig. 5.9b Mean Tensile strength data at $23^{\circ} \mathrm{C}$ for all mixes at different ages

Fig. 5.10a Mean tensile strength data at $40^{\circ} \mathrm{C}$ for all mixes at different ages (bar chart)

Fig. 5.10b Mean tensile strength data at $40^{\circ} \mathrm{C}$ for all mixes at different ages

Fig. 5.11a Mean tensile strength data at $60^{\circ} \mathrm{C}$ for all mixes at different ages(bar chart)

Fig. $5.11 \mathrm{~b}$ Mean tensile strength data at $60^{\circ} \mathrm{C}$ for all mixes at different ages

Fig. 5.12 Mean 7-day Splitting Tensile Strength for all mixes at different temperatures

Fig. 5.13 Mean 28-day Splitting Tensile Strength for all mixes at different temperatures

Fig. 5.14 Mean 90-day Splitting Tensile Strength for all mixes at different temperatures

Fig. 5.15 Effect of slag addition on splitting tensile strength of $A A B$ at different temperatures: (a) $23^{\circ} \mathrm{C}$, (b) $40^{\circ} \mathrm{C}$, and (c) $60^{\circ} \mathrm{C}$.

Fig. 5.16 Experimental setup to determine flexural strength of concrete according to ASTM C293/ C293M-10

Fig. 5.18 Effect of slag addition on the flexural strength of $A A B$ at different temperatures: (a) $23^{\circ} \mathrm{C}$, (b) $40^{\circ} \mathrm{C}$, and (c) $60^{\circ} \mathrm{C}$.

Fig. 6.1 Methods of propagating and receiving ultrasonic pulses:

(a) Direct Transmission, (b) Indirect or surface Transmission, and (c) Semi-direct Transmission; $(T)=$ Transmitter;

$(R)=$ Receiver (Panzera et al. 2011). 
Fig. 6.2 (a) Variation of $E_{c}$ vs. $v^{2}$ for all specimens and

(b) Variation of $E_{c}$ vs. $v$ for all $A A B$ mixes cured at $23^{\circ} \mathrm{C}$

Fig. 6.3 (a) Variation of $E_{c}$ vs. $v^{2}$ for all specimens and

(b) Variation of $E_{c}$ vs. $v$ for all AAB mixes cured at $40^{\circ} \mathrm{C}$

Fig. 6.4 Variation of $E_{c}$ vs. $v^{2}$ for all specimens and

(b) Variation of $E_{c}$ vs. $v$ for all AAB mixes cured at $60^{\circ} \mathrm{C}$

Fig. 6.5 (a) Variation of $E_{c}$ vs. $v^{2}$ for all specimens and

(b) Variation of $E_{c}$ vs. $v$ for all specimens

Fig. 6.6 (a) Variation of $f_{c}{ }^{\prime}$ vs. $v^{4}$ for all specimens and

(b) Variation of $f_{c}{ }^{\prime}$ vs. $v$ for AAB mixes cured at $23^{\circ} \mathrm{C}$

Fig. 6.7 Variation of $f_{c}{ }^{\prime}$ vs. $v^{4}$ for all specimens and

(b) Variation of $f_{c}^{\prime}$ vs. $v$ for $A A B$ mixes cured at $40^{\circ} \mathrm{C}$

Fig. 6.8 Variation of $f_{c}{ }^{\prime}$ vs. $v^{4}$ for all specimens and

(b) Variation of $f_{c}{ }^{\prime}$ vs. $v$ for AAB mixes cured at $60^{\circ} \mathrm{C}$

Fig. 6.9 (a) Variation of $f_{c}{ }^{\prime}$ vs. $v^{4}$ for all specimens and

(b) Variation of $f_{c}{ }^{\prime}$ vs. $v$ for all specimens

Fig. 6.10 Experimental setup for variation of $\sigma_{c}$ and $\sigma_{c} / f_{c}{ }^{\prime}$ with ultrasonic pulse velocity for all specimens.

Fig. 6.11 (a) Variation of $\sigma_{c}$ vs. $v^{4}$ for all specimens and

(b) Variation of $\sigma_{c}$ vs. $v$ for AAB mixes cured at $23^{\circ} \mathrm{C}$

Fig. 6.12 (a) Variation of $\sigma_{c}$ vs. $v^{4}$ for all specimens and

(b) Variation of $\sigma_{c}$ vs. $v$ for AAB mixes cured at $40^{\circ} \mathrm{C}$

Fig. 6.13 (a) Variation of $\sigma_{c}$ vs. $v^{4}$ for all specimens and

(b) Variation of $\sigma_{c}$ vs. $v$ for AAB mixes cured at $60^{\circ} \mathrm{C}$

Fig. 6.14 (a) Variation of $\sigma_{c}$ vs. $v^{4}$ for all specimens (scatter plot for each mix);

(b) Variation of $\sigma_{c}$ vs. $v^{4}$ for all specimens (scatter plot with line for each mix);

(c) Variation of $\sigma_{c}$ vs. $v$ for all specimens (scatter plot for each mix); and

(d) Variation of $\sigma_{c}$ vs. $v$ for all specimens (scatter plot with line for each mix).

Fig. 6.15 (a) Variation of $\sigma_{c} / f_{c}{ }^{\prime}$ vs. $v^{4}$ for all specimens and

(b) Variation of $\sigma_{c} / f_{c}{ }^{\prime}$ vs. $v$ for $A A B$ mixes cured at $23^{\circ} \mathrm{C}$

Fig. 6.16 (a) Variation of $\sigma_{c} / f_{c}{ }^{\prime}$ vs. $v^{4}$ for all specimens and

(b) Variation of $\sigma_{c} / f_{c}^{\prime}$ vs. $v$ for $A A B$ mixes cured at $40^{\circ} \mathrm{C}$

Fig. 6.17 (a) Variation of $\sigma_{c} / f_{c}{ }^{\prime}$ vs. $v^{4}$ for all specimens and

(b) Variation of $\sigma_{c} / f_{c}^{\prime}$ vs. $v$ for $A A B$ mixes cured at $60^{\circ} \mathrm{C}$ 
Fig. 6.18 (a) Variation of $\sigma_{c} / f_{c}{ }^{\prime}$ vs. $v^{4}$ for all specimens (scatter plot for each mix); (b) Variation of $\sigma_{c} / f_{c}{ }^{\prime}$ vs. $v^{4}$ for all specimens (scatter plot with line for each mix);

(c) Variation of $\sigma_{c} / f_{c}{ }^{\prime}$ vs. $v$ for all specimens (scatter plot for each mix); and

(d) Variation of $\sigma_{c} / f_{c}^{\prime}$ vs. $v$ for all specimens (scatter plot with line).

Fig. 7.1 Comparison between the predicted compressive strengths and the experimental values

Fig. 7.2 Comparison between predicted and experimental compressive strengths for a few example $A A B$ concrete mixes 


\section{CHAPTER 1}

\section{INTRODUCTION}

The present study is aimed at the characterization of binder materials produced by the reaction of industrial wastes, namely fly ash and slag, with alkaline sodium silicate solution and sodium hydroxide and correlating their properties from micro- to specimen level. This chapter outlines background information on these alkali-activated binders (AAB) and motivation for the present study. Also, the goals, and objectives are discussed.

\subsection{Background}

According to the World Business Council for Sustainable Development, "Concrete is the most widely used material on earth apart from water, with nearly three tons used annually for each man, woman, and child." Concrete industry contributes at least $5-8 \%$ of the global carbon dioxide emissions (Provis and van Deventer, 2009). The decomposition of the limestone during the manufacture of cement has a two-fold effect on nature - (i) it emits substantial amount of $\mathrm{CO}_{2}$, and (ii) it reduces limestone resources. Moreover, the rapid development of infrastructure in various countries all over the world has resulted in the shortage of cement at some places. In the absence of any other viable alternative for portland cement (PC), this situation may lead to huge demand and low supply of cement, thereby, hindering sustainable development.

Hence, there is a need to develop an alternative material, which will not only reduce the demand for $\mathrm{PC}$, but also decrease the $\mathrm{CO}_{2}$ emission. From these criteria, the proposed material must possess mechanical and structural properties comparable to PC but it should emit $\mathrm{CO}_{2}$ at a much lower rate. A possible solution to this problem might be the use of alkali-activated binders (AAB) or inorganic polymers.

Inorganic polymers, more commonly referred to as "geopolymers", are alumino-silicate materials which exhibit excellent physical and chemical properties and a diverse range of potential applications: precast structures and non-structural elements, concrete pavements, containment and immobilization of toxic, hazardous and radioactive wastes, advanced structural tooling and refractory ceramics, and fire resistant composites used in buildings, 
aeroplanes, shipbuilding, racing cars, and the nuclear power industry. In 1981, Professor Davidovits of France produced binders by mixing alkalis with burnt mixture of kaolinite, limestone and dolomite (Davidovits, 1982). He called the binders "geopolymer" since they have polymeric structure. He also used several trademarks such as Pyrament, Geopolycem and Geopolymite for the binder (Davidovits, 1994). This type of materials belongs to the alkaline binding system $\mathrm{Me}_{2} \mathrm{O}-\mathrm{Me}_{2} \mathrm{O}_{3}-\mathrm{SiO}_{2}-\mathrm{H}_{2} \mathrm{O}$, as discovered by Glukhovsky in 1957 (Shi et al., 2006). Early researches have shown that geopolymers are cheap to produce and can be made when naturally occurring materials (fly ash, slag or metakaolin) are mixed with sodium hydroxide $(\mathrm{NaOH})$ and water (Davidovits, 1988c; Smith and Comrie, 1988). Geopolymerisation is regarded as the analogue of zeolites synthesis since the chemistry involved is similar, although the resulting products are different in composition and structure. Geopolymeric products, however, do not have stoichiometric composition and comprise mixtures of amorphous to semi-crystalline structure and crystalline Al-Si particles (Davidovits, 1991). Inspite of the complexities in their molecular structures, they can be used extensively in real world applications. Literature review shows that although several researchers have conducted studies on the microstructural aspects of $A A B$ using Scanning electron microscopy (SEM) and energy dispersive X-ray (EDS), X-ray diffraction (XRD), Fourier Transform Infrared Spectroscopy (FTIR), the primary focus of the research was to understand the underlying mechanisms of reactions and morphology of this complex system (Van Jaarsveld 2000; Davidovits 1983; Rees et al., 2004, Breck, 1974; Barbosa et al. 2000; Lee and van Deventer, 2002; Rees 2007; and Muzek et al., 2012). Some researchers studied the synthesis of $A A B$ with room temperature curing and performed qualitative characterization (van Deventer et al., 2010 and Quillin et al., 2011) and also including slag as the precursor (Quillin et al., 2011), but no systematic studies on quantifying the volume fractions of alkali-activated binder products from the microanalysis and volume stoichiometry of the reaction products were reported. Also, there have not been any studies to correlate the microstructural characteristics of AAB systems with their specimen level characteristics. The motivation behind the present study are: (a) quantitative evaluation of volume fractions of the different chemical phases in the microstructure of $A A B$ systems containing different proportions of fly ash and slag and (b) correlating the compressive strength of $A A B$ concrete with these microstructural volume fractions. The motivations are elaborated in the next section. 


\subsection{Motivation}

Much of the development of alkali-activated or alkaline cements has been based on activated slags. But, there is great potential for utilization of other by-products. During the past two decades, alkali-activated cements and concretes have attracted strong interests all over the world due to their advantages of low energy cost, appreciable serviceability and good durability compared to Portland cements. A major incentive for further development of such cements is generated by the annual output of fly ashes from power plants and other by-product materials, which is so enormous that there is a constant need to find new uses for them. In the US, approximately $49 \%$ of the utility wastes (e.g. fly ash which can be produced while generating electricity from coal) are simply landfilled, $41 \%$ are contained in surface impoundments, and about $10 \%$ are disposed of by discharging into old quarry operations. Increasingly, storage is conducted "on site" due to reduced costs to the utilities (Shi et al. 2006). The use of fly ash as precursor incurs high heat energy consumption to achieve compressive strength comparable to PC concrete (Han and Pyzik 2011, Rangan and Wallah 2006). Slag has high water demand and is almost as expensive as PC (Provis and van Deventer 2009). There are limited studies which considered the combination of fly ash and slag as precursors in the $A A B$ system. Several studies have been conducted to study the microstructural characteristics of AAB systems (Rees et al. 2004, Muzek et al. 2012, Lee and van Deventer 2002) and several other studies have been conducted to study the strength characteristics of concrete with AAB (Wallah and Rangan 2006, Davidovits 1994, Provis and van Deventer 2009). However there is no systematic study to correlate the microstructural properties of $A A B$ systems with the strength characteristics at specimen level. The following section discusses the goals of the present study.

\subsection{Goals}

The present research is aimed at making a significant contribution towards the development and characterization of alkali-activated material concrete and also to promote its use for practical purposes. The use of $A A B$ for practical purposes will reduce $\mathrm{CO}_{2}$ emission by replacing $\mathrm{PC}$; manufacturing of $\mathrm{AAB}$ consumes less heat energy compared to $\mathrm{PC}$ clinker; and use of industrial by-products divert them from landfills, thus encouraging green and sustainable construction. The global perspective of the present study is to develop a singlecomponent alkali activated cementitious product, whose hydration (polymerization reaction in this case) will be initiated by the addition of water only, as in the case of Portland 
cement. That will facilitate the use of this product in real-world applications and overcome the current inconvenience of having to use at least three different components to produce concrete from the alkali activated materials. Keeping the broad goals in mind, the present study focuses on developing and characterizing $A A B$ samples at microstructural level; characterizing $A A B$ samples at specimen level; and correlating their properties from microto specimen level. The objectives are elaborated in the next section.

\subsection{Research Objectives}

The objectives of the present study are:

- Develop various mixes using fly ash and slag in varying proportions and evaluate them at three different curing temperatures: $23^{\circ} \mathrm{C}, 40^{\circ} \mathrm{C}$, and $60^{\circ} \mathrm{C}$.

- Characterize AAB samples at microstructural level to determine their chemical compositions both qualitatively and quantitatively (details are provided in section 1.4.1)

- Characterize AAB samples at specimen level to determine various strength characteristics (compressive, splitting tensile and flexural) and nondestructive properties (ultrasonic pulse velocity and dynamic modulus of elasticity) (details in section 1.4.2)

- Formulate a model to correlate the microstructural properties with the specimen level mechanical properties using nonlinear regression and validating predicted results with experimental data (elaborated in section 1.4.3)

\subsubsection{Characterization at microstructural level}

- Conduct X-Ray Diffraction (XRD) and Fourier Transform Infrared Spectroscopy (FTIR) for qualitative identification of the chemical composition of the AAB microstructure

- Conduct Scanning Electron Microscopy (SEM) and Energy Dispersive X-Ray Spectroscopy (EDS) for observing the morphology of the AAB microstructure and its quantitative estimation

- Conduct Isothermal calorimetry and degree of reaction experiments to study the progress of chemical reactions when the alkali activators react with fly ash and/or slag 
- Compressive strength test of hardened AAB pastes to identify the best activatorprecursor combination (details in section 3.2)

- Optimization using General Algebraic Modeling System (GAMS) to establish the chemical composition of the products of fly ash and/or slag reaction with alkali activator

\subsubsection{Characterization at specimen level: both destructive and nondestructive testing}

- Conduct Compressive, splitting tensile, and flexural strength tests of hardened AAB concrete specimens to measure the strength characteristics at specimen level (details in Chapter 5)

- Conduct Dynamic modulus of elasticity test of hardened AAB concrete specimens to get an idea about stiffness of concrete with $A A B$ (details in section 6.2)

- Conduct Ultrasonic pulse velocity (UPV) test of hardened AAB concrete specimens and its correlation with compressive strength and modulus of elasticity for indirect determination of strength and stiffness characteristics (details in Chapter 6)

- Determine the effect of gradually increasing applied compressive stress of hardened $A A B$ concrete on UPV to study the behavior of $A A B$ when exposed to externally applied load (details in section 6.5)

\subsubsection{Statistical tools to correlate microlevel to specimen level properties}

- Nonlinear regression using $\mathrm{R}$ to for predicting compressive strength as a function of microstructural phase volume fractions and UPV

- Most suitable prediction model selected out of 18 possible models based on least mean square error

The next chapter presents a detailed review of the current state-of-the-art of research on $A A B$, as well as a thorough literature review of the history of $A A B$ research and the relevant chemical reactions and experimental techniques. 


\section{CHAPTER 2}

\section{LITERATURE REVIEW}

This chapter presents a thorough literature review regarding research on $A A B$, starting with the history of their development, followed by the relevant terminologies and the chemical reactions involved. This chapter also discusses the available information regarding the application of $A A B$ and the testing techniques to analyze their microstructural properties, followed by the nondestructive characterizations used in this study and the basis for the concept of the proposed model to correlate the microscale properties with the specimen level properties.

\subsection{History of Concretes with Alkali Activated Binders}

The first use of concrete with alkali-activated binder materials was in the form of geopolymer concrete. The term geopolymer was coined by Davidovits (1982). Extensive research on geopolymer technology has immense commercial significance because these materials can be used for construction purposes as a replacement for Portland cement (PC).

In 1981, Davidovits of France produced binders by mixing alkalis with burnt mixture of kaolinite, limestone and dolomite (Davidovits 1982). He called the binders "geopolymer" since they have polymeric structure. He also used several trademarks such as Pyrament, Geopolycem and Geopolymite for the binder (Davidovits 1994). This type of materials belongs to the alkaline binding system $\mathrm{Me}_{2} \mathrm{O}-\mathrm{Me}_{2} \mathrm{O}_{3}-\mathrm{SiO}_{2}-\mathrm{H}_{2} \mathrm{O}$, as discovered by Glukhovsky in 1957 (Shi et al., 2006). Early researches have shown that geopolymers are cheap to produce and can be made by the reaction of industrial wastes like fly ash, metakaolin, or slag with $\mathrm{NaOH}$ and water (Davidovits, 1988; Smith and Comrie, 1988). Geopolymerisation is regarded as the analogue of zeolites synthesis since the chemistry involved is similar, although the resulting products are different in composition and structure. Geopolymeric products, however, do not have stoichiometric composition and comprise mixtures of amorphous to semi-crystalline structure and crystalline Al-Si particles (Davidovits, 1991). Inspite of the complexities in their molecular structures, they have widespread real world applications. One of the major applications include waste encapsulation. Research was also conducted to identify the influence of metal contaminants such as copper and lead. 
Several researchers have studied the microstructure of the geopolymer concrete and also the chemistry of polymerization. The process of polymerization in geopolymer concrete was specifically termed as "geopolymerization" by Davidovits in 1972 (Davidovits, 1988). The three known chemical units in the geopolymer structure are: (i) Si-O-Al-O, or polysialate group, (ii) Si-O-Al-O-Si-O, or poly (sialate-siloxo) group, and (iii) Si-O-Al-O-Si-O -Si-O, or poly (sialate-disiloxo) group. They were well accepted by researchers in the beginning but later researchers did not accept these terms (Provis and van Deventer, 2009).

If the above terminologies were accepted, then, it would be implied that geopolymer microstructure consisted of $\mathrm{Si} / \mathrm{Al}$ ratios with integer values only. In order to satisfy adequate compressive strength requirement, the value of this integer should lie between 1 and 3 , as explained more elaborately in section 2.2. The term 'sialate' was already in vogue since the 1950 s to describe the salts of the sialic acid, a nine-carbon monosaccharide and an important component of several biochemical systems within the human body (Provis and van Deventer, 2009). Moreover, the integral values of the Si/Al ratio provide a onedimensional representation of a three-dimensional network, which leads to incorrect interpretations about the geopolymer characteristics. This system of nomenclature was quite popular among the researchers during the early days of geopolymer research. However, towards the end of the $20^{\text {th }}$ century, the researchers understood the limitations of this system of nomenclature. Also, there was an urge among the researchers to unite the fields of research of geopolymer, sol-gel and zeolite chemistry and this concept received greater preference over the specific terminology used for geopolymer concrete (Rees, 2007).

Different analytical techniques such as XRD, FTIR and SEM/EDS were used to conduct indepth analysis of the effect of the various components of the geopolymer system, such as the alkali metal activator, different sources of aluminosilicates for the precursor, and also the effect of additives like basalt fibers, alkali-feldspar and blast furnace slag (Provis and van Deventer, 2009). The next section discusses briefly about the chemistry of geopolymers (or $A A B)$. 


\subsection{Terminology and Chemistry of Geopolymer (or AAB)}

Inorganic polymers, more commonly referred to as "geopolymers", are alumino-silicate compounds of alkali metals such as sodium or potassium. These polymers exhibit excellent physical and chemical properties and a diverse range of potential applications. They include precast structures and non-structural elements, concrete pavements and products, containment and immobilization of toxic, hazardous and radioactive wastes, advanced structural tooling and refractory ceramics, and fire resistant composites used in buildings, aeroplanes, shipbuilding, racing cars, and the nuclear power industry. A geopolymer comprises of alkali activated alumionsilicate cement with low calcium content. The chemical structure is primarily composed of $\mathrm{Si}-\mathrm{O}-\mathrm{Si}$ and $\mathrm{Si-O}-\mathrm{Al}$ tetrahedral bonds arranged in a solid amorphous aluminosilicate network as analyzed by $\mathrm{x}$-ray diffraction technique. The $\mathrm{Al}^{3+}$ has a coordination state of IV, with its charge neutralized by an alkali cation, mostly $\mathrm{Na}^{+}$or $\mathrm{K}^{+}$. The synthesis of these geopolymer products includes an aluminosilicate product as precursor and a combination of an aqueous alkali hydroxide source and an alkali silicate solution as activator. The most common sources of aluminosilicate include industrial byproducts such as fly ash, slag, kaolin or metakaolin.

Several attempts have been made to draw the schematic diagrams of the three-dimensional geopolymer structure, but their two-dimensional representation has come across appreciable hindrances due to the inherent complexities in the geopolymer structure. The schematic diagram presented by Provis et al. (2005) is considered to be the most useful by the current researchers (Provis and van Deventer, 2009).

The geopolymer network consists of a mixture of amorphous and crystalline phases, which coexist in both the precursor as well as the reaction product. These complications have resulted in a dearth of literature regarding direct structural analysis of geopolymers. However, indirect experimental designs and data analysis techniques have been employed by researchers to come up with enough useful information about geopolymer chemistry, although there is much scope for further investigation on characterization of geopolymers and their chemistry.

Although the chemistry of geopolymers are totally different from that of Portland cement, the mechanical properties of the geopolymerization reaction products have been found to be analogous to those of the cement hydration products. Due to this similarity in their 
mechanical behavior, geopolymer technology is beginning to enjoy extensive use in the construction industry, as explained later in this chapter. Before proceeding with that, it is necessary to discuss about the various terminologies related to geopolymers and also the various chemical reactions pertaining to polymerization.

The term 'geopolymer' was first introduced by Davidovits (1982) to describe a family of mineral binders with chemical composition similar to zeolites but with an amorphous microstructure. He also suggested the use of the term 'poly(sialate)' for the chemical designation of geopolymers based on silico-aluminate (Davidovits, 1988a, 1988b, 1991; van Jaarsveld et. al., 2002a); Sialate is an abbreviation for silicon-oxo-aluminate. Poly(sialates) are chain and ring polymers with $\mathrm{Si}^{4+}$ and $\mathrm{Al}^{3+}$ in IV-fold coordination with oxygen and range from amorphous to semi-crystalline with the empirical formula in Eq. (2.1):

$$
\mathrm{M}_{\mathrm{n}}\left(-\left(\mathrm{SiO}_{2}\right) \mathrm{z}-\mathrm{AlO}_{2}\right)_{\mathrm{n}} \cdot w \mathrm{H}_{2} \mathrm{O}
$$

where " $z$ " is 1,2 or 3 or higher up to $32 ; M$ is a monovalent cation such as potassium or sodium, and " $n$ " is a degree of polycondensation (Davidovits, 1984, 1988b, 1994b, 1999). Davidovits (1988b; 1991; 1994b; 1999) has also distinguished 3 types of polysialates, namely the Poly(sialate) type (-Si-O-Al-O), the Poly(sialate-siloxo) type (-Si-O-Al-O-Si-O) and the Poly(sialate-disiloxo) type (-Si-O-Al-O-Si-O). The structures of these polysialates can be schematized as in Fig. 2.1.

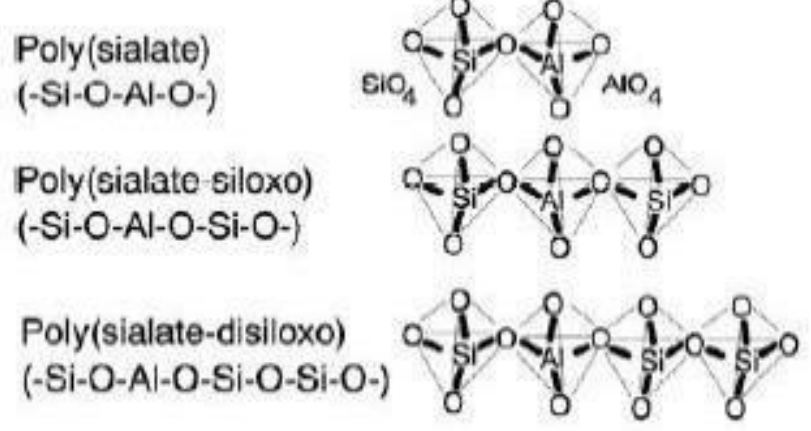

Fig. 2.1 Structure of polysialates (Wallah and Rangan 2006)

Geopolymerization involves the chemical reaction of alumino-silicate oxides $\left(\mathrm{Si}_{2} \mathrm{O}_{5}, \mathrm{Al}_{2} \mathrm{O}_{2}\right)$ with alkali polysilicates yielding polymeric Si-O-Al bonds. Polysilicates are generally sodium or potassium silicate supplied by chemical industry or manufactured fine silica powder as a 
by-product of ferro-silicon metallurgy. Eq. 2.2 shows an example of polycondensation by alkali into poly(sialatesiloxo).

Unlike ordinary Portland/pozzolanic cements, geopolymers do not form calcium silicatehydrate $(\mathrm{CSH})$ for matrix formation and strength, but utilize the polycondensation of silica and alumina precursors and a high alkali content to attain structural strength. Therefore, geopolymers are sometimes referred to as alkali activated aluminosilicate binders (Davidovits, 1994a; Palomo et. al., 1999; Roy, 1999; van Jaarsveld et. al., 2002a). However, Davidovits (1999; 2005) stated that using the term 'alkali-activated' could create significant confusion and generate false granted ideas about geopolymer concrete. For example, the use of the term 'alkali-activated cement' or 'alkali-activated fly ash' can be confused with the term 'Alkali-aggregate reaction (AAR)', a harmful property well known in concrete. The last term of Eq. 2.2b indicates that water is released during the chemical reaction that occurs in the formation of geopolymers. This water is expelled from the mixture during the curing process (Provis and van Deventer 2009).

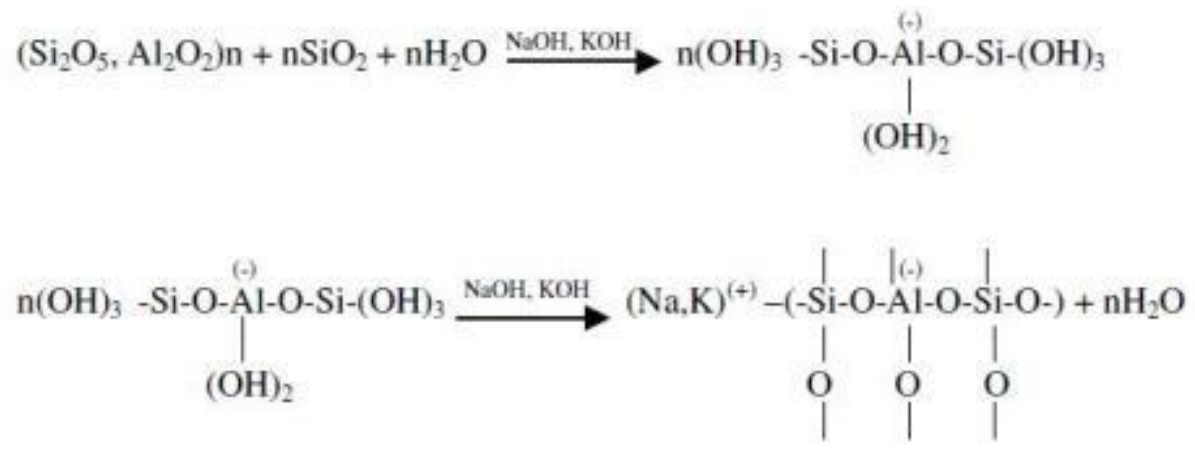

Geopolymerization is an exothermic process that is carried out through oligomers (dimer, trimer) which provide the actual unit structures for the three dimensional macromolecular edifice (Davidovits, 1988b). One of several hardening mechanisms involves the chemical reaction of alumino-silicate oxides with alkalis and alkali-polysilicates yielding polymeric $\mathrm{Si}-$ O-Al bonds with a $\left(\mathrm{Si}_{2} \mathrm{O}_{5}, \mathrm{Al}_{2} \mathrm{O}_{2}\right)_{\mathrm{n}}$ formula. This is accomplished by calcining alumino-silicate hydroxides $\left(\mathrm{Si}_{2} \mathrm{O}_{5}, \mathrm{Al}_{2}(\mathrm{OH})_{4}\right)$ through the reaction $2\left(\mathrm{Si}_{2} \mathrm{O}_{5}, \mathrm{Al}_{2}(\mathrm{OH})_{4}\right) \rightarrow 2\left(\mathrm{Si}_{2} \mathrm{O}_{5}, \mathrm{Al}_{2} \mathrm{O}_{2}\right)_{\mathrm{n}}+$ $4 \mathrm{H}_{2} \mathrm{O}$ or by condensation of $\mathrm{SiO}$ and $\mathrm{Al}_{2} \mathrm{O}$ vapors according to reaction $4 \mathrm{SiO}$ (vapor) + $2 \mathrm{Al}_{2} \mathrm{O}$ (vapor) $+4 \mathrm{O}_{2} \rightarrow\left(\mathrm{Si}_{2} \mathrm{O}_{5}, \mathrm{Al}_{2} \mathrm{O}_{2}\right)_{\mathrm{n}}$ which also produces condensed silica fume and corundum ( $2 \mathrm{SiO}+\mathrm{O}_{2} \rightarrow 2 \mathrm{SiO}_{2}$ and $\mathrm{Al}_{2} \mathrm{O}+\mathrm{O}_{2} \rightarrow \mathrm{Al}_{2} \mathrm{O}_{3}$ ) (Davidovits, 1988b). 
The basic steps of geopolymerisation involve dissolution of solid alumino-silicate oxides in $\mathrm{MOH}$ solution (M: alkali metal), diffusion or transportation of dissolved Al and Si complexes from the particle surface to the inter-particle space, formation of a gel phase resulting from the polymerization between added silicate solution and $\mathrm{Al}$ and $\mathrm{Si}$ complexes and finally hardening of the gel phase (Xu, 2001).

The following reaction scheme is proposed by $\mathrm{Xu}$ and Van Deventer (2000) for the polycondensation taking place during geopolymerisation of minerals:

Al-Si material (s) $+\mathrm{MOH}(\mathrm{aq})+\mathrm{Na}_{2} \mathrm{SiO}_{3}$ (s or aq)

$\rightarrow$ Al-Si material $(\mathrm{s})+\left[\mathrm{M}_{\mathrm{z}}\left(\mathrm{AlO}_{2}\right)_{\mathrm{x}}\left(\mathrm{SiO}_{2}\right)_{\mathrm{y}} \cdot n \mathrm{MOH} \cdot \mathrm{mH}_{2} \mathrm{O}\right] \mathrm{gel}$

$\rightarrow$ Al-Si material $(\mathrm{s})\left[\mathrm{M}_{\mathrm{a}}\left(\left(\mathrm{AlO}_{2}\right)_{\mathrm{a}}\left(\mathrm{SiO}_{2}\right)_{\mathrm{b}}\right) \cdot n \mathrm{MOH} \cdot \mathrm{mH}_{2} \mathrm{O}\right]$

In the first two steps of the reactions in Eq. 2.3, the amount of Al-Si material used depends on the particle size, the extent of dissolution of Al- Si materials and the concentration of the alkaline solution. The formation of $\left[\mathrm{M}_{z}\left(\mathrm{AlO}_{2}\right)_{x}\left(\mathrm{SiO}_{2}\right)_{y} \cdot n \mathrm{MOH} \cdot \mathrm{mH}_{2} \mathrm{O}\right]$ gel essentially relies on the extent of dissolution of alumino-silicate materials, while geopolymers with amorphous structure are formed during the last step of the reaction in Eq. 2.3. The time required for the alumino-silicate solution to form a continuous gel depends on raw material processing conditions (Ivanova et al., 1994). Dissolution of the starting materials is the major step that has a twofold role. Firstly, polysialate forming species are liberated from the starting materials in a similar way as in the formation of zeolite precursors (Grutzeck and Siemer, 1997; Duxson et al., 2007). Secondly, dissolution activates the surface and binding reactions take place contributing significantly to the final strength of the structure. The extent of the dissolution step in geopolymerisation is not fully clear while the extent to which other factors complement or not dissolution needs to be further examined (Phair, 2001).

Under alkaline conditions, alumino-silicates are transformed into extremely reactive materials and it is generally believed that the dissolution process is initiated by the presence of hydroxyl ions. Higher amounts of hydroxyl ions facilitate the dissociation of different silicate and aluminate species, promoting thus further polymerization (Davidovits, 1988d; Phair et al., 2000; Yip et al., 2005). However, if a very high alkaline environment (>30 mol\% overall $\mathrm{Na}_{2} \mathrm{O}$ content) is used, the connectivity of silicate anions may be reduced resulting thus in poor polymerization (Singh et al., 2005). Panagiotopoulou et al. (2007) 
studied the dissolution of different alumino-silicate industrial minerals and by-products and reported that the extent of dissolution is higher when $\mathrm{NaOH}$ instead of $\mathrm{KOH}$ is used. This is due to the smaller size of $\mathrm{Na}+$ which can better stabilize the silicate monomers and dimers present in the solution, enhancing thus the minerals dissolution rate (Xu and Van Deventer, $2000 \mathrm{~b}, 2003)$. It was also reported that Si and Al seem to have a synchronized leaching behavior in both alkaline media. Mikuni et al. (2007) studied the dissolution of different types of fly ashes in caustic soda solutions up to $15 \mathrm{~N}$ at $25^{\circ} \mathrm{C}$ and $80^{\circ} \mathrm{C}$. It was reported that high dissolution of $\mathrm{Al}_{2} \mathrm{O}_{3}$ is seen in $80^{\circ} \mathrm{C}$, while increased dissolution of $\mathrm{SiO}_{2}$ takes place during leaching with increasing $\mathrm{NaOH}$ concentrations in $25^{\circ} \mathrm{C}$. The ability to model the kinetics of a geopolymeric system enables the preparation of mixtures for specific applications and improves quality control during production. Provis et al. (2005) developed a model describing chemical reaction kinetics, providing thus valuable insights into the reaction processes. This model provides a framework that predicts the behaviour of geopolymer-forming systems.

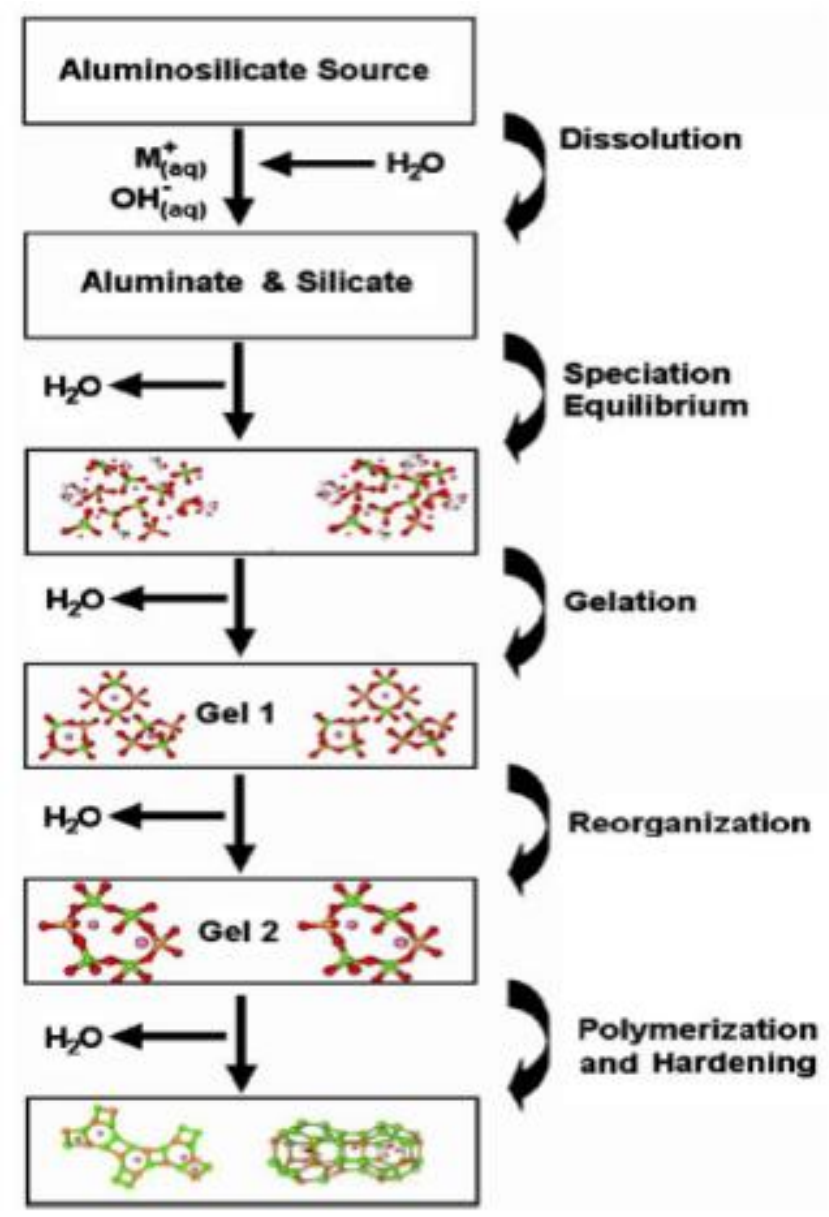

Fig. 2.2 Conceptual modeling of polymerization (Provis et al., 2005) 
The reaction kinetic framework developed by Provis and Van Deventer (2007b, c), using Energy Dispersive X-ray diffractometry may be used to determine the setting rate of geopolymers. Comparison of model output with experimental data shows that the model is able to provide a plausible description of geopolymerisation.

With the knowledge of the basic chemistry of polymerization already discussed, the following section sheds light on the various applications and utilities of the geopolymers.

\subsection{Applications of Geopolymers (or AAB)}

One of the major applications of geopolymers is their use in the development of green or sustainable construction materials. The major advantage of the geopolymers over the commonly used Portland cement materials is the low $\mathrm{CO}_{2}$ emission. Moreover, the aluminosilicates used as the precursors are mostly industrial by-products such as fly ash, slag, metakaolin, or silica fume. The usage of these industrial by-products not only prevents their disposal on landfills, but also ensures the reduction in usage of Portland cement. The manufacturing process of Portland cement involves the consumption of limestone from natural resources and also a lot of energy is used up during the clinkering phase. From this point of view, the use of the by-products is a step towards sustainable development (Provis and van Deventer, 2009).

Microstructure and properties of geopolymers depend strongly on the nature of the initial raw materials even though the macroscopic characteristics of alumino-silicate-based geopolymers may appear similar, since the same silicon and aluminum bonding and the same gel phase binder are present (Duxson et al., 2007c). Through microstructural investigations it becomes clear that the ratio of the starting materials influences the homogeneity of the geopolymer microstructure, which in turn affects thermal conductivity and compressive strength (Subaer and Van Riessen, 2007). Davidovits characterised geopolymers as thermo-setting organic resins, with the difference of being stable up to $1000-1200^{\circ} \mathrm{C}$ (Davidovits, 1988b). These synthetic mineral products possess properties such as hard surfaces (4-7 on the Mohs scale), thermal stability, high surface smoothness and easy moldability, thus can be useful for tooling, moulding art objects, ceramics as well as building materials (Davidovits, 1988a). Geopolymers harden rapidly at room temperature and may acquire compressive strength in the range of $20 \mathrm{MPa}$ after only $4 \mathrm{~h}$. The final 28- 
day compressive strength may reach 70-100 MPa (Hermann et al., 1999; Hardjito et al., 2002).

The unique properties of the geopolymeric binders apart from their high early strength also include low alkali-aggregate expansion, freeze-thaw, sulfate and corrosion resistance (Davidovits, 1988e). Geopolymers tested for encapsulation of toxic wastes proved quite efficient due to their minimal response to acid leaching (Comrie et al., 1988). Geocements (later termed as geopolymers) were created in accordance with a hypothesis put forward by Prof. V. Glukhovsky (Provis and van Deventer, 2009) that the structure formation processes in the alkaline alumino-silicate binders corresponded to geological transformations of alumino-silicate minerals taking place in nature. Optimal thermomechanical properties of the metakaolin- and fly ash based geocements may be reached in compositions with a microstructure represented by an average amount of thermostable zeolites, since just these phases are characterised by a smooth dehydration and subsequent re-crystallisation into stable anhydrous alkaline alumino-silicates without destruction of the framework (Krivenko et al., 2005; Krivenko and Kovalchuk, 2002b, 2007).

Geopolymeric cements and concretes also show very low shrinkage in air after drying, preventing formation of cracks (Davidovits, 1988b). According to Sofi et al. (2007), the properties of inorganic polymer concretes are similar to Portland cement-based concretes and depend upon the mix design and curing technique. It is of high importance to study under certain working conditions the compatibility between the $\mathrm{C}-\mathrm{S}-\mathrm{H}$ gel (formed during hydration of the PC) and the geopolymer gel (Goretta et al., 2004; Yip et al., 2005; Duxson et al., 2007c). These advantages make geopolymerisation a promising technology for new construction materials even though the cost for manufacturing Portland cement is relatively low (0.05-0.08 USD/kg, year 2006).

Rangan et al. (2005) have identified various economic benefits of using fly ash based geopolymer concrete, by taking into account that the cost of purchasing fly ash (excluding transportation) is relatively low. Therefore, after taking into account the cost of activator liquids, it was estimated that the production of fly ash-based geopolymer concrete may be $10-30 \%$ cheaper than that of Portland cement concrete. This is not the case though in practice, as the large cement companies usually control the supply of raw materials, including fly ash, which is often locked up by long term agreements. 
Some of the applications of geopolymers based on their Si/Al ratio were tabulated by Wallah and Rangan in 2006, as follows (Table 2.1):

Table 2.1 Applications of Geopolymeric Materials Based on Si:Al Atomic Ratio (Wallah and Rangan, 2006)

\begin{tabular}{|c|c|}
\hline Si:Al ratio & Applications \\
\hline 1 & $\begin{array}{c}\text { - Bricks } \\
\text { - Ceramics } \\
\text { - Fire protection }\end{array}$ \\
\hline 2 & $\begin{array}{l}\text { - Low } \mathrm{CO}_{2} \text { cements and concretes } \\
\text { - Radioactive and toxic waste encapsulation }\end{array}$ \\
\hline 3 & $\begin{array}{l}\text { - Fire protection fibre glass composite } \\
\quad \text { - Foundry equipment } \\
\text { - Heat resistant composites, } 200^{\circ} \mathrm{C} \text { to } 1000^{\circ} \mathrm{C} \\
\text { - Tooling for aeronautic titanium processing }\end{array}$ \\
\hline$>3$ & $\begin{array}{l}\text { - Sealants for industry, } 200^{\circ} \mathrm{C} \text { to } 600^{\circ} \mathrm{C} \\
\text { - Tooling for aeronautics SPF aluminium }\end{array}$ \\
\hline $20-35$ & - Fire resistant and heat resistant fibre composites \\
\hline
\end{tabular}

In addition to the above usage, geopolymers have the advantage that they can be made from recycled mineral wastes, the wide use of $\mathrm{low}-\mathrm{CO}_{2}$ geopolymeric cements would reduce carbon-dioxide emissions from the cement and concrete industries by almost $80 \%$ (Davidovits, 1999). Since geopolymers are considered as two-component systems (reactive solid components - alkaline activation solution) they can be used as suitable binders in precast industry for the manufacture of reinforced products such as large-diameter pipes and roofing tiles (Yip et al., 2004; Buchwald, 2006).

The applications of geopolymeric binders have been tested in pilot studies worldwide. Some products have reached industrial applications, such as new class of special and blended cements, building products, advanced mineral binders for severe environments, temperature stable resins for moulds and forms and ceramic-ceramic composites (Davidovits, 1988b; Davidovits, 1999; Provis and van Deventer, 2009; and Muzek et al., 2012). Immobilization techniques are used for the treatment of large amounts of heavy metals and radioactive wastes, thus geopolymerisation has received over the years significant attention due to its low cost, flexibility and increased durability versus time (Davidovits et al., 1990; Davidovits, 1991). 
Based on the above discussion, the main inspiration behind the present research was the application of geopolymers to a green construction material which supports sustainable development. The low cost of the raw materials and the low $\mathrm{CO}_{2}$ emission are the main advantages of these kinds of advanced construction materials.

In order to develop the one-part commercial geopolymer product, it is essential to adopt a step-by-step approach. At first, the target should be to develop an optimal two-part geopolymer product (precursor and activator will be distinct materials). In the next step, the aim will be to develop a one-part geopolymer by preblending the precursor and the activating materials. A brief background of available research on this step-by-step approach, which is of great interest in recent times, is provided in the next section.

\subsection{Current Trend of Research on Geopolymer (or AAB)}

Towards the beginning of the $21^{\text {st }}$ century, several researchers placed their emphasis on developing model systems to investigate the various properties of geopolymer concrete chemistry. The microstructural evolution of geopolymers received significant attention in particular (Lee and van Deventer, 2002). The majority of the early research work on aluminosilicate geopolymer lacked scientific details because the publications were patented (Davidovits 1982, 1984). The work throughout the 1980s has been summarized in the proceedings of a conference held in France in 1988 and also in a review paper by Davidovits in 1991 (Provis and van Deventer, 2009).

The groundwork for aluminosilicate geopolymer research was formed by the studies of Palomo and Glasser (1992) and Rahier et al. (1996, 1997). These studies were based on metakaolin geopolymers. Over the course of time, various research groups have been conducting in-depth research on geopolymers in different countries across the world, such as Spain (Granizo and Blanco 1998, Palomo et al. 1999), New Zealand (Barbosa et al. 2000), Germany (Buchwald 2006), and Australia (Yip and van Deventer 2003, Duxson et al. 2005a and 2005b, Stevenson and Sagoe-Crentsil 2005, Perera et al. 2005). Most of the significant research on geopolymers to date have been reviewed and summarized in a research paper by Komnitsas and Zaharaki (2007). A book published by the researchers in Australia has summarized all the research on geopolymers including the trend of current research and scope for future work on geopolymers (Provis and van Deventer, 2009). 
The primary requirement in order to develop a geopolymer product is to identify an appropriate aluminosilicate used as the precursor. Sophisticated microanalysis techniques like quantitative scanning electron microscopy or devitrification may be used for chemical analysis of the aluminosilicate materials, in order to select the most suitable one. However, the ideal aluminosilicate may not always be readily available to the user, and it might be more economical to use whichever material is available locally. If the locally available material does not meet the desired criteria of the user, it has to be enhanced accordingly. The ultimate goal of the user is to obtain an optimal combination of the chemical and mechanical properties and the cost of the aluminosilicate. Ground granulated blast furnace slag (GGBFS) is an excellent source of aluminosilicates and possesses sufficient reactivity. But it is almost as expensive as portland cement (PC) (Provis and van Deventer, 2009).

In the practical industry a 'sweet spot' is targeted by the manufacturers such that price, reactivity, water demand and strength characteristics are optimized (Provis and van Deventer, 2009). This optimal combination is unique to each geographical location due to different availabilities of the raw materials, as well as the socio-economic condition of the region in question. So, there cannot be a single globally 'optimal' geopolymer composition, but there can be a collection of possible mix designs comprising a wide range of raw materials to obtain a balance between commercial and technical objectives (Provis and van Deventer 2009). However, this balance is difficult to achieve and the researchers are looking for a simple but effective approach to help the geopolymer industry to flourish.

Also, the chemistry of reactions associated with PC has been a popular research topic for a few decades now and a lot of useful information is available regarding this subject. Geopolymers have been hampered from that point of view, because this is a relatively new field of research and not enough information is available for the purpose of manufacturing a new construction material. Hence, advanced scientific techniques must be implemented in order to have a thorough understanding of geopolymer chemistry, so that the optimal combination of price and mechanical and physical properties of the material are obtained (Provis and van Deventer, 2009).

Hence the present study aims to address the above issues by developing a group of $A A B$ systems containing different proportions of fly ash and slag. Three different curing temperatures have been adopted and the optimal combination of fly ash, slag, curing 
temperature was found out from strength characteristics of concrete with $A A B$. The $A A B$ were also characterized at both microstructural and specimen levels. The volume fractions of the different chemical phases in the $A A B$ microstructure obtained from microanalyses and the specimen level ultrasonic pulse velocities were then used to predict the specimen level compressive strength by developing a nonlinear regression model. If the geopolymer product has to be sold in the market as a replacement for portland cement, then the ultimate goal is a one-part blend has to be manufactured which will have reactive properties analogous to portland cement. The characterizations and the prediction model developed in this study will significantly contribute towards helping the user in predicting the compressive strength behavior of the $A A B$ and thus encourage its application in the real world. As fly ash has been chosen as the basic precursor for development of the two-part finished product, the following section will briefly discuss about the research on fly ash geopolymers (or AAB).

\subsection{Fly Ash Based Geopolymer (or AAB) - A Brief Overview}

The most commonly used source of aluminosilicates as precursor for geopolymer concrete are metakaolin and fly ash. Of these two, fly ash has gained popularity among the researchers because it can react with the activating solution at lower temperatures and also it has lower water-demand. Some of the most extensive and noteworthy studies on fly ash based geopolymer concrete in recent times have been conducted by Fernandez-Jimenez and Palomo (2003), Skvara et al. (2006), Rangan et al. (2005) and Duxson et al. (2005a). They placed their emphasis on intermediate phases formed during the polymerization reactions. In the present study, fly ash was chosen as the base precursor material due to its easy availability and also its compatibility with the requirements of a green construction material.

The following sections provide information regarding the different experimental techniques that have been chosen to characterize the proposed material, starting with the microanalysis techniques.

\subsubsection{Microstructure of fly ash based AAB}

Before discussing about the experimental techniques used to study the microstructure of the $A A B$, a brief outline about the microstructure is presented in this section. 


\subsubsection{General characterization of AAB gels}

Two major groups of materials are being used as precursors for the production of $A A B$ as alternative for PC. Those groups are: (i) silica and alumina-rich materials such as class F fly ash or metakaolin and (ii) calcium, silicon, and aluminum-rich materials, such as blast furnace slag. The main reaction product formed due to the hydration of slag is a calcium silicate hydrate due to slag hydratioon, $\mathrm{CSH}(\mathrm{S})$, which resembles the calcium silicate hydrate (CSH) produced by hydration of PC.

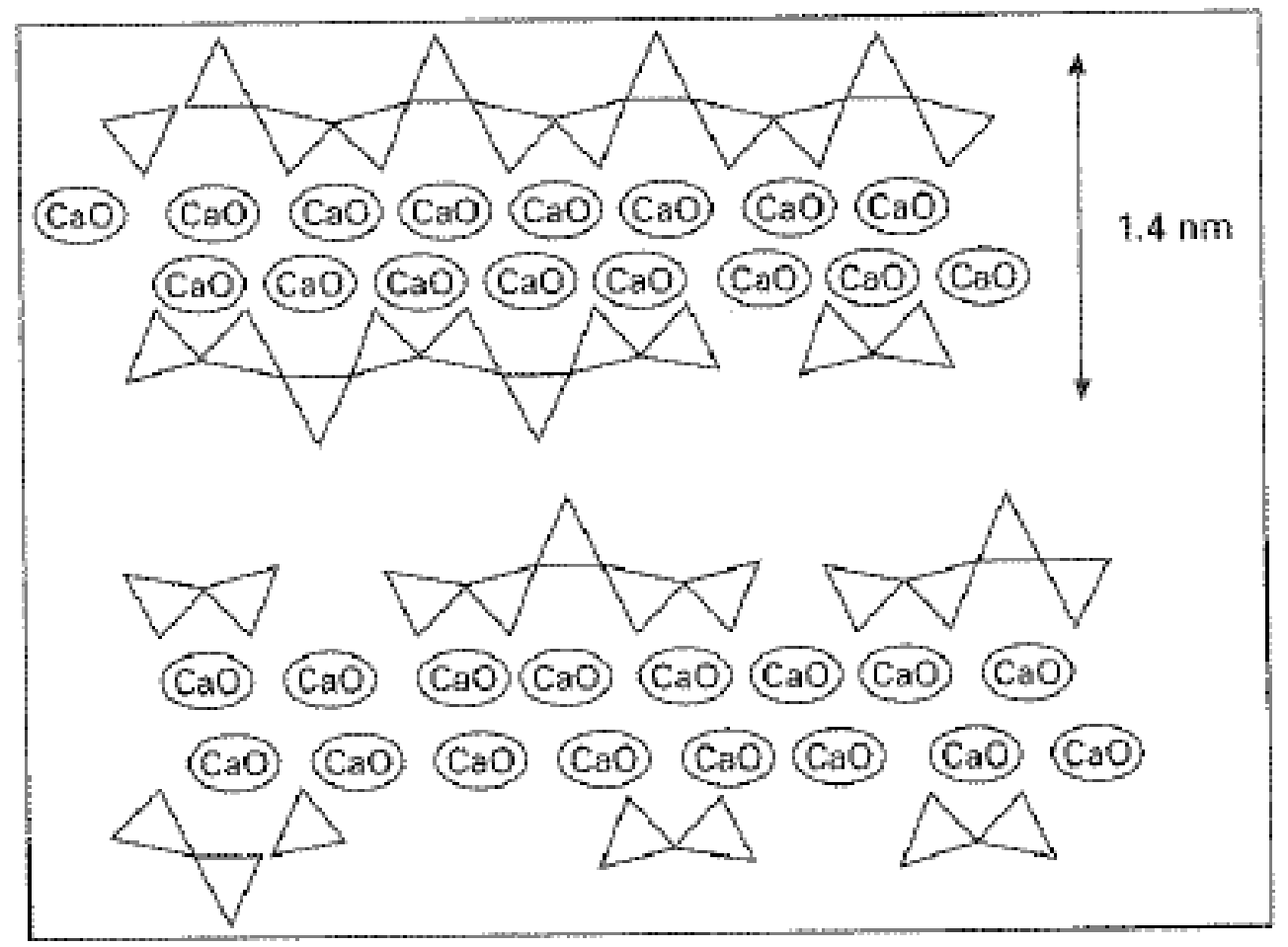

Fig. 2.3 Structural model proposed for CSH gel in PC (Taylor, 1990)

However, when fly ash is activated with an alkaline solution, the chemistry and microstructure of the reaction products are vastly different from that of PC. The main reaction product of the alkali activation of fly ash is an alkaline aluminosilicate. It is comprised of silicon and aluminum tetrahedra arranged to form a three-dimensional structure (Davidovits 1994; Barbosa et al. 2000; Palomo et al. 2004a, Fernandez-Jimenez et al. 2006a, Criado et al. 2007b, Duxson et al. 2007a). The cavities formed within the network can accommodate alkaline cations to compensate the charge imbalance resulting from the replacement of Si(IV) by Al(III). Terminal hydroxyl groups also exist on the gel 
surface, although their presence has little influence on the surface of the AAB concrete at specimen level (Fig. 2.4).

Several factors affect the microstructure and chemical composition of the alkaline aluminosilicate gel. The most important ones are: (i) nature of precursor, (ii) type of alkali activator, (iii) concentration of the activating solution, (iv) curing temperature, and (v) duration of curing. The term ' $\mathrm{N}-\mathrm{A}-\mathrm{S}-\mathrm{H}^{\prime}$ ' was coined by Fenandez-Jimenez and Palomo (2005b) to denote the sodium aluminosilicate, in contrast to geopolymer. Geopolymer is more accepted as a commercial name, while $\mathrm{N}-\mathrm{A}-\mathrm{S}-\mathrm{H}$ is well accepted by cement professionals and researchers (Provis and van Deventer 2009). A detailed description of the roles of silicon, aluminum and sodium in the $\mathrm{N}-\mathrm{A}-\mathrm{S}-\mathrm{H}$ microstructure is provided in the following sections.

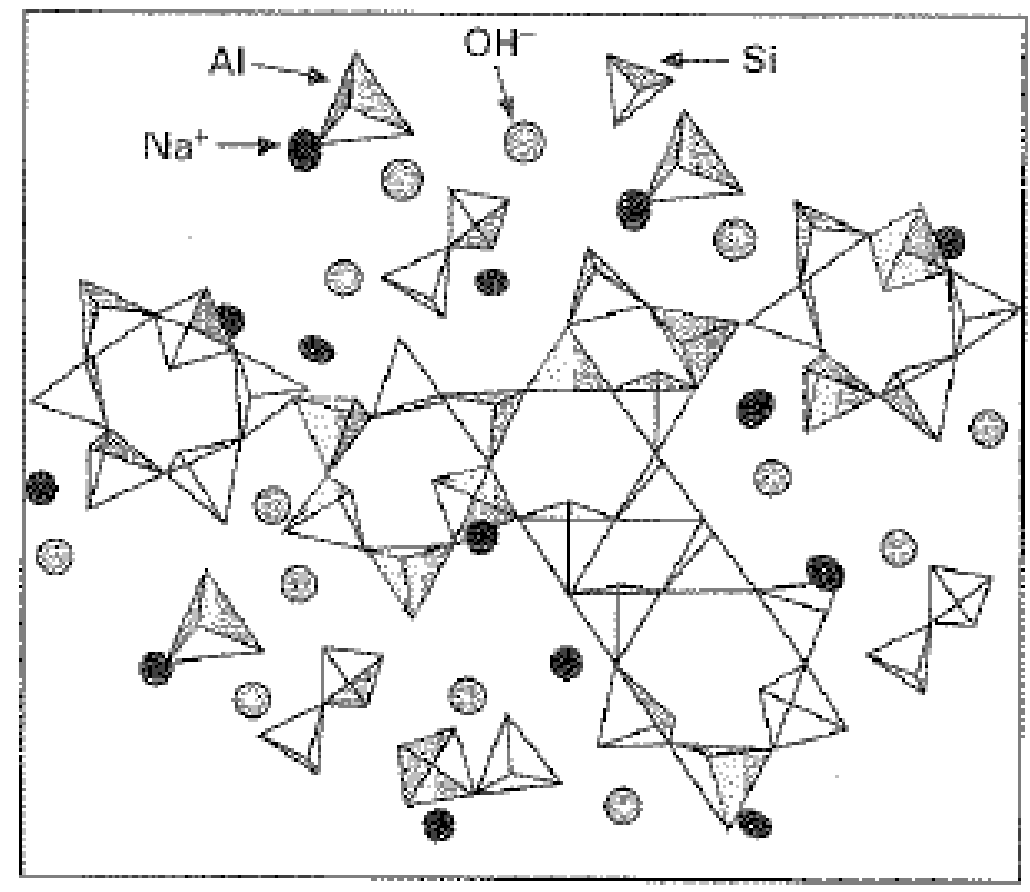

Fig. 2.4 Two-dimensional representation of the structural model proposed for $\mathrm{N}-\mathrm{A}-\mathrm{S}-\mathrm{H}$ gel (Provis and Van Deventer 2009 based on data from Criado 2007).

\subsubsection{Role of silicon in $\mathrm{N}-\mathrm{A}-\mathrm{S}-\mathrm{H}$ gel structure}

Available research has established that the structure of the N-A-S-H gel in any AAB sample depends on the degree of reaction, curing temperature and especially the presence of soluble silica in the alkali activator. The last factor has to be accounted for because the silica 
present in the N-A-S-H does not necessarily come from the precursor. It may also come from the alkali activator. In fact, the silica present in sodium silicate is highly soluble and consequently incorporated into the $\mathrm{N}-\mathrm{A}-\mathrm{S}-\mathrm{H}$ matrix. It has been found that the $\mathrm{SiO}_{2} / \mathrm{Na}_{2} \mathrm{O}$ ratio of the sodium silicate solution governs the degree of silica polymerization in the activating solution and hence influences the intermediate structural stages involved in formation of the N-A-S-H matrix (Provis and van Deventer, 2009).

In addition, the Si/Al ratio in the $\mathrm{N}-\mathrm{A}-\mathrm{S}-\mathrm{H}$ should not be increased indefinitely. As mentioned in section 2.3, the Si/Al ratio suitable for the $\mathrm{N}-\mathrm{A}-\mathrm{S}-\mathrm{H}$ matrix in the AAB system should be ideally around 2 in order to use it for low $\mathrm{CO}_{2}$ emission binders. Some researchers opine that this ratio has an effect on the thermodynamic stability of the AAB microstructure (Provis and van Deventer 2009).

\subsubsection{Role of aluminum in N-A-S-H gel}

Highly concentrated solutions of alkaline silicates are generally metastable and possess moderate $\mathrm{pH}$. As a result, the presence of soluble silicates is not sufficient to produce a chemically hardened material. Compounds formed by silicates re-dissolve in water. Alkaline aluminosilicate solubility is extremely low, however, even if the concentration is very small (in the order of $\mathrm{mmol} / \mathrm{l}$ ) (Glasser and Harvey 1984, Gasteiger et al. 1992). In alkaline aluminosilicates, the condensation reactions are chemically initiated by aluminum. Hence, the amount of aluminum present in the reactive system plays an important role in the formation of the N-A-S-H matrix and consequently affects the other mechanical properties of the AAB. If a particular fly ash contains high amount of initial reactive alumina, then it is highly reactive and viceversa. De Silva et al. (2007) indicate that the reactive alumina in fly ash must exceed a certain threshold around $20 \%$ for the resulting material to exhibit suitable mechanical properties. The fly ash used as the starting material for the present study contained $22.73 \%$ alumina.

\subsubsection{Role of sodium in N-A-S-H gel structure}

The role of alkali cations in the structure of the hydrated aluminosilicate gel is related to balancing the negative charge generated during the uptake of $\mathrm{AlO}_{4}$ tetrahedral units. But, little information is available in this regard. Duxson et al. (2005) showed that sodium cation can neutralize the negative charge due to $\mathrm{AlO}^{-}$in two ways: (i) Sodium associated with 
aluminum inside the gel structure and (ii) sodium present in the solution which fills the pores, thereby neutralizing the charge on the $\mathrm{Al}(\mathrm{OH})_{4}{ }^{-}$groups. The latter case was observed in case of aluminosilicates with Si/Al ratio $\leq 1.40$ (Provis and van Deventer, 2009).

\subsection{Microanalysis Techniques}

\subsubsection{X-ray diffraction (XRD)}

$X$-ray diffraction (XRD) is a technique which can be used to identify the crystalline phases in a solid material (Van Jaarsveld, 2000; Rees et al., 2004; and Rees, 2007). The technique works on the principle that the constructive interference of X-rays diffracted from the planes of atoms within the solid give rise to a characteristic diffraction peak or a sequence of peaks that are unique to a particular material. Thus, XRD may be a useful tool for the present study even though the amount of information which can be obtained is limited due to the substantial amorphous nature of geopolymers. However it does provide information regarding the extent to which starting materials (precursor and activating solution) have reacted (Van Jaarsveld, 2000). Fig. 2.5 presents the XRD pattern of geopolymers when slag and kaolinite are used as raw materials. The analysis of samples $A$ and $B$, synthesized at $60^{\circ} \mathrm{C}$ and $80^{\circ} \mathrm{C}$ respectively for $48 \mathrm{~h}$ and left for curing for 28 days, reveals the presence of quartz, magnetite and maghemite which were initially seen in the unreacted slag. The presence of remaining kaolinite indicates that the initially used quantity of slag has not fully reacted during geopolymerisation. Synthetic sodalite, $\mathrm{Na}_{8} \mathrm{Al}_{6} \mathrm{Si}_{6} \mathrm{O}_{24}(\mathrm{OH})_{2}\left(\mathrm{H}_{2} \mathrm{O}\right)_{2}$, is produced by replacing $\mathrm{Cl}^{-}$with $\mathrm{OH}^{-}$when $\mathrm{NaOH}$ reacts with kaolinite according to reaction (Eq. 2.4) (Komnitsas et al., 2007):

$$
3 \mathrm{Al}_{2}\left(\mathrm{Si}_{2} \mathrm{O}_{5}\right)(\mathrm{OH})_{4}+8 \mathrm{NaOH} \rightarrow \mathrm{Na}_{8} \mathrm{Al}_{6} \mathrm{Si}_{6} \mathrm{O}_{24}(\mathrm{OH})_{2}\left(\mathrm{H}_{2} \mathrm{O}\right)_{2}+7 \mathrm{H}_{2} \mathrm{O}
$$

$A A B$ which harden at room temperatures are usually $X$-ray amorphous. In the noncrystalline state, the diffraction of X-rays results in broad diffuse halo rather than sharp peaks (Kamhangrittirong et al., 2007). Examination of sodium silicate glasses by Roode and Hemmings (1985) showed the presence of peaks corresponding to low molecular weight silicates. There was a marked shift in the halo to the higher 2-theta max with increasing $\mathrm{Na}_{2} \mathrm{O}$ content. If similar logic is applied to $A A B$, it can be concluded that $A A B s$ are the amorphous equivalent of most of the major crystalline framework silico-aluminates. 


\subsubsection{XRD of fly ash-based AAB}

The main crystalline phases of fly ash detected from XRD (Fig. 2.5, Kamhangrittirong et al., (2007) were quartz $\left(\mathrm{Q}, \mathrm{SiO}_{2}\right)$, mullite $\left(\mathrm{A}, \mathrm{Al}_{2} \mathrm{O}_{3}\right)$ and magnetite $\left(\mathrm{M}, \mathrm{Fe}_{2} \mathrm{O}_{3}\right)$. The crystalline pattern of samples showed a shoulder at 2-theta ranging from 20 to $30^{\circ}$, indicating the presence of amorphous phases (Kamhangrittirong et al., 2007). The humps in XRD patterns of geopolymers are different from that in the original fly ash, which indicates the dissolution of fly ash glass phases and formation of amorphous structure in the geopolymer. This observation is in consistent with that published by Davidovits (1983). Besides this hump, the crystalline phase of hematite, magnetite and partially silica-alumina phases still appeared in the geopolymer, which appears to agree with the observation of non-dissolved fly ash spheres under SEM images (Kamhangrittirong et al., 2007).

Fig. 2.5 (Kamhangrittirong et al., 2007) shows the XRD diffractograms obtained for all hardened $A A B$ pastes and also the fly ash raw material. The main crystalline phases identified in fly ash are quartz $\left(\mathrm{SiO}_{2}\right)$ and mullite $\left(\mathrm{Al}_{6} \mathrm{Si}_{2} \mathrm{O}_{13}\right)$. Fly ash also consists of an Xray amorphous aluminosilicate material, demonstrated by the broad hump from approximately 20 to $40^{\circ} 2 \theta$. It can be seen from Fig. 2.5 that no significant change in intensity for the quartz or mullite peaks was observed in the geopolymer samples. This was expected, because it is predominantly the X-ray amorphous (glassy) phases in fly ash that undergo dissolution and subsequent geopolymerisation at high $\mathrm{pH}$ of 14 .

A distinguishing feature between the $A A$ reference sample $(\mathrm{Si} / \mathrm{Al}=1.95)$ and the other $\mathrm{AABs}$ $(\mathrm{Si} / \mathrm{Al}=2.2)$ is the formation of hydroxy sodalite, a low silica zeolite $\left(\mathrm{Na}_{6}\left(\mathrm{Si}_{6} \mathrm{Al}_{6} \mathrm{O}_{24}\right) \cdot 8 \mathrm{H}_{2} \mathrm{O}\right)$. This is to be expected because the hydrothermal $\mathrm{NaOH}$ treatment of fly ash is known to produce zeolites such as hydroxy sodalite. It should be noted that the geothermal silica sample (GP) does show some small peaks in regions indicating minor sodalite formation. This could occur if the silica dissolved slowly and the silicate species in solution did not migrate far from the particle surface. This results in regions which are silica rich and others which are silica deficient. It is possible that the silica deficient gel is able to form the low silica crystalline hydroxy sodalite phase, while the X-ray amorphous phase with higher silicate content binds the phase separated system. The HC compound shows a small hump in the region $20-25^{\circ} 2 \theta$. A hump in this region is characteristic of amorphous silica. This indicates that there may be some unreacted rice hull ash in the $\mathrm{HC}$ system (Kamhangrittirong et al., 2007). 


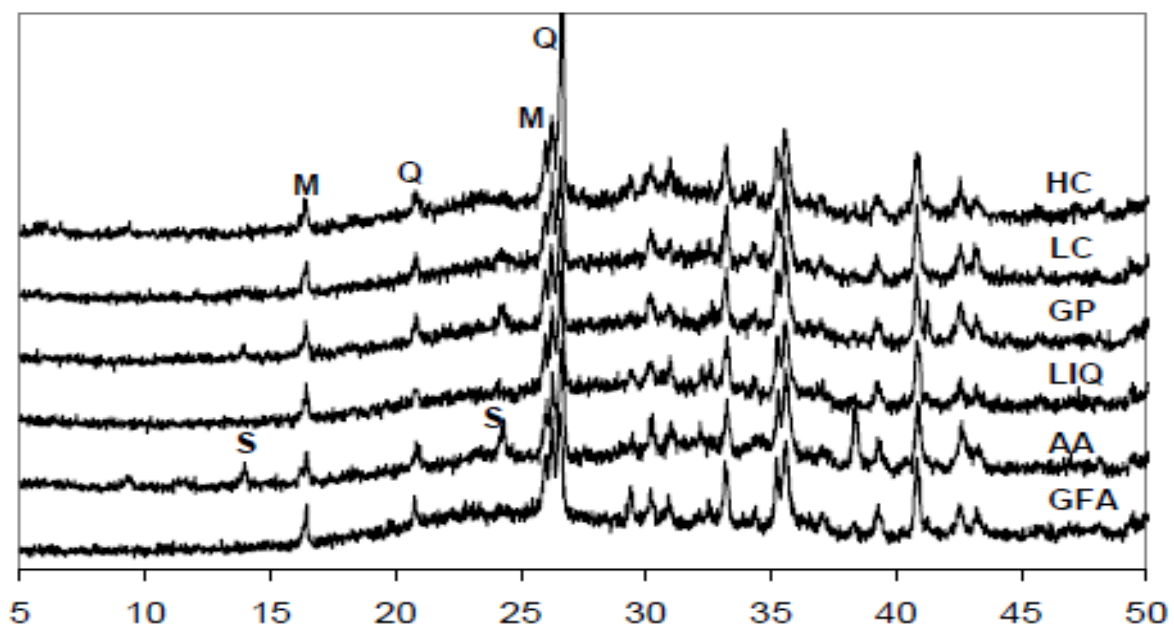

2-Theta (deg)

Fig. 2.5 XRD diffractograms of geopolymers derived from flyash and solid silicate material: GP - geothermal silica, LC - low carbon rice hull ash, HC - high carbon rice hull ash. Reference samples: LIQ - silicate solution; AA - alkali activation only. GFA - unreacted flyash; S - hydroxy sodalite; Q - quartz; M - Mullite (Kamhangrittirong et al., 2007).

In general, the X-ray diffractograms for all silicate activated geopolymers were similar (Fig 2.5). Other than those mentioned above, no new crystalline phases were identified as products of the reactions. Although XRD is an analytical technique commonly used to investigate geopolymer systems, the technique has significant limitations due to the apparent amorphous nature of geopolymer materials. The XRD diffractograms show that the raw materials and most of the newly formed geopolymer products are X-ray amorphous. For this reason, other analytical techniques need to be used in conjunction with XRD to provide insight into the structural characteristics of AABs (Rees et al., 2004).

In another study, the results of XRD of PC and AAB concrete were compared by KupwadePatil and Allouche (2011). The PC specimen exhibited peaks of sygenite at 16, 22 and 32 degree 2-theta. Peaks of thenardite were observed at 22, 48, 49 and $59^{\circ} 2$-theta. The potassium and sodium in Portland cement were found to exist as sulfate phases and due to the $\mathrm{NaOH}$ exposure and elevated temperature conditions, the PC exhibited the additional formation of syngenite. 


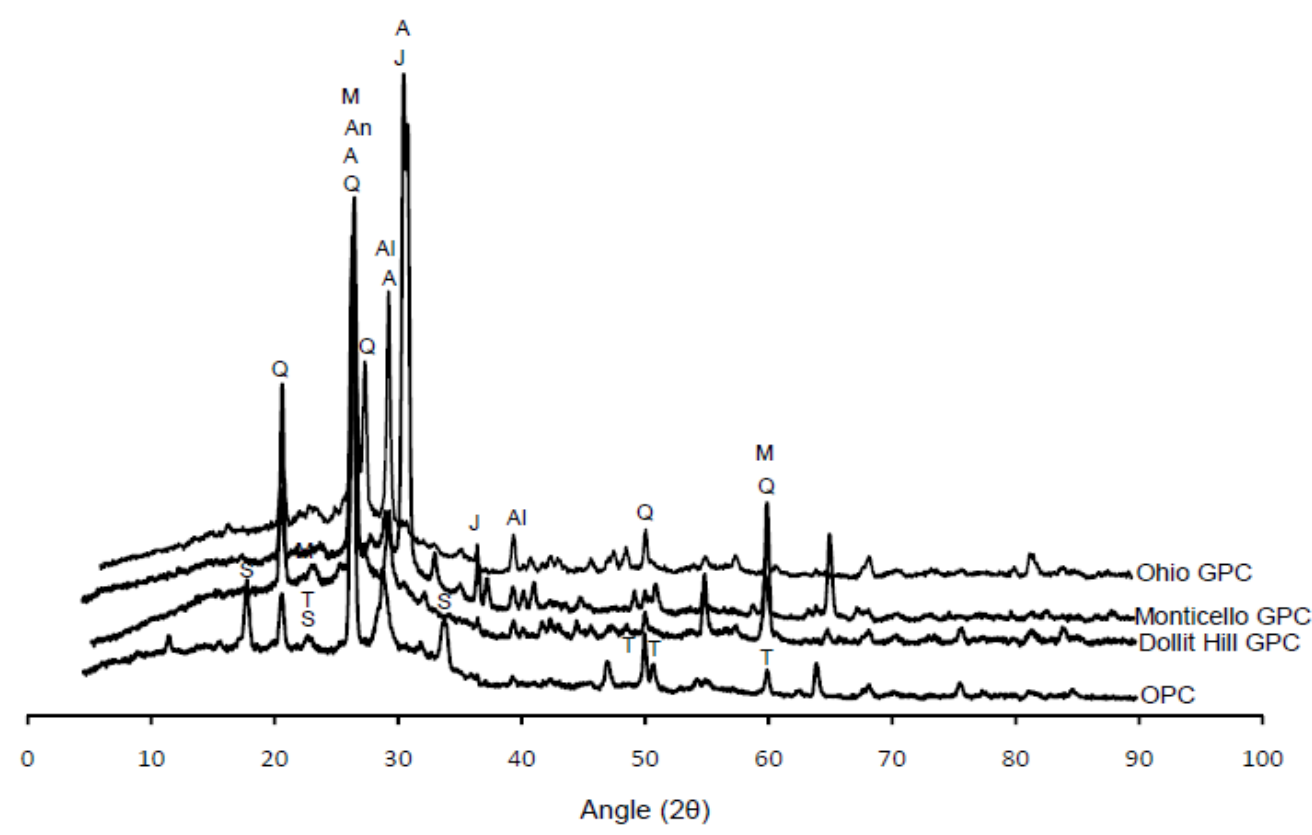

S - Syngenite, T - Thenardite, Q - Quartz, A-Analcime, An-Anorthite, M-Mullite, J-Jadeite, Al- Albite

Fig. 2.6 XRD Analysis of geopolymer concrete (GPC) and Portland Cement (OPC) [KupwadePatil and Allouche (2011)]

XRD analysis of the geopolymer concrete showed presence of quartz, analcime, anorthite, mullite, jadeite and albite. The presence of anorthite phases indicates that calcium ion from the limestone coarse aggregate is reacting with the Na-poly(sialate-siloxo) along with aluminosilicate forming Ca-poly(sialate), anorthite and albite. Albite can be associated with the strength enhancement region of the geopolymer matrix (Kupwade-Patil and Allouche, 2011). Previous research has shown that compressive strength increases from 20 to $90 \mathrm{MPa}$ with $40 \sim 50 \%$ addition of albite. The analcime phase belongs to the zeolite group. This analcime is formed when fly ash is mixed with $\mathrm{NaOH}$, and acts a precursor for geopolymerization. The GPC specimens made with Monticello fly ash showed the presence of jadeite which belongs to the family of aluminosilicates. The mullite phase is partially involved in the zeolitization process and less reactive compared to other aluminosilicates.

\subsubsection{SEM/EDS}

Scanning electron microscopy (SEM) is an imaging technique using a beam of focused electrons to scan the surface of specimens. The scanning assembly is composed of a 
tungsten filament heated by high voltage. A series of electromagnetic lenses guide the electrons towards the target and the electron beam meets the surface of the specimen through a small aperture. The impact of the electron beam with the surface of the specimen generates a volume of excited atoms depending on the accelerating voltage, which is usually around $5 \sim 10 \mathrm{keV}$ for the specimens used in the current study. This impact also causes some of the electrons from the specimen to be released as secondary electrons. When the other electrons from the scanning beam hit the nuclei of the atoms of the specimen, they are reflected back from the sample as backscattered electrons. SEM images are produced by scanning one spot on the surface of the specimen at a time in a grid-like raster pattern. Areas on the surface which reflect large volume of electrons appear bright, while the areas which reflect less volume of electrons, appear dark on the image generated. It is worth mentioning here that the smoothness of the surface of the specimen governs the accelerating voltage. If the accelerating voltage is too high and the surface of the specimen has undulations, then the electrons scatter from the surface and the quality of the resulting image is tarnished. This necessitates the polishing of the surface of the specimens before being scanned through the microscope. The details of the polishing technique will be discussed in the following section.

\subsubsection{SEM results}

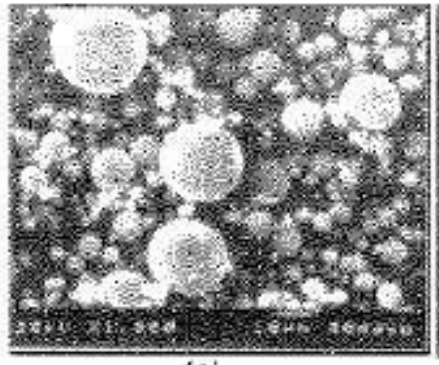

(a)

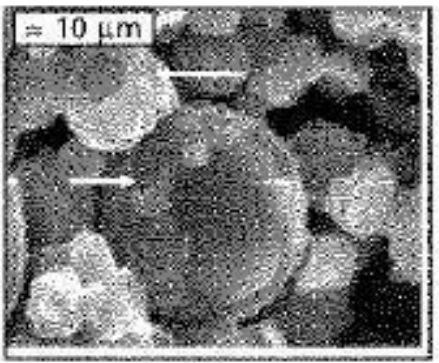

(b)

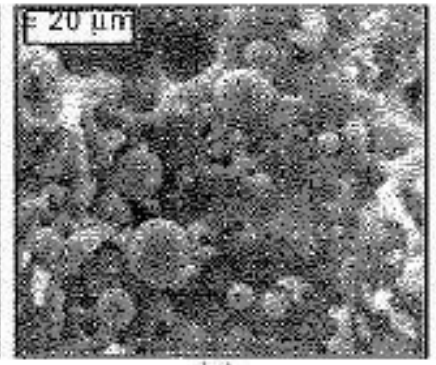

(c)

Fig. 2.7 SEM images: (a) original fly ash; (b) fly ash activated with $8 \mathrm{M} \mathrm{NaOH}$ for 20 hours at $85^{\circ} \mathrm{C}$ (showing reaction details for small spheres); (c) fly ash activated with sodium silicate (Provis and Van Deventer 2009 with data from Fernandez-Jimenez 2005d).

The microstructure of $A A B$ concrete produced from fly ash precursor depends on several factors such as (i) particle size distribution of fly ash, (ii) mineral composition of the initial fly ash, (iii) type of alkali activator, and (iv) concentration of the activating solution (Provis and van Deventer 2009). The characteristic morphology obtained through SEM analysis of 
the fly ash used in their study has been shown in Fig. 2.7(a). The microstructure was made up of a series of spherical vitreous particles of various sizes in the range of $10-200 \mu \mathrm{m}$. The spheres were hollow in general but some of them contained other particles of smaller size inside them. The changes in the fly ash microstructure after alkali activation with subsequent thermal curing are provided in Figs. 2.7(b) and 2.7(c). The primary reaction product resulting from the alkali activation was a sodium silicate gel that gave rise to the cementitious matrix. Some small fly ash particles which have already reacted with the alkaline liquid coexist with the unreacted particles and even with the spherical particles partially covered with the reaction products (Fig. 2.7(b) and and 2.7(c)). Those spherical particles which were covered by the reaction products slowed down the degree of reaction to some extent.

Muzek et al. (2012) observed sodium silicate gel was observed as the majority product, along with the unreacted FA particles, up to 28 days age for all the specimens. The microstructure was highly inhomogeneous and the matrix was full of loosely structured FA grains of different sizes. Numerous circular cavities surrounding FA particles were evident in the gel. Tubular vitreous network representing FA was found to surround the cavities (Figs. 2.8a through $\mathrm{d}$ ). The considerable amount of unreacted spheres, as well as the presence of pores in the AAB matrix (Fig. 2.8d) indicated an incomplete reaction in the system and could explain why the alkali activated fly ash samples showed a lower degree of reaction. Fig. 2.8 clearly showed inhomogeneous glass-like matrix of the amorphous aluminosilicate gel. The unreacted spheres of FA indicated an incomplete reaction in the systems investigated. The low degree of reaction (up to $32.86 \%$ after 28 days), associated with low reactivity of FA used also confirmed this finding. 


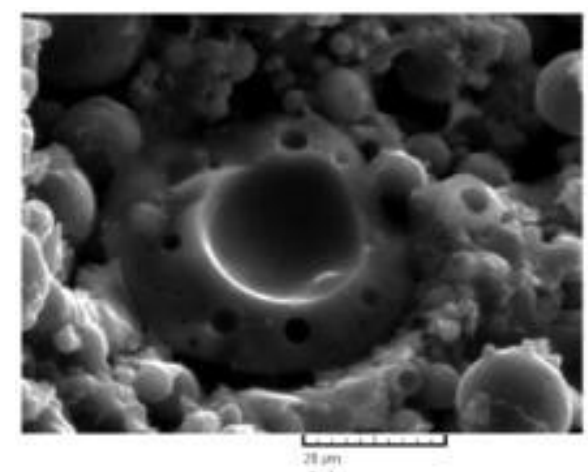

(a)

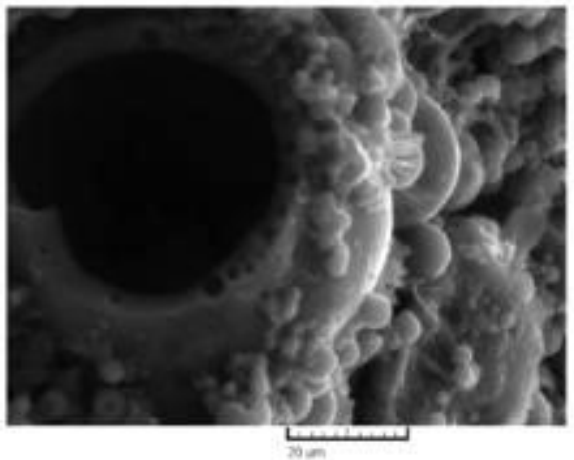

(c)

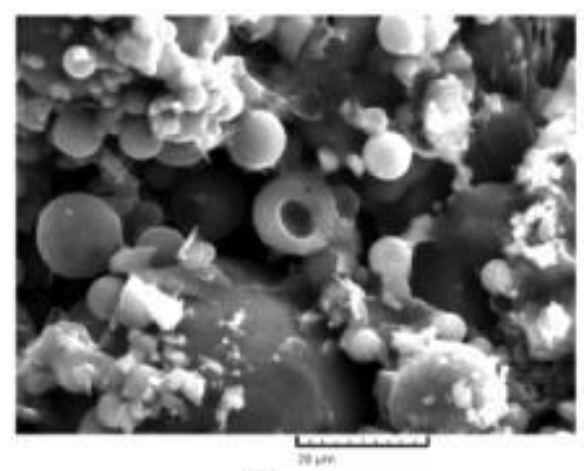

(b)

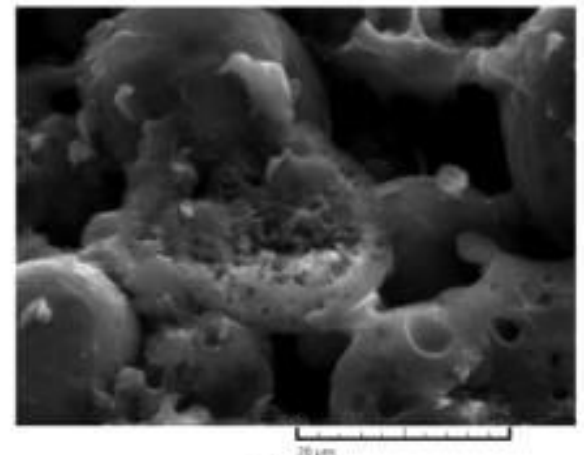

(d)

Fig. 2.8 SEM micrographs of the hardened alkali activated fly ash samples (Muzek et al. 2012)

\subsubsection{Energy Dispersive $X$-ray Spectroscopy (EDS) results}

Energy Dispersive X-ray Spectroscopy (EDS) analysis of gel showed that gel mostly consists of the phases containing $\mathrm{Na}-\mathrm{Si}-\mathrm{Al}$ in the binder paste matrix suggesting the formation of silicate-activated gel by polymerization throughout the inter particles volume (De Silva et al., 2007 and Lloyd et al., 2009). This correlates with the published works of Lee and Deventer (2002) meaning that, in a medium with a high concentration of dissolved silica, the species dissolved from the surface of FA particles migrate from the surface into the bulk solution. In addition to $\mathrm{Na}, \mathrm{Si}$ and $\mathrm{Al}$, small amounts of $\mathrm{Fe}, \mathrm{Ca}, \mathrm{K}$ and $\mathrm{Mg}$ was also observed in the gel by EDS analysis (Fig. 2.9). These remnants (Fe, $\mathrm{Ca}, \mathrm{K}, \mathrm{Mg}$ ) obviously represent the FA phases, which for various reasons, did not dissolve during alkali activation. Lloyd et al. (2009) suggested that during alkaline activation these remnants may even disperse through the gel. According to Muzek et al. (2012), different solubility of phases in the aluminosilicate gel formed determines the distance of these remnants from the surface of 
FA particle. It appears that Mg does not disperse in the gel to the same extent as Ca (Fig. 2.9). The properties of resulting geopolymer systems depend on not only the composition and reactivity of the fly ash used, but also on the initial $\mathrm{SiO}_{2} / \mathrm{Al}_{2} \mathrm{O}_{3}$ ratio in the mixture (Fig. 2.9). Pre-processing (e.g. fine grinding and polishing the surface of the paste specimens) and/or use of a combination of raw materials of different reactivity, as well as selection of an activator in a geopolymer system are required to achieve the desired product properties (Muzek et al. 2012).

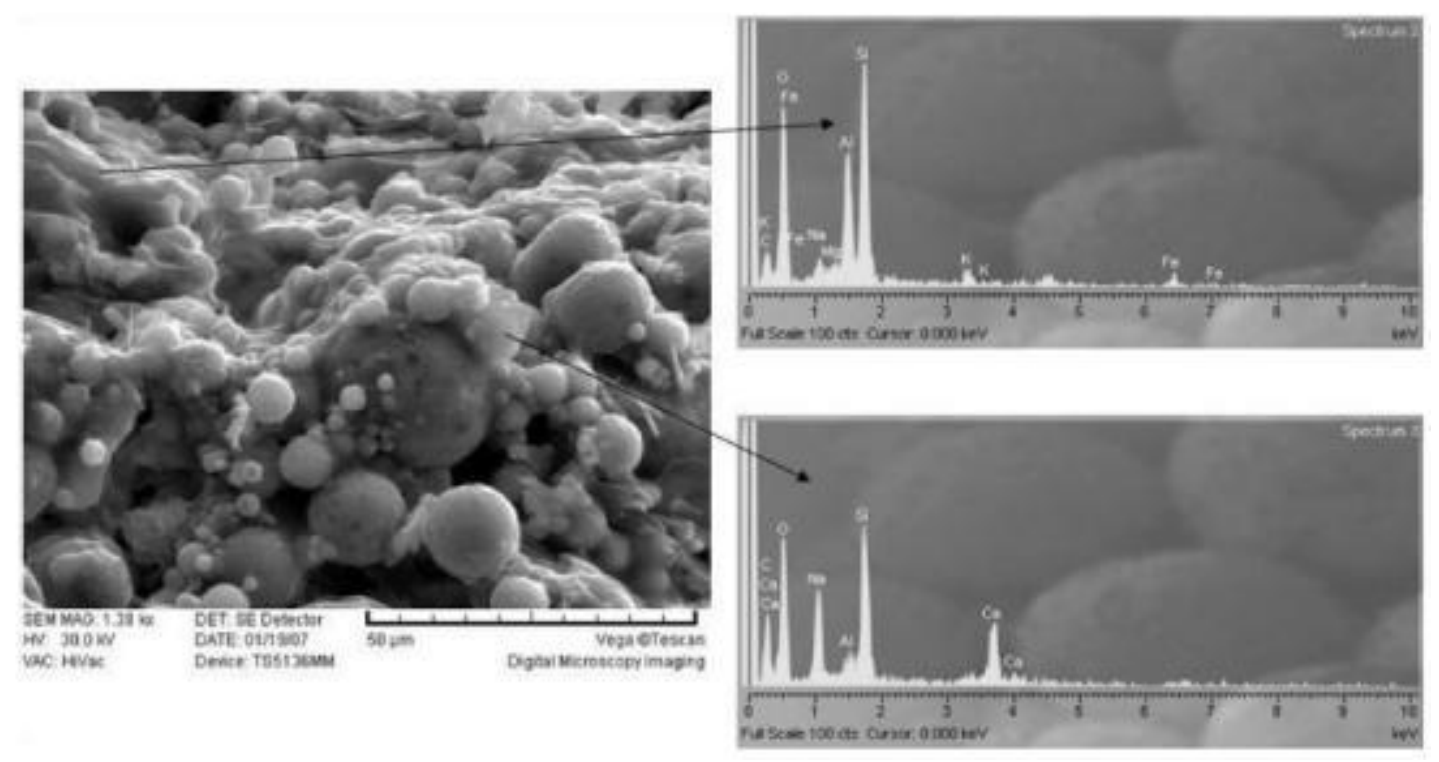

Fig. 2.9 SEM micrographs and EDS analysis of the hardened alkali activated fly ash samples (Muzek et al. 2012)

\subsection{Fourier Transform Infra-Red (FTIR) spectroscopy}

Mid-Infrared (IR) spectroscopy is an extremely reliable and well recognized fingerprinting method. Many substances can be characterized, identified and also quantified. One of the strengths of IR spectroscopy is its ability as an analytical technique to obtain spectra from a very wide range of solids, liquids and gases. Traditionally IR spectrometers have been used to analyze solids, liquids and gases by means of transmitting the infrared radiation directly through the sample. Where the sample is in a liquid or solid form the intensity of the spectral features is determined by the thickness of the sample and typically this sample thickness cannot be more than a few tens of microns. 
In the recent years, several aluminosilicate minerals have been examined through Fourier Transform Infra-Red (FTIR) spectroscopy (Breck, 1974; Barbosa et al., 2000; van Jaarsveld and van Deventer, 1999; and Lee and van Deventer, 2003). Majority of the results were concerned with the behavior of the ( $\mathrm{Si}, \mathrm{Al}-\mathrm{O}$ ) band, which is found close to the $1000 \mathrm{~cm}^{-1}$. Based on the available research, some IR characteristic bands spectra and corresponding geopolymer precursors are available to the users (Barbosa et al., 2000). The details are provided in Table 2.2 .

Table 2.2 IR Characteristic Bands of AAB Chemical Units/bonds

\begin{tabular}{|c|c|}
\hline Geopolymer chemical units/bonds & IR characteristic bands \\
\hline $\mathrm{Si}-\mathrm{O}$ & $1080-1100 \mathrm{~cm}-1$ (symmetrical vibration) \\
\hline $\mathrm{Si}(\mathrm{Al})-\mathrm{O}$ & $1008 \mathrm{~cm}-1$ (asymmetrical vibration) \\
\hline $\mathrm{Al}-\mathrm{OH}$ & $\begin{array}{c}914 \mathrm{~cm}-1 \text { (6 coordinated Al-OH stretching } \\
\text { vibration) }\end{array}$ \\
\hline $\mathrm{Si}-\mathrm{OH}$ & $840 \mathrm{~cm}-1$ (bending vibration) \\
\hline Al-O & $\begin{array}{c}798 \mathrm{~cm}-1 \text { (4 coordinated Al-OH stretching } \\
\text { vibration) }\end{array}$ \\
\hline $\mathrm{Si}-\mathrm{O}$ & $694 \mathrm{~cm}-1$ (symmetrically stretching vibration) \\
\hline $\mathrm{Si}-\mathrm{O}-\mathrm{Al}$ & $540 \mathrm{~cm}-1$ (bending vibration) \\
\hline Si-O & $469 \mathrm{~cm}-1$ (in-plane bending vibration) \\
\hline
\end{tabular}

A systematic investigation of the framework structures of many synthetic zeolites were conducted in the mid-infrared by Flaningen et al. (1971). Interpretations of these spectra were based on assignment of the infrared bands to certain structural groups in the various zeolite frameworks (Davidovits 1999). In order to conduct this assignment on AAB, it is necessary to have knowledge of the basic polymeric structure. Hence, the investigation of AAB through FTIR spectroscopy complements the analyses through $X$-ray structural analysis and MAS-NMR spectroscopy.

Chollet and Horgnies (2011) analyzed the surface of concrete (with surface preparation using different chemical reagents) using FTIR spectroscopy and detected the following spectra. 
Table 2.3 IR Characteristic Bands of Chemical Units/bonds in Portland Cement Concrete Surface Treated by Chemical Reagents (Chollet and Horgnies, 2011)

\begin{tabular}{|c|c|}
\hline Bond/chemical unit & FTIR band associated $\left(\mathrm{cm}^{-1}\right)$ \\
\hline $\mathrm{O}-\mathrm{H}$ (in Portlandite, $\mathrm{Ca}(\mathrm{OH})_{2}$ ) & 3640 \\
\hline $\mathrm{SiO} 4$ (in $\mathrm{CSH}$ ) & 974 \\
\hline $\mathrm{S}-\mathrm{O}$ (in $\mathrm{SO}_{4}{ }^{2-}$ units) & 1111 \\
\hline $\mathrm{C}-\mathrm{O}\left(\right.$ in $\left.\mathrm{CaCO}_{3}\right)$ & $712,872,1410,1800,2510$ \\
\hline $\mathrm{O}-\mathrm{H}\left(\right.$ in $\mathrm{H}_{2} \mathrm{O}$ ) & $1650,3200-3400$ \\
\hline $\mathrm{C}=\mathrm{O}\left(\right.$ in $\left.\mathrm{CO}_{2}\right)$ & $2000-2200$ \\
\hline $\mathrm{Si}-\mathrm{O}-\mathrm{CH}_{3}$ (in Siloxane units) & 778,1270 \\
\hline Si-O-Si (in Siloxane units) & $1000-1200$ \\
\hline $\mathrm{CH}_{2} / \mathrm{CH}_{3}$ & 2850,2925 \\
\hline $\mathrm{CH}_{2} / \mathrm{CH}_{3}$ & 1453 \\
\hline $\mathrm{CH}=\mathrm{CH}$ & 3026 \\
\hline $\mathrm{C}-\mathrm{H}$ (in aromatic units) & $699,760,3060$ \\
\hline $\mathrm{C}-\mathrm{H}$ & 1383 \\
\hline $\mathrm{N}-\mathrm{H}$ & 1520,3300 \\
\hline $\mathrm{C}-\mathrm{N}$ & 1570 \\
\hline $\mathrm{C}=\mathrm{O}$ (in urea units) & $1640-1725$ \\
\hline C-O (in ester units) & $1010-1220$ \\
\hline
\end{tabular}

In a study on synthesis and characterization of materials based on inorganic polymers of alumina and silica (metakaolin based sodium polysialate polymers), Barbosa et al. (2000) also implemented FTIR techniques to identify the possible phases in their material. On the formation of the polymer, the following changes in the spectra were noted:

(i) The presence of water increased the intensity of the bands at about 3500 and $1650 \mathrm{~cm}^{-1}$.

(ii) Major disruption of the Al environment was indicated by the loss of the Si-O-Al band at $810 \mathrm{~cm}-1$ which was replaced by several weaker bands in the range of $600-800 \mathrm{~cm}^{-1}$.

(iii) The presence of sodium carbonate was indicated by the band at $1460 \mathrm{~cm}^{-1}$. 
The spectra for the present study were obtained using the PerkinElmer Spectrum 100 fitted with Attenuated Total Reflectance (ATR) arrangement. The technique of ATR has in recent years revolutionized solid and liquid sample analyses because it combats the most challenging aspects of infrared analyses, namely sample preparation and spectral reproducibility (http://www.utsc.utoronto.ca/ traceslab/ATR_FTIR.pdf).

\section{Principles of ATR}

An attenuated total reflection accessory operates by measuring the changes that occur in a totally internally reflected infrared beam when the beam comes into contact with a sample (indicated in Fig. 2.10).

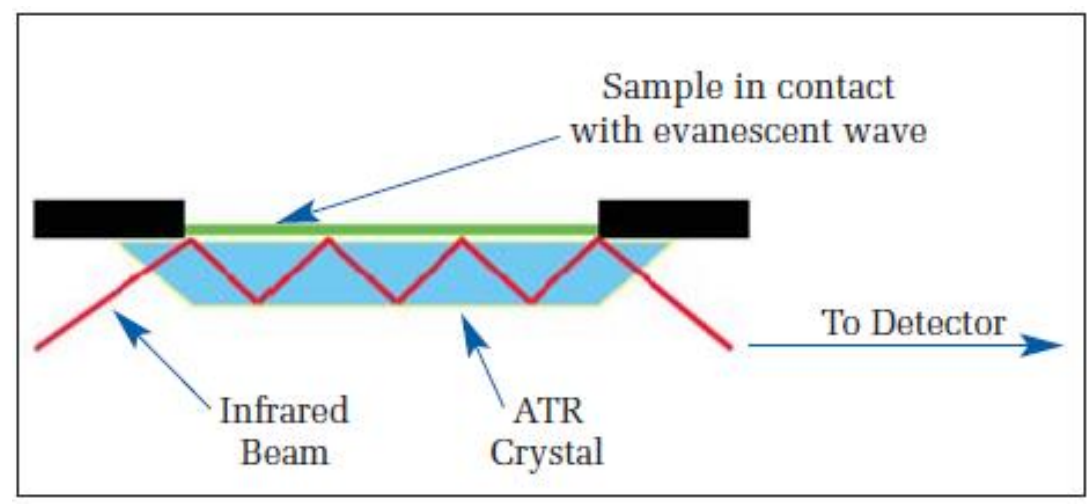

Fig. 2.10 Multiple reflection ATR system (http://www.utsc.utoronto.ca/ traceslab/ATR_FTIR.pdf)

An infrared beam is directed onto an optically dense crystal with a high refractive index at a certain angle. This internal reflectance creates an evanescent wave that extends beyond the surface of the crystal into the sample held in contact with the crystal. It can be easier to think of this evanescent wave as a bubble of infrared that sits on the surface of the crystal. This evanescent wave protrudes only a few microns $(0.5 \mu-5 \mu)$ beyond the crystal surface and into the sample. Consequently, there must be good contact between the sample and the crystal surface. In regions of the infrared spectrum where the sample absorbs energy, the evanescent wave will be attenuated or altered. The attenuated energy from each evanescent wave is passed back to the IR beam, which then exits the opposite end of the crystal and is passed to the detector in the IR spectrometer. The system then generates an infrared spectrum. 
For the technique to be successful, the following two requirements must be met:

- The sample must be in direct contact with the ATR crystal, because the evanescent wave or bubble only extends beyond the crystal $0.5 \mu-5 \mu$.

- The refractive index of the crystal must be significantly greater than that of the sample or else internal reflectance will not occur - the light will be transmitted rather than internally reflected in the crystal. Typically, ATR crystals have refractive index values between 2.38 and 4.01 at $2000 \mathrm{~cm}^{-1}$. It is safe to assume that the majority of solids and liquids have much lower refractive indices.

\subsection{Nondestructive Characterization of Cement Using Ultrasound Techniques}

Smith et al. (2002) investigated the correlation between hydration mechanism and ultrasonic measurements in aluminous cement using ultrasound techniques. The ultrasonic characterizations were done at $5,20,40$ and $60^{\circ} \mathrm{C}$. The relative humidity was equal to $95 \%$. The experimental set-up used for ultrasonic measurements consisted of setting short pulses of acoustic waves across the specimen. These waves are radiated by a source (transducer) with sufficiently low amplitude of vibration for the cement to remain in its viscoelastic or elastic state depending on whether it is a liquid or a solid.

Reflection pulse echo technique allows measurement the transit time related to the ultrasonic velocity. The experimental set-up is designed to operate in a semi-infinite mode (Fig. 2.11), which means that the dimensions of the tested sample are very large compared to the ultrasonic wavelength. A transducer sends wideband pulses of longitudinal ultrasonic waves with a central frequency of $1 \mathrm{MHz}$, which propagates into a buffer acting as a delay line. Considering the dimensions of the mould $(100 \times 50 \times 10 \mathrm{~mm})$, the average particle size of the cement powder $(10 \mu \mathrm{m})$ and the typical value of the longitudinal wave velocity of about $3500 \mathrm{~m} / \mathrm{s}$ measured on 24-h old cement samples, the value of the central frequency $(1 \mathrm{MHz})$ has been chosen in order to be in accordance with the semi-infinite mode $[\lambda$ (wavelength) $<$ dimensions of the mould] and with the homogeneity of the material $[\lambda$ (wavelength) >> average particle size] (Smith et al. 2002). The longitudinal wave velocity has been measured in the $10-\mathrm{mm}$ direction. The proportion of transmitted wave inside the cement-based material depends on the reflection coefficient at the buffer/cement interface. 
The transit time, $t$ (in seconds), through the cement sample was related to its thickness, e, and the velocity of longitudinal wave, $V_{L}\left(\mathrm{~m} \mathrm{~s}^{-1}\right)$, as follows:

$$
V_{L}=\frac{2 e}{t}
$$

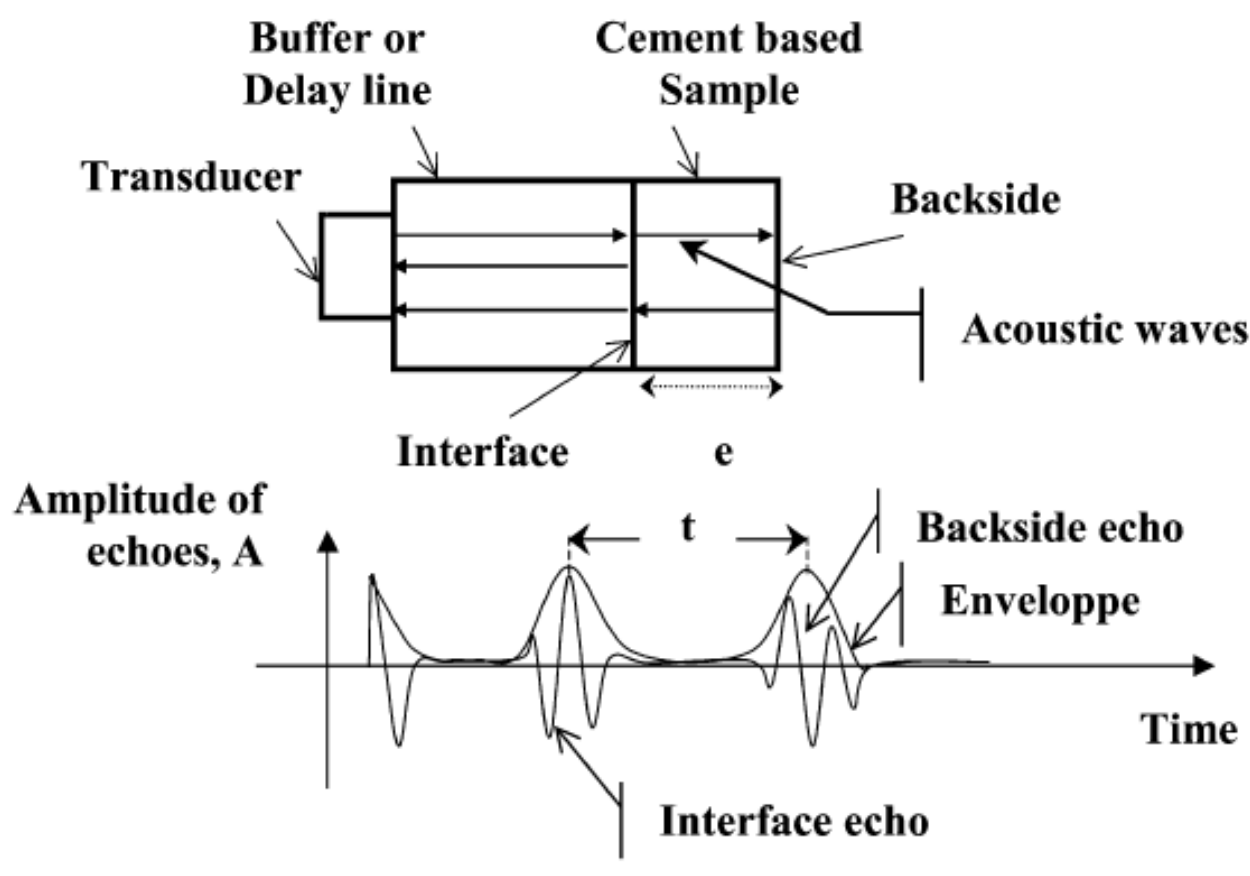

Fig. 2.11 Experimental setup for ultrasonic measurements (Smith et al. 2002).

Their experimental set-up also permitted measurement of the amplitude, $A$, of the waves reflected at the buffer/cement interface. The corresponding reflection coefficient, $R$, was related to the acoustic impedance (in $\mathrm{kg} \mathrm{m}^{-2} \mathrm{~s}^{-1}$ ) of the two materials, namely the cement $\left(Z_{\text {cement }}\right)$ and the buffer $\left(Z_{\text {buffer }}\right)$, by the following relation (Smith et al. 2002):

$$
R=\frac{Z_{\text {cement }}-Z_{\text {buffer }}}{Z_{\text {cement }}+Z_{\text {buffer }}}
$$

Buffer was made of poly(methyl methacrylate) (PMMA), commercially known as Plexiglas, which has acoustic impedance close to that of PC when it is in the plastic state (Smith et al. 2002).

In the next section, the modeling concept to correlate the microscale and the specimen level characteristics will be described. 


\subsection{Correlation between Microscale and Mechanical Characteristics at Specimen Level Using Nondestructive Characterizations}

In order to have a comprehensive understanding of the composition of geopolymer concrete on its mechanical properties, it is necessary to formulate a correlation between the microstructural characteristics and the specimen level properties. Recently, FernandezJimenez and Palomo (2003), by interpreting FTIR and NMR results, showed how important the role of the reactive aluminum is in the kinetics of gel formation and in the mechanical strength behavior when working with fly ashes. They analyzed the relationship between mechanical strengths and the relative amount of $Q^{4}(4 A l)$ versus $Q^{4}(3 A l)+Q^{4}(2 A l)$ units in gels. From these results, it was concluded that the mechanical strength of the geopolymer increases during formation of an Al-rich aluminosilicate gel (Gel 1) in the first stage of the alkaline activation of fly ash particles, but increases further as a result of the Si enrichment of the material (formation of Gel 2 Si enriched aluminosilicate gel) (Fig.2.12).
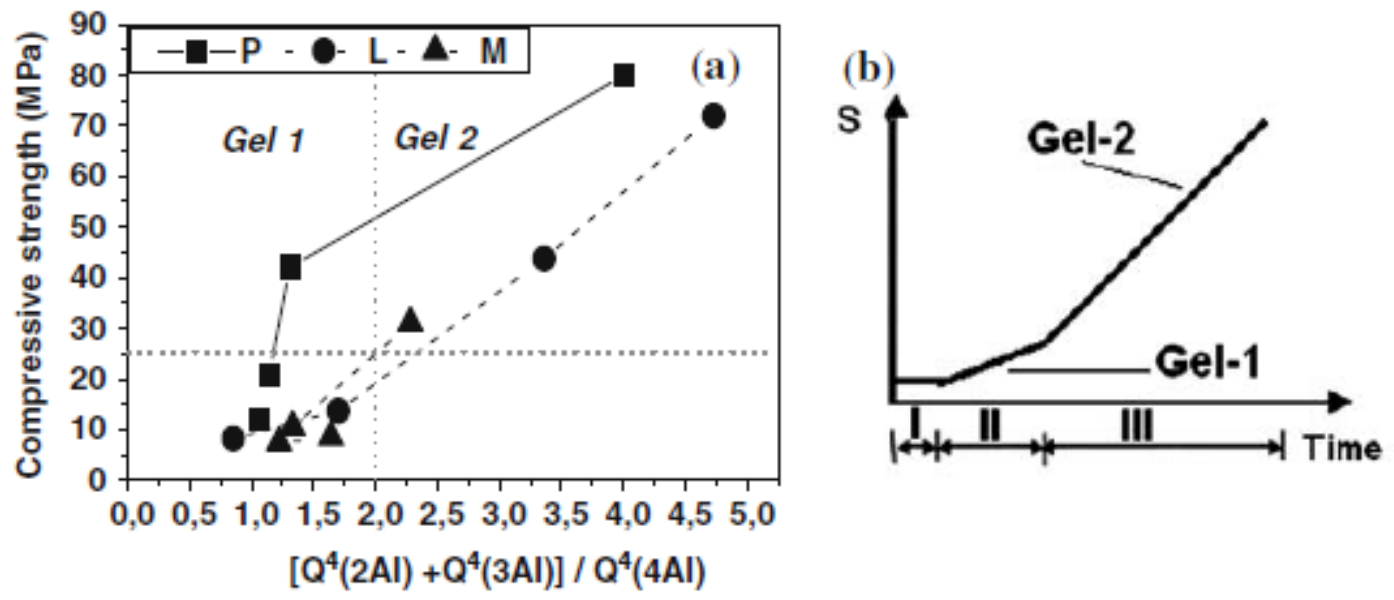

Fig. 2.12 (a) Mechanical strength versus $\mathrm{Q}^{4}(2 \mathrm{Al})+\mathrm{Q}^{4}(3 \mathrm{Al}) / \mathrm{Q}^{4}(4 \mathrm{Al})$ ratios deduced by $\mathrm{NMR}$ spectroscopy for three fly ashes with different reactive alumina content $(P \approx 18.0 \%$; $\mathrm{L} \approx 22.5 \% ; \mathrm{M} \approx 12.6 \%$ ); (b) Schematic description of mechanical properties evolution with reaction time as function of chemical composition of gel (Fernandez-Jimenez and Palomo, 2003).

Popovics (1973) proposed a constitutive model for PC, by correlating the compressive strength development with the modulus of elasticity. It was found that the model proposed by Popovics can be used for $A A B$ concrete with minor modification to the expression for the curve fitting factor (Sarker 2008). 
The in-place value of concrete compressive strength, $f_{c}^{\prime}$, as a general index of concrete strength can be determined by nondestructive testing (NDT) methods. The commonly used NDT methods to predict fc include the rebound hammer test, the ultrasonic pulse velocity (UPV) test, maturity, and cast-in-place cylinders. ACI 228.1R-031 provides a guideline for applying these NDT methods. As found by many researchers, the combined methods that refer to the use of two or more in-place testing methods can lead to a more accurate and reliable prediction. Among the combined methods, the one most frequently used is a combination of the rebound hammer test and the UPV test, known as SonReb (Huang et al. 2011). This combination technique is advantageous because the rebound number (RN) obtained by the rebound hammer test provides information about the concrete strength near the surface, whereas the results obtained from the UPV test reflects the interior concrete properties.

There are three techniques that are commonly used to predict $f_{c}{ }^{\prime}$ based on the SonReb measurements: computational modeling, artificial intelligence, and parametric multivariable regression models. Computational modeling is based on the modeling of complex physical phenomena. Popovics (1973) reviewed the mathematical models for the prediction of the $\mathrm{f}_{\mathrm{c}}$ of PC concrete. Lin et al. established mathematical models for predicting the UPV in concrete. Computational modeling, however, is often not practical due to the complexity of the model and/or the time consuming numerical computation. Artificial intelligence, including the artificial neural network (ANN) and the fuzzy logic method, is a nonparametric statistical tool without knowing the theoretical relationships between the input and the output. Artificial intelligence only provides the best fit between the predictions and the observations; it gives no physical meaning for the relationship between the input and the output. Parametric multi-variable regression models, on the other hand, can be more easily implemented and used in practice for future applications (such as the reliability assessment of reinforced PC concrete structures incorporating field data). In particular, the confidence interval of a prediction calculated by a parametric regression model can reflect the accuracy of the estimation, and the statistics of the model parameters of the model can provide insights on how each variable in the model influences the prediction. A number of parametric regression models using the SonReb measurements (UPV and RN) to predict fC have been developed. As the regression models can only be applied to the concrete with the same characteristics of the concrete used for their calibration, those models are not sufficiently valid because of the limited range of the calibration data used. Therefore, a robust regression model based on a wider range of concrete properties is needed for more 
general use. In addition to the SonReb measurements, other variables may be needed in the model to improve the accuracy of the prediction (Huang et al. 2011).

With these considerations, the use of a probabilistic multi-variable regression model appears to be the most practical approach for the present study. However, there is limited data available for UPV test on geopolymer concrete. Bondar et al. (2010) conducted UPV tests to characterize alkali activated natural pozzolan concrete. So, it is necessary to conduct thorough UPV testing of fly ash based geopolymer before using the data for modeling purposes in the current study.

The correlation between the microstructural properties and the mechanical properties at the specimen level will be established by using the statistical software called ' $R$ '. A brief discussion on this software is provided in the following section:

\subsection{Brief Overview of $\mathbf{R}$}

$R$ is an open source programming language and software environment for statistical analysis. The software is based on the ' $S$ ' programming language. It was first developed in the University of Auckland, New Zealand. The source code for R is written mainly using C, Fortran, and R. R is available for free download under the GNU General Public License, and pre-compiled binary versions are provided for various operating systems. There are various mirrors of the original software environment for each country. The latest version ( $4^{\text {th }}$ Edition) of the book, "Statistics for Research", written by Chilko, Wearden and Harner (2011), professors of the Department of Statistics at West Virginia University, will include extensive examples of $\mathrm{R}$ programming to demonstrate its effectiveness in dealing with practical problems in the fields of biotechnology, transportation engineering, etc. The advantages of using $\mathrm{R}$ as programming software are:

- $\mathrm{R}$ is open source software; so, researchers from anywhere in the world can contribute to it by adding their own codes or packages for specific functions or specific areas of study.

- Many of R's standard functions are written in R itself, which makes it easy for users to follow the algorithmic choices made.

- For intensive computation, subroutines or functions written in $\mathrm{C}, \mathrm{C}++$, Fortran or Java can also be linked and called by the advanced users during compilation. 
- Due to its $\mathrm{S}$ heritage, $\mathrm{R}$ has stronger object-oriented programming facilities than most statistical computing languages and users can obtained desired outputs through simple statistical commands.

- $\mathrm{R}$ can also incorporate the document markup language, LaTeX into its coding by virtue of its Sweave function. The codes written in RStudio, when complied, produce the output as well-formatted PDF files. The output also supports high resolution graphs and mathematical symbols.

The next section will outline the various challenges that might be faced during the present study.

\subsection{Summary from Literature Review and Limitations of Existing Research}

After a thorough study of available literature, it was evident that research on geopolymer materials has been in vogue for almost 50 years. Alkali activation of aluminosilicate materials such as Class F fly ash or metakaolin accompanied by high temperature curing has been adopted as a common technique by the researchers to produce "geopolymers". The chemistry of polymerization is very complex and different microanalysis techniques have to be employed to understand the formation of the "geopolymers". The term geopolymer commonly refers to inorganic polymers comprising of sodium or potassium cations attached to aluminosilicates. However, in the present study the combination for an optimal binder material is being sought. Hence, fly ash will be replaced with different proportions of slag in the precursor. From the point of view of sustainability, slag will be added to observe whether the desirable mechanical properties of the binder can be achieved at lower curing temperature, thus making the binders more economical as well as ecofriendly. The addition of slag, however introduces $\mathrm{Ca}^{2+}$ ions into the aluminosilicate structure of the precursor. Thus the terminology "geopolymer" will no longer be accurate for the binder. Hence, for the purpose of the present study, the material will be referred to as alkali activated binder $(A A B)$ for microscale studies and concrete with $A A B$ when talking about specimen level studies.

Several researchers have conducted studies on the microstructural aspects of $A A B$ using Scanning electron microscopy (SEM) and energy dispersive X-ray (EDS), X-ray diffraction (XRD), Fourier Transform Infrared Spectroscopy (FTIR) as mentioned above, the primary 
focus of the research was to understand the underlying mechanisms of reactions and morphology of this complex system (Van Jaarsveld 2000; Davidovits 1983; Rees et al., 2004, Breck, 1974; Barbosa et al. 2000; and Lee and van Deventer 2002). No systematic studies on quantifying the volume fractions of alkali-activated binder products from the microanalysis and volume stoichiometry of the reaction products were reported. Also, limited studies have been conducted to understand the interactions of alkali-activated binder pastes from the fly ash and calcium-silicate-hydrate paste from slag. The use of fly ash as precursor incurs high heat energy consumption to achieve compressive strength comparable to PC concrete (Han and Pyzik 2011, Rangan and Wallah 2006). Slag has high water demand and is almost as expensice as PC (Provis and van Deventer 2009). There are limited studies which considered the combination of fly ash and slag as precursors in the $A A B$ system. Several studies have been conducted to study the microstructural characteristics of AAB systems (Rees et al. 2004, Muzek et al. 2012, Lee and van Deventer 2002) and several other studies have been conducted to study the strength characteristics of concrete with AAB (Wallah and Rangan 2006, Davidovits 1994, Provis and van Deventer 2009). However there is no systematic study to correlate the microstructural properties of AAB systems with the strength characteristics at specimen level.

Based on literature review and limitations of existing research, the proposed study was aimed at developing alkali-activated binder at relatively low curing temperatures of $23^{\circ} \mathrm{C}$, $40^{\circ} \mathrm{C}$, and $60^{\circ} \mathrm{C}$. This was followed by characterizing the alkali-activated binder products at both micro- and specimen levels using different experiments. The next step was development of a model to predict the microstructural phase volume fractions by optimizing the results from SEM/EDS. A nonlinear regression model was then developed to correlate the compressive strengths of concrete with $A A B$ with the microstructural phase volumes and the ultrasonic pulse velocities. This prediction model will enable the user to gain substantial amount of control over the quality of the finished product. Consequently, the alkaliactivated binder concrete products will be accepted in a much greater widespread manner, as compared to the present scenario. The first steps towards development of a two-part binder have also been proposed as a part of the present study.

The following chapter will describe the materials and mixture proportions. 


\section{CHAPTER 3}

\section{MATERIALS AND MIX PROPORTIONS}

This chapter describes the materials and mixture proportions for that were developed for the evaluation of microstructural, and specimen level mechanical properties and nondestructive characterizations.

\subsection{Materials}

\subsubsection{Coarse aggregate}

One type of crushed limestone (Greer \#57) from Arrow Concrete, WV was used. Aggregates used conformed to ASTM C33/C33M - 13 (Standard Specifications for Concrete Aggregates). Tables 3.1 and 3.2 show some physical properties of the aggregate and the sieve analysis data.

Table 3.1 Properties of Coarse Aggregates

\begin{tabular}{|c|c|}
\hline Properties & Values \\
\hline Nominal size (mm) & 9.5 \\
\hline Absorption (\%) & 0.53 \\
\hline SSD specific gravity & 2.69 \\
\hline Bulk specific gravity & 2.68 \\
\hline Apparent specific gravity & 2.72 \\
\hline
\end{tabular}

Table 3.2 Sieve Analysis Result

\begin{tabular}{|c|c|}
\hline Sieve size & Percentage passing \\
\hline $12.5 \mathrm{~mm}$ & 100 \\
\hline $9.5 \mathrm{~mm}$ & 88.1 \\
\hline $4.75 \mathrm{~mm}$ & 13.7 \\
\hline $2.36 \mathrm{~mm}$ & 1.3 \\
\hline $1.18 \mathrm{~mm}$ & 1.02 \\
\hline
\end{tabular}




\subsubsection{Fine aggregate}

Locally available river sand from Ohio River, primarily composed of quartz (silica) and conforming to ASTM C33/C33M - 13 was used for this study. Tables 3.3 and 3.4 show the properties of sand, the sieve analysis results and the mineral composition of sand, respectively.

Table 3.3 Properties of Fine Aggregate

\begin{tabular}{|c|c|}
\hline Properties & Values \\
\hline SSD specific gravity & 2.61 \\
\hline Bulk specific gravity & 2.59 \\
\hline Apparent specific gravity & 2.65 \\
\hline Absorption (\%) & 1.0 \\
\hline Fineness modulus & 2.79 \\
\hline
\end{tabular}

Table 3.4a Sieve Analysis of Sand

\begin{tabular}{|c|c|}
\hline \multirow{2}{*}{ Sieve size } & Percentage passing \\
\cline { 2 - 2 } & River sand \\
\hline $9.5 \mathrm{~mm}$ & 100 \\
\hline $4.75 \mathrm{~mm}$ & 97.2 \\
\hline $2.36 \mathrm{~mm}$ & 82.3 \\
\hline $1.18 \mathrm{~mm}$ & 69 \\
\hline $600 \mu \mathrm{m}$ & 54.6 \\
\hline $300 \mu \mathrm{m}$ & 16.1 \\
\hline $150 \mu \mathrm{m}$ & 2.0 \\
\hline $75 \mu \mathrm{m}$ & 0.7 \\
\hline
\end{tabular}


Table 3.4b Mineral Composition of Sand

\begin{tabular}{|c|c|}
\hline Mineral & Percentage present \\
\hline Brown opaque quartz & 37.3 \\
\hline Black opaque quartz & 10.3 \\
\hline Leucoxene & 7.0 \\
\hline Zircon & 6.3 \\
\hline Tourmaline & 2.6 \\
\hline Garnet & 2.9 \\
\hline Hornblende & 16.7 \\
\hline Silimanite & 6.1 \\
\hline Hypersthene & 2.2 \\
\hline Augite & 1.6 \\
\hline Cyanite & 1.1 \\
\hline Epidote & 0.9 \\
\hline Muscovite & 2.7 \\
\hline Titanite & 0.7 \\
\hline Rutile & 0.5 \\
\hline Pyrite & 0.0 \\
\hline Tremolite & 0.8 \\
\hline
\end{tabular}

\subsubsection{Fly ash}

The Class F fly ash (FA) used in this study conforming to ASTM C618 (Standard Specification for Coal Fly Ash and Raw Calcined Natural Pozzolan for Use as a Mineral Admixture in Portland Cement Concrete), was obtained from Arrow Concrete, WV. The specific gravity, specific surface area and oxide composition (provided by Arrow Concrete) are listed in Table 3.5 .

\subsubsection{Slag}

Ground granulated blast furnace slag or slag (SG) is defined as a finely ground glassy granular material formed when molten blast-furnace slag is rapidly chilled. Slag is varying in size depending on its chemical composition and method of production as well as that of its 
iron source. Slag used for this study was from Arrow Concrete, WV conforming to AASHTO M 302/ ASTM C989 (Standard Specification for Ground Granulated Blast-Furnace Slag for Use in Concrete and Mortar). Typical properties of the slag and oxide composition (provided by Arrow Concrete) are shown in Table 3.5.

Table 3.5 Basic Properties of Fly ash and Slag

\begin{tabular}{|c|c|c|}
\hline Materials & Fly Ash & Slag $^{*}$ \\
\hline Specific gravity & 2.47 & 2.88 \\
\hline Specific surface $\left(\mathrm{m}^{2} / \mathrm{kg}\right)$ & 490 (Blaine) & 580 (Blaine) \\
\hline Loss of ignition, \% & 3.00 & 0.06 \\
\hline $\mathrm{SiO}_{2}, \%$ & 49.34 & 36.0 \\
\hline $\mathrm{Al}_{2} \mathrm{O}_{3} \%$ & 22.73 & 12.0 \\
\hline $\mathrm{CaO}^{2} \%$ & 3.09 & 42.0 \\
\hline $\mathrm{MgO}^{2} \%$ & 1.06 & 6.0 \\
\hline $\mathrm{SO}_{3} \%$ & 0.97 & 0.2 \\
\hline $\mathrm{Na}_{2} \mathrm{O} \%$ & 1.15 & 0.74 \\
\hline $\mathrm{K}_{2} \mathrm{O}, \%$ & 1.60 & 1.8 \\
\hline $\mathrm{Fe}_{2} \mathrm{O}_{3} \%$ & 16.01 & 1.2 \\
\hline
\end{tabular}

* The $\mathrm{pH}$ value (in water) for the slag is in the range of $10.5 \sim 12.7$.

\subsubsection{Sodium hydroxide [ $\mathrm{NaOH}]$}

Sodium Hydroxide beads supplied by Essential Depot were used. The beads were used because it is easier to dissolve beads (compared to tablets) in any other dissolving liquid (e.g. sodium silicate solution or water). The beads were more than $98 \%$ pure.

\subsubsection{Sodium silicate $\left[\mathrm{Na}_{2} \mathrm{O} .2 \mathrm{SiO}_{2}\right]$}

Sodium silicate used for this research was supplied by PQ Corporation. The sodium silicate was industrial grade sodium poly-silicate containing $55.9 \%$ water and $44.1 \%$ solids. Silicon Oxide $\left(\mathrm{SiO}_{2}\right)$ to Sodium Oxide $\left(\mathrm{Na}_{2} \mathrm{O}\right)$ ratio was $2: 1$. 


\subsubsection{Mixing water}

Mixing water used in this study was locally manufactured distilled water. It was assumed to have a density of $1000 \mathrm{~kg}$ per cubic meter at room temperature.

\subsubsection{High range water reducing admixture (HRWRA)}

Commercially available high-range water reducing admixture used in this study was Glenium NS 3030 (supplied by BASF Chemicals), generally composed of a polycarboxylate ether, in water and conforming to ASTM C 494 Type F (Specification for Chemical Admixtures for Concrete). It does not affect the mechanical strength and mineralogical composition of hydrated PC paste as found by Puertas et al. (2005) through XRD and FTIR.

\subsection{Selection Criteria for Mix Proportions}

The current study aims to develop a new kind of construction material. So, it is of utmost importance to define the starting combinations wisely. It has already been mentioned that the starting materials can be categorized into two groups - Precursor and activating solution. As the precursors are primarily composed of industrial by-products, they will lead to lots of uncertainties in the characteristics of the finished product. Moreover, the activating solution reacts with the precursor through a polymerization mechanism, whose chemistry is yet to be fully decoded. This polymerization process governs the development of strength of the building material and it is dependent on several factors - (i) the ratio of $\mathrm{SiO}_{2} / \mathrm{Na}_{2} \mathrm{O}$ in the activating silicate solution; (ii) the ratio of $\mathrm{SiO}_{2} / \mathrm{Na}_{2} \mathrm{O}$ in the precursoractivating solution mixture (also known as Ms ratio or Ms modulus); (iii) the ratio of $\mathrm{SiO}_{2} / \mathrm{Al}_{2} \mathrm{O}_{3}$ in the precursor; (iv) the ratio of water-to-AAB solids (w/s); and (v) the curing temperature, i.e., the temperature at which the polymerization is allowed to occur. Evidently, there are plenty of parameters which can be varied in order to study the change in behavior of the finished $A A B$ product. For the purpose of the present work, the mixture proportions were designed in such a way that an optimum Ms modulus can be selected from a range of possible values in the initial step. Later on, keeping this optimum Ms modulus fixed, the curing temperature and the proportion of different industrial by-products in the precursor were varied to conduct in-depth analyses on the behavior of the finished product. A suitable value for w/s, which ensured sufficient workability, was also kept fixed for all the mixture proportions to maintain uniformity. The rationale behind selection of each 
parameter was based on the suggestions and observations made by previous researchers and they have been explained elaborately in the following paragraphs of the chapter.

As mentioned earlier, prominent researchers in the field of AAB concrete have shown that an alkali activated cementitious mix attains the highest compressive strength when the silicon to aluminum molar ratio ( $\mathrm{Si}: \mathrm{Al}$ ) lies within the range of $1: 1$ and $3: 1$ (Davidovits, 1988). So, in the initial step, fly ash and sodium silicate solution $\left(\mathrm{SiO}_{2} / \mathrm{Na}_{2} \mathrm{O}=2: 1\right)$ were batched so that $\mathrm{Si}: \mathrm{Al}$ ratio approximately equal to $2: 1$ would be maintained upon blending them.

Also, an extensive study on the development and the manufacture of fly ash (or Class F fly ash) based $A A B$ concrete has been in progress at Curtin University of Australia. Results of that study have already been reported in several publications (Hardjito et. al., 2002a; Hardjito et. al., 2003, 2004a, 2004b, 2005a, 2005b; Rangan et. al., 2005a, 2005b). Complete details of that study are available in a Research Report by Hardjito and Rangan (2005). The mixture proportions followed by the researchers for that study gave some guidelines on how to choose the Ms modulus. They used Ms modulus of 2. Skvara et al. (2006) used a range of Ms modulus from 1.0 to 1.6. In order to arrive at the optimum Ms modulus for the combinations used in the present study, a batch of trial mixtures were prepared and tested for compressive strength of hardened $A A B$ paste specimens. The different values of the Ms modulus used for the trial mixtures were 1.2, 1.4, 1.6, and 1.8. The Ms modulus which resulted in the best compressive strength will be taken as the Ms modulus for the remaining mixture proportions to be used for the purpose of the present study. For each mixture proportion, replicate specimens were tested at 3 different ages, each corresponding to 3 different curing temperatures. Total specimens for compressive strength test of hardened $A A B$ paste for 10 different mixture proportions $=10$ (number of mixture proportions) $* 3$ (different ages) $* 3$ (different curing temperatures) $* 2$ (replicate specimens for each case) $=180$. The same scheme of parameters within parentheses was followed to calculate total number of samples corresponding to each experiment throughout the rest of the document.

The molarity of the $\mathrm{NaOH}$ solution used is another important factor affecting the compressive strength of the $A A B$ concrete. From available literature, it was found that molarity in the range of $8-14$ results in very high compressive strength values (Lloyd and Rangan, 2010). The maximum compressive strength is achieved when the molarity is in the 
range of 12 (Mustafa Al Bakri et al., 2011). In the present study $\mathrm{NaOH}$ was used in the form of powder and not as a solution. So, the equivalent molarity of the $\mathrm{NaOH}$ in the present case was checked at the end of the mix design to see whether it satisfied the desired range. The equivalent molarity of $\mathrm{NaOH}$ was computed to be 12.67 which was in close agreement with the value suggested by existing literature. The sample calculation is provided later in section 3.7.

The temperature of curing is another aspect of the mixing procedure which deserves special attention. Previous research has shown that if the starting materials are heated to a temperature in the range of $950^{\circ} \mathrm{C}$ (Han and Pyzik, 2011 and Pacheco-Torgal et al., 2007), then the finished $A A B$ product exhibits excellent characteristics as a building material. However, a substantial amount of energy would be consumed in attaining such a high temperature. As mentioned in Section 2.15, one of the main motivations behind the present research is to develop a green construction material. So, the finished product must be economic as well as energy-efficient. From this point of view, the idea to heat the starting materials to elevated temperatures was rejected. Rangan (2008) showed that desirable compressive strength values were obtained by was obtained if the curing temperature of $80^{\circ} \mathrm{C}$ was used. Based on the findings from the research by Rangan (2008), three different curing temperatures of $23^{\circ} \mathrm{C}$ (room temperature), $40^{\circ} \mathrm{C}$, and $60^{\circ} \mathrm{C}$ were adopted for the present study. The idea is to compare the different properties of the finished product at different temperatures and propose an ideal curing temperature for practical uses of the material, which will optimize the combination of economy and strength characteristics of the material for use in construction purposes.

The chemistry of geopolymerisation has proven that the compressive strength development of the material is enhanced at elevated temperatures, because the rate of the polymerization reaction increases. As the present study makes a compromise on the temperature of curing, it was necessary to introduce $\mathrm{Ca}^{2+}$ ions into the system to enhance the compressive strength properties. This technique has been followed by Skvara et al. (2006). For the present study, slag was used as the source of $\mathrm{Ca}^{2+}$ ions. The $\mathrm{Ca}^{2+}$ ions impart additional compressive strength by forming calcium silicate hydrate (CSH) as a hydration product. Slag has weak hydraulic properties and the hydration of slag may be thought to be analogous to the hydration of PC. The only difference is the formation of the secondary $\mathrm{CSH}$ or $\mathrm{CSH}(\mathrm{S})$ which has different stoichiometry than the primary CSH produced by the hydration of PC. For the present study, different percentage replacements of fly ash 
by slag were adopted to identify the change in its mechanical and chemical characteristics. The different percentage replacements of fly ash by slag used in the present study are $15 \%$, $30 \%, 50 \%, 70 \%, 85 \%$ and $100 \%$. The $100 \%$ fly ash case is denoted as the datum or base case.

The w/s was initially taken as 0.20 based on the calculations shown by Rangan (2008). This w/s worked satisfactorily for the $100 \%$ fly ash case. However, when slag was introduced into the system for partial replacement of fly ash, the workability was very poor and the mix became too stiff to cast into molds. So, high range water reducing admixture (HRWRA) was added accordingly in order to achieve desired workability based on maintaining uniform slump height. This was kept consistent for all mixture proportions used in the present study. At first, the compressive strength results are presented for the initial mixtures to achieve the optimum Ms modulus. The samples were 2" cubes of hardened paste with AAB. Total no. of specimens for compressive strength test of hardened $A A B$ paste $=10$ (number of mixture proportions) $* 3$ (different ages) *3 (different curing temperatures) *2 (replicate specimens for each case $)=180$. The mixture proportions used in the present study and encompassing all the above guidelines are summarized in the following paragraphs and tables (Tables 3.6 through 3.11).

Table 3.6 3-day Compressive Strength Test Results for Initial FA 100 Mixtures

\begin{tabular}{|c|c|c|c|}
\hline Mix & Ms & Temp & $\begin{array}{c}\text { Cube Compressive } \\
\text { Strength (MPa [psi]) }\end{array}$ \\
\hline \multirow{12}{*}{ FA 100} & 1.2 & \multirow{4}{*}{$23^{\circ} \mathrm{C}$} & $11.3[1640]$ \\
\hline & 1.4 & & 13.8 [2000] \\
\hline & 1.6 & & $6.9[1000]$ \\
\hline & 1.8 & & $4.5[650]$ \\
\hline & 1.2 & \multirow{4}{*}{$40^{\circ} \mathrm{C}$} & $18.3[2660]$ \\
\hline & 1.4 & & 22.9 [3320] \\
\hline & 1.6 & & $14.6[2120]$ \\
\hline & 1.8 & & $5.5[800]$ \\
\hline & 1.2 & \multirow{4}{*}{$60^{\circ} \mathrm{C}$} & $32.7[4750]$ \\
\hline & 1.4 & & $38.0[5510]$ \\
\hline & 1.6 & & $25.5[3700]$ \\
\hline & 1.8 & & $16.9[2450]$ \\
\hline
\end{tabular}


Table 3.7 7-day Compressive Strength Test Results for Initial FA 100 Mixtures

\begin{tabular}{|c|c|c|c|}
\hline Mix & Ms & Temp & $\begin{array}{c}\text { Cube Compressive } \\
\text { Strength (MPa [psi]) }\end{array}$ \\
\hline \multirow{12}{*}{ FA 100} & 1.2 & \multirow{4}{*}{$23^{\circ} \mathrm{C}$} & 13.9 [2010] \\
\hline & 1.4 & & $18.6[2700]$ \\
\hline & 1.6 & & $7.9[1150]$ \\
\hline & 1.8 & & $5.7[820]$ \\
\hline & 1.2 & \multirow{4}{*}{$40^{\circ} \mathrm{C}$} & $24.5[3550]$ \\
\hline & 1.4 & & 27.7 [4020] \\
\hline & 1.6 & & $15.5[2250]$ \\
\hline & 1.8 & & $8.3[1200]$ \\
\hline & 1.2 & \multirow{4}{*}{$60{ }^{\circ} \mathrm{C}$} & $34.9[5060]$ \\
\hline & 1.4 & & $42.1[6110]$ \\
\hline & 1.6 & & $26.2[3800]$ \\
\hline & 1.8 & & $17.9[2600]$ \\
\hline
\end{tabular}

Table 3.8 28-day Compressive Strength Test Results for Initial FA 100 Mixtures

\begin{tabular}{|c|c|c|c|}
\hline Mix & Ms & Temp & $\begin{array}{c}\text { Cube Compressive } \\
\text { Strength (MPa [psi]) }\end{array}$ \\
\hline \multirow{12}{*}{ FA 100} & 1.2 & \multirow{4}{*}{$23^{\circ} \mathrm{C}$} & $15.2[2200]$ \\
\hline & 1.4 & & 19.6 [2850] \\
\hline & 1.6 & & $9.1[1320]$ \\
\hline & 1.8 & & $7.9[1140]$ \\
\hline & 1.2 & \multirow{4}{*}{$40^{\circ} \mathrm{C}$} & 26.9 [3900] \\
\hline & 1.4 & & $30.0[4350]$ \\
\hline & 1.6 & & 16.5 [2400] \\
\hline & 1.8 & & $9.0[1300]$ \\
\hline & 1.2 & \multirow{4}{*}{$60^{\circ} \mathrm{C}$} & 38.4 [5570] \\
\hline & 1.4 & & $49.8[7230]$ \\
\hline & 1.6 & & $27.6[4000]$ \\
\hline & 1.8 & & $19.0[2750]$ \\
\hline
\end{tabular}

Based on the findings from the above table, it was decided that $A A B$ containing $100 \%$ fly ash with Ms modulus of 1.4 was the best performing mixture proportion in terms of compressive strength (indicated by bold font). This Ms modulus value of 1.4 was kept uniform throughout all the other tests performed during the present study. As mentioned earlier, the alkali activated fly ash in the AAB was replaced partially by slag in order to study 
the effect of addition of $\mathrm{Ca}^{2+}$ ions into the system. The compressive strength results for some of the cases where fly ash was replaced by slag are provided below:

Table 3.9 3-day Compressive Strength Test Results for Initial AAB Hardened Pastes with FA and Different Percentages of SG

\begin{tabular}{|c|c|c|c|}
\hline Mix & Ms & Temp & $\begin{array}{c}\text { Cube Compressive } \\
\text { Strength (MPa [psi]) }\end{array}$ \\
\hline FA 85 SG 15 & \multirow{9}{*}{1.4} & \multirow{3}{*}{$23^{\circ} \mathrm{C}$} & 16.5 [2400] \\
\hline FA 70 SG 30 & & & $30.3[4440]$ \\
\hline FA 50 SG 50 & & & $43.8[6350]$ \\
\hline FA 85 SG 15 & & \multirow{3}{*}{$40{ }^{\circ} \mathrm{C}$} & 28.4 [4120] \\
\hline FA 70 SG 30 & & & $32.2[4670]$ \\
\hline FA 50 SG 50 & & & $51.3[7440]$ \\
\hline FA 85 SG 15 & & \multirow{3}{*}{$60^{\circ} \mathrm{C}$} & $34.2[4960]$ \\
\hline FA 70 SG 30 & & & $48.6[7050]$ \\
\hline FA 50 SG 50 & & & $57.2[8300]$ \\
\hline
\end{tabular}

Table 3.10 7-day Compressive Strength Test Results for Initial AAB Hardened Pastes with FA and Different Percentages of SG

\begin{tabular}{|c|c|c|c|}
\hline Mix & Ms & Temp & $\begin{array}{c}\text { Cube Compressive } \\
\text { Strength (MPa [psi]) }\end{array}$ \\
\hline FA 85 SG 15 & \multirow{9}{*}{1.4} & \multirow{3}{*}{$23^{\circ} \mathrm{C}$} & 23.1 [3350] \\
\hline FA 70 SG 30 & & & $33.0[4790]$ \\
\hline FA 50 SG 50 & & & 52.5 [7610] \\
\hline FA 85 SG 15 & & \multirow{3}{*}{$40^{\circ} \mathrm{C}$} & 30.0 [4350] \\
\hline FA 70 SG 30 & & & $37.1[5380]$ \\
\hline FA 50 SG 50 & & & $56.2[8150]$ \\
\hline FA 85 SG 15 & & \multirow{3}{*}{$60{ }^{\circ} \mathrm{C}$} & $38.7[5620]$ \\
\hline FA 70 SG 30 & & & $57.0[8270]$ \\
\hline FA 50 SG 50 & & & 62.6 [9080] \\
\hline
\end{tabular}


A summary of the scheme for selecting the suitable combination of the precursors are provided in Table 3.11.

Table 3.11 Initial Scheme for Selection of Precursor Combinations

\begin{tabular}{|c|c|c|c|}
\hline Precursor & Ms modulus & Curing temps & $\begin{array}{c}\text { Age } \\
\text { (days) }\end{array}$ \\
\hline $\begin{array}{l}100 \% \text { Fly ash } \\
\text { (base mixture) }\end{array}$ & $\begin{array}{c}\text { Total } \mathrm{SiO}_{2} / \mathrm{Na}_{2} \mathrm{O} \\
=1.2,1.4,1.6 \\
1.8\end{array}$ & $23^{\circ} \mathrm{C}, 40^{\circ} \mathrm{C}, 60^{\circ} \mathrm{C}$ & $3,7,28$ \\
\hline $85 \%$ Fly ash + 15\% slag & 1.4 & $23^{\circ} \mathrm{C}, 40^{\circ} \mathrm{C}, 60^{\circ} \mathrm{C}$ & $3,7,28$ \\
\hline $70 \%$ Fly ash $+30 \%$ slag & 1.4 & $23^{\circ} \mathrm{C}, 40^{\circ} \mathrm{C}, 60^{\circ} \mathrm{C}$ & $3,7,28$ \\
\hline $50 \%$ Fly ash $+50 \%$ slag & 1.4 & $23^{\circ} \mathrm{C}, 40^{\circ} \mathrm{C}, 60^{\circ} \mathrm{C}$ & $3,7,28$ \\
\hline $30 \%$ Fly ash $+70 \%$ slag & 1.4 & $23^{\circ} \mathrm{C}, 40^{\circ} \mathrm{C}, 60^{\circ} \mathrm{C}$ & $3,7,28$ \\
\hline $15 \%$ Fly ash $+85 \%$ slag & 1.4 & $23^{\circ} \mathrm{C}, 40^{\circ} \mathrm{C}, 60^{\circ} \mathrm{C}$ & $3,7,28$ \\
\hline $100 \%$ slag (second datum) & 1.4 & $23^{\circ} \mathrm{C}, 40^{\circ} \mathrm{C}, 60^{\circ} \mathrm{C}$ & $3,7,28$ \\
\hline $\begin{array}{l}\text { Pre blend } 100 \% \text { fly ash and solid } \\
\qquad \mathrm{NaOH} \text { for } 15 \text { days }\end{array}$ & 1.4 & $23^{\circ} \mathrm{C}, 40^{\circ} \mathrm{C}, 60^{\circ} \mathrm{C}$ & $3,7,28$ \\
\hline $\begin{array}{l}\text { Pre blend } 100 \% \text { fly ash and solid } \\
\mathrm{NaOH} \text { for } 30 \text { days }\end{array}$ & 1.4 & $23^{\circ} \mathrm{C}, 40^{\circ} \mathrm{C}, 60^{\circ} \mathrm{C}$ & $3,7,28$ \\
\hline $\begin{array}{l}\text { Pre blend } 100 \% \text { fly ash and solid } \\
\mathrm{NaOH} \text { for } 60 \text { days }\end{array}$ & 1.4 & $23^{\circ} \mathrm{C}, 40^{\circ} \mathrm{C}, 60^{\circ} \mathrm{C}$ & $3,7,28$ \\
\hline
\end{tabular}

Table 3.12 presents the final proportions of all the mixtures used for the experiments conducted on the $A A B$ at microscale as well as specimen level, after the initial optimum Ms modulus was established. The proportion of the fine aggregate and the coarse aggregates along with the amounts of sodium silicate and sodium hydroxide have been provided for all the mixtures. The chemistry of the admixture does not influence the chemistry of AAB or inorganic polymer as the admixture is based on organic polycarboxylate. 
Table 3.12 Final Concrete Mix Proportions for Alkali-activated Fly ash and/or Slag (Ms modulus $=1.4)$

\begin{tabular}{|c|c|c|c|c|c|}
\hline \multirow{2}{*}{ Precursor } & \multirow{2}{*}{ Mixture } & Fly ash & Slag & $\begin{array}{l}\text { Sodium } \\
\text { silicate }\end{array}$ & $\begin{array}{l}\text { Sodium } \\
\text { hydroxide }\end{array}$ \\
\hline & & $\mathrm{kg} / \mathrm{m}^{3}$ & $\mathrm{~kg} / \mathrm{m}^{3}$ & $\mathrm{~kg} / \mathrm{m}^{3}$ & $\mathrm{~kg} / \mathrm{m}^{3}$ \\
\hline $100 \%$ Fly ash & FA 100 & 400 & 0 & 129.43 & 10.57 \\
\hline $\begin{array}{c}85 \% \text { Fly ash }+ \\
15 \% \text { slag }\end{array}$ & FA 85 SG 15 & 340 & 60 & 129.43 & 10.57 \\
\hline $\begin{array}{c}70 \% \text { Fly ash }+ \\
30 \% \text { slag }\end{array}$ & FA 70 SG 30 & 280 & 120 & 129.43 & 10.57 \\
\hline $\begin{array}{c}50 \% \text { Fly ash }+ \\
50 \% \text { slag }\end{array}$ & FA 50 SG 50 & 200 & 200 & 129.43 & 10.57 \\
\hline $\begin{array}{c}30 \% \text { Fly ash }+ \\
70 \% \text { slag }\end{array}$ & FA 30 SG 70 & 120 & 280 & 129.43 & 10.57 \\
\hline $\begin{array}{c}15 \% \text { Fly ash }+ \\
85 \% \text { slag }\end{array}$ & FA 15 SG 85 & 60 & 340 & 129.43 & 10.57 \\
\hline $100 \%$ slag & SG 100 & 0 & 400 & 129.43 & 10.57 \\
\hline $\begin{array}{c}\text { Pre blend } 100 \% \\
\text { fly ash and solid } \\
\mathrm{NaOH} \text { for } 15 \\
\text { days }\end{array}$ & FA 100 p15 & 400 & 0 & 129.43 & 10.57 \\
\hline $\begin{array}{c}\text { Pre blend } 100 \% \\
\text { fly ash and solid } \\
\mathrm{NaOH} \text { for } 30 \\
\text { days }\end{array}$ & FA 100 p30 & 400 & 0 & 129.43 & 10.57 \\
\hline $\begin{array}{c}\text { Pre blend } 100 \% \\
\text { fly ash and solid } \\
\mathrm{NaOH} \text { for } 60 \\
\text { days }\end{array}$ & FA 100 p60 & 400 & 0 & 129.43 & 10.57 \\
\hline
\end{tabular}

Note: The quantity of coarse aggregate was kept constant at $1209 \mathrm{~kg} / \mathrm{m}^{3}$ and that of fine aggregate at $651 \mathrm{~kg} / \mathrm{m}^{3}$ for all mixes. The quantity of HRWRA used was in the range of $5060 \sim 6745 \mathrm{ml} / \mathrm{m}^{3}$ maintain uniform slump $(180-200 \mathrm{~mm})$. The $\mathrm{w} / \mathrm{s}$ was kept constant at 0.2 for all concrete mixes.

\subsection{Mixing Procedure}

In this section, the different steps involved in mixing the materials in order to produce concrete with $A A B$ are explained in detail, starting with the dry mix followed by adding the 
activating solution and finally mixing the necessary amount of water and HRWRA to achieve the desired workability.

\subsubsection{Preparation of dry mix}

The dry raw materials were blended in the beginning to obtain a dry mixture. Initially, dry sand, dry limestone and fly ash and/or slag or both mixed uniformly to ensure best quality of the concrete specimen. The details are shown in Figure 3.1.
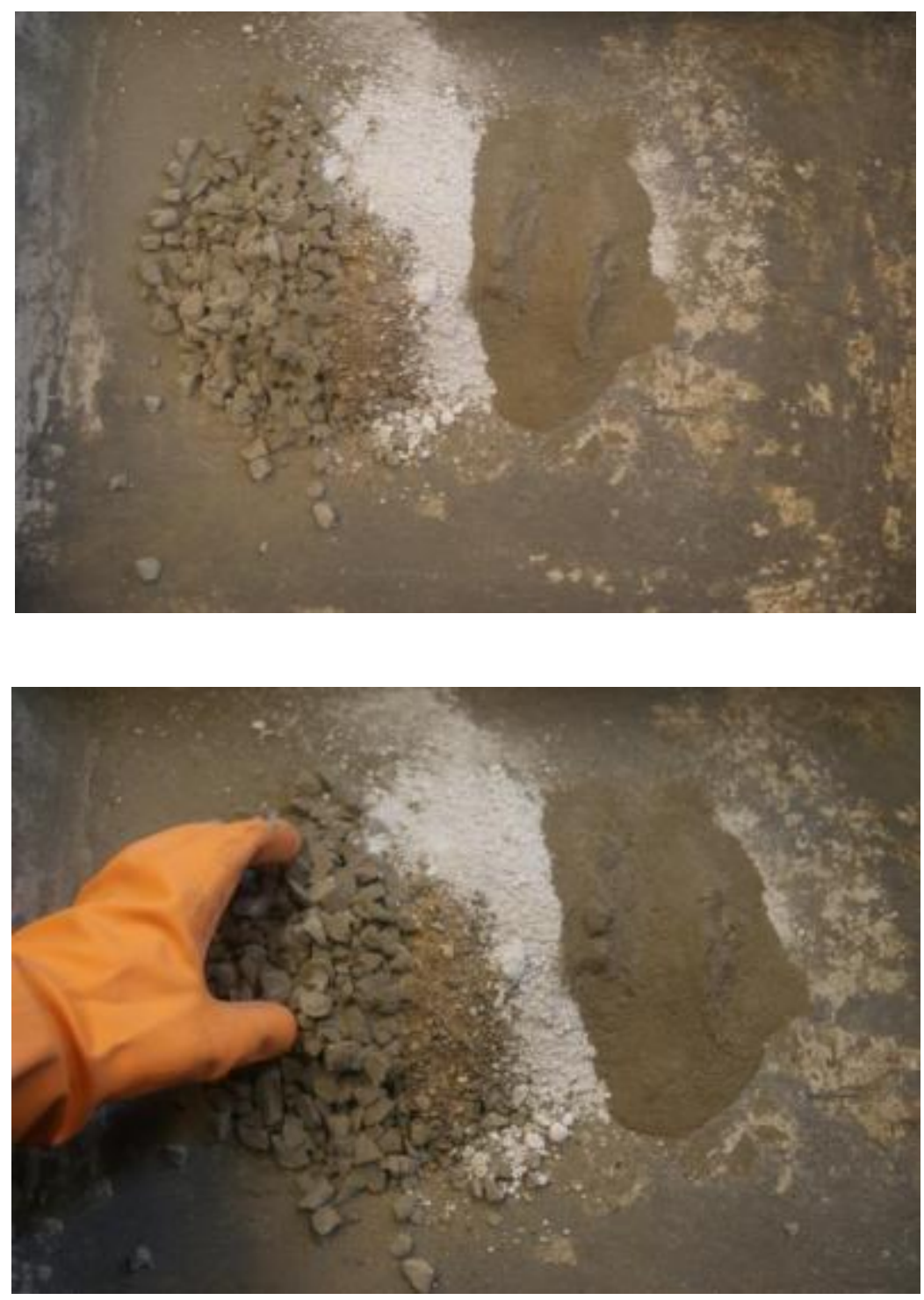

Fig. 3.1 Mixing the aggregates and the precursor in dry state 


\subsubsection{Preparation of liquid mix}

Water, Sodium Silicate and Sodium Hydroxide were mixed in proper proportions to obtain a uniform blend. The alkaline compounds are shown in Figure 3.2.

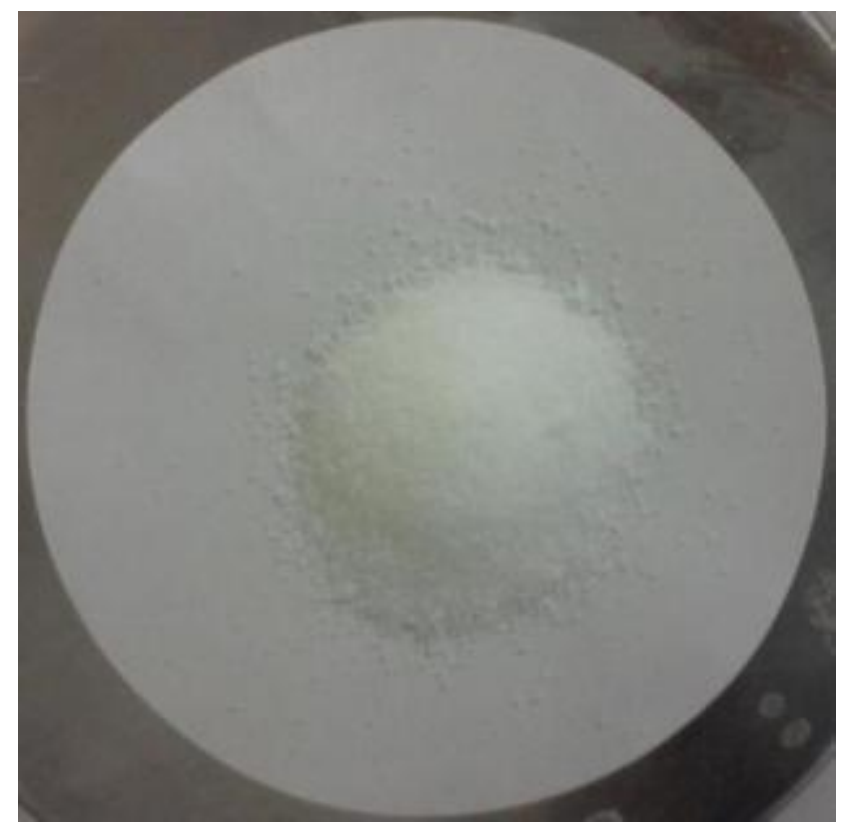

(a) Sodium hydroxide powder

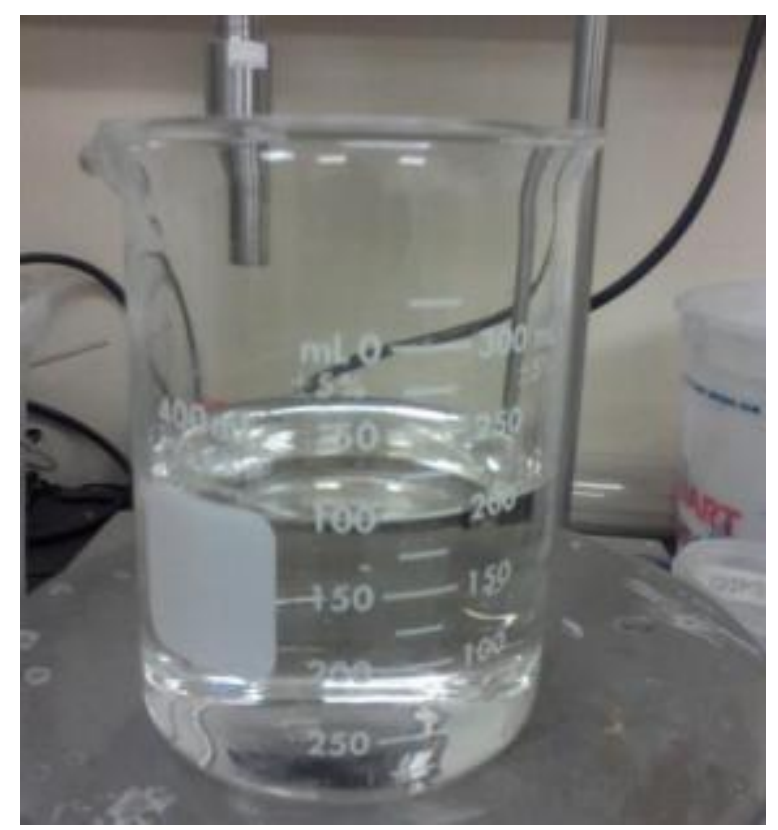

(b) Sodium silicate solution

Fig. 3.2 Alkaline activating agents: (a) Sodium hydroxide powder and (b) Sodium silicate solution

\subsubsection{Combination of solid and liquid mix}

The liquid mixture was added to the solid mixture to prepare a cohesive mixture. As the $A A B$ tends to set very rapidly very small quantity of concrete was batched at a time. For this reason, hand mixing was preferred over machine mixing. The liquid and solid mixtures were combined very carefully, to avoid any kind of chemical burn due to the corrosive nature of the sodium hydroxide. The mix was prepared very rapidly to ensure desirable workability while casting them into molds. The curing procedure is described in the following section. 


\subsection{Curing Procedure}

The same curing regime was followed for each mixture proportion and it was kept consistent for all experiments.

Heat-curing of fly ash-based $A A B$ concrete is generally recommended. Heat-curing substantially assists the chemical reaction that occurs in the $A A B$ paste. Both curing time and curing temperature influence the compressive strength of $A A B$ concrete. The specimens were cured after 24 hours of casting. Those samples are cured in 3 different temperatures; $23^{\circ} \mathrm{C}$ (room temperature) and $40^{\circ} \mathrm{C}, 60^{\circ} \mathrm{C}$ (the last two temperatures were obtained in an oven) respectively for 24 hours.

The sample calculations have been provided in sections 3.5 through 3.7 .

\subsection{Sample Calculations for the Mix Design}

The mix design was prepared based on the findings made by Lloyd and Rangan (2010) and Chowdhury (2011). Concrete mixture design process is vast and generally based on performance criteria. Some simple guidelines for the design of heat-cured low-calcium fly ash-based AAB concrete have been proposed [Hardjito et al, 2004; Rangan, 2008; Sumajouw, 2007]. The performance criteria of an $A A B$ concrete mixture depend on the application. For simplicity, the compressive strength of hardened concrete and the workability of fresh concrete are selected as the performance criteria. In order to meet these performance criteria, the alkaline liquid-to-fly ash ratio by mass, w/s ratio by mass, the heat-curing temperature, and the heat-curing time were identified as major governing parameters.

With regard to alkaline liquid-to-fly ash ratio by mass, values in the range of 0.30 and 0.45 are recommended, based on the results obtained from numerous mixtures made in the laboratory over a period of six years. Wet-mixing time of 4 minutes and steam-curing at $60^{\circ} \mathrm{C}$ for 24 hours after casting, were proposed. Increased wet mixing time increased the compressive strength by $30 \%$.

The design assumed that the aggregates are in saturated-surface-dry (SSD) condition. In other words, the coarse and fine aggregates in an $A A B$ concrete mixture must neither be too dry to absorb water from the mixture nor too wet to add water to the mixture. In practical 
applications, aggregates may contain water over and above the SSD condition. Therefore, the extra water in the aggregates above the SSD condition must be estimated and included in the calculation of $\mathrm{w} / \mathrm{s}$ ratio. The mixture design process for the present study is illustrated by the following Example.

The target density for the concrete was $2400 \mathrm{~kg} / \mathrm{m}^{3}$. The ratio of the combined mass of the aggregates to the total mass was $77.5 \%$.

So, total mass of aggregates $=.775 * 2400=1860 \mathrm{~kg} / \mathrm{m}^{3}$

Alkaline liquid to fly ash mass ratio $=0.35$

Mass of fly ash $=\frac{2400-1860}{1+0.35}=400 \mathrm{~kg} / \mathrm{m}^{3}$

This satisfies the criterion that the fly ash content should not exceed $407 \mathrm{~kg} / \mathrm{m}^{3}$. Mass of alkaline liquid $=2400-1860-400=140 \mathrm{~kg} / \mathrm{m}^{3}$.

The alkaline liquid consists of sodium hydroxide powder and sodium silicate solution. For a modulus ratio of 1.4 , the $\mathrm{SiO}_{2} / \mathrm{Na}_{2} \mathrm{O}$ ratio in the alkaline liquid should be 1.4 . In this case, $\mathrm{Na}_{2} \mathrm{O}$ denotes the equivalent $\mathrm{Na}_{2} \mathrm{O}$ included in the sodium hydroxide as well as the sodium silicate solution. The sodium silicate solution used in the present study has chemical composition $\mathrm{Na}_{2} \mathrm{O} .2 \mathrm{SiO}_{2}$. The sodium silicate solution contains $55.9 \%$ water and $44.1 \%$ solids, i.e. $55.9 \%$ water, $29.4 \% \mathrm{SiO}_{2}$, and $14.7 \% \mathrm{Na}_{2} \mathrm{O}$ by weight. Thus, water $/ \mathrm{SiO}_{2}$ in the mixture $=1.9014$.

The resultant $\mathrm{SiO}_{2} / \mathrm{Na}_{2} \mathrm{O}$ ratio in the alkaline liquid $=1.4$ and the total mass of the alkaline liquid is $140 \mathrm{~kg} / \mathrm{m}^{3}$. Converting all compounds to equivalent $\mathrm{SiO}_{2}$ terms by mass, it can be said that

$\mathrm{Na}_{2} \mathrm{O}+\mathrm{SiO}_{2}+$ water $=140$

Or, $\mathrm{Na}_{2} \mathrm{O}+1.4 \mathrm{Na}_{2} \mathrm{O}+$ water $=140$

Or, (1/1.4) $\mathrm{SiO}_{2}+\mathrm{SiO}_{2}+1.9014 \mathrm{SiO}_{2}=140$

Or, $\mathrm{SiO}_{2}=\frac{140}{\left(\frac{1}{1.4}\right)+1+1.9014}=38.72$

So, $\mathrm{Na}_{2} \mathrm{O}=38.72 / 1.4=27.656$

$\mathrm{Na}_{2} \mathrm{O}$ content in sodium silicate $=38.72 / 2=19.36$

Water content in the sodium silicate solution $=1.9014 * 38.72=73.62$

Remaining $\mathrm{Na}_{2} \mathrm{O}$ (corresponding to $\mathrm{NaOH}$ ) $=8.2976$

From stoichiometry, $\mathrm{Na}_{2} \mathrm{O}+\mathrm{H}_{2} \mathrm{O}=2 \mathrm{NaOH}$ 
i.e. 62 units by mass of $\mathrm{Na}_{2} \mathrm{O}$ produce 80 units by mass of $\mathrm{NaOH}$.

So, $8.2976 \mathrm{~kg}$ of $\mathrm{Na}_{2} \mathrm{O}$ corresponds to $10.7066 \mathrm{~kg}$ of $\mathrm{NaOH}$.

Total mass of alkaline liquid $=19.36+38.72+73.62+10.7066=141.7066 \mathrm{~kg} / \mathrm{m}^{3}$

So the corresponding amounts of each of these entities in $140 \mathrm{~kg} / \mathrm{m}^{3}$ of the alkaline liquid, calculated by unitary method, were as follows:

$\mathrm{Na}_{2} \mathrm{O}=19.13 \mathrm{~kg} / \mathrm{m}^{3}$

$\mathrm{SiO}_{2}=38.26 \mathrm{~kg} / \mathrm{m}^{3}$

Water $=72.74 \mathrm{~kg} / \mathrm{m}^{3}$

$\mathrm{NaOH}=10.57 \mathrm{~kg} / \mathrm{m}^{3}$.

Thus, the final mix design for this case can be summarized as:

Fly ash $=400 \mathrm{~kg} / \mathrm{m}^{3}$

Sodium silicate solution $=19.13+38.26+72.74=129.43 \mathrm{~kg} / \mathrm{m}^{3}$

Sodium hydroxide $=10.57 \mathrm{~kg} / \mathrm{m}^{3}$

Total aggregate $=1860 \mathrm{~kg} / \mathrm{m}^{3}$

Fine aggregate to coarse aggregate ratio was taken as 0.35:0.65

So, fine aggregate content $=0.35 * 1860=651 \mathrm{~kg} / \mathrm{m}^{3}$

Coarse aggregate content $=0.65 * 1860=1209 \mathrm{~kg} / \mathrm{m}^{3}$

\subsection{Calculation for Additional Water to Achieve Desired Workability}

Total water in the $\operatorname{mix}=72.74 \mathrm{~kg} / \mathrm{m}^{3}$

Weight of $A A B$ solids $=400+19.13+38.26+10.57=467.96 \mathrm{~kg} / \mathrm{m}^{3}$

Water to $A A B$ solids ratio $(\mathrm{w} / \mathrm{s})=0.155$

From Lloyd and Rangan (2010), w/s of 0.2 0.22 must be adopted in order to achieve moderate to high workability, while maintaining a compressive strength in the range of 35 40 MPa. For the present study, the w/s was kept constant at 0.2.

For target $\mathrm{w} / \mathrm{s}=0.2$,

water required to be added externally into the $\operatorname{mix}=0.2 * 467.96=93.592 \mathrm{~kg} / \mathrm{m}^{3}$

Water already present in the mix $=72.74 \mathrm{~kg} / \mathrm{m}^{3}$

So, additional water required $=20.852 \mathrm{~kg} / \mathrm{m}^{3}$ 
When slag was mixed with fly ash, the mix became too stiff at a quicker rate due to the nature of the slag particles. The slag particles have the characteristics that they absorb greater quantity of moisture as compared to fly ash particles. In order to maintain the w/s ratio constant at 0.2 as well as desired workability, high range water reducing admixture (HRWRA) was added accordingly.

\subsection{Calculation for Effective Molarity of $\mathrm{NaOH}$ in the Mix}

Sodium hydroxide in the $\operatorname{mix}=10.57 \mathrm{~kg} / \mathrm{m}^{3}$

Additional water required to achieve w/s of $0.2=20.852 \mathrm{~kg} / \mathrm{m}^{3}$

It was assumed that the additional water corresponds to an equivalent sodium hydroxide solution.

So, $10.57 \mathrm{~kg}$ of $\mathrm{NaOH}$ present in $20.852 \mathrm{~kg}$ of water

Or, $\frac{10.57}{40}$ moles of $\mathrm{NaOH}$ present in $20.852 \mathrm{cc}$ of water

Or, $\frac{10.57}{40} \times \frac{1000}{20.852}$ moles of $\mathrm{NaOH}$ present in 1000 , i.e. 1 liter of water

Or, 12.673 moles of $\mathrm{NaOH}$ present in 1 liter of water.

Hence, from definition, the effective molarity of $\mathrm{NaOH}$ in the mix was 12.673 .

In this chapter, the details of the materials and the mix design procedures have been discussed along with a sample calculation. The following chapter will talk about the characterizations of $A A B$ at microstructural level and develop a model to estimate the quantities of the different phases present in the microstructure. 


\section{CHAPTER 4}

\section{CHARACTERIZATION OF HARDENED ALKALI ACTIVATED BINDER PASTE AT MICROSTRUCTURAL LEVEL}

\subsection{XRD}

$X$-ray diffraction was performed on $(10 * 3 * 3 * 2)=180$ samples using a Bruker D8 Discovery $\mathrm{X}$-ray Diffractometer. The CuKa X-rays were generated at $40 \mathrm{~mA}$ and $40 \mathrm{kV}$. Scans were performed over 0 to $100^{\circ} 2 \theta$ range at $0.02^{\circ} 2 \theta$ steps and integrated at the rate of 2 seconds step $^{-1}$. The powder samples used for the XRD analyses were obtained by crushing the hardened samples that were used for SEM/EDS. The same powder samples were also used for the FTIR analyses. The chemical reactions that produce the polymer products when fly ash is activated with an alkali solution are very sensitive to the ambient conditions of temperature and relative humidity. Hence, the above arrangement was adopted to ensure that the samples used for the different microanalysis techniques were all generated from the same source specimen and the corresponding chemical reactions took place under identical ambient conditions of temperature and relative humidity. The findings from the $\mathrm{XRD}$ analyses are as follows:

XRD diffractogram for a 28-day $A A B$ specimen containing $100 \%$ fly ash with Ms modulus = 1.4 , curing temperature of $40^{\circ} \mathrm{C}$, and $w / s=0.20$ is shown in Fig. 4.1. The 2-theta range for observing the XRD pattern was varied from 0 to 100 . This specimen showed predominantly $X$-ray amorphous character. Peaks of quartz $\left(\mathrm{SiO}_{2}\right)$ and mullite $\left(\mathrm{Al}_{6} \mathrm{Si}_{2} \mathrm{O}_{13}\right)$ were visible along with those of analcime $\left(\mathrm{NaAlSi}_{2} \mathrm{O}_{6} \cdot \mathrm{H}_{2} \mathrm{O}\right)$ and hydroxy sodalite $\left(\mathrm{Na}_{6}\left(\mathrm{Si}_{6} \mathrm{Al}_{6} \mathrm{O}_{24}\right) \cdot 8 \mathrm{H}_{2} \mathrm{O}\right)$. The respective peaks have been denoted by $Q, M, A n$, and $S$ in Figs. 4.1 and 4.2. Those peaks showed the presence of sodium aluminate chemical bonds having (Si-O-Al) chemical structure. Peaks were also observed for analcime and hydroxy sodalite where the $\mathrm{Na}^{+}$cation has penetrated into the aluminosilicate ( $\mathrm{Si}-\mathrm{O}-\mathrm{Al}$ ) chemical structure. Polymerization proceeded as $\mathrm{Na}$ entered into the Si-O-Al structures. The hump or the shoulder in the figure also confirmed the presence of amorphous phases co-existing with crystalline phases. 


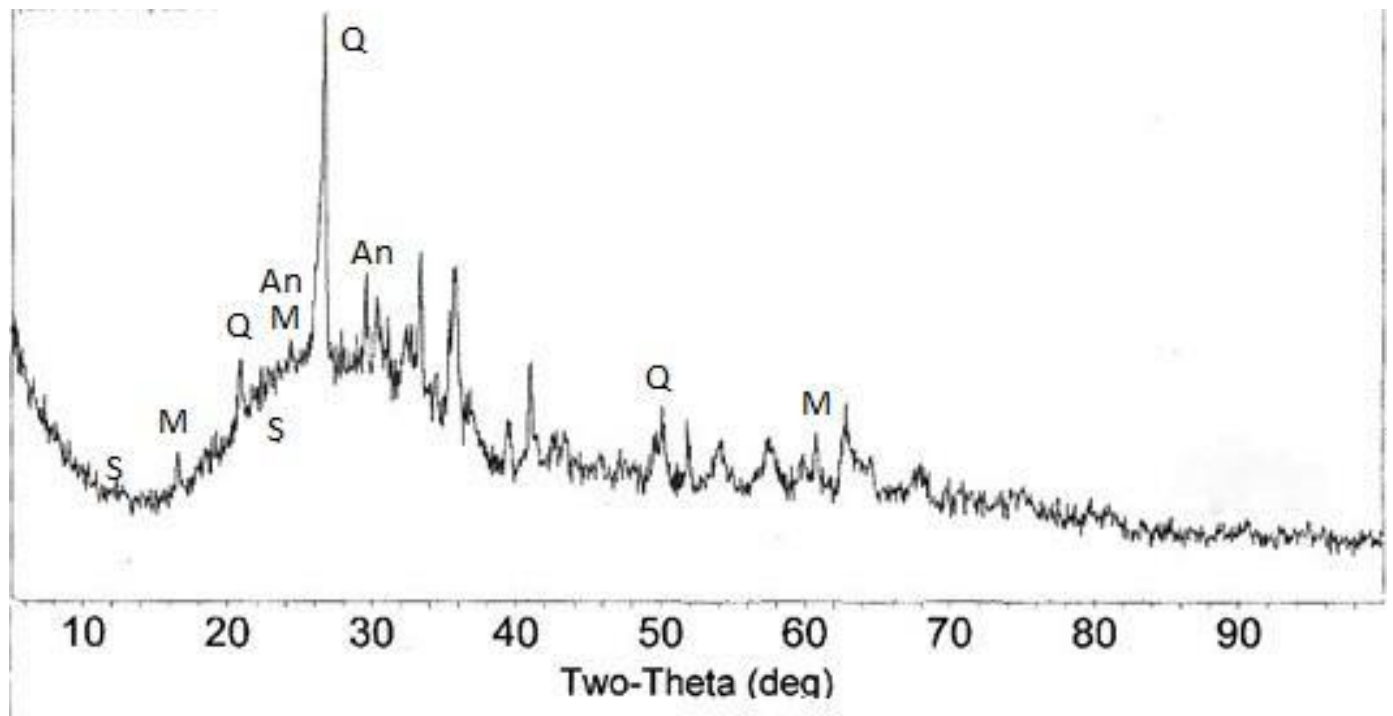

Fig. 4.1 Typical XRD pattern of 28-day FA $100 \mathrm{AAB}$ specimen at curing temperature of $40^{\circ} \mathrm{C}$. ( $\mathrm{S}=$ hydroxy sodalite, $\mathrm{M}=$ Mullite, $\mathrm{Q}=\mathrm{Quartz}, \mathrm{An}=$ Analcime)

XRD diffractograms obtained for some representative AAB pastes are presented in Fig. 4.2. The main crystalline phases identified in raw fly ash powder (not shown here for brevity) were quartz $\left(\mathrm{SiO}_{2}\right)$ and mullite $\left(\mathrm{Al}_{6} \mathrm{Si}_{2} \mathrm{O}_{13}\right)$. The hardened $A A B$ pastes showed the presence of quartz, mullite, analcime and hydroxy sodalite which were identified by their characteristic peaks. The hardened $A A B$ pastes also showed the presence of an X-ray amorphous aluminosilicate material, demonstrated by the broad hump from approximately 20 to $40^{\circ} 2 \theta$. It can be seen from Fig. 4.2 that no significant change in intensity for the quartz or mullite peaks was observed in the AAB samples. This was expected (van Jaarsveld, 2000), because it is predominantly the X-ray amorphous (glassy) phases in fly ash that undergo dissolution and subsequent geopolymerisation at high $\mathrm{pH}$. The hump in the region of 20 to $40^{\circ} 2 \theta$ is characteristic of amorphous silica. This indicated that there may be some unreacted fly ash in the system.

Another notable feature was the formation of hydroxy sodalite, a low silica zeolite $\left(\mathrm{Na}_{6}\left(\mathrm{Si}_{6} \mathrm{Al}_{6} \mathrm{O}_{24}\right) \cdot 8 \mathrm{H}_{2} \mathrm{O}\right)$. The samples showed some small peaks in regions indicating minor sodalite formation. This could occur if the silica dissolved slowly and the silicate species in solution did not migrate far from the particle surface. This results in regions which are silica rich and others which are silica deficient. It is possible that the silica deficient gel is able to form the low silica crystalline hydroxy sodalite phase, while the X-ray amorphous phase with higher silicate content binds the phase separated system. These observations were in 
close agreement with the findings from previous researchers (Rees et al., 2004; KupwadePatil and Allouche, 2011; and, Kamhangrittirong et al., 2007).

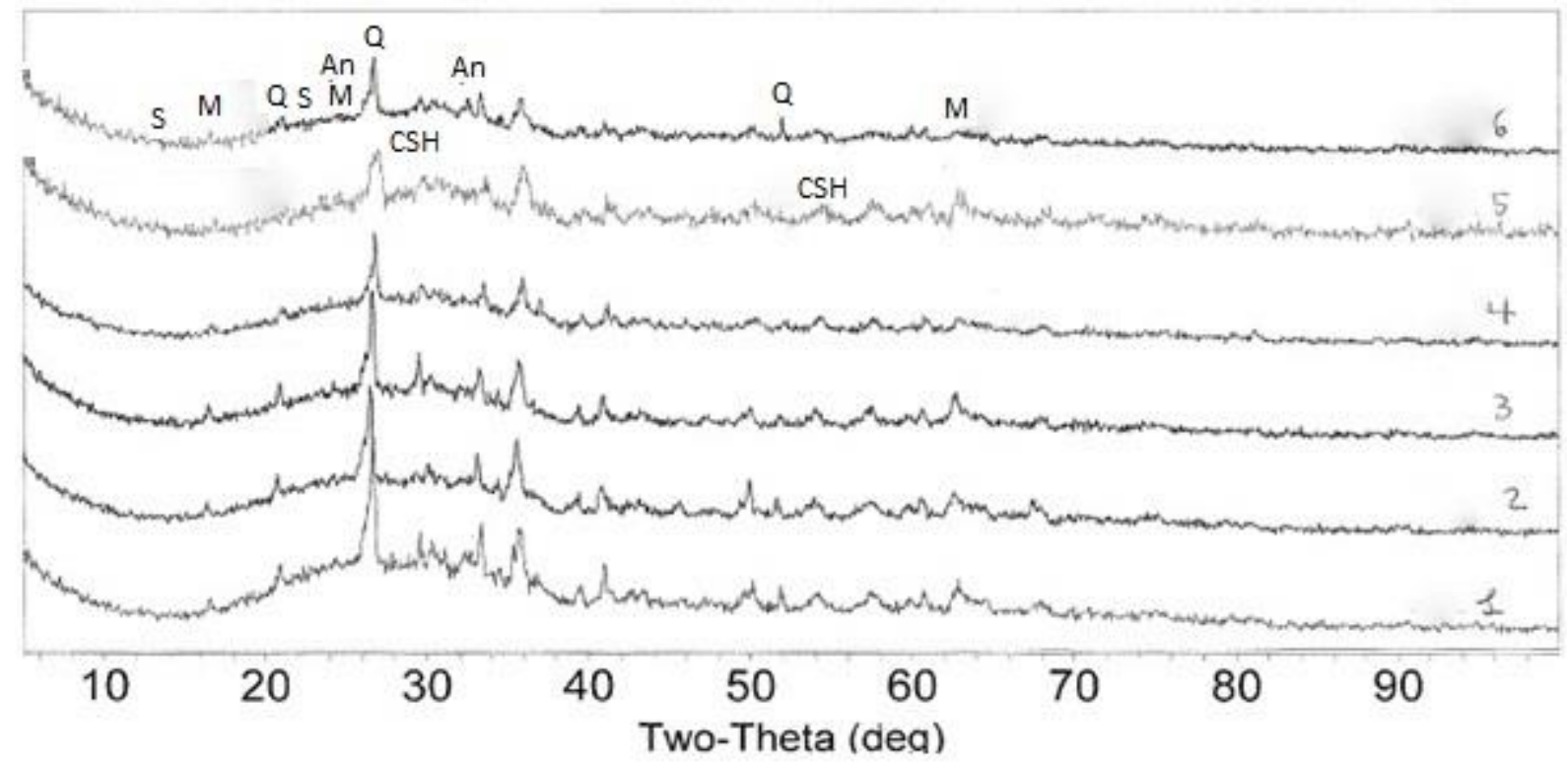

Fig. 4.2 XRD results for six different mixture proportions and each sample being tested at 28-day age - (1) FA 100 cured at $23^{\circ} \mathrm{C}$, (2) FA 100 cured at $40^{\circ} \mathrm{C}$, (3) FA 100 cured at $60^{\circ} \mathrm{C}$, (4) FA 50 SG 50 cured at $40^{\circ} \mathrm{C}$, (v) SG 100 cured at $40^{\circ} \mathrm{C}$, and (6) FA 100 preblended with $\mathrm{NaOH}$ for 7 days and cured at $40^{\circ} \mathrm{C}$. ( $\mathrm{S}=$ hydroxy sodalite, $\mathrm{M}=$ Mullite, $\mathrm{Q}=\mathrm{Quartz}, \mathrm{An}=$ Analcime, $\mathrm{CSH}=$ Calcium silicate hydrate due to slag, $\mathrm{CSH}(\mathrm{S})$ ).

In the case of samples containing either slag or a combination of fly ash and slag as precursor, presence of $\mathrm{CSH}(\mathrm{S})$ was observed from the small peaks which represented the amorphous calcium silicate hydrate matrix. These observations were in compliance with the findings from previous researchers (Skvara et al. 2006; Sakulich, 2009). The XRD results for sample 5 (Fig. 4.2), which corresponds to the case of SG 100 cured at $40^{\circ} \mathrm{C}$, showed the presence of Calcium Oxide peaks. This occurrence indicates the formation of calcium silicate hydrate $[\mathrm{CSH}(\mathrm{S})]$ in the microstructure of the polymer product as a result of slag hydration. The slag hydration process was assumed to be similar to Portland Cement hydration. It results in the formation of calcium silicate hydrate matrix similar to the case of PC but having a different $\mathrm{Ca} / \mathrm{Si}$ ratio. This hydration takes place simultaneously with the polymerization reactions related to the alkali activation of fly ash. 
Other than those mentioned above, no new crystalline phases were identified as products of the reactions. Although $X R D$ is an analytical technique commonly used to investigate $A A B$ systems, the technique has significant limitations due to the amorphous nature of $A A B$ materials. The XRD diffractograms show that the raw materials and most of the newly formed $A A B$ products are $X$-ray amorphous.

The present study requires knowledge about the quantity of the different phases in the microstructure of the polymer product. For this reason, other analytical techniques need to be used in conjunction with XRD to provide insight into the microstructural characteristics of $A A B$. FTIR studies were first conducted to corroborate the XRD results because of uncertainty in the microstructural composition of the polymer product. Then SEM/EDS techniques were implemented for further quantification.

\subsection{FTIR Results}

The chemical composition and the structural bonds present in the AAB samples were investigated by Fourier Transform infrared (FTIR) spectroscopy. FTIR spectra were obtained for the same 180 powder samples as mentioned in section 4.1 using a PerkinElmer Spectrum 100 FTIR spectrometer with Universal ATR accessory, in absorbance mode, within the frequency range of $4000-400 \mathrm{~cm}^{-1}$. The samples were the same ones as used for the $\mathrm{XRD}$ and other microanalyses, as mentioned in the previous section. Different FTIR spectrometers are available for studying different kinds of samples. The study of solids or powder samples using FTIR is relatively new compared to the traditionally used technique with $\mathrm{KBr}$ pellets. Some features of analyzing solids using FTIR have been described below.

\section{Analyzing solids using FTIR}

Solids are generally best analyzed on the single reflection ATR accessories; diamond being the preferred choice as probe crystal for most applications because of its robustness and durability. After the crystal area has been cleaned and the background collected, the solid material is placed onto the small crystal area (Figure $4.3 \mathrm{a}$ ). Experience has shown that ideal results from powder samples have been achieved by placing just enough sample to cover the crystal area (http://www.utsc.utoronto.ca/ traceslab/ATR_FTIR.pdf). The sample height should not be more than a few millimeters. Once the solid has been placed on the crystal area, the pressure arm should be positioned over the crystal/sample area. When using the 
Spectrum 100 Series' Universal ATR accessory, the pressure arm locks into a precise position above the diamond crystal (Figure $4.3 \mathrm{~b}$ ). Force is applied to the sample, pushing it onto the diamond surface.
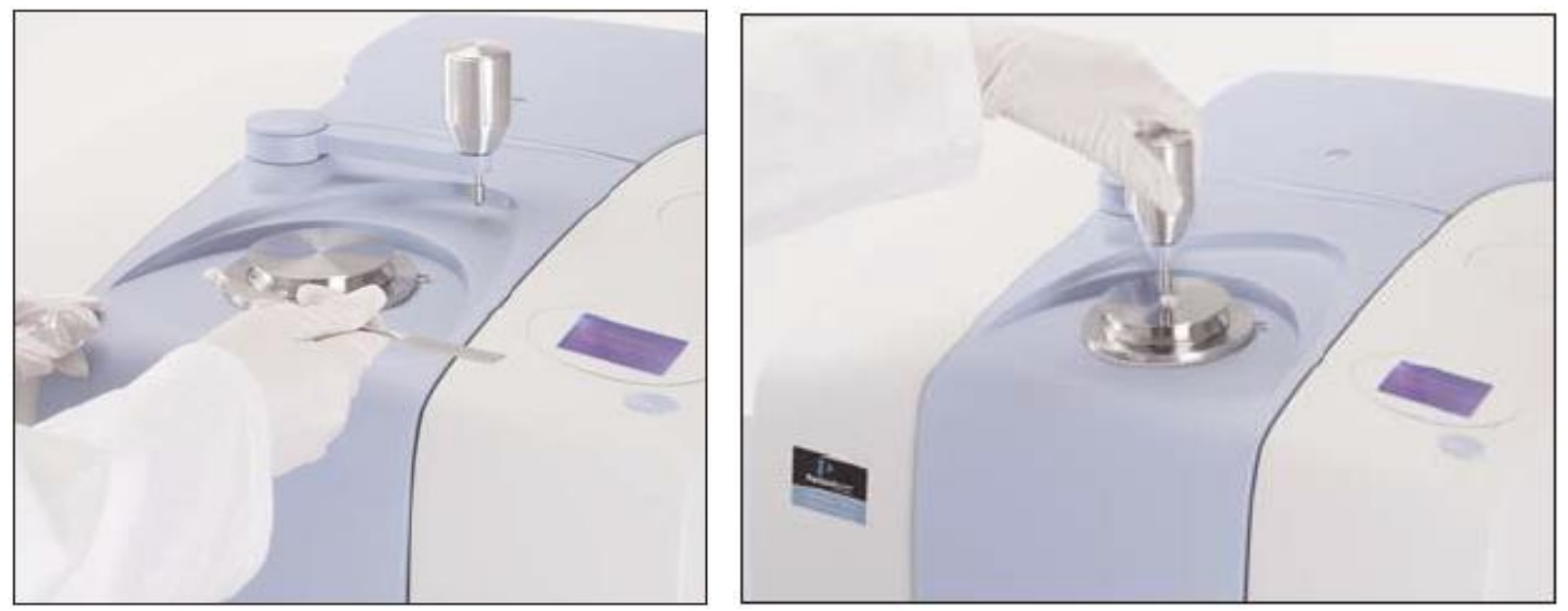

Fig. 4.3 (a) Placing a powder sample onto the Universal diamond ATR top-plate; (b) Applying pressure to a solid sample on the Universal diamond ATR top-plate (http://www.utsc.utoronto.ca/ traceslab/ATR_FTIR.pdf).

PerkinElmer's revolutionary Spectrum ${ }^{\mathrm{TM}}$ FT-IR software utilizes a 'Preview Mode' which allows the quality of the spectrum to be monitored in real-time while fine tuning the exerted force. It is good practice to apply pressure until the strongest spectral bands have an intensity which extends beyond $70 \% \mathrm{~T}$, namely from a baseline at $100 \% \mathrm{~T}$ down to $70 \% \mathrm{~T}$. Good sample/crystal interface contact has been achieved once this rule has been satisfied. This is very easy to achieve with soft samples and fine powders (PerkinElmer manual). The FTIR spectra for the hardened $A A B$ pastes and unreacted precursor, i.e., fly ash and/or slag before alkali-activation, are shown in Fig. 4.4.

The FTIR spectra were collected for both the precursor (fly ash powder) and the finished product (28-day age AAB specimen with $100 \%$ fly ash at Ms modulus of 1.4 and w/s $=0.2$ ). The figure compares the absorbance spectra for fly ash powder and $A A B$ containing $100 \%$ fly ash at three different temperatures of $23^{\circ} \mathrm{C}, 40^{\circ} \mathrm{C}$ and $60^{\circ} \mathrm{C}$. The spectra for $A A B$ containing $100 \%$ fly ash at $23^{\circ} \mathrm{C}$ shows a chemical shift of about $10 \mathrm{~cm}^{-1}$ in the range of wave number of $1008 \mathrm{~cm}^{-1}$. This shows the progress of the polymerization reaction. Also, the spectra for $A A B$ with $100 \%$ fly ash at $60^{\circ} \mathrm{C}$ show a chemical shift w.r.t. the spectra corresponding to the $A A B$ with $100 \%$ fly ash at $40^{\circ} \mathrm{C}$. In other words, the chemical shift 
increases with increase in curing temperature. This was an indication of the increased rate of reaction with the increase in curing temperature. The results are consistent with the findings made by Barbosa et al. (2000) and Rees (2007). Presence of Al-OH bonds were also detected in each of the $A A B$ spectra in the region of $910 \mathrm{~cm}^{-1}$. Peaks associated with amorphous silica appear at around $1000 \mathrm{~cm}^{-1}, 900 \mathrm{~cm}^{-1}$ and $500 \mathrm{~cm}^{-1}$, these peaks correspond respectively to the stretching, bending and rocking of the Si-O-Si bond. The peak near 1000 $\mathrm{cm}^{-1}$ was observed at $1043 \mathrm{~cm}^{-1}$ for the raw fly ash powder. This wave number was taken as the datum w.r.t. which the peak shifts for all the AAB samples were calculated.

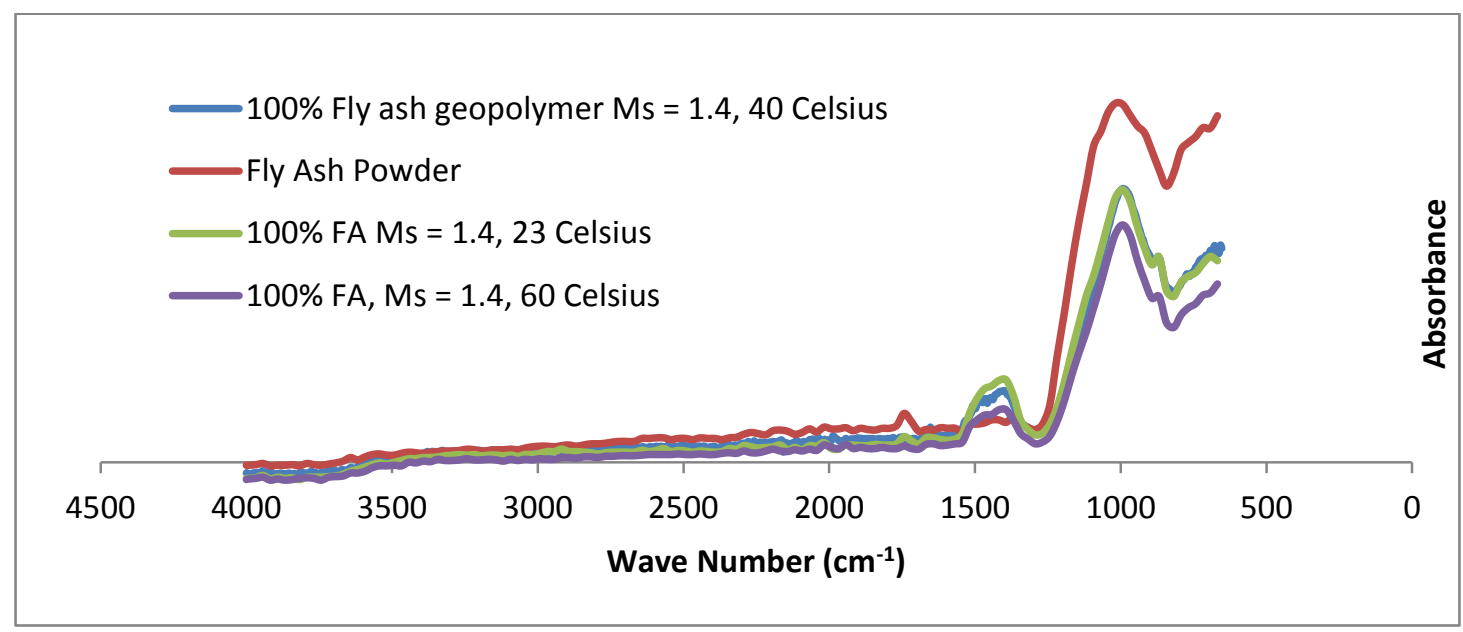

Fig. 4.4 Comparing FTIR absorbance spectra of fly ash powder and $100 \%$ fly ash based AAB. As evident from Fig. 4.4, the peaks near $1000 \mathrm{~cm}^{-1}$ and $900 \mathrm{~cm}^{-1}$ are of lower intensity for all $A A B$ specimens, compared to the raw fly ash powder. This indicated that silica in raw fly ash powder has reacted to some extent to form the AAB. The FTIR spectra of all AAB samples show a shoulder in the region of approximately $1100 \mathrm{~cm}^{-1}$ to $1080 \mathrm{~cm}^{-1}$. This region corresponds to the strongest peak in the unreacted fly ash spectra and therefore it was thought to be due to unreacted fly ash present in the AAB. The peak near $1000 \mathrm{~cm}^{-1}$ (most intense for raw fly ash powder at $1043 \mathrm{~cm}^{-1}$ ) was indicative of silicate stretching and it shifted after the reaction which produced the $A A B$. Following the reaction of the raw fly ash with the activating solution, a structural reorganization occurs in which aluminium ions are incorporated into the $\mathrm{SiO}_{4}$ tetrahedra, forming the Si-O-Al network. The extent of the peak shift has been found previously to correlate with the amount of aluminium incorporated into the silicate structure at constant alkali content. Furthermore, the addition of alkali, forming non-bridging oxygens of the form Si-O- $\mathrm{Na}^{+}$, causes a lowering of the molecular vibration force constant and therefore shifting of the peak associated with the asymmetric stretching of $\mathrm{Si}-\mathrm{O}-\mathrm{Si}(\mathrm{Al})$ bond to lower wavenumbers (Rees 2007). FTIR spectra were obtained for all 
the different mixture proportions at 28-day age. In Fig.4.5, sample FTIR spectra for FA 100, FA 50 SG 50, and SG 100 samples cured at $40^{\circ} \mathrm{C}$ temperature. Apart from the varied peak shift mentioned above, FTIR spectra for the $A A B$ appeared quite similar, indicating that all have similar bonding on a molecular level. The peak shifts for the different AAB mixtures at 28-day age are shown in Table 4.1.

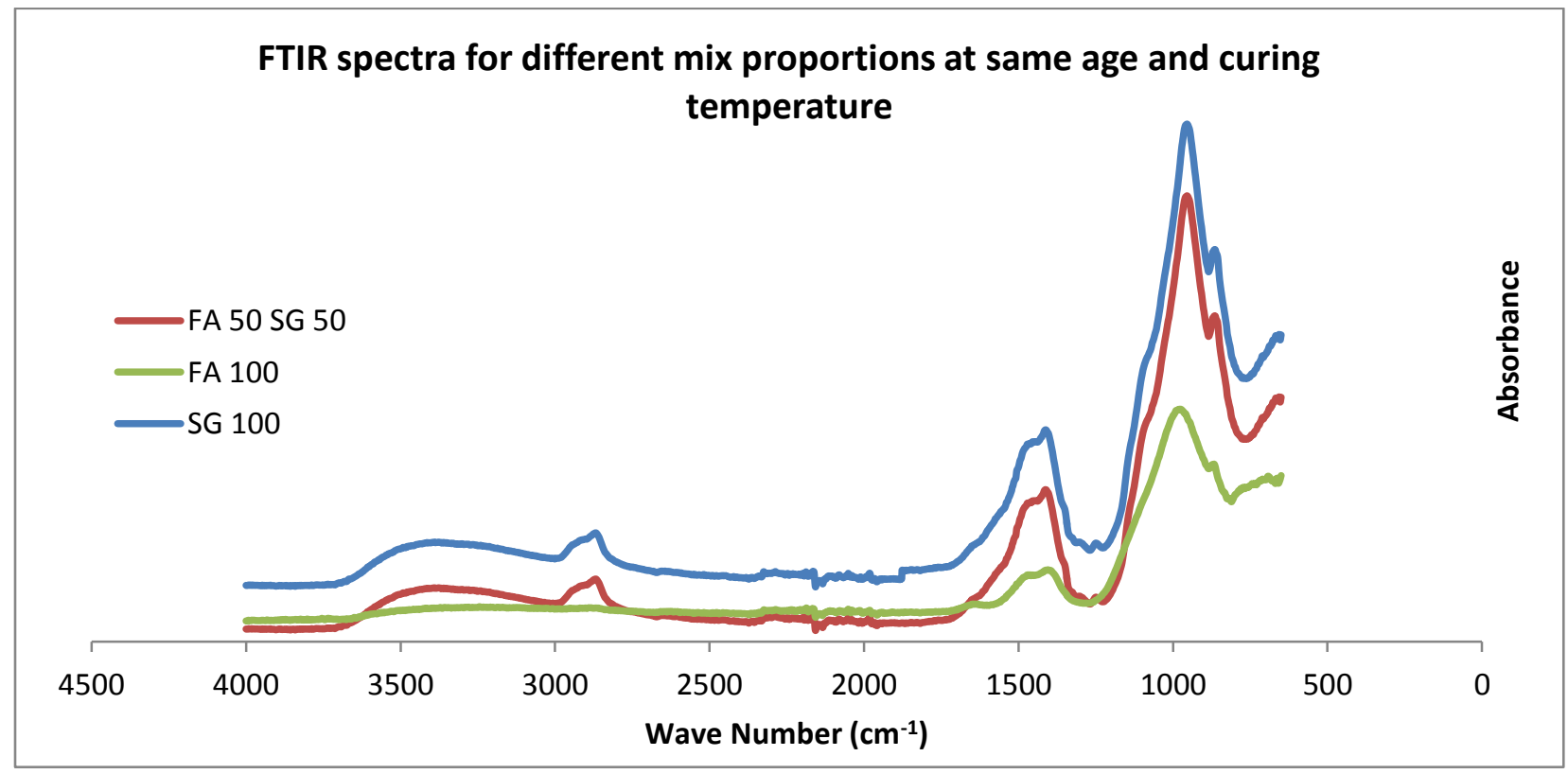

Fig. 4.5 Comparing FTIR absorbance spectra of FA 100, FA 50 SG 50, and SG 100 AAB samples.

Table 4.1 Characteristic Si-O-Si peak (Shift w.r.t. $1043 \mathrm{~cm}^{-1}$ ) for the Different AAB Mixtures at 28-day Age

\begin{tabular}{|c|c|c|c|}
\hline \multirow{2}{*}{ Mixture Proportion (AAB) } & \multicolumn{3}{|c|}{ Characteristic Si-O-Si peak (Shift w.r.t. $1043 \mathrm{~cm}^{-1}$ ) } \\
\cline { 2 - 4 } & $23^{\circ} \mathrm{C}$ & $40^{\circ} \mathrm{C}$ & $60^{\circ} \mathrm{C}$ \\
\hline FA 100 & $1018(25)$ & $1013(30)$ & $1003(40)$ \\
\hline FA 85 SG 15 & $1002(41)$ & $1000(43)$ & $998(45)$ \\
\hline FA 70 SG 30 & $998(45)$ & $996(47)$ & $993(50)$ \\
\hline FA 50 SG 50 & $984(59)$ & $980(63)$ & $975(68)$ \\
\hline FA 30 SG 70 & $962(81)$ & $956(87)$ & $959(84)$ \\
\hline FA 15 SG 85 & $949(94)$ & $946(97)$ & $942(101)$ \\
\hline FA 100 p15 & $1018(25)$ & $1013(30)$ & $1003(40)$ \\
\hline FA 100 p30 & $1018(25)$ & $1013(30)$ & $1003(40)$ \\
\hline FA 100 p60 & $1018(25)$ & $1013(30)$ & $1003(40)$ \\
\hline
\end{tabular}


As mentioned previously, the present study requires knowledge about the quantity of the different phases in the microstructure of the polymer product. Thus SEM/EDS techniques were implemented for further quantification of the phases which were confirmed to be present in the AAB microstructure through the XRD and FTIR studies.

\subsection{SEM/EDS}

A state-of-the-art thermal Field Emission Scanning Electron Microscope (FE-SEM), JSM$7600 \mathrm{~F}$ (accompanied by an EDS analyzer), supplied by JEOL Limited (Fig. 4.6) was used for the imaging process on $(10 * 3 * 3 * 2)=180$ hardened paste samples. After curing, these samples were crushed into powder and used for XRD and FTIR. The JSM-7600F incorporates a large specimen chamber which can accommodate specimen stages containing multiple samples at a time. The EDS microanalyzer had an adequate take off angle and the samples need not be tilted for analysis. The samples were fixed on the appropriate specimen stage and copper tapes were attached to the surface of the samples and the specimen holder to ensure uniform electrical conductivity of the assembly. The operating voltage was $15 \mathrm{kV}$ and the current at the surface of the specimen was $65.4 \sim 67.0 \mu \mathrm{A}$. The images were captured at two different magnifications of 2500x and 5000x respectively, at nine different locations for each specimen. A vacuum of $9.6 \times 10^{-5} \mathrm{~Pa}$ was applied while collecting the data (Kar, 2010).

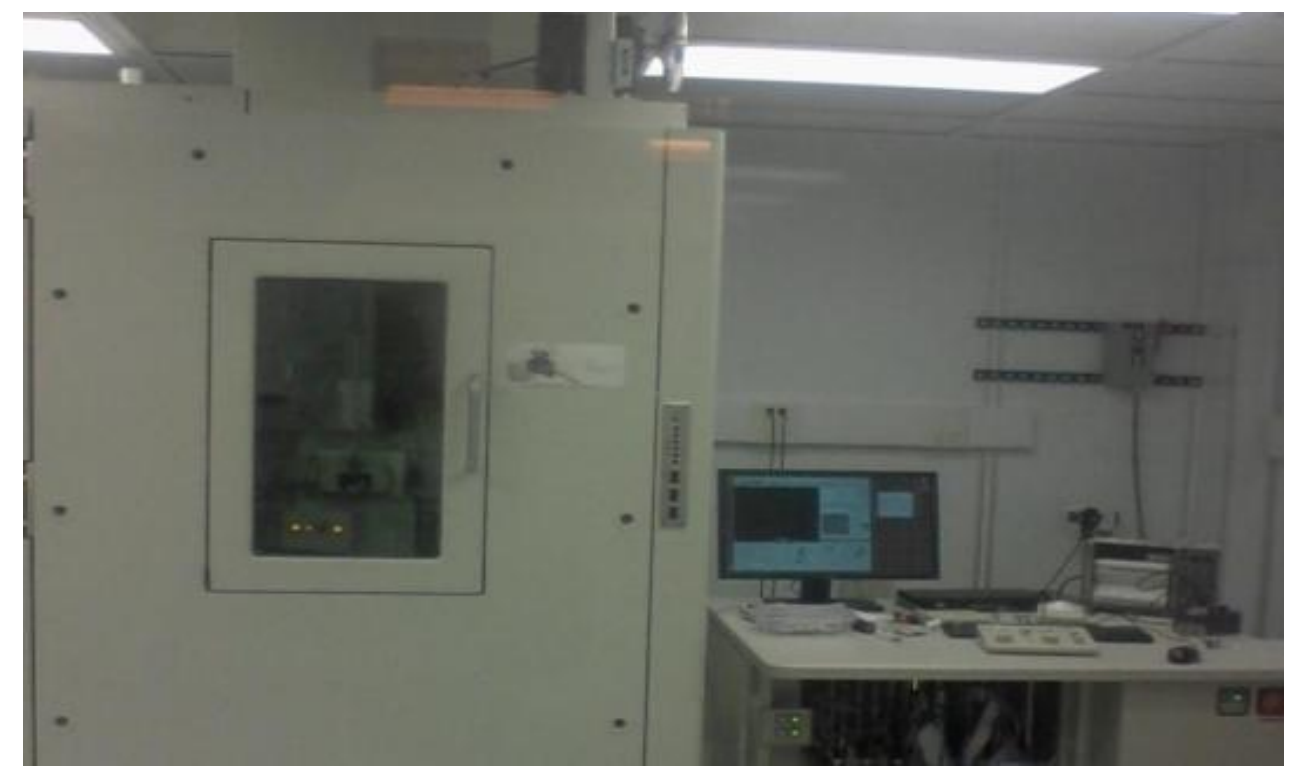

Fig. 4.6 Field Emission Scanning Electron Microscope (FE-SEM), JSM-7600F (accompanied by an EDS analyzer), supplied by JEOL Limited 
The details of polishing the samples for the purpose of SEM and EDS analyses have been provided below.

\subsubsection{Polishing/Sample preparation for SEM/EDS}

After adequate hand mixing (precursor and activating agent) with small quantity at a time and necessary curing, the samples for the SEM and microanalysis by EDS were cast in cylindrical plastic moulds having $10 \mathrm{~mm}$ diameter and $25 \mathrm{~mm}$ in height. A cylindrical disc of approximately $3 \mathrm{~mm}$ thickness and $10 \mathrm{~mm}$ in diameter was then cut out from the central portion of each specimen using a hand-held diamond cutting machine manufactured by Dremel Inc.

The samples were then embedded in resin for convenient handling and to improve the surface which will be studied under the electron microscope. Two different mounting techniques are available - hot compression mounting and cold mounting into the cups where the samples are embedded in resin. In case of the former, a temperature of up to $200^{\circ} \mathrm{C}$ and a force of upto $50 \mathrm{kN}$ is required during the embedding of the specimens, which might cause damage to the specimens. To avoid such difficulties, cold mounting procedure was adopted for the purpose of the present study. The EpoFix kit was purchased from Struers for the cold mounting of hardened AAB pastes for this study. The specimens were glued to the bottom of the $30 \mathrm{~mm}$ diameter mounting cups with some weak adhesive before the resin is poured, so that the specimen stays in place during the whole procedure. The walls of the mounting cup should be coated with a thin layer of silicone oil before pouring the resin to facilitate the dismounting of the hardened resin-with-embedded-specimen assembly from the cup. The resin was first prepared by mixing an epoxy and a compatible hardener in $15 / 2$ volume ratio in a separate cup followed by thorough hand-mixing and continuous stirring. The hardening period was 12 hours. But, the samples were removed from the cup after 24 hours just for the sake of safety.

The surfaces of the samples were then polished mechanically and the final average thickness was about $2.5 \mathrm{~mm}$. Before SEM and microanalysis by EDS, the specimens were allowed to dry at $50 \%$ humidity and $40^{\circ} \mathrm{C}$ for 48 hours in an environmental chamber to reduce the time of achieving desired vacuum pressure which depends on presence of moisture in the sample being tested. Then they were coated with a $15 \mathrm{~nm}$ layer of platinum in argon gas atmosphere at a high vacuum of $5.0 \times 10^{-6}$ Torrs, in order to make them electrically conductive in nature, as elaborated in section 4.3.2. The samples were stored in 
99.8\% laboratory grade methanol in air-tight vial until the SEM studies were conducted to stop the continued hydration at respective ages.

In order to get good resolution of the SEM/EDS the surfaces of the specimens had to be polished before the microanalyses. The specimens were polished using a TegraPol-31 fitted with Tegra Force 5 machine by Struers Inc.. The polishing technique comprised of the following steps:

The specimen was initially polished using MD-Piano 600, a resin-bonded diamond grinding disc with surface finish comparable to SiC-paper grit 80 for plane grinding of materials. In the second step, the specimen was polished with MD-Piano 1200 for 5 minutes. MD-Piano 1200 is a grinding disc with surface equivalent to SiC-paper grit 1200 used for fine grinding purposes. The third step was polishing the specimens using MD-Mol disc (Taffeta woven $100 \%$ wool surface) for 3 minutes, with aluminum oxide powder (particle dia of $3.0 \mu \mathrm{m}$ ) as polishing paste. The final step was polishing the specimens using MD-Mol disc for 2 minutes using alumina slurry (particle dia of $0.3 \mu \mathrm{m}$ ).

The grinder speed was maintained at $150 \mathrm{rpm}$ for each step. Tegra Force 5 was used to apply a force of $5 \sim 15 \mathrm{~N}$ on the specimens during each polishing cycle. Water was used a lubricant throughout the process. After each polishing cycle, the specimen was cleaned using an ultrasonic cleaner for 1 minute. It is worth mentioning that, to avoid contamination, different discs should be used for different particle diameters. To check the quality of polishing, the surface of the specimen was studied in optical microscope before it was sputtered with Platinum in order to make it ready for SEM/EDS analyses.

The TegraPol-31 polisher-grinder assembly, manufactured by Struers Inc., was used to prepare the specimens for microanalyses. The assembly consists of a single sturdy rotating magnetic disc unit. It is $300 \mathrm{~mm}$ in diameter and it can rotate at speeds of 150 or $300 \mathrm{rpm}$. There is also an attached outlet which allows a steady flow of water onto the disc for lubrication. MD series discs or pianos with varying surfaces roughness indices were used for the different stages of polishing as mentioned in the above section. The polish abrasives alumina slurry and aluminum oxide powder were purchased from Electron Microscopy Services. The ultrasonic cleaner works on the principle of introducing millions of tiny bubbles through ultrasonic energy on to the specimen. The bubbles expand and collapse in a rapid manner and create mechanical scrubbing action to remove the dirt from the specimen. 
Following the polishing procedure, the samples had to be coated with a layer of conductive material in order to make them properly observable under SEM and suitable for examination through EDS. The details of sputtering are provided in the following section.

\subsubsection{Sputtering the samples before SEM/EDS}

The hardened AAB paste samples polished to be studied under SEM and EDS were nonconductors of X-rays. In order to make them suitable for analysis under SEM and EDS, the samples were coated with a thin layer of platinum. Denton Vacuum Desk $V$ sputtering equipment (Fig. 4.7) was used for this purpose. The equipment controls the duration of sputtering. The duration is user-defined, depending on the desired thickness of the deposition. For the present study, the duration of sputtering chosen was 120 seconds after trial and error to achieve the desired thickness of sputtering. The resolution of the resulting SEM image was the selection criteria for the duration of sputtering. During the sputtering operation, the current flow in the machine was $18 \mathrm{mAmps}$. The thickness of the sputtered layer was usually $15 \mathrm{~nm}$ which is governed by the duration for which the sample is kept in the sputtering chamber. The whole procedure took place in a vacuum created by the vacuum chamber shown in Fig. 4.7.

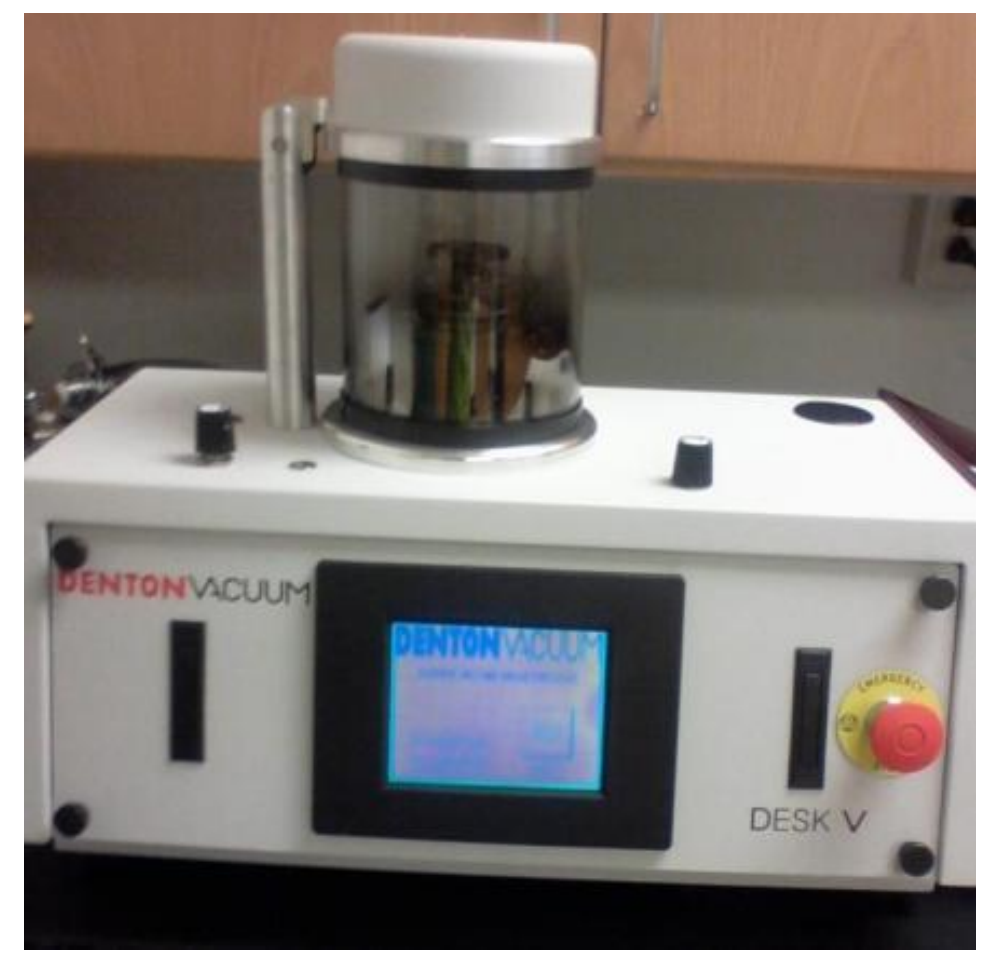

Fig. 4.7 Denton Vacuum Desk V Sputtering equipment 
For the sake of brevity, selected SEM images are shown in order to identify the morphology of the specimens used for the present study (Figs 4.8a through $4.8 \mathrm{f}$ ).

\subsubsection{SEM results}

Figs. 4.8 (a) through (f) show the typical microstructural features of FA 100 AAB specimens at three different temperatures and two different magnifications at each temperature. In general, the microstructure of the FA 100 AAB specimens was highly inhomogeneous and primarily made up of the reaction product resulting from the alkali activation - a sodium aluminosilicate gel that gave rise to the cementitious matrix. The matrix was full of loosely structured fly ash grains of different sizes. Numerous circular cavities belonging to fly ash particles and surrounded by tubular vitreous network were evident in the gel (Figs. 4.8 (a) through (f)). Some small fly ash particles which have already reacted with the alkaline liquid, coexist with the unreacted particles (spherical vitreous particles of various sizes in the range of $10-200 \mu \mathrm{m})$. There were also some spherical particles partially covered with the reaction products (Fig. 4.8 (c) and (d)) which consequently reduced the rate of reaction to some extent. The considerable amount of unreacted spheres, as well as the presence of pores in the matrix (Figs. 4.8a, 4.8c, 4.8d) indicated incomplete reaction. The amount of sodium aluminosilicate gel present in the cementitious matrix was found to increase with rise in curing temperature. Thus it corroborated the findings from the FTIR studies that the degree of reaction was enhanced at higher temperature. The unreacted spherical particles of FA 100 specimens indicated incomplete reaction which confirmed the low degree of reaction values (about $28.9 \%$ after 28 days for a curing temperature of $40^{\circ} \mathrm{C}$ ). 
FA 100 23C 28-d

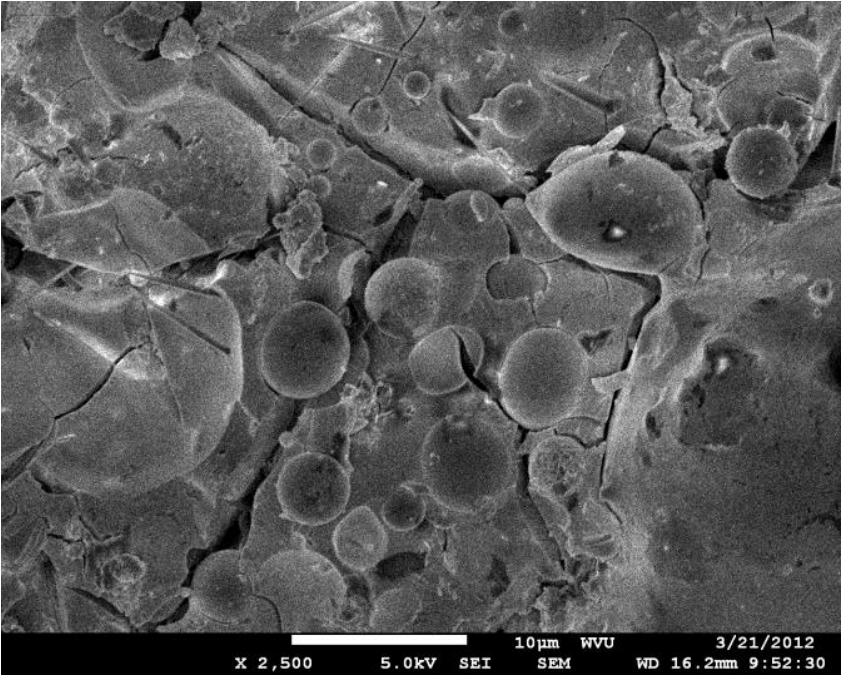

(a) $2500 x$

FA $10040 C$ 28-d

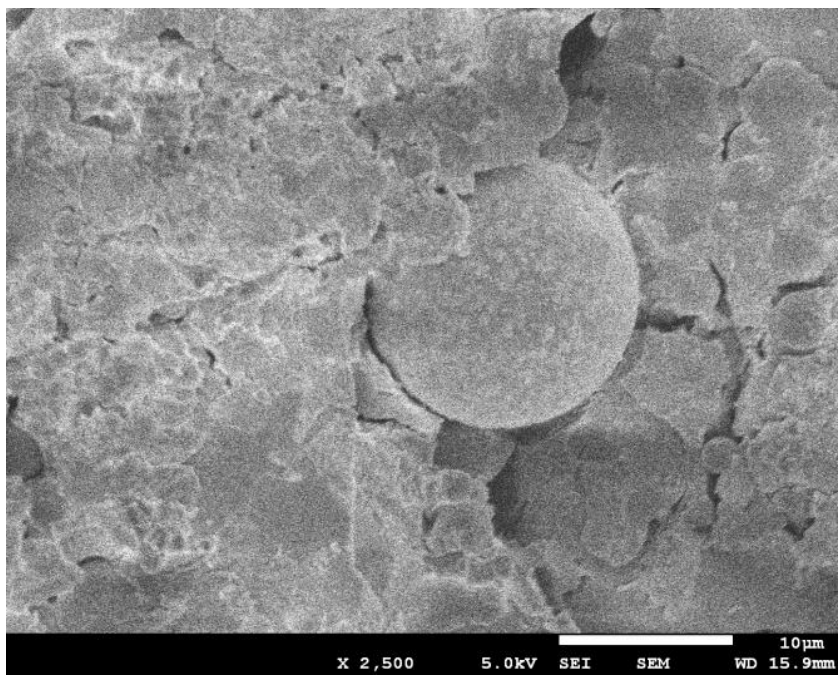

(c) $2500 x$

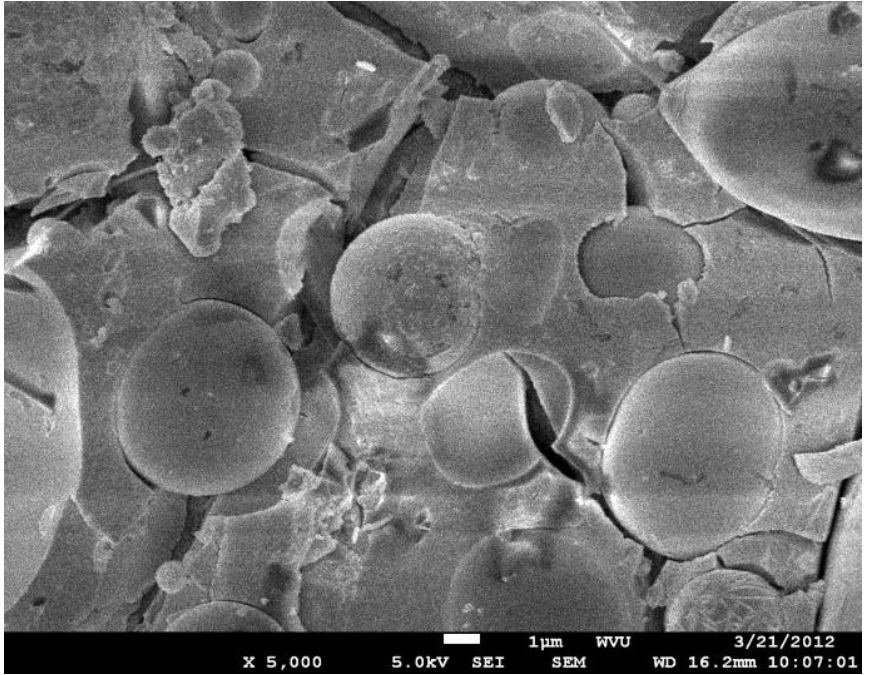

(b) $5000 x$

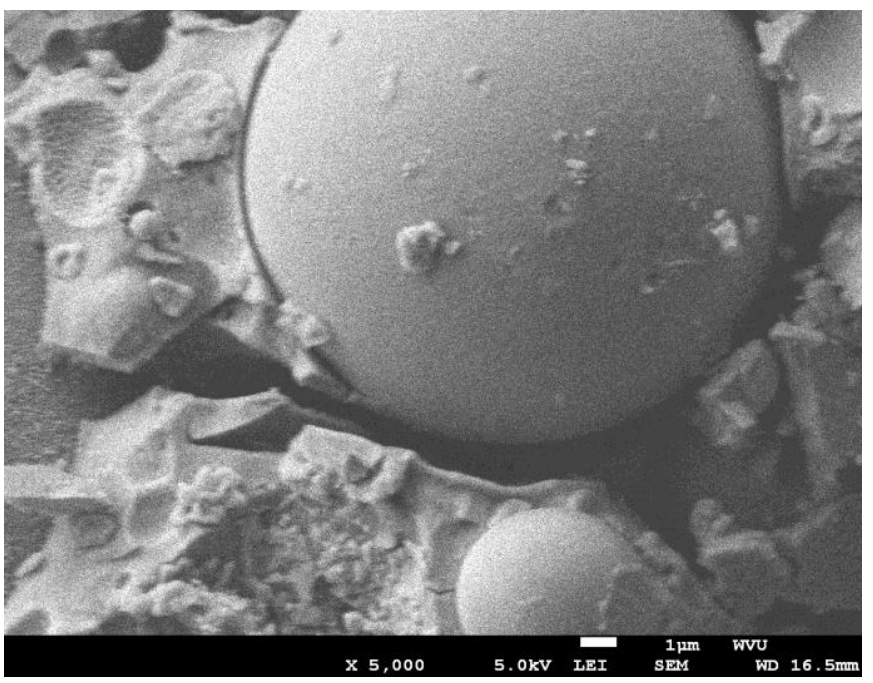

(d) $5000 x$ 


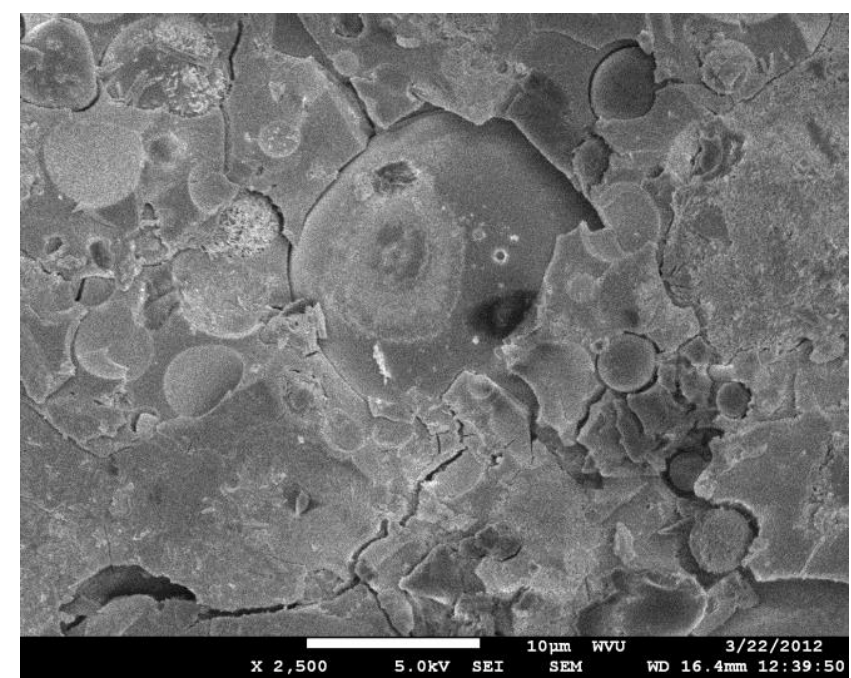

(e) $2500 x$

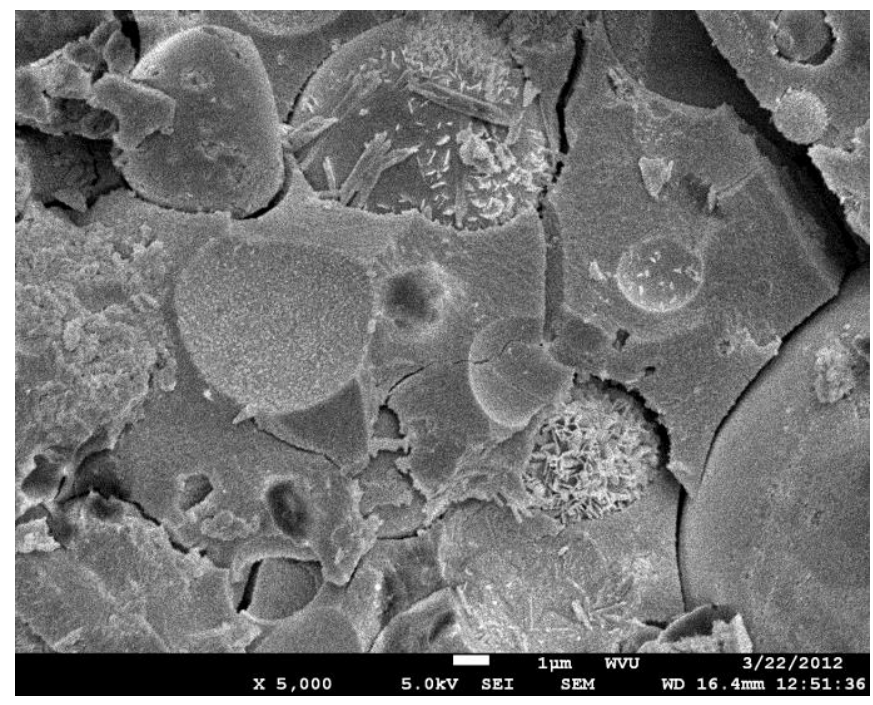

(f) $5000 x$

Fig. 4.8 Example SEM images of 28-days old FA $100 \mathrm{AAB}$ paste specimens at two different magnifications - 2500x and 5000x: (a) and (b) $23^{\circ} \mathrm{C}$, (c) and (d) $40^{\circ} \mathrm{C}$, and (e) and (f) $60^{\circ} \mathrm{C}$. Five different points were scanned at nine different locations on each specimen at each magnification to obtain a total of 90 data points in each case.

The patterns observed in the case of the present study are in agreement with the results obtained by Skvara et al. (2006), Provis and van Deventer (2009), Kupwade-Patil and Allouche (2011), and Muzek et al. (2012). The following set of figures have been provided to illustrate the influence of adding $\mathrm{Ca}^{2+}$ ions through partial or full replacement of fly ash by slag (Figs. 4.9a through 4.9 ). 
FA 85 SG 15

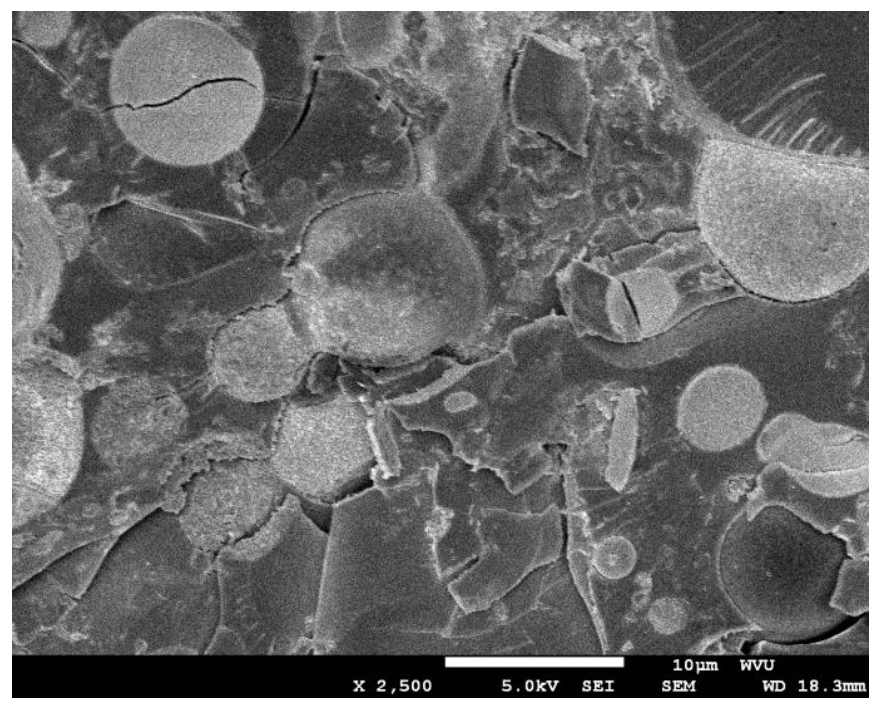

(a) $2500 x$

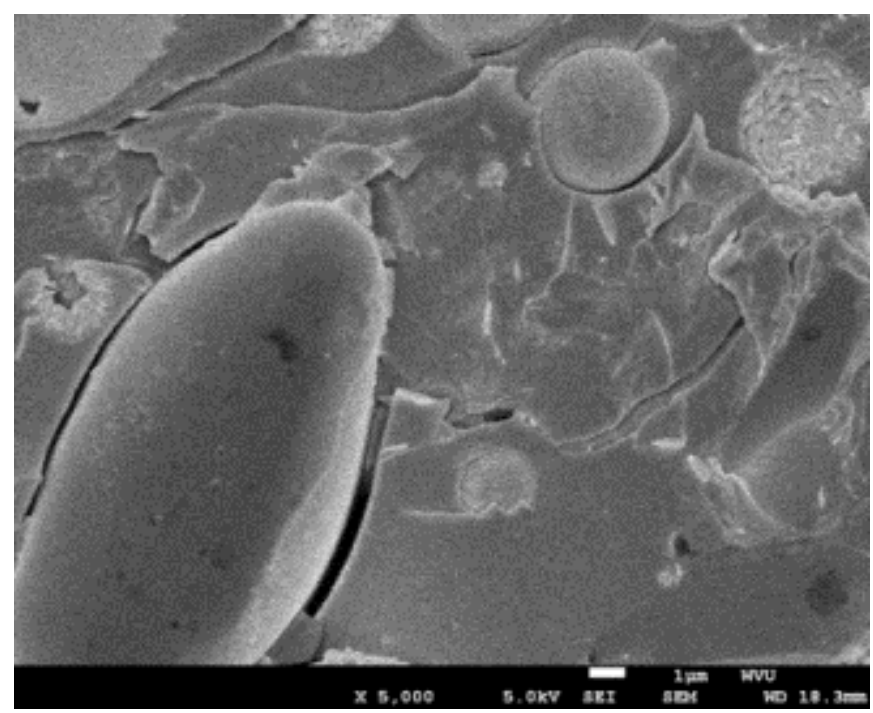

(b) $5000 x$

FA 50 SG 50

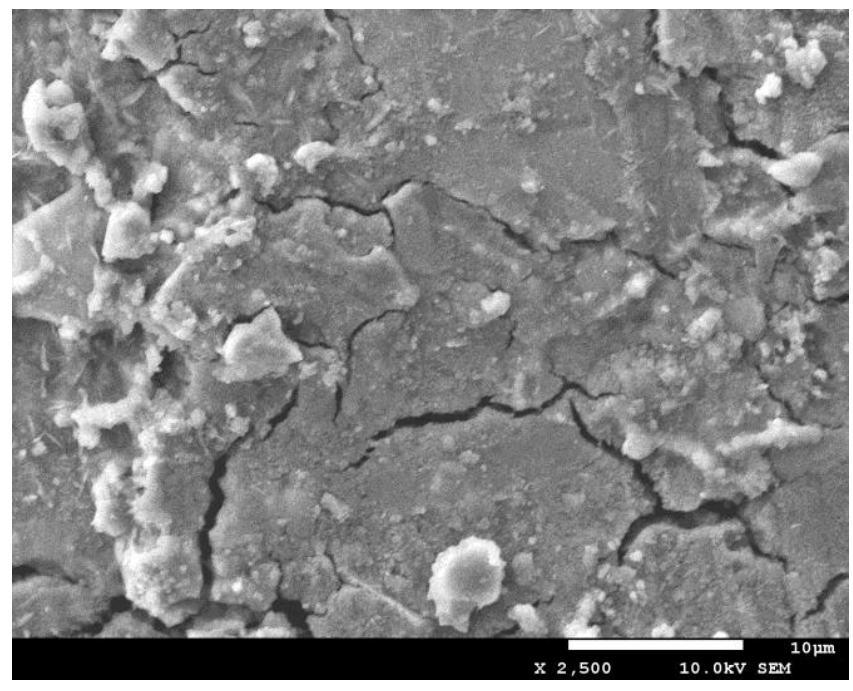

(c) $2500 x$

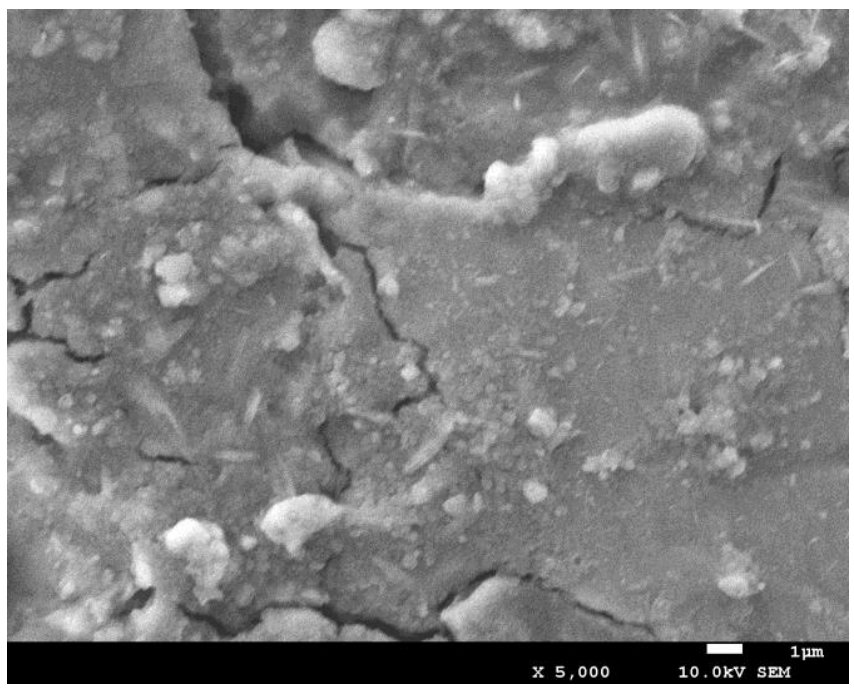

(d) $5000 x$ 


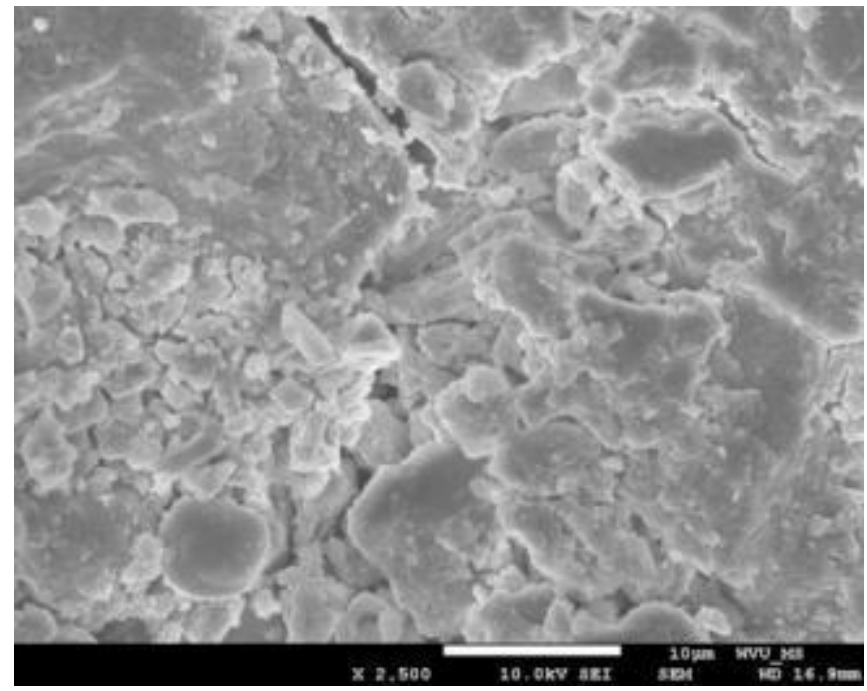

(e) $2500 x$

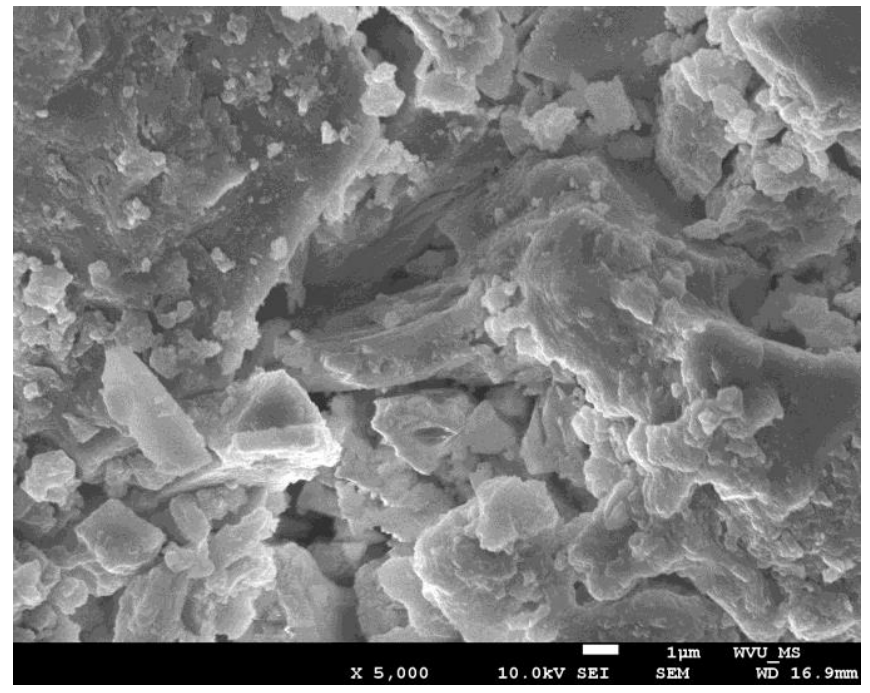

(f) $5000 x$

Fig. 4.9 Example SEM images of 28-days old $A A B$ paste specimens cured at $40^{\circ} \mathrm{C}$ and at two different magnifications - 2500x and 5000x: (a) and (b) FA 85 SG 15 (c) and (d) FA 50 SG 50, and (e) and (f) SG 100. Five different points were scanned at nine different locations on each specimen at each magnification to obtain a total of 90 data points in each case.

Figs. 4.9 (a) through (f) show the typical microstructural features of (i) FA 85 SG 15, (ii) FA 50 SG 50, and (iii) SG $100 \mathrm{AAB}$ samples cured at $40^{\circ} \mathrm{C}$ temperature and two different magnifications have been shown for each case. The patterns observed in the case of the present study are in agreement with the results obtained by Skvara et al. (2006). The lighter areas indicated the $\mathrm{CSH}(\mathrm{S})$ phase formed due to the hydration of slag. The $\mathrm{CSH}(\mathrm{S})$ was identified through SEM morphology from their fibrous to irregular grains forming reticular network. The preceding figures, thus, showed the co-existence of sodium aluminosilicate matrix due to alkali activation of fly ash and $\mathrm{CSH}(\mathrm{S})$ formation due to slag hydration.

In the case of the preblended $A A B$ samples, the SEM revealed morphologies similar to the normal AAB mixes. Sample SEM images for FA 100 p30 AAB mix cured at $60^{\circ} \mathrm{C}$ is shown in Fig. 4.10. 


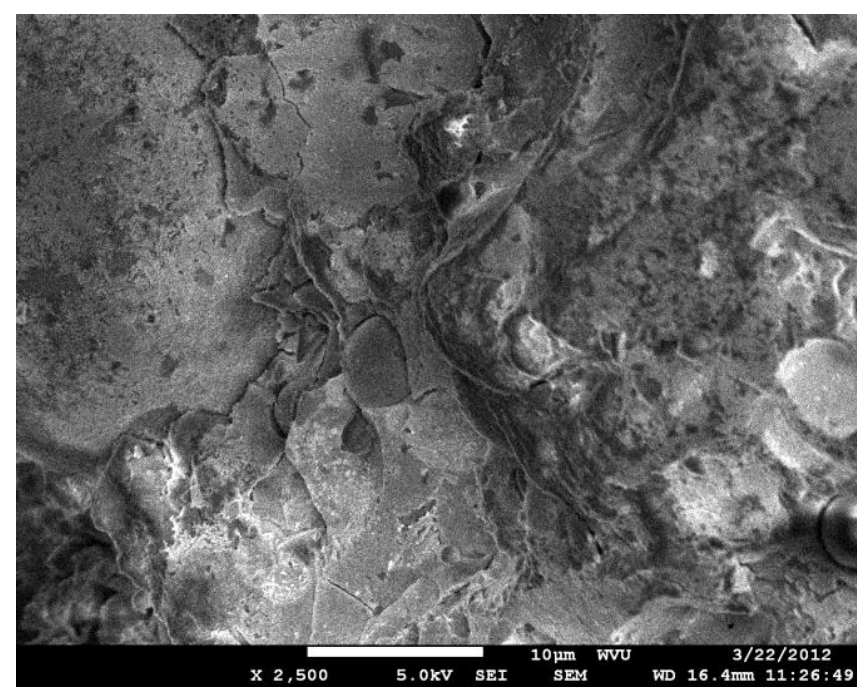

(a) $2500 x$

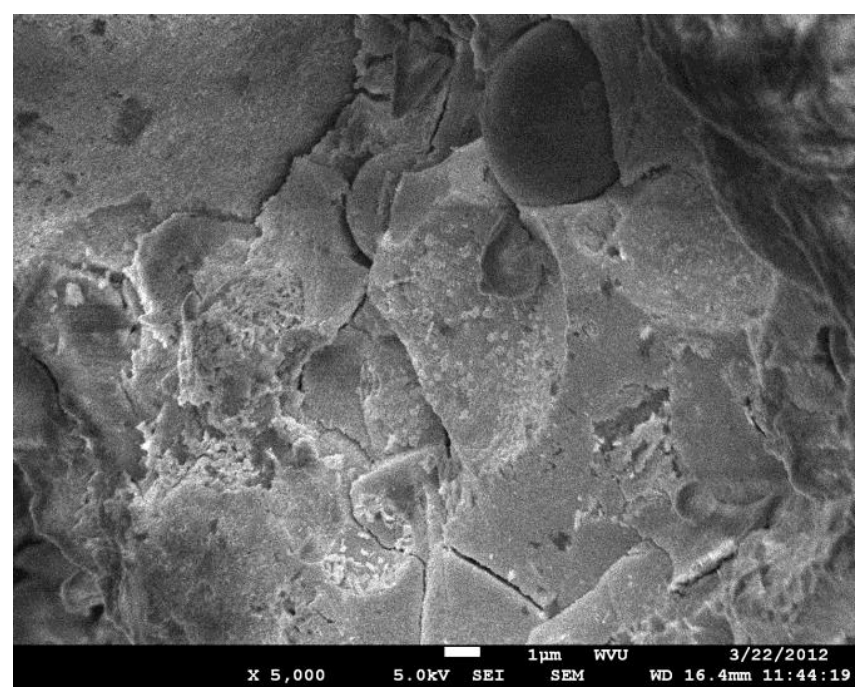

(b) $5000 x$

Fig. 4.10 (a) and (b) Example SEM images of 28-days old paste of FA 100 p30 AAB mix cured at $60^{\circ} \mathrm{C}$ specimens at two different magnifications - 2500x and 5000x. Five different points were scanned at nine different locations on each specimen at each magnification to obtain a total of 90 data points in each case.

The SEM observations only provide qualitative characterization of the AAB microstructure by identification of the various chemical phases present there. As the present study required quantitative knowledge of the chemical phases present in the microstructure of the $A A B$ samples, EDS analyses were conducted. The details are presented in the following section.

\subsection{EDS Results}

Energy dispersive X-ray spectroscopy (EDS) is used together with SEM on the same 180 samples as mentioned in section 4.3. However, the EDS technique scans the whole specimen, instead of just the surface. The energy of the X-rays emitted by the impact of the electron beam with the specimen depends on the nature of the specimen. The X-rays are usually collected by a Lithium drifted silicon detector which must be operated at the temperatures close to that of liquid Nitrogen. The X-ray strikes the silicon detector and a photoelectron is generated, which travels through the silicon and generates electron-hole pairs. The strong electric field which is applied attracts the electrons and holes to opposite ends of the detector, thereby generating current pulses. The size of this pulse is governed by the number of electron-hole pairs which, in turn, is controlled by the incoming X-ray. The $X$-ray spectra thus acquired can be used to identify the elemental composition of the 
specimen. The EDS equipment used for the present study cannot detect elements with atomic numbers less than 4 (atomic number of Beryllium) because the Lithium drifted silicon detector is protected by a Beryllium window. The absorption of the soft X-rays by the Beryllium thus hinders the detection of the elements located below it in the periodic table. Hence, the presence of hydrogen cannot be detected with this technique.

For each location, five EDS spectra were acquired with the help of the INCA systems software that is used by the Oxford spectrometer. The working distance was maintained at $15 \mathrm{~mm}$ and the probe current $8(65.4 \sim 67.0 \mu \mathrm{A})$ in order for the EDS analyzer to work properly. Each sample was approximately divided in three locations. The microanalysis was done at five randomly chosen points for each location at each magnification for every sample. Thus for each sample, for three locations, at each magnification, 45 points were analyzed. Finally for two magnifications (2500x and 5000x), 90 points were analyzed for each of the ten different mixes at every age $(7,28$, and 90 days). The points for microanalysis were chosen randomly to minimize the influence of the heterogeneity of the $A A B$ microstructure. In selected locations of sample, also average microanalysis (not point analysis) was conducted to verify the variations compared to point analysis. Out of the 90 points, 60 points were used to formulate the model used for estimating the volume of the hydrated products and the remaining 30 points were used to validate the predictions from the proposed model. These 60 points were chosen randomly for the same reason as mentioned above. As a typical example for a given mixture proportion and 2500x magnification, Figs. 4.11a and 4.11b show EDS images for FA 100 AAB hardened paste and FA 50 SG 50 AAB hardened paste with curing temperature of $40^{\circ} \mathrm{C}$. A similar procedure was followed for the other cases. The hardened alkali activated material pastes were observed under the SEM at two different magnifications - 2500x and 5000x.

EDS analysis showed that the matrix primarily consisted of the phases containing $\mathrm{Na}-\mathrm{Si}-\mathrm{Al}$ in the bulk region in case of the specimens where fly ash was the main precursor. In addition to $\mathrm{Na}$, $\mathrm{Si}$ and $\mathrm{Al}$, traces of $\mathrm{Fe}, \mathrm{Ca}, \mathrm{K}$ and $\mathrm{Mg}$ were also observed in these specimens (Fig. 4.11). These remnants (Fe, $\mathrm{Ca}, \mathrm{K}, \mathrm{Mg}$ ) obviously represented the unreacted fly ash phases, which did not dissolve during alkali activation. When slag was present in greater amounts, the presence of $\mathrm{Ca}^{2+}$ was more prominent (Fig. 4.11). 
(a)

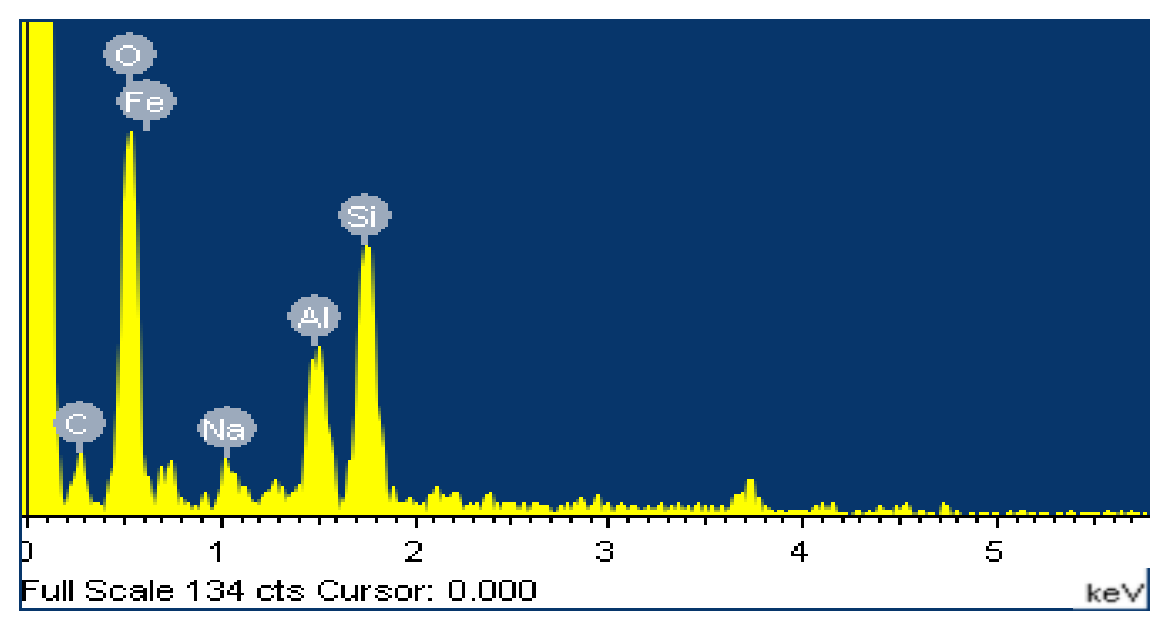

FA 50 SG 50

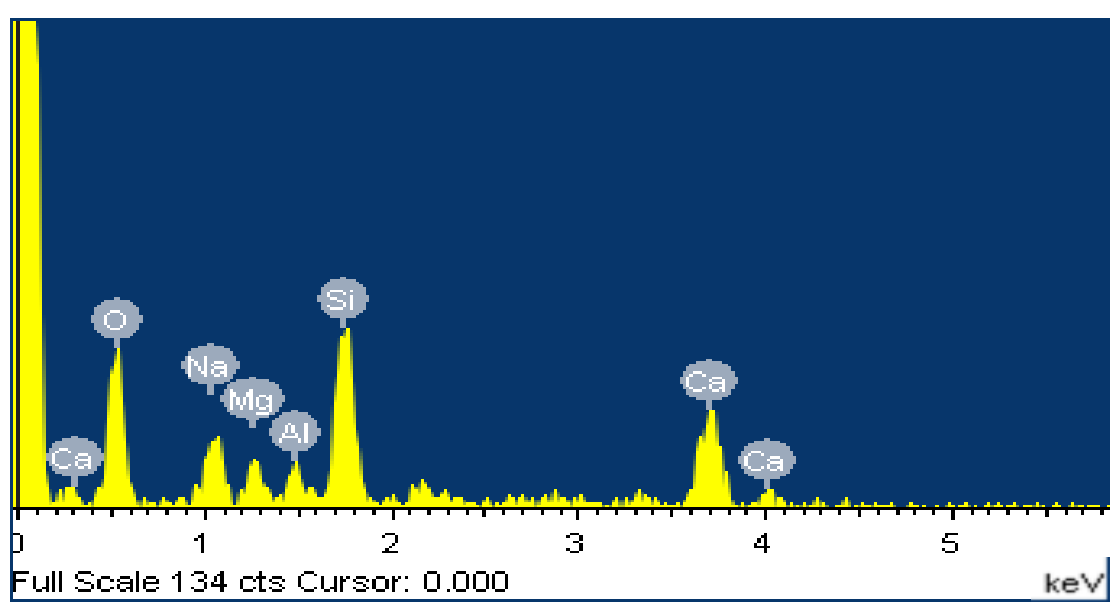

(b)

Fig. 4.11 Example EDS images of 28-days old $A A B$ paste specimens cured at $40^{\circ} \mathrm{C}$ : (a) FA 100 and (b) FA 50 SG 50. Five different points were scanned at nine different locations on each specimen at each of two different magnifications to obtain a total of 90 data points in each case.

EDS microanalyses were carried out on a total of 90 data points for each sample as mentioned above. The results obtained from the microanalysis were in terms of the atomic percentages of the different elements present in the AAB microstructure. The Si/Al, $\mathrm{Na} / \mathrm{Al}$ and and $\mathrm{Ca} / \mathrm{Si}$ ratios were computed for each of the 90 data points. They were plotted on 3D axes using OriginPro 9 software (Figs. 4.12 and 4.13). The concept of 3D plot was used by Famy et al. (2003) to characterize the CSH and its phase compositions in case of PC mortars through the solution of simultaneous algebraic equations. The results of the works done by previous researchers showed that typical $A A B$ composition proposed by Davidovits 
is generally expressed as $n M_{2} \mathrm{O} \mathrm{Al}{ }_{2} \mathrm{O}_{3} \cdot x \mathrm{SiO}_{2} \cdot y \mathrm{H}_{2} \mathrm{O}$; where $1<n<1.6 ; 2<x<3.5 ; 3<y<7$; and M: Na, K (Muzek et al 2012).

For the present study, the alkali activator comprised of sodium silicate solution and sodium hydroxide. Hence, $M$ represents $\mathrm{Na}, n$ represents the $\mathrm{Na}_{2} \mathrm{O} / \mathrm{Al}_{2} \mathrm{O}_{3}$ molar ratio, and $x$ represents the $\mathrm{SiO}_{2} / \mathrm{Al}_{2} \mathrm{O}_{3}$ molar ratio. From stoichiometry, it is evident that 1 mole of $\mathrm{Na}_{2} \mathrm{O}$ is equivalent to 2 moles of $\mathrm{Na} ; 1$ mole of $\mathrm{Al}_{2} \mathrm{O}_{3}$ is equivalent to 2 moles of $\mathrm{Al}$ and 1 mole of $\mathrm{SiO}_{2}$ is equivalent to 1 mole of $\mathrm{Si}$. Hence the ranges for the oxide ratios mentioned above can be transformed to their equivalent elemental ratios as follows: $1<\mathrm{Na} / \mathrm{Al}$ (atomic ratio) $<1.6$ and $1<\mathrm{Si} / \mathrm{Al}<1.75$ (atomic ratio). These ranges were used to analyze the results from the EDS analyses using the concept of 3-D plots.

This approach was somewhat similar to the point-count procedure as proposed by Feng et al. (2004). This approach had been successfully applied by Kar et al. (2012) for systems containing PC along with different combinations of fly ash, slag and silica fume as supplementary cementitious materials. The total number of points analyzed by EDS for each sample that comprised of $\mathrm{Si} / \mathrm{Al}$, and $\mathrm{Na} / \mathrm{Al}$ ratios in the given range and $\mathrm{Ca} / \mathrm{Si}$ ratios less than 0.1 were counted as representing the polymer product component of the total paste volume. It was assumed that the polymer products formed due to alkali activation of fly ash comprised of very low calcium content. Hence the $\mathrm{Ca} / \mathrm{Si}$ ratios for these products were assumed to be less than 0.1. As mentioned earlier in section 4.3, the SEM/EDS microanalyses were carried out at randomly chosen points to account for the heterogeneity of the microstructure of the cement paste. Each of the scanned areas was approximately $120 \mu \mathrm{m}$ by $120 \mu \mathrm{m}$ square. The polymer product was detected from SEM morphology and features. They were present as highly inhomogeneous structures and the matrix was full of loosely structured fly ash grains of different sizes. Numerous circular cavities belonging to fly ash particles were evident in the matrix. Cavities were surrounded by tubular vitreous network. The ratio of the number of points representing the polymer product to the total number of data points for each sample was taken as the representative volume fraction of polymer for each sample. The volume fraction from SEM was compared with the results from the proposed algebraic equation and the square of the errors was minimized using optimization technique with the help of the General Algebraic Modeling System (GAMS). The optimal $\mathrm{Na} / \mathrm{Al}$ and $\mathrm{Si} / \mathrm{Al}$ atomic ratios were computed for each specimen. Thus, corresponding unique values of $n, x$ and $y$ were obtained which most nearly represents the chemical composition of the polymer product. 
A similar approach was followed to find the volume fraction of $\mathrm{CSH}(\mathrm{S})$ in case of mixtures containing slag in addition to fly ash. The range of $\mathrm{Ca} / \mathrm{Si}$ atom ratio in $\mathrm{CSH}(\mathrm{S})$ in case of slag cements is about 1.4 to 1.6 (Taylor 1997). Thus, from the 3D plots of the microanalysis data, the number of points at which the Si/Ca ratio lies in the range of $\mathrm{CSH}(\mathrm{S})$ were counted and expressed as a fraction of the total number of data points. The volume fraction of the polymer product from the theoretical approach was computed using the $n, x$, and $y$ values derived from the optimization technique. This was compared with the experimental values in case of the mixtures with slag and they showed very good agreement as shown later in section 4.10 .

Some example 3-D plots have been shown in figs. 4.12 and 4.13 for the sake of brevity. The first set of plots depicts the results at different curing temperatures for 7-day old FA 100 AAB samples (Fig. 4.12).

An increase in the number of points representing the reaction product due to alkali activation of fly ash was observed when the curing temperature was increased for both FA 100 mixes as well as mixes containing partial or full replacement of fly ash with slag (Fig. 4.13). 


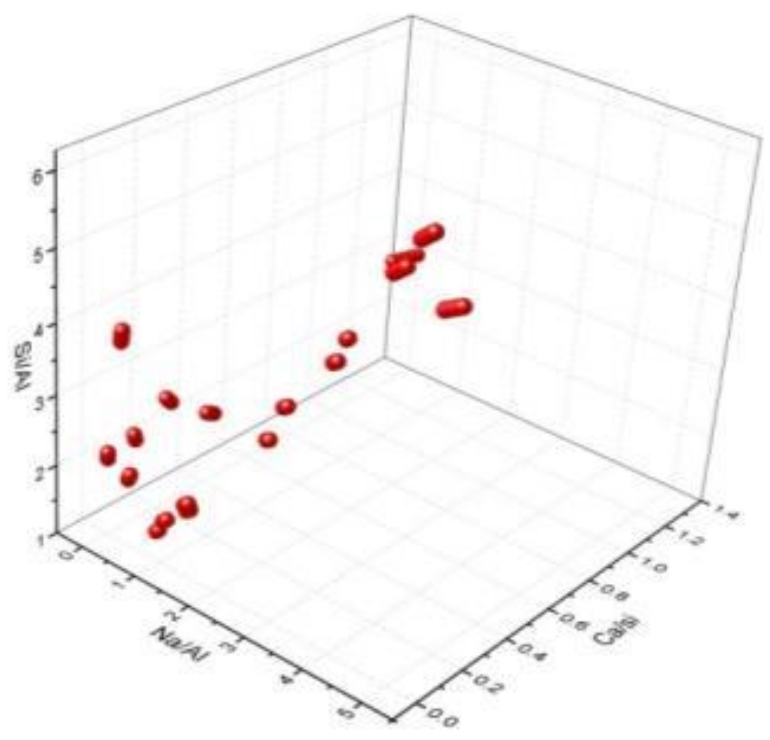

(a) $23^{\circ} \mathrm{C}$

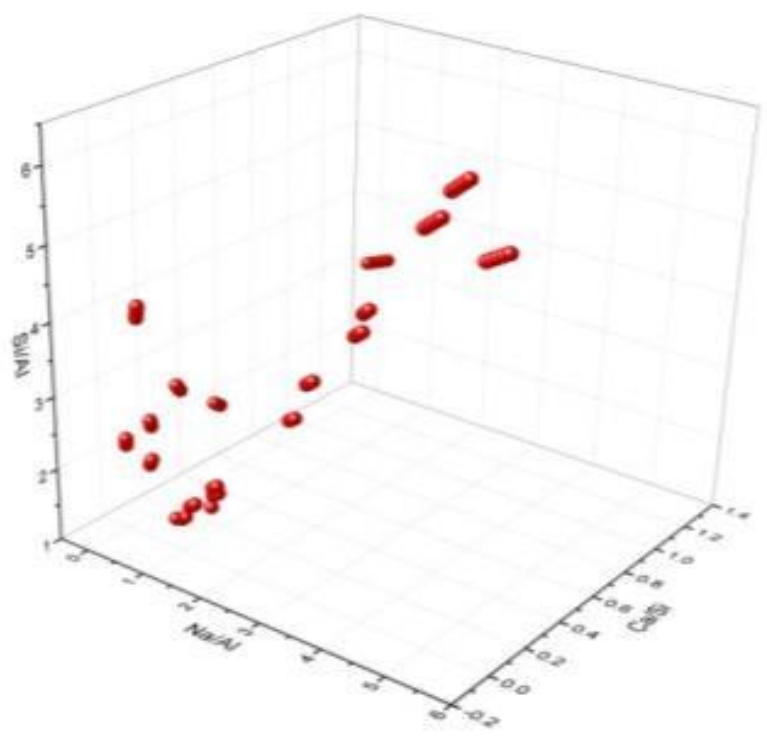

(b) $40^{\circ} \mathrm{C}$

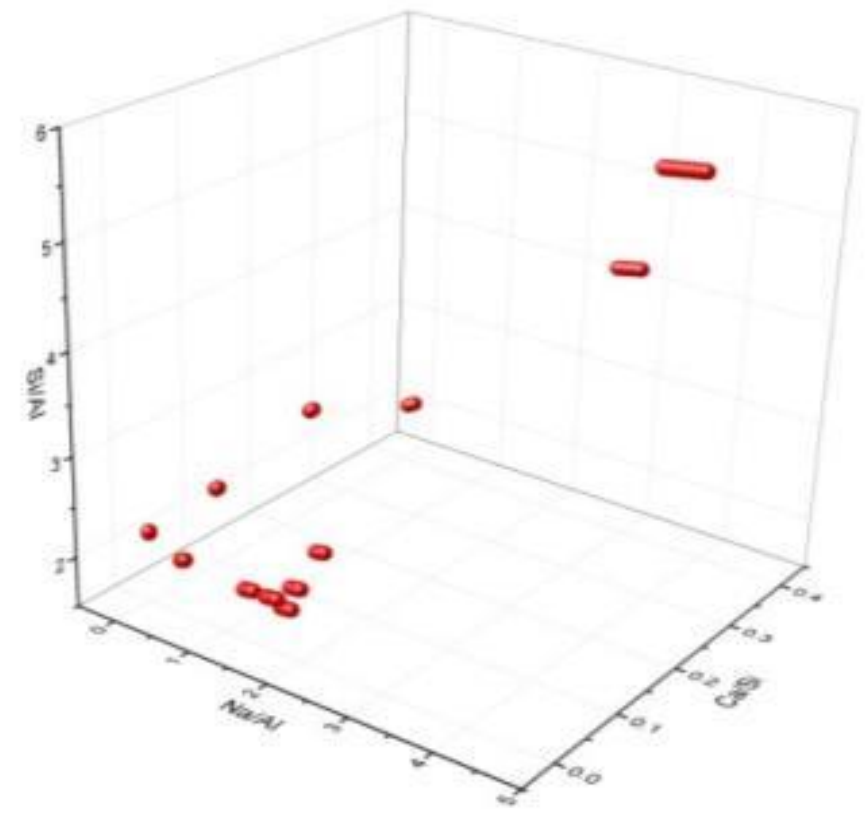

(c) $60^{\circ} \mathrm{C}$

Fig. 4.12 3D plots of $\mathrm{Na} / \mathrm{Al}, \mathrm{Si} / \mathrm{Al}$ and $\mathrm{Ca} / \mathrm{Si}$ atomic ratios for a typical 7-day old FA $100 \mathrm{AAB}$ paste at three different curing temperatures: (a) $23^{\circ} \mathrm{C}$, (b) $40^{\circ} \mathrm{C}$, and (c) $60^{\circ} \mathrm{C}$. 
The following 3-D plots are presented for AAB samples containing $50 \%$ and full replacement of fly ash with slag.

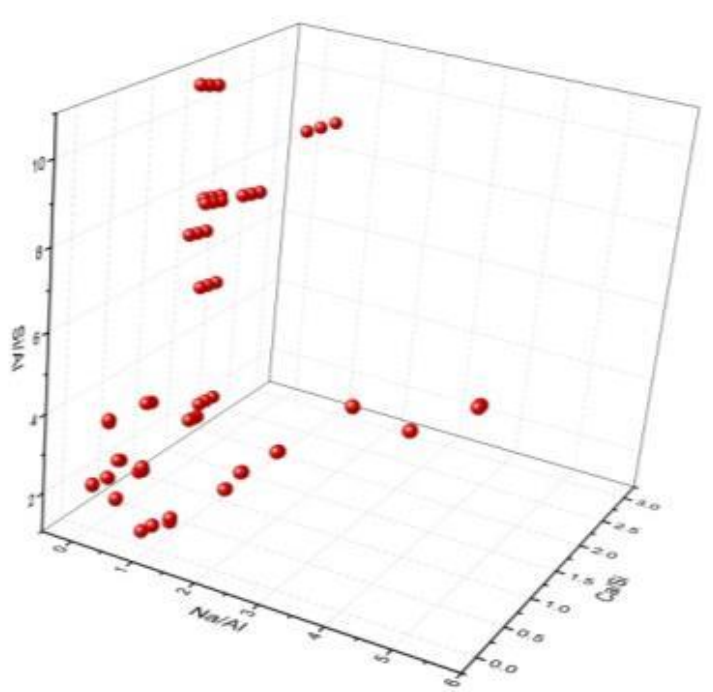

(a) FA 50 SG 50

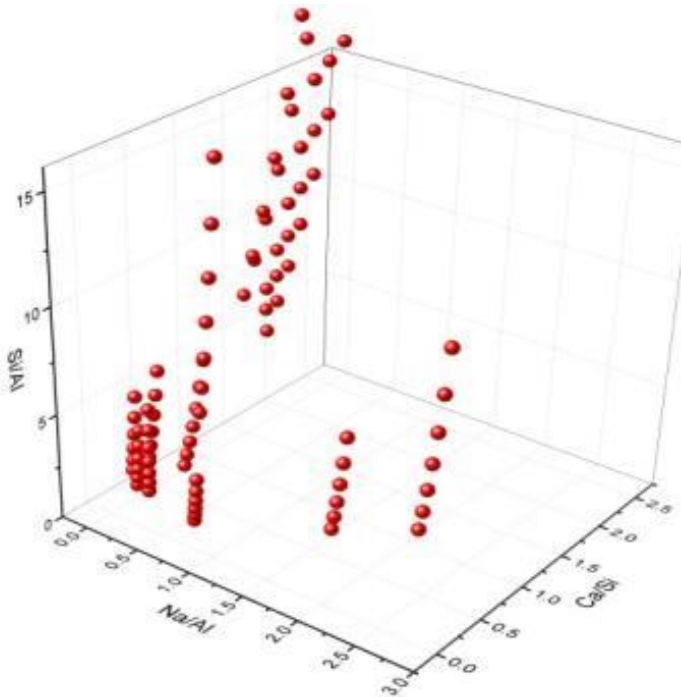

(b) SG 100

Fig. 4.13 Typical 3D plots of $\mathrm{Na} / \mathrm{Al}, \mathrm{Si} / \mathrm{Al}$ and $\mathrm{Ca} / \mathrm{Si}$ atomic ratios for (a) FA 50 SG 50 and (b) SG $100 \mathrm{AAB}$ pastes at curing temperature of $23^{\circ} \mathrm{C}$.

The 3D plots of the atom ratios for all the other mixes at different ages and different curing temperatures are provided in the Appendix.

\subsection{Analysis of Microscale Test Results Using Volume Stoichiometry and Optimization}

The volume stoichiometry and optimization were combined to estimate the theoretical volume fractions. The comparison between the experimentally obtained values and those obtained by the optimization technique for all the different mix proportions were evaluated.

The results of the different microscale experiments will be analyzed and used to estimate the quantities of the reaction products of alkali activation of the precursors. A combination of optimization tools and the volume stoichiometry of the chemical reactions associated with the alkali activation of fly ash and/or slag was adopted for this purpose. The relevant steps have been discussed in details in this section.

The chemistry of the polymerization reaction produced by the alkali activation of fly ash was obtained from available literature. The volume stoichiometry associated with this reaction 
was used in the present study to calculate the amount of AAB products formed when fly ash was activated with alkalis. As the fly ash used in this study was locally available and not analyzed previously, the general formula for the reacted $A A B$ paste product was expressed as $n \mathrm{Na}_{2} \mathrm{O} \cdot \mathrm{Al}_{2} \mathrm{O}_{3} \cdot x \mathrm{SiO}_{2} \cdot y \mathrm{H}_{2} \mathrm{O}$ due to its unknown chemical composition. Microanalysis using SEM and EDS were conducted to identify the approximate chemical composition of the AAB product. Optimization techniques were used on the microanalysis results and the estimated quantities of hydrated products to determine $n, x$, and $y$.

\subsubsection{Chemical reactions during alkali activation of fly ash}

The schematic formation of $A A B$ material can be shown as described by Eqns. (2.2) and (2.3). The equations have been provided again for reference (Provis and van Deventer 2009):

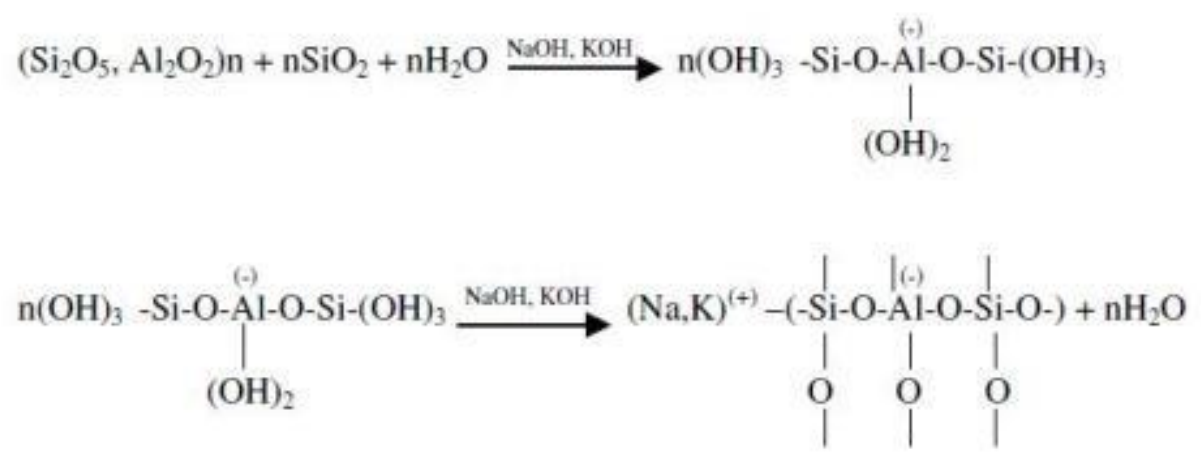

The polymerisation process involves a substantially fast chemical reaction under alkaline condition on Si-Al minerals, that results in a three-dimensional polymeric chain and ring structure consisting of Si-O-Al-O bonds, as follows (Davidovits 1999):

$$
\mathrm{M}_{n}\left[-\left(\mathrm{SiO}_{2}\right) z-\mathrm{AlO}_{2}\right]_{n} \cdot w \mathrm{H}_{2} \mathrm{O}
$$

Where: $M=$ the alkaline element or cation such as potassium, sodium or calcium; the symbol - indicates the presence of a bond, $\mathrm{n}$ is the degree of polycondensation or polymerisation; $z$ is $1,2,3$, or higher, up to 32 .

As mentioned earlier, the above formula for the sodium aluminosilicate complex can also be expressed as $n \mathrm{Na}_{2} \mathrm{O} \cdot \mathrm{Al}_{2} \mathrm{O}_{3} \cdot x \mathrm{SiO}_{2} \cdot y \mathrm{H}_{2} \mathrm{O}$. Combining the above formulations, the equation for the formation of the reaction product from the alkali activation of fly ash can be written as 


$$
n\left(\mathrm{Si}_{2} \mathrm{O}_{5} \cdot \mathrm{Al}_{2} \mathrm{O}_{2}\right)+2 n \mathrm{SiO}_{2}+4 n \mathrm{H}_{2} \mathrm{O}+\mathrm{NaOH} \rightarrow n \mathrm{Na}_{2} \mathrm{O} \cdot \mathrm{Al}_{2} \mathrm{O}_{3} \cdot x \mathrm{SiO}_{2} \cdot y \mathrm{H}_{2} \mathrm{O}+\Delta \text { (exothermic) }
$$

\subsubsection{Reaction mechanism of alkali activation of slag}

When calcium compounds are not added, the binder is considered to be alkaline. The microstructure of the product is composed of bonds provided only by alkaline aluminasilicate groups, such as sodium-potassium zeolites, mica, or hydrous mica. When calcium compounds are added, the binders are alkali-alkali earth producing CSH and alkali earth alumino-silicates.

These binders have been found to obtain hydraulic hardening without depending on hydration with water of binders containing a high content of basic calcium minerals like $\mathrm{C}_{3} \mathrm{~S}$, $\mathrm{C}_{2} \mathrm{~S}, \mathrm{C}_{3} \mathrm{~A}, \mathrm{C}_{4} \mathrm{AF}$, and $\mathrm{CA}$ (Provis and van Deventer 2009).

Talling and Brandstetr (1995) were able to modify the theory regarding natural mineral binders, which was governed by the principle, that hydraulic hardening occurs only with compounds containing elements belonging to the second group in the Periodic Table ( $\mathrm{Mg}$, $\mathrm{Ca}, \mathrm{Sr}, \mathrm{Ba})$. Those elements are alkali earth metals with complex formation in the third (aluminum), fourth (silicon), fifth (phosphate) and sixth (sulfate) groups. The capacity to obtain hydraulic hardening is also present in compounds containing elements from the first group ( $\mathrm{Li}, \mathrm{Na}, \mathrm{K}, \mathrm{Cs}, \mathrm{Rb}$ ) of alkaline metals with pairs of complex formation in the third and fourth (alumina-silicates), second and fourth (alkali earth silicates) and the second and third (alkali earth aluminate) groups.

The theoretical approach is using alkali activated alumino-silicate binder is to produce hydration products similar to the more stable weathering products in nature. Alkali activated binders can be prepared with a wide variety of natural materials or waste materials with minimum amount of processing. A variety of alkaline materials can be used to promote binding properties. Accessory components can be used to direct or promote hydration reactions and crystallization. Generally a source of silica and/or alumina and a source of alkali are required. When needed, additional modifiers can be used. Combinations of silica/alumina sources as well as mixed alkali sources usually impart better properties due to optimum structure formation during hydration. 
The hydration of an alkali activated slag binder revealed the formation of a natrolite-type sodium alumino-silicate hydrate, $\mathrm{CSH}$, analcime, scolecite, calcite, epistilbite and gismondine and gyrolite.

For the chemical designation of AAB or more traditionally, geopolymers based on silicoaluminates, the term polysialate was suggested. Sialate is an abbreviation for silicon-oxoaluminate. As mentioned in Chapter 2, geopolymers are synthetic mineral products formed under alkaline conditions. Geopolymer chemistry is mainly the chemistry of different clays in alkaline environment at temperature up to $150-200^{\circ} \mathrm{C}$. This resembles the soil silicate cements developed in Ukraine in 1957.

Mixtures containing slag and fly ash activated with sodium hydroxide are low-cost binders with high early strength development. However, they showed high sensitivity to drying resulting in loss of tensile strength and fast carbonation. The mixes showed efflorescence of salts and irritation on skin contact. The binders also exhibited rapid setting. This was controlled by grinding the binder with small amounts of anhydrous lime, clinker, gypsum or phosphogypsum. The concrete properties were equal or slightly superior to the reference concrete made with portland cement. Corrosion-resistant concretes were developed by using soda-alkali melt and $\mathrm{NaOH}$. The maximum compressive strength was obtained by a mix containing $49-53 \%$ slag, $41-45 \%$ fly ash and $7 \% \mathrm{NaOH}$.

For the purpose of simplicity in the present study, it is assumed that the Calcium silicate hydrate $[\mathrm{CSH}(\mathrm{S})]$ is produced from the hydration reaction of slag which is equivalent to 'weak' cement due to its latent hydraulic property. The balanced chemical equation for the hydration of slag can, therefore, be written as:

$$
\begin{aligned}
& \mathrm{C}_{3} \mathrm{~S}+\left(6.9-n^{\prime}\right) \mathrm{H} \rightarrow \mathrm{C}_{n^{\prime}} \mathrm{SH}_{3.9}(\text { or } \mathrm{CSH}(\mathrm{S}))+\left(3-n^{\prime}\right) \mathrm{CH} \\
& \mathrm{C}_{2} \mathrm{~S}+\left(5.9-n^{\prime}\right) \mathrm{H} \rightarrow \mathrm{C}_{n^{\prime}} \mathrm{SH}_{3.9}(\text { or } \mathrm{CSH}(\mathrm{S}))+\left(2-n^{\prime}\right) \mathrm{CH}
\end{aligned}
$$

It should be noted that due to the assumption that slag behaves as weak cement, in this case the $\mathrm{C}_{3} \mathrm{~S}$ and the $\mathrm{C}_{2} \mathrm{~S}$ contents of the slag was treated individually, instead of the slag as a whole. The following section will discuss the estimation of the volume fractions of the reaction products using the stoichiometry of the chemical reactions mentioned in sections 4.5.1 and 4.5.2. 


\subsection{Estimation of Quantities of the Products of Alkali Activation of Fly Ash and Hydration of Slag}

\subsubsection{Estimation of polymer product due to alkali activation of fly ash}

From Eqn. 4.2 it is evident that $n$ moles of $\mathrm{Si}_{2} \mathrm{O}_{5} \cdot \mathrm{Al}_{2} \mathrm{O}_{2}$ (which represents fly ash in this case) produces 1 mole of the polymer product. Now, $n$ moles of $\mathrm{Si}_{2} \mathrm{O}_{5} \cdot \mathrm{Al}_{2} \mathrm{O}_{2}$ contains $n$ moles of aluminum oxide. $\mathrm{Si}_{2} \mathrm{O}_{5} \cdot \mathrm{Al}_{2} \mathrm{O}_{2}$ can be written as $2 \mathrm{SiO}_{2} \cdot \mathrm{Al}_{2} \mathrm{O}_{3}$. The oxide composition for the fly ash was obtained from the local plant and they provided the compositions in terms of $\mathrm{SiO}_{2}$ and $\mathrm{Al}_{2} \mathrm{O}_{3}$. So, this minor adjustment was made while writing the formula. Thus, it can be said that $\mathrm{n}$ moles of $\mathrm{Al}_{2} \mathrm{O}_{3}$ produce 1 mole of the polymer product when the reaction is fully completed.

Now, Molecular weight of $\mathrm{Al}_{2} \mathrm{O}_{3}=2 * 27+3 * 16=102$ grams per mole.

Molecular weight of the polymer product, $n \mathrm{Na}_{2} \mathrm{O} \cdot \mathrm{Al}_{2} \mathrm{O}_{3} \cdot x \mathrm{SiO}_{2} \cdot y \mathrm{H}_{2} \mathrm{O}$ (in terms of $n, x$ and $y$ ) $=$ $[(2 * 23+16) * n+(28+2 * 16) * x+(102)+(18) * y]=(62 n+60 x+102+18 y)$ grams per mole.

So, it can be said that $102 n$ grams of $\mathrm{Al}_{2} \mathrm{O}_{3}$ produces $(62 n+60 x+102+18 y)$ grams of $n \mathrm{Na}_{2} \mathrm{O} \cdot \mathrm{Al}_{2} \mathrm{O}_{3} \cdot x \mathrm{SiO}_{2} \cdot y \mathrm{H}_{2} \mathrm{O}$ when the reaction is fully completed. The fly ash used for the present study contained $22.73 \% \mathrm{Al}_{2} \mathrm{O}_{3}$ by weight. By unitary method, 100 grams of fly ash

used in the present study will produce $\left[\frac{22.73(62 n+60 x+102+18 y)}{102 n}\right]$ grams of $n \mathrm{Na}_{2} \mathrm{O} \cdot \mathrm{Al}_{2} \mathrm{O}_{3} \cdot x \mathrm{SiO}_{2} \cdot y \mathrm{H}_{2} \mathrm{O}$ after complete reaction. The specific gravity of the fly ash used is 2.47. Hence $1 \mathrm{cc}$ volume of fly ash contains 2.47 grams of fly ash by weight. So, $1 \mathrm{cc}$ volume of the fly ash used will produce $\left[\frac{22.73 \times 2.47(62 n+60 x+102+18 y)}{102 n \times 100}\right]$ grams of $n \mathrm{Na}_{2} \mathrm{O} \cdot \mathrm{Al}_{2} \mathrm{O}_{3} \cdot x \mathrm{SiO}_{2} \cdot y \mathrm{H}_{2} \mathrm{O}$ after complete reaction. Since the present study deals with the volume stoichiometry of the polymerization reaction, the next step is to determine the theoretical volume of $A A B$ product formed as a result of it. The weight of the $A A B$ product obtained from the above expression was divided by its mass density to compute its volume. In this study, ' $c c^{\prime}$ is used as the unit for solid volume and ' $\mathrm{LL}^{\prime}$ ' for liquid volume.

The work done by Duxson et al. (2005) showed that the mass density of the AAB reaction product depends on the $\mathrm{Si} / \mathrm{Al}$ ratio of the precursor. For the present study, the $\mathrm{Si} / \mathrm{Al}$ ratio in the precursor is 2.1. By linear interpolation of the results obtained by Duxson et al. (2005), the mass density of aluminosilicate product for the present study was found to be 1.7904 
$\mathrm{gm} / \mathrm{cc}$. So, the volume of AAB product (in $\mathrm{cc}$ ) formed by the alkali activation of $1 \mathrm{cc}$ volume of fly ash was found to be

$$
v_{A A B}=\frac{22.73 \times 2.47(62 n+60 x+102+18 y)}{102 n \times 100 \times 1.7904}
$$

At any given age, let $\alpha_{F A}$ denote the degree of reaction of the fly ash. Then the volume of $A A B$ reaction product formed by the alkali activation of $1 \mathrm{cc}$ of fly ash was expressed as

$$
v_{A A B, \alpha}=\alpha_{F A} \times \frac{22.73 \times 2.47(62 n+60 x+102+18 y)}{102 n \times 100 \times 1.7904}=\frac{\alpha_{F A}}{n} \times(0.1906 n+0.1844 x+0.3136+0.0554 y) \mathrm{cC}
$$

The total volume of the $A A B$ paste at any degree of reaction, $\propto_{F A}$, consists of the volume of $A A B$ reaction product in the paste at that instant and also the unreacted residue that is present in the paste. The volume of unreacted residue (in $\mathrm{cc}$ ) produced by $1 \mathrm{cc}$ of fly ash at any degree of reaction, $\propto_{F A}$ was expressed as

$$
v_{\text {unreacted }}=1-\propto_{F A}
$$

So, the total volume of paste, $v_{\mathrm{hcp}, \mathrm{FA}}$ (in $\mathrm{Cc}$ ) produced by the alkali activation of $1 \mathrm{cc}$ of fly ash any degree of reaction, $\propto_{F A}$ was

$$
v_{h c p, F A}=v_{A A B, \alpha}+v_{\text {unreacted }}=\frac{\alpha_{F A}}{n} \times(0.1906 n+0.1844 x+0.3136+0.0554 y)+\left(1-\propto_{F A}\right)
$$

So, the volume fraction of the $A A B$ reaction product present in the reacted paste at any degree of reaction $\propto_{F A}$ was

$$
v_{f . A A B, \propto}=\frac{v_{A A B, \propto}}{v_{h c p, F A}}
$$

The optimization technique was used to minimize the difference between the theoretical volume fraction calculated using the above expression and the experimental volume fractions computed using the 3-D plots of the data from SEM/EDS microanalyses. Similar calculations were made when the precursor was made by combining fly ash with slag as either partial or full replacement. The relevant calculations are explained elaborately in the following section.

\subsubsection{Estimation of polymer product and CSH(S) for $\mathrm{P} \%$ fly ash combined with Q\% slag}

Slag is assumed to behave like weak cement. From the volume stoichiometry of slag hydration in Eqn. (4.1), it was found that 1 volume of $C_{3} S$ produces $\frac{\left(56.08 n^{\prime}+130.2\right) / 1.69}{228 / 3.21}$ volume of $\mathrm{CSH}(\mathrm{S})$ at full hydration. Now, $100 \mathrm{~mL}$ of slag used for the present study contains 52.5 $\mathrm{mL}$ of $\mathrm{C}_{3} \mathrm{~S}$. So, $52.5 \mathrm{~mL}$ of $\mathrm{C}_{3} \mathrm{~S}$ contributes 


$$
52.5 \times \frac{\left(56.08 n^{\prime}+130.2\right) / 1.69}{228 / 3.21}
$$

$\mathrm{mL}$ of $\mathrm{CSH}(\mathrm{S})$ per $100 \mathrm{~mL}$ of the unreacted cement.

Similarly, using Eqn. (4.2), 1 volume of $\mathrm{C}_{2} \mathrm{~S}$ produces $\frac{\left(56.08 n^{\prime}+132.14\right) / 1.85}{172 / 3.28}$ volume of $\mathrm{CSH}(\mathrm{S})$ at full hydration. Now, $100 \mathrm{~mL}$ of the slag used for the present study contains $21.7 \mathrm{~mL}$ of $\mathrm{C}_{2} \mathrm{~S}$. So, $\mathrm{C}_{2} \mathrm{~S}$ contributes

$$
21.7 \times \frac{\left(56.08 n^{\prime}+130.2\right) / 1.69}{172 / 3.28}
$$

$\mathrm{mL}$ of $\mathrm{CSH}(\mathrm{S})$ per $100 \mathrm{~mL}$ of the unreacted cement.

So, at any instant of time, $t$ or any degree of slag hydration, $\alpha_{\text {slagr }}$ the total volume of $\mathrm{CSH}(\mathrm{S})$ due to $\mathrm{C}_{3} \mathrm{~S}$ and $\mathrm{C}_{2} \mathrm{~S}$ hydration, $V_{\mathrm{CSH}(\mathrm{S})}$ can be obtained by adding the above two expressions. It comes out to be

$$
v_{C S H(S)}=\propto_{\text {slag }} \times\left(0.399 n^{\prime}+0.926\right)
$$

$\mathrm{mL}$ per $1 \mathrm{cc}$ of the slag.

The details of the above calculations have been presented in a previous study by Kar et al. (2012). The next step was to calculate the total volume of the products due to slag hydration. From the study made by Chen and Brouwers (2007), it was found that the volume of $\mathrm{CSH}(\mathrm{S})$ was approximately $90 \%$ of the total volume of the hydrated paste. For the sake of simplicity of the present study, the total volume of the hydrated paste due to slag hydration was calculated as

$$
v_{h c p, S G}=1.1 \times v_{C S H(S)}
$$

Now for example, let there be a mixture proportion containing $\mathrm{P} \%$ of fly ash and $\mathrm{Q} \%$ of slag

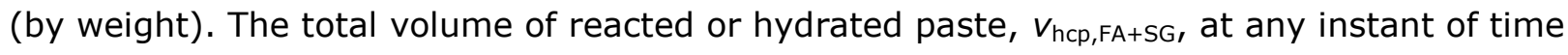
was then expressed as the sum of the volume of hydrated paste due to the alkali activation of fly ash and that due to slag hydration.

So,

$$
\begin{aligned}
& v_{h c p, F A+S G}=v_{h c p, F A}+v_{h c p, S G}=\frac{P \times \propto_{F A}}{100 n} \times(0.1906 n+0.1844 x+0.3136+0.0554 y)+\left(1-\propto_{F A}\right)+\frac{Q \times 1.1 \times v_{C-S-H(S)}}{100} \\
& \text { Or, } v_{h c p, F A+S G}=\frac{P \times \alpha_{F A}}{100 n} \times(0.1906 n+0.1844 x+0.3136+0.0554 y)+\left(1-\propto_{F A}\right)+\frac{Q \times 1.1 \times \alpha_{\text {slag }} \times\left(0.399 n^{\prime}+0.926\right)}{100}
\end{aligned}
$$


The volume fraction, $v_{f . A A B, \propto}$, of the $\mathrm{AAB}$ reaction product with respect to the total paste volume at any degree of reaction was expressed as

$$
\begin{gathered}
v_{f . A A B, \propto}=\frac{v_{A A B, \propto}}{v_{h c p, F A+S G}} \\
=\frac{\frac{P \times \propto_{F A}}{100 n} \times(0.1906 n+0.1844 x+0.3136+0.0554 y)}{\frac{P \times \propto_{F A}}{100 n} \times(0.1906 n+0.1844 x+0.3136+0.0554 y)+\left(1-\propto_{F A}\right)+\frac{Q \times 1.1 \times \propto_{\text {slag }} \times\left(0.399 n^{\prime}+0.926\right)}{100}}
\end{gathered}
$$

Similarly, the volume fraction of the $\mathrm{CSH}(\mathrm{S})$ with respect to the total paste volume at any instant was expressed as

$$
\begin{gathered}
v_{f . C S H(S), \propto}=\frac{v_{C S H(S), \propto}}{v_{h c p, F A+S G}} \\
=\frac{Q \times \propto_{\text {slag }} \times\left(0.399 n^{\prime}+0.926\right)}{100} \\
\frac{P \times \propto_{F A}}{100 n} \times(0.1906 n+0.1844 x+0.3136+0.0554 y)+\left(1-\propto_{F A}\right)+\frac{Q \times 1.1 \times \propto_{\text {slag }} \times\left(0.399 n^{\prime}+0.926\right)}{100}
\end{gathered}
$$

The optimization technique was used to minimize the difference between the theoretical volume fraction calculated using the above expression and the experimental volume fractions computed using the 3-D plots of the data from SEM/EDS microanalyses. The details about the optimization are explained elaborately later in the present study. But before that, it is important to discuss about the degree of reaction of the precursors in some more detail.

\subsection{Degree of Reaction at Different Ages}

As mentioned earlier, the specimens were cured at three different temperatures. One of the major factors that govern the progress of polymerization, is the curing temperature. Hence, it is of utmost importance to have knowledge of the influence of the curing temperature on the degree of reaction. The technique suggested by Fernandez-Jimenez et al. (2006) was followed to determine the degree of reaction.

After curing (at each respective temperature), the alkali activated fly ash was attacked with $1: 20 \mathrm{HCl}$ to determine the amount of fly ash that had been converted to sodium aluminosilicate phase and the portion that had not reacted with the alkaline solutions; in other words, to determine the degree of reaction for fly ash $\alpha_{\mathrm{FA}}$, since this attack provokes 
the dissolution of the chief reaction products of the alkali activation of fly ash (alkaline aluminosilicate gel and zeolites) in the acid, while the fraction of ash not activated by the alkalis remains in the insoluble residue.

The $1: 20 \mathrm{HCl}$ solution was supplied by Fisher Scientific. The experimental procedure followed in the acid attack consisted in adding $1 \mathrm{~g}$ of activated fly ash to a beaker containing $250 \mathrm{ml}$ of $(1: 20) \mathrm{HCl}$. The mixture was stirred with a plastic rotor for three hours, after which it was filtered and washed with de-ionized water to a neutral $\mathrm{pH}$. The insoluble residue was first dried at $100^{\circ} \mathrm{C}$ and then at $1000^{\circ} \mathrm{C}$; the degree of reaction, $\alpha_{F A}$, was found by determining weight loss. $1000^{\circ} \mathrm{C}$ was attained using an Isotemp Muffle Furnace from Fisher Scientific. Some salient features of the muffle furnace are:

- Basic muffle furnace with $1125^{\circ} \mathrm{C}\left(2057^{\circ} \mathrm{F}\right)$ maximum heat

- Simple 3-button control with toggle to display setpoint or actual temperature during operation

- Chamber is heated by side-mounted electric resistance heaters

- Elements are embedded in removable, molded alumina-silicate ceramic fiber panels for easy replacement

- Top-mounted exhaust port allows easy venting

- Welded steel cabinet with baked-on finish

The values for degree of reaction obtained for the present study in case of FA 100 mixes at different ages are provided in Table 4.2 and a sample calculation is shown below.

\section{Sample Calculation}

The case of FA 100 sample cured at $60^{\circ} \mathrm{C}$ and 90 days age is showed as an example. Initial weight of the sample in the filter paper $=0.24 \mathrm{~g}$

Weight loss after heating at $1000^{\circ} \mathrm{C}=0.13 \mathrm{~g}$

Weight insoluble in $\mathrm{HCl}=0.24-0.13=0.11 \mathrm{~g}$

Percent insoluble in $\mathrm{HCl}=0.11 / 0.24=0.458$

Degree of reaction $=\%$ soluble in $\mathrm{HCl}=1-0.458=0.542$ or $54.2 \%$ 
Table 4.2 Degree of Reaction of Alkali-activated Fly ash at Different Temperatures

\begin{tabular}{|c|c|c|c|}
\hline \multirow{2}{*}{ Temperature } & \multicolumn{3}{|c|}{ Age } \\
\cline { 2 - 4 } & 7 days & 28 days & 90 days \\
\hline $23^{\circ} \mathrm{C}$ & 0.138 & 0.261 & 0.416 \\
\hline $40^{\circ} \mathrm{C}$ & 0.147 & 0.270 & 0.475 \\
\hline $60^{\circ} \mathrm{C}$ & 0.310 & 0.400 & 0.542 \\
\hline
\end{tabular}

In order to validate the test results from the present study, the degree of fly ash reaction values were compared with corresponding values from available literature (Smilauer et al., 2011; and Deja and Antosiak, 2012). The comparisons are shown in the Table 4.3 and graphically depicted in Fig. 4.14.

Table 4.3 Comparison between Fly ash Degrees of Reaction from Present Study and External Data

\begin{tabular}{|c|c|c|c|c|c|c|}
\hline \multirow{2}{*}{$\begin{array}{c}\text { Age } \\
(\text { Days })\end{array}$} & \multicolumn{2}{|c|}{$23^{\circ} \mathrm{C}$} & \multicolumn{2}{|c|}{$40^{\circ} \mathrm{C}$} & \multicolumn{2}{c|}{$60^{\circ} \mathrm{C}$} \\
\cline { 2 - 7 } & $\begin{array}{c}\text { Expt } \\
\text { data }\end{array}$ & $\begin{array}{c}\text { External data } \\
\text { (Smilauer et al., 2011) }\end{array}$ & $\begin{array}{c}\text { Expt } \\
\text { data }\end{array}$ & $\begin{array}{c}\text { External data } \\
\text { (Smilauer et al., 2011) }\end{array}$ & $\begin{array}{c}\text { Expt } \\
\text { data }\end{array}$ & $\begin{array}{c}\text { External data } \\
\text { (Deja and Antosiak, 2012) }\end{array}$ \\
\hline 7 & 0.138 & 0.143 & 0.147 & 0.150 & 0.310 & 0.310 \\
\hline 28 & 0.261 & 0.265 & 0.270 & 0.280 & 0.400 & 0.400 \\
\hline 90 & 0.416 & 0.427 & 0.475 & 0.480 & 0.542 & 0.580 \\
\hline
\end{tabular}

Thus it was seen that the experimental values were in close agreement with the data from existing literature.

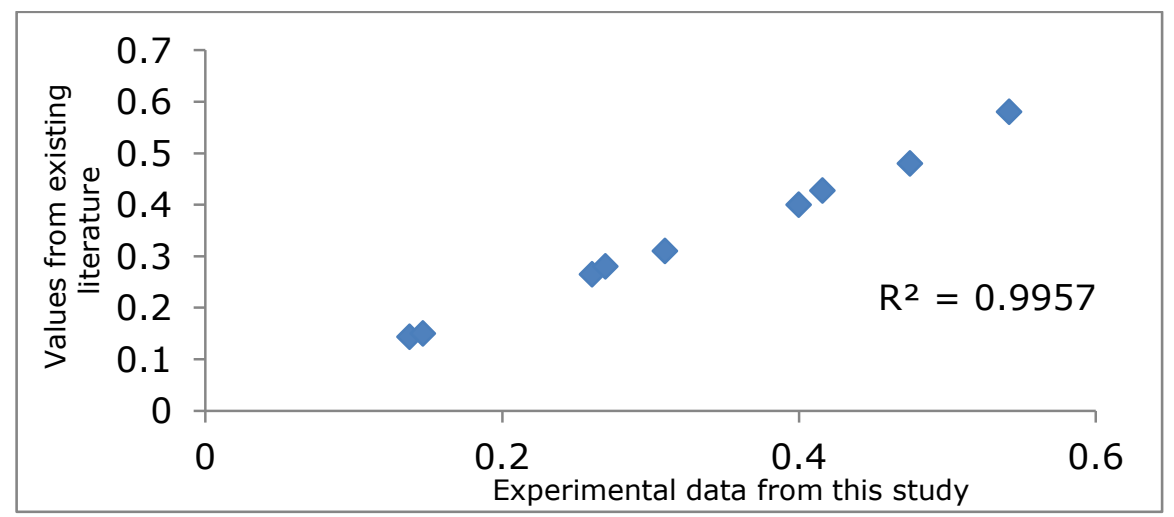

Fig. 4.14 Correlation between values of degree of reaction of fly ash from present study and those from existing literature. 
In the case of slag hydration, however, the values for rate of hydration were obtained from a previous study by Kar et al. (2012). That study was conducted at constant temperature of $23^{\circ} \mathrm{C}$. From the findings of other researchers, it was observed (Fernandez-Jimenez and Puertas, 1997) that the rate of slag hydration remained almost equal even at elevated temperatures (Fig. 4.15).

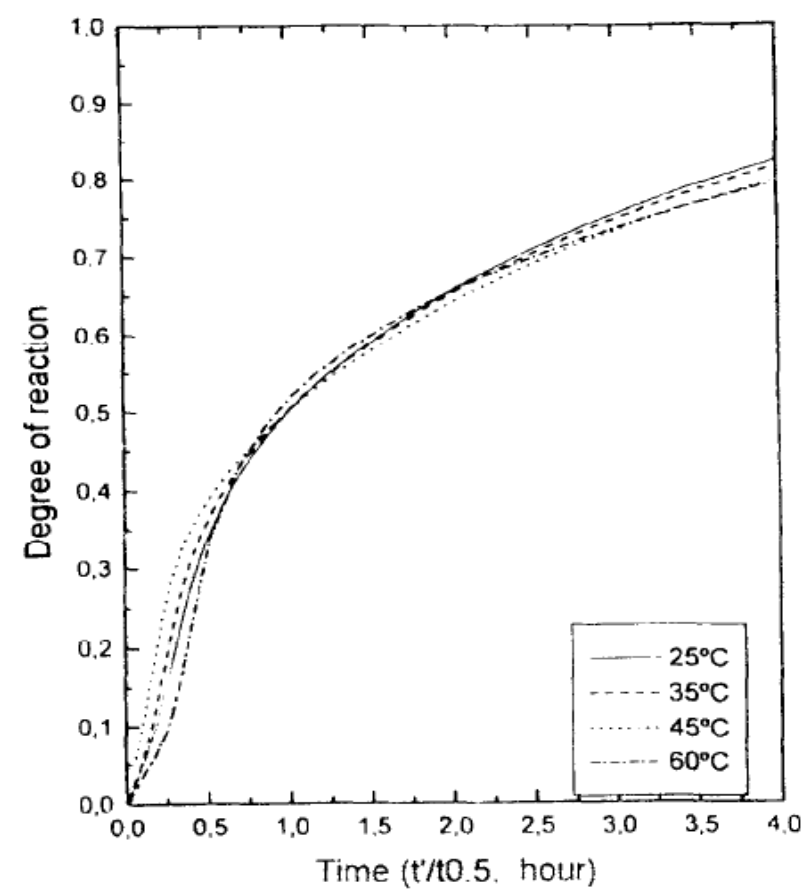

Fig. 4.15 Degree of slag hydration at different curing temperatures (Fernandez-Jimenez and Puertas, 1997).

The results of the slag degrees of hydration have been summarized in Table 4.4.

Table 4.4 Degree of Reaction (Average Value and Range) of Alkali-activated Slag at Different Temperatures

\begin{tabular}{|c|c|c|c|}
\hline \multirow{2}{*}{ Temperature } & \multicolumn{3}{|c|}{ Age } \\
\cline { 2 - 4 } & 7 days & 28 days & 90 days \\
\hline $23^{\circ} \mathrm{C}$ & $0.25(0.2-0.3)$ & $0.35(0.3-0.4)$ & $0.55(0.4-0.6)$ \\
\hline $40^{\circ} \mathrm{C}$ & $0.25(0.2-0.3)$ & $0.35(0.3-0.4)$ & $0.55(0.4-0.6)$ \\
\hline $60^{\circ} \mathrm{C}$ & $0.25(0.2-0.3)$ & $0.35(0.3-0.4)$ & $0.55(0.4-0.6)$ \\
\hline
\end{tabular}


Isothermal calorimetry studies were conducted for further qualitative investigation of how the polymerization reaction proceeds. The details are explained in the following section.

\subsection{Isothermal Calorimetry}

Calorimetry tests were carried out on $(10 * 3 * 3 * 1)=90$ samples, as per ASTM C1679-09 (Standard Practice for Measuring Hydration Kinetics of Hydraulic Cementitious Mixtures Using Isothermal Calorimetry). The calorimeter used was the TAM-Air model manufactured by TA Instruments. The sealed ampoule arrangement was used and the data were collected using the TAM Assistant software provided with the machine. The isothermal calorimetry experiments were carried out according to the ASTM C1679-09. The raw materials to be mixed were weighed accurately with the balance that is accurate to the $10000^{\text {th }} \mathrm{gram}$. The total weight of the AAB binder mix was kept at $5 \mathrm{~g}$ for all cases. The calorimeter is set at the desired temperature, at least 24 hours before the start of the test. The new experiment wizard was started on the computer. The channels to be loaded are selected and the relevant data are entered. The reference channels are loaded with the blank ampoules, as slowly and as carefully as possible, so as to avoid disturbing the calorimeter. The baseline correction is chosen or rejected, according to the will and need of the user. If chosen, the baseline correction starts a countdown timer, set as 30 minutes, by default. For this study, the blank ampoule was used to run the baseline measurement. All the samples to be measured by one run of the calorimeter were mixed simultaneously. The mixing time is noted and must be kept consistent for all subsequent tests with similar samples. Once all the samples have mixed uniformly and placed in the respective ampoules, they are simultaneously loaded into the calorimeter as slowly as possible. The "measuring time" button is pressed on the software window and the TAM-Air starts measuring the heats of hydration. The test setup is shown in Fig. 4.16. 


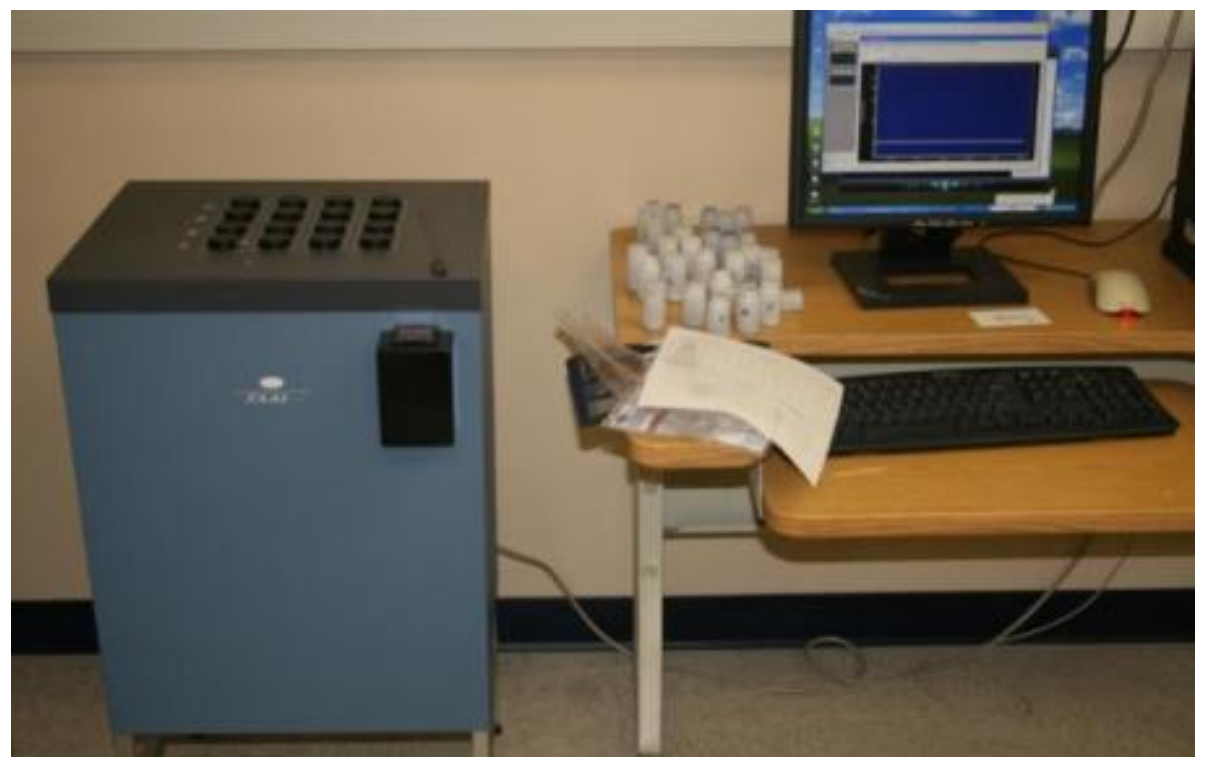

Fig. 4.16 Test setup for the isothermal calorimetry test using the TAM-Air instrument.

The calorimetry test was conducted to evaluate the rate of hydration. The experiments were carried out on 5 grams of each $A A B$ sample at temperatures of $23^{\circ} \mathrm{C}, 40^{\circ} \mathrm{C}$ and $60^{\circ} \mathrm{C}$ (with a variation of $\pm 0.2^{\circ} \mathrm{C}$ in each case). The data obtained from the experiments, as described above, are provided in Fig. 4.17 which plots of the heat flow from the AAB pastes with respect to time.

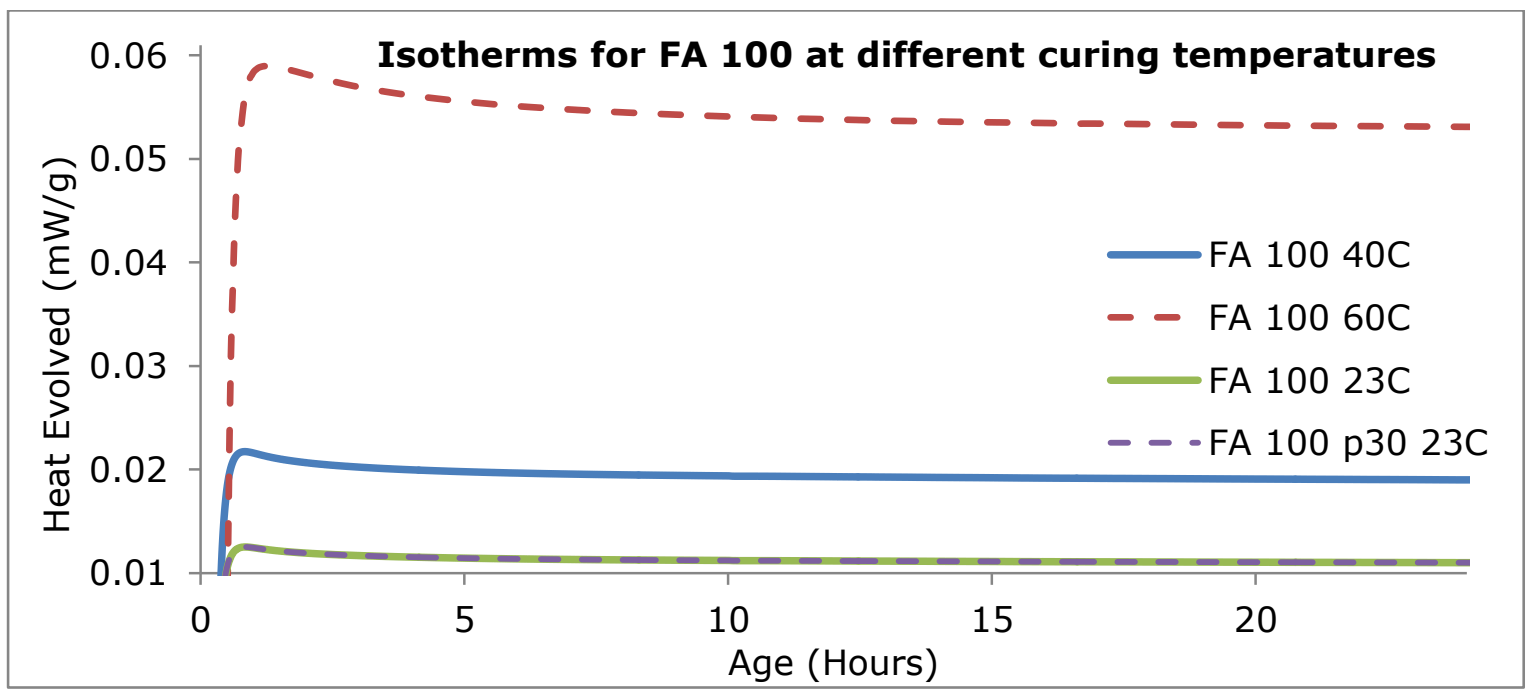

Fig. 4.17 Example of isotherms for FA 100 at different curing temperatures 
The plots of heat flow against time indicated the relative rates of hydration of the different cementitious pastes at different temperatures and different combinations of precursors. For the sake of brevity, sample plots are provided in Fig. 4.17 to compare the isotherms for FA $100 \mathrm{AAB}$ at different curing temperatures. Evidently, the heat evolved was the least for the sample cured at $23^{\circ} \mathrm{C}$, while it was the largest for the sample cured at $60^{\circ} \mathrm{C}$. The isotherms were practically identical for the normal FA 100 mix and the FA 100 mix preblended with $\mathrm{NaOH}$ for different durations at each temperature. The isotherm for FA 100 p30 has been shown as an example in fig. 4.17. It was also observed that the area under the curve increased with increasing temperature. These results confirmed the findings from FTIR and SEM. Moreover, the trend of the degree of reaction values was confirmed by the nature of the isotherms. The optimization technique adopted in order to obtain the chemical composition of the reaction products of the alkali activation of fly ash and/or slag have been described in the next section.

\subsection{Optimization Using GAMS}

The unknown parameters that needed to be solved in the present study were the $\mathrm{Na}_{2} \mathrm{O} / \mathrm{Al}_{2} \mathrm{O}_{3}(n), \mathrm{SiO}_{2} / \mathrm{Al}_{2} \mathrm{O}_{3}(x)$, and $\mathrm{H}_{2} \mathrm{O} / \mathrm{Al}_{2} \mathrm{O}_{3}(y)$ ratios in the polymer product formed due to the alkali activation of fly ash and the $\mathrm{Ca} / \mathrm{Si}$ ratio in the case of slag. The parameters were obtained by comparing experimental values with theoretical predictions using a constrained nonlinear least squares approach. Let $t$ denote an index for time. However, the parameter that is dependent on time was the degree of reaction in case of alkali activation of fly ash and the degree of hydration in case of slag.

In the present study, the specimens were studied at three different curing temperatures and for each curing temperature three different ages were selected for the experiments. Hence, for the present study there were $3 * 3=9$ different indices corresponding to $t$. Note that $t$ can take values from 1 to 9 corresponding to 7 days, 28 days and 90 days at each of $23^{\circ} \mathrm{C}$, $40^{\circ} \mathrm{C}$ and $60^{\circ} \mathrm{C}$. In case of slag, the degree of hydration was found to be independent of the curing temperature. The index $t$ can take the values 1,2 , and, 3 corresponding to 7 days, 28 days, and 90 days.

Let $v_{f, A A B}^{e x p, t}$ and $v_{f, C S H}^{e x p, t}$ denote the experimentally determined volume fractions of the AAB reaction product and $\mathrm{CSH}(\mathrm{S})$ respectively at time $t$. Let $v_{f, A A B}^{\text {pred,t }}$ and $v_{f, C S H(S)}^{\text {pred,t }}$ denote the predicted volume fractions of the $A A B$ reaction product and $\mathrm{CSH}(\mathrm{S})$ respectively at time $t$. For the FA 100 mixture proportion, the values of $n, x$, and, $y$ can be determined by solving 
the nonlinear constrained optimization problem so that $n, x$, and, $y$ satisfy the criteria for the reacted $A A B$ paste product.

$$
\begin{aligned}
& \min \sum_{t=1}^{9}\left(v_{f, A A B}^{\text {exp,t}}-v_{f, A A B}^{\text {pred,t }}\right)^{2} \\
& 1 \leq n \leq 1.6 \\
& 2 \leq x \leq 3.5 \\
& 3 \leq y \leq 7
\end{aligned}
$$

For fly ash combined with slag, knowing the volume fraction of AAB at time $t, v_{f, C-S-H(S)}^{t}$ can be determined using the formula provided in Eqn. (4.18). The values of $n^{\prime}$ and $\alpha^{\prime, t}$ can be determined by minimizing the sum of square differences between $v_{f, C S H(S)}^{\text {exp,t }}$ and $v_{f, C S H(S)}^{\text {pred,t }}$ as shown below.

$$
\begin{gathered}
\min \sum_{t=1}^{3}\left(v_{f, C S H(S)}^{\text {exp } t}-v_{f, C S H(S)}^{\text {pred }, t}\right)^{2} \\
1.1 \leq n^{\prime} \leq 1.4
\end{gathered}
$$

The nine different values of the time index, $t$, in case of FA 100 were represented by the degrees of reaction of fly ash at each corresponding age. Hence, the optimization scheme produced nine different equations for three unknowns. The formulations for each of these equations were coded in the General Algebraic Modeling System (GAMS) (Rosenthal 2008) and solved using the in-built CONOPT solver (Drud 2004) - a popular solver for nonlinear optimization problems (Baazara et al. 2006). The problem at hand was ideally a minimization problem - the optimized values for $n, x$, and, $y$ were taken as those for which the difference between the predicted and the experimental values were the minimum.

\section{Sample coding in GAMS}

OPTION NLP = CONOPT;

SETS

I Temp and Age Index /I1*I9 /;

PARAMETERS
$\begin{array}{ll}\text { ALP(I) } & \text { EXPer } \\ \text { I } & \\ \text { I1 } & \mathbf{0 . 1 4 2} \\ \text { I2 } & 0.150 \\ \text { I3 } & 0.310 \\ \text { I4 } & 0.265 \\ \text { I5 } & 0.275 \\ \text { I6 } & 0.400\end{array}$




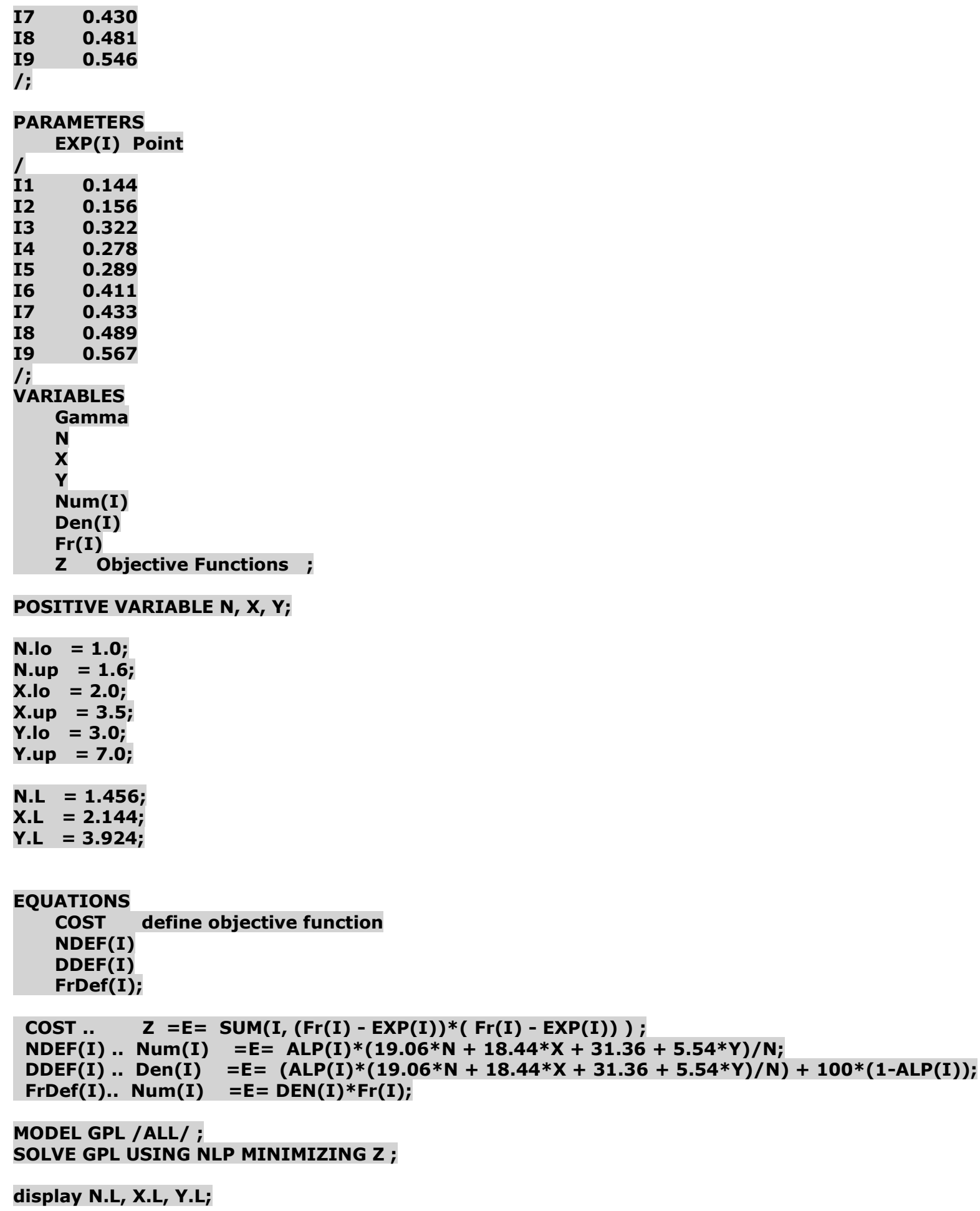

\subsubsection{Results from optimization}

The output from GAMS was the set of values of $n, x, y$ and, $n^{\prime}$ for which the differences between the experimental and theoretical values of the volume fractions were minimum. 
The optimization technique produced the following solutions: (i) $n=1.230$, (ii) $x=2.634$, and, (iii) $y=4.673$. The $n^{\prime}$ value of 1.4 for each AAB mix containing partial or full replacement of fly ash with slag were obtained from a previous study by Kar et al. (2012). The first three solutions provided the optimized chemical composition for the AAB activation reaction. The solution for $n^{\prime}$ provided the optimized chemical composition for $\mathrm{CSH}(\mathrm{S})$ when slag was present in the precursor.

The results, obtained using the optimization technique, were then used to compute the volume fractions of the reaction products. Those results were then compared with experimental data to validate the technique.

\subsection{Comparison of Experimental and Predicted Data for Reacted AAB Paste Product and CSH(S) Using Results from Optimization}

In this section, comparisons have been presented between the predicted and experimental values of the volume fraction of the reaction products due to alkali activation of fly ash and that of slag. The volume fractions have been denoted by $v_{f, A A B}$ and $v_{f, C S H(S)}$, respectively. At first, the results for alkali activated fly ash have been presented.

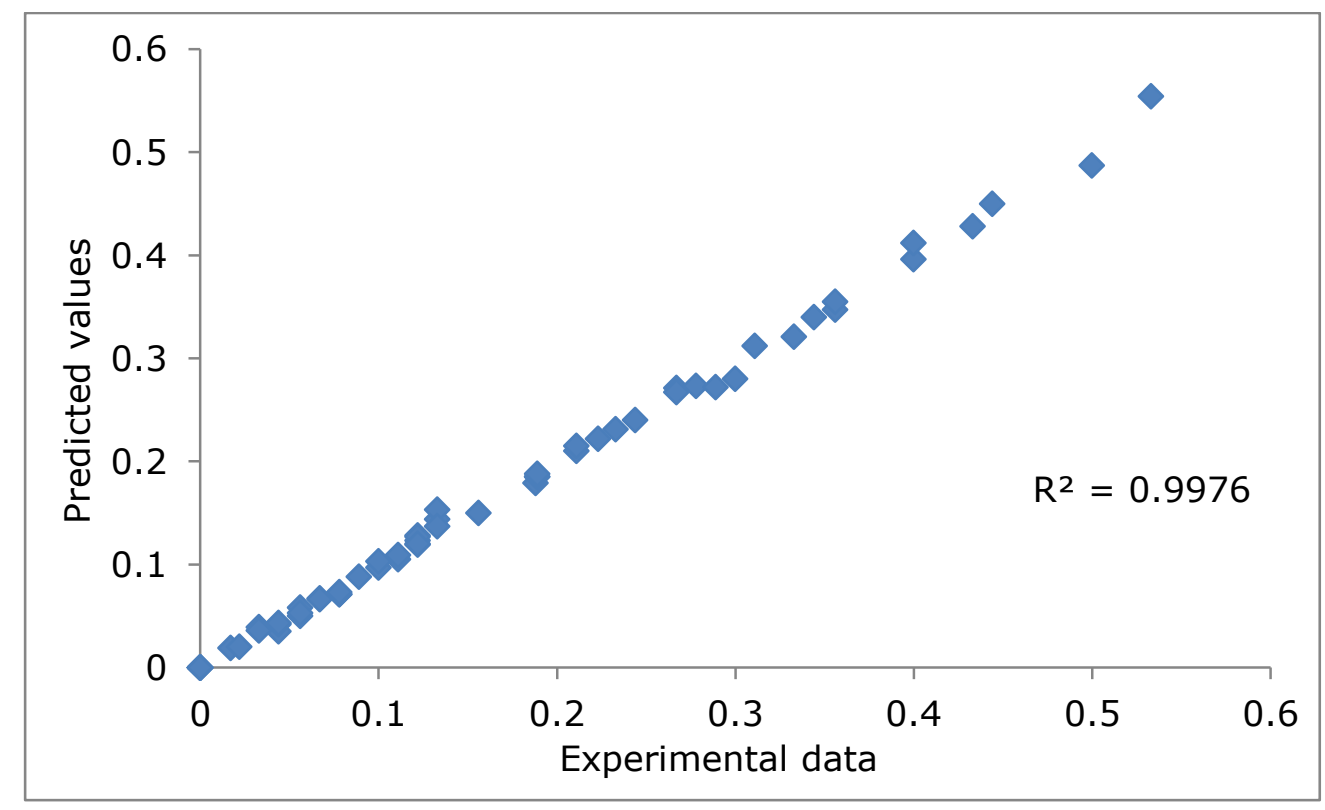

Fig. 4.18 Correlation between predicted and experimental values of $v_{f, A A B}$ 
From the plot, fig. 4.18, it was observed that the predicted and experimental values of $v_{f, A A B}$ were in close agreement with each other for all the mixes at each of three different curing temperatures. The volume fractions of the $A A B$ were found to decrease with increasing slag content as expected. $\mathrm{R}^{2}$ value representing the correlation between the experimental and the predicted volume fractions was 0.9976. In the Table 4.5, experimental and predicted values of $v_{f, A A B}$ have been provided for all the mixture proportions at different ages and each of the three different curing temperatures.

Table 4.5 Comparison between Predicted and Experimental Values of Volume Fraction of AAB

\begin{tabular}{|c|c|c|c|c|c|c|c|}
\hline \multirow{3}{*}{ Mix } & \multirow{3}{*}{$\begin{array}{c}\text { Age } \\
\text { (Days) }\end{array}$} & \multicolumn{6}{|c|}{$V_{f, A A B}$} \\
\hline & & \multicolumn{2}{|c|}{$23^{\circ} \mathrm{C}$} & \multicolumn{2}{|c|}{$40^{\circ} \mathrm{C}$} & \multicolumn{2}{|c|}{$60^{\circ} \mathrm{C}$} \\
\hline & & expt & pred & expt & pred & expt & pred \\
\hline \multirow{3}{*}{ FA 100} & 7 & 0.133 & 0.144 & 0.133 & 0.153 & 0.333 & 0.321 \\
\hline & 28 & 0.267 & 0.271 & 0.300 & 0.280 & 0.400 & 0.412 \\
\hline & 90 & 0.433 & 0.428 & 0.500 & 0.487 & 0.533 & 0.554 \\
\hline \multirow{3}{*}{ FA 85 SG 15} & 7 & 0.122 & 0.119 & 0.122 & 0.128 & 0.267 & 0.267 \\
\hline & 28 & 0.223 & 0.222 & 0.233 & 0.231 & 0.344 & 0.34 \\
\hline & 90 & 0.356 & 0.347 & 0.400 & 0.396 & 0.444 & 0.45 \\
\hline \multirow{3}{*}{ FA 70 SG 30} & 7 & 0.100 & 0.097 & 0.100 & 0.103 & 0.211 & 0.215 \\
\hline & 28 & 0.188 & 0.179 & 0.189 & 0.185 & 0.289 & 0.272 \\
\hline & 90 & 0.278 & 0.273 & 0.311 & 0.312 & 0.356 & 0.355 \\
\hline \multirow{3}{*}{ FA 50 SG 50} & 7 & 0.067 & 0.067 & 0.078 & 0.071 & 0.156 & 0.15 \\
\hline & 28 & 0.122 & 0.123 & 0.122 & 0.127 & 0.189 & 0.188 \\
\hline & 90 & 0.189 & 0.185 & 0.211 & 0.210 & 0.244 & 0.24 \\
\hline \multirow{3}{*}{ FA 30 SG 70} & 7 & 0.033 & 0.039 & 0.044 & 0.042 & 0.089 & 0.088 \\
\hline & 28 & 0.078 & 0.071 & 0.078 & 0.073 & 0.111 & 0.109 \\
\hline & 90 & 0.111 & 0.105 & 0.122 & 0.120 & 0.133 & 0.137 \\
\hline \multirow{3}{*}{ FA 15 SG 85} & 7 & 0.017 & 0.019 & 0.022 & 0.020 & 0.044 & 0.043 \\
\hline & 28 & 0.044 & 0.035 & 0.033 & 0.036 & 0.056 & 0.053 \\
\hline & 90 & 0.056 & 0.05 & 0.056 & 0.058 & 0.067 & 0.066 \\
\hline \multirow{3}{*}{ SG 100} & 7 & 0.000 & 0.000 & 0.000 & 0.000 & 0.000 & 0.000 \\
\hline & 28 & 0.000 & 0.000 & 0.000 & 0.000 & 0.000 & 0.000 \\
\hline & 90 & 0.000 & 0.000 & 0.000 & 0.000 & 0.000 & 0.000 \\
\hline \multirow{3}{*}{ FA 100 p15 } & 7 & 0.133 & 0.144 & 0.133 & 0.153 & 0.333 & 0.321 \\
\hline & 28 & 0.267 & 0.271 & 0.300 & 0.280 & 0.400 & 0.412 \\
\hline & 90 & 0.433 & 0.428 & 0.500 & 0.487 & 0.533 & 0.554 \\
\hline \multirow{3}{*}{ FA 100 p30 } & 7 & 0.133 & 0.144 & 0.133 & 0.153 & 0.333 & 0.321 \\
\hline & 28 & 0.267 & 0.271 & 0.300 & 0.280 & 0.400 & 0.412 \\
\hline & 90 & 0.433 & 0.428 & 0.500 & 0.487 & 0.533 & 0.554 \\
\hline \multirow{3}{*}{ FA 100 p60 } & 7 & 0.133 & 0.144 & 0.133 & 0.153 & 0.333 & 0.321 \\
\hline & 28 & 0.267 & 0.271 & 0.300 & 0.280 & 0.400 & 0.412 \\
\hline & 90 & 0.433 & 0.428 & 0.500 & 0.487 & 0.533 & 0.554 \\
\hline
\end{tabular}

Next, the results for alkali activated slag have been discussed. 


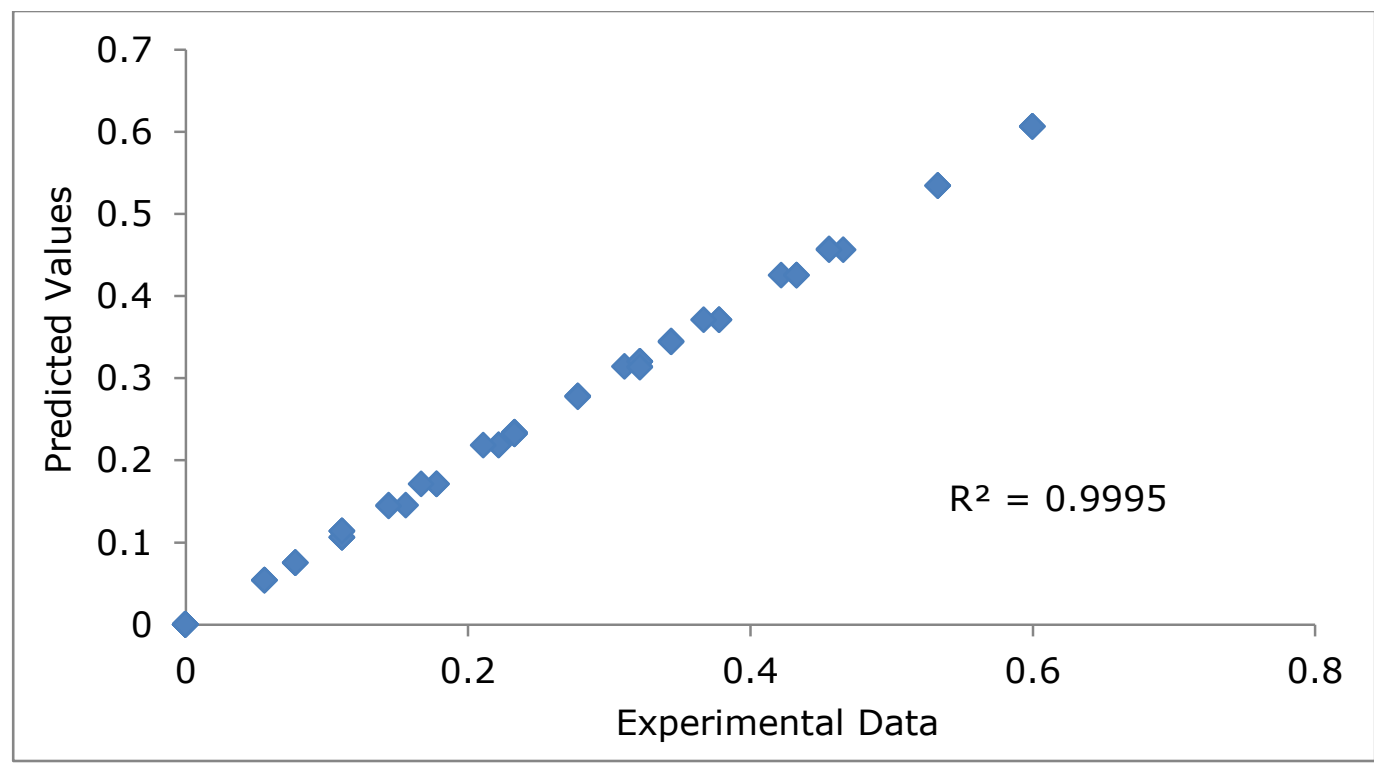

Fig. 4.19 Correlation between predicted and experimental values of $v_{f, C S H(S)}$

From the plot, Fig. 4.19, it was observed that the predicted and experimental values of $V_{f, C S H(S)}$ were in close agreement with each other. The volume fractions of the CSH(S) were found to increase with increasing slag content as expected. $\mathrm{R}^{2}$ value representing the correlation between the experimental and the predicted volume fractions was 0.9995 .

In Table 4.6, experimental and predicted values of $v_{f, C S H(S)}$ have been provided for all the mixture proportions at different ages and each of the three different curing temperatures. 
Table 4.6 Comparison between Predicted and Experimental Values of Volume Fraction of $\mathrm{CSH}(\mathrm{S})$

\begin{tabular}{|c|c|c|c|c|c|c|c|}
\hline \multirow{3}{*}{ Mix } & \multirow{3}{*}{$\begin{array}{c}\text { Age } \\
\text { (Days) }\end{array}$} & \multicolumn{6}{|c|}{$V_{f, C S H(S)}$} \\
\hline & & \multicolumn{2}{|c|}{$23^{\circ} \mathrm{C}$} & \multicolumn{2}{|c|}{$40^{\circ} \mathrm{C}$} & \multicolumn{2}{|c|}{$60^{\circ} \mathrm{C}$} \\
\hline & & expt & pred & expt & pred & expt & pred \\
\hline \multirow{3}{*}{ FA 100} & 7 & 0.000 & 0.000 & 0.000 & 0.000 & 0.000 & 0.000 \\
\hline & 28 & 0.000 & 0.000 & 0.000 & 0.000 & 0.000 & 0.000 \\
\hline & 90 & 0.000 & 0.000 & 0.000 & 0.000 & 0.000 & 0.000 \\
\hline \multirow{3}{*}{ FA 85 SG 15} & 7 & 0.056 & 0.054 & 0.056 & 0.054 & 0.056 & 0.054 \\
\hline & 28 & 0.078 & 0.075 & 0.078 & 0.075 & 0.078 & 0.075 \\
\hline & 90 & 0.111 & 0.114 & 0.111 & 0.114 & 0.111 & 0.114 \\
\hline \multirow{3}{*}{ FA 70 SG 30} & 7 & 0.111 & 0.106 & 0.111 & 0.106 & 0.111 & 0.106 \\
\hline & 28 & 0.144 & 0.145 & 0.156 & 0.145 & 0.144 & 0.144 \\
\hline & 90 & 0.222 & 0.219 & 0.222 & 0.218 & 0.211 & 0.218 \\
\hline \multirow{3}{*}{ FA 50 SG 50} & 7 & 0.178 & 0.171 & 0.178 & 0.171 & 0.167 & 0.171 \\
\hline & 28 & 0.233 & 0.234 & 0.233 & 0.232 & 0.233 & 0.232 \\
\hline & 90 & 0.344 & 0.345 & 0.344 & 0.344 & 0.344 & 0.344 \\
\hline \multirow{3}{*}{ FA 30 SG 70} & 7 & 0.233 & 0.234 & 0.233 & 0.233 & 0.233 & 0.233 \\
\hline & 28 & 0.311 & 0.314 & 0.322 & 0.314 & 0.322 & 0.313 \\
\hline & 90 & 0.456 & 0.457 & 0.466 & 0.456 & 0.456 & 0.456 \\
\hline \multirow{3}{*}{ FA 15 SG 85} & 7 & 0.278 & 0.278 & 0.278 & 0.278 & 0.278 & 0.277 \\
\hline & 28 & 0.378 & 0.371 & 0.378 & 0.371 & 0.367 & 0.371 \\
\hline & 90 & 0.533 & 0.534 & 0.533 & 0.534 & 0.533 & 0.534 \\
\hline \multirow{3}{*}{ SG 100} & 7 & 0.322 & 0.320 & 0.322 & 0.320 & 0.322 & 0.32 \\
\hline & 28 & 0.422 & 0.425 & 0.433 & 0.425 & 0.433 & 0.425 \\
\hline & 90 & 0.600 & 0.606 & 0.600 & 0.606 & 0.600 & 0.606 \\
\hline \multirow{3}{*}{ FA 100 p15 } & 7 & 0.000 & 0.000 & 0.000 & 0.000 & 0.000 & 0.000 \\
\hline & 28 & 0.000 & 0.000 & 0.000 & 0.000 & 0.000 & 0.000 \\
\hline & 90 & 0.000 & 0.000 & 0.000 & 0.000 & 0.000 & 0.000 \\
\hline \multirow{3}{*}{ FA 100 p30 } & 7 & 0.000 & 0.000 & 0.000 & 0.000 & 0.000 & 0.000 \\
\hline & 28 & 0.000 & 0.000 & 0.000 & 0.000 & 0.000 & 0.000 \\
\hline & 90 & 0.000 & 0.000 & 0.000 & 0.000 & 0.000 & 0.000 \\
\hline \multirow{3}{*}{ FA 100 p 60} & 7 & 0.000 & 0.000 & 0.000 & 0.000 & 0.000 & 0.000 \\
\hline & 28 & 0.000 & 0.000 & 0.000 & 0.000 & 0.000 & 0.000 \\
\hline & 90 & 0.000 & 0.000 & 0.000 & 0.000 & 0.000 & 0.000 \\
\hline
\end{tabular}

In the next section, the observations on variation of phase volumes with time have been presented for different combinations of fly ash and slag at different temperatures. 


\subsection{Variation of Reacted AAB Paste Product and $\operatorname{CSH}(S)$ and the Total Hydrated Paste Volumes with Time for Different Combinations of Fly Ash and Slag at Different Temperatures}

From Fig. 4.20, it was observed that the volume fractions of the $A A B$ and $C S H(S)$ increase with age for FA $100 \mathrm{mix}$, which is thought to be the reason behind the development of compressive strength at the specimen level. It was also observed that the increase in curing temperature resulted in an increase in the development of the volume fractions of the $A A B$ and $\mathrm{CSH}(\mathrm{S})$. This phenomenon corresponded to the increasing rate of compressive strength development with increase in curing temperature.

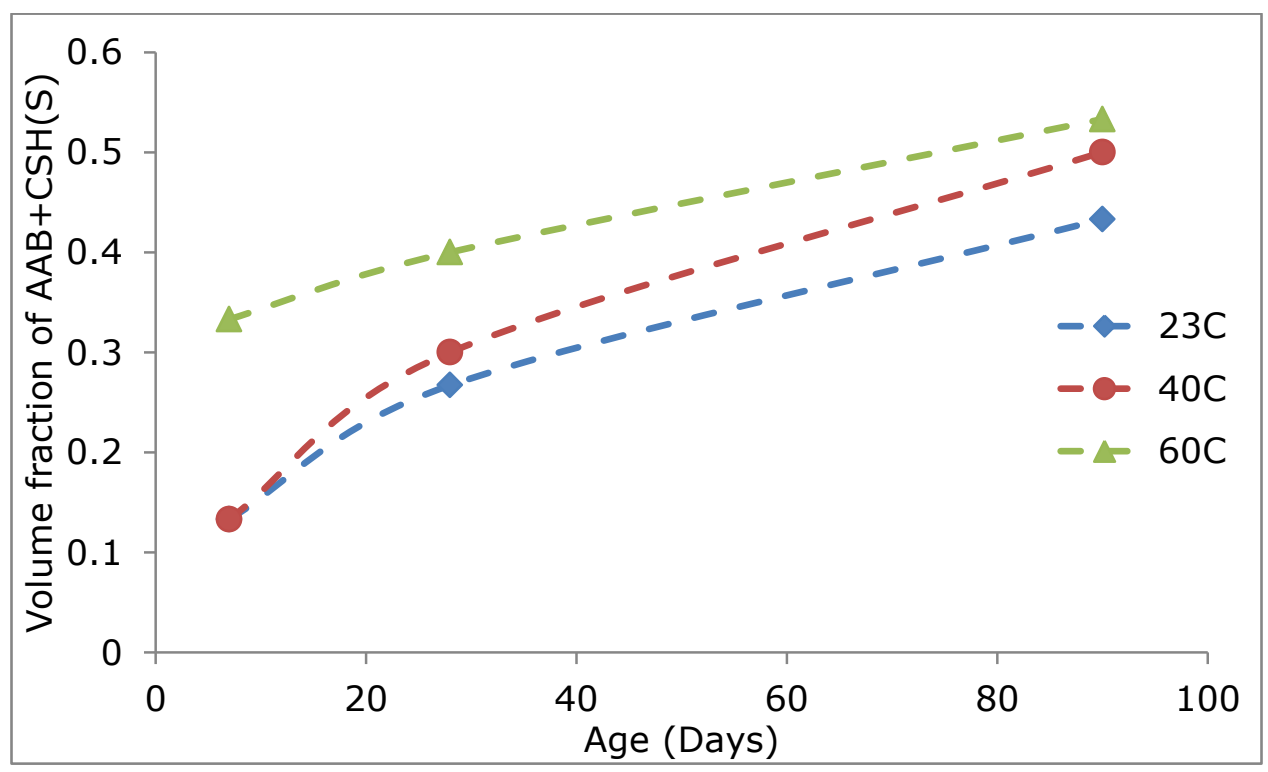

Fig. 4.20 Volume fraction of $A A B+C S H(S)$ pastes for FA 100 at different temperatures

From Figs. 4.21 through 4.24, it was observed that the volume fractions of the $A A B$ and $\mathrm{CSH}(\mathrm{S})$ increase with age for all mixes, which is thought to be the reason behind the development of compressive strength at the specimen level. It was also observed that the increase in curing temperature resulted in an increase in the development of the volume fractions of the $A A B$ and $\mathrm{CSH}(\mathrm{S})$. This led to the increasing rate of compressive strength development with increase in curing temperature and the data have been presented in Table 4.7. 


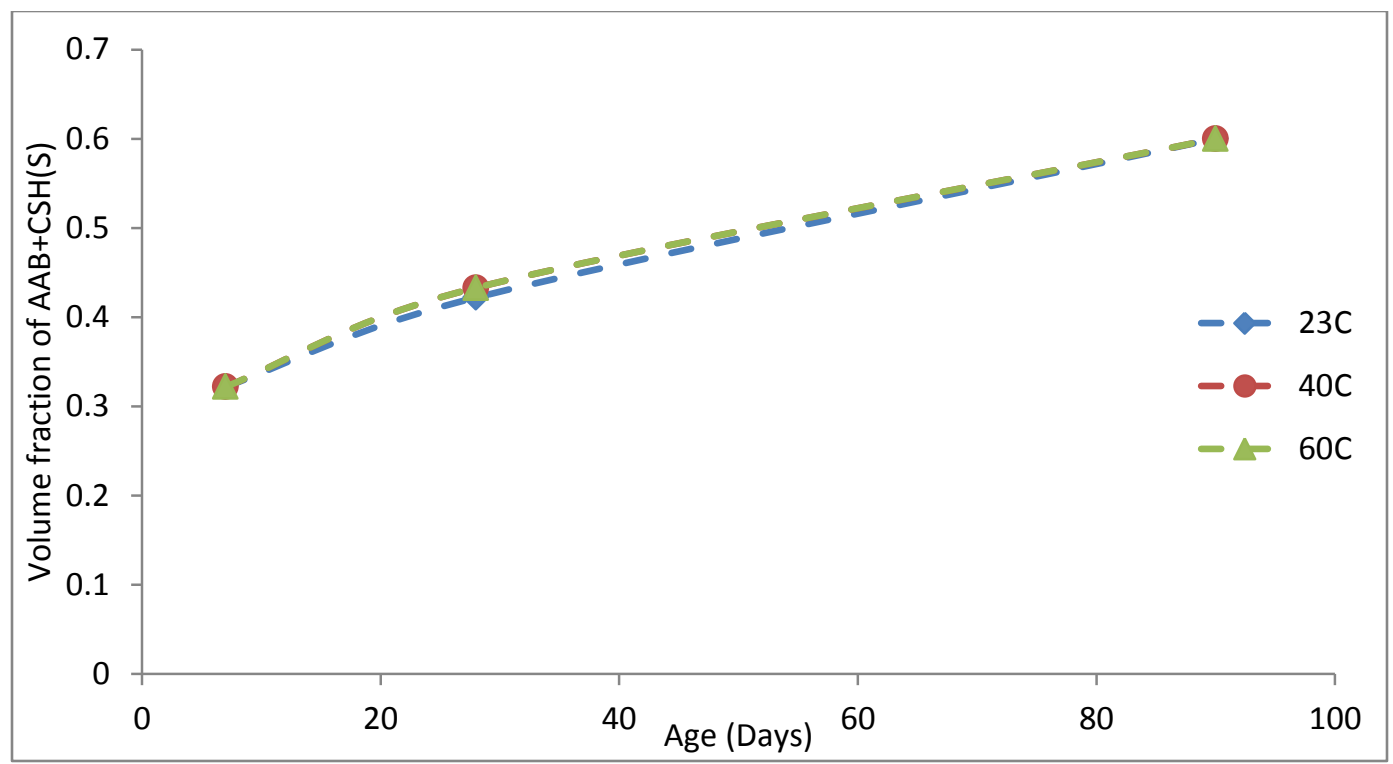

Fig. 4.21 Volume fraction of $A A B+C S H(S)$ pastes for SG 100 at different temperatures

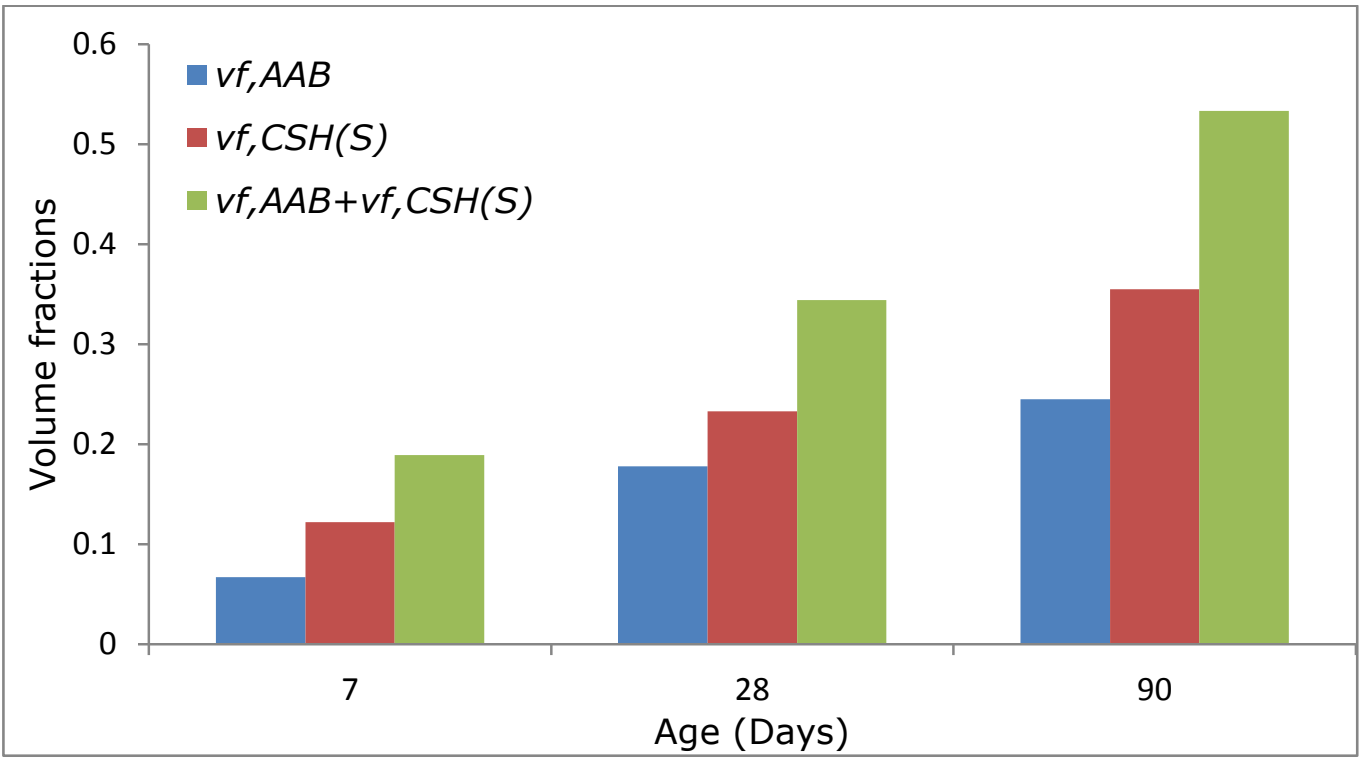

Fig. 4.22 Volume fractions of $A A B$ paste, $C S H(S)$ and total $A A B+C S H(S)$ for FA 50 SG 50 at $23^{\circ} \mathrm{C}$ 


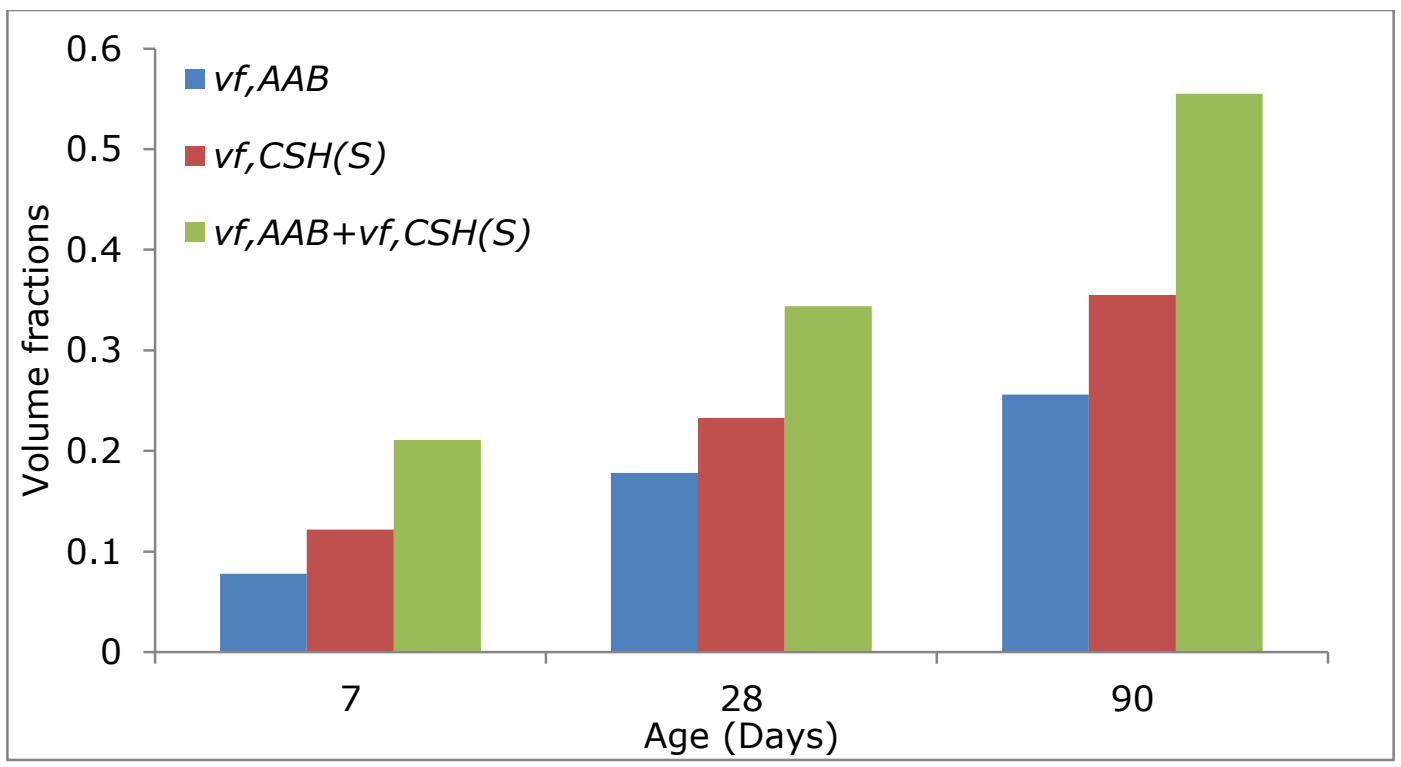

Fig. 4.23 Volume fractions of $A A B$ paste, $C S H(S)$ and total $A A B+C S H(S)$ for $F A 50$ SG 50 at $40^{\circ} \mathrm{C}$

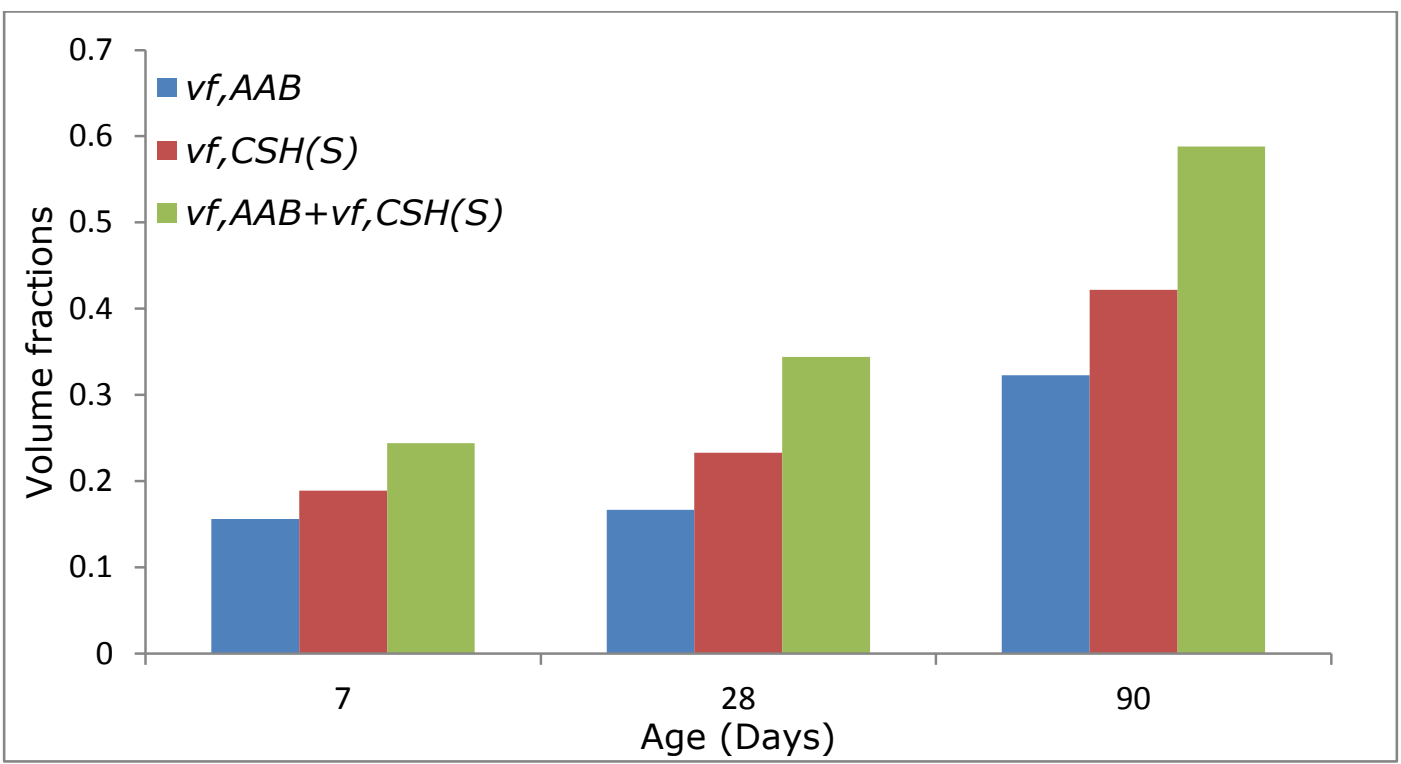

Fig. 4.24 Volume fractions of $A A B$ paste, $C S H(S)$ and total $A A B+C S H(S)$ for $F A 50$ SG 50 at $60^{\circ} \mathrm{C}$ 
Table 4.7 Volume Fractions of Reacted Phases of AAB $\left(v_{f, A A B}+v_{f, C S H}(s)\right)$ at Different Ages for all Mixture Proportions Cured at Different Temperatures

\begin{tabular}{|c|c|c|c|c|}
\hline \multirow[b]{2}{*}{ Mix } & \multirow{2}{*}{$\begin{array}{c}\text { Age } \\
\text { (Days) }\end{array}$} & \multicolumn{3}{|c|}{$v_{f, A A B}+v_{f, C S H(S)}$} \\
\hline & & $23^{\circ} \mathrm{C}$ & $40^{\circ} \mathrm{C}$ & $60^{\circ} \mathrm{C}$ \\
\hline \multirow{3}{*}{ FA 100} & 7 & 0.133 & 0.133 & 0.333 \\
\hline & 28 & 0.267 & 0.300 & 0.400 \\
\hline & 90 & 0.433 & 0.500 & 0.533 \\
\hline \multirow{3}{*}{ FA 85 SG 15} & 7 & 0.178 & 0.178 & 0.323 \\
\hline & 28 & 0.301 & 0.311 & 0.422 \\
\hline & 90 & 0.467 & 0.511 & 0.555 \\
\hline \multirow{3}{*}{ FA 70 SG 30} & 7 & 0.211 & 0.211 & 0.322 \\
\hline & 28 & 0.332 & 0.345 & 0.433 \\
\hline & 90 & 0.500 & 0.533 & 0.567 \\
\hline \multirow{3}{*}{ FA 50 SG 50} & 7 & 0.245 & 0.256 & 0.323 \\
\hline & 28 & 0.355 & 0.355 & 0.422 \\
\hline & 90 & 0.533 & 0.555 & 0.588 \\
\hline \multirow{3}{*}{ FA 30 SG 70} & 7 & 0.266 & 0.277 & 0.322 \\
\hline & 28 & 0.389 & 0.400 & 0.433 \\
\hline & 90 & 0.567 & 0.588 & 0.589 \\
\hline \multirow{3}{*}{ FA 15 SG 85} & 7 & 0.295 & 0.300 & 0.322 \\
\hline & 28 & 0.422 & 0.411 & 0.423 \\
\hline & 90 & 0.589 & 0.589 & 0.600 \\
\hline \multirow{3}{*}{ SG 100} & 7 & 0.322 & 0.322 & 0.322 \\
\hline & 28 & 0.422 & 0.433 & 0.433 \\
\hline & 90 & 0.600 & 0.600 & 0.600 \\
\hline \multirow{3}{*}{ FA 100 p 15} & 7 & 0.133 & 0.133 & 0.333 \\
\hline & 28 & 0.267 & 0.300 & 0.400 \\
\hline & 90 & 0.433 & 0.500 & 0.533 \\
\hline \multirow{3}{*}{ FA 100 p30 } & 7 & 0.133 & 0.133 & 0.333 \\
\hline & 28 & 0.267 & 0.300 & 0.400 \\
\hline & 90 & 0.433 & 0.500 & 0.533 \\
\hline \multirow{3}{*}{ FA 100 p60 } & 7 & 0.133 & 0.133 & 0.333 \\
\hline & 28 & 0.267 & 0.300 & 0.400 \\
\hline & 90 & 0.433 & 0.500 & 0.533 \\
\hline
\end{tabular}

In this chapter, the different microanalysis techniques and the characterization of the $A A B$ pastes have been presented in details. The next chapter will present the specimen level properties of hardened $A A B$ samples that were determined through destructive tests. 


\section{CHAPTER 5}

\section{PROPERTIES OF CONCRETE WITH ALKALI ACTIVATED BINDER AT SPECIMEN LEVEL: DESTRUCTIVE TESTS}

In this chapter, the destructive tests - namely, tests for compressive strength, splitting tensile strength, and flexural strength - to evaluate the characteristics of $A A B$ at specimen level are discussed in details.

\subsection{Test for Compressive Strength}

Sampling the concrete delivered to a project is important to test if the concrete meets the requirements of the job specification and for quality control. For testing the concrete, cylindrical and prisms specimens are cast with the requirements of ASTM C31/C 31 M-12 (Standard Practice for Making and Curing Concrete Test Specimens in the Field). If the specimens are made and standard cured, the resulting strength test data when the specimens are tested are able to be used for acceptance testing for a specified compressive strength, and for checking adequacy of mixture proportions for strength and quality control. If the specimens are made and field cured, the data are used for determination of whether the structure is capable of being put in service, comparison with test results from various inplaced methods (as the Maturity method), checking adequacy of curing and determining the time for formwork removal. In conclusion the results of the test are used as basis for quality control of concrete proportioning, mixing, and placing operations; determination of compliance with specifications; control for evaluating effectiveness of admixtures; and similar uses. Compressive strength is the single most important property of concrete evaluation. For 28-day design strength the WVDOH specifies $27.58 \mathrm{MPa}$ (4000 psi) for deck concrete (Neville 2007).

The compressive strength test was conducted at three different ages for the three curing temperatures for the purpose of identifying the influence of temperature as well as mix proportion on the strength development of AAB with time. Compressive strengths of 101.6 mm (4 in.) diameter and 203.2 mm (8 in.) long cylinder specimens were measured in accordance with ASTM C39/C39M - 12a (Standard Test Method for Compressive Strength of Cylindrical Concrete Specimens). The curing regime described in section 3.4 was followed. Tests were conducted on $(10 * 3 * 3 * 3)=270$ specimens at 7,28 , and 90 days after casting. 
The test setup is shown in Fig. 5.1. Average values of compressive strength of 3 specimens for each mixture proportion are reported in Table 5.1.

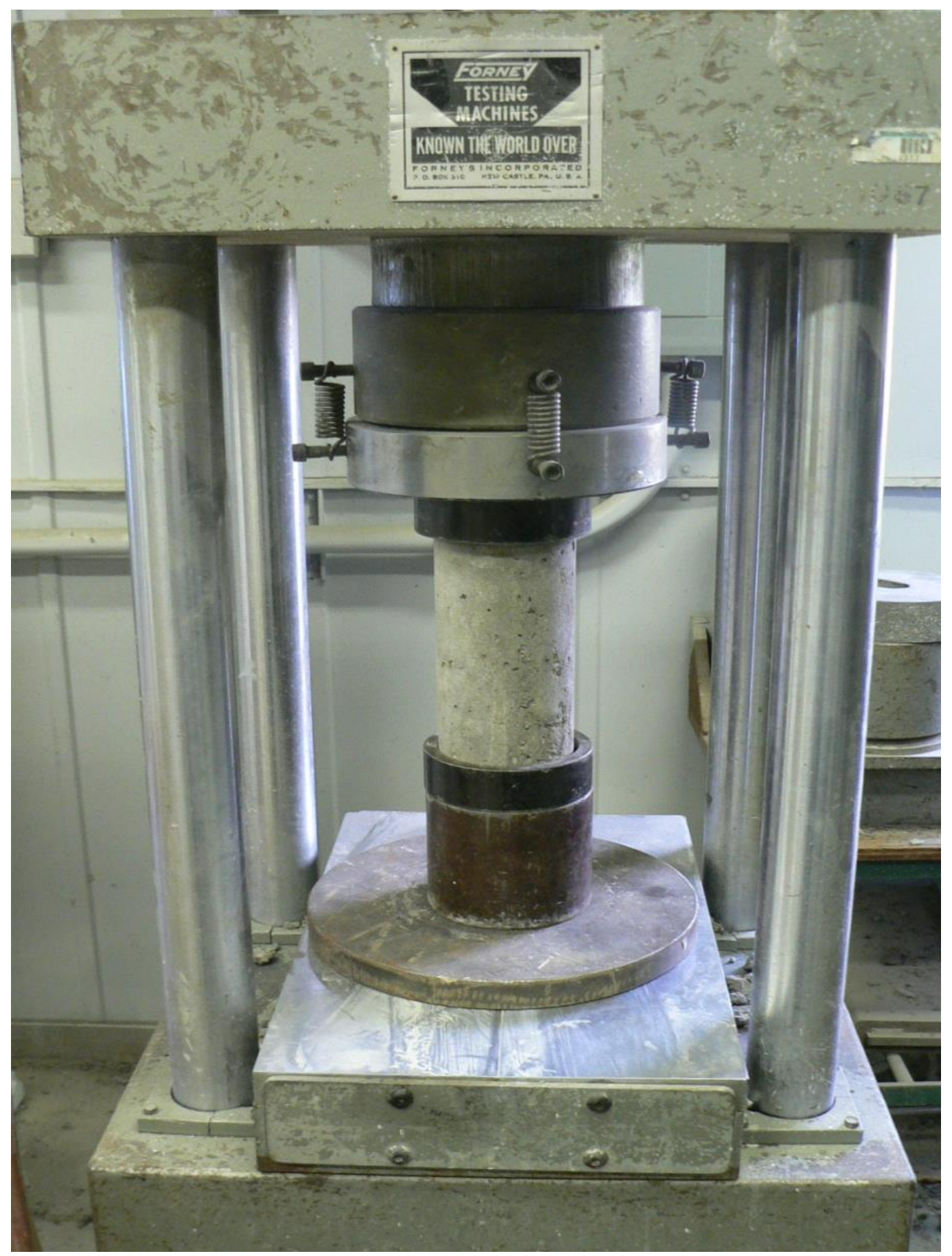

Fig. 5.1 Setup for testing of compressive strength according to ASTM C39/C39M - 12a 
Table 5.1 Compressive Strength Results at Different Ages for all AAB Cylinders Cured at Different Temperatures

\begin{tabular}{|c|c|c|c|c|}
\hline \multirow[t]{2}{*}{ Mix } & \multirow{2}{*}{$\begin{array}{c}\text { Age } \\
\text { (Days) }\end{array}$} & \multicolumn{3}{|c|}{$\begin{array}{c}\text { Compressive strength } \\
\text { (MPa [psi]) }\end{array}$} \\
\hline & & $23^{\circ} \mathrm{C}$ & $40^{\circ} \mathrm{C}$ & $60^{\circ} \mathrm{C}$ \\
\hline \multirow{3}{*}{ FA 100} & 7 & $20.9[3030]$ & 30.3 [4400] & $45.5[6600]$ \\
\hline & 28 & $27.7[4020]$ & $33.3[4830]$ & $57.0[8270]$ \\
\hline & 90 & 29.1 [4220] & $35.1[5090]$ & $60.0[8710]$ \\
\hline \multirow{3}{*}{ FA 85 SG 15} & 7 & $26.9[3900]$ & $35.3[5120]$ & $58.9[8550]$ \\
\hline & 28 & $33.6[4880]$ & $40.7[5900]$ & $59.7[8660]$ \\
\hline & 90 & $35.4[5140]$ & $42.8[6210]$ & $62.8[9110]$ \\
\hline \multirow{3}{*}{ FA 70 SG 30} & 7 & $33.1[4800]$ & $41.9[6080]$ & $59.7[8660]$ \\
\hline & 28 & $39.0[5660]$ & $48.0[6960]$ & $67.9[9850]$ \\
\hline & 90 & $41.0[5950]$ & $50.5[7330]$ & 71.5 [10370] \\
\hline \multirow{3}{*}{ FA 50 SG 50} & 7 & $41.8[6070]$ & $60.7[8810]$ & $65.9[9560]$ \\
\hline & 28 & $45.1[6540]$ & 61.7 [8950] & 76.1 [11040] \\
\hline & 90 & $47.5[6890]$ & 64.9 [9420] & $80.1[11620]$ \\
\hline \multirow{3}{*}{ FA 30 SG 70} & 7 & $42.8[6210]$ & $60.7[8810]$ & $69.3[10060]$ \\
\hline & 28 & $47.1[6830]$ & $63.3[9180]$ & $78.5[11390]$ \\
\hline & 90 & 49.5 [7180] & 66.7 [9680] & 82.7 [12000] \\
\hline \multirow{3}{*}{ FA 15 SG 85} & 7 & $44.6[6470]$ & $61.7[8950]$ & $72.2[10480]$ \\
\hline & 28 & $48.5[7040]$ & $65.7[9530]$ & 80.8 [11720] \\
\hline & 90 & $51.0[7400]$ & $69.1[10030]$ & $84.4[12250]$ \\
\hline \multirow{3}{*}{ SG 100} & 7 & $45.6[6620]$ & $62.0[9000]$ & $73.3[10640]$ \\
\hline & 28 & $51.1[7410]$ & $67.7[9820]$ & $81.5[11830]$ \\
\hline & 90 & 53.8 [7810] & 71.2 [10330] & 85.0 [12330] \\
\hline \multirow{3}{*}{ FA 100 p 15} & 7 & $21.0[3050]$ & $30.3[4400]$ & $45.5[6600]$ \\
\hline & 28 & $27.6[4000]$ & $33.2[4820]$ & $57.1[8290]$ \\
\hline & 90 & $29.1[4220]$ & $35.1[5090]$ & $60.0[8710]$ \\
\hline \multirow{3}{*}{ FA 100 p30 } & 7 & 20.9 [3030] & $30.3[4400]$ & $45.5[6600]$ \\
\hline & 28 & $27.7[4020]$ & $33.2[4820]$ & $57.1[8290]$ \\
\hline & 90 & $29.2[4240]$ & $35.1[5090]$ & $60.0[8710]$ \\
\hline \multirow{3}{*}{ FA 100 p60 } & 7 & 20.9 [3030] & 30.4 [4410] & $45.5[6600]$ \\
\hline & 28 & $27.7[4020]$ & $33.3[4830]$ & $57.0[8290]$ \\
\hline & 90 & 29.1 [4220] & $35.2[5110]$ & $60.1[8720]$ \\
\hline
\end{tabular}

The variation of compressive strength with age for all mixes at each curing temperature is shown in the following set of figures.

In Fig. 5.2, the comparison between the compressive strengths of different $A A B$ mixtures cured at $23^{\circ} \mathrm{C}$ has been provided. It was observed that the compressive strength increased with increase in percentage of slag in the precursor. AAB made with fly ash as precursor showed the least 28-day compressive strength (27.7 MPa) while that made with slag as precursor showed the highest 28-day compressive strength (51.1 $\mathrm{MPa}$ ). This trend was 
evident for all the three ages that were studied. Preblending the fly ash with $\mathrm{NaOH}$ did not seem to have any influence on the compressive strength values. FA 100 p30 and FA 100 p60 specimens showed the same mean compressive strength values as FA 100 specimens, while FA 100 p15 showed mean compressive strength of $21.0 \mathrm{MPa}$. This minor variation $(0.48 \%)$ can attributed to human error in the experiment.

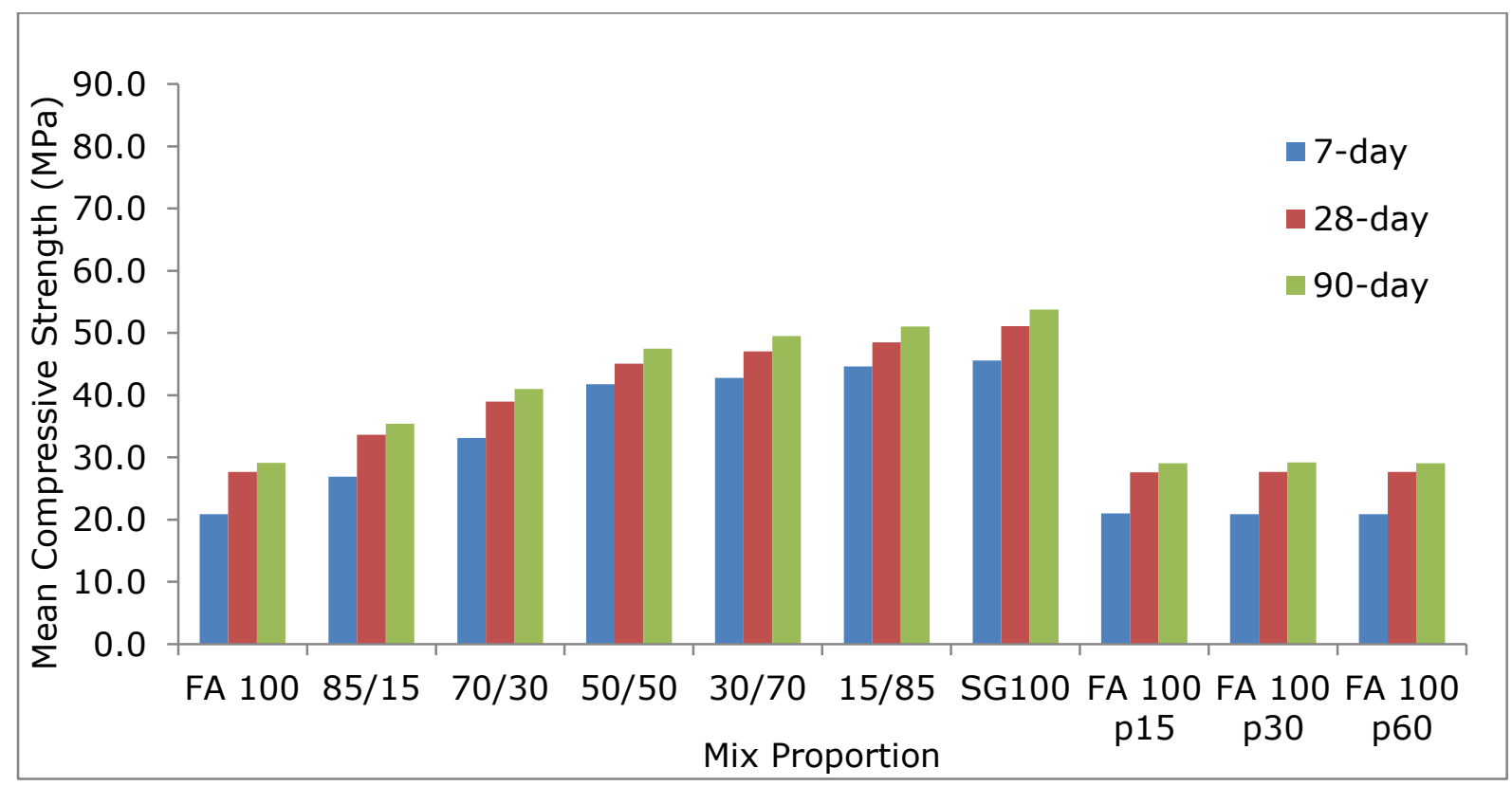

Fig. 5.2a Compressive strength data at $23^{\circ} \mathrm{C}$ for all mixes at different ages (Bar chart)

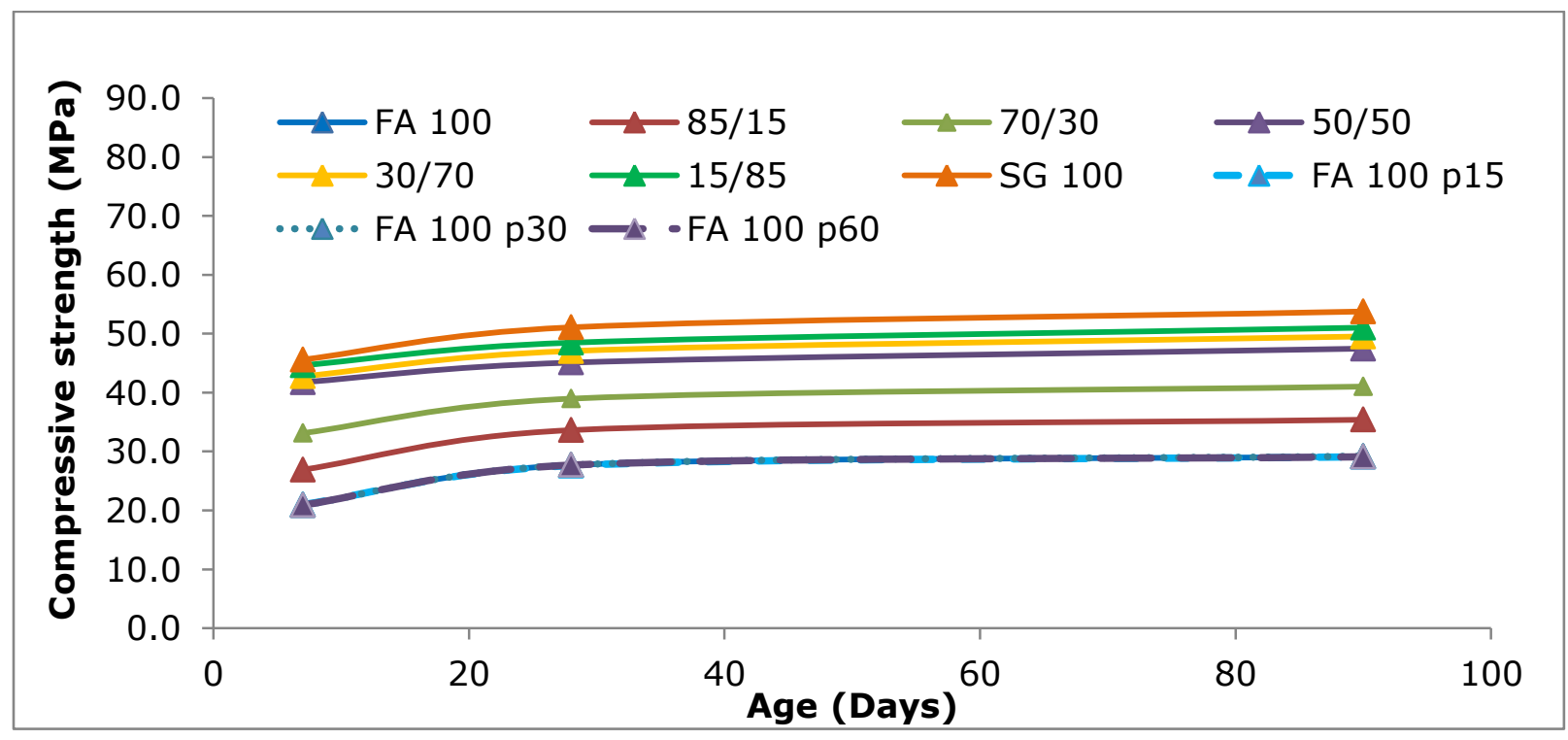

Fig. 5.2b Compressive strength data at $23^{\circ} \mathrm{C}$ for all mixes at different ages 
In Fig. 5.3, the comparison between the compressive strengths of different $A A B$ mixtures cured at $40^{\circ} \mathrm{C}$ has been provided. It was observed that the compressive strength increased with increase in percentage of slag in the precursor. AAB made with fly ash as precursor showed the least 28-day compressive strength (33.3 MPa) while that made with slag as precursor showed the highest 28-day compressive strength (67.7 $\mathrm{MPa}$ ). This trend was evident for all the three ages that were studied. Preblending the fly ash with $\mathrm{NaOH}$ did not seem to have any influence on the compressive strength values.

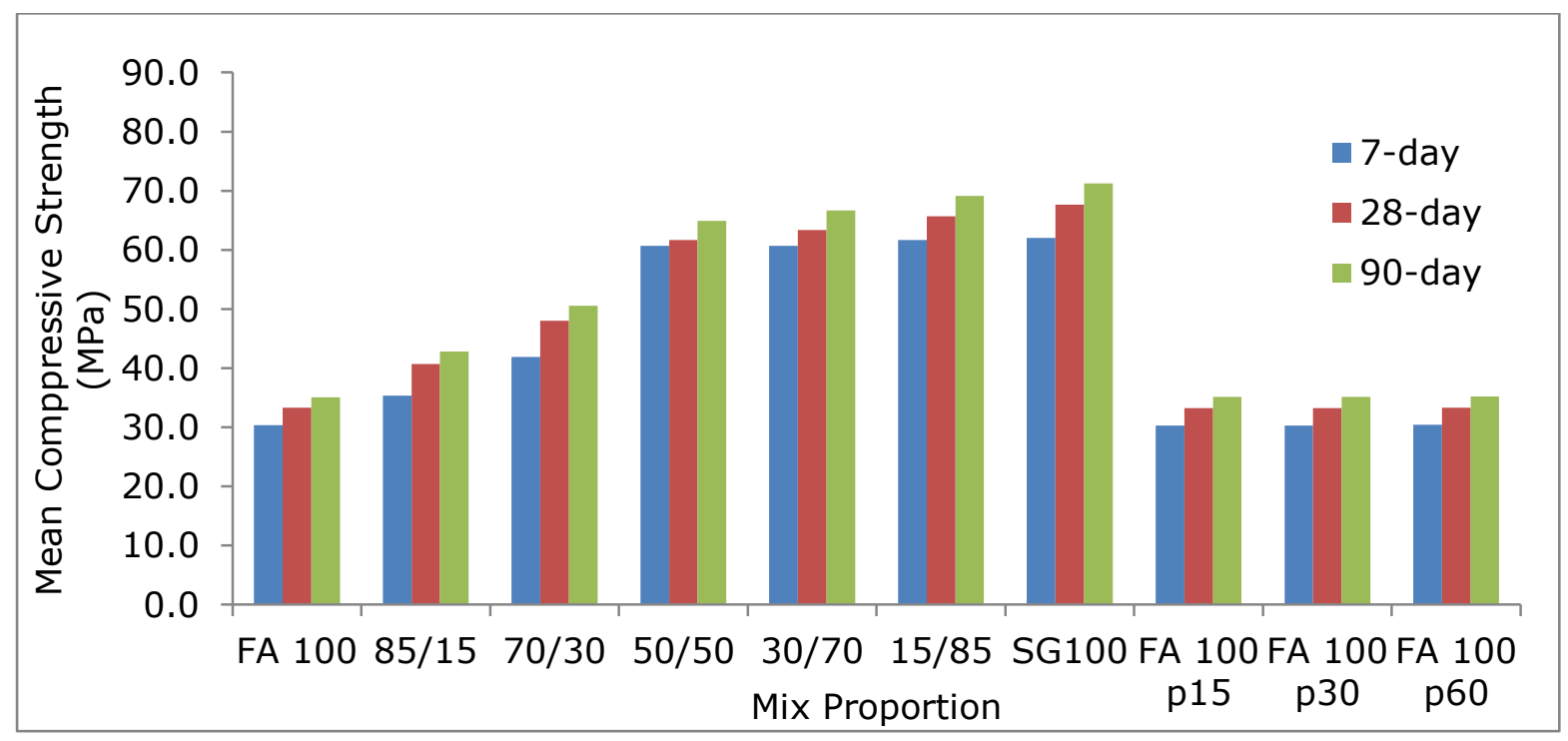

Fig. 5.3a Compressive strength data at $40^{\circ} \mathrm{C}$ for all mixes at different ages (bar chart)

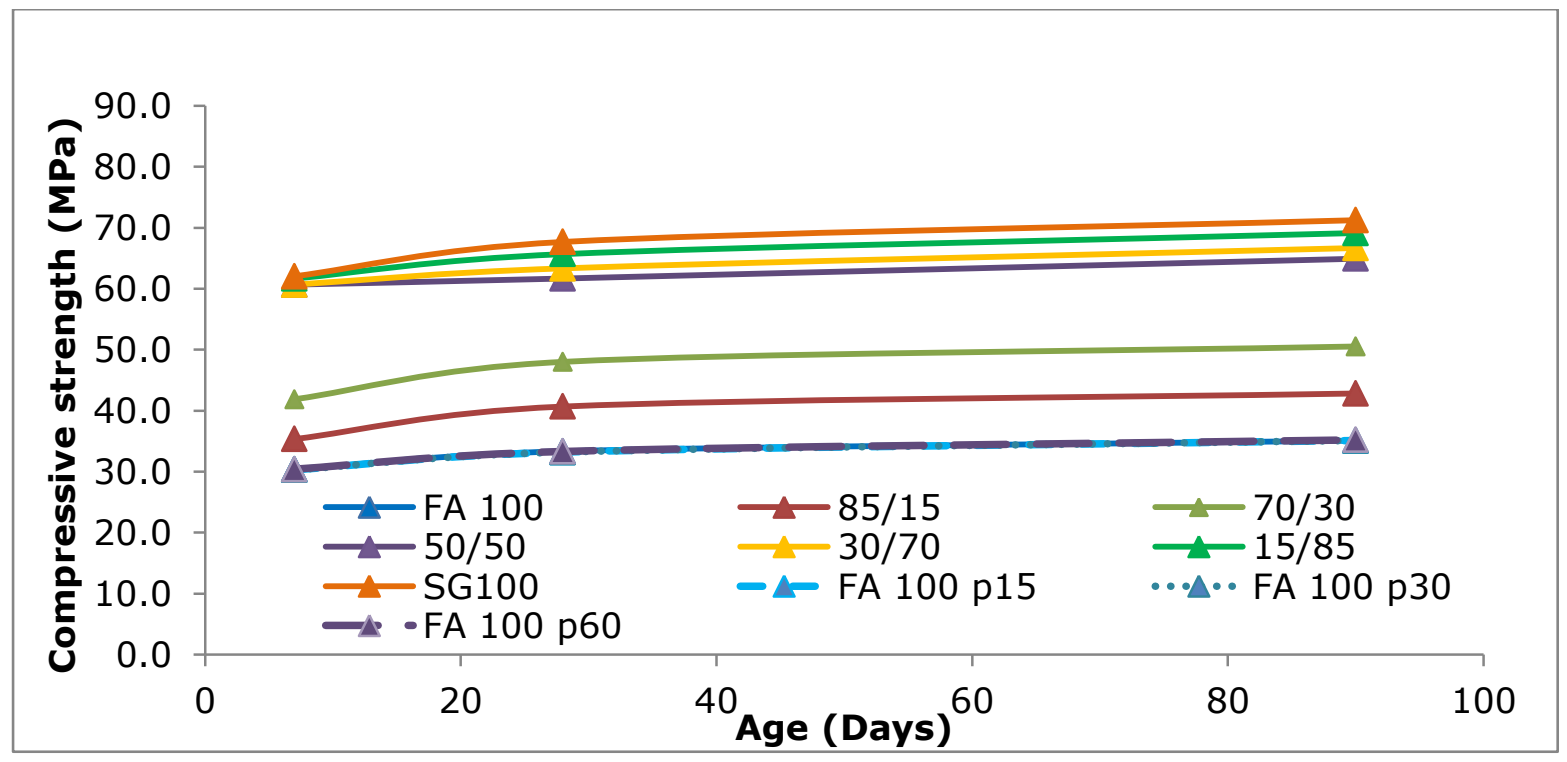

Fig. 5.3b Compressive strength data at $40^{\circ} \mathrm{C}$ for all mixes at different ages 
In Fig. 5.4, the comparison between the compressive strengths of different $A A B$ mixtures cured at $60^{\circ} \mathrm{C}$ has been provided. It was observed that the compressive strength increased with increase in percentage of slag in the precursor. AAB made with fly ash as precursor showed the least 28-day compressive strength (57.0 MPa) while that made with slag as precursor showed the highest 28-day compressive strength (81.5 $\mathrm{MPa}$ ). This trend was evident for all the three ages that were studied. Preblending the fly ash with $\mathrm{NaOH}$ did not seem to have any influence on the compressive strength values.

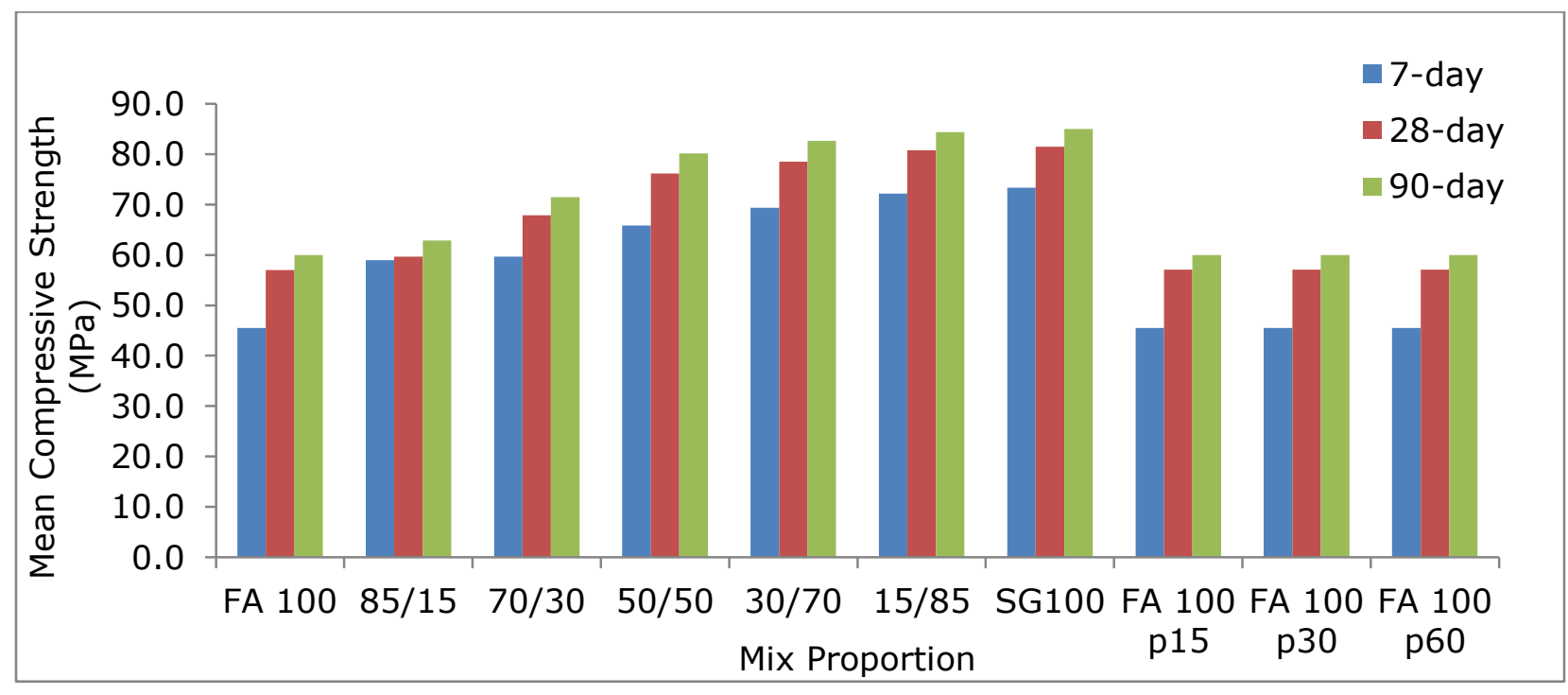

Fig. 5.4a Compressive strength data at $60^{\circ} \mathrm{C}$ for all mixes at different ages (bar chart)

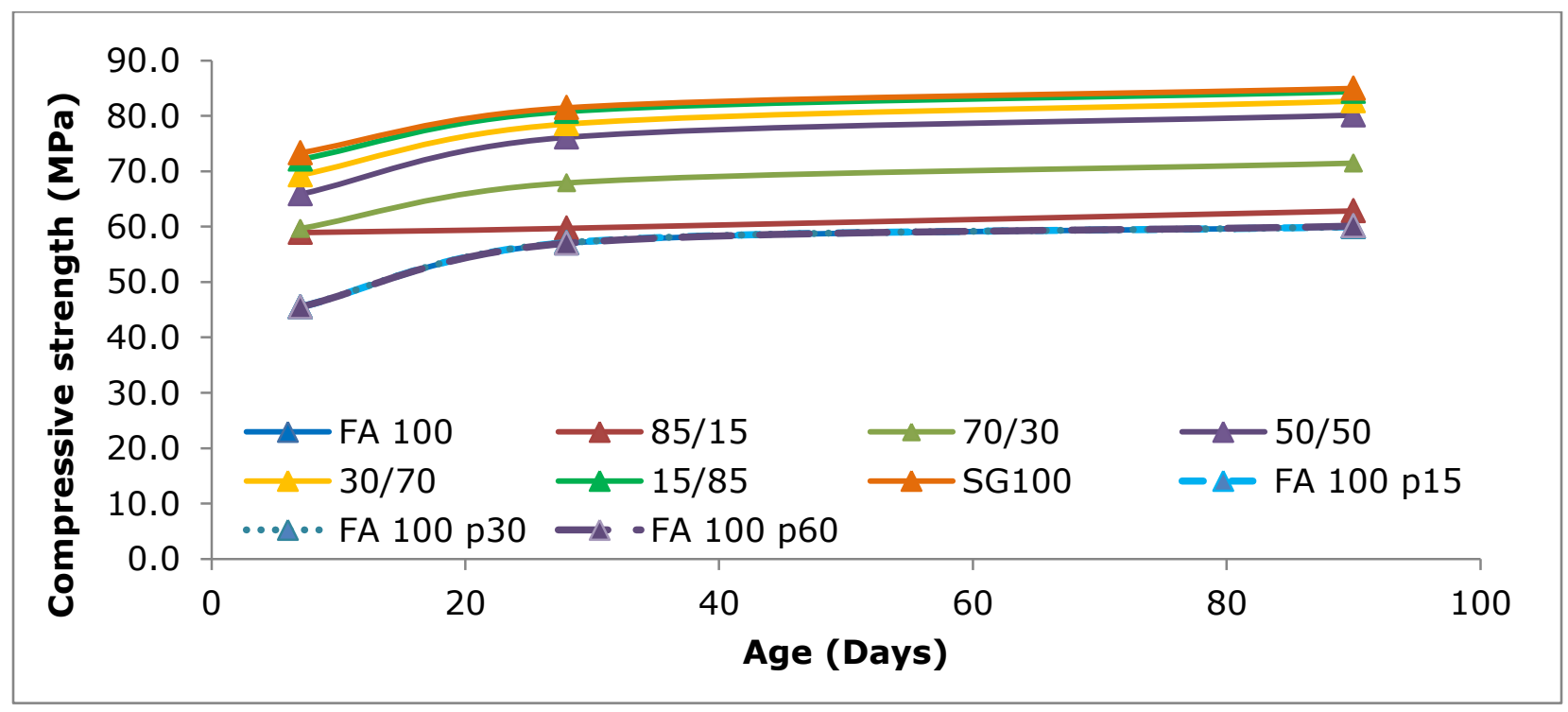

Fig. 5.4b Compressive strength data at $60^{\circ} \mathrm{C}$ for all mixes at different ages 
From figs. 5.2 through 5.4, it was observed that the 90-day compressive strength values were about $105 \%$ of the 28 -day compressive strength values. In other words, nearly $95 \%$ of the total compressive strength was achieved after 28 days for all the mixes.

\subsubsection{Effect of age on strength of concrete}

In concrete practice, the compressive strength is traditionally characterized by the value at 28-day age (Neville 2007). There is no remarkable scientific significance of such a choice. It is simply the case that PC concrete gained early strength slowly and it was necessary to base the strength description on a specimen where considerable cement hydration had already taken place. The specific choice of an age which was a multiple of weeks was intentionally done so that the testing, placing or other such practical implementations would fall on the same day of the week as the casting day. This ensured that the practical implementations would be scheduled on a week day. It is arguable that a shorter period than 28 days could be chosen as the representative strength but it is this value which has been established in practice for concrete. Thus, for the AAB concrete characterized in the present study, the 28-day compressive strength was considered the representative value for compressive strength.

A situation may arise that the 28-day compressive strength for a particular AAB mixture proportion has to be estimated from a known compressive strength value at an earlier age, say 7 days. In that case, the relationship between the 28-day compressive strength and its corresponding 7-day must be known from the experimental compressive strength values. Similar case may arise in case of the 90-day compressive strength. At an age of 90 days, concrete is thought to attain nearly its maximum compressive strength.

Table 5.2 shows the relationship of the 7-day and 90-day compressive strengths w.r.t the 28-day compressive strength values for all mixes at different curing temperatures. 
Table 5.2 Ratios of 7-day and 90-day Compressive Strengths of AAB w.r.t their 28day Compressive Strength Values for all Mixes at Different Curing Temperatures

\begin{tabular}{|c|c|c|c|}
\hline Temperature & Mix & $f C^{\prime}{ }_{7} / f C^{\prime}{ }_{28}$ & $f C^{\prime}{ }_{90} / f C^{\prime}{ }_{28}$ \\
\hline \multirow{10}{*}{$23^{\circ} \mathrm{C}$} & FA 100 & 0.75 & 1.05 \\
\hline & FA 85 SG 15 & 0.80 & 1.05 \\
\hline & FA 70 SG 30 & 0.85 & 1.05 \\
\hline & FA 50 SG 50 & 0.93 & 1.05 \\
\hline & FA 30 SG 70 & 0.91 & 1.05 \\
\hline & FA 15 SG 85 & 0.92 & 1.05 \\
\hline & SG 100 & 0.89 & 1.05 \\
\hline & FA $100 \mathrm{p} 15$ & 0.76 & 1.05 \\
\hline & FA 100 p30 & 0.75 & 1.05 \\
\hline & FA 100 p60 & 0.75 & 1.05 \\
\hline \multirow{10}{*}{$40^{\circ} \mathrm{C}$} & FA 100 & 0.91 & 1.05 \\
\hline & FA 85 SG 15 & 0.87 & 1.05 \\
\hline & FA 70 SG 30 & 0.87 & 1.05 \\
\hline & FA 50 SG 50 & 0.98 & 1.05 \\
\hline & FA 30 SG 70 & 0.96 & 1.05 \\
\hline & FA 15 SG 85 & 0.94 & 1.05 \\
\hline & SG 100 & 0.92 & 1.05 \\
\hline & FA $100 \mathrm{p} 15$ & 0.91 & 1.06 \\
\hline & FA 100 p30 & 0.91 & 1.06 \\
\hline & FA 100 p60 & 0.91 & 1.06 \\
\hline \multirow{10}{*}{$60^{\circ} \mathrm{C}$} & FA 100 & 0.80 & 1.05 \\
\hline & FA 85 SG 15 & 0.99 & 1.05 \\
\hline & FA 70 SG 30 & 0.88 & 1.05 \\
\hline & FA 50 SG 50 & 0.87 & 1.05 \\
\hline & FA 30 SG 70 & 0.88 & 1.05 \\
\hline & FA 15 SG 85 & 0.89 & 1.04 \\
\hline & SG 100 & 0.90 & 1.04 \\
\hline & FA $100 \mathrm{p} 15$ & 0.80 & 1.05 \\
\hline & FA 100 p30 & 0.80 & 1.05 \\
\hline & FA 100 p60 & 0.80 & 1.05 \\
\hline
\end{tabular}

The variation of compressive strength values with curing temperature at each age are shown in the following set of figures. In fig. 5.5, the comparative 7-day compressive strength values for the different mixes are shown. It was easily identified that the compressive strength values increased with increase in curing temperature. 


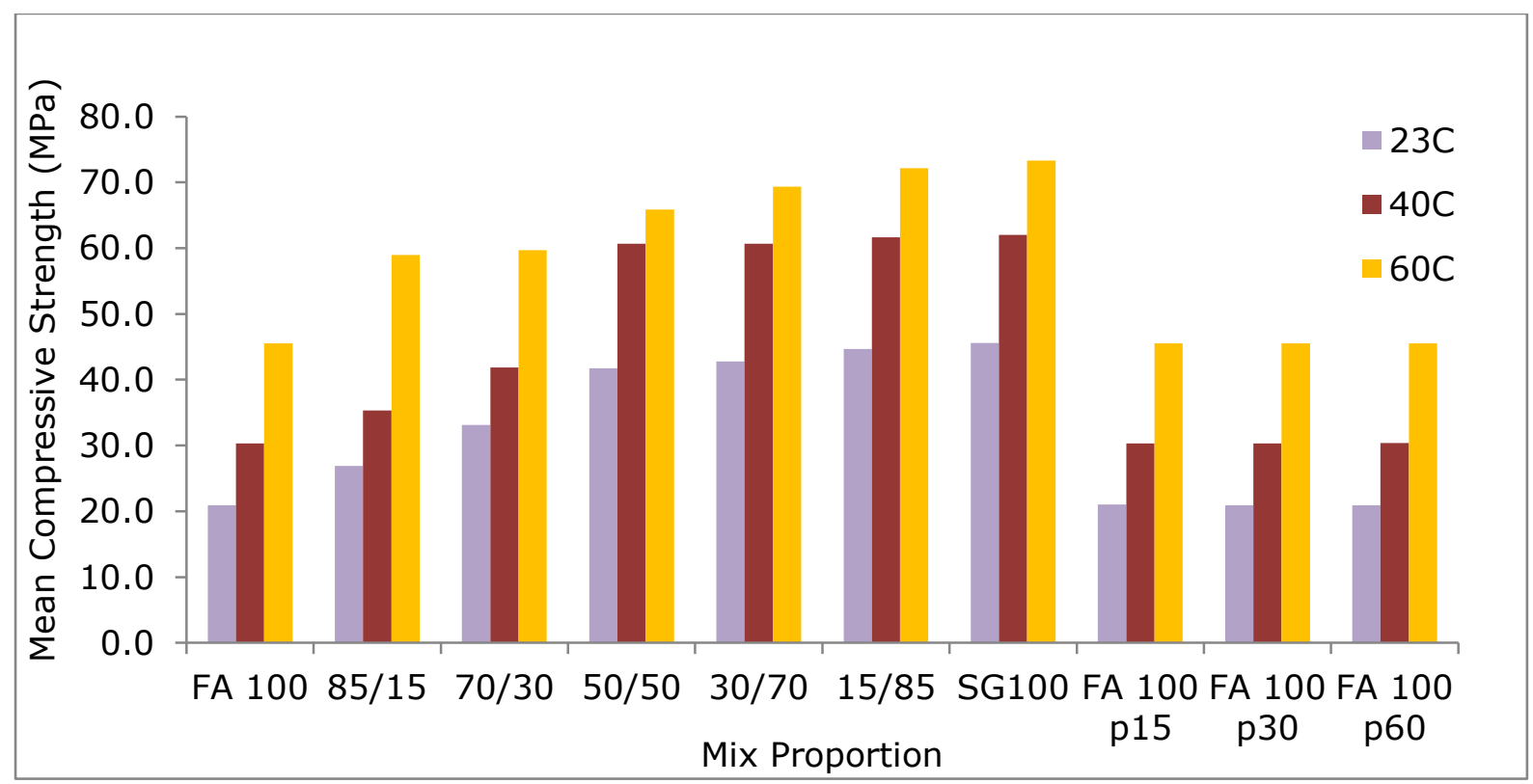

Fig. 5.5 Compressive strength data at 7-day age for all mixes cured at different temperatures

In Fig. 5.6, the comparative 28-day compressive strength values for the different mixes are shown. It was easily identified that the compressive strength values increased with increase in curing temperature.

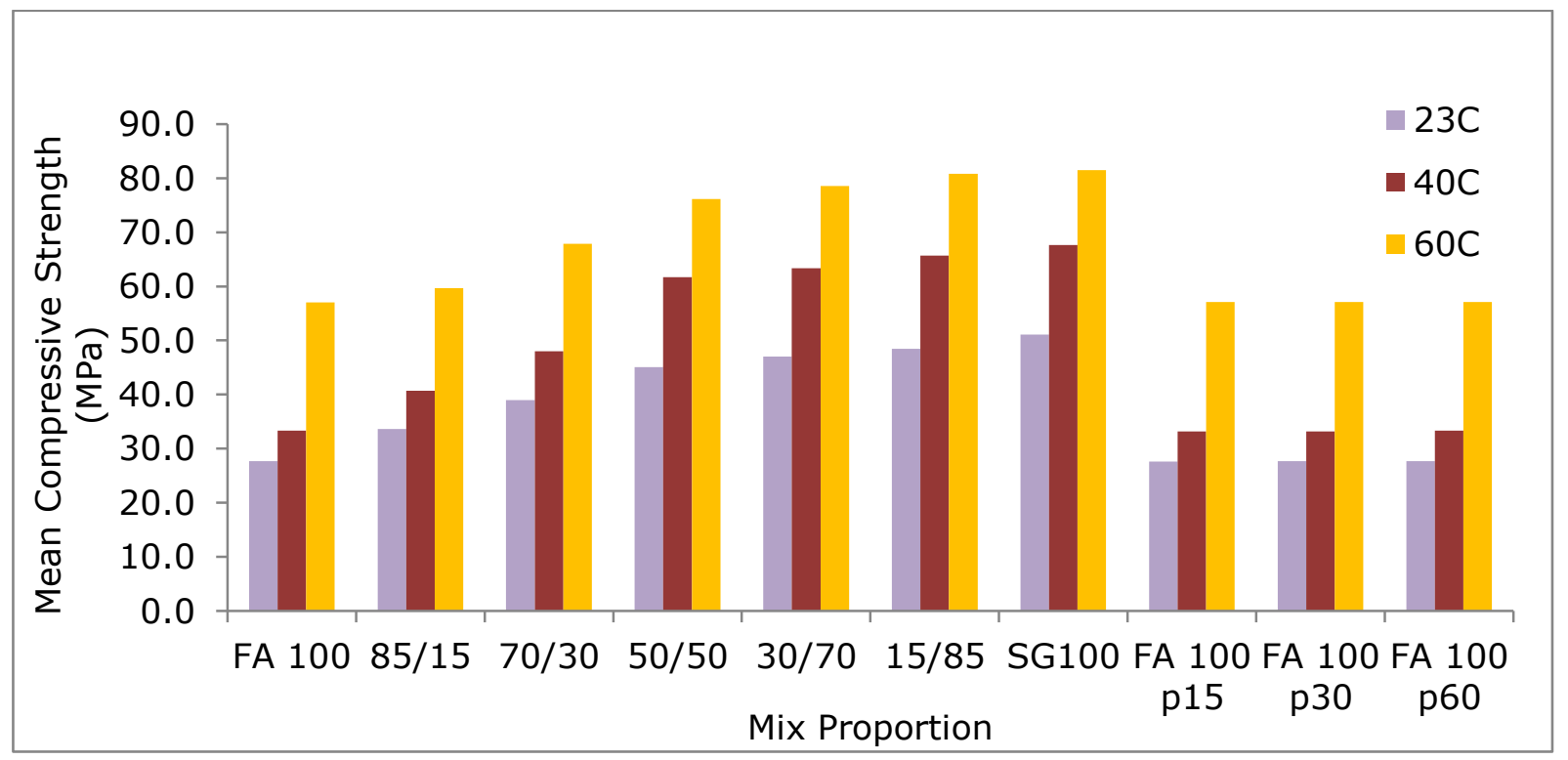

Fig. 5.6 Compressive strength data at 28-day age for all mixes cured at different temperatures 
In Fig. 5.7, the comparative 90-day compressive strength values for the different mixes are shown. It was easily identified that the compressive strength values increased with increase in curing temperature. The compressive strengths for all mixes have been summarized and presented in Table 5.2.

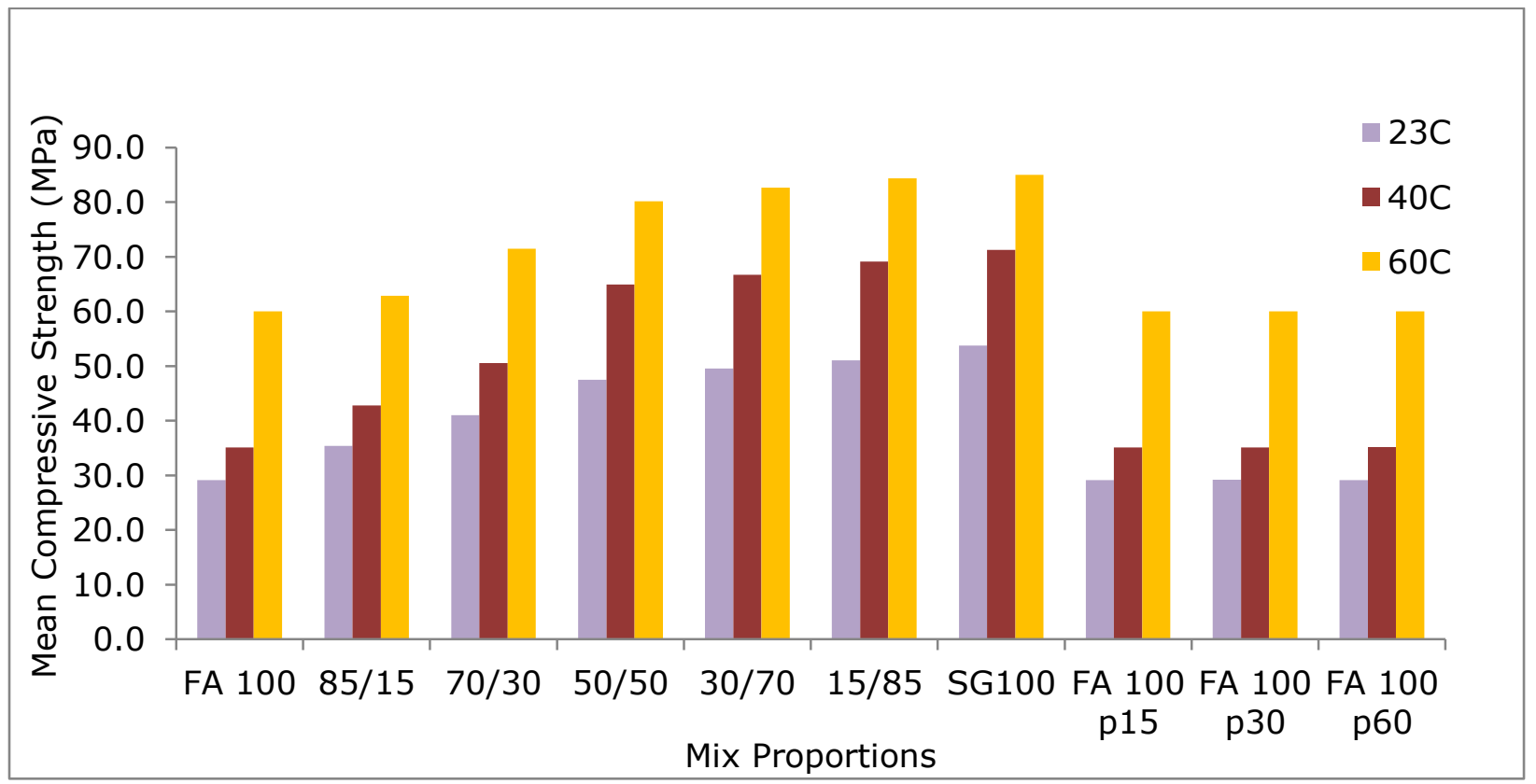

Fig. 5.7 Compressive strength data at 90-day age for all mixes cured at different temperatures 
As mentioned earlier, one of the objectives of the present study was to identify the effect of addition of $\mathrm{Ca}^{2+}$ ions into the sodium aluminosilicate system which in turn affect the specimen level characteristics of AABs. The source of the $\mathrm{Ca}^{2+}$ ions was slag. In the next section, the effects of adding slag to the precursor on the compressive strength have been presented.

\subsubsection{Effect of slag addition on compressive strength of AAB concrete}

In Fig. 5.8, the development of compressive strength of the $A A B$ has been shown with increasing percentages of slag in the precursor mix. It was observed that, at each curing temperature, the addition of slag had a positive effect on the compressive strength. Maximum compressive strength was achieved when fly ash was replaced fully by slag, i.e. $100 \%$ slag replacement. These observations were consistent across all ages.

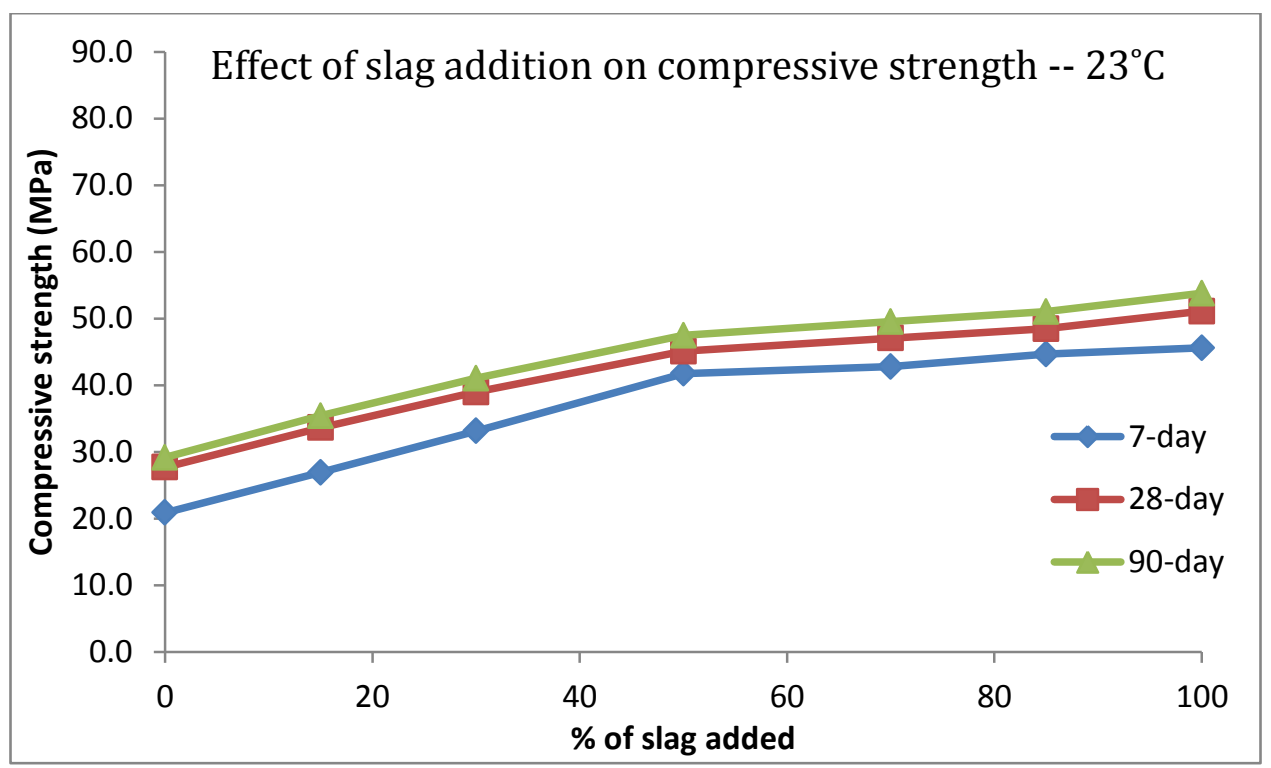

(a) 


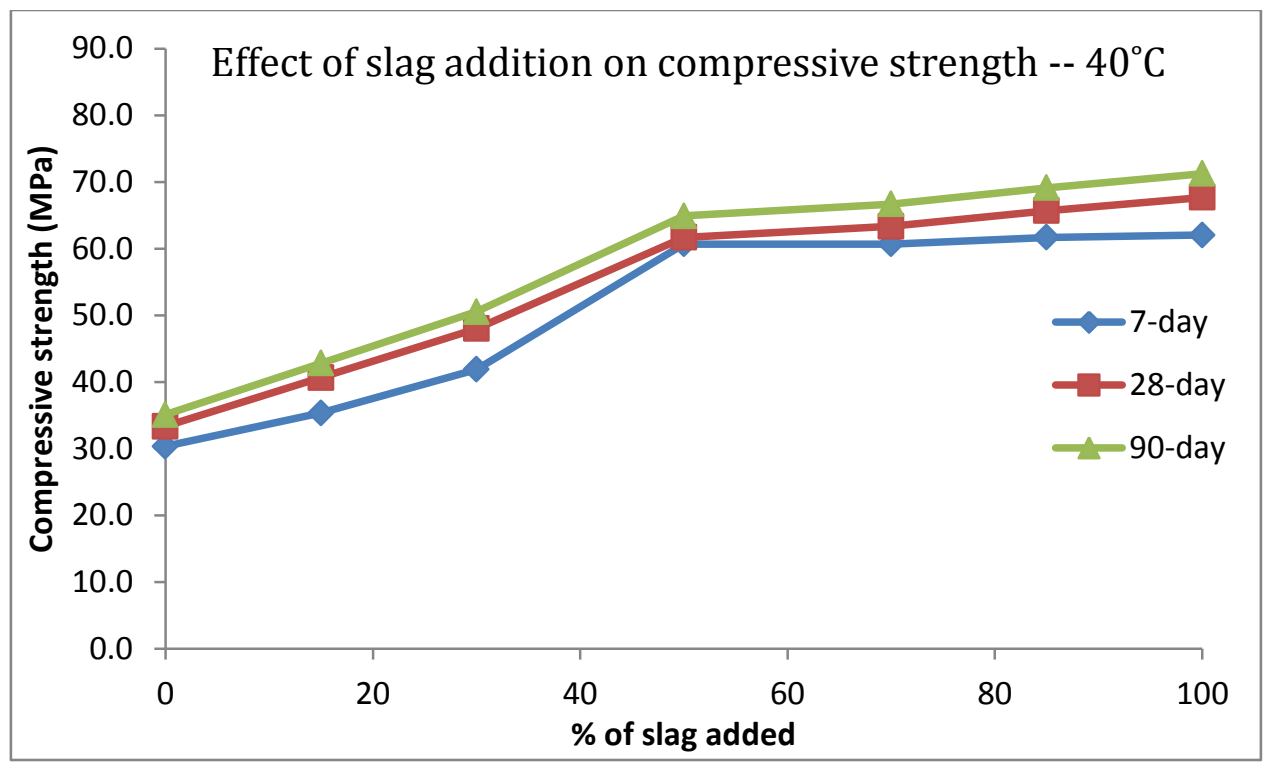

(b)

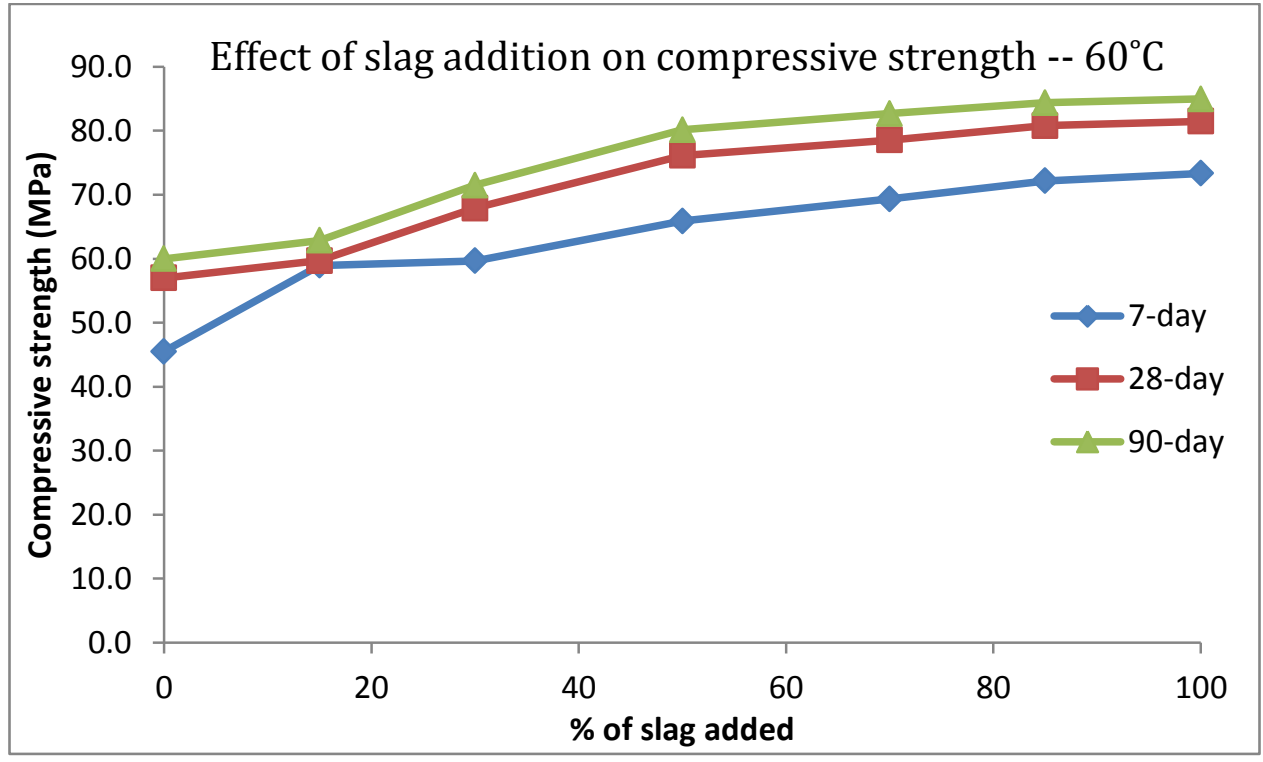

(c)

Fig. 5.8 Effect of slag addition on compressive strength of $A A B$ at different temperatures: (a) $23^{\circ} \mathrm{C}$, (b) $40^{\circ} \mathrm{C}$, and (c) $60^{\circ} \mathrm{C}$.

Apart from compressive strength, another important mechanical property of concrete is the splitting tensile strength. The testing procedure and the results are presented in the following section. 


\subsection{Splitting Tensile Strength Test}

The tensile strength of concrete with $A A B$ was measured by performing the cylinder splitting test on $100 \mathrm{~mm}(4 \mathrm{in}) \times 200 \mathrm{~mm}(8$ in) concrete cylinders for $(10 * 3 * 3 * 3)=270$ specimens. 4 in. by 8 in. cylinders were previously used for this kind of test by Bondar et al. (2010). The test results are given in Table 5.3. These test results show that the tensile splitting strength of $A A B$ concrete is only a fraction of the compressive strength, as in the case of PC concrete. ASTM C496/ 496M-11 (Standard Test Method for Splitting Tensile Strength of Cylindrical Concrete Specimens) provides the expression to determine the characteristic principal tensile strength.

Table 5.3 Splitting Tensile Strength Results at Different Ages for all AAB Cylinders Cured at Different Temperatures

\begin{tabular}{|c|c|c|c|c|}
\hline \multirow{2}{*}{$\operatorname{Mix}$} & \multirow{2}{*}{ Age (Days) } & \multicolumn{3}{|c|}{ Splitting Tensile strength (MPa [psi]) } \\
\hline & & $23^{\circ} \mathrm{C}$ & $40^{\circ} \mathrm{C}$ & $60^{\circ} \mathrm{C}$ \\
\hline \multirow{3}{*}{ FA 100} & 7 & $2.13[310]$ & $3.02[440]$ & $4.50[650]$ \\
\hline & 28 & $2.82[410]$ & $3.53[510]$ & $5.64[820]$ \\
\hline & 90 & 2.97 [430] & 3.68 [530] & $5.94[860]$ \\
\hline \multirow{3}{*}{ FA 85 SG 15} & 7 & $2.74[400]$ & $3.36[490]$ & $5.83[850]$ \\
\hline & 28 & $3.43[500]$ & $3.89[560]$ & $5.91[860]$ \\
\hline & 90 & $3.61[520]$ & $4.10[590]$ & $6.22[900]$ \\
\hline \multirow{3}{*}{ FA 70 SG 30} & 7 & $3.38[490]$ & $4.08[590]$ & $5.91[860]$ \\
\hline & 28 & $3.97[580]$ & $4.67[680]$ & $6.72[980]$ \\
\hline & 90 & $4.18[610]$ & $4.91[710]$ & $7.08[1030]$ \\
\hline \multirow{3}{*}{ FA 50 SG 50} & 7 & $4.26[620]$ & $5.63[820]$ & $6.52[950]$ \\
\hline & 28 & $4.60[670]$ & 6.15 [890] & $7.54[1090]$ \\
\hline & 90 & $4.84[700]$ & $6.48[940]$ & $7.93[1150]$ \\
\hline \multirow{3}{*}{ FA 30 SG 70} & 7 & $4.36[630]$ & $5.86[850]$ & $6.86[1000]$ \\
\hline & 28 & $4.80[700]$ & $6.44[930]$ & $7.78[1130]$ \\
\hline & 90 & $5.05[730]$ & $6.78[980]$ & $8.18[1190]$ \\
\hline \multirow{3}{*}{ FA 15 SG 85} & 7 & $4.55[660]$ & $6.02[870]$ & $7.15[1040]$ \\
\hline & 28 & $4.94[720]$ & $6.71[970]$ & $8.00[1160]$ \\
\hline & 90 & $5.20[750]$ & $7.07[1030]$ & $8.36[1210]$ \\
\hline \multirow{3}{*}{ SG 100} & 7 & $4.64[670]$ & $6.24[910]$ & $7.26[1050]$ \\
\hline & 28 & $5.21[750]$ & 6.84 [990] & $8.07[1170]$ \\
\hline & 90 & $5.48[800]$ & $7.20[1040]$ & $8.41[1220]$ \\
\hline \multirow{3}{*}{ FA 100 p15 } & 7 & $2.10[300]$ & $3.01[440]$ & $4.50[650]$ \\
\hline & 28 & $2.81[410]$ & $3.53[510]$ & $5.65[820]$ \\
\hline & 90 & $2.96[430]$ & $3.68[530]$ & $5.94[860]$ \\
\hline \multirow{3}{*}{ FA 100 p30 } & 7 & $2.10[300]$ & $3.02[440]$ & $4.50[650]$ \\
\hline & 28 & 2.82 [410] & $3.53[510]$ & $5.64[820]$ \\
\hline & 90 & $2.96[430]$ & $3.67[530]$ & $5.94[860]$ \\
\hline \multirow{3}{*}{ FA 100 p60 } & 7 & $2.10[300]$ & $3.02[440]$ & $4.50[650]$ \\
\hline & 28 & $2.82[410]$ & $3.53[510]$ & $5.64[820]$ \\
\hline & 90 & $2.96[430]$ & $3.67[530]$ & $5.93[860]$ \\
\hline
\end{tabular}


The variation of splitting tensile strength with age for all mixes at each curing temperature is shown in the following set of figures.

In Fig. 5.9, the comparison between the splitting tensile strengths of different $A A B$ mixtures cured at $23^{\circ} \mathrm{C}$ has been provided. It was observed that the splitting tensile strength increased with increase in percentage of slag in the precursor. AAB made with fly ash as precursor showed the least tensile strength $(2.13 \mathrm{MPa})$ while that made with slag as precursor showed the highest tensile strength (5.48 $\mathrm{MPa}$ ). This trend was evident for all the three ages that were studied. Preblending the fly ash with $\mathrm{NaOH}$ did not seem to have any influence on the tensile strength values. FA 100 p15, FA 100 p30 and FA 100 p60 specimens showed the same tensile strength values as FA 100 specimens.

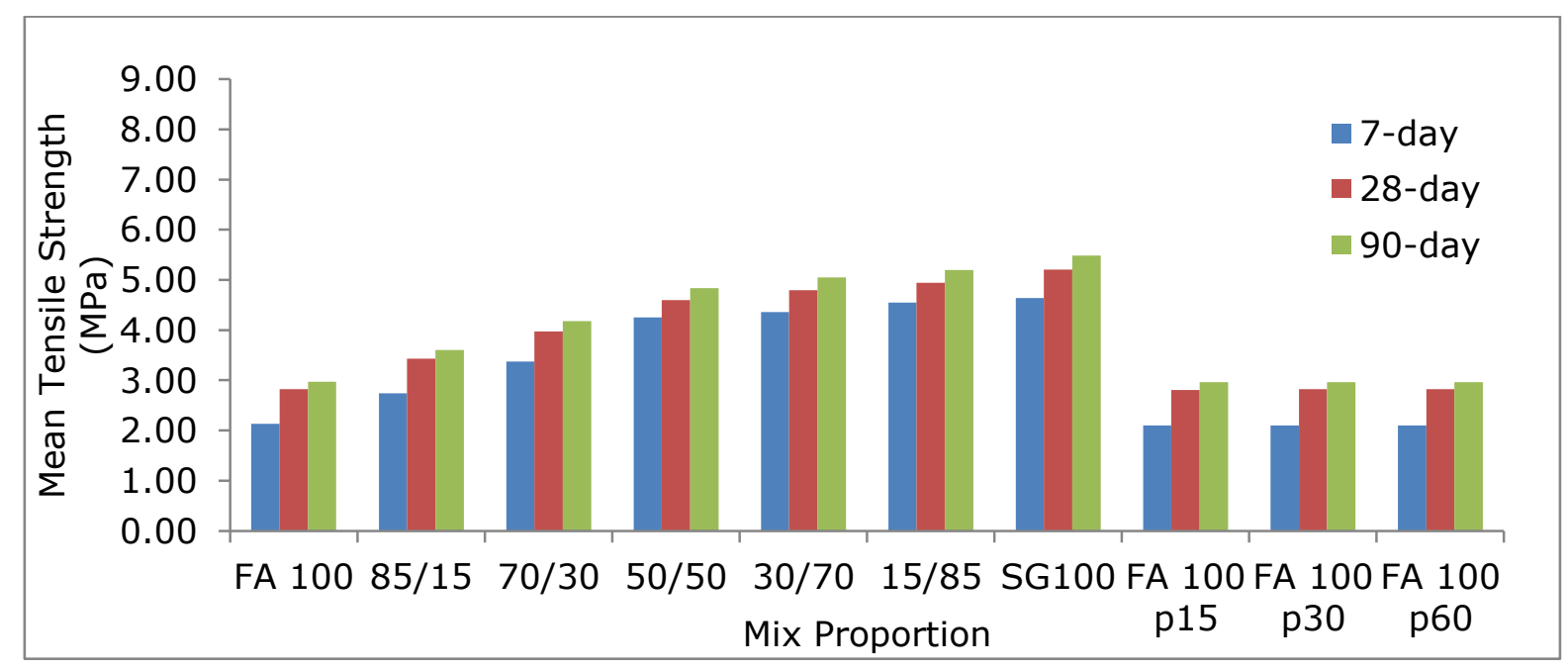

Fig. 5.9a Mean Tensile strength data at $23^{\circ} \mathrm{C}$ for all mixes at different ages (bar chart)

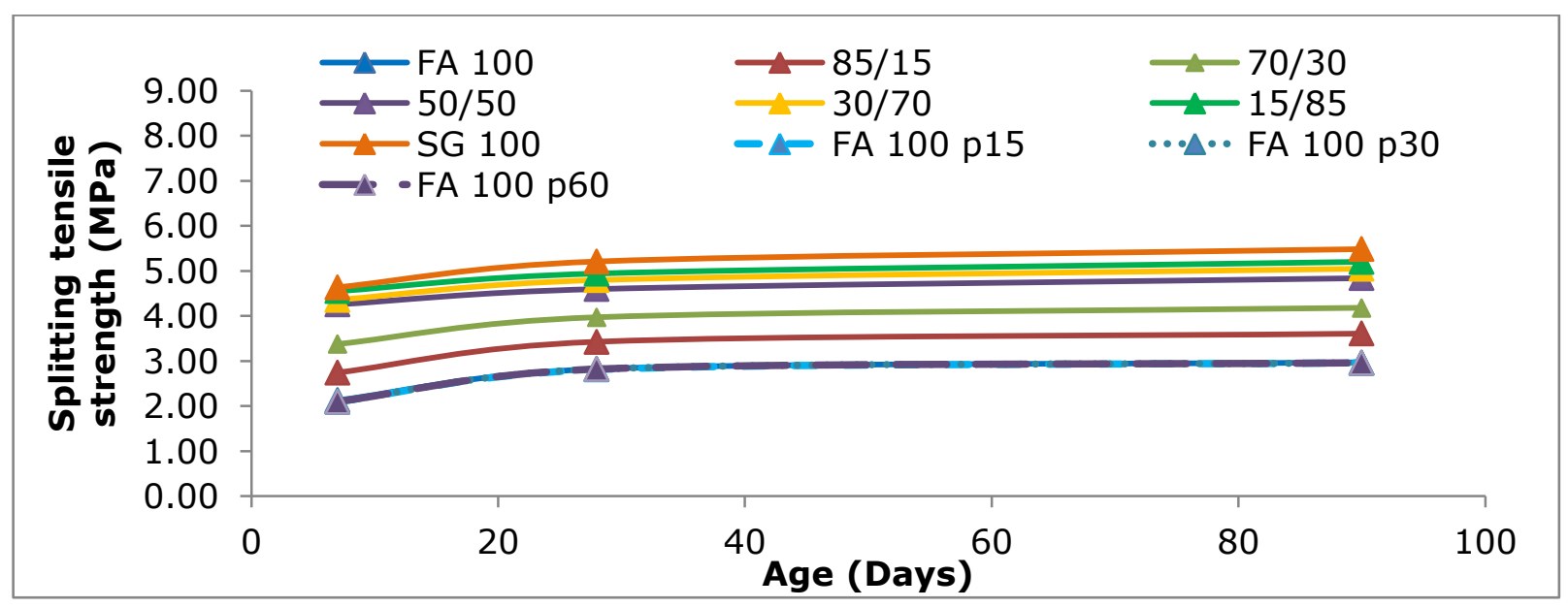

Fig. 5.9b Mean Tensile strength data at $23^{\circ} \mathrm{C}$ for all mixes at different ages 
In Fig. 5.10, the comparison between the splitting tensile strengths of different $A A B$ mixtures cured at $40^{\circ} \mathrm{C}$ has been provided. It was observed that the tensile strength increased with increase in percentage of slag in the precursor. $A A B$ made with fly ash as precursor showed the least tensile strength (3.02 $\mathrm{MPa}$ ) while that made with slag as precursor showed the highest tensile strength (7.20 MPa). This trend was evident for all the three ages that were studied. Preblending the fly ash with $\mathrm{NaOH}$ did not seem to have any influence on the tensile strength values.

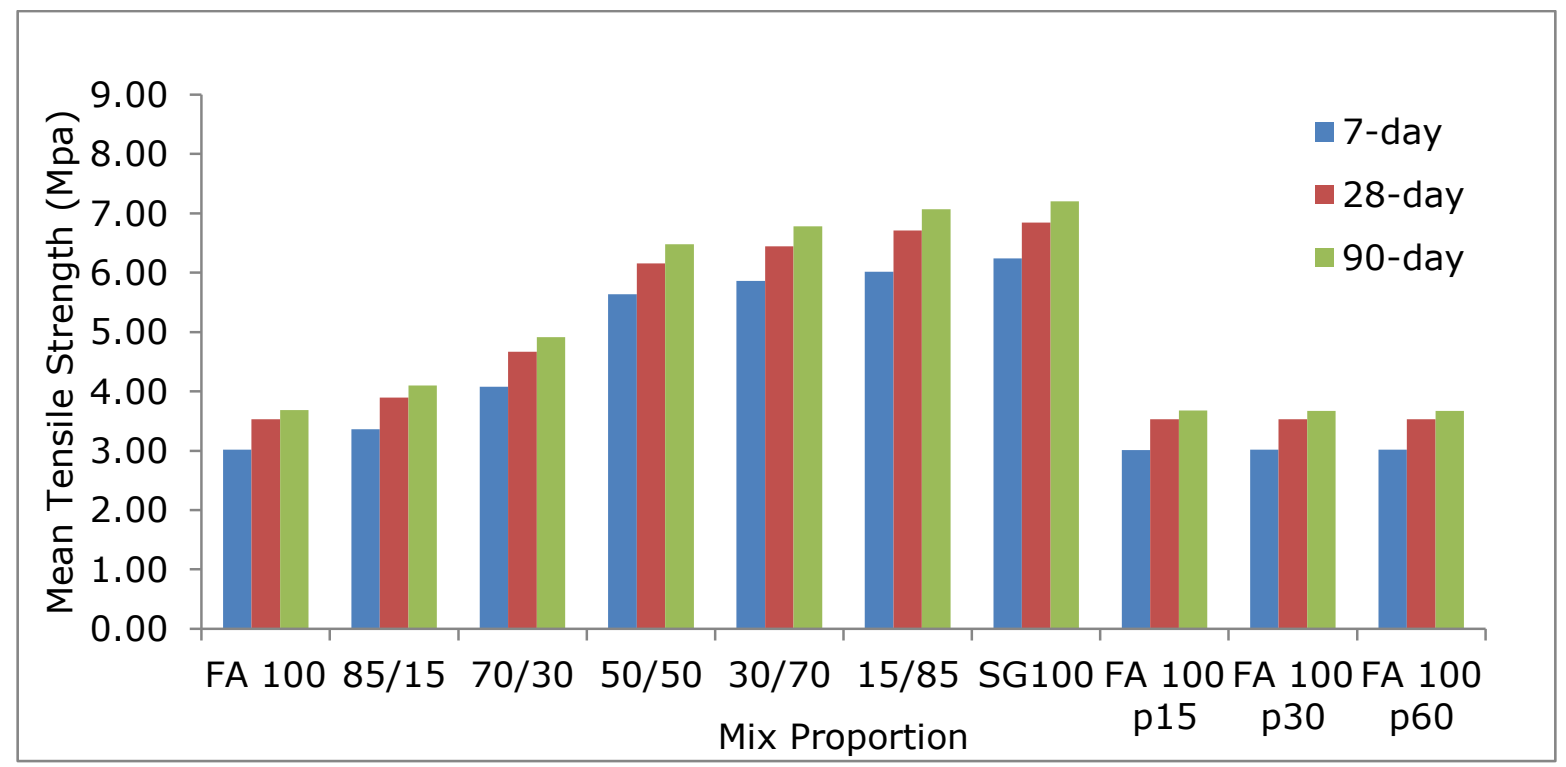

Fig. 5.10a Mean tensile strength data at $40^{\circ} \mathrm{C}$ for all mixes at different ages (bar chart)

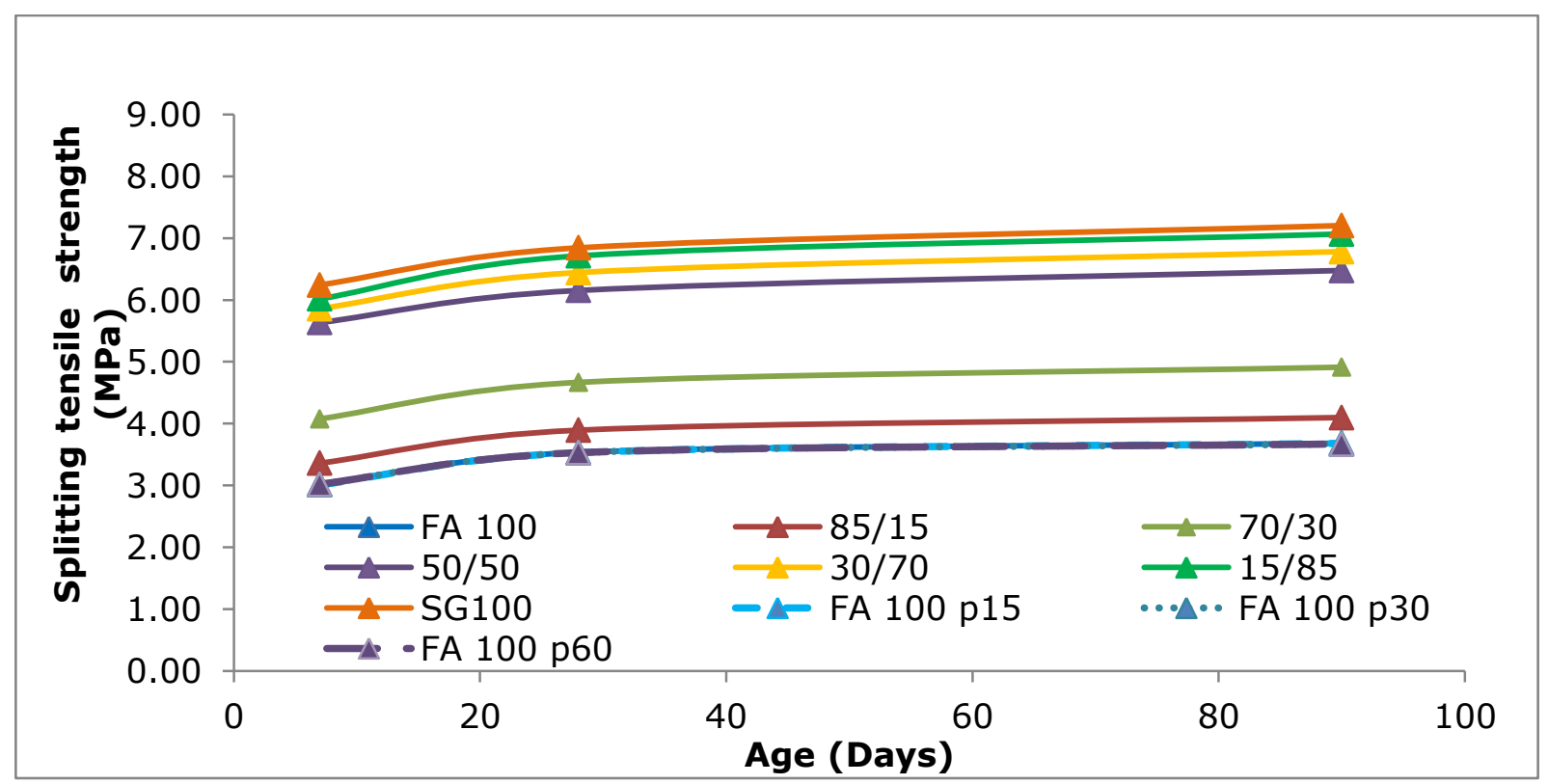

Fig. 5.10b Mean tensile strength data at $40^{\circ} \mathrm{C}$ for all mixes at different ages 
In Fig. 5.11, the comparison between the splitting tensile strengths of different $A A B$ mixtures cured at $60^{\circ} \mathrm{C}$ has been provided. It was observed that the compressive strength increased with increase in percentage of slag in the precursor. $A A B$ made with fly ash as precursor showed the least tensile strength (4.50 MPa) while that made with slag as precursor showed the highest tensile strength (8.41 MPa). This trend was evident for all the three ages that were studied. Preblending the fly ash with $\mathrm{NaOH}$ did not seem to have any influence on the tensile strength values.

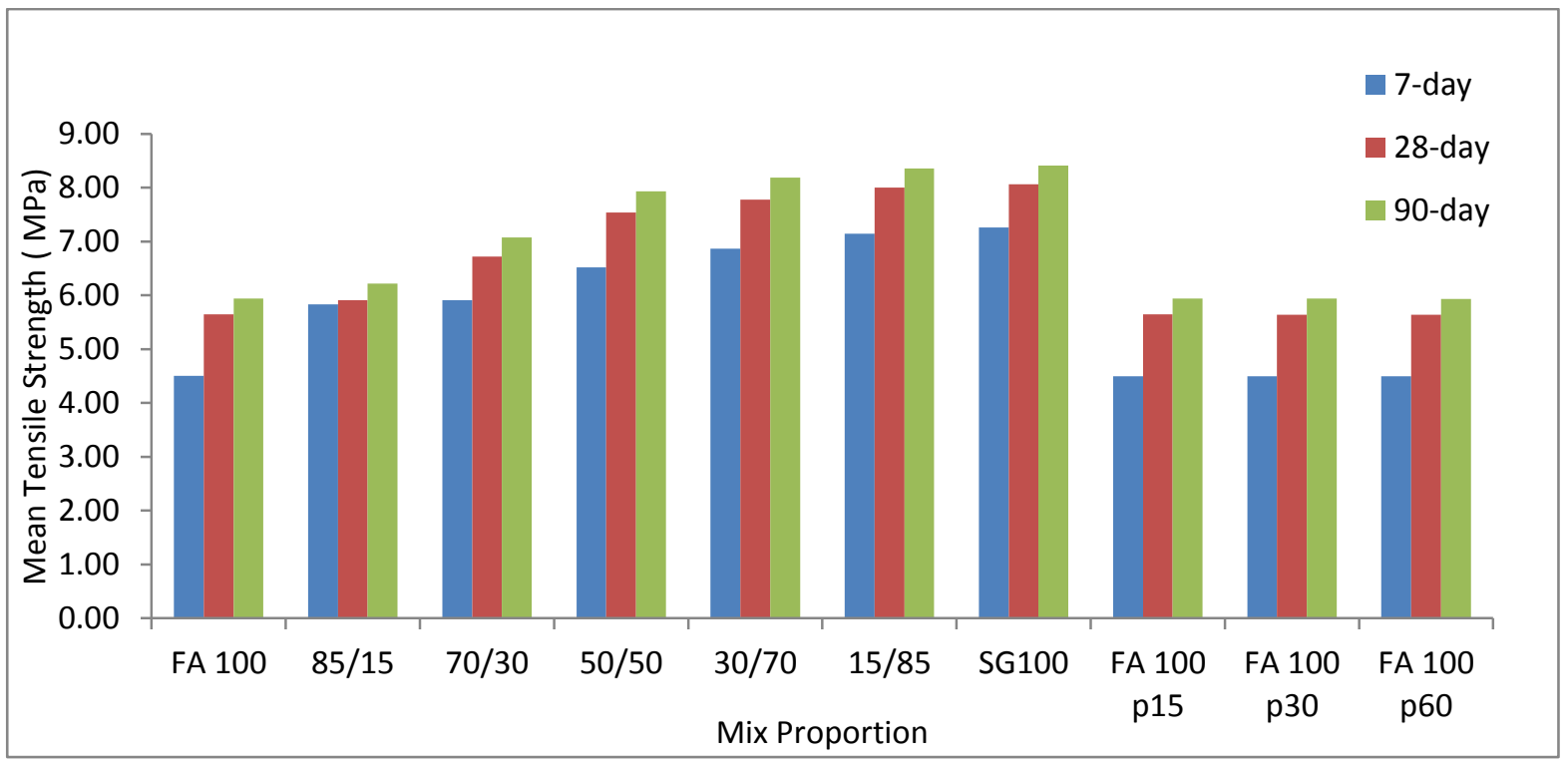

Fig. 5.11a Mean tensile strength data at $60^{\circ} \mathrm{C}$ for all mixes at different ages (bar chart)

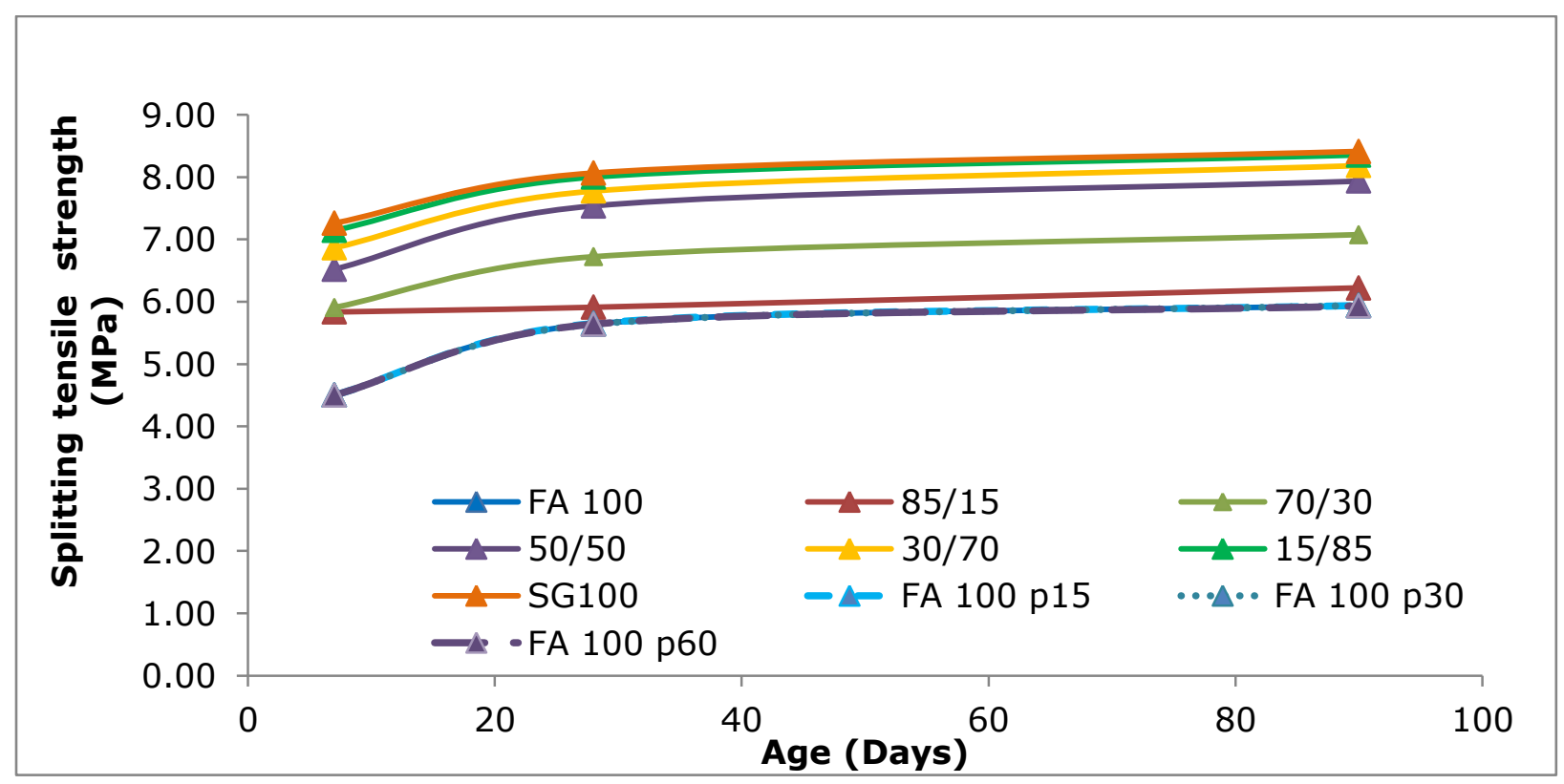

Fig. $5.11 \mathrm{~b}$ Mean tensile strength data at $60^{\circ} \mathrm{C}$ for all mixes at different ages 
The variation of splitting tensile strength values with curing temperature at each age are shown in the following set of figures. In Fig. 5.12, the comparative 7-day splitting tensile strength values for the different mixes are shown. It was easily identified that the tensile strength values increased with increase in curing temperature.

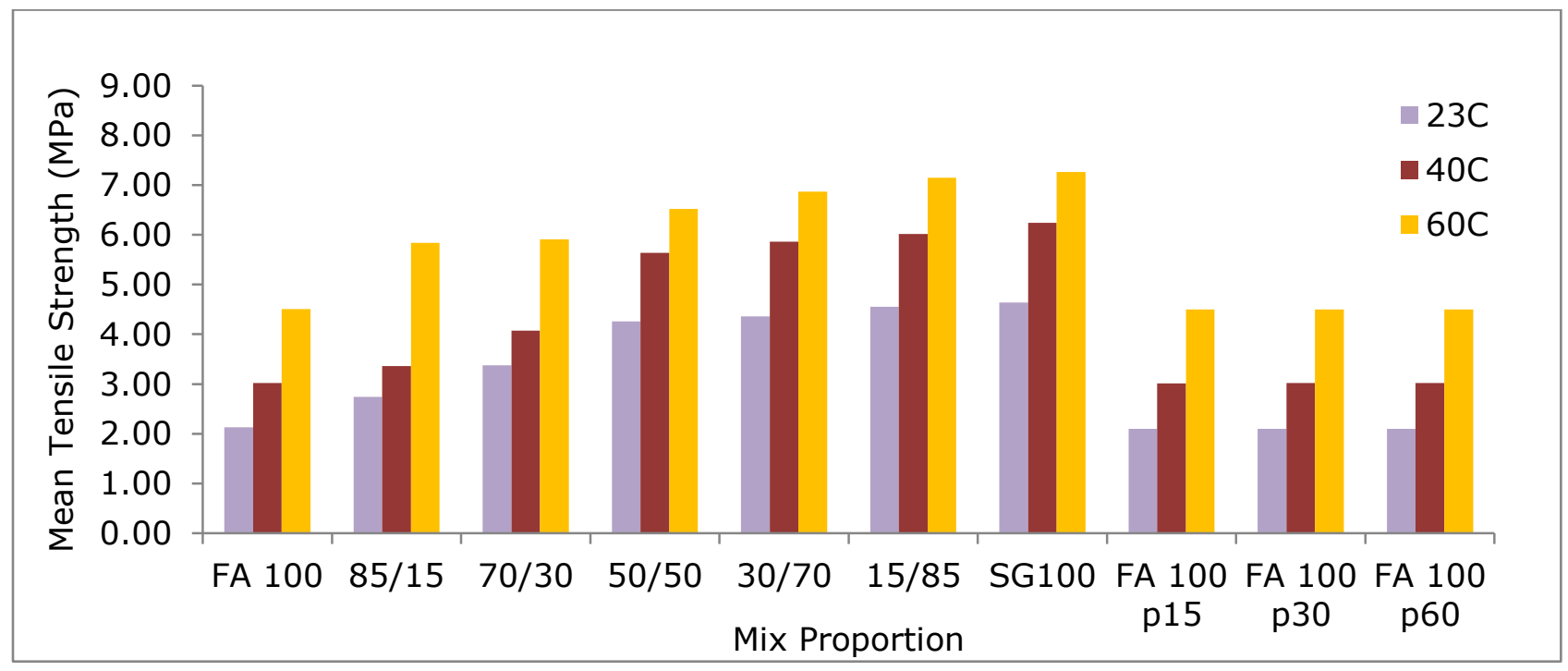

Fig. 5.12 Mean 7-day Splitting Tensile Strength for all mixes at different temperatures

In Fig. 5.13, the comparative 28-day splitting tensile strength values for the different mixes are shown. It was easily identified that the tensile strength values increased with increase in curing temperature.

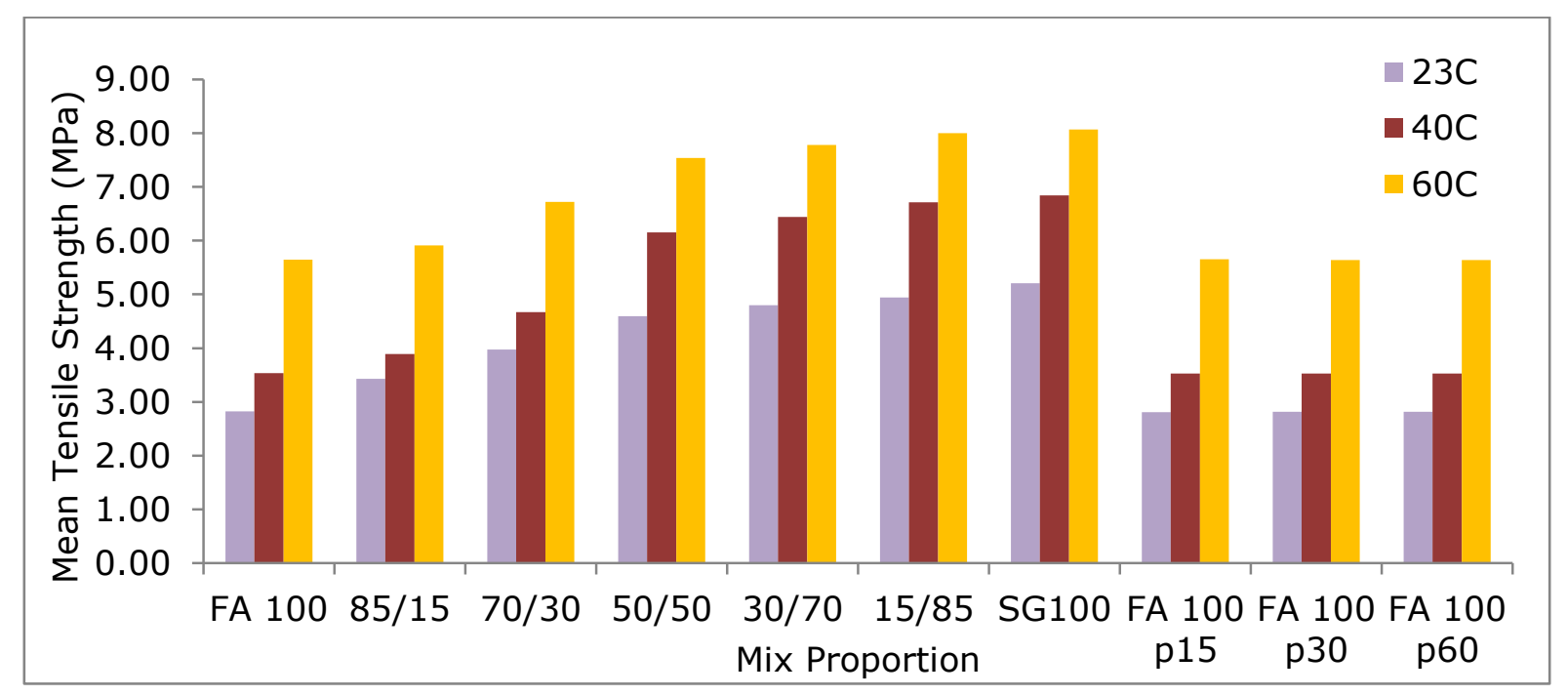

Fig. 5.13 Mean 28-day Splitting Tensile Strength for all mixes at different temperatures 
In Fig. 5.14, the comparative 90-day compressive strength values for the different mixes are shown. It was easily identified that the tensile strength values increased with increase in curing temperature.

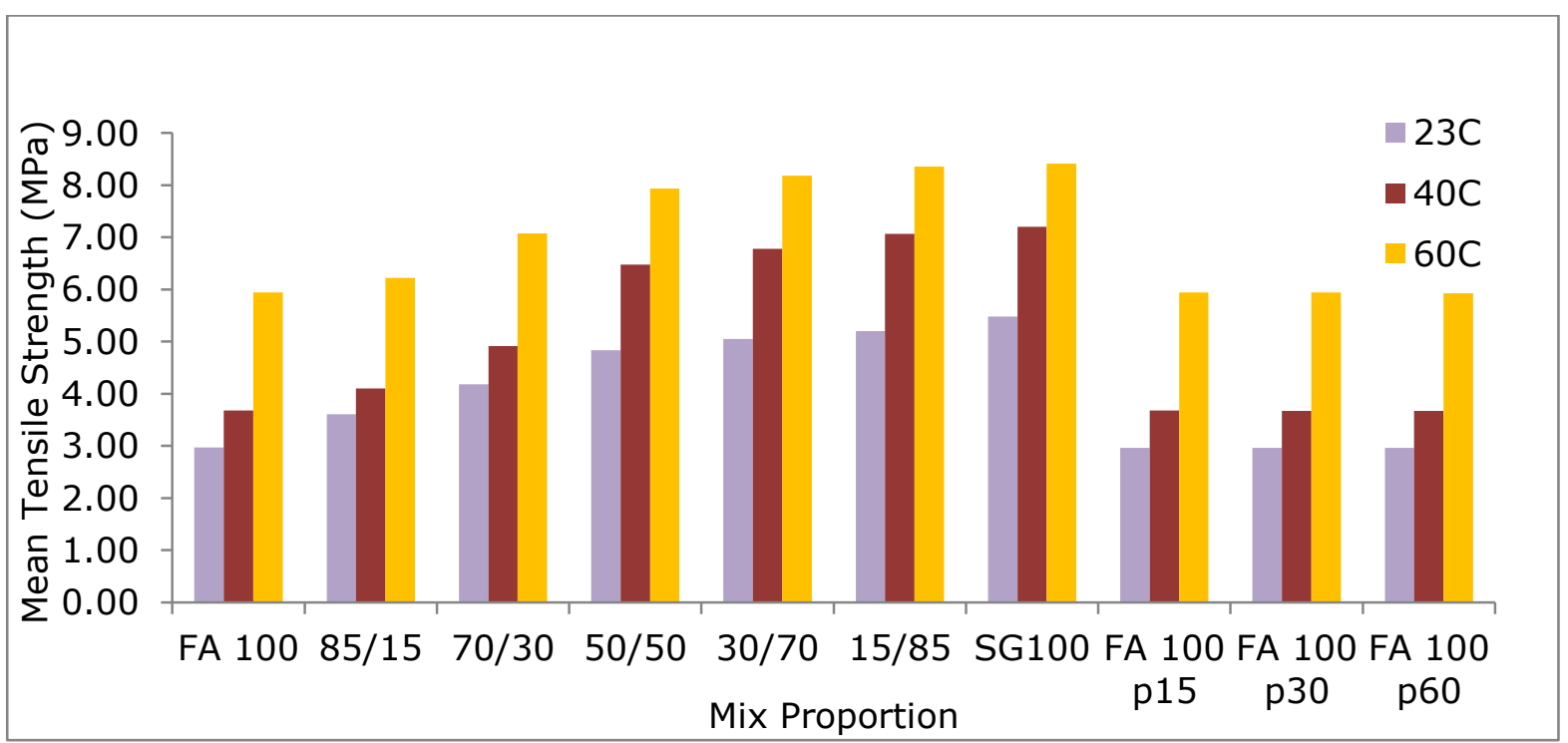

Fig. 5.14 Mean 90-day Splitting Tensile Strength for all mixes at different temperatures

In the next section, the effects of adding slag to the precursor on the splitting tensile strength have been presented.

\subsection{Effect of Slag Addition on Splitting Tensile Strength}

In Fig. 5.15, the development of tensile strength of the AAB has been shown with increasing percentages of slag in the precursor mix. It was observed that, at each curing temperature, the addition of slag had a positive effect on the tensile strength. Maximum tensile strength was achieved when fly ash was replaced fully by slag, i.e. $100 \%$ slag replacement. These observations were consistent across all ages. 


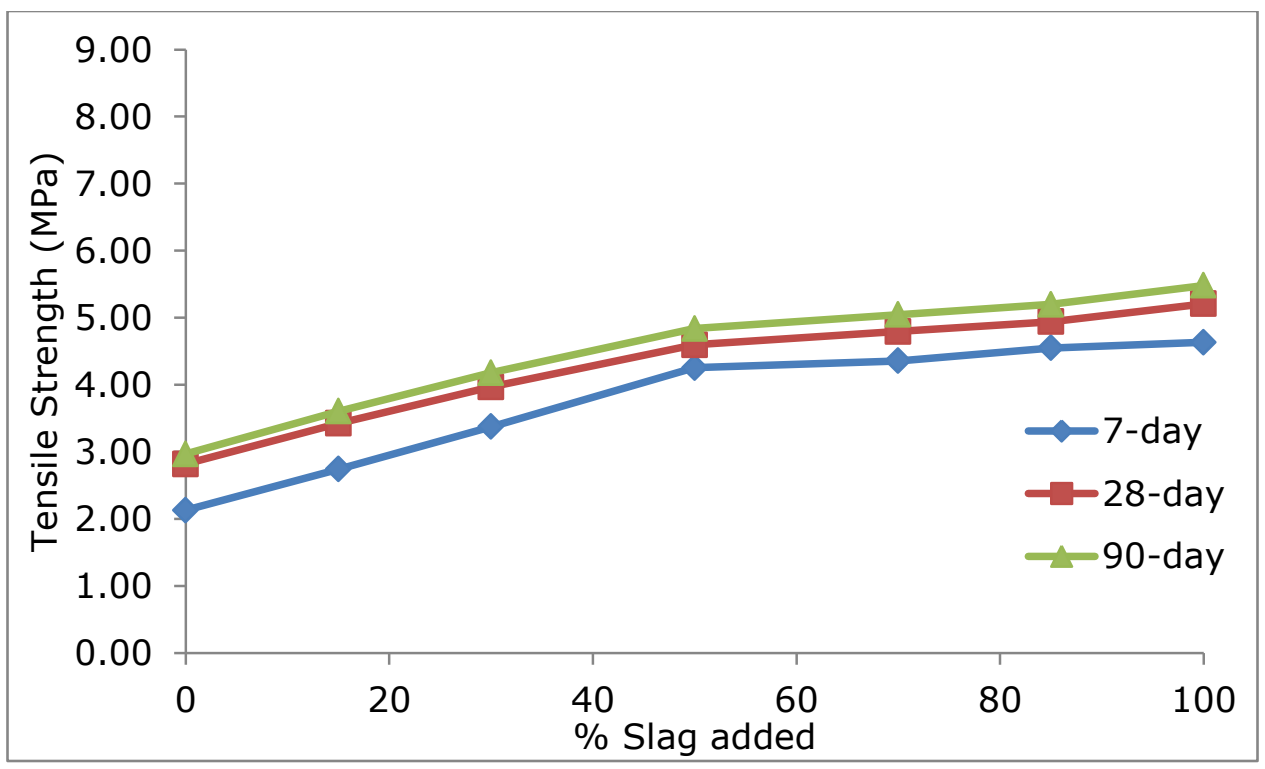

(a)

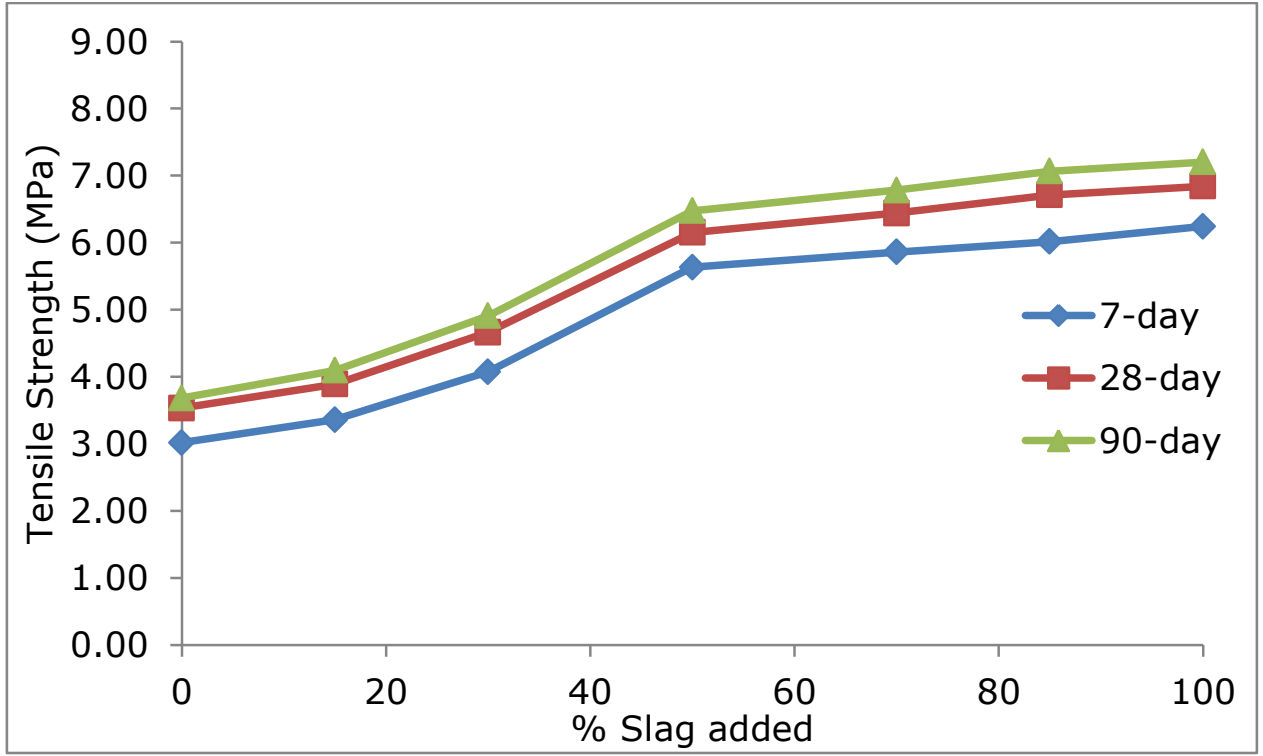

(b) 


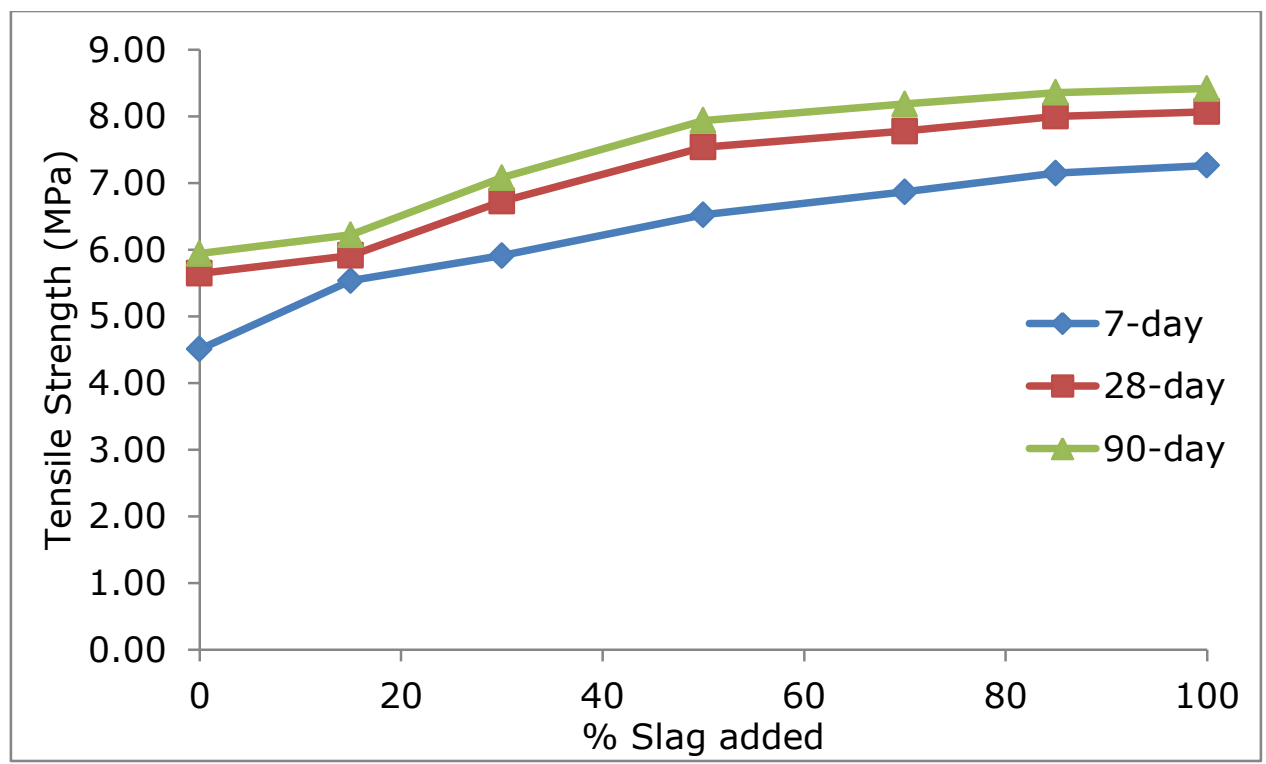

(c)

Fig. 5.15 Effect of slag addition on splitting tensile strength of $A A B$ at different temperatures: (a) $23^{\circ} \mathrm{C}$, (b) $40^{\circ} \mathrm{C}$, and (c) $60^{\circ} \mathrm{C}$.

Although compressive strength is the most commonly used characteristic property of concrete, its tensile strength is also of importance to the user during the design of structural elements such as highway and airfield slabs. In the next section, the relationship between the compressive strength and the splitting tensile strength has been described in details.

\subsection{Relation between Splitting Tensile Strength and Compressive Strength}

The tensile and compressive strengths of concrete are definitely related but there is not direct proportionality (Neville 2007). It has been observed from existing literature that the tensile strength increases with increase in compressive strength. However, the rate of increase of the tensile strength decreases with time. Different researchers have proposed different empirical formulas to establish the relationship between the tensile and compressive strengths for PC concrete.

Those equations can be generally represented as

$$
f_{t}=k\left(f_{c}^{\prime}\right)^{n}
$$


where $f_{t}$ and $f_{c}{ }^{\prime}$ denote the tensile and compressive strengths respectively and $k$ and $n$ denote coefficients of the model. ACI 318-11 (2011) suggested a value of 0.5 for $n$, based on experiments conducted on cylinders. Some researchers found a value of 0.66 for $n$ (Neville 2007). For the present study, a relationship was established between the tensile and compressive strengths of the $A A B$ through statistical regression using ' $R$ ' software package. Using nonlinear regression in $\mathrm{R}$, the equation expressing the relationship between the tensile and the compressive strengths was obtained as

$$
f_{t}=0.11\left(f_{c}{ }^{\prime}\right)^{0.97}[\text { in } \mathrm{MPa}]
$$

The mean square error was 0.0006 . Since the power of $f_{c}{ }^{\prime}$ in the above equation came out to be very close to 1.0, a new regression was obtained using $R$, and the equation expressing the linear relationship between the tensile and the compressive strengths was obtained as

$$
f_{t}^{\prime}=0.0998 * f_{c}^{\prime}[\text { in } \mathrm{MPa}]
$$

This equation gave a mean square error of 1.489218 . This mean square error can be reduced by adding an intercept to Equation 5.1c, which results in the following equation.

$$
f_{t}{ }^{\prime}=0.0975 * f_{c}{ }^{\prime}+0.1259054[\text { in } \mathrm{MPa}]
$$

This equation gave a very small mean square error of $1.972 \times 10^{-29}$. The relevant R-code has been presented below:

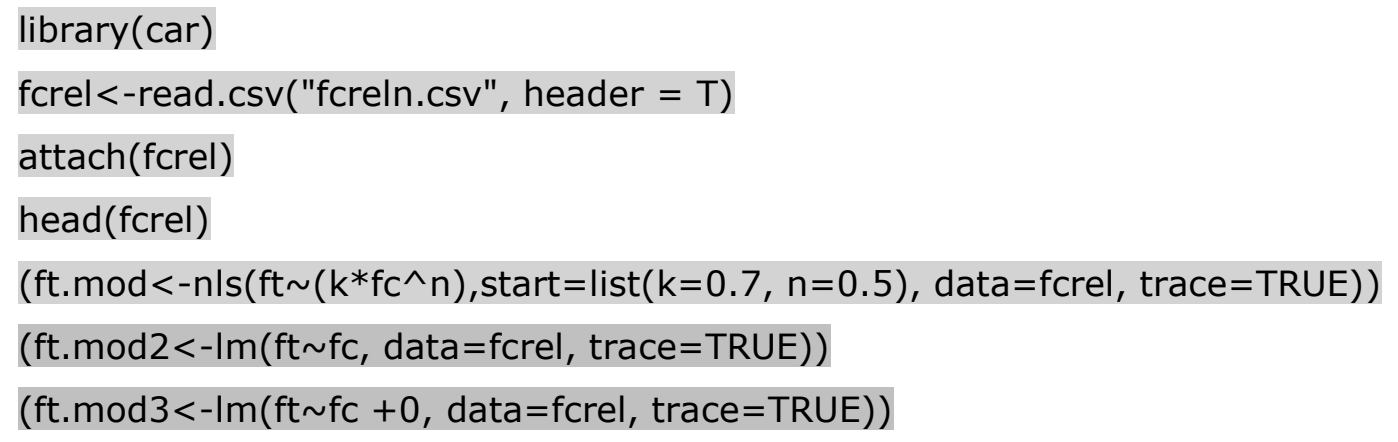

Another important characteristic that needed to be determined was the flexural strength. The experimental method and relevant results are provided in the following section.

\subsection{Modulus of Rupture}

The flexural strength values were obtained from modulus of rupture tests using $75 \mathrm{~mm}$ ( 3 in) $\times 75 \mathrm{~mm}(3 \mathrm{in}) \times 275 \mathrm{~mm}(11 \mathrm{in})($ width $\times$ depth $\times$ length $)$ prisms for $(10 * 3 * 1 * 3)=90$ specimens. The flexural strength values were obtained in accordance with ASTM 
C293/C293M-10 (Standard Test Method for Flexural Strength of Concrete (Using Simple Beam with Center-Point Loading)) on 28-day old samples for each mixture proportion. The test setup with a specimen after testing is shown in the following figure (Fig. 5.14).

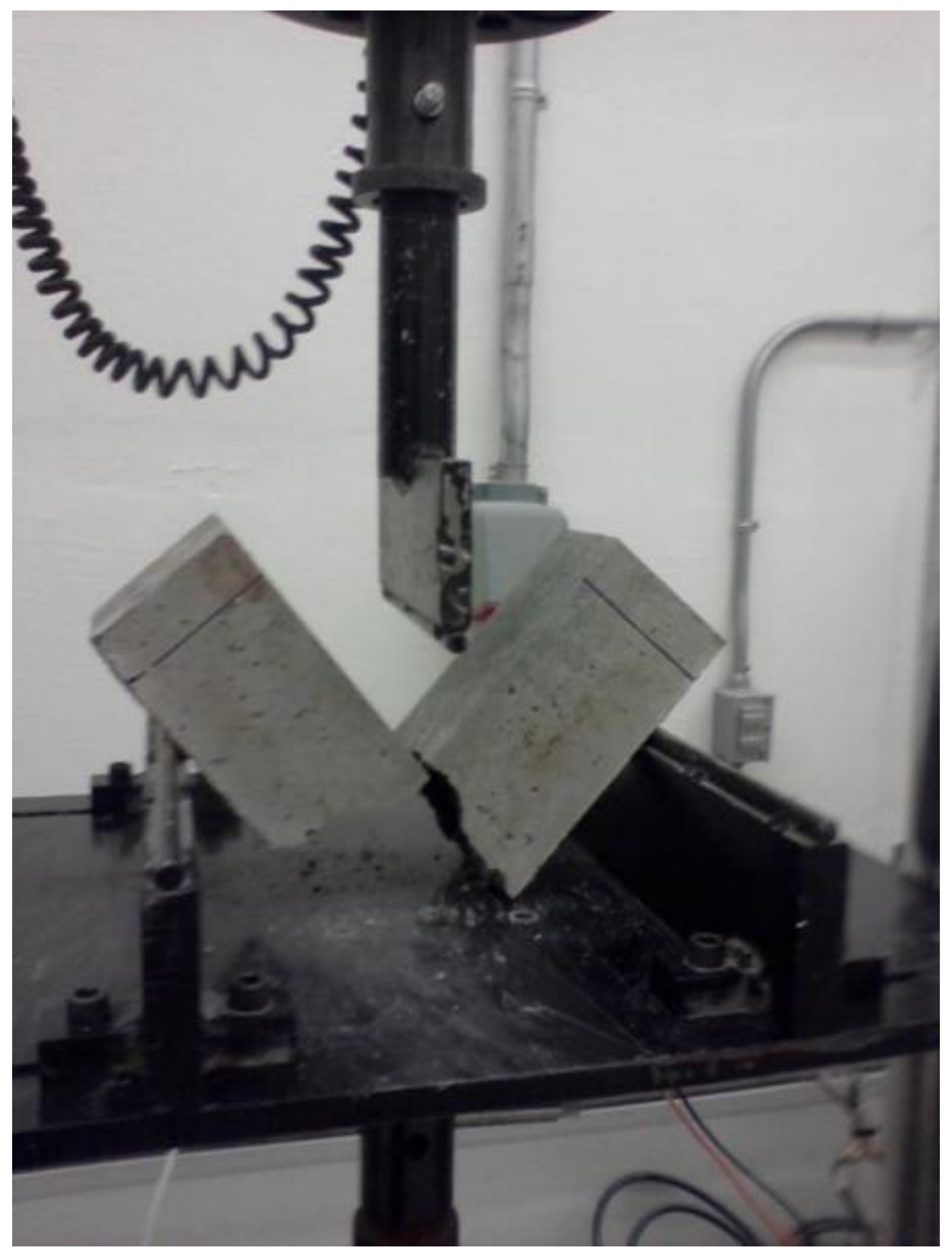

Fig. 5.16 Concrete with $A A B$ specimen after testing in three-point bending according to ASTM C293/ C293M-10

The test results are shown as follows. This test was conducted for 28-day old specimens only. The modulus of rupture (MoR) was computed using the formula suggested by ASTM C293/C293M-10 (Standard Test Method for Flexural Strength of Concrete (Using Simple Beam with Center-Point Loading)). The results of the flexural strength are summarized in Table 5.4. 
Table 5.4 Flexural Strength Results at 28 days for all AAB Cylinders Cured at Different Temperatures

\begin{tabular}{|c|c|c|c|}
\hline \multirow{2}{*}{ Mix } & \multicolumn{3}{|c|}{$\begin{array}{c}\text { Modulus of Rupture, MoR } \\
\text { (MPa [psi]) }\end{array}$} \\
\cline { 2 - 4 } & $23^{\circ} \mathrm{C}$ & $40^{\circ} \mathrm{C}$ & $60^{\circ} \mathrm{C}$ \\
\hline FA 100 & $0.625[90]$ & $1.063[150]$ & $1.223[180]$ \\
\hline FA 85 SG 15 & $0.877[130]$ & $1.276[190]$ & $1.569[230]$ \\
\hline FA 70 SG 30 & $1.745[250]$ & $2.419[350]$ & $3.022[440]$ \\
\hline FA 50 SG 50 & $3.926[570]$ & $4.442[640]$ & $6.688[970]$ \\
\hline FA 30 SG 70 & $5.421[790]$ & $6.775[980]$ & $9.646[1400]$ \\
\hline FA 15 SG 85 & $6.279[910]$ & $7.453[1080]$ & $10.842[1570]$ \\
\hline SG 100 & $8.767[1270]$ & $11.806[1710]$ & $13.288[1930]$ \\
\hline FA 100 p15 & $0.625[90]$ & $1.061[150]$ & $1.220[180]$ \\
\hline FA 100 p30 & $0.625[90]$ & $1.060[150]$ & $1.222[180]$ \\
\hline FA 100 p60 & $0.63[90]$ & $1.063[150]$ & $1.223[180]$ \\
\hline
\end{tabular}

In Fig. 5.17, the comparison between the 28-day flexural strengths of different $A A B$ mixtures cured at three different temperatures has been provided. It was observed that the flexural strength increased with increase in percentage of slag in the precursor. AAB made with fly ash as precursor showed the least flexural strength ( $0.63 \mathrm{MPa})$ while that made with slag as precursor showed the highest compressive strength (13.288 $\mathrm{MPa}$ ). This trend was evident for all the three temperatures that were studied. Preblending the fly ash with $\mathrm{NaOH}$ did not seem to have any influence on the flexural strength values.

It was also observed that the flexural strengths increased with increase in curing temperature. 


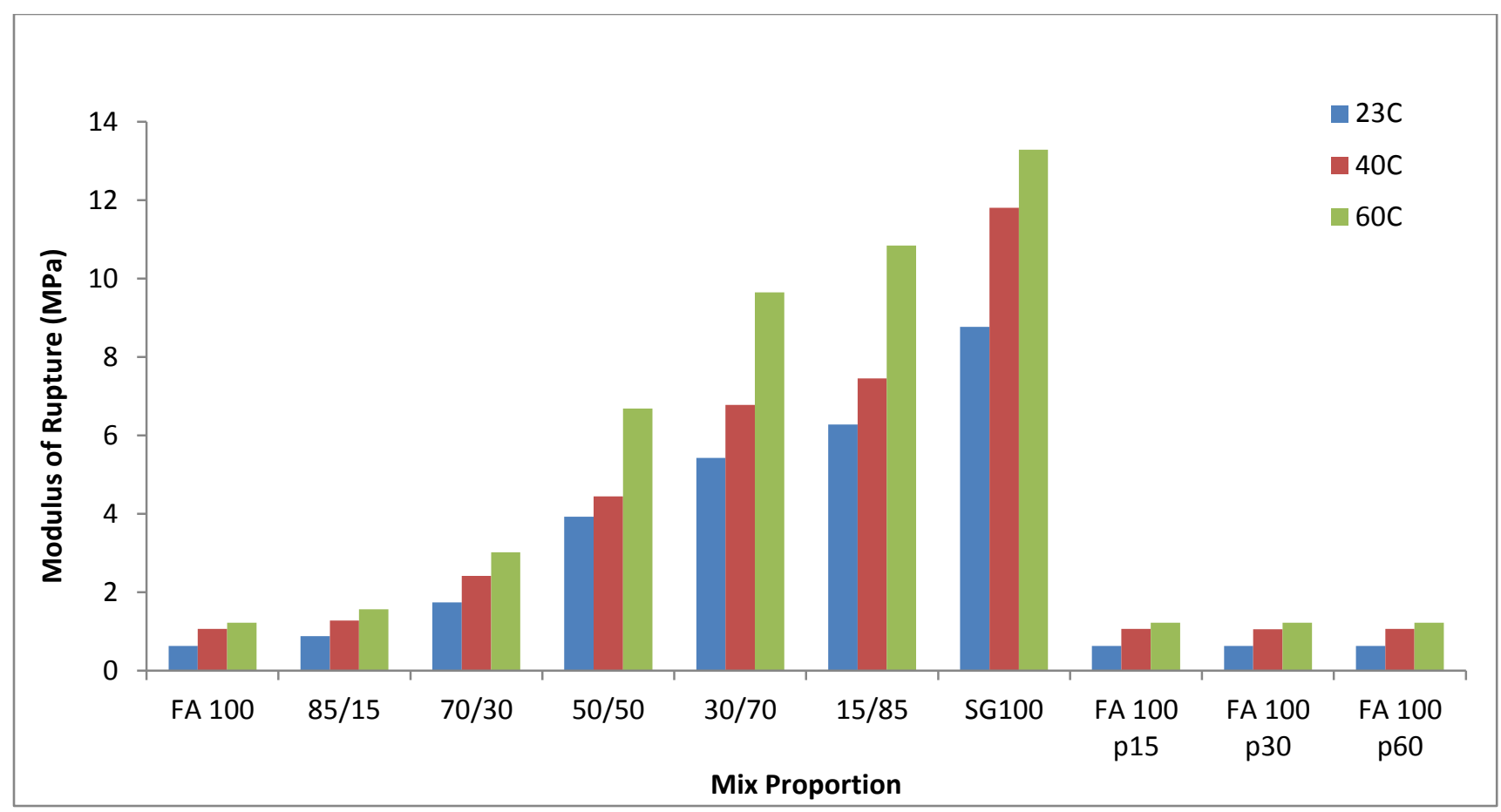

Fig. 5.17 28-day Modulus of Rupture values for all mix proportions

In the next section, the effects of adding slag to the precursor on the flexural strength have been presented.

\subsection{Effect of Slag Addition on Flexural Strength}

In Fig. 5.18, the development of flexural strength of the $A A B$ has been shown with increasing percentages of slag in the precursor mix. It was observed that, at each curing temperature, the addition of slag had a positive effect on the flexural strength. Maximum flexural strength was achieved when fly ash was replaced fully by slag, i.e. $100 \%$ slag replacement. These experiments were conducted on 28-day old specimens only. 


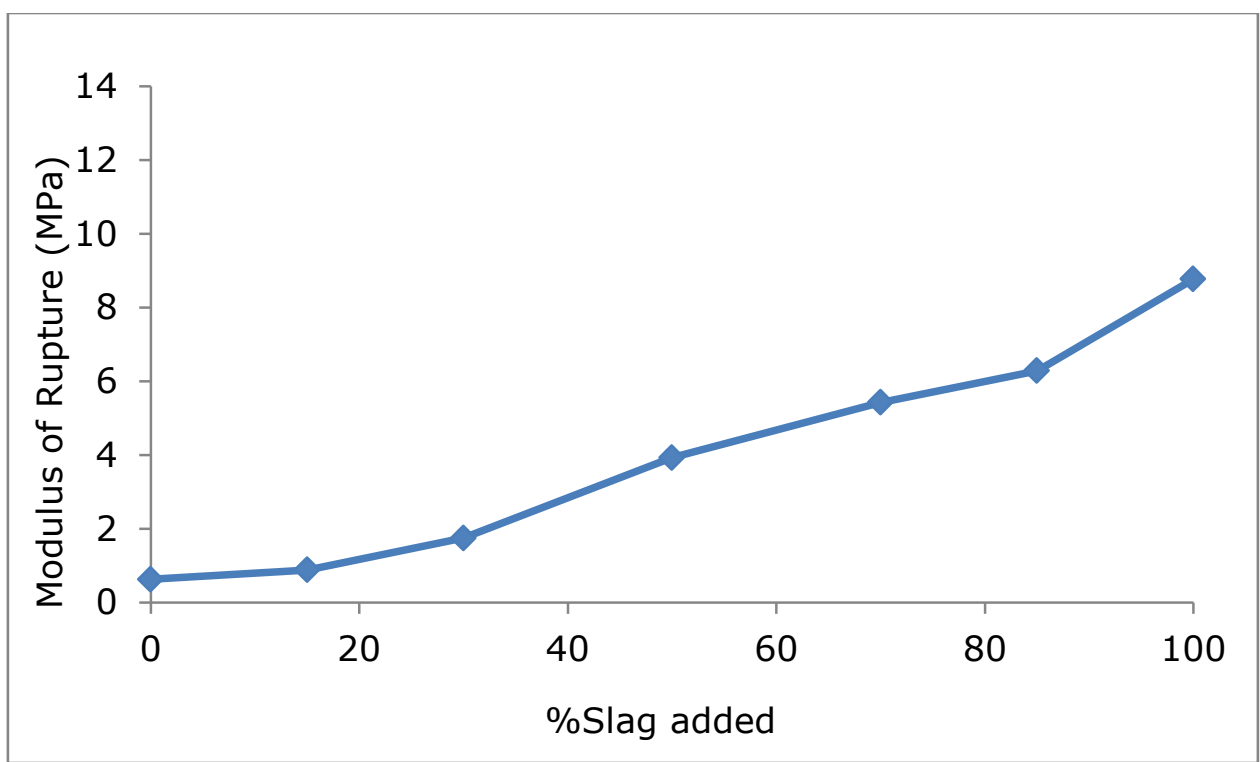

(a)

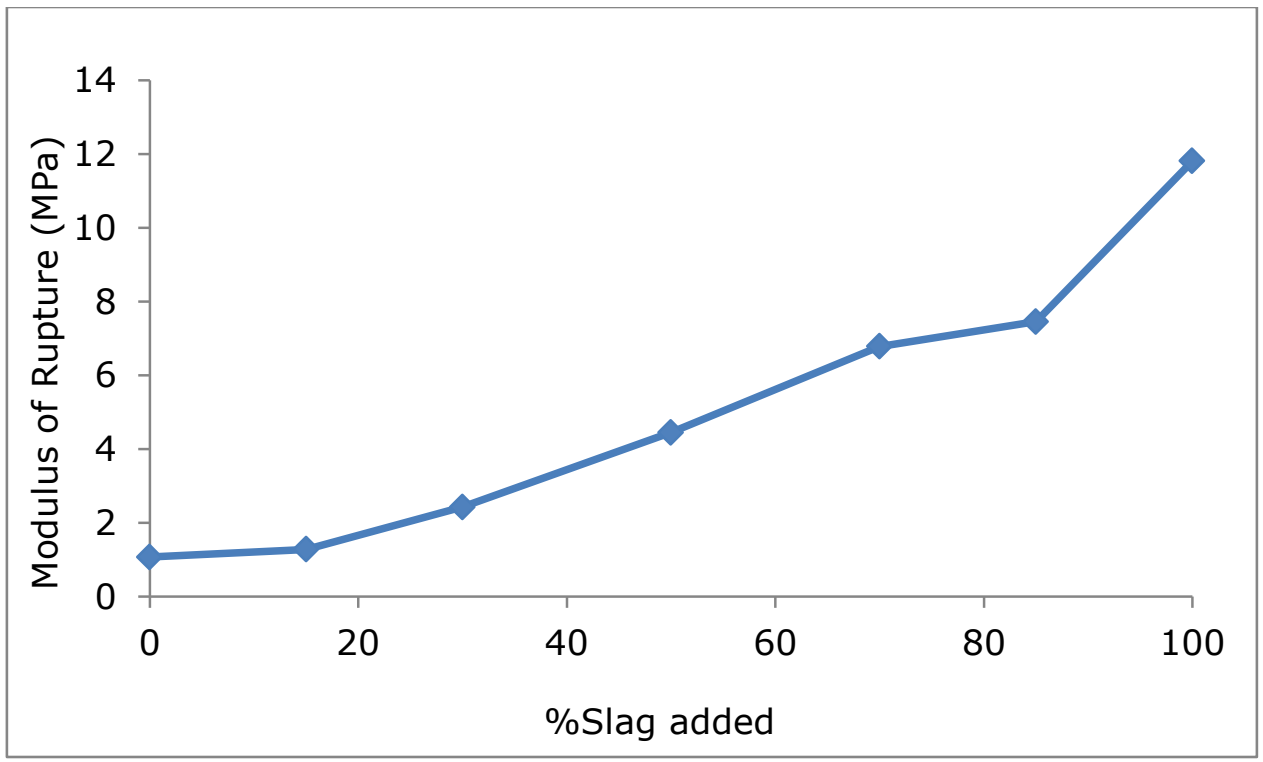

(b) 


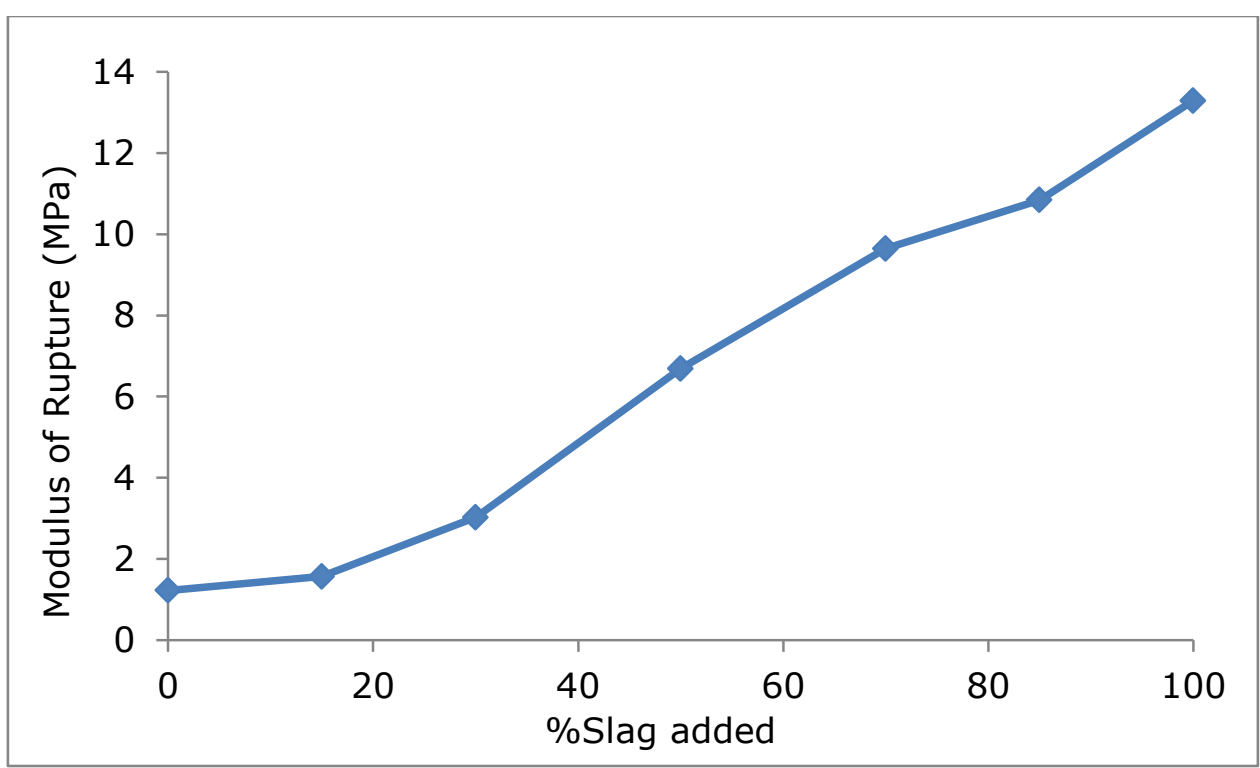

(c)

Fig. 5.18 Effect of slag addition on the flexural strength of $A A B$ at different temperatures: (a) $23^{\circ} \mathrm{C}$, (b) $40^{\circ} \mathrm{C}$, and (c) $60^{\circ} \mathrm{C}$.

In the following section, the relationship between the flexural strength and the compressive strength has been discussed elaborately.

\subsection{Relation between Flexural Strength and Compressive Strength}

Several expressions have been developed to express the relationship between the flexural and compressive strengths of PC concrete (Mindess 2002). The relationship that is used by $\mathrm{ACI}$ for PC concrete is

$$
f_{r}^{\prime}=0.6 \sqrt{ } f_{c}^{\prime}[\text { in } \mathrm{MPa}]
$$

where $\mathrm{f}_{\mathrm{r}}{ }^{\prime}$ denotes the modulus of rupture and $\mathrm{fc}^{\prime}$ denotes the compressive strength.

Similar relationship was developed in the present study to correlate the flexural strength of $A A B$ concrete with its compressive strength. Nonlinear regression was conducted using ' $\mathrm{C}^{\prime}$ statistical software package.

Using the nonlinear regression command in $\mathrm{R}$, the relationship between the flexural strength and the compressive strength was found to be

$$
f_{r}^{\prime}=0.639 \sqrt{ } f_{c}^{\prime} \quad[\text { in } \mathrm{MPa}]
$$


The mean square error was 10.18 .

The relevant $\mathrm{R}$-code was:

$<<>>=$

library(car)

fcrel<-read.csv("fcreln.csv", header = T)

attach(fcrel)

head(fcrel)

fr. $\bmod <-\operatorname{nls}\left(f r \sim\left(a * f c 28^{\wedge} 0.5\right)\right.$, start $=$ list $(a=1)$, data $=$ fcrel, trace $=$ TRUE $)$

summary(fr.mod)

(a)

On summarizing the results from the destructive tests, the following results were observed:

From Table 5.2, it can be seen that the compressive strength for FA 50 SG 50 cured at $40^{\circ} \mathrm{C}$ exceeds the compressive strength for FA 100 cured at $60^{\circ} \mathrm{C}$. This observation was true for all ages, i.e. 7 days, 28 days and 90 days. Similarly, the compressive strength for FA 30 SG 70 cured at $40^{\circ} \mathrm{C}$ exceeds the compressive strength for FA 85 SG 15 cured at $60^{\circ} \mathrm{C}$. Also, the compressive strength for SG 100 cured at $40^{\circ} \mathrm{C}$ was greater than that for FA 70 SG 30 cured at $60^{\circ} \mathrm{C}$.

From Table 5.3, it can be seen that the tensile strength for FA 50 SG 50 cured at $40^{\circ} \mathrm{C}$ exceeds the tensile strength for FA 100 cured at $60^{\circ} \mathrm{C}$. This observation was true for all ages, i.e. 7 days, 28 days and 90 days. Similarly, the tensile strength for FA 30 SG 70 cured at $40^{\circ} \mathrm{C}$ exceeds the tensile strength for FA 85 SG 15 cured at $60^{\circ} \mathrm{C}$. Also, the tensile strength for SG 100 cured at $40^{\circ} \mathrm{C}$ was greater than that for FA 70 SG 30 cured at $60^{\circ} \mathrm{C}$.

From Table 5.4, it can be seen that the flexural strength for FA 50 SG 50 cured at $40^{\circ} \mathrm{C}$ exceeds the flexural strength for FA 100 as well as FA 85 SG 15 cured at $60^{\circ} \mathrm{C}$. This observation was true for all ages, i.e. 7 days, 28 days and 90 days. Similarly, the flexural strength for FA 30 SG 70 cured at $40^{\circ} \mathrm{C}$ exceeds the flexural strength for FA 50 SG 50 cured at $60^{\circ} \mathrm{C}$. Also, the flexural strength for SG 100 cured at $40^{\circ} \mathrm{C}$ was greater than that for FA 30 SG 70 cured at $60^{\circ} \mathrm{C}$. 
Hence it can be concluded that the compressive strength, tensile strength and flexural strength of $A A B$ depends on both the curing temperature and the amount of slag in the precursor mix. The decrease in curing temperature can be compensated by replacement of fly ash with slag in the precursor mix. The user will have to decide the best combination of precursors and the corresponding curing temperature according to the locally available resources. Depending on the cost of power needed to achieve a certain curing temperature and the relative cost of adding different proportions of slag into the precursor mix, the user will have to arrive at a combination which will be best suited to his needs in terms of application as well as economy. The costs of the different materials generally vary from one location to another due to the different climates and availability of resources. So, the optimal combination of precursor and curing temperature will also depend on the location. Hence, instead of a unique optimal combination for AABs, it will be better to customize the optimal combination according to the need of the user.

$40^{\circ} \mathrm{C}$ can be achieved throughout the day and night in some places like the Indian subcontinent, mid-western Africa, Northern and North Eastern parts of South America and some islands in the Indian Ocean, which have tropical climate. $60^{\circ} \mathrm{C}$ temperature can be achieved only with the use of an oven. Hence it is suitable for precast units mainly. From the compressive strength test results, it was observed that the gain in compressive strength due to curing at $60^{\circ} \mathrm{C}$ is $19.38 \%$ of that at $40^{\circ} \mathrm{C}$. But curing at higher temperature involves high amount of energy consumption. So, it might be advisable, especially in the case of developing and under-developed countries, to compromise on the compressive strength to some extent and adopt a curing temperature of $40^{\circ} \mathrm{C}$. This approach is encouraged based on sustainability criteria.

This chapter discusses the destructive testing techniques to characterize AAB. But it is not usually possible in the field to conduct these tests. Hence it is necessary to resort to nondestructive characterizations to evaluate the behavior of structures in service. The next chapter will focus on nondestructive characterizations of AAB in details. 


\section{CHAPTER 6}

\section{PROPERTIES OF CONCRETE WITH ALKALI ACTIVATED BINDER AT SPECIMEN LEVEL: NONDESTRUCTIVE CHARACTERIZATIONS}

In this chapter, the nondestructive tests - namely, tests for ultrasonic pulse velocity and dynamic modulus of elasticity - to evaluate the characteristics of AAB at specimen level are discussed in details.

\subsection{Ultrasonic Pulse Velocity Measurements}

The present study conducted on these materials is aimed at predicting their performance when used in the field, through NDE. For this purpose, ultrasonic pulse velocity method was adopted. The pulse velocity method has been established as a reliable means of estimating properties and it provides reliable, quick, safe, inexpensive and non-invasive quality control of structural elements affected by earthquake, fatigue, conflagration or other catastrophic scenarios (Leslie \& Cheeseman, 1949; Elvery, 1973; Bungey, 1982). The velocity of ultrasonic pulses traveling in a solid depends on the density and elastic properties of the material. Hence, ultrasonic pulse velocity can often be used to assess the overall quality of a material, as well as to determine their elastic properties (Marfisi et al., 2005). Indirect estimation of parameters like compressive strength and modulus of elasticity can be achieved through measurement of ultrasonic pulse velocity, thereby avoiding the usual destructive evaluation techniques.

The testing technique involves the generation of pulses of longitudinal, elastic stress waves by an electro-acoustical transducer in direct contact with the surface of the concrete specimen being tested (Komlos et al., 1996). After traversing through the material, the pulses are received and converted into electrical energy by a second transducer. The direction in which the maximum energy is propagated is at right angles to the face of the transmitting transducer; however, it is possible to detect pulses travelling through concrete in some other direction. In other words it is possible, to make measurements of pulse velocity (BS 12504-4, 2004 and ASTM C597) by placing the two transducers on either: $a$. opposite faces - a. direct transmission, b. adjacent faces - semi-direct transmission; and c. the same face - indirect or surface transmission (Panzera et al. 2011). 

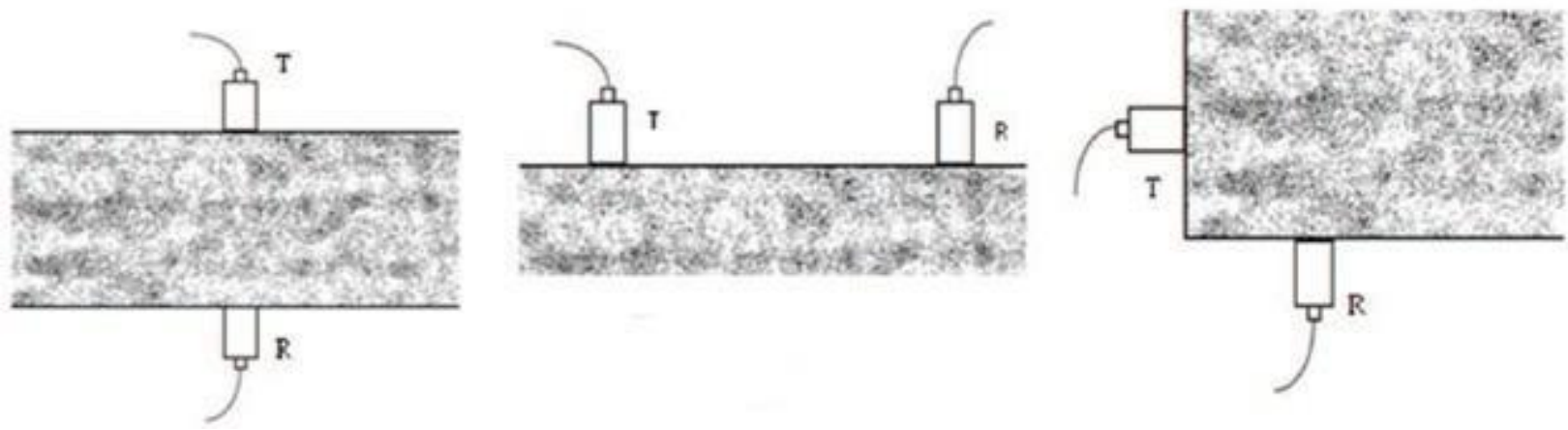

Fig. 6.1 Methods of propagating and receiving ultrasonic pulses: (a) Direct Transmission, (b) Indirect or surface Transmission, and (c) Semi-direct Transmission; ( $T$ ) = Transmitter; (R) = Receiver (Panzera et al. 2011).

Previous research shows that direct transmission is the most sensitive, and indirect transmission the least sensitive. Indirect transmission adopted only in the following cases: (i) when just one face of the structural element is accessible, (ii) when the depth of a surface defect or crack is to be determined or (iii) when the quality of the surface concrete relative to the overall quality is of interest. The velocity, $v$, is calculated from the distance, $l$, between the two transducers and the electronically measured transit time, $t$, of the pulse as:

$$
v=l / t
$$

Ultrasonic pulse velocity method is usually very helpful in detecting the presence of cracks in a structural element. The detection method works on the principle that the pulses are not transmitted through large air voids in a material. Therefore, if such a void lies directly in the pulse path the instrument will indicate the time taken by the pulse that circumvents the void by the quickest route. It is thus possible to detect large voids when a grid of pulse velocity measurements is made over a region in which these voids are located. A viscous material, such as a jelly or grease, is commonly used as a coupling agent to ensure that the vibrational energy enters the test object and can be detected by the receiving transducer (PUNDIT, 1992). A number of researchers have developed theoretical models for the prediction of relationships between pulse velocity and physic-mechanical properties, such as modulus of elasticity, compressive strength, density, porosity and permeability. Other interests are focused on the correlation between pulse velocities and cement characteristics, 
such as water/cement ratio, aggregate particle size, hydration process and curing temperature effects (Panzera et al. 2011).

In the present study, the compressive strength and the modulus of elasticity of the $A A B$ specimens were determined experimentally and the ultrasonic pulse velocities were also measured separately in direct transmission. Then theoretical approach was used to express the compressive strength and modulus of elasticity values as functions of the ultrasonic pulse velocity values. Linear regression was carried out using ' $R$ ' statistical analysis package in order to establish the relationships between the compressive strength and the ultrasonic pulse velocity as well as between the modulus of elasticity and ultrasonic pulse velocity. Finally, equations were proposed to predict the compressive strength and modulus of elasticity using the ultrasonic pulse velocities as input.

In the next step, the behavior of specimens subjected to gradually increasing compressive stress was observed. The ultrasonic pulse velocities corresponding to the applied stress was recorded. Then, equations were generated to establish the relationship between the applied compressive stress and the corresponding ultrasonic velocities.

Subsequently, in order to predict the condition of a structural element under applied stress, the present study computed the extent of loading, or what fraction of the compressive load has already been exerted on the structure, i.e., the ratio of the applied stress to the compressive strength ratio. Equations were then generated to express this ratio as a function of the ultrasonic pulse velocities.

The ultrasonic pulse velocity testing method followed the guidelines prescribed by ASTM C597-09 (Standard Test Method for Pulse Velocity Through Concrete). The ultrasonic pulse velocities were obtained from tests on $101.6 \mathrm{~mm}$ (4 in) diameter and $203.2 \mathrm{~mm}$ (8 in) long cylinders for $(10 * 3 * 3 * 2)=180$ specimens. The apparatus included transducers kept in contact with concrete, a pulse generator with a frequency in the range of 10 to $150 \mathrm{kHz}$, an amplifier, a time measuring circuit, and a digital display of the time taken by the pulse of longitudinal waves to travel between the transducers. The observations are provided in Table 6.1. 


\section{Test equipment}

The equipment used for conducting the UPV testing and signal processing in this research program were: 1) a pulse velocity tester (V-Meter II), and 2) two $150 \mathrm{kHz}$ transducers.

A pulse velocity tester (V-Meter II), manufactured by James Instruments Company, generates an ultrasonic pulse in the transmitting transducer and measures the transit time taken by the pulse to receive the receiving transducer through the medium. It gives a direct reading of the time of transmission of an ultrasonic pulse passing from a transmitting to a receiving transducer with resolutions of 0.1 micro seconds. It mainly consisted of high voltage pulse generator, which generates a high voltage pulses triggered by charging the capacitance to a high voltage; a built-in microcomputer -- central processing unit which controls all the functions and is capable of recording the delay due to the different transducers and corrections are made automatically by subtracting the delay caused; receiving amplifier which is used for amplifying the received signal; and a master clock which generates the timing pulses for the 0.1 micro sec unit.

The transducers consisted of lead zirconate titanate (PZT4) ceramic piezo electric elements mounted in stainless steel cases. The elements are very tightly held on to the inside face of the case to provide highly efficient acoustic transmission. The shock excitation of the pulse generator causes the transducer to oscillate mechanically at its own natural frequency. Different sizes of piezo-electric element and case enable different pulse frequencies to be obtained. The transducers selected for this study were $150 \mathrm{kHz}$ transducers. The adequate amount of coupling agent was applied at each location where the testing was conducted. The transducers were firmly pressed at the test location to make sure the transducers were in complete contact with the test surface so that, all the energy of the pulse is traversed directly through the concrete. 
Table 6.1 Ultrasonic Pulse Velocity Results at Different Ages for all AAB Specimens

\begin{tabular}{|c|c|c|c|c|}
\hline \multirow{2}{*}{ Mix } & \multirow{2}{*}{$\begin{array}{c}\text { Age } \\
\text { (Days) }\end{array}$} & \multicolumn{3}{|c|}{$\begin{array}{c}\text { Ultrasonic pulse velocity } \\
(\mathrm{Km} / \mathrm{s})\end{array}$} \\
\hline & & $23^{\circ} \mathrm{C}$ & $40^{\circ} \mathrm{C}$ & $60^{\circ} \mathrm{C}$ \\
\hline \multirow{3}{*}{ FA 100} & 7 & 4.04 & 4.33 & 4.69 \\
\hline & 28 & 4.33 & 4.63 & 5.21 \\
\hline & 90 & 4.37 & 4.64 & 5.28 \\
\hline \multirow{3}{*}{ FA 85 SG 15} & 7 & 4.31 & 4.64 & 5.42 \\
\hline & 28 & 4.65 & 4.65 & 5.51 \\
\hline & 90 & 4.71 & 4.69 & 5.54 \\
\hline \multirow{3}{*}{ FA 70 SG 30} & 7 & 4.63 & 4.64 & 5.69 \\
\hline & 28 & 4.94 & 4.65 & 5.70 \\
\hline & 90 & 5.23 & 4.92 & 5.82 \\
\hline \multirow{3}{*}{ FA 50 SG 50} & 7 & 5.53 & 5.51 & 5.89 \\
\hline & 28 & 5.71 & 5.55 & 5.90 \\
\hline & 90 & 5.80 & 5.59 & 6.05 \\
\hline \multirow{3}{*}{ FA 30 SG 70} & 7 & 5.62 & 5.68 & 6.12 \\
\hline & 28 & 5.82 & 5.74 & 6.13 \\
\hline & 90 & 5.85 & 5.80 & 6.26 \\
\hline \multirow{3}{*}{ FA 15 SG 85} & 7 & 5.75 & 5.75 & 6.32 \\
\hline & 28 & 5.83 & 5.85 & 6.34 \\
\hline & 90 & 5.88 & 5.87 & 6.36 \\
\hline \multirow{3}{*}{ SG 100} & 7 & 5.98 & 5.85 & 6.32 \\
\hline & 28 & 6.03 & 5.90 & 6.38 \\
\hline & 90 & 6.08 & 5.93 & 6.39 \\
\hline \multirow{3}{*}{ FA 100 p15 } & 7 & 4.04 & 4.33 & 4.69 \\
\hline & 28 & 4.33 & 4.63 & 5.21 \\
\hline & 90 & 4.37 & 4.64 & 5.28 \\
\hline \multirow{3}{*}{ FA 100 p30 } & 7 & 4.04 & 4.33 & 4.69 \\
\hline & 28 & 4.33 & 4.63 & 5.21 \\
\hline & 90 & 4.37 & 4.64 & 5.28 \\
\hline \multirow{3}{*}{ FA 100 p60 } & 7 & 4.04 & 4.33 & 4.69 \\
\hline & 28 & 4.33 & 4.63 & 5.21 \\
\hline & 90 & 4.37 & 4.64 & 5.28 \\
\hline
\end{tabular}

In the next section, the experimental procedure and test results for the dynamic modulus of elasticity have been discussed in details.

\subsection{Dynamic Modulus of Elasticity}

The dynamic modulus of elasticity values were obtained from tests using $101.6 \mathrm{~mm}$ (4 in) diameter and $203.2 \mathrm{~mm}$ ( 8 in) long cylinders for the same 180 specimens mentioned in section 6.1. The modulus of elasticity values were obtained in accordance with ASTM C21508 (Standard Test Method for Fundamental Transverse, Longitudinal, and Torsional 
Resonant Frequencies of Concrete Specimens) on 7-day, 28-day, and 90-day old samples for each mixture proportion and curing temperature.

Table 6.2 Dynamic Modulus of Elasticity Results at Different Ages for all AAB Mixes

\begin{tabular}{|c|c|c|c|c|}
\hline \multirow{2}{*}{ Mix } & \multirow{2}{*}{$\begin{array}{c}\text { Age } \\
\text { (Days) }\end{array}$} & \multicolumn{3}{|c|}{$\begin{array}{l}\text { Dynamic modulus of elasticity } \\
(\mathrm{GPa})\end{array}$} \\
\hline & & $23^{\circ} \mathrm{C}$ & $40^{\circ} \mathrm{C}$ & $60^{\circ} \mathrm{C}$ \\
\hline \multirow{3}{*}{ FA 100} & 7 & 15.5 & 18.7 & 23.5 \\
\hline & 28 & 20.3 & 21.2 & 25.6 \\
\hline & 90 & 22.2 & 21.4 & 26.6 \\
\hline \multirow{3}{*}{ FA 85 SG 15} & 7 & 17.5 & 22.3 & 26.4 \\
\hline & 28 & 20.3 & 22.4 & 26.6 \\
\hline & 90 & 22.3 & 22.5 & 26.8 \\
\hline \multirow{3}{*}{ FA 70 SG 30} & 7 & 17.6 & 22.7 & 26.6 \\
\hline & 28 & 22.0 & 23.1 & 27.4 \\
\hline & 90 & 23.2 & 23.4 & 27.5 \\
\hline \multirow{3}{*}{ FA 50 SG 50} & 7 & 18.3 & 27.0 & 27.5 \\
\hline & 28 & 23.1 & 27.2 & 28.3 \\
\hline & 90 & 23.3 & 27.4 & 29.3 \\
\hline \multirow{3}{*}{ FA 30 SG 70} & 7 & 20.9 & 27.6 & 29.6 \\
\hline & 28 & 23.5 & 27.7 & 30.6 \\
\hline & 90 & 23.6 & 27.8 & 30.9 \\
\hline \multirow{3}{*}{ FA 15 SG 85} & 7 & 21.6 & 28.1 & 30.9 \\
\hline & 28 & 23.8 & 28.5 & 31.1 \\
\hline & 90 & 23.9 & 28.7 & 31.1 \\
\hline \multirow{3}{*}{ SG 100} & 7 & 23.1 & 28.5 & 31.1 \\
\hline & 28 & 23.9 & 28.8 & 31.2 \\
\hline & 90 & 24.9 & 28.8 & 31.2 \\
\hline \multirow{3}{*}{ FA 100 p15 } & 7 & 15.5 & 18.7 & 23.5 \\
\hline & 28 & 20.3 & 21.2 & 25.6 \\
\hline & 90 & 22.2 & 21.4 & 26.6 \\
\hline \multirow{3}{*}{ FA 100 p30 } & 7 & 15.5 & 18.7 & 23.5 \\
\hline & 28 & 20.3 & 21.2 & 25.6 \\
\hline & 90 & 22.2 & 21.4 & 26.6 \\
\hline \multirow{3}{*}{ FA 100 p60 } & 7 & 15.5 & 18.7 & 23.5 \\
\hline & 28 & 20.3 & 21.2 & 25.6 \\
\hline & 90 & 22.2 & 21.4 & 26.6 \\
\hline
\end{tabular}

In the next section, the variations of dynamic modulus of elasticity with ultrasonic pulse velocities have been analyzed in depth.

\subsection{Variation of Dynamic Modulus of Elasticity with UPV}

The wave velocity, $v$, in a homogeneous, isotropic and elastic medium is related to the dynamic modulus of elasticity, $E_{c}$, by the expression: 


$$
v^{2}=\frac{E_{c}(1-\mu)}{\rho(1+\mu)(1-2 \mu)}
$$

Where $\rho$ is density and $\mu$ is Poisson's ratio (Neville, 2007).

Eqn. (6.2) can be re-written as

$$
v^{2} \propto E_{c} \text { or } v^{2}=k \cdot E_{c}
$$

where $k$ is the proportionality constant.

Density was found to be constant (as shown later in section 6.6) for each different mix and Poisson's ratio was assumed to be constant for a particular specimen. Nilsen and Aitcin (1992) showed that though the value of the Poisson's ratio cannot always be determined with absolute accuracy, it varies within a small range of 0.16 to 0.25 . The corresponding reduction in the computed value of the modulus of elasticity is only about $11 \%$ (Neville 2007). So, the above technique is of satisfactory application, particularly in field applications. The experimental results for dynamic modulus of elasticity and the corresponding ultrasonic pulse velocity results are provided in Fig. 6.2 through Fig. 6.5. The experimental data were used to formulate equations through linear regression to predict the dynamic modulus values using ultrasonic velocity values as input parameter. The results showed that the ultrasonic pulse velocities increased with increasing modulus of elasticity. In general, higher values of modulus of elasticity were obtained at higher temperatures. Equations were obtained using ' $\mathrm{R}$ ' for the variation of modulus of elasticity, $E_{c}$, with the square of the ultrasonic pulse velocities, $v^{2}$. Eqn. (6.3) shows that theoretically the linear relationship between $v^{2}$ and $E_{c}$ can be represented by a straight line passing through the origin. But that requires a regression regime forcing intercept to be zero. Consequently, $\mathrm{R}^{2}$ cannot be used as a measure of accuracy of the prediction model (Eisenhauer, 2003). Hence, the sum of squares due to errors $\left(\mathrm{SS}_{\mathrm{E}}\right)$ are used as a measure of accuracy, and models with and without intercepts were developed to test which form of the equation produces lesser $\mathrm{SS}_{\mathrm{E}}$ (Table 6.3).

Similar equations (with and without intercepts) were also obtained to express linear relationship between $E$ and $v$. This provided a simpler form of the model. Relationships were obtained for each of the three curing temperatures and another set of equations were generated for all the mixture proportions taken together. 


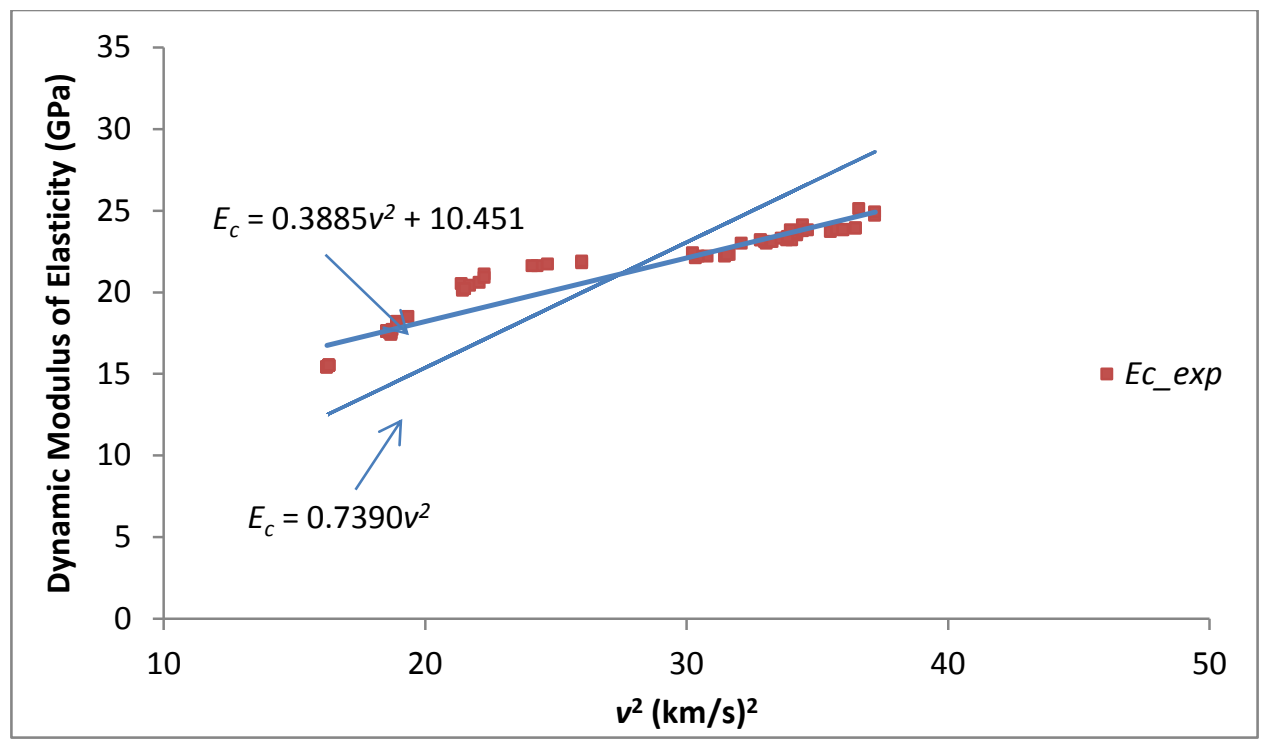

(a)

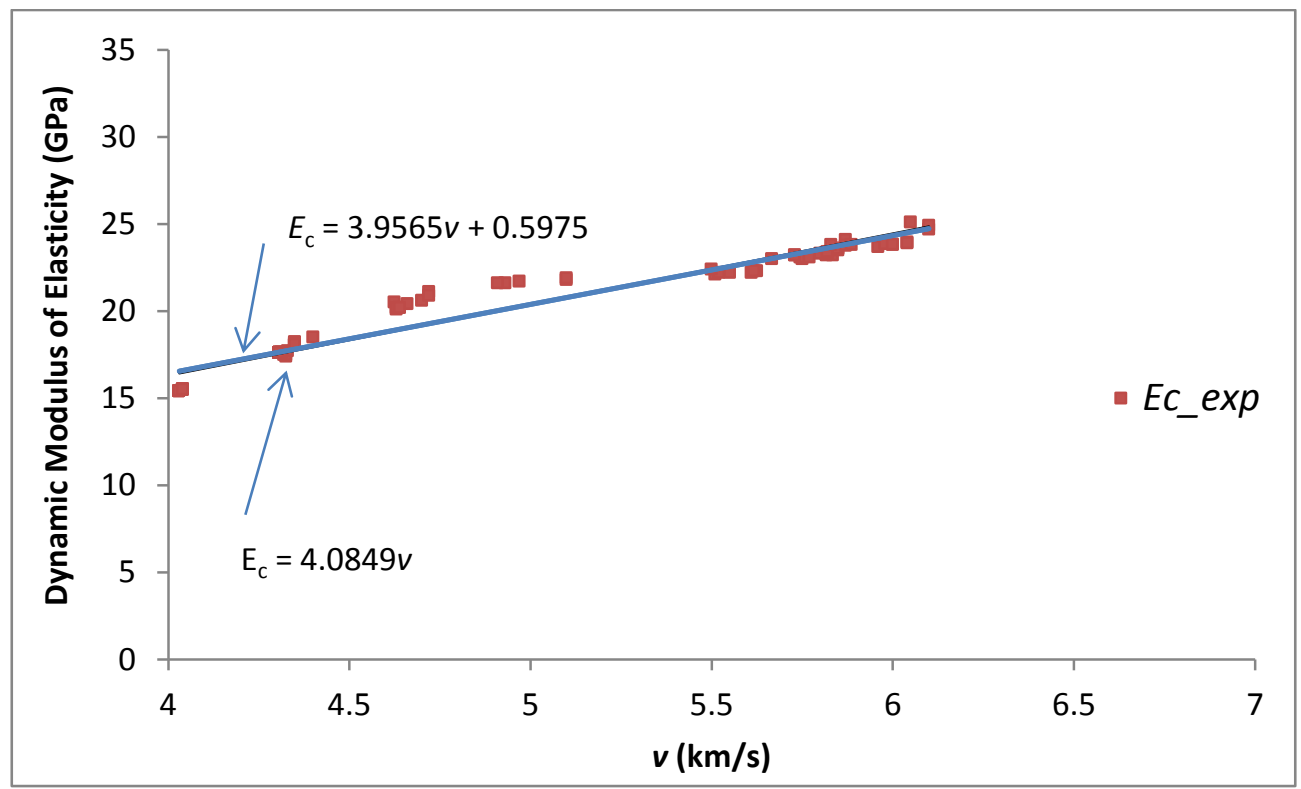

(b)

Fig. 6.2 (a) Variation of $E_{c}$ vs. $v^{2}$ for all specimens and (b) Variation of $E_{c}$ vs. $v$ for all AAB mixes cured at $23^{\circ} \mathrm{C}$ 


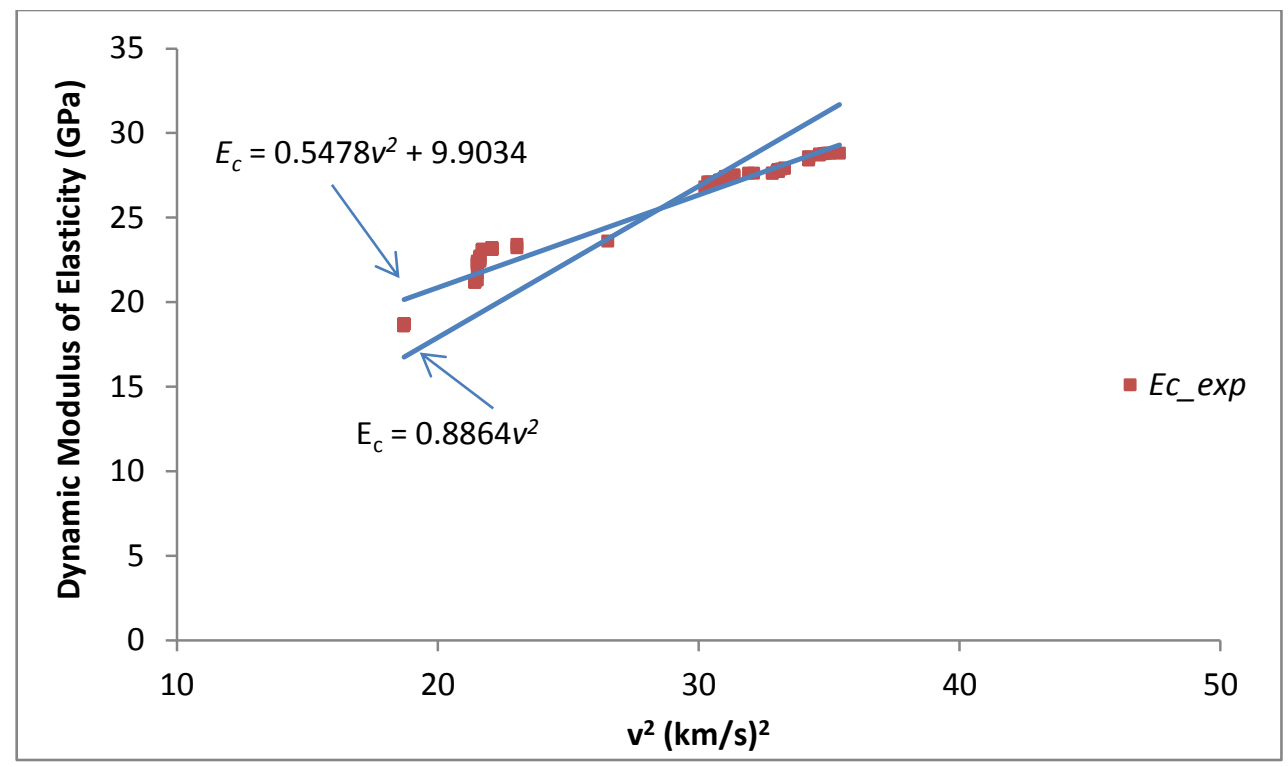

(a)

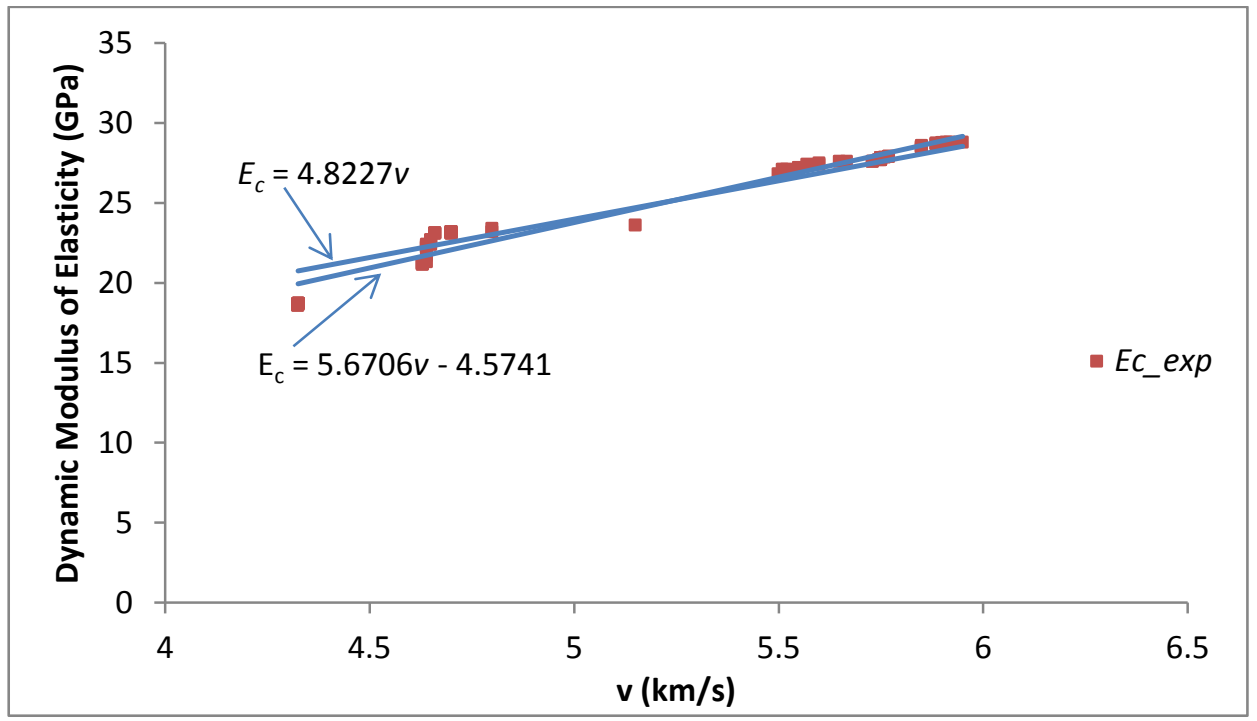

(b)

Fig. 6.3 (a) Variation of $E_{c}$ vs. $v^{2}$ for all specimens and (b) Variation of $E_{c}$ vs. $v$ for all AAB mixes cured at $40^{\circ} \mathrm{C}$ 


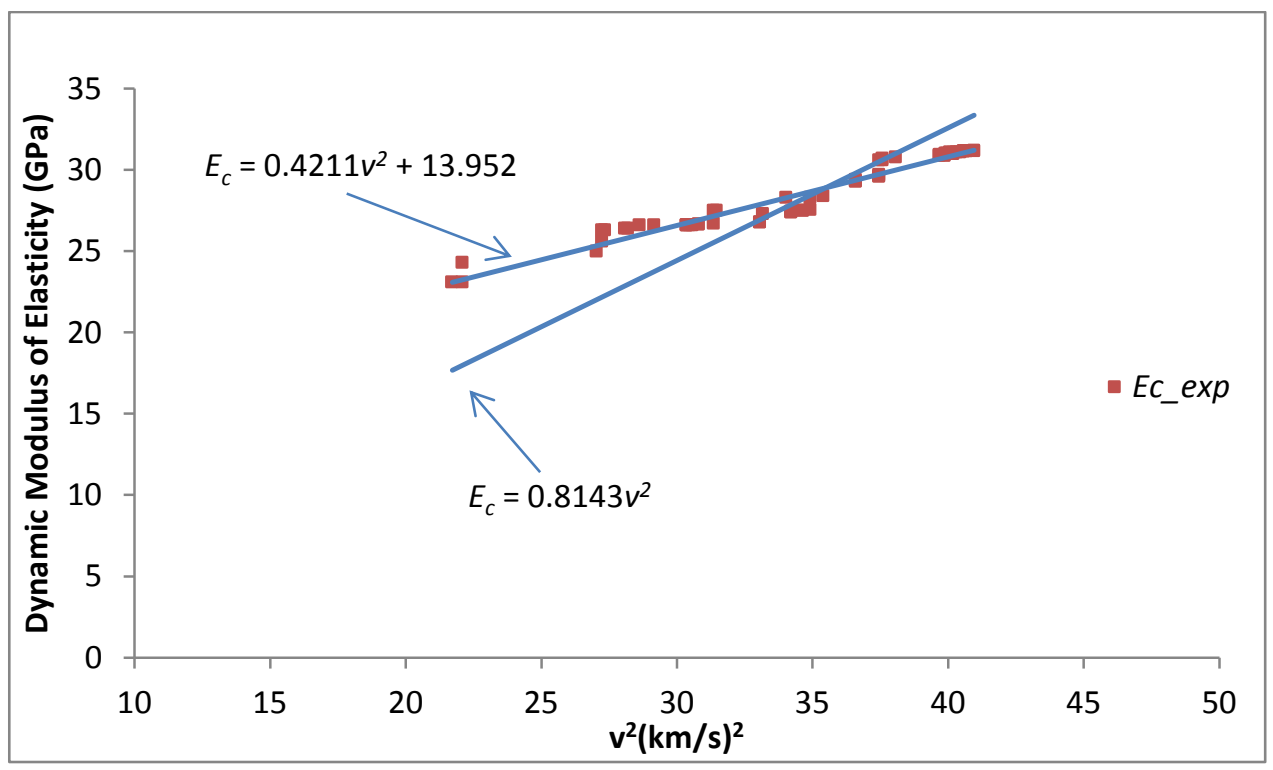

(a)

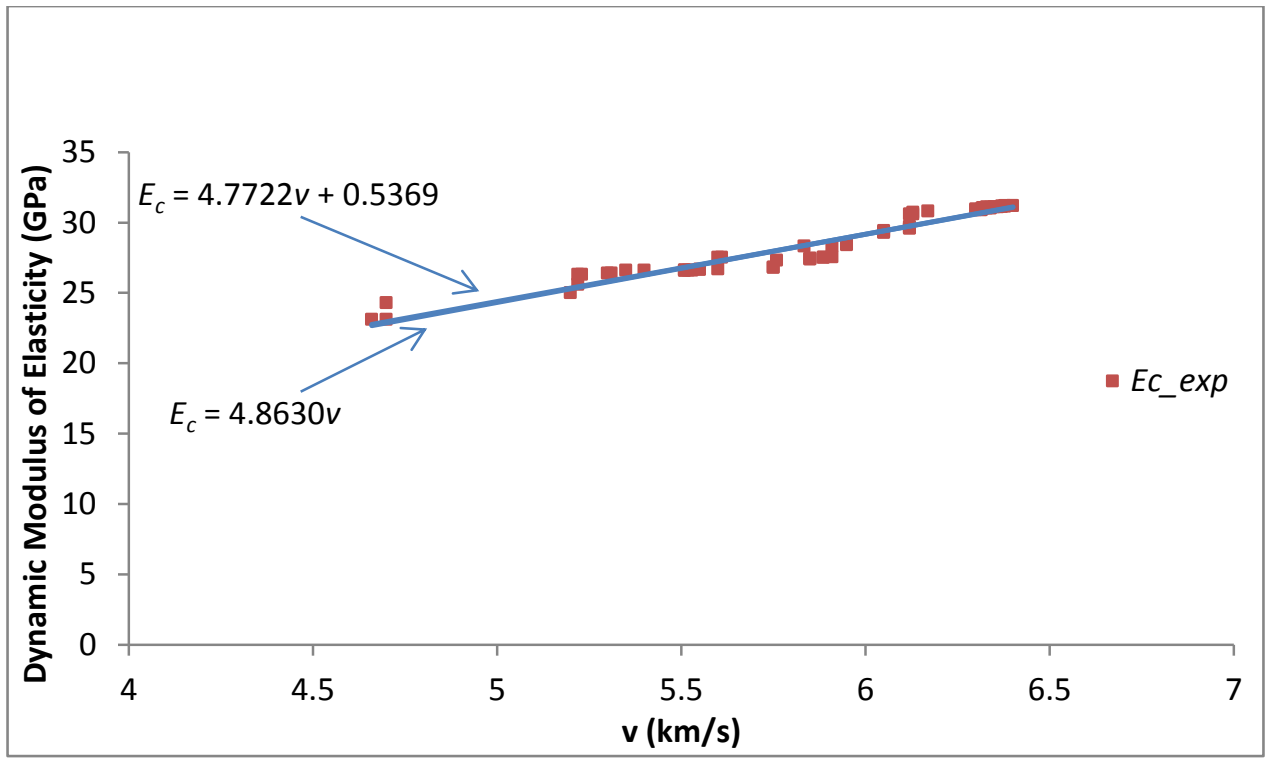

(b)

Fig. 6.4 Variation of $E_{c}$ vs. $v^{2}$ for all specimens and (b) Variation of $E_{c}$ vs. $v$ for all AAB mixes cured at $60^{\circ} \mathrm{C}$ 


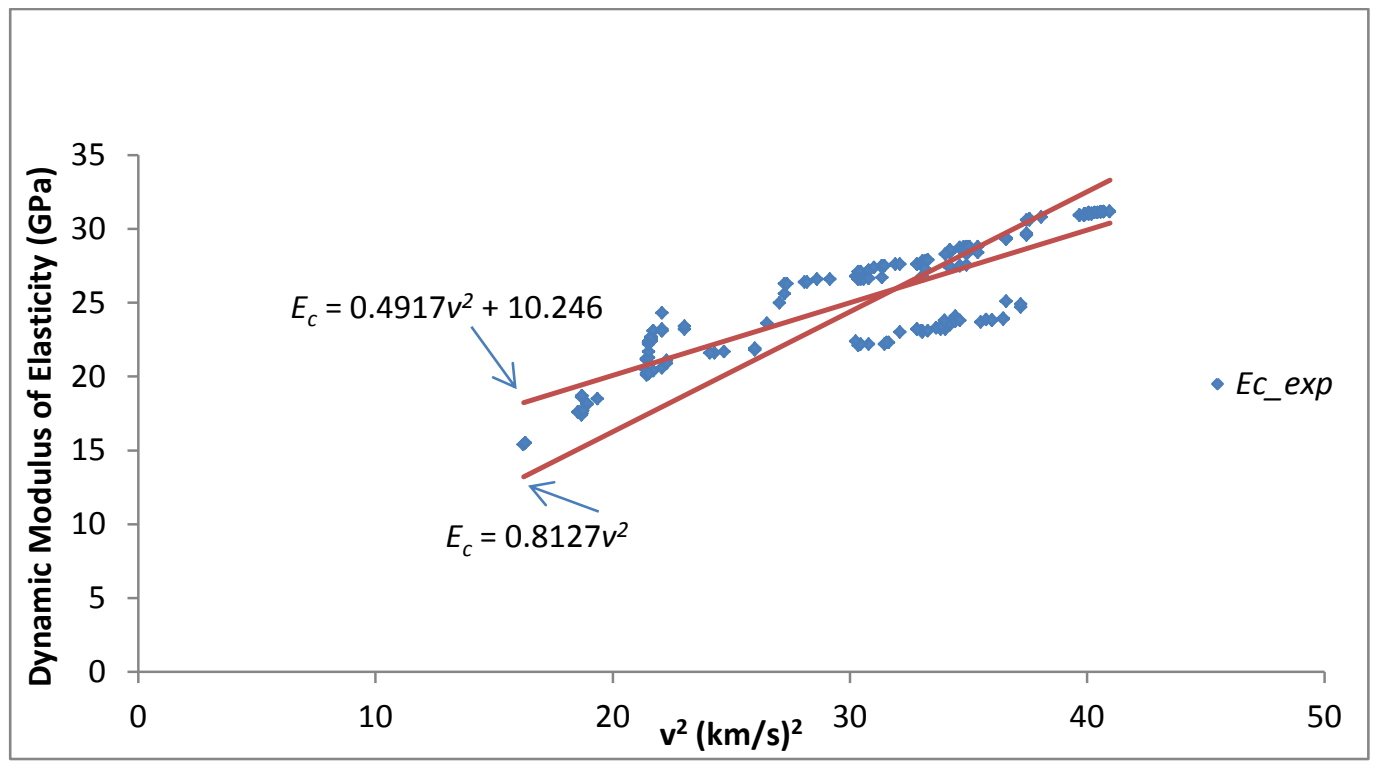

(a)

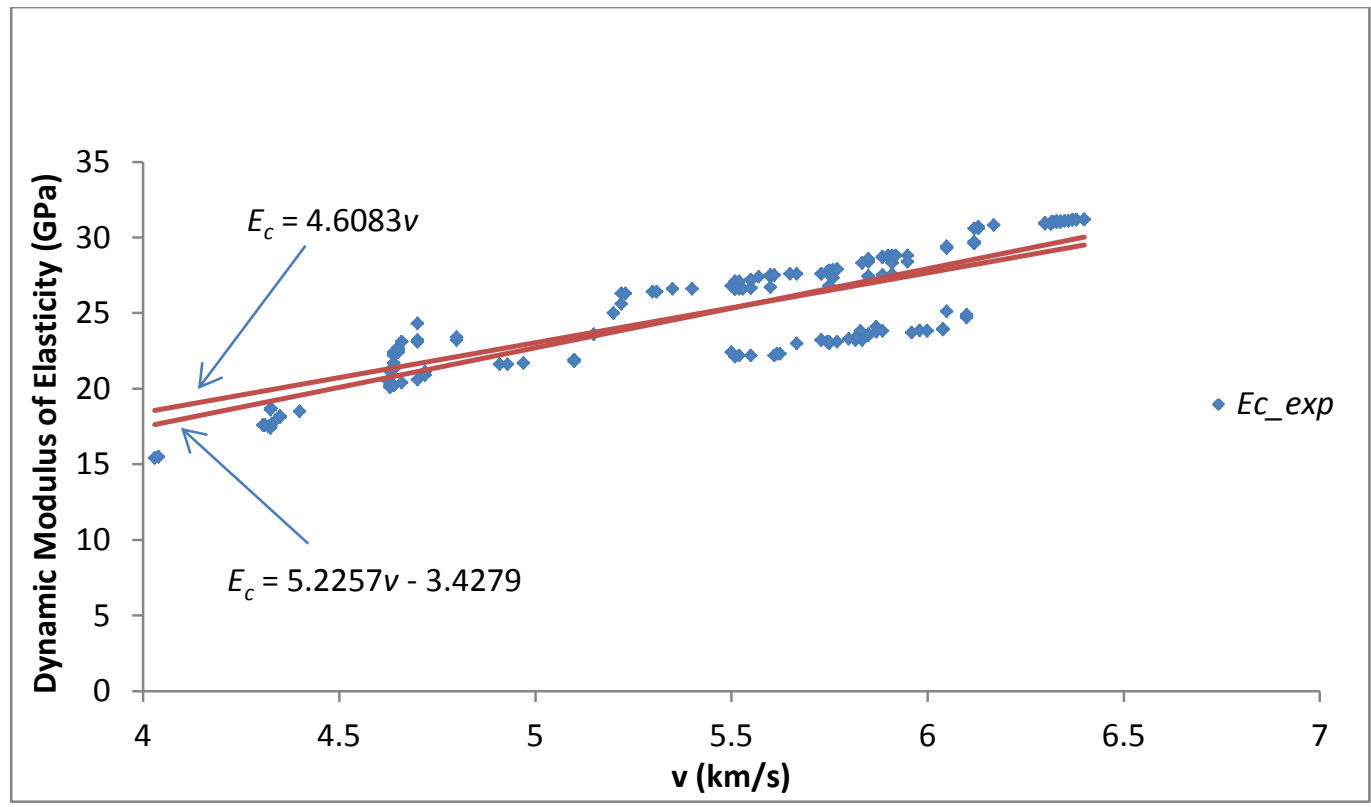

(b)

Fig. 6.5 (a) Variation of $E_{c}$ vs. $v^{2}$ for all specimens and (b) Variation of $E_{c}$ vs. $v$ for all specimens 
The different equations for the cases mentioned above have been provided in the Table 6.3, along with their corresponding $\mathrm{SS}_{\mathrm{E}}$ values.

Table 6.3 Variation of $E_{c}$ vs. $v^{2}$ and $E_{c}$ vs. $v$

\begin{tabular}{|c|c|c|}
\hline Temperature & $\begin{array}{l}\text { Equation without } \\
\text { intercept }\left(\mathrm{SS}_{\mathrm{E}}\right)\end{array}$ & Equation with intercept $\left(\mathrm{SS}_{\mathrm{E}}\right)$ \\
\hline \multirow{2}{*}{$23^{\circ} \mathrm{C}$} & $E_{c}=0.7390 v^{2}(858.33)$ & $E_{c}=0.3885 v^{2}+10.451(61.51)$ \\
\hline & $E_{c}=4.0849 \mathrm{~V}(48.92)$ & $E_{c}=3.9565 v+0.5975(48.22)$ \\
\hline \multirow{2}{*}{$40^{\circ} \mathrm{C}$} & $E_{c}=0.8864 v^{2}(495.52)$ & $E_{c}=0.5478 v^{2}+9.9034(56.86)$ \\
\hline & $E_{c}=4.8227 \mathrm{~V}(73.44)$ & $E_{c}=5.6706 \mathrm{~V}-4.5741(46.77)$ \\
\hline \multirow{2}{*}{$60^{\circ} \mathrm{C}$} & $E_{c}=0.8143 v^{2}(289.52)$ & $E_{c}=0.4211 v^{2}+13.9520(17.38)$ \\
\hline & $E_{c}=4.8630 \mathrm{~V}(20.72)$ & $E_{c}=4.7722 v+0.5369(20.61)$ \\
\hline \multirow{2}{*}{ All specimens } & $E_{c}=0.8127 v^{2}(1703.69)$ & $E_{c}=0.4917 v^{2}+10.2460(775.63)$ \\
\hline & $E_{c}=4.6083 \mathrm{~V}(800.65)$ & $E_{c}=5.2257 \mathrm{~V}-3.4279(771.24)$ \\
\hline
\end{tabular}

In order to understand the effects of the different curing temperatures, different equations were developed for each curing temperature. However, if the curing temperature is unknown during field applications, then the user can utilize the general equation obtained for all specimens taken together. For each of the cases, it was noticed that the equations obtained in case of $E_{c}$ expressed as $f(v)$ showed lesser $\mathrm{SS}_{\mathrm{E}}$ values than the corresponding equations which expressed $E_{c}$ as $f\left(v^{2}\right)$ in most cases. Also, the equations with intercept resulted in lower $\mathrm{SS}_{\mathrm{E}}$ values compared to the corresponding equations without intercept.

\section{Sample codes from $\mathbf{R}$}

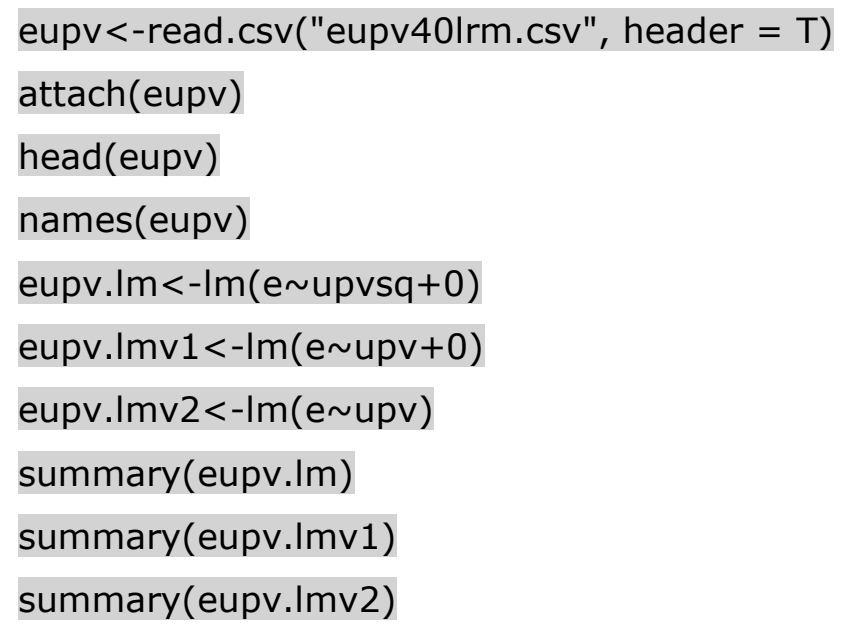


Different sets of equations were obtained in order to express the relationship between the modulus of elasticity values and the ultrasonic pulse velocities, for each of the three different curing temperatures, as well as for all the specimens considered together. The last set of equations would be useful if the curing temperature is unknown. In the field, it might be useful for the engineer to measure the ultrasonic pulse velocity at different locations on a structural element made out of the $A A B$. The suggested equations can then be used to predict the modulus of elasticity at the corresponding locations. These values can be used to detect the presence of deterioration in the structure. The modulus of elasticity values increase with increasing ultrasonic pulse velocities. Hence, the presence of low values of the pulse velocity at any location in the structure, compared to its neighboring locations will indicate low modulus of elasticity at that location. This will indicate the presence of deterioration to the field engineer.

The ultimate objective in the field may be to predict the load bearing capacity and hence, the compressive strength of a structure or to detect the presence of possible deterioration in the structure. The compressive strength cannot be directly measured in the field because that will involve cutting cores from the structure and testing them individually. Hence, alternative nondestructive techniques have to be adopted to determine the compressive strength values as discussed in the following section.

\subsection{Variation of Compressive Strength with UPV}

It has been established by researchers that the modulus of elasticity of concrete increases with its compressive strength, but there are different theories on the exact relationship between these two parameters. The expression for the modulus of elasticity of concrete, $E_{c \prime}$ in psi units, recommended by ACI 318-11: Building Code Requirements for Structural Concrete and Commentary, for structural calculations, applicable to normal weight concrete, is

$$
E_{c}=57000 \sqrt{f^{\prime}}{ }_{c}
$$

Where $f^{\prime}{ }_{c}$ is the compressive strength of standard test cylinders in psi units (Neville 2007).

The above expression can be rewritten as

$$
{f^{\prime}}_{c} \propto E_{c}^{2}
$$

Combining Eqns. (6.3) and (6.5), 


$$
f_{c}^{\prime} \propto v^{4}
$$

The present study aims at establishing an equation to correlate the compressive strength and the ultrasonic pulse velocity. So, in the field, if the ultrasonic pulse velocity is measured at different locations in a structure, the compressive strength values can be predicted. Thus, the load bearing capacity of the structure can be estimated. Moreover, if the estimated values show some anomalies at certain locations, the possibility of deterioration due to cracks can be determined.

The relationship between the modulus of elasticity and the compressive strength as mentioned earlier, holds good for PC concrete. As the present study deals with a different material, it is necessary to establish a different set of equations to describe the relationship between the modulus of elasticity and the compressive strength for this new material. The parameter that is measured in the field is the ultrasonic pulse velocity. The present study develops equations to express the modulus of elasticity as a function of the ultrasonic pulse velocity and also the compressive strength as a function of the ultrasonic pulse velocity. Theoretically, the modulus of elasticity is proportional to the square of the ultrasonic pulse velocity and the compressive strength is proportional to the fourth power of the ultrasonic pulse velocity. Hence the present study expresses $E_{c}=f\left(v^{2}\right)$ and $f_{c}^{\prime}=f\left(v^{4}\right)$. However, if the predicted values of the $E_{c}$ or the $f_{c}{ }^{\prime}$ (determined by expressing them as functions of $v$ ) lies on the linear region of their respective curves, then $E_{c}$ or $f_{c}{ }^{\prime}$ will both be linearly correlated with $v$. As a result, the present study expresses $E_{c}=f(v)$ and $f_{c}{ }^{\prime}=f(v)$ in addition to the expressions already mentioned. The latter case was considered in order to obtain a simpler model. Also, Eqn. (6.6) shows that theoretically the linear relationship between $v^{4}$ and $f_{c}{ }^{\prime}$ can be represented by a straight line passing through the origin. But that requires regression through origin and $\mathrm{R}^{2}$ cannot be used as a measure of accuracy of the prediction model (Eisenhauer, 2003). Hence, the sum of squares due to errors $\left(S_{E}\right)$ are used as a measure of accuracy, and models with and without intercepts were developed to test which form of the equation produces lesser $\mathrm{SS}_{\mathrm{E}}$ (Table 6.4).

Different graphs were obtained for the three different curing temperatures used in the study. In addition, another set of equations and graphs are provided in the case of the compressive strength data for all the specimens taken together irrespective of the curing temperature. This is of great use in predicting the compressive strength from the ultrasonic 
pulse velocity value when the curing temperature is unknown. The variations of the compressive strength with ultrasonic pulse velocities have been presented in the following plots (Figs. 6.6 through 6.9). The results showed that the ultrasonic pulse velocities increased with increasing compressive strength. In general, higher values of compressive strength were obtained at higher temperatures. The highest compressive strength was obtained for the 90 -day age specimens cured at $60^{\circ} \mathrm{C}$ for 24 hours.

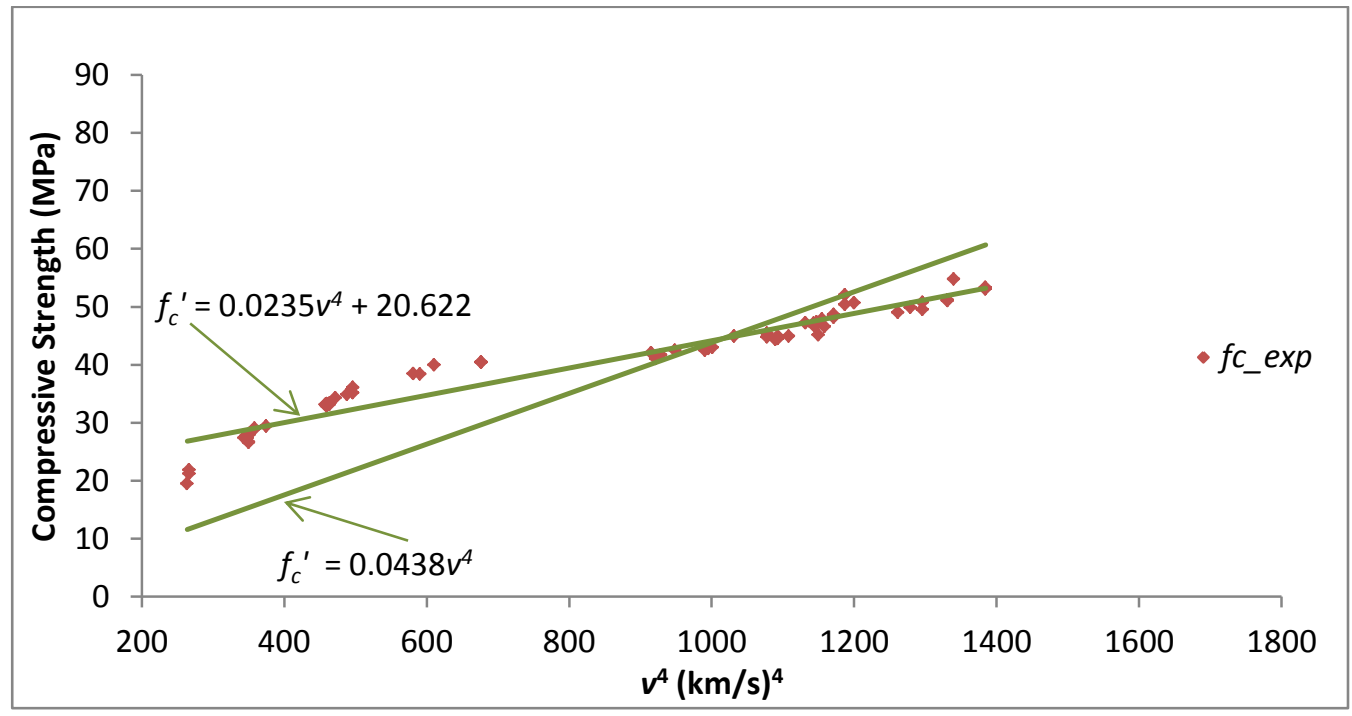

(a)

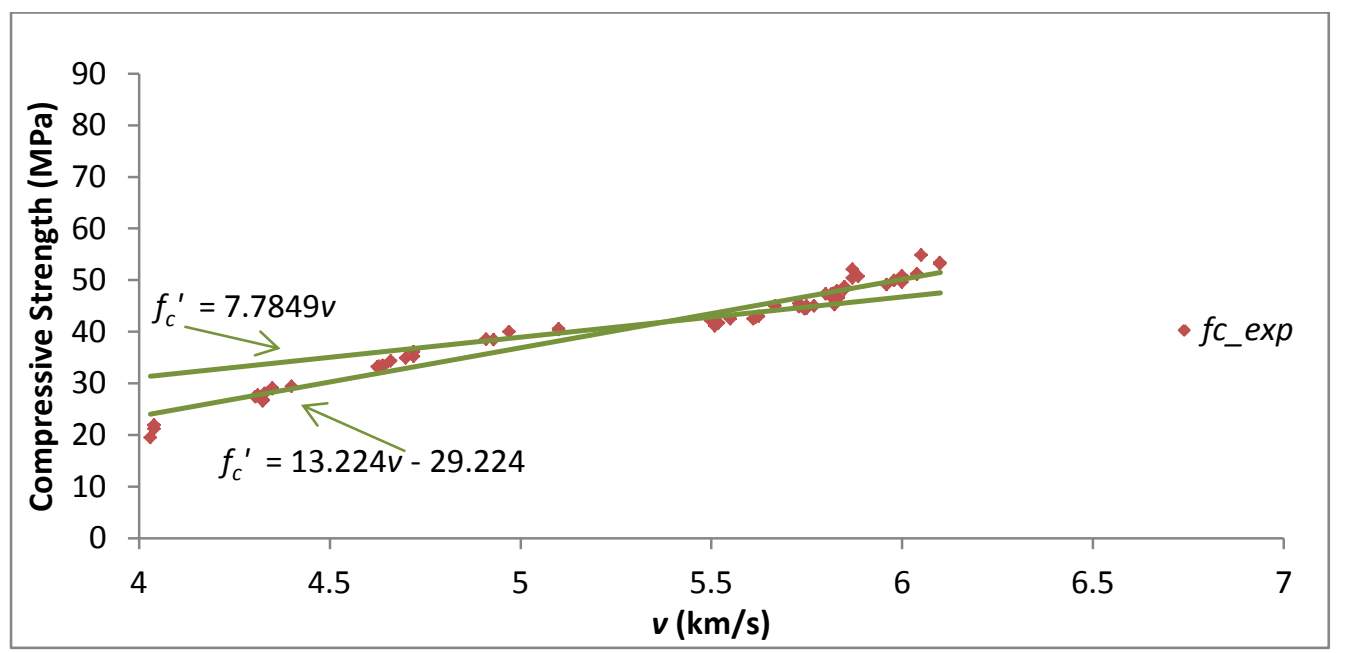

(b)

Fig. 6.6 (a) Variation of $f_{c}{ }^{\prime}$ vs. $v^{4}$ for all specimens and (b) Variation of $f_{c}{ }^{\prime} v s . v$ for AAB mixes cured at $23^{\circ} \mathrm{C}$ 


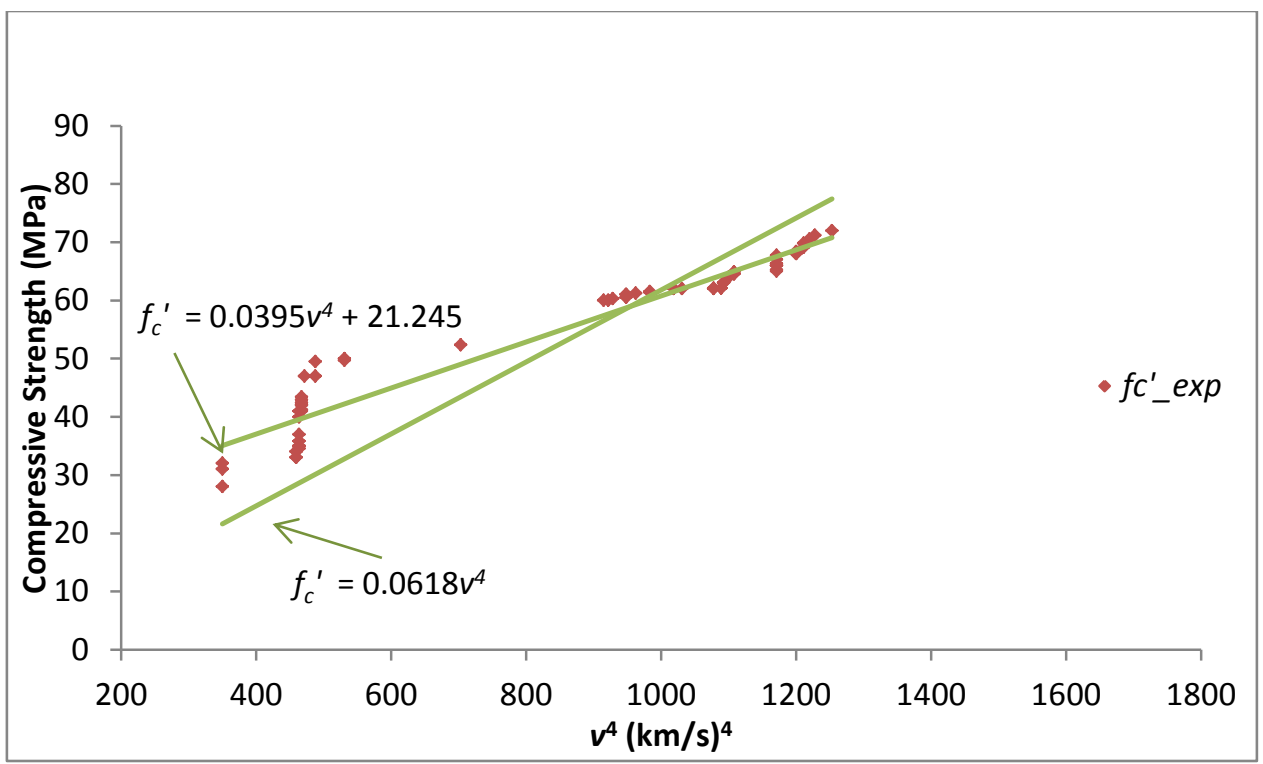

(a)

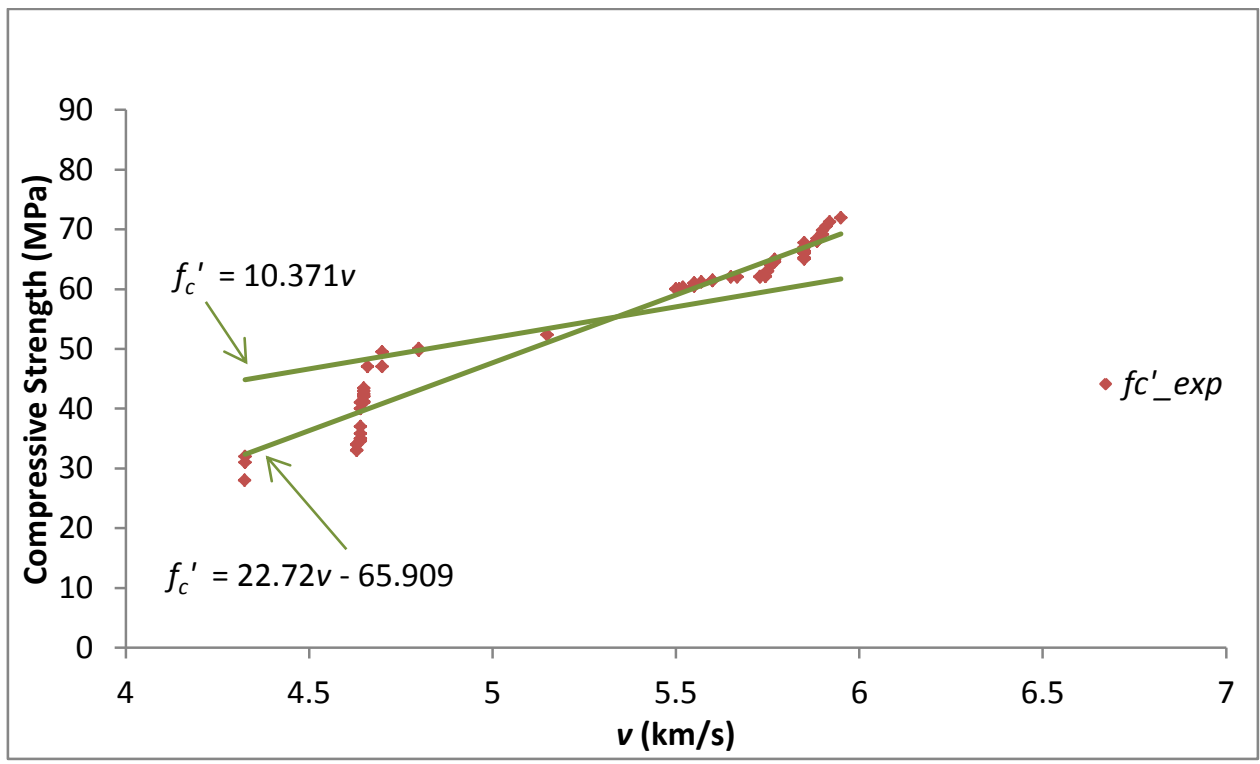

(b)

Fig. 6.7 Variation of $f_{c}{ }^{\prime}$ vs. $v^{4}$ for all specimens and (b) Variation of $f_{c}{ }^{\prime}$ vs. $v$ for AAB mixes cured at $40^{\circ} \mathrm{C}$ 


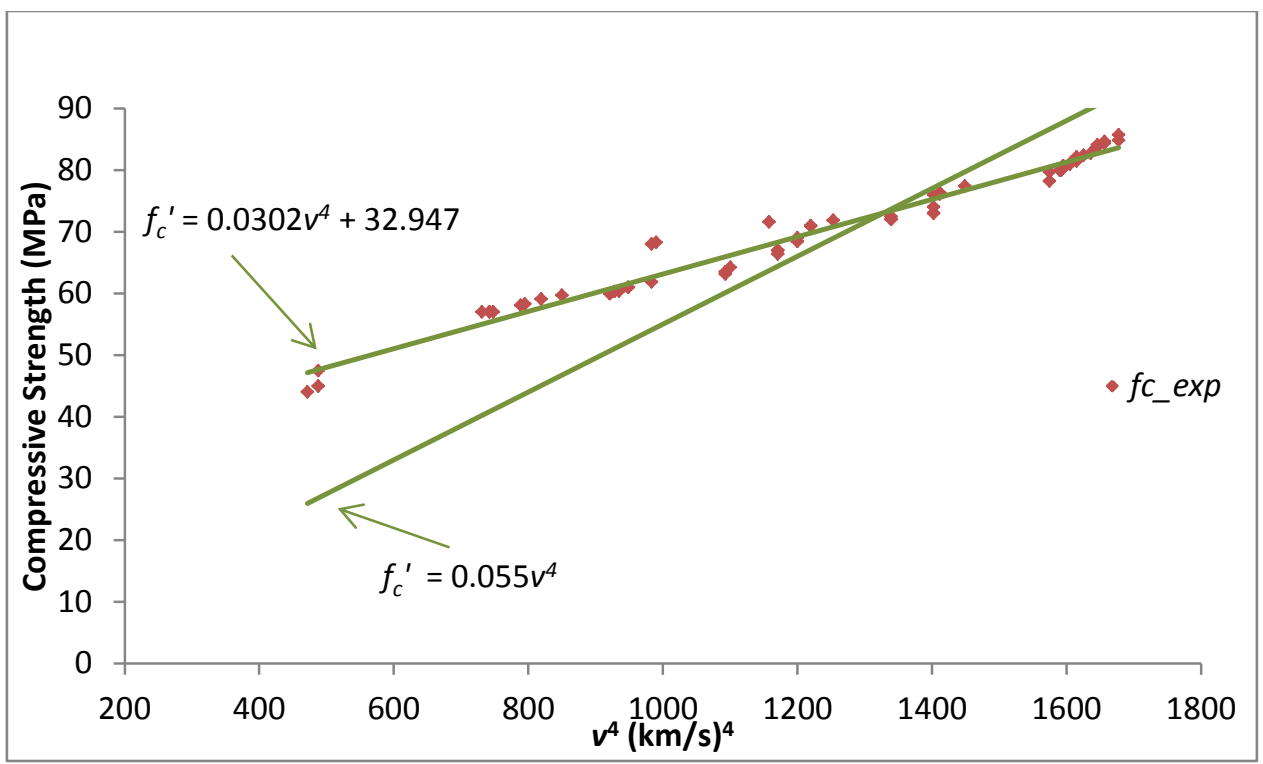

(a)

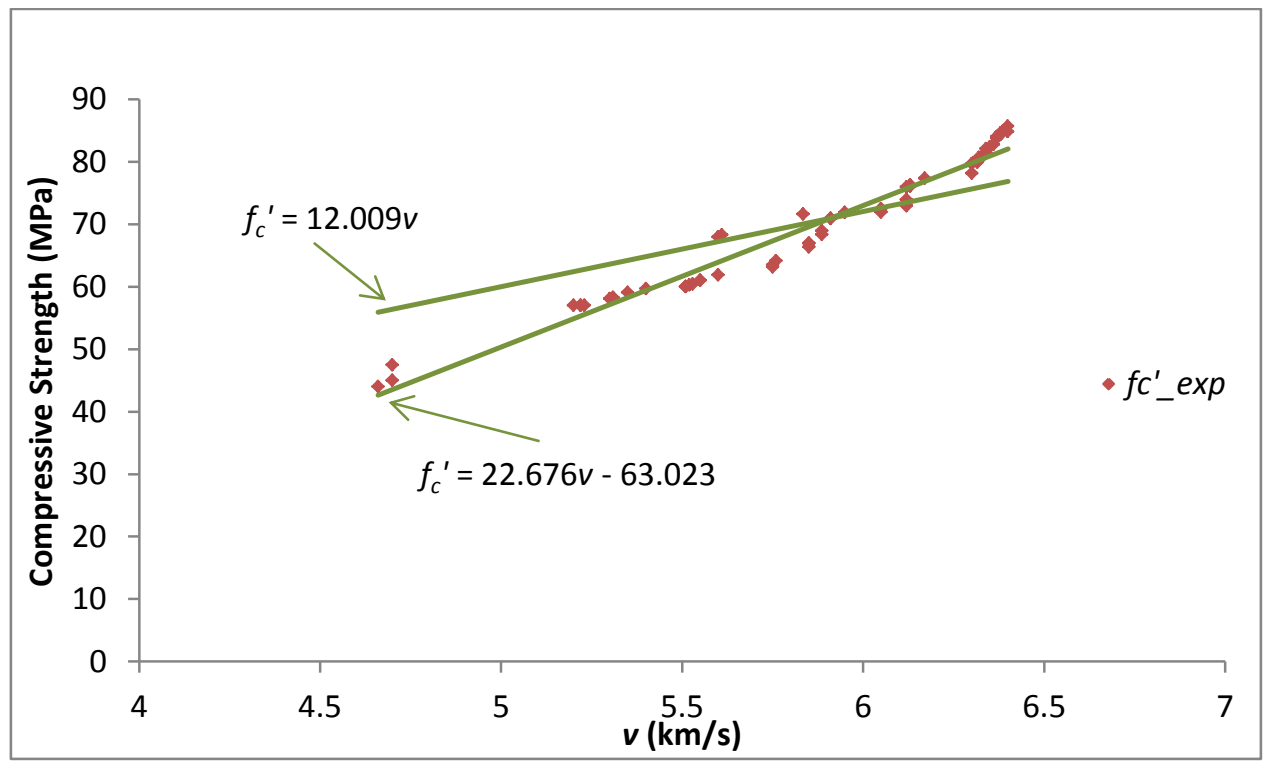

(b)

Fig. 6.8 Variation of $f_{c}{ }^{\prime}$ vs. $v^{4}$ for all specimens and (b) Variation of $f_{c}{ }^{\prime}$ vs. $v$ for AAB mixes cured at $60^{\circ} \mathrm{C}$ 


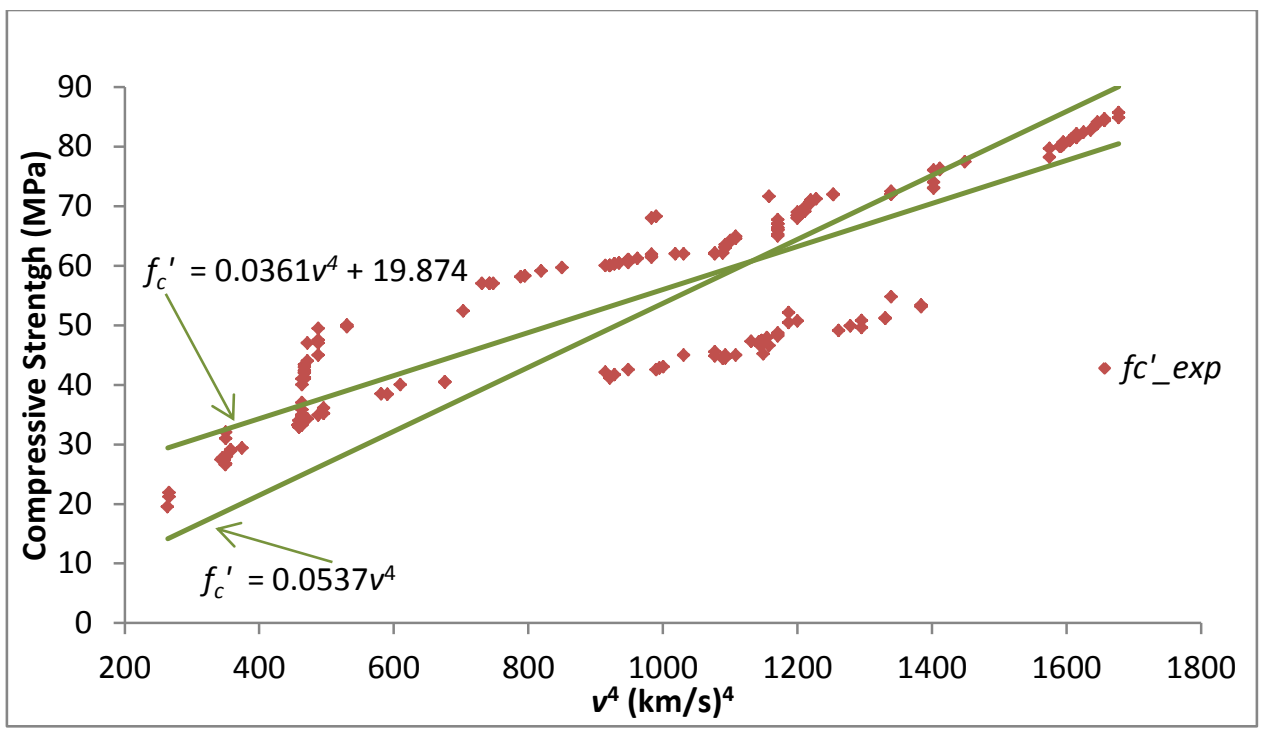

(a)

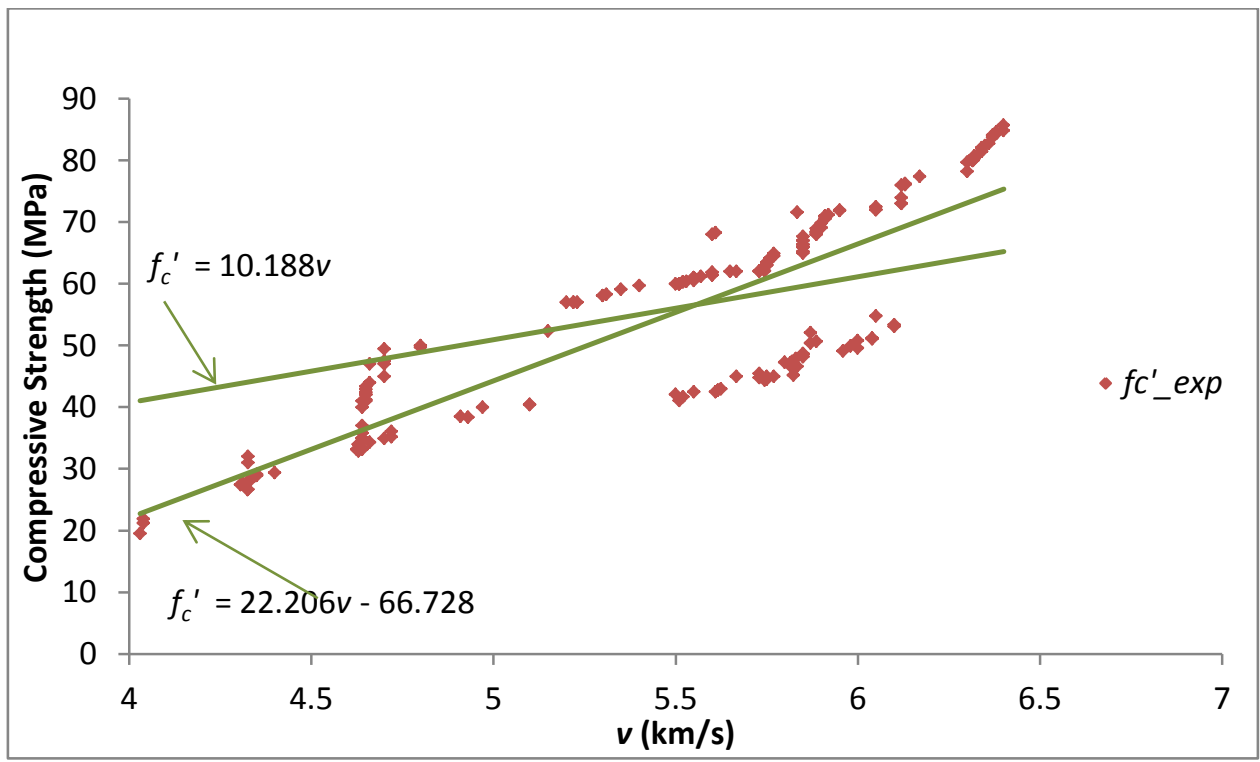

(b)

Fig. 6.9 (a) Variation of $f_{c}{ }^{\prime}$ vs. $v^{4}$ for all specimens and (b) Variation of $f_{c}{ }^{\prime}$ vs. $v$ for all specimens

The different equations for the cases mentioned above have been provided in Table 6.4, along with their corresponding $\mathrm{SS}_{\mathrm{E}}$ values. 
Table 6.4 Variation of $f_{c}^{\prime}$ vs. $v^{4}$ and $f_{c}^{\prime}$ vs. $v$

\begin{tabular}{|c|c|c|}
\hline Temperature & Equation without intercept $\left(\mathrm{SS}_{\mathrm{E}}\right)$ & Equation with intercept $\left(\mathrm{SS}_{\mathrm{E}}\right)$ \\
\hline \multirow{2}{*}{$23^{\circ} \mathrm{C}$} & $f_{c}^{\prime}=0.0438 \mathrm{~V}^{4}(4570.57)$ & $f_{c}^{\prime}=0.0235 \mathrm{~V}^{4}+20.622(329.48)$ \\
\cline { 2 - 3 } & $f_{c}^{\prime}=7.7849 \mathrm{~V}(1056.35)$ & $f_{c}^{\prime}=13.224 \mathrm{~V}-29.224(214.45)$ \\
\hline \multirow{2}{*}{$40^{\circ} \mathrm{C}$} & $f_{c}=0.0618 \mathrm{v}^{4}(4515.80)$ & $f_{c}=0.0395 \mathrm{~V}^{4}+21.245(736.83)$ \\
\cline { 2 - 3 } & $f_{c}^{\prime}=10.3708 \mathrm{~V}(3735.58)$ & $f_{c}^{\prime}=22.7200 \mathrm{~V}-65.909(607.91)$ \\
\hline \multirow{2}{*}{$60^{\circ} \mathrm{C}$} & $f_{c}^{\prime}=0.0550 \mathrm{v}^{4}(5208.10)$ & $f_{c}^{\prime}=0.0302 \mathrm{v}^{4}+32.947(186.60)$ \\
\cline { 2 - 3 } & $f_{c}^{\prime}=12.009 \mathrm{~V}(1792.51)$ & $f_{c}^{\prime}=22.676 \mathrm{~V}-63.023(275.04)$ \\
\hline \multirow{2}{*}{ All specimens } & $f_{c}^{\prime}=0.0537 \mathrm{v}^{4}(23028.00)$ & $f_{c}^{\prime}=0.0361 \mathrm{v}^{4}+19.874(12506.59)$ \\
\cline { 2 - 3 } & $f_{c}^{\prime}=10.1883 \mathrm{~V}(24225.75)$ & $f_{c}^{\prime}=22.2060 \mathrm{~V}+66.728(13080.24)$ \\
\hline
\end{tabular}

As in the case of modulus of elasticity, different equations were developed (with and without intercept) for each curing temperature in order to understand the effects of the different curing temperatures. However, if the curing temperature is unknown during field applications, then the user can utilize the general equation obtained for all specimens taken together. For each of the cases, it was noticed that the equations obtained in case of $f_{c}{ }^{\prime}$ expressed as $f(v)$ showed lesser $S_{E}$ values than the corresponding equations which expressed $f_{c}{ }^{\prime}$ as $\mathrm{f}\left(v^{4}\right)$ in most cases but not all the cases. Also, the equations with intercept resulted in lower $\mathrm{SS}_{\mathrm{E}}$ values compared to the corresponding equations without intercept.

\section{Sample codes from $\mathbf{R}$}

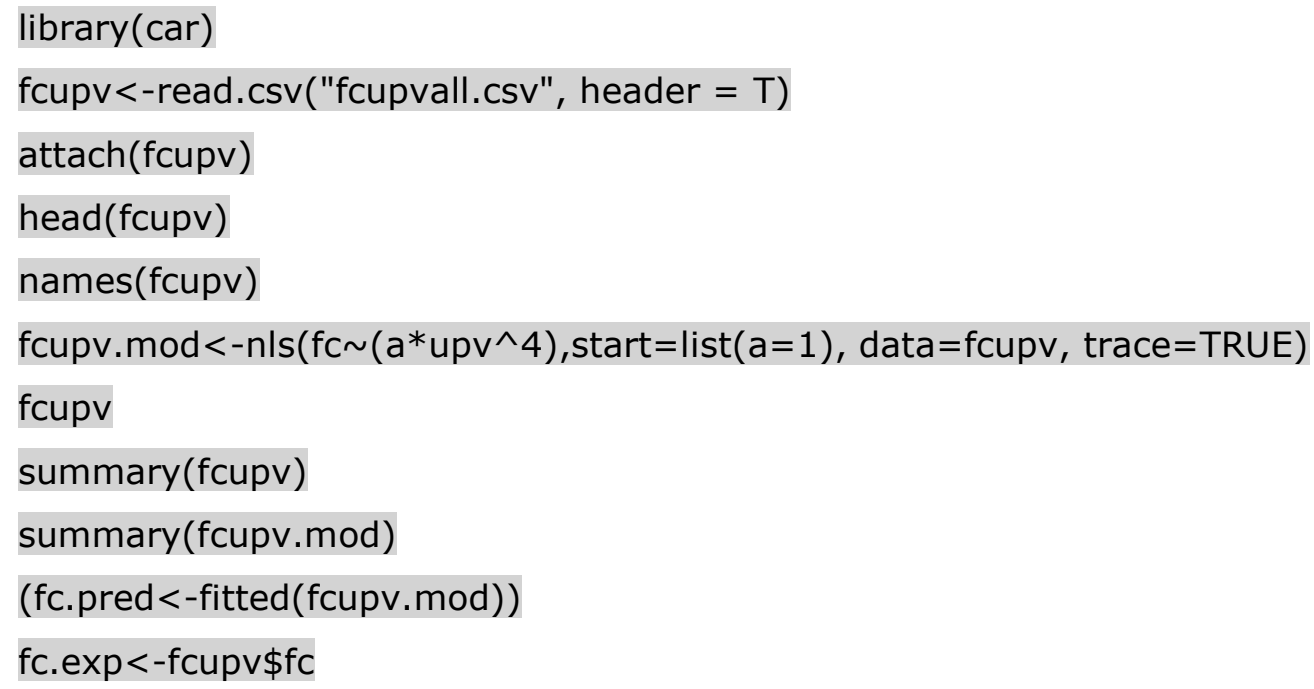


Two different sets of equations were obtained in order to express the relationship between the modulus of elasticity values and the ultrasonic pulse velocities, for each of the three different curing temperatures, as well as for all the specimens considered together. The last set of equations would be useful if the curing temperature is unknown. In the field, it might be useful for the engineer to measure the ultrasonic pulse velocity at different locations on a structural element made out of the $A A B$. The suggested equations can then be used to predict compressive strength at the corresponding locations. These values can be used to detect the presence of deterioration in the structure if some locations show low ultrasonic pulse velocities which will imply loss of compressive strength, and hence, the presence of deterioration.

It was generally observed that the ultrasonic pulse velocity values had positive correlation with the compressive strength as well as the modulus of elasticity values. It was also observed that the ultrasonic pulse velocities decreased as the applied stress increased. Hence, it was concluded that if the measured ultrasonic pulse velocities were lower than the predicted values, it was an indication of deterioration in the structural element.

In a nutshell, when the ultrasonic pulse velocities are measured at different locations on a structural element in the field, the recorded values will be examined to detect anomalies. If a particular location or a set of locations depict ultrasonic pulse velocities lower than the predicted values from the proposed equations, the user should be aware that the structure has deteriorated and the necessary measures should be adopted.

In case of field evaluation or in-situ testing of structures to be built out of $A A B$, it is necessary to have an estimate of the load carrying capacity of a structure and the detection of cracking in a structure. Based on the ultrasonic pulse velocity results, the user will have an idea about the extent to which the structure has been stressed or the extent of damage to the structure. The velocities can be measured at different locations on the structure and the user can identify anomalies in the results. If the velocities are very low at some locations as compared to the others, it means that the structure has been loaded to a great extent at those particular points and there is possibility of failure. For this purpose, the present study observed the variation of the ultrasonic pulse velocity with gradually increasing compressive loading (upto $90 \%$ of the measured compressive strength determined previously) on standard test cylinders made out of the material used in the 
study. Relationships were developed to express the applied stress as linear functions of $v$ as well as $v^{4}$. The relevant plots and results are discussed in details in the following section.

\subsection{Effect of Gradually Increasing Applied Compressive Stress on UPV}

In order to find out the effect on compressive stress that has been exerted on the structure, the present study looked at the variation of ultrasonic pulse velocity with applied compressive stress $\left(\sigma_{c}\right)$. Experiments were conducted to study the behavior of $\mathrm{AAB}$ to gradually increasing compressive stress using the same cylindrical test specimens that were used for measuring the dynamic modulus of elasticity. They had identical dimensions and compositions to the compressive strength specimens. The observations were recorded for the corresponding ultrasonic pulse velocities at definite intervals of gradually increasing compressive loads to an extent that the loading was stopped just before the specimens failed in compression. For each of the specimens, $0.9 f_{c}^{\prime}$ (i.e. the compressive strength for that particular mixture proportion) was chosen as the limit to which they were loaded. Plots were made and equations were developed at each temperature to express $\sigma_{c}$ as functions of $v$ and $v^{4}$. These experiments were conducted on 28-day old specimens only. The experimental setup is shown in Fig. 6.10.

The results (Figs. 6.11 through 6.14) showed that the maximum ultrasonic pulse velocities were observed at zero applied stresses. In other words, the ultrasonic pulse velocities were the largest when the structure was not subjected to any stress, i.e., there was no deterioration. As the applied stress was increased gradually, the ultrasonic pulse velocities decreased appreciably. The lowest ultrasonic pulse velocities were observed when the applied stresses were the largest, i.e., when the structural element was close to failure. Linear regression was carried out using $\mathrm{R}$ statistical package. Equations were obtained for the variation of applied strength, $\sigma_{c}$, with the fourth power of the ultrasonic pulse velocities, $v^{4}$, as well as between $\sigma_{c}$ and $v$. These relationships were obtained for each of the three

curing temperatures. Another set of equations were generated for all the mixture proportions taken together, irrespective of the curing temperatures. 

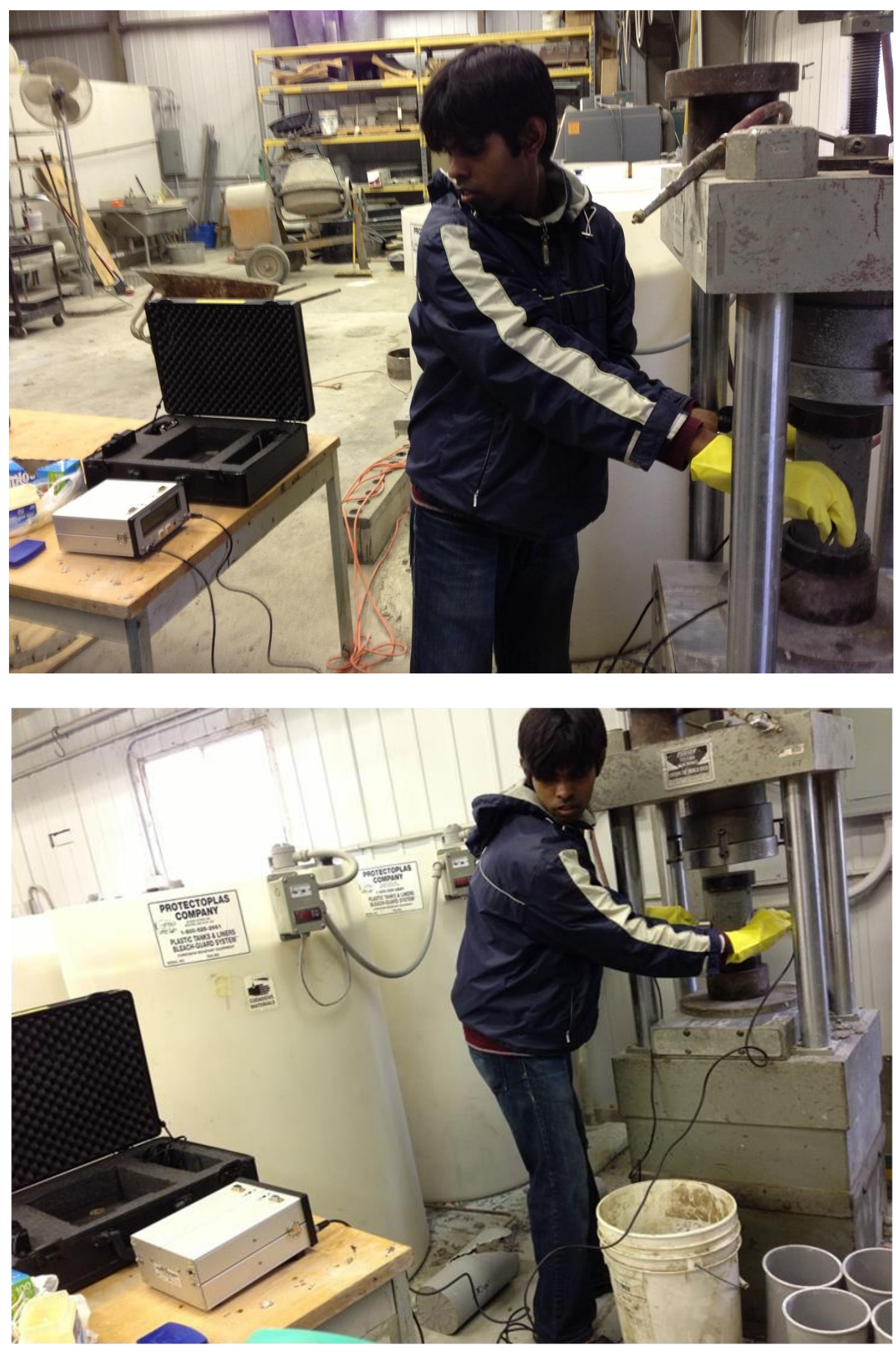

Fig. 6.10 Experimental setup for variation of $\sigma_{c}$ and $\sigma_{c} / f_{c}{ }^{\prime}$ with ultrasonic pulse velocity for all specimens. 


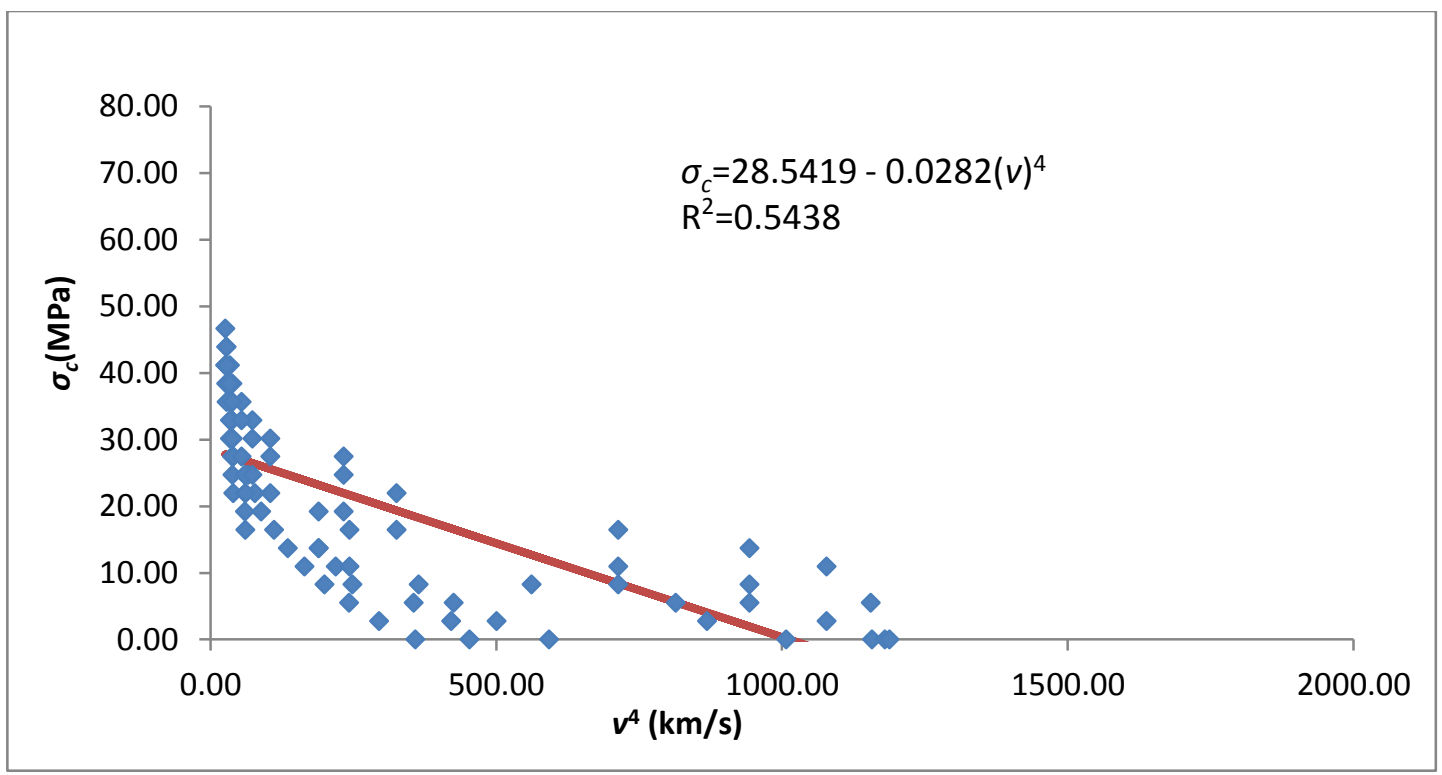

(a)

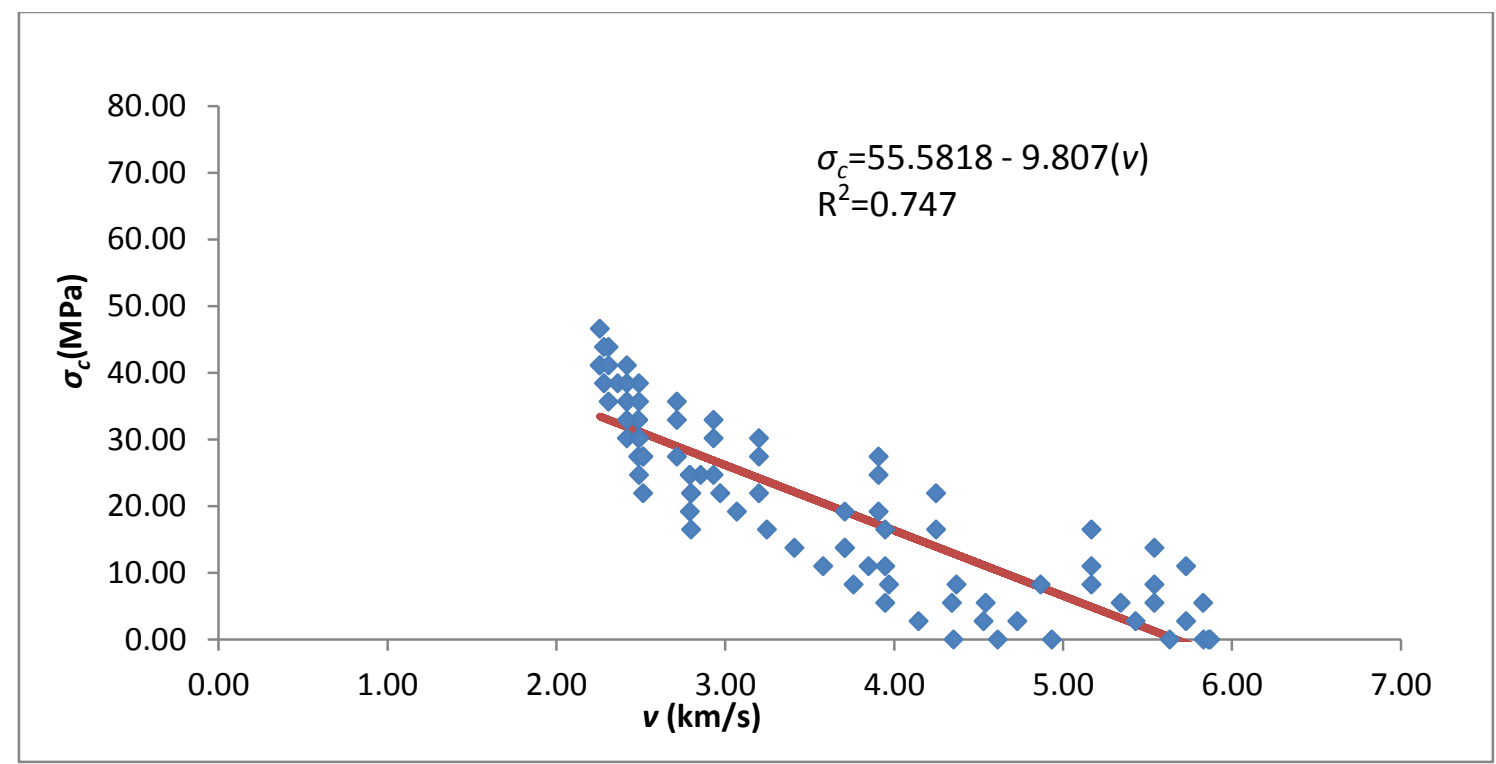

(b)

Fig. 6.11 (a) Variation of $\sigma_{c}$ vs. $v^{4}$ for all specimens and (b) Variation of $\sigma_{c}$ vs. $v$ for AAB mixes cured at $23^{\circ} \mathrm{C}$ 


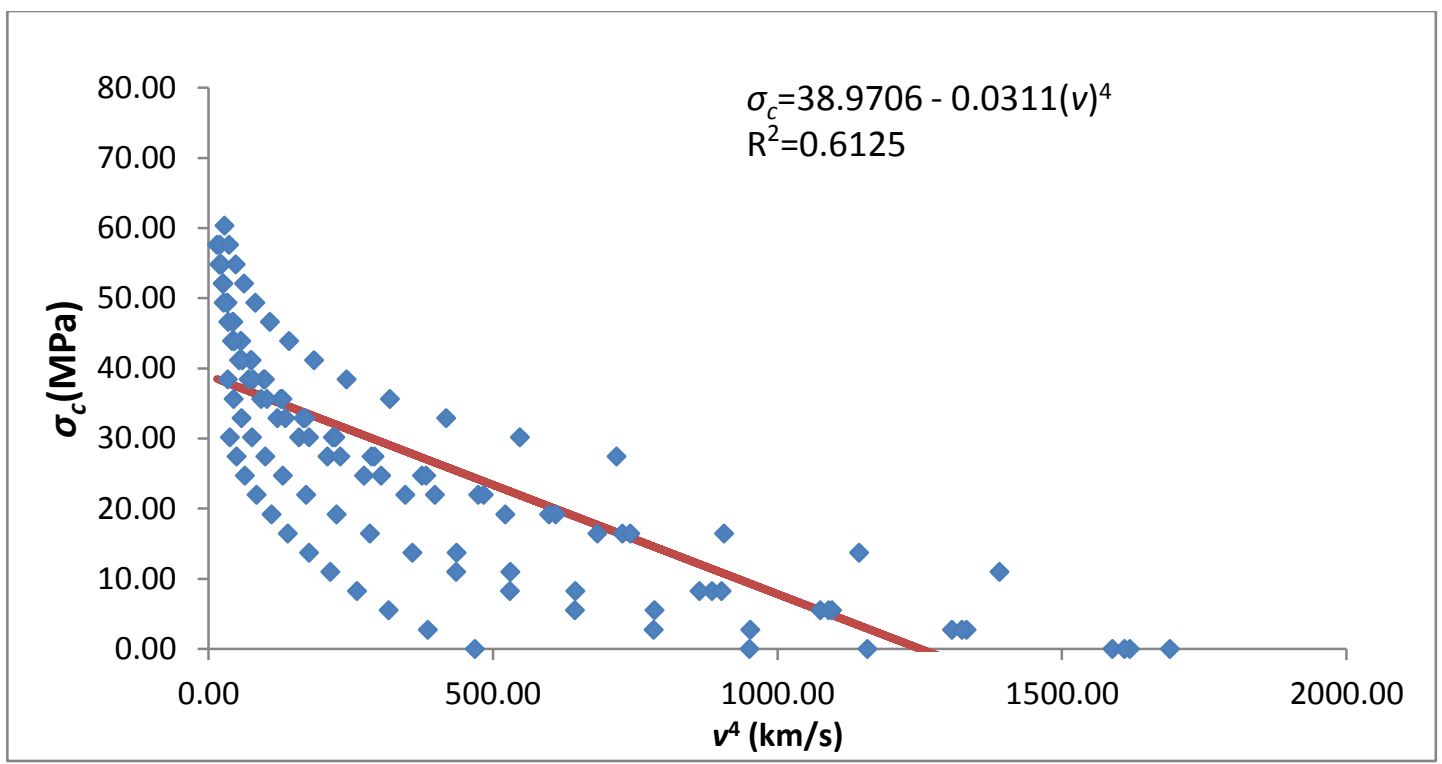

(a)

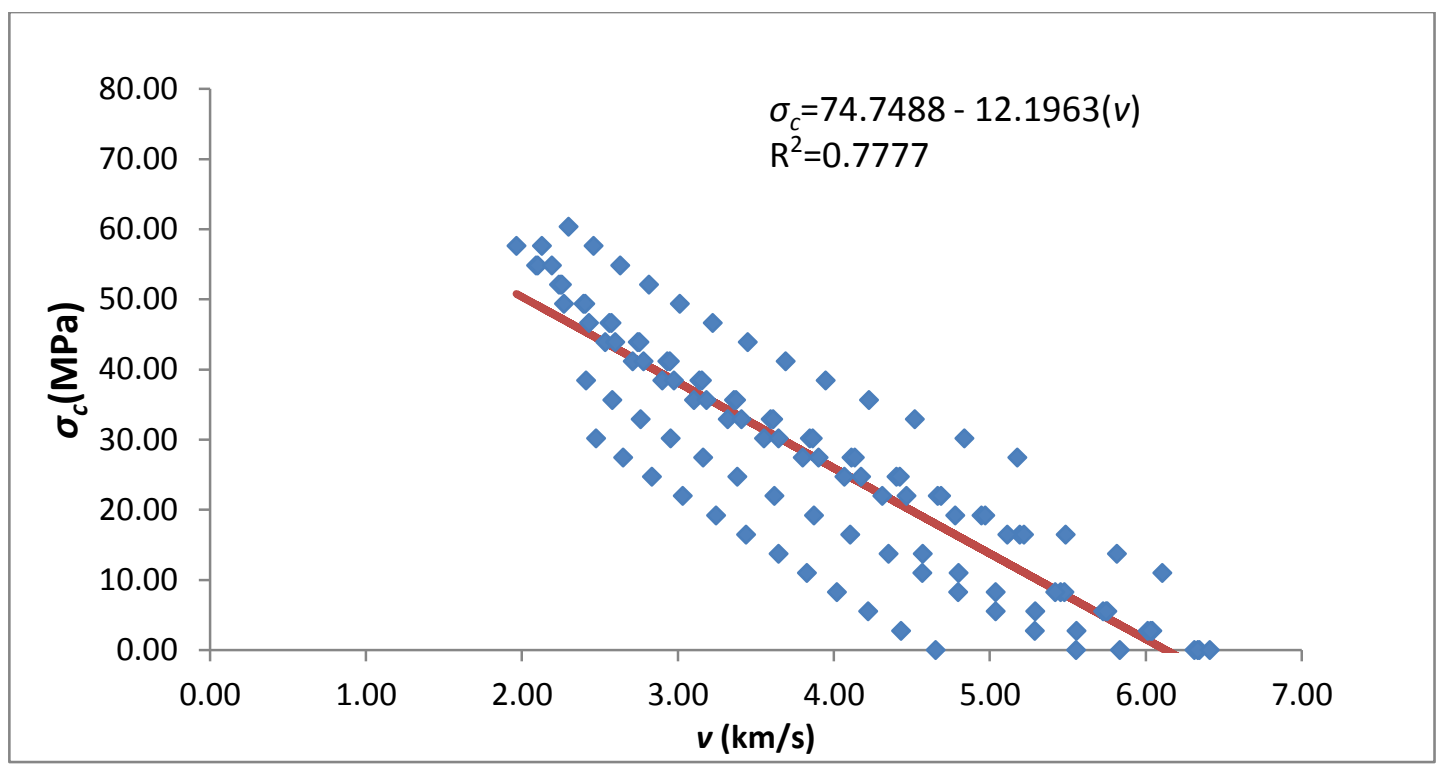

(b)

Fig. 6.12 (a) Variation of $\sigma_{c}$ vs. $v^{4}$ for all specimens and (b) Variation of $\sigma_{c}$ vs. $v$ for AAB mixes cured at $40^{\circ} \mathrm{C}$ 


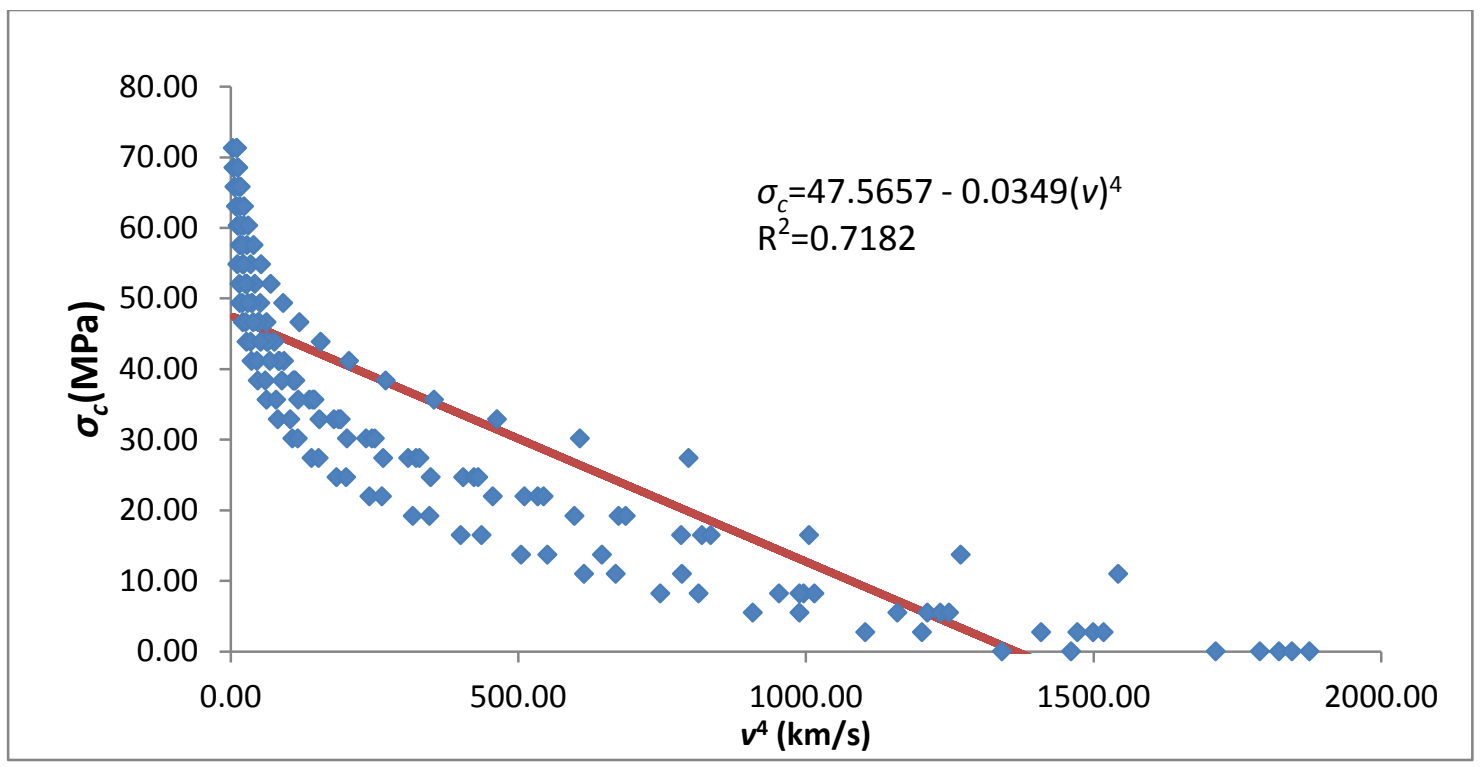

(a)

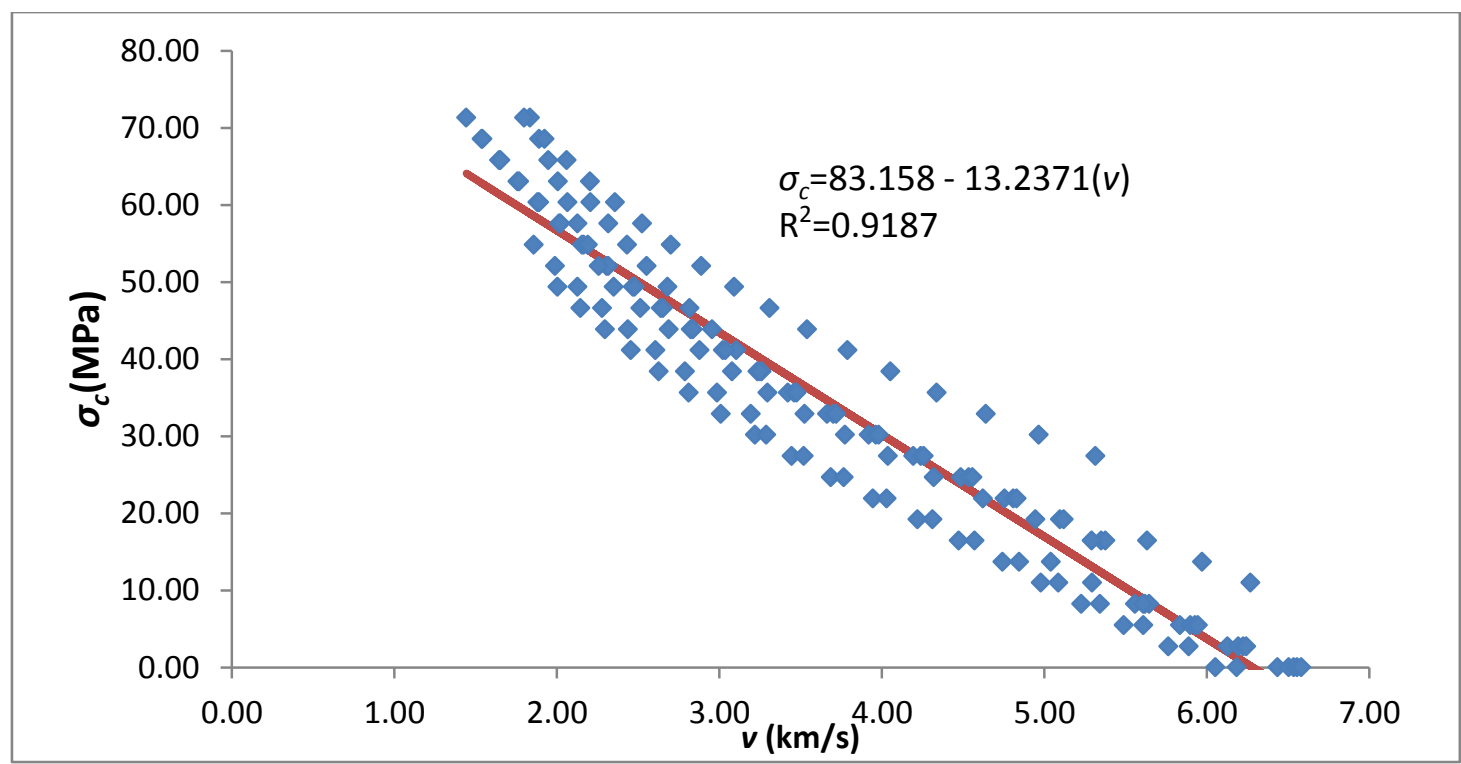

(b)

Fig. 6.13 (a) Variation of $\sigma_{c}$ vs. $v^{4}$ for all specimens and (b) Variation of $\sigma_{c}$ vs. $v$ for AAB mixes cured at $60^{\circ} \mathrm{C}$ 


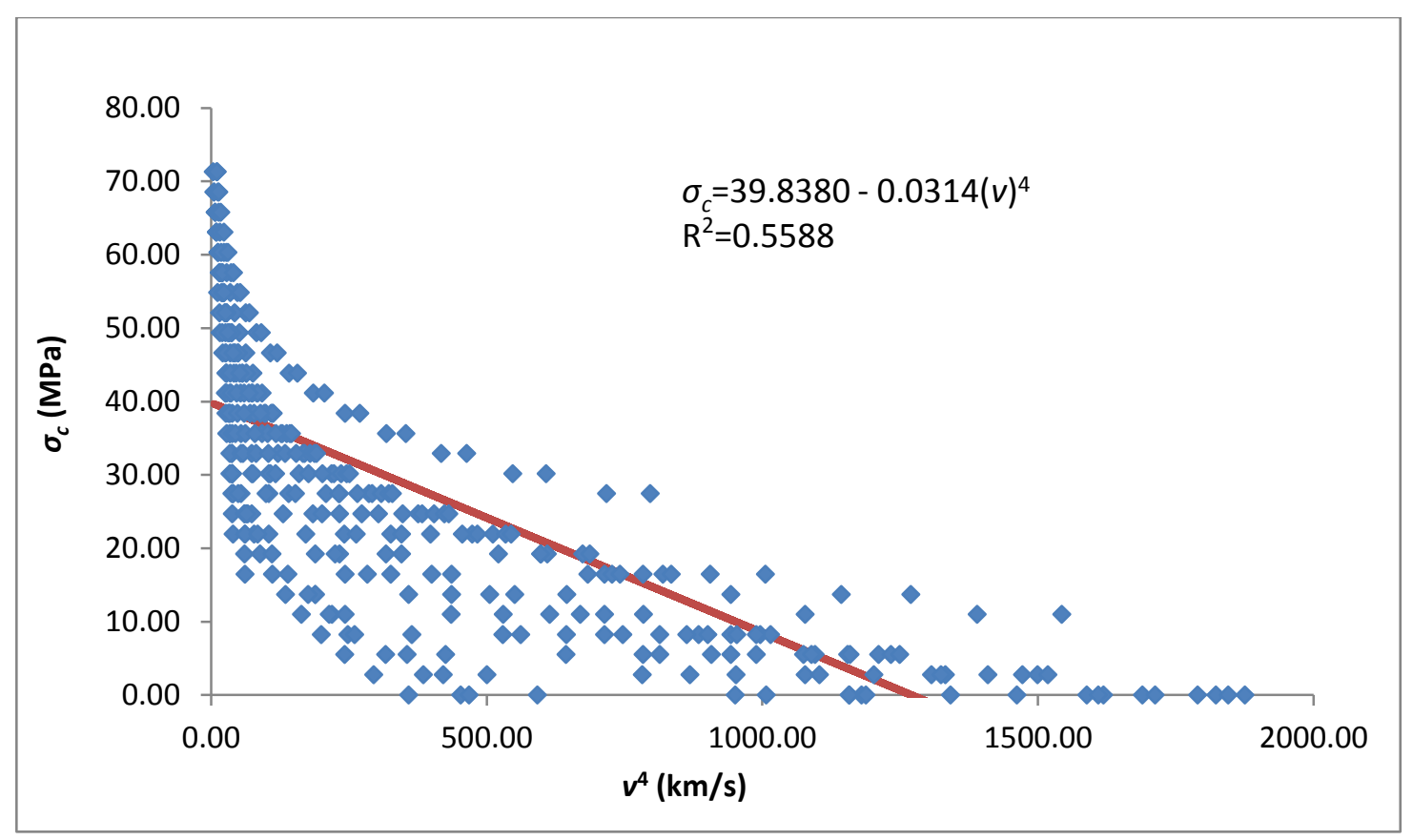

(a)

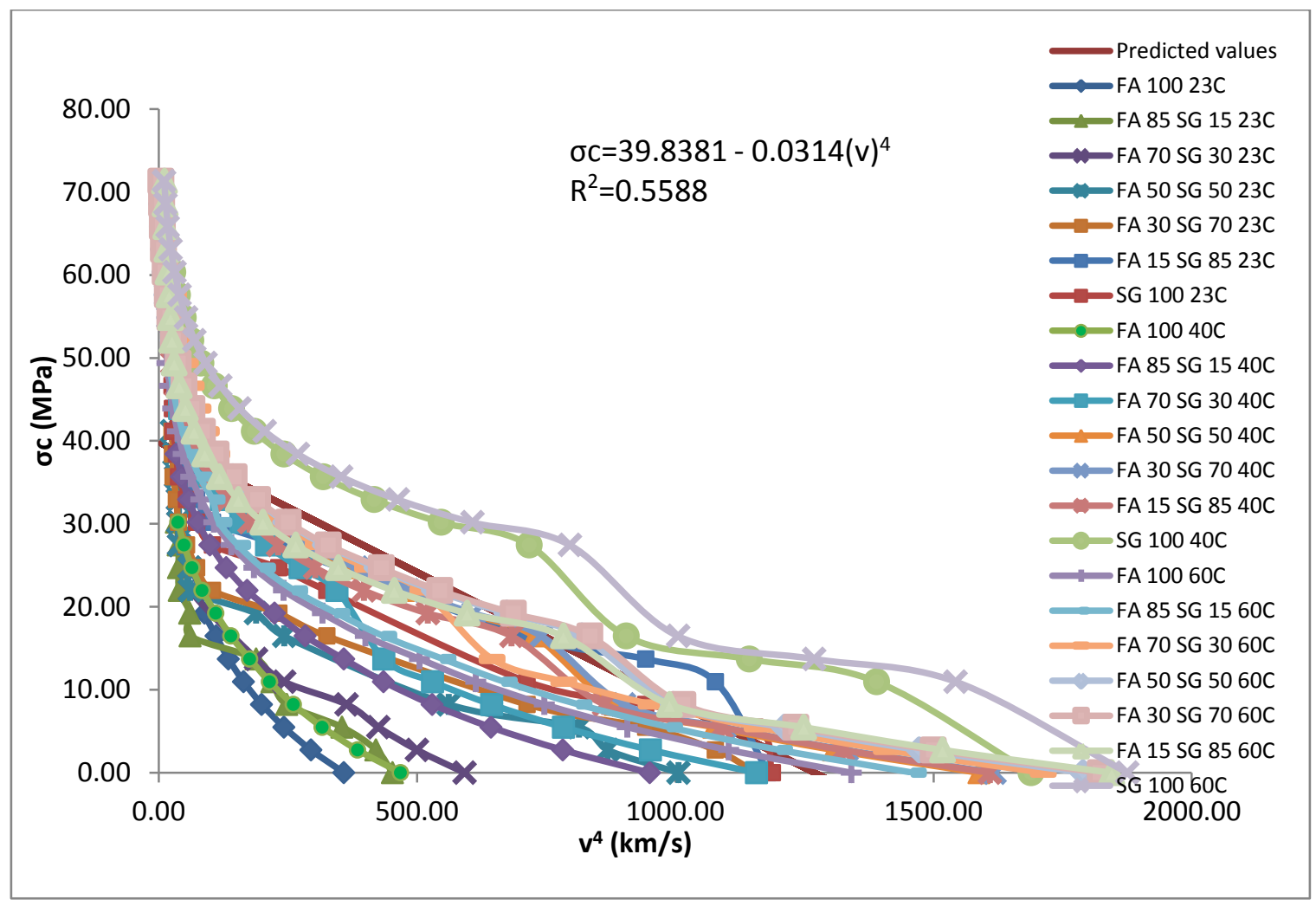

(b) 


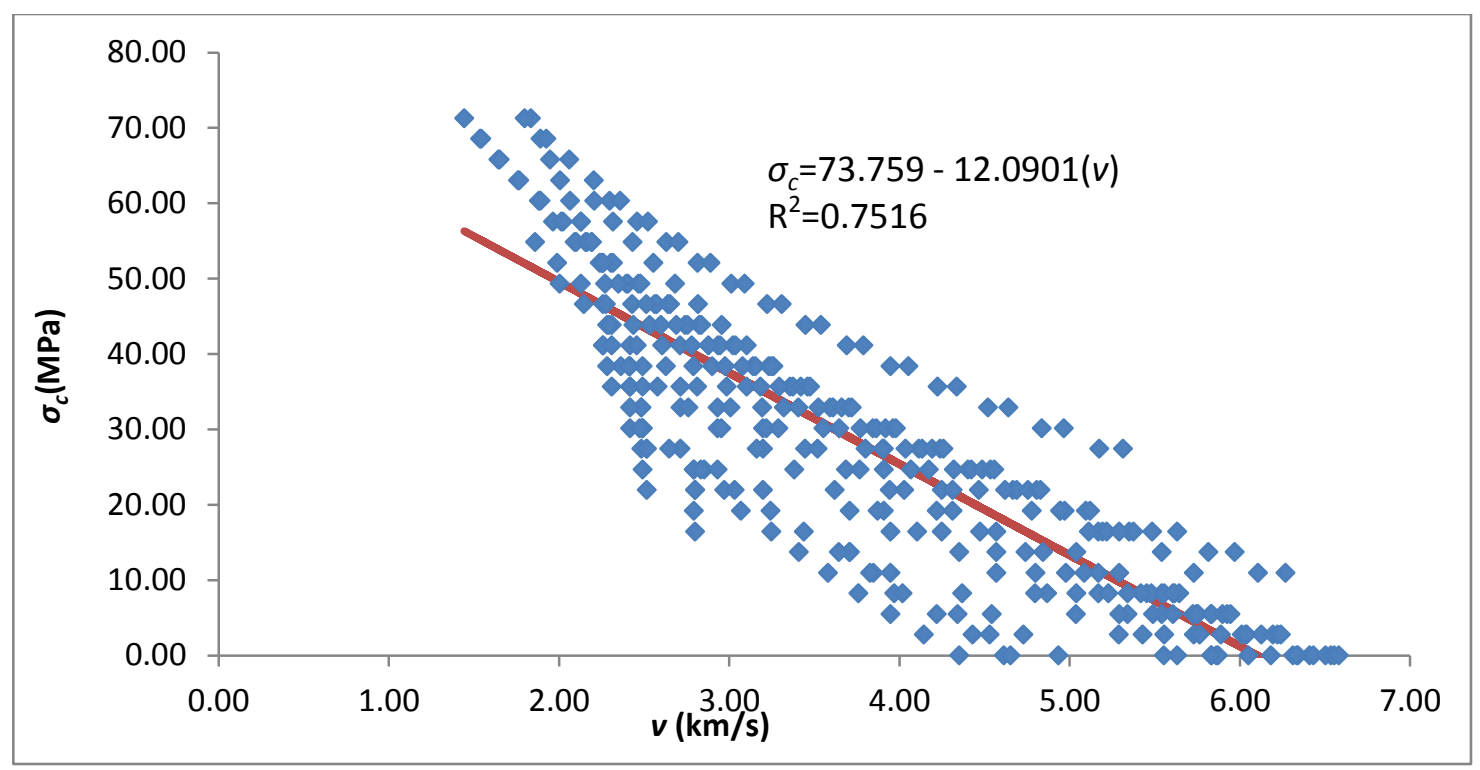

(c)

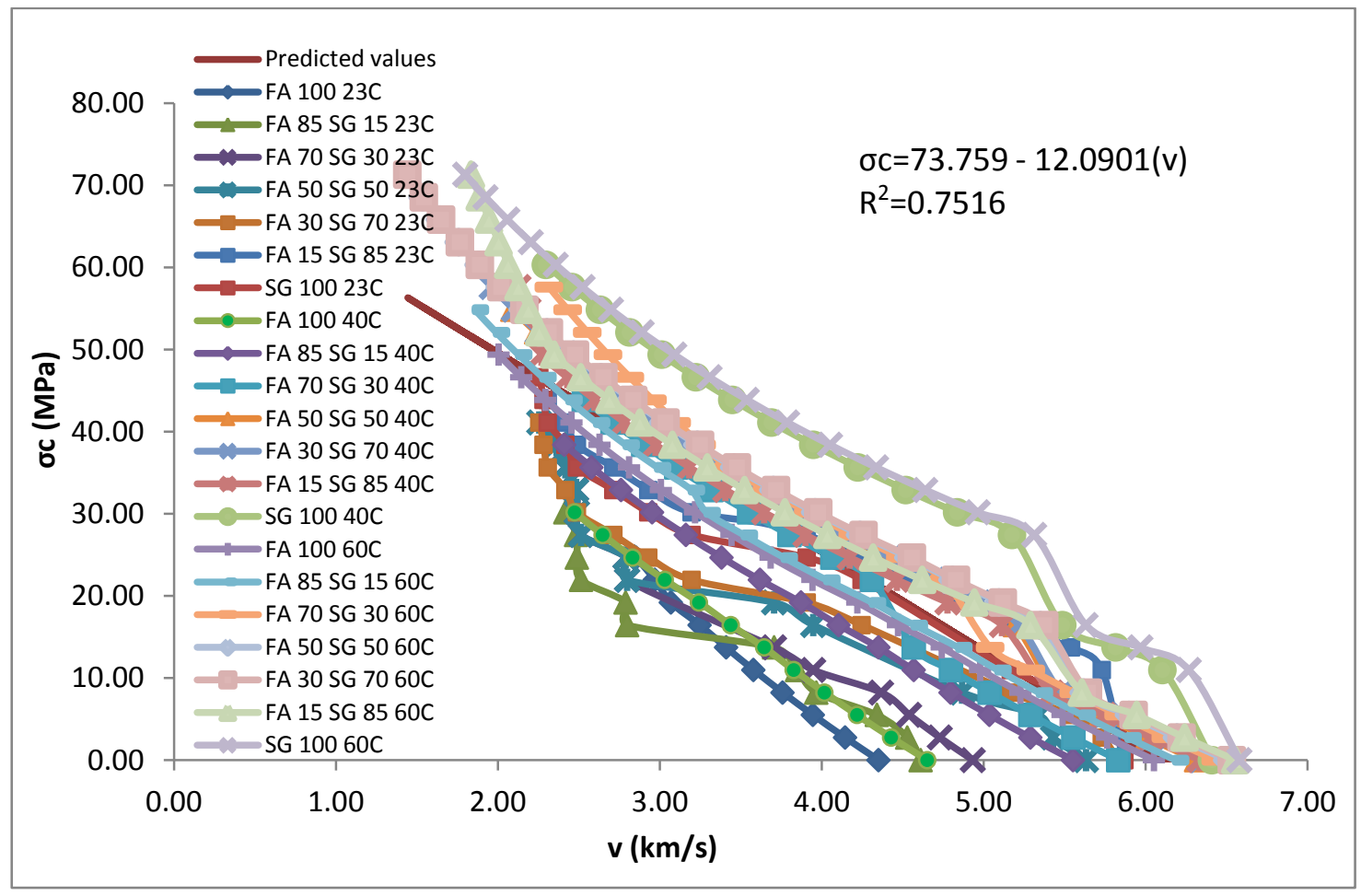

Fig. 6.14 (a) Variation of $\sigma_{c}$ vs. $v^{4}$ for all specimens (scatter plot for each mix); (b) Variation of $\sigma_{c}$ vs. $v^{4}$ for all specimens (scatter plot with line for each mix); (c) Variation of $\sigma_{c}$ vs. $v$ for all specimens (scatter plot for each mix); and (d) Variation of $\sigma_{c}$ vs. $v$ for all specimens (scatter plot with line for each mix). 
The different equations for the cases mentioned above have been provided in Table 6.5, along with their corresponding $\mathrm{R}^{2}$ values. For each of the cases, it was noticed that the equations obtained in case of $\sigma_{c}$ expressed as $f(v)$ showed slightly better $\mathrm{R}^{2}$ values than the corresponding equations which expressed $\sigma_{c}$ as $f\left(v^{4}\right)$.

Table 6.5 Variation of $\sigma_{c}$ vs. $v^{4}$ and $\sigma_{c}$ vs. $v$

\begin{tabular}{|c|c|c|}
\hline Temperature & Equation & $\mathrm{R}^{2}$ \\
\hline \multirow{2}{*}{$23^{\circ} \mathrm{C}$} & $\sigma_{c}=28.5419-.0282 \mathrm{v}^{4}$ & 0.5438 \\
\cline { 2 - 3 } & $\sigma_{c}=55.5818-9.807 \mathrm{~V}$ & 0.7470 \\
\hline \multirow{2}{*}{$40^{\circ} \mathrm{C}$} & $\sigma_{c}=38.9706-0.0311 \mathrm{v}^{4}$ & 0.6125 \\
\cline { 2 - 3 } & $\sigma_{c}=74.7488-12.1963 \mathrm{~V}$ & 0.7777 \\
\hline \multirow{2}{*}{$60^{\circ} \mathrm{C}$} & $\sigma_{c}=47.5657-0.0349 \mathrm{~V}^{4}$ & 0.7182 \\
\cline { 2 - 3 } & $\sigma_{c}=83.1580-13.2371 \mathrm{~V}$ & 0.9187 \\
\hline \multirow{2}{*}{ All specimens } & $\sigma_{c}=39.8380-0.0314 \mathrm{~V}^{4}$ & 0.5588 \\
\cline { 2 - 3 } & $\sigma_{c}=73.7590-12.0901 \mathrm{~V}$ & 0.7516 \\
\hline
\end{tabular}

Subsequently, in order to find out the extent of loading, or what fraction of the compressive load has already been exerted on the structure, the present study looks at the ratio of the applied stress to the compressive strength ratio $\left(\sigma_{c} / f_{c}{ }^{\prime}\right)$. Plots were made and equations were developed at each temperature to express $\sigma_{c} / f_{c}{ }^{\prime}$ as functions of $v$ and $v^{4}$. These experiments were conducted on 28-day old specimens only and the plots are shown in Figs. 6.15 to 6.18 .

The results showed that the maximum ultrasonic pulse velocities were observed when the $\sigma_{d} / f_{c}{ }^{\prime}$ ratio was zero, i.e., at zero applied stresses (Figs. 6.15 through 6.18). In other words, the ultrasonic pulse velocities were the largest when the structure was not subjected to any stress, i.e., there was no deterioration. As the $\sigma_{d} / f_{c}^{\prime}$ ratio was increased gradually, the ultrasonic pulse velocities decreased appreciably. The lowest ultrasonic pulse velocities were observed when the $\sigma_{d} / f_{c}{ }^{\prime}$ ratios were the largest, i.e., when the structural element was close to failure. Linear regression was carried out using $\mathrm{R}$ statistical package. Equations were obtained for the variation of $\sigma_{d} / f_{c}{ }^{\prime}$ ratio with the fourth power of the ultrasonic pulse velocities, $v^{4}$, as well as between $\sigma_{d} / f_{c}{ }^{\prime}$ ratio and $v$. These relationships were obtained for 
each of the three curing temperatures. Another set of equations were generated for all the mixture proportions taken together, irrespective of the curing temperatures.

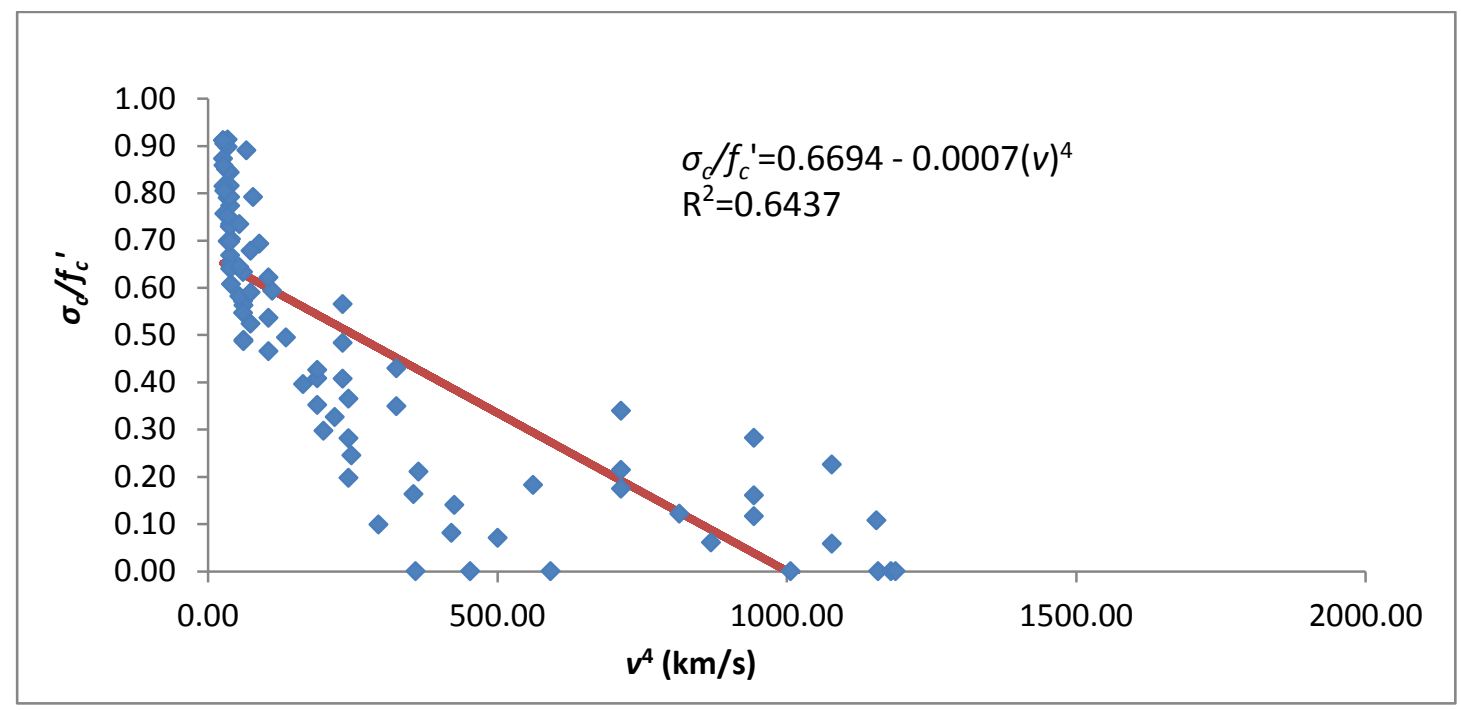

(a)

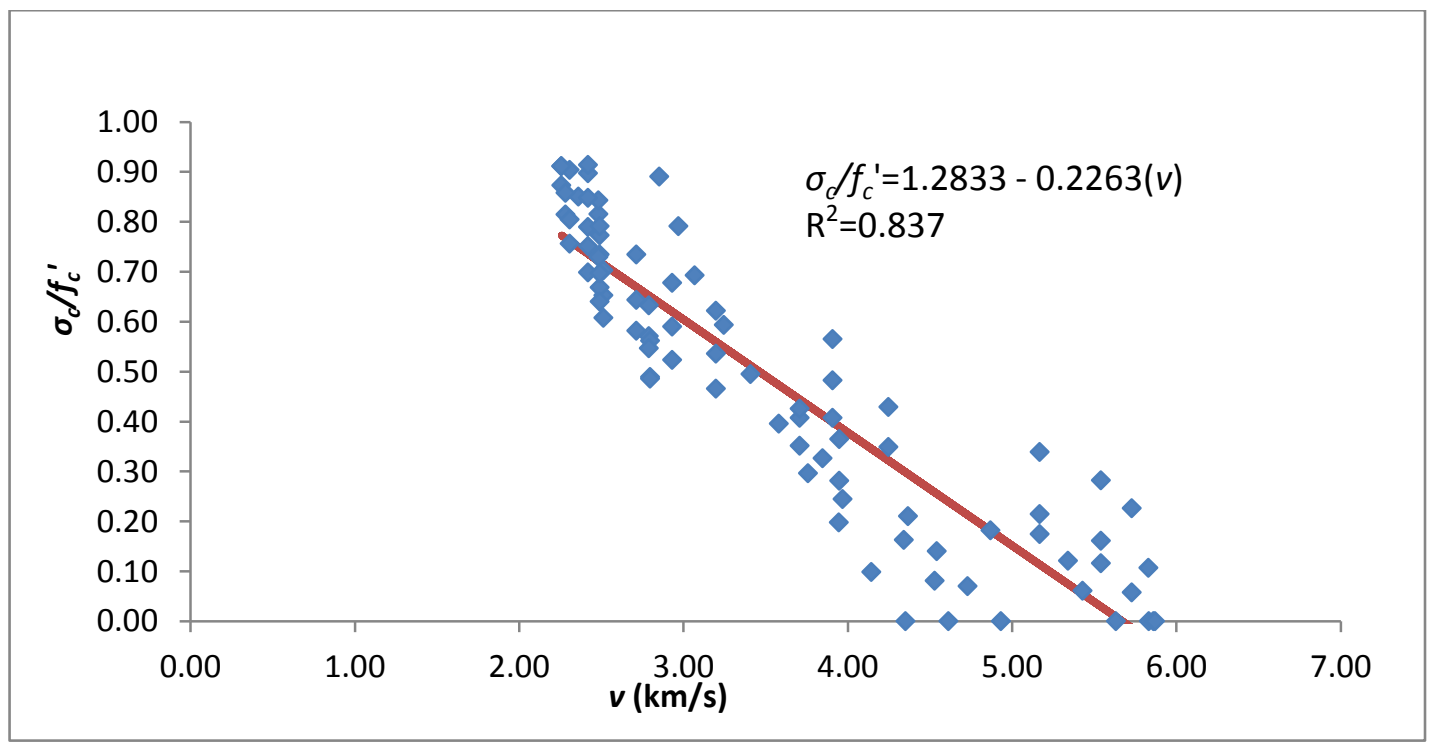

(b)

Fig. 6.15 (a) Variation of $\sigma_{c} / f_{c}{ }^{\prime}$ vs. $v^{4}$ for all specimens and (b) Variation of $\sigma_{c} / f_{c}{ }^{\prime}$ vs. $v$ for $A A B$ mixes cured at $23^{\circ} \mathrm{C}$ 


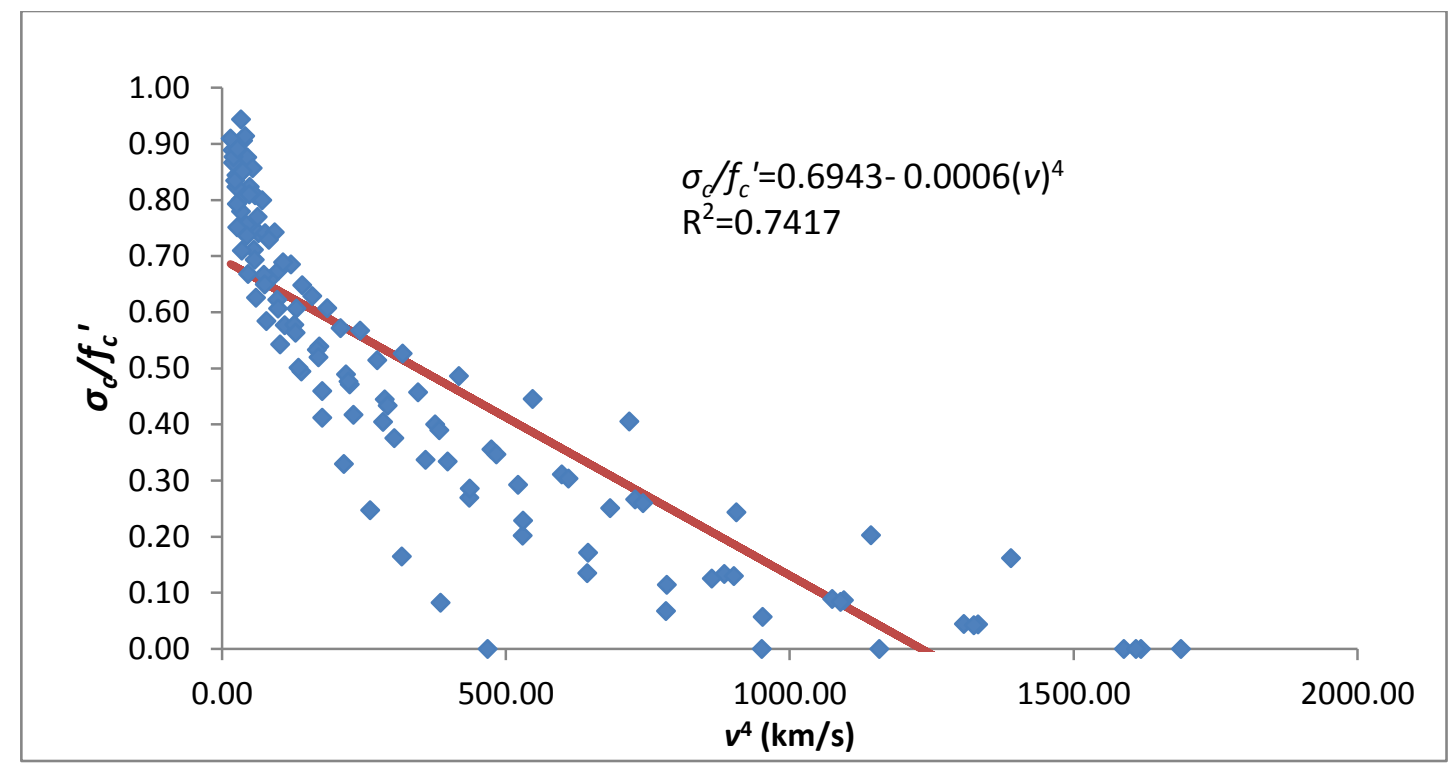

(a)

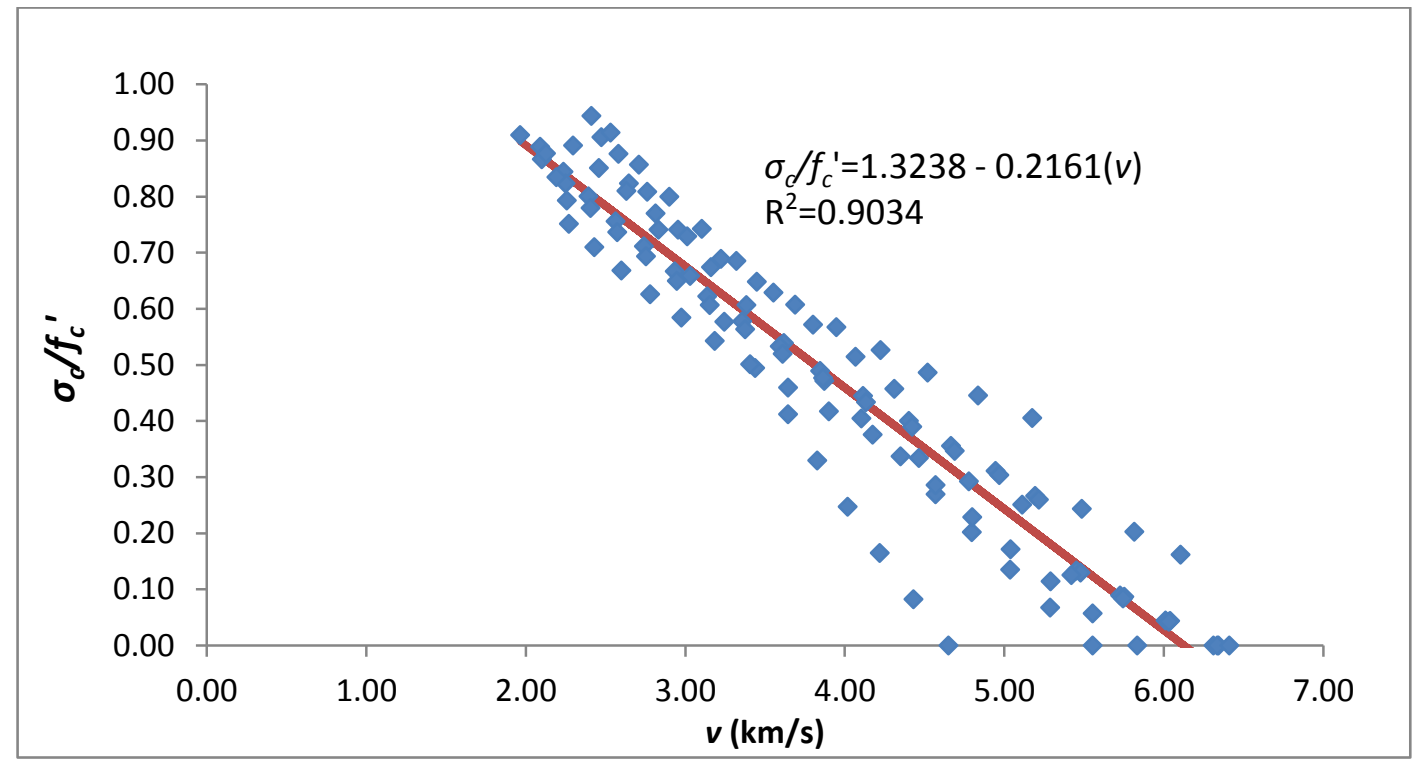

(b)

Fig. 6.16 (a) Variation of $\sigma_{c} / f_{c}{ }^{\prime}$ vs. $v^{4}$ for all specimens and (b) Variation of $\sigma_{c} / f_{c}{ }^{\prime}$ vs. $v$ for $A A B$ mixes cured at $40^{\circ} \mathrm{C}$ 


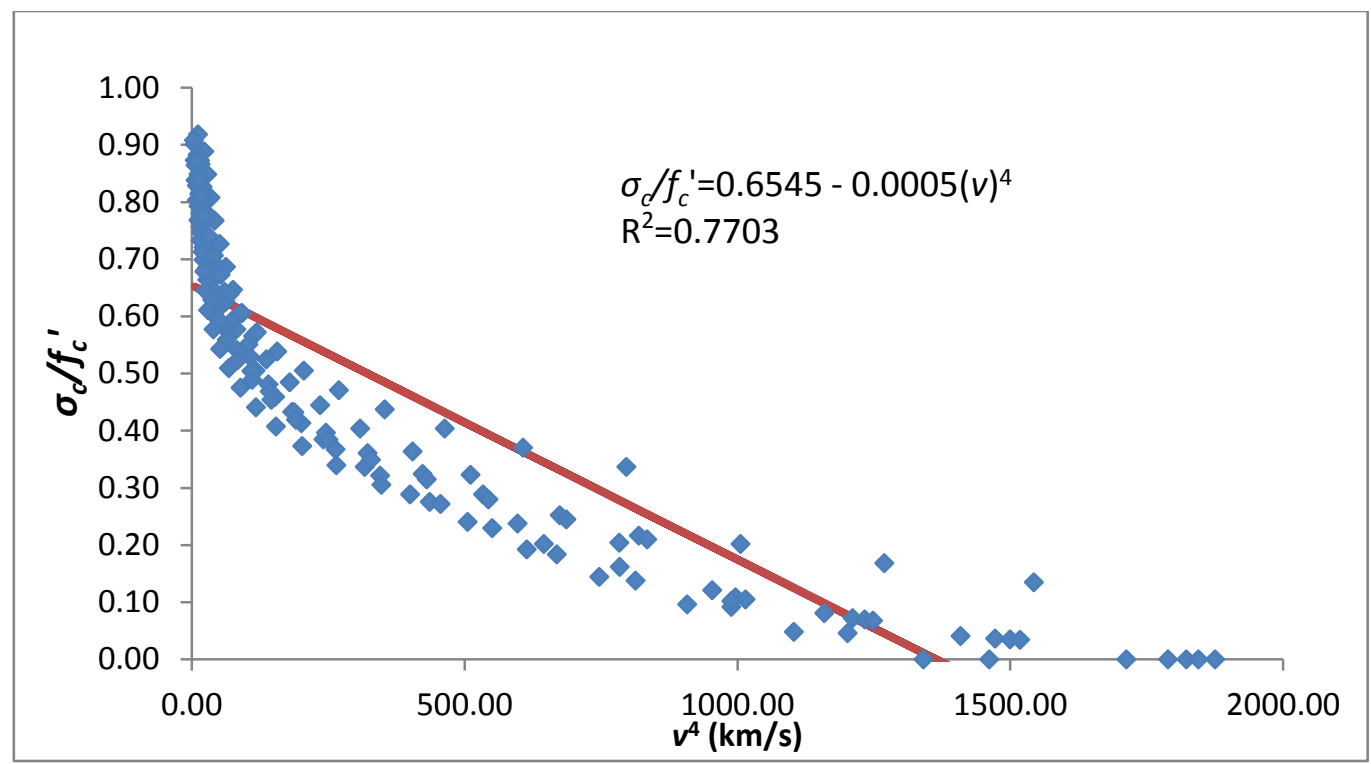

(a)

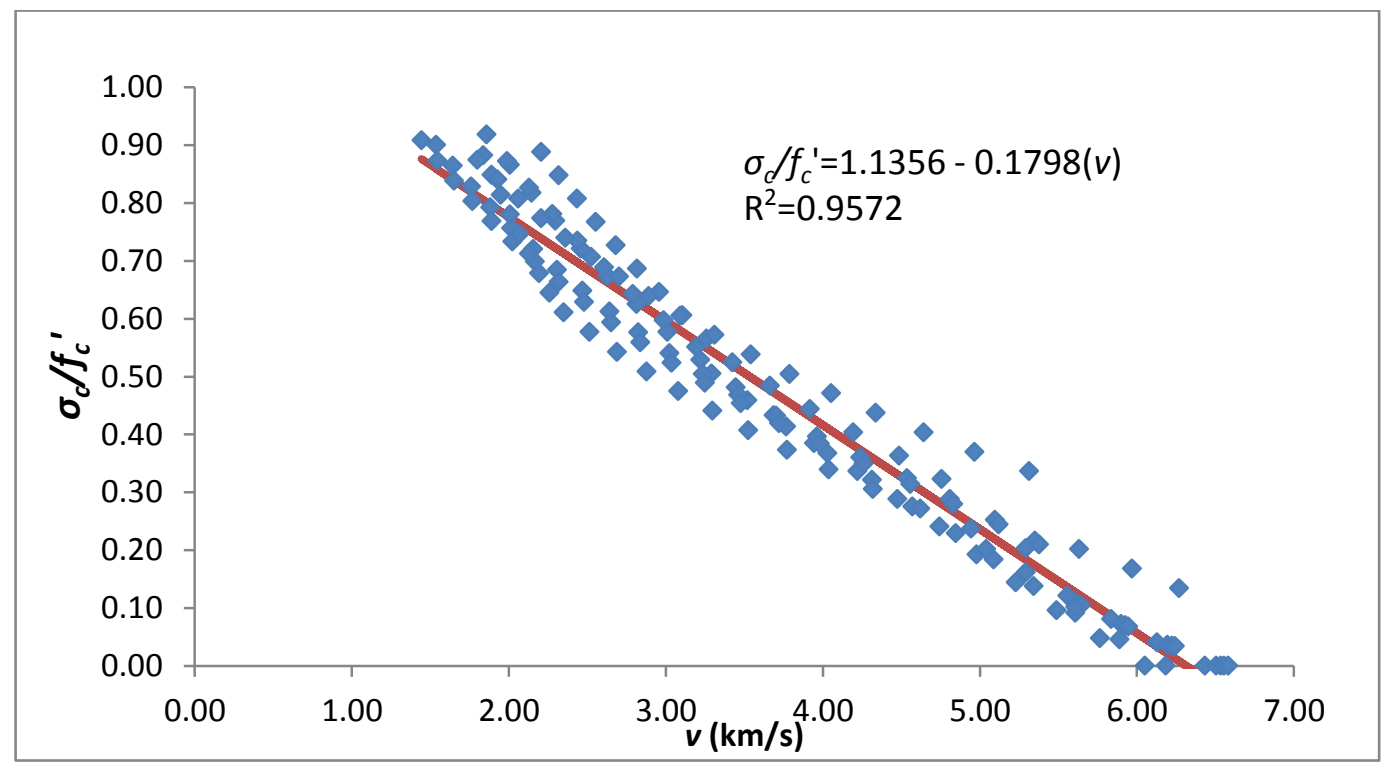

(b)

Fig. 6.17 (a) Variation of $\sigma_{c} / f_{c}{ }^{\prime}$ vs. $v^{4}$ for all specimens and (b) Variation of $\sigma_{c} / f_{c}{ }^{\prime}$ vs. $v$ for $A A B$ mixes cured at $60^{\circ} \mathrm{C}$ 


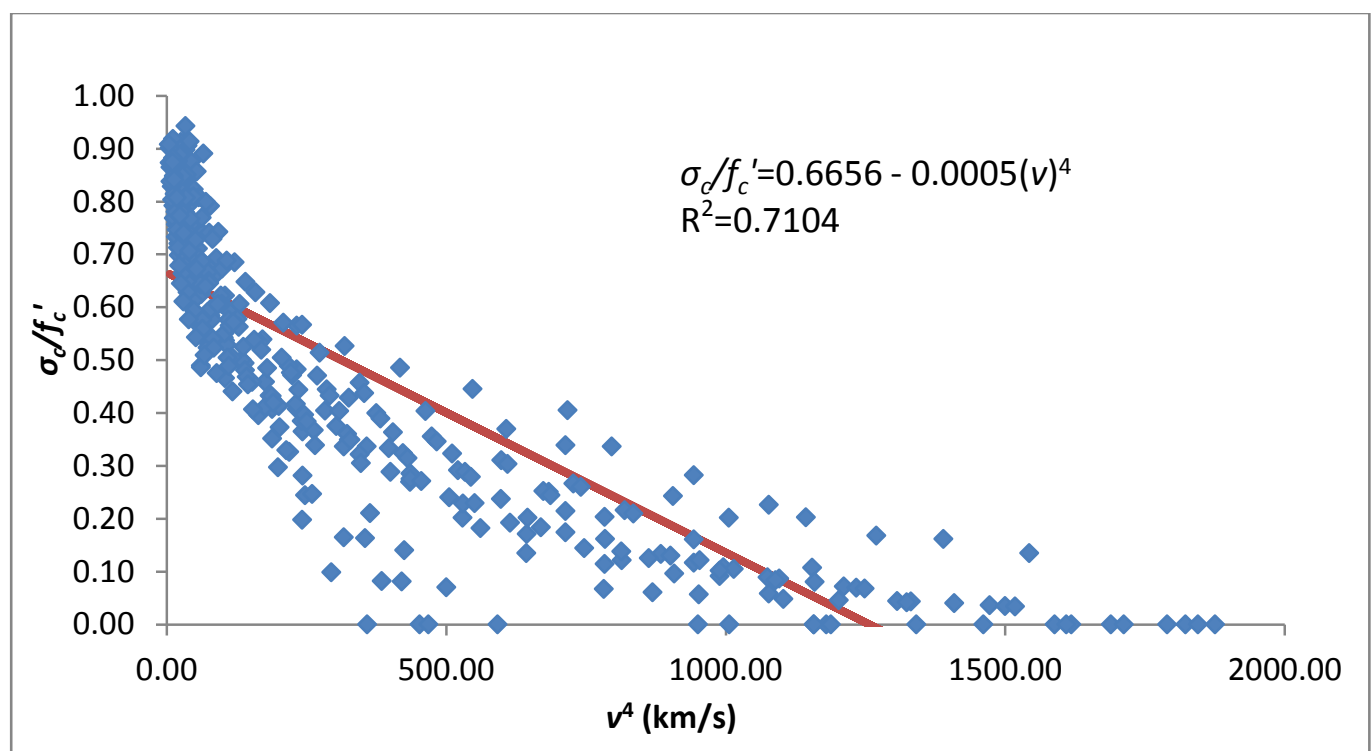

(a)

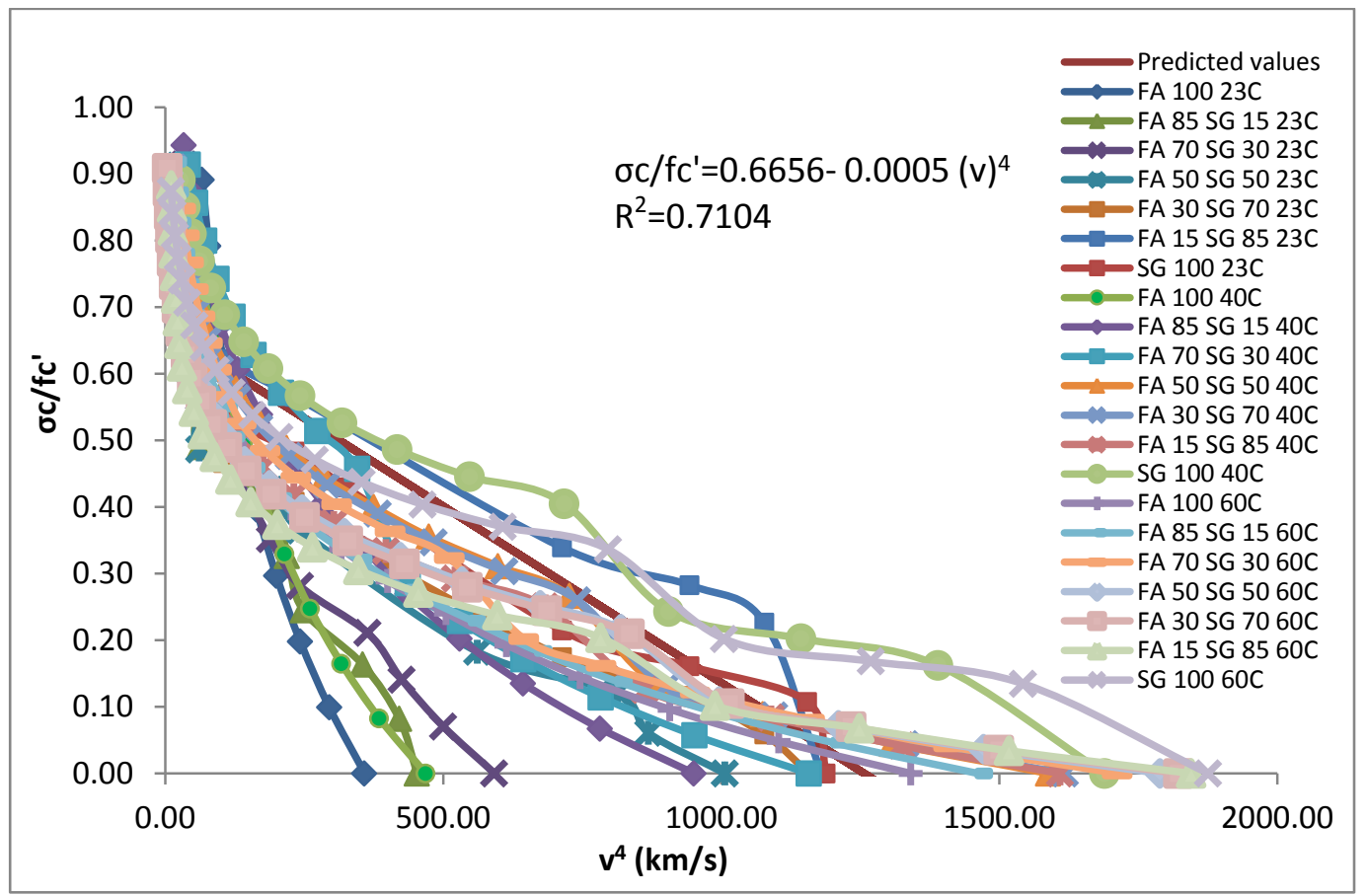

(b) 


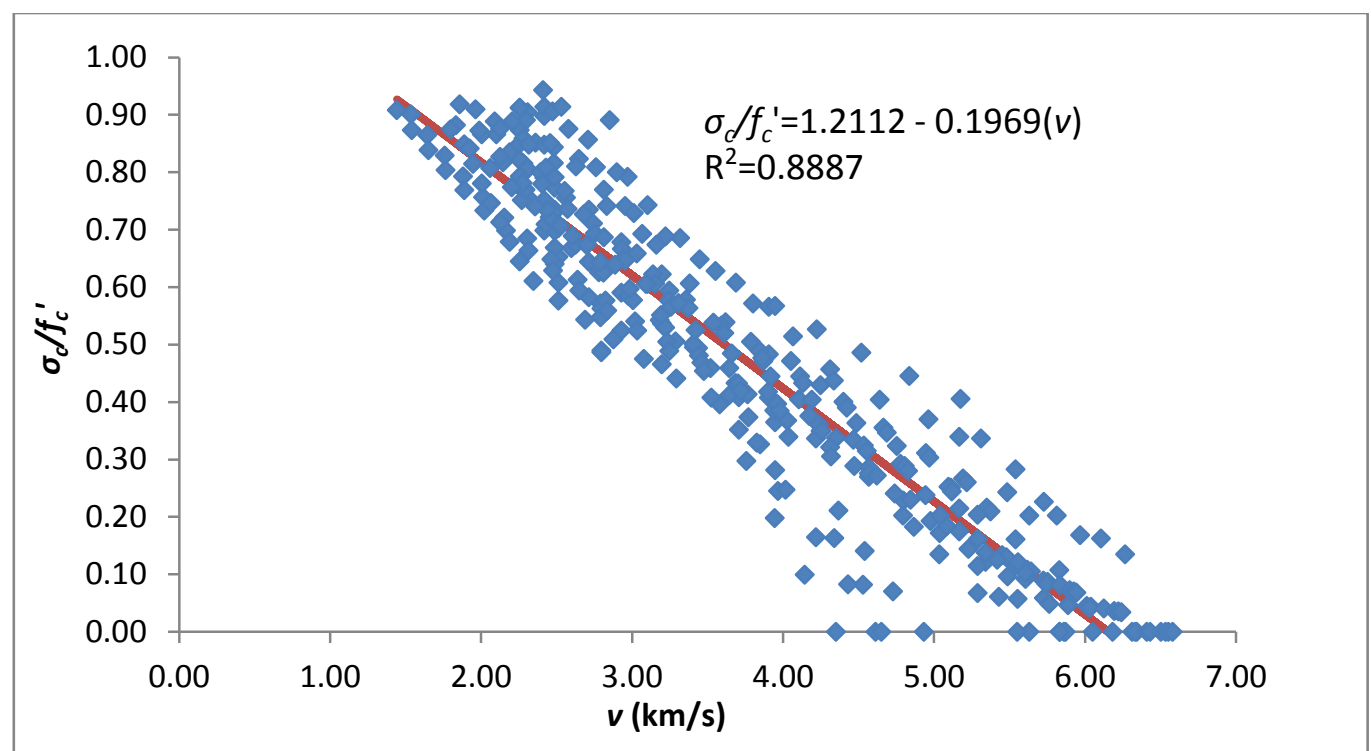

(c)

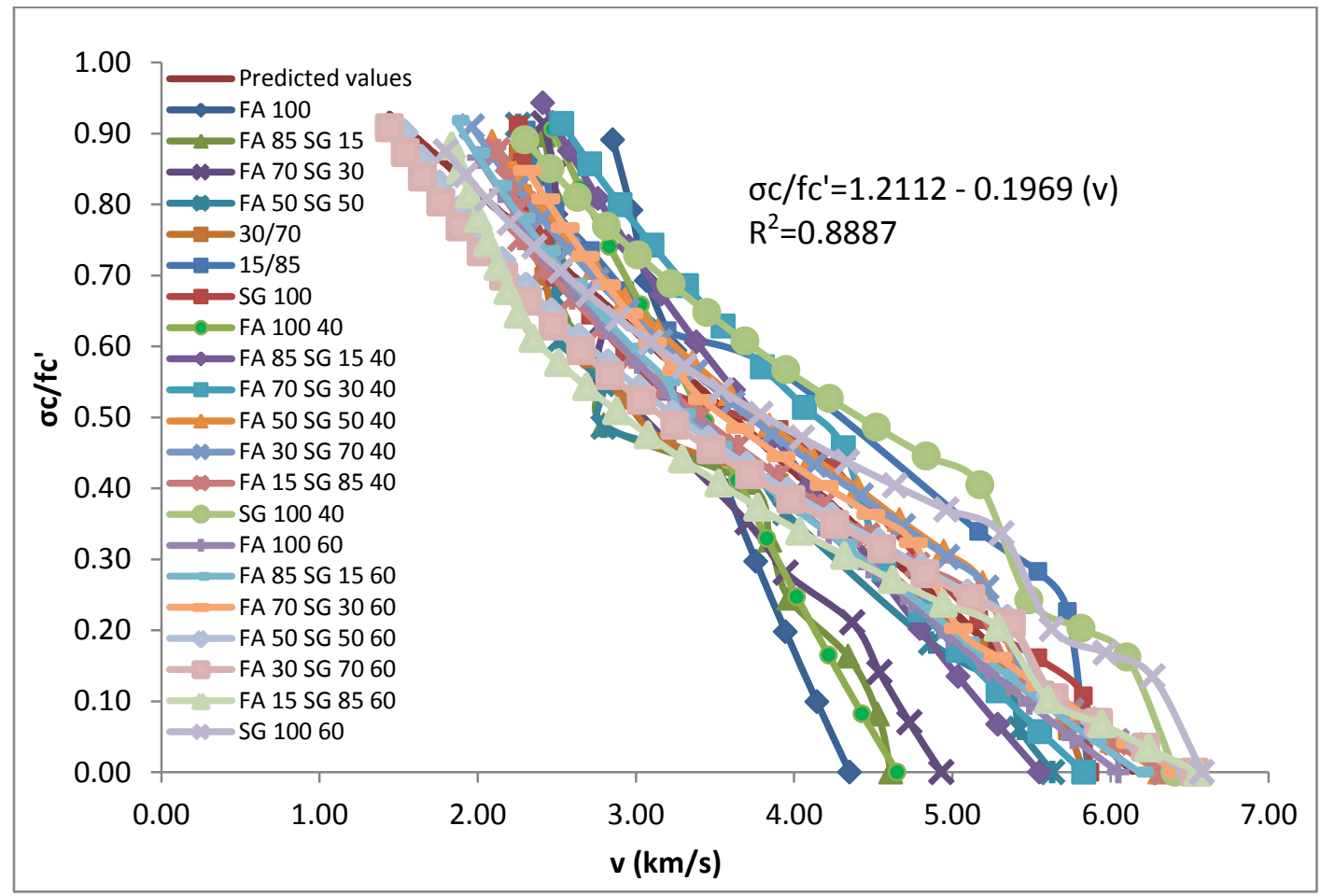

(d)

Fig. 6.18 (a) Variation of $\sigma_{c} / f_{c}^{\prime}$ vs. $v^{4}$ for all specimens (scatter plot for each mix); (b) Variation of $\sigma_{c} / f_{c}{ }^{\prime}$ vs. $v^{4}$ for all specimens (scatter plot with line for each mix); (c) Variation of $\sigma_{c} / f_{c}{ }^{\prime}$ vs. $v$ for all specimens (scatter plot for each mix); and (d) Variation of $\sigma_{c} / f_{c}{ }^{\prime}$ vs. $v$ for all specimens (scatter plot with line). 
The different equations for the cases mentioned above have been provided in Table 6.6, along with their corresponding $\mathrm{R}^{2}$ values. For each of the cases, it was noticed that the equations obtained in case of $\sigma_{d} / f_{c}{ }^{\prime}$ ratio expressed as $f(v)$ showed significantly better $\mathrm{R}^{2}$ values than the corresponding equations which expressed $\sigma_{d} / f_{c}{ }^{\prime}$ ratio as $f\left(v^{4}\right)$.

After comparing Fig. 6.14 (d) with Fig. 6.18 (d), it can be seen that the $\sigma / f_{c}^{\prime}$ as $f(v)$ is a better model than $\sigma$ as $f(v)$.

Table 6.6 Variation of $\sigma_{c} / f_{c}{ }^{\prime}$ vs. $v^{4}$ and $\sigma_{c} / f_{c}{ }^{\prime}$ vs. $v$

\begin{tabular}{|c|c|c|}
\hline Temperature & Equation & $\mathrm{R}^{2}$ \\
\hline \multirow{2}{*}{$23^{\circ} \mathrm{C}$} & $\sigma_{c} / f_{c}^{\prime}=0.6694-0.0007 \mathrm{~V}^{4}$ & 0.6437 \\
\cline { 2 - 3 } & $\sigma_{c} / f_{c}^{\prime}=1.2833-0.2263 \mathrm{~V}$ & 0.8370 \\
\hline \multirow{2}{*}{$40^{\circ} \mathrm{C}$} & $\sigma_{c} / f_{c}^{\prime}=0.6944-0.0006 \mathrm{~V}^{4}$ & 0.7417 \\
\cline { 2 - 3 } & $\sigma_{c} / f_{c}^{\prime}=1.3238-0.2161 \mathrm{~V}$ & 0.9034 \\
\hline \multirow{2}{*}{$60^{\circ} \mathrm{C}$} & $\sigma_{c} / f_{c}^{\prime}=0.6545-0.0005 \mathrm{~V}^{4}$ & 0.7703 \\
\cline { 2 - 3 } & $\sigma_{c} / f_{c}^{\prime}=1.1356-0.1798 \mathrm{~V}$ & 0.9572 \\
\hline \multirow{2}{*}{ All specimens } & $\sigma_{c} / f_{c}^{\prime}=0.6657-0.0005 \mathrm{v}^{4}$ & 0.7104 \\
\cline { 2 - 3 } & $\sigma_{c} / f_{c}^{\prime}=1.2112-0.1969 \mathrm{~V}$ & 0.8887 \\
\hline
\end{tabular}

\section{Sample codes from $\mathbf{R}$}

$<<>>=$

upvfcvar<-read.csv("upvfcvar.csv", header = T)

attach(upvfcvar)

head(upvfcvar)

names(upvfcvar)

(upvfcvar. Im23<-Im(strvar23 upv23pow4))

(upvfcvar.Im40<-Im(strvar40 upv40pow4))

(upvfcvar.Im60<-Im(strvar60 upv60pow4))

(upvfcvar.Imalldata<-Im(strvaralldata upvalldatapow4))

summary(upvfcvar.Im23)

summary(upvfcvar.Im40)

summary(upvfcvar.Im60)

summary(upvfcvar.Imalldata) 


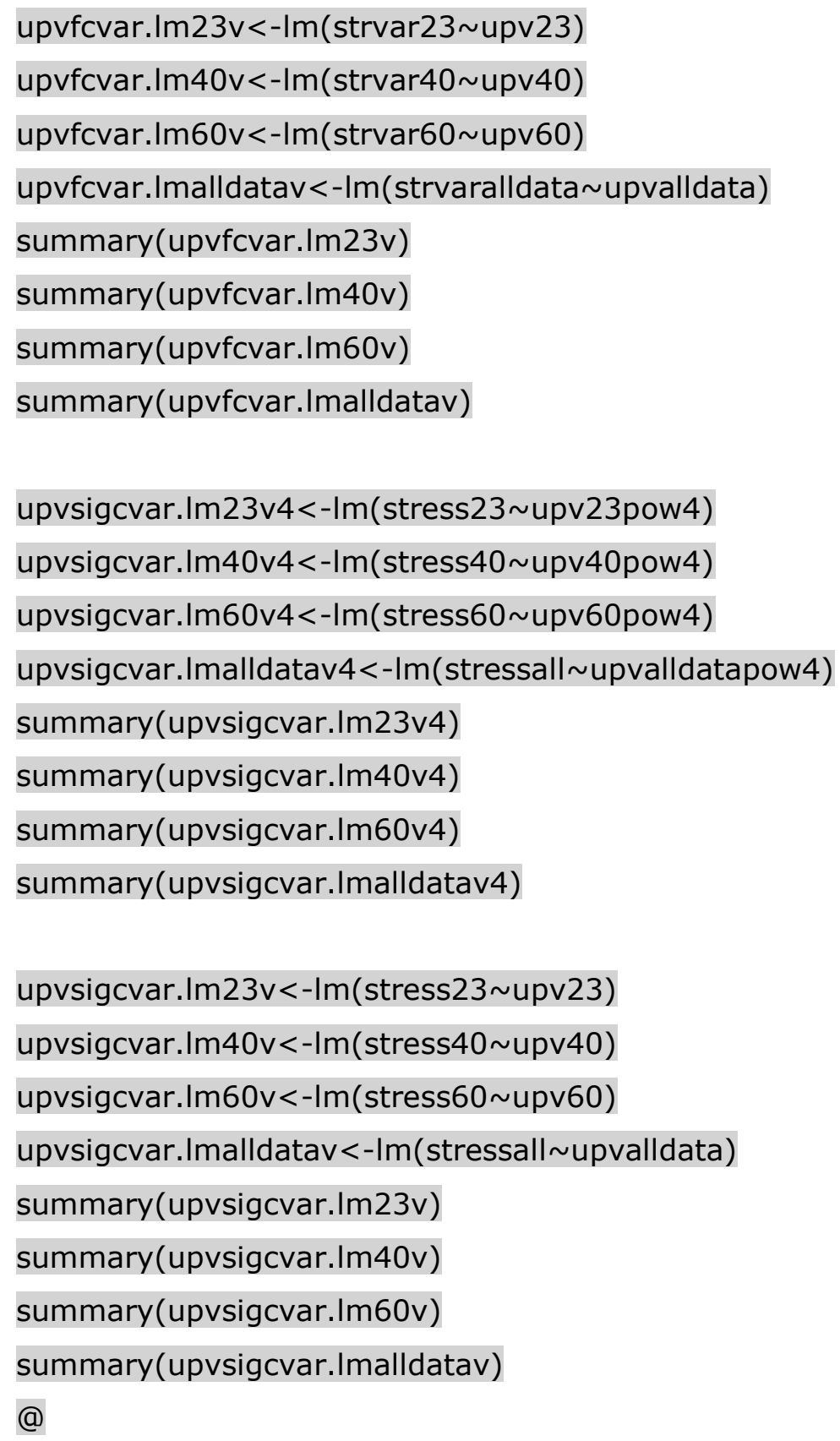

Now, as the present study was aimed at developing a new construction material which can serve as an alternative to PC concrete, it was necessary to check whether the density of the material was comparable to that for PC concrete. The details are provided in the following section. 


\subsection{Density of Concrete with AAB}

The density of concrete primarily depends on the unit mass of aggregates used in the mixture and other factors like air voids and entrained air. Because the type of aggregates in all the mixtures did not vary, the density of the hardened $A A B$ specimens should vary only marginally between 2330 to $2430 \mathrm{~kg} / \mathrm{m}^{3}$. (Hardjito and Rangan, 2005). For the present study, the minimum mass density was $2317.67 \mathrm{~kg} / \mathrm{m}^{3}$ and the maximum mass density was $2342.33 \mathrm{~kg} / \mathrm{m}^{3}$ across all specimens including the different combinations of age and temperature. In practice, the density of normal weight PC concrete lies within the range of 2200 to $2600 \mathrm{~kg} / \mathrm{m}^{3}$ (Neville 2007). So, concrete with AAB was comparable to PC concrete regarding the aspect of density. The maximum, minimum, mean values and corresponding coefficients of variation (COV) are summarized in Table 6.7.

It was observed that the mean densities increased with increase in curing temperature. The maximum and minimum densities at $23^{\circ} \mathrm{C}$ and $40^{\circ} \mathrm{C}$ were coincidentally equal. At all three curing temperatures, the COVs were extremely small which showed that the specimens were more or less consistent in nature.

Table 6.7 Density of AAB Concrete Specimens at Different Curing Temperatures

\begin{tabular}{|c|c|c|c|c|}
\hline Temperature & $\begin{array}{c}\text { Maximum } \\
\left(\mathrm{kg} / \mathrm{m}^{3}\right)\end{array}$ & $\begin{array}{c}\text { Minimum } \\
\left(\mathrm{kg} / \mathrm{m}^{3}\right)\end{array}$ & $\begin{array}{c}\text { Mean } \\
\left(\mathrm{kg} / \mathrm{m}^{3}\right)\end{array}$ & $\begin{array}{c}\text { COV } \\
(\%)\end{array}$ \\
\hline $23^{\circ} \mathrm{C}$ & 2330.00 & 2317.67 & 2323.84 & 0.270 \\
\hline $40^{\circ} \mathrm{C}$ & 2330.00 & 2317.67 & 2325.07 & 0.264 \\
\hline $60^{\circ} \mathrm{C}$ & 2342.33 & 2330.00 & 2336.17 & 0.268 \\
\hline
\end{tabular}

\subsection{Comparison between Concrete with AAB and PC Concrete}

This section presents a comparison between the different properties of concrete with $A A B$ that were evaluated in this study, with the corresponding values of the same properties for PC concrete (Table 6.8) 
Table 6.8 Comparison between Concrete with AAB and PC

\begin{tabular}{|c|c|c|}
\hline Property & $\begin{array}{l}\text { Concrete with AAB } \\
\text { (from this study) }\end{array}$ & $\begin{array}{c}\text { PC Concrete } \\
\text { (from Neville 2007) }\end{array}$ \\
\hline$f_{c}^{\prime}$ & $\begin{array}{c}20.9 \text { to } 85.0 \mathrm{MPa} \\
\text { (3030 to } 12330 \mathrm{psi})\end{array}$ & $\begin{array}{l}20 \sim 40 \mathrm{MPa}(3000 \sim 6000 \mathrm{psi}) \\
\text { upto } 80 \mathrm{MPa}(12,000 \mathrm{psi}) \text { for HPC* }\end{array}$ \\
\hline$f_{t}^{\prime}$ & $\begin{array}{l}2.13 \sim 5.94 \mathrm{MPa} \\
(310 \sim 860 \mathrm{psi})\end{array}$ & $\begin{array}{l}2 \sim 5 \mathrm{MPa}(300 \sim 700 \mathrm{psi}) \\
\text { upto } 6 \mathrm{MPa}(900 \mathrm{psi}) \text { for HPC* }\end{array}$ \\
\hline$f_{r}^{\prime}$ & $\begin{aligned} 0.63 & \sim 13.29 \mathrm{MPa} \\
(90 & \sim 1930 \mathrm{psi})\end{aligned}$ & $\begin{array}{l}3 \sim 5 \mathrm{MPa}(400 \sim 700 \mathrm{psi}) \\
\text { upto } 7 \mathrm{MPa}(1020 \mathrm{psi}) \text { for HPC* }\end{array}$ \\
\hline UPV & $4.04 \sim 6.39 \mathrm{~km} / \mathrm{s}$ & $\begin{array}{c}4 \sim 5.5 \mathrm{~km} / \mathrm{s} \\
\text { upto } 6 \mathrm{~km} / \mathrm{s} \text { for HPC* }\end{array}$ \\
\hline $\begin{array}{l}\text { Modulus of } \\
\text { Elasticity }\end{array}$ & $15.5 \sim 31.2 \mathrm{GPa}$ & $\begin{array}{l}14 \sim 41 \mathrm{GPa} \\
\text { upto } 55 \mathrm{GPa} \text { for } \mathrm{HPC} *\end{array}$ \\
\hline Density & $2330 \sim 2342 \mathrm{~kg} / \mathrm{m}^{3}$ & $2200 \sim 2600 \mathrm{~kg} / \mathrm{m}^{3^{*}}$ \\
\hline
\end{tabular}

In this chapter, the nondestructive characterizations of $A A B$ are discussed and equations were developed to express the compressive strength, dynamic modulus of elasticity and applied stress as functions of ultrasonic pulse velocity respectively. The following chapter will discuss a technique to establish a correlation between the microstructural properties and the specimen level characteristics of the AAB. 


\section{CHAPTER 7}

\section{CORRELATION BETWEEN MICROSTRUCTURAL PROPERTIES AND SPECIMEN LEVEL PROPERTIES OF CONCRETE WITH ALKALI ACTIVATED BINDER}

The present study developed a multi-variable linear regression model to predict concrete compressive strength such that the combined influence of the microstructure as well as the specimen level properties was included in the model.

\subsection{Basis of Model Development}

Many attempts have been made in the past to formulate a suitable mathematical model to predict the compressive strength of concrete, particularly PC concrete, at various ages with satisfactory accuracy. According to some researchers, compressive strength depends on the cement composition, cement degree of hydration, and aggregate types, sizes and shapes (de Larrard, 1999; de Larrard and Belloc, 1997). They proposed a comprehensive model for predicting the concrete compressive strength on the basis of the mixture composition and accounting for the physical and chemical characteristics of the concrete mixture, such as cement type and degree of hydration and proportions of aggregates and cement (de Larrard and Belloc, 1997). Other researchers investigated the relationship between clinker phase composition and strength after a certain hydration period using multiple linear regression analysis and thus assuming an additive action of the phases involved (Abd et al., 2008).

The simplest form of such a model can be expressed as

$$
f_{c}^{\prime}=a+b\left(\mathrm{C}_{3} \mathrm{~S}\right)+c\left(\mathrm{C}_{2} \mathrm{~S}\right)+d\left(\mathrm{C}_{3} \mathrm{~A}\right)+e\left(\mathrm{C}_{4} \mathrm{AF}\right)
$$

Where,

$f_{c}{ }^{\prime}$ was the compressive strength; $C_{3} S, C_{2} S, C_{3} A$, and $C_{4} A F$ represented the mineral phases present in cement; and $a, b, c, d$, e were the respective regression coefficients.

The multi-variate linear equation was the focus of numerous research efforts over many years. Some researchers used this equation and tried to find out which of the four phases contributes most to the strength of the cement (Abd et al., 2008), and others tried to 
improve this linear model by introducing other variables that affect cement strength to the original equation (Liu et al., 2009, Huang et al., 2011). The initial phases react to produce the hydration products which finally govern the compressive strength. The present study already established an equation to determine the volume of the reaction products due to the alkali activation of the precursors. Hence, those volumes were used as input parameters for the final model instead of the initial composition of the raw materials. However, other parameters also needed to be incorporated to enhance the accuracy of prediction.

Given the fast pace of field construction, there is a need for a model which can accurately predict the compressive strength of concrete at different ages. Waiting for 28 days to obtain the compressive strength would hinder the speed of construction. Thus, lack of knowledge regarding the 28-day compressive strength would be a deterrent to quality control at the construction sites. Hence, both the producer and purchaser or user need a rapid and reliable way to predict the 28 day compressive strength instead of waiting for the traditional 28 days results. Rapid determination or prediction of the strength of concrete could be obtained by: (i) suitable prediction model which considers the microstructural properties of the $A A B$, and (ii) accelerated strength testing results.

Some existing compressive strength prediction models for PC concrete combined these two aspects. In one such case, the accelerated strength test results were obtained indirectly through nondestructive testing, such as rebound hammer test (Liu et al., 2009, Huang et al., 2011) or ultrasonic pulse velocity tests (Abd et al., 2008, Huang et al., 2011). The basic concept of the model was to produce a reliable relationship between compressive strength of concrete and its own characteristics at the microstructural level as well as the specimen level. Due to the uncertainties associated with the microstructure of concrete, the models must be formulated using some experimental results (Abd et al. 2008). In the conventional material modeling process, regression analysis is an important tool for constructing a model (Liu et al., 2009).

It is evident from the present study that the compressive strengths of the $A A B$ cubes in Chapter 3 and those of the $A A B$ concrete cylinders in Chapter 5 showed similar trends. This is true in case of each of the three different curing temperatures as well as in case of different percentages of slag being used to replace fly ash. Hence it was understood that the microstructural properties of the $A A B$ definitely influenced the characteristics of the AMM concrete specimens. All the above findings and suggestions were kept in mind while 
developing a model to correlate the microstructural properties with the specimen level properties.

The concept of quantitative determination of the different phases in the AAB microstructure was combined with the results from the ultrasonic pulse velocity test in order to come up with a multi-variable regression model for $A A B$ concrete. The idea was to express the compressive strength as a function of the volume of microstructural phases and the UPV results. For this purpose, two major aspects were considered:

(i) The mechanisms involved in $A A B$ chemistry have not been fully decoded yet. So, to overcome this issue, the present study must adopt a multi-variate nonlinear regression model instead of a simple linear regression model.

(ii) The present study involved mixture proportions where fly ash was partially replaced by slag. The polymerization of fly ash proceeded by alkali activation, whereas, slag hydration proceeded in a way similar to weak portland cement hydration. So, combination of these two phenomena was considered while developing the model to predict the compressive strength.

\subsection{Formulation of Proposed Regression Model}

The proposed nonlinear regression model can be expressed as

$$
f_{\mathrm{c}}^{\prime}=\operatorname{nlf}\left(V_{f, A A B,} V_{f, C S H}(S), V\right)
$$

where $f_{c}{ }^{\prime}$ is the $A A B$ compressive strength;

nlf denotes nonlinear function;

$\mathrm{V}_{\mathrm{f}, \mathrm{AAB}}=$ volume fraction of reacted $A A B$ paste products at any degree of reaction, $\alpha_{\mathrm{FA}} ; \mathrm{V}_{\mathrm{f}, \mathrm{CSH}(\mathrm{S})}$

$=$ volume fraction of $\mathrm{CSH}(\mathrm{S})$ at degree of slag hydration, $\alpha$ (microstructural properties);

$v$ denotes the results obtained from the ultrasonic pulse velocity test at the specimen level.

The equation will be of the form

$$
f_{\mathrm{c}}^{\prime}=\mathrm{a}\left(V_{f, A A B}\right)^{\mathrm{b}}+\mathrm{c}\left(V_{f, C S H(S)}\right)^{\mathrm{d}}+\mathrm{e}(V)^{\mathrm{f}}+k+\varepsilon
$$


where $a$ and $b$ are obtained from the nonlinear regression to denote the effect of $v_{f, A A B}$;

$c$ and $d$ are obtained from the nonlinear regression to denote the effect of $v_{f, C S H}(S)$;

$e$ and $f$ are obtained from the nonlinear regression to denote the effect of the ultrasonic pulse velocity; and

$k$ denotes the effect of all other uncertainties in the study ;

$\varepsilon$ denotes the error term which is normally distributed with zero mean and constant variance.

The volume fractions were determined using the technique described in section 4.9. The ultrasonic pulse velocities were determined experimentally using the procedure described in section 6.1. The statistical analyses were performed using the software called ' $R$ ' which is available for free on the internet. The ' $\mathrm{nls}()^{\prime}$ ' command in ' $\mathrm{R}$ ' was used to model the nonlinear regression of the multiple variables used in the present study.

Instead of selecting an arbitrary empirical equation to represent the compressive strength model, the present study referred to the equations suggested by previous researchers (Huang et al., 2011). Several multi-variable regression models have been previously developed and published in various refereed journals and conference proceedings. To be statistically unbiassed in selection and application, the models suggested by previous researchers (Huang et al., 2011, Panzera et al., 2011) were modified to satisfy the requirements of the present study. The models were formulated using 60 out of a total of 90 experimental data points as calibration data. The remaining 30 data points were then used to test the accuracy and the validation of the proposed model. The relevant details have been presented in section 7.3. Before going in to that, this section will discuss how the different models were modified and fitted to the available data.

For each model form, two different regression equations were fitted to the available data i) with a regression constant, and ii) without a regression constant. In each case, the independent variables or regressors were the volume fractions of the $A A B$ reaction product and the $\mathrm{CSH}(\mathrm{S})$ due to slag hydration (both dimensionless quantities), along with the ultrasonic pulse velocity (in $\mathrm{km} / \mathrm{s}$ ). The independent variable or regressand was the compressive strength (in MPa). Table 7.1 gives the model forms which were obtained as outputs from $\mathrm{R}$ using nonlinear regression. 
Table 7.1 Different Models for $f_{c}^{\prime}$ in Terms of $v_{f, A A B}, v_{f, C S H(s)}$ and $v$

\begin{tabular}{|c|c|c|}
\hline $\begin{array}{c}\text { Model } \\
\text { No. }\end{array}$ & With constant & without constant \\
\hline 1 & $f_{c}^{\prime}=-4.535 v_{1}+13.852 v_{2}+18.264 v-55.323$ & $f_{c}^{\prime}=5.0169 V_{1}+40.0923 v_{2}+7.7533 \mathrm{~V}$ \\
\hline 2 & $f_{c}^{\prime}=0.899 v_{1}^{3}+38.861 v_{2}^{3}+18.979 v-57.001$ & $f_{c}^{\prime}=-14.0199 v_{1}^{3}+99.2694 v_{2}^{3}+8.8446 v$ \\
\hline 3 & $f_{c}^{\prime}=39.893 v_{1}+87.858 v_{2}-0.0013 v^{4}+28.093$ & $f_{c}^{\prime}=89.8 v_{1}+129.4 v_{2}+.0069 v^{4}$ \\
\hline 4 & $\begin{array}{c}f_{c}^{\prime}=-8.808 v_{1}+10.746 v_{2}- \\
89.740 v+10.135 v^{2}+223.932\end{array}$ & $\begin{aligned} f_{c}^{\prime}= & 5.4075 v_{1}+11.2982 v_{2}^{-} \\
& 3.9182 v+2.1528 v^{2}\end{aligned}$ \\
\hline 5 & $\begin{array}{c}\ln \left(f_{c}^{\prime}\right)=0.1660 v_{1}+0.2621 v_{2}+2.1694 \ln (v)+ \\
0.0583\end{array}$ & $\ln \left(f_{c}^{\prime}\right)=0.1596 v_{1}+0.2400 v_{2}+2.2063 \ln (v)$ \\
\hline 6 & $\begin{array}{c}\ln \left(f_{c}^{\prime}\right)=0.0134 \ln \left(V_{1}\right)- \\
0.0025 \ln \left(V_{2}\right)+2.3219 \ln (V)-0.1024\end{array}$ & $\begin{array}{c}\ln \left(f_{c}^{\prime}\right)=0.0151 \ln \left(V_{1}\right)- \\
0.0056 \ln \left(V_{2}\right)+2.2629 \ln (V)\end{array}$ \\
\hline 7 & $\ln \left(f_{c}^{\prime}\right)=0.4253\left(\sqrt{\ln }\left(\left(v_{1}+v_{2}\right)^{3}(v)^{4}\right)\right)+3.0873$ & $\ln \left(f_{C}^{\prime}\right)=1.8948\left(\sqrt{\ln }\left(\left(v_{1}+v_{2}\right)^{3}(V)^{4}\right)\right)$ \\
\hline 8 & $\begin{array}{c}\sqrt{f_{c}^{\prime}}=-0.4385 / v_{1}- \\
0.5091 / v_{2}+0.0861 v^{*}\left(1 / v_{1}+1 / v_{2}\right)+7.0568\end{array}$ & $\begin{array}{c}\sqrt{f_{c}^{\prime}}=-0.6128 / v_{1}^{-} \\
0.8665 / v_{2}+0.2100 v^{*}\left(1 / v_{1}+1 / v_{2}\right)\end{array}$ \\
\hline 9 & $f_{c}^{\prime}=40.45 v_{1}+88.38 v_{2}+26.63$ & $f_{c}^{\prime}=106.341 v_{1}+142.702 v_{2}$ \\
\hline
\end{tabular}

Symbols:

$$
\begin{aligned}
& v_{1}=v_{f, A A B} \\
& v_{2}=V_{f, C H H(S)} \\
& v=\text { ultrasonic pulse velocity }
\end{aligned}
$$

In the next section, the selection of the most suitable model for the purpose of the present study is discussed.

\subsection{Selection of Suitable Prediction Model}

The statistical measure that was used to select the most suitable model was the mean square error. The models were ranked based on their respective mean square errors. The model having the least mean square error was assigned Rank 1 . The rankings increased with increasing mean square errors. The results have been shown in Table 7.2. Evidently, Model 1 performed the best when the regression constant was considered, i.e. Model 1 had the least mean square error. Similarly, for the case without regression constant Model 4 was the most accurate. Although Model 4 without constant had the least mean square error, it was ideal to propose an equation with the constant as the prediction model. The constant accounts for all the uncertainties in the model which arise from the variables that are 
considered during regression for the sake of simplicity. The uncertainties mentioned here generally occur due to the shape and size of the specimen, shape and size of the aggregates used and interactions between the particles of the binder and the aggregates.

Comparing all the models together, Model 1 was found to have the least mean square error among the models with constants. Also, the mean square error for Model 1 was 0.053 whereas the mean square error for Model 4 without constant was 0.026 . So, even if Model 1 was selected over Model 4, accuracy would not be compromised much. Thus, Model 1 with constant (Eqn. 7.3) was selected as the best ranking or most accurate model based on the mean square error values.

$$
f_{c}^{\prime}=-4.535 v_{1}+13.852 v_{2}+18.264 v-55.323
$$

Table 7.2 Rankings of Compressive Strength Models Based on Mean Square Errors

\begin{tabular}{|c|c|c|c|c|}
\hline $\begin{array}{c}\text { Model } \\
\text { No. }\end{array}$ & $\begin{array}{c}\text { Mean Square Error } \\
\text { (with constant) }\end{array}$ & $\begin{array}{c}\text { Rank (With } \\
\text { constant) }\end{array}$ & $\begin{array}{c}\text { Mean Square Error } \\
\text { (without constant) }\end{array}$ & $\begin{array}{c}\text { Rank (without } \\
\text { constant) }\end{array}$ \\
\hline 1 & 0.053 & 1 & 4.559 & 2 \\
\hline 2 & 0.128 & 2 & 9.763 & 4 \\
\hline 3 & 0.886 & 4 & 7.069 & 3 \\
\hline 4 & 0.910 & 5 & 0.026 & 8 \\
\hline 5 & 1806.167 & 9 & 1806.231 & 7 \\
\hline 6 & 1797.345 & 7 & 1797.278 & 9 \\
\hline 7 & 1797.345 & 7 & 1828.525 & 6 \\
\hline 8 & 1522.051 & 6 & 1697.487 & 5 \\
\hline 9 & 0.846 & 3 & 16.035 & \\
\hline
\end{tabular}

It was also interesting to note that Model 9 which expressed $f_{c}{ }^{\prime}$ as functions of $v_{f, A A B}$ and $\mathrm{V}_{\mathrm{f}, \mathrm{CSH}(\mathrm{S})}$ only was not as accurate as Model 1 for both cases, i.e. with constant and without constant. Thus it was essential to include ultrasonic pulse velocity as an input parameter in the model. The next section discusses the statistical significance of the independent variables or regressors in the model.

\subsection{Significance of Independent Variables}

"In statistical testing, a result is deemed statistically significant if it is so extreme (without external variables which would influence the correlation results of the test) that such a result would be expected to arise simply by chance only in rare circumstances. 
Popular levels of significance are $10 \%(0.1), 5 \%(0.05), 1 \%(0.01), 0.5 \%(0.005)$, and $0.1 \%(0.001)$. If a test of significance gives a $p$-value lower than or equal to the significance level, the null hypothesis is rejected at that level. Such results are informally referred to as 'statistically significant (at the $p=0.05$ level, etc.)'. For example, if someone argues that "there's only one chance in a thousand this could have happened by coincidence", a 0.001 level of statistical significance is being stated. The lower the significance level chosen, the stronger the evidence required (Fisher, 1926)."

While specifying any regression model it is necessary to analyze whether all the independent variables are statistically significant or not. If all the independent variables included in the model are not significant, then the sum of squares due to the residuals increases. Hence, the output from $\mathrm{R}$ was analyzed to determine the statistical significance of the variables. The $p$-values of the model parameters provided an indication of the most significant parameters influencing the compressive strength. Those $p$-values of the model parameters were used to compare between the models with the regression constant and that without a regression constant.

The outputs for Model 1 have been presented in Table 7.3.

Table 7.3 Output from $\mathbf{R}$ for Model 1 (with constant)

\begin{tabular}{|c|c|c|c|c|}
\hline \multicolumn{5}{|c|}{ Formula: fc $\sim\left(\mathrm{a} * \mathrm{vf} \_\mathrm{AAB}+\mathrm{c} * \mathrm{vf} \_\mathrm{CSH}+\mathrm{e} * \mathrm{upv}+\mathrm{k}\right)$} \\
\hline Parameters: & Estimate & Std. Error & t value & $\operatorname{Pr}(>|\mathrm{t}|)$ \\
\hline $\mathrm{a}$ & 4.535 & 7.099 & 0.639 & $0.5255(\mathrm{)}$ \\
\hline $\mathrm{c}$ & 13.852 & 7.767 & 1.783 & $0.0799()$. \\
\hline $\mathrm{e}$ & 18.264 & 1.282 & 14.242 & $<2 \mathrm{E}-16(* * *)$ \\
\hline $\mathrm{k}$ & -55.323 & 6.232 & -8.877 & $2.85 \mathrm{E}-12(* * *)$ \\
\hline
\end{tabular}

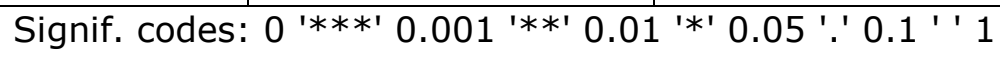

The null hypothesis $\left(\mathrm{H}_{0}\right)$ tested in this case was $\mathrm{a}=0, \mathrm{c}=0$, and $\mathrm{e}=0$ against the alternative hypothesis $\left(H_{a}\right)$ that $a \neq 0, c \neq 0$, and $e \neq 0$. From Table 7.3a, it was observed that the ultrasonic pulse velocity was statistically significant at 0.001 level $(0.1 \%)$ based on the $\operatorname{Pr}(>|t|)$ values from the ' $R$ ' output. In other words, the null hypothesis $H_{0}$ : $e=0$ could not be rejected with $99.9 \%$ confidence. The volume fraction of $\mathrm{CSH}(\mathrm{S})$ was significant at 0.1 level $(10 \%)$, i.e., $H_{0}$ : $a=0$ could not be rejected with a $90 \%$ confidence. The volume fraction of $A A B$ was significant at level $1(100 \%)$, i.e., $\mathrm{H}_{0}: b=0$ could not be rejected with a 
$0 \%$ confidence. The significance of variables only gives an idea about the confidence with which the null hypothesis may be accepted or rejected, but it is up to the engineer to decide which independent variables to include in the regression model. For the present case, the influence of the volume fractions have been retained in the model as the objective is to predict the compressive strength of concrete with $A A B$ as a function of both micro and specimen level properties. The accuracy of the proposed model is discussed in the next section.

\subsection{Test for Accuracy of the Proposed Model}

After Model 1 was found to be the most accurate in terms of mean square error, the validity of the model was checked by its predicting accuracy of the experimental data from the present study. In Fig. 7.1, the comparison between the predicted compressive strengths and the experimental values showed that they were in very good agreement with corresponding $\mathrm{R}^{2}$ value of 0.898 .

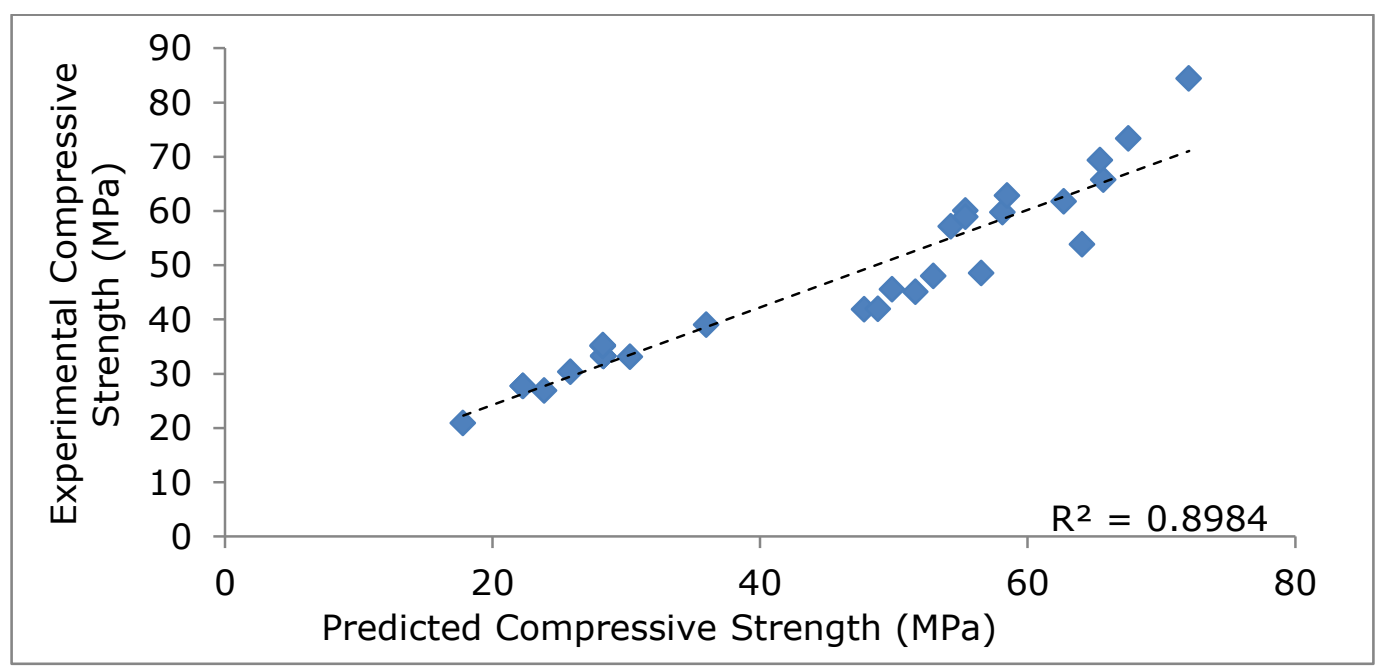

Fig. 7.1 Comparison between the predicted compressive strengths and the experimental values

The data points were scattered nearly evenly around the dotted line denoting the predicted compressive strengths, indicating that the predictions were almost unbiased. Thus, the accuracy of the model was assessed and established using an intuitive measure i.e. the 
mean square error as well as the coefficient of regression, $R^{2}$, which corroborated the "goodness of fit."

After establishing Model 1 as the most accurate model for all mixes in the present study, the next step was to test its accuracy in predicting the compressive strengths for individual mixes.

Fig 7.2 shows the comparison of the predicted and experimental compressive strengths for some of the mixes in the present study. All mixes have not been shown here for the sake of brevity. The plots for FA 100 cured at $60^{\circ} \mathrm{C}$, FA 50 SG 50 cured at $40^{\circ} \mathrm{C}$ and SG 100 cured at $40^{\circ} \mathrm{C}$ have been shown as examples.

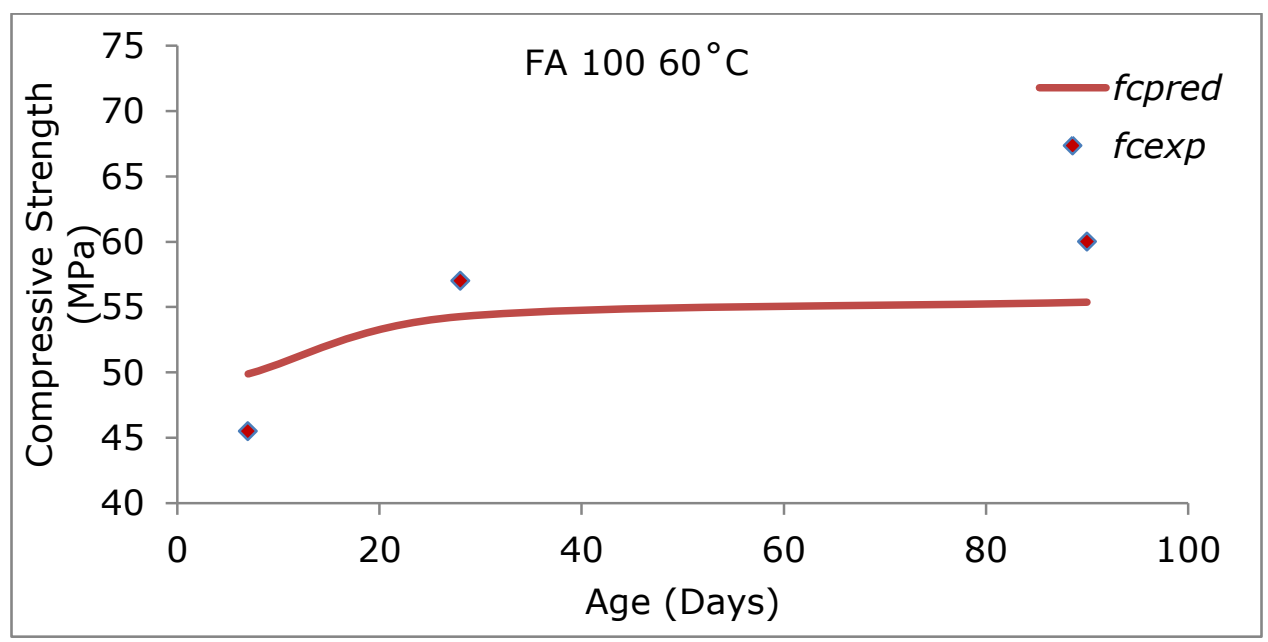

(a)

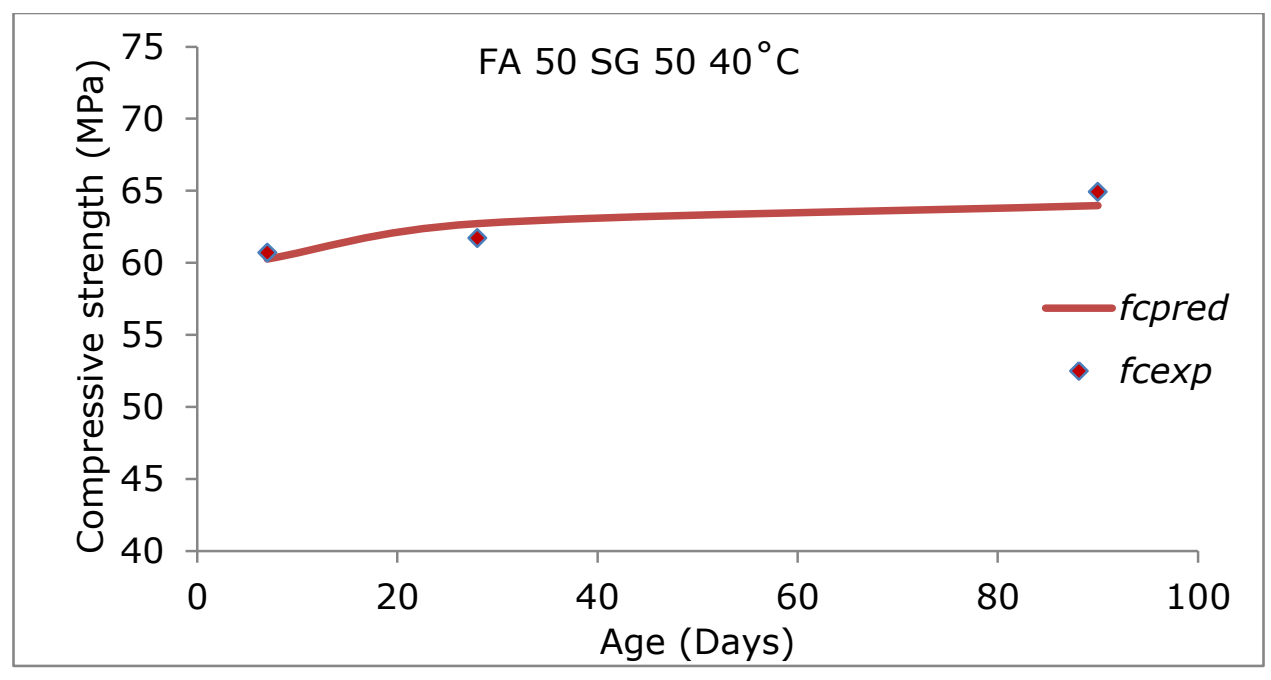

(b) 


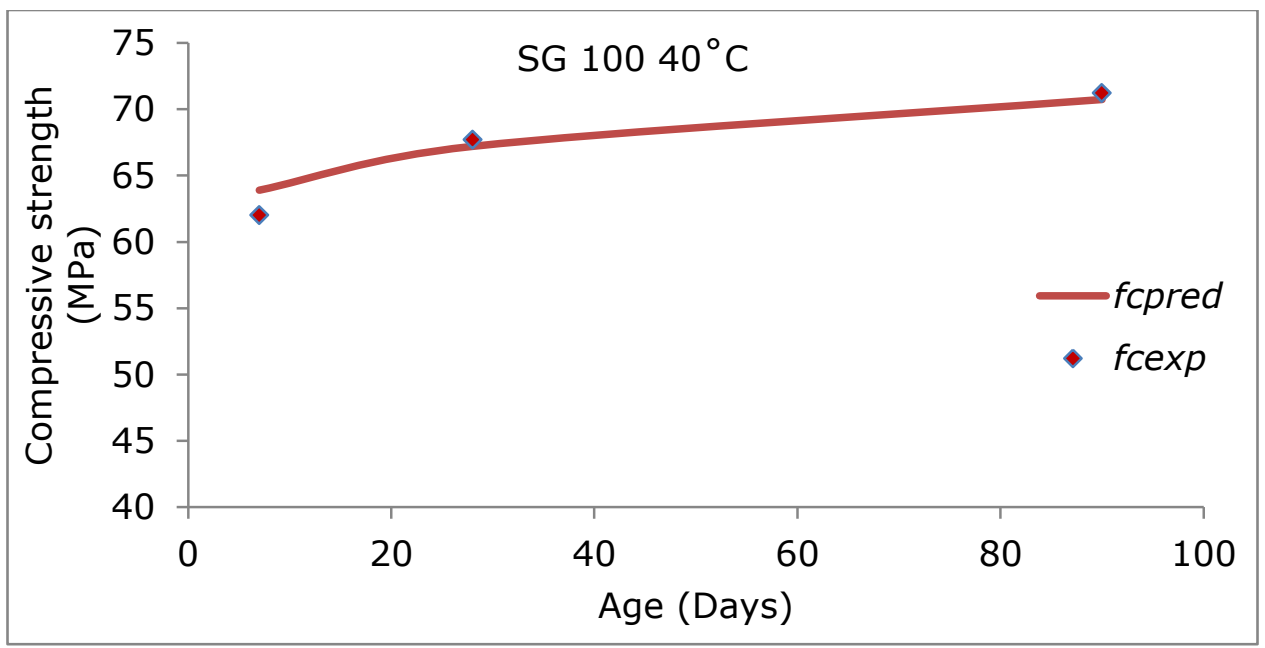

(c)

Fig. 7.2 Comparison between predicted and experimental compressive strengths for a few example $A A B$ concrete mixes

The experimental and predicted values for the compressive strengths were found to be reasonably close to each other by inspection.

Hence, for field engineers during practical use, compressive strengths can be predicted through the knowledge of ultrasonic pulse velocities only without any significant loss of accuracy, if the microstructural volume fractions are unknown. The models specified in Chapter 6, Table 6.4 can be used for this purpose. When the model contains only the ultrasonic pulse velocities as the independent variable, the constant in those cases represent the uncertainties due to the shape and size of the specimen, shape and size of the aggregates used and interactions between the particles of the binder and the aggregates.

An example code written in $\mathrm{R}$ for generating the prediction model has been shown below. The codes for all the different models that were considered in the study have been furnished in the Appendix.

\section{Coding in $\mathbf{R}$}

\section{Model1:}

$<<>>=$

library(car) 
library(nls2)

compstr<-read.csv("ModelData.csv", header = T)

validnstr<-read.csv("ValidnData.csv", header=T)

attach(compstr)

attach(validnstr)

fc. $\bmod <-n l s\left(f c \sim\left(a * v f \_A A B+c^{*} v f \_C S H+e^{*} u p v+k\right)\right.$, start=list $(a=52, c=25, e=4, k=6)$,

data $=$ compstr, trace $=F$ )

summary(fc.mod)

fc. pred<-predict(fc. mod, newdata=data.frame(validnstr))

mean(validnstr\$fc-fc.pred)^2

@

In this chapter, the details of the compressive strength prediction model were discussed in details with emphasis on establishing a correlation between the microstructure and the specimen level properties. The next chapter will discuss the summary of the present study from Chapters 1 through 7, the relevant conclusions and the scope for further research. 


\section{CHAPTER 8 \\ SUMMARY AND CONCLUSIONS}

\subsection{Conclusions from the Present Study}

\subsubsection{Characterization of alkali activated concrete at microstructural level}

- XRD diffractograms revealed the presence of primarily amorphous phases in the AAB microstructure along with the presence of quartz, mullite, analcime and 180ydroxyl sodalite which were identified by their characteristic peaks.

- FTIR spectra showed the presence of Si-O-Si as well as Si-O-Al bonds and the presence of unreacted raw materials in microstructure of the AAB. The progress of reaction with increasing temperature or addition of $\mathrm{Ca}^{2+}$ ions through slag was also visible.

- SEM images showed that in general, the microstructure of the FA 100 AAB specimens was highly inhomogeneous and primarily made up of the reaction product resulting from the alkali activation - a sodium aluminosilicate gel that gave rise to the cementitious matrix. When slag was added, the lighter areas on the images indicated the $\mathrm{CSH}(\mathrm{S})$ phase formed due to the hydration of slag. $\mathrm{CSH}(\mathrm{S})$ was identified through SEM morphology from their fibrous to irregular grains forming reticular network.

- EDS analysis showed that the matrix primarily consisted of the phases containing $\mathrm{Na}-\mathrm{Si}-\mathrm{Al}$ in the bulk region in case of the specimens where fly ash was the main precursor. In addition to $\mathrm{Na}, \mathrm{Si}$ and $\mathrm{Al}$, traces of $\mathrm{Fe}, \mathrm{Ca}, \mathrm{K}$ and $\mathrm{Mg}$ were also observed in these specimens. These remnants ( $\mathrm{Fe}, \mathrm{Ca}, \mathrm{K}, \mathrm{Mg}$ ) obviously represented the unreacted fly ash phases, which did not dissolve during alkali activation. When slag was present in greater amounts, the presence of $\mathrm{Ca}^{2+}$ was more prominent.

- The degree of reaction of fly ash when activated with alkaline solution was found to increase appreciably with increase in curing temperature. However, in case of slag, the degree of reaction remained more or less independent of curing temperature.

- Isothermal calorimetry results showed that the area under the calorimetry curves for FA 100 AAB specimens increased with increasing temperature which indicated higher degree of reaction at elevated curing temperatures. 
- The predicted and experimental values of the volume fractions of $A A B$ as well as $\mathrm{CSH}(\mathrm{S})$ were in close agreement with each other showing the accuracy of the combined volume stoichiometry and optimization technique.

\subsubsection{Properties of alkali activated concrete at specimen level: destructive tests}

- It was observed that the compressive strength increased with the increasing percentage of slag added to $A A B$ concrete for all curing conditions and ages.

- It was observed that the splitting tensile strength increased with the increasing percentage of slag added to $A A B$ concrete for all curing conditions and ages.

- It was observed that the flexural strength increased with the increasing percentage of slag added to AAB concrete for all curing conditions and ages. These observations highlight the beneficial effects of slag as calcium ions to enhance the strength to otherwise only aluminosilicate (fly ash) precursor.

- $\quad A A B$ concrete was comparable to PC concrete regarding the aspect of density.

- Depending on the cost of power needed to achieve a certain curing temperature and the relative cost of adding different proportions of slag into the precursor mix, the user will have to arrive at a combination which will be best suited to his needs in terms of application as well as economy. The costs of the different materials generally vary from one location to another due to the different climates and availability of resources. So, the optimal combination of precursor and curing temperature will also depend on the location. Hence, instead of a unique optimal combination for AABs, it will be better to customize the optimal combination according to the need of the user.

\subsubsection{Properties of alkali activated concrete at specimen level: nondestructive characterizations}

- The ultrasonic pulse velocity increased with increasing dynamic modulus of elasticity. The modulus of elasticity was proportional to the square of the ultrasonic pulse velocity with significantly high $\mathrm{R}^{2}$ values. This was true for each of the curing temperatures studied.

- The general correlations developed between modulus of elasticity and ultrasonic pulse velocity combining all the curing temperatures and ages, also followed the 
trend of correlations with different curing temperatures; that the general correlation enables the technique to be used in case of $A A B$ concrete having unknown curing temperature.

- The ultrasonic pulse velocity increased with the increase of compressive strength. The correlations show that the compressive strength is proportional to the fourth power of ultrasonic pulse velocity, but the linear correlation with velocity also produced good results. This was true for each of the curing temperatures studied.

- The general correlations developed between compressive strength and ultrasonic pulse velocity combining all the curing temperatures and ages, also produced good correlations; this will make it possible that the technique can be used in case of $A A B$ concrete having unknown curing temperature.

- For the correlations of ultrasonic pulse velocity with the applied stress in concrete, the ultrasonic pulse velocities were found to be largest when the $A A B$ concrete specimen were not subjected to any stress, i.e., there was no deterioration. As the $\sigma_{d} / f_{c}^{\prime}$ ratio was increased gradually, the ultrasonic pulse velocities decreased appreciably. The lowest ultrasonic pulse velocities were observed when the $\sigma_{d} / f_{c}{ }^{\prime}$ ratios were the largest, i.e., when the concrete specimen was close to failure.

- The general correlations developed between $\sigma_{d} / f_{c}{ }^{\prime}$ ratio and ultrasonic pulse velocity function $f(v)$ indicate that first order correlations were superior compared to fourth order correlations. In other words, by normalizing the stress level of different $A A B$ concrete with respect to their corresponding ultimate strengths, the general correlations between ultrasonic pulse velocity and stress level can be made linear.

- The ultrasonic pulse velocity technique can be effectively used to estimate the modulus of elasticity, compressive strength, and stress level of $A A B$ concrete for wide range of mixes, curing temperature, and ages. This will help in monitoring the quality control and deterioration of the different $A A B$ concrete structures in the field. Even in case of previously made $A A B$ concretes where curing temperature, ages, and $A A B$ mix sources are not known, the present correlations can still be used to estimate the strength, modulus of elasticity, and stress level with reasonable accuracy. 


\subsubsection{Correlation between microstructural properties and specimen level properties of alkali activated concrete}

- Eqn. 7.3 was the most efficient in predicting the compressive strength of $A A B$ concrete as a function of the microstructural volume fractions and the ultrasonic pulse velocities at specimen level, thereby establishing a correlation between the microstructural and the specimen level properties.

- The influence of the ultrasonic pulse velocities dominated the influence of the microstructural properties. Hence, it microstructural information is not available to the end user or the field engineer, he or she can use Table 6.3 for prediction purposes.

\subsection{Flow Chart for Compressive Strength Prediction of Concrete with $A A B$ and Summary of Parameters and Number of Samples/Specimens for Various Experiments in the Study}

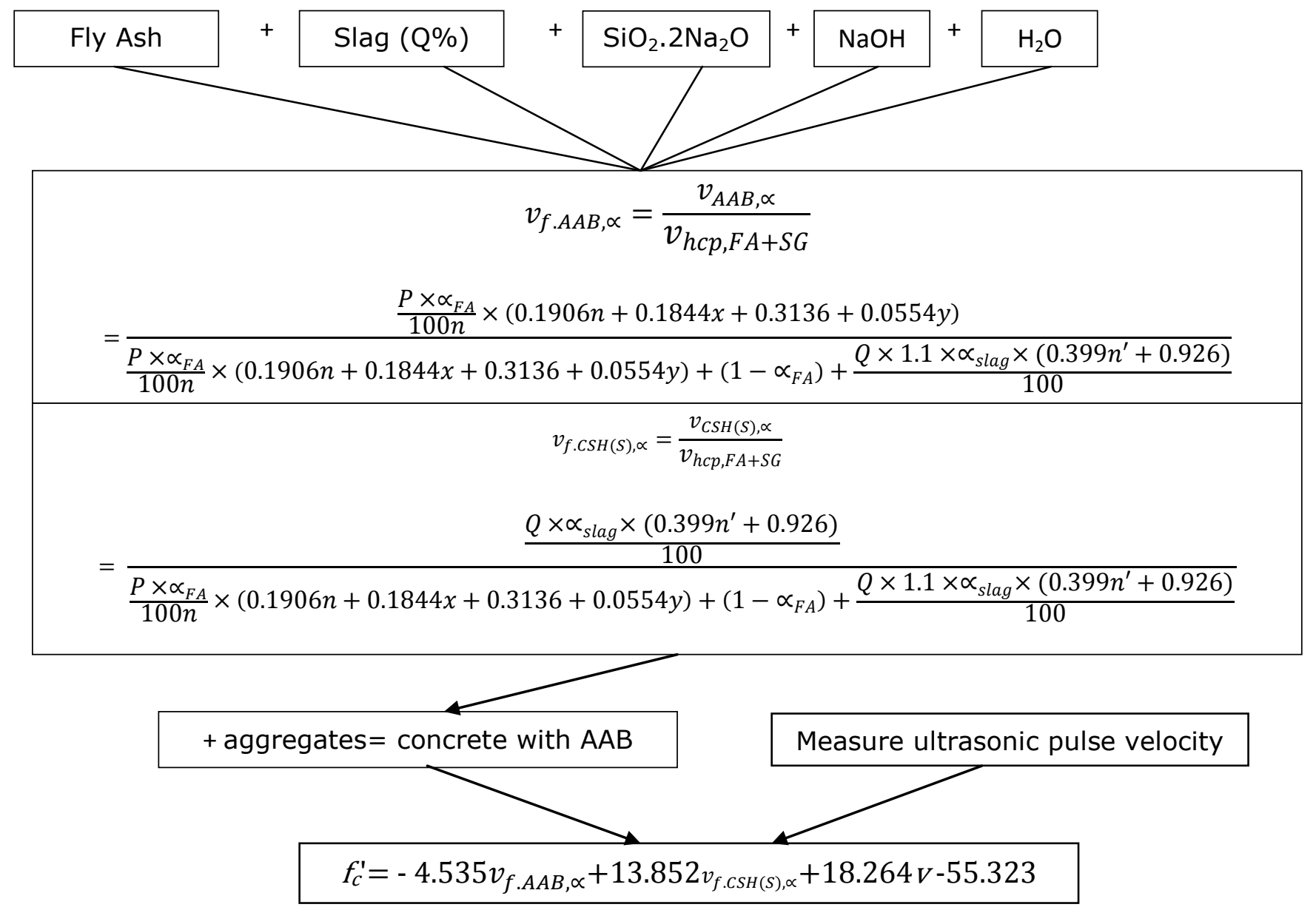


The different steps followed in this study to predict the compressive strength of concrete with $A A B$ were shown through the flow chart above. Next, the different parameters and the number of samples/specimens for the various experiments in this study are summarized:

- Total number of precursor mixture types $=7+3=10$

- $\quad$ Curing Temperatures: $23^{\circ} \mathrm{C}, 40^{\circ} \mathrm{C}, 60^{\circ} \mathrm{C}$

- $\quad$ Ages for testing of compressive strength of concrete with AAB: 7-day, 28-day, 90-day

For initial testing, compressive strength of hardened $A A B$ pastes will be conducted. For each mixture proportion, replicate specimens were tested at 3 different ages, each corresponding to 3 different curing temperatures. Total specimens for compressive strength test of hardened $A A B$ paste for 10 different mixture proportions $=10$ (number of mixture proportions) $* 3$ (different ages) $* 3$ (different curing temperatures) * 2 (replicate specimens for each case $)=180$. The same scheme of parameters within parentheses was followed to calculate total number of samples corresponding to each experiment throughout the rest of the document. 
Table 8.1 Summary of Samples/specimens tested for Different Experiments

\begin{tabular}{|c|c|}
\hline Type of test & No. of samples/specimens tested \\
\hline \multicolumn{2}{|c|}{ (A) Microstructural Analyses } \\
\hline XRD* & $10 * 3 * 3 * 2=180$ \\
\hline FTIR* & $10 * 3 * 3 * 2=180$ \\
\hline Isothermal Calorimetry & $10 * 3 * 3 * 1=90$ \\
\hline SEM* & $10 * 3 * 3 * 2=180$ \\
\hline EDS* & $10 * 3 * 3 * 2=180$ \\
\hline \multicolumn{2}{|c|}{ (B) Specimen level destructive testing } \\
\hline Compressive strength & $10 * 3 * 3 * 3=270$ \\
\hline Splitting tensile strength & $10 * 3 * 3 * 3=270$ \\
\hline Flexural strength (28-day only) & $10 * 3 * 1 * 3=90$ \\
\hline \multicolumn{2}{|c|}{ (C) Specimen level nondestructive testing } \\
\hline Ultrasonic pulse velocity (UPV)* & $10 * 3 * 3 * 2=180$ \\
\hline Dynamic modulus of elasticity* & $10 * 3 * 3 * 2=180$ \\
\hline $\begin{array}{l}\text { Effect of compressive strength on UPV } \\
\text { (28-day only)* }\end{array}$ & $10 * 3 * 1 * 3=90$ \\
\hline
\end{tabular}

Overall, the total number of samples/specimens tested were = $180+180+90+270+90+270+180=1260$

\subsection{Practical Application of the Present Study}

The primary use of an $A A B$ is to replace $P C$ in construction and thus it should possess strength and stiffness characteristics comparable to PC. The ultimate goal of the user is to obtain an optimal combination of the chemical and mechanical properties and the cost of the aluminosilicate, so that price, chemical reactivity, water demand and strength characteristics are optimized. This optimal combination is unique to each geographical location due to different availabilities of the raw materials, as well as the socio-economic condition of the region in question. 
This study has shown that the compressive strength, tensile strength and flexural strength of $A A B$ depends on both the curing temperature and the amount of slag in the precursor mix. The decrease in curing temperature can be compensated by replacement of fly ash with slag in the precursor mix. The user will have to decide the best combination of precursors and the corresponding curing temperature according to the locally available resources. Depending on the cost of power needed to achieve a certain curing temperature and the relative cost of adding different proportions of slag into the precursor mix, the user will have to arrive at a combination which will be best suited to his/her needs in terms of application as well as economy. The costs of the different materials generally vary from one location to another due to the different climates and availability of resources. So, the optimal combination of precursor and curing temperature will also depend on the location and the climate. Hence, instead of a unique optimal combination for AABs, it will be better to customize the optimal combination according to the need of the user.

\subsection{Recommendations for Future Work}

Based on the findings from the present study, some possible ideas to conduct further research in the field of concrete with $A A B$ are as follows:

1. A comprehensive data base can be formed for the chemical composition of the sodium aluminosilicate hydrate gel formed by the alkali-activation of fly ash by studying fly ash from different sources because they will have different oxide ratios.

2. SEM image analysis, mercury intrusion porosimetry, nitrogen absorption, or any other suitable techniques can be used to estimate the porosity and pore size distributions. This information can be used to study shrinkage behavior of concrete with AAB.

3. Quantitative X-ray diffraction (QXRD) and magic angle spinning - nuclear magnetic resonance (MAS - NMR) techniques can be used to validate or enhance the accuracy of the technique proposed in the present study to estimate the microstructural phase volume fractions.

4. XRD and FTIR techniques can be used to identify any possible influence of the HRWRA on the chemistry of $A A B$ by the study of fly ash and/or slag blended with only the admixture and no alkali activator. 
5. Alumina fibers or basalt fibers can be introduced in the concrete mix and study its effect on the tensile and flexural strength characteristics of concrete with $A A B$. The reinforcements may also increase the compressive strength and that can be another topic for further research.

6. Infrared thermography (IRT) technique can be used for detecting the presence of cracks in concrete with $A A B$ specimens in the field through nondestructive evaluation.

7. If steel reinforcement is used in concrete with $A A B$, it may also be of interest to the engineer to study their nature of corrosion while in service. 


\section{References}

1. Abd, S. M., Mohd. Zain, M. F., and Abdul Hamid, R., 2008, "Modeling the Prediction of Compressive Strength for Cement and Foam Concrete", International Conference of Construction and Building Technology (ICCBT 2008), Kuala Lumpur, Malaysia.

2. ACI Committee 318, 2011, "ACI 318-11: Building Code Requirements for Structural Concrete and Commentary," American Concrete Institute, Farmington Hills, MI, USA

3. ASTM C1679-09 (Standard Practice for Measuring Hydration Kinetics of Hydraulic Cementitious Mixtures Using Isothermal Calorimetry), 2013 Annual Book of ASTM Standards, Vol. 04.02, Concrete and Aggregates, American Society for Testing and Materials.

4. ASTM C215-08 (Standard Test Method for Fundamental Transverse, Longitudinal, and Torsional Resonant Frequencies of Concrete Specimens), 2013 Annual Book of ASTM Standards, Vol. 04.02, Concrete and Aggregates, American Society for Testing and Materials.

5. ASTM C293/C293M-10 (Standard Test Method for Flexural Strength of Concrete (Using Simple Beam With Center-Point Loading)), 2013 Annual Book of ASTM Standards, Vol. 04.02, Concrete and Aggregates, American Society for Testing and Materials.

6. ASTM C31/C31M-12 (Standard Practice for Making and Curing Concrete Test Specimens in the Field), 2013 Annual Book of ASTM Standards, Vol. 04.02, Concrete and Aggregates, American Society for Testing and Materials.

7. ASTM C33M-13 (Standard Specification for Concrete Aggregates), 2013 Annual Book of ASTM Standards, Vol. 04.02, Concrete and Aggregates, American Society for Testing and Materials.

8. ASTM C39/C39M-12a (Standard Test Method for Compressive Strength of Cylindrical Concrete Specimens), 2013 Annual Book of ASTM Standards, Vol. 04.02, Concrete and Aggregates, American Society for Testing and Materials.

9. ASTM C494 Type F (Specification for Chemical Admixtures for Concrete), 2013 Annual Book of ASTM Standards, Vol. 04.02, Concrete and Aggregates, American Society for Testing and Materials.

10. ASTM C496/496M-11 (Standard Test Method for Splitting Tensile Strength of Cylindrical Concrete Specimens), 2013 Annual Book of ASTM Standards, Vol. 04.02, Concrete and Aggregates, American Society for Testing and Materials. 
11. ASTM C597-09 (C597-09 Standard Test Method for Pulse Velocity Through Concrete), 2013 Annual Book of ASTM Standards, Vol. 04.02, Concrete and Aggregates, American Society for Testing and Materials.

12. ASTM C618 (Standard Specification for Coal Fly Ash and Raw or Calcined Natural Pozzolan for Use in Concrete), 2013 Annual Book of ASTM Standards, Vol. 04.02, Concrete and Aggregates, American Society for Testing and Materials.

13. ASTM C989 (Standard Specification for Slag Cement for Use in Concrete and Mortars), 2013 Annual Book of ASTM Standards, Vol. 04.02, Concrete and Aggregates, American Society for Testing and Materials.

14. Barbosa, V. F. F., Mackenzie, K. J. D., and Thaumaturgo, C., 2000, "Synthesis and thermal behaviour of potassium sialate geopolymers", Materials Letters, Vol. 57, 1477 - 1482 pp.

15. Bazaara, M.S., Sherali, H.D., Shetty, C.M., 2006, Nonlinear programming: theory and algorithms, John Wiley and Sons, Hoboken, NJ, USA.

16. Bondar, D., Lynsdale, C. J., Milestone, N. B., Hassani, N. and Ramezanianpour, A. A., 2010, "Engineering Properties of Alkali Activated Natural Pozzolan Concrete", Coventry University and The University of Wisconsin Milwaukee Centre for Byproducts Utilization, Second International Conference on Sustainable Construction Materials and Technologies, June 28 - June 30, 2010, Università Politecnica delle Marche, Ancona, Italy. Main Proceedings ed. Zachar, J., Claisse, P., Naik, T. R., Ganjian, E. ISBN 978-1-4507-1490-7, http://www.claisse.info/Proceedings.htm

17. Breck, D. W., 1974, Zeolite Molecular Sieves, Structure, Chemistry and Use, John Wiley \& Sons, New York.

18. British Standard BS EN 12504-4, 2004, Testing concrete, Determination of ultrasonic pulse velocity.

19. Buchwald, A., 2006, "What are geopolymers? Current state of research and technology, the opportunities they offer, and their significance for the precast industry", Betonwerk+Fertigteil-Technik, Vol. 72, 42 - 49 pp.

20. Bungey J. H., 1982, The Testing of Concrete in Structures, SUNY University Press, New York

21. Chen, W. and Brouwers, H. J. H., 2007, "The hydration of slag, part 1: reaction models for alkali-activated slag", J. Mater. Sci., Vol. 42, 428-443 pp.

22. Chollet, M. and Horgnies, M., 2011, "Analyses of the surfaces of concrete by Raman and FT-IR spectroscopies: comparative study of hardened samples after demoulding 
and after organic post-treatment", Surface and Interface Analysis, Vol. 43, 714-725 pp.

23. Chowdhury, S., 2011, "Development of High Volume Fly Ash and/ or Slag Modified Concrete and Geopolymer Concrete as Sustainable Construction Materials", M. S. Thesis submitted to West Virginia University, 2011.

24. Comrie, D.C., Paterson, J.H., Ritcey, D.J., 1988, "Geopolymer Technologies in Toxic Waste Management", In: Davidovits, J., Orlinski, J. (Eds.), Proceedings of the 1st International Conference on Geopolymer '88, vol. 1. Compiegne, France, 1-3 June, pp. $107-123$.

25. Criado, M., 2007, "Nuevos materiales Cementantes basados en ka activacion alclaina de cenizas volantes. Caracterizacion de geles N-A-S-H en function del contenido de silice soluble. Efecto del $\mathrm{Na}_{2} \mathrm{SO}_{4}{ }^{\prime \prime}, \mathrm{Ph}$. D. Thesis submitted to Universidad Autonoma de Madrid, Madrid, Spain.

26. Criado, M., Fernandez-Jimenez, A., Palomo, A., Sobrados, I., and Sanz, J., 2007b, "Effect of the $\mathrm{SiO}_{2} / \mathrm{Na}_{2} \mathrm{O}$ ratio on the alkali activation of fly ash. Part II: ${ }^{29} \mathrm{Si}$ MAS-NMR Survey", Microp. Mesop. Mat., Vol. 109, 525 - 534 pp.

27. Davidovits, J., 1982, "Mineral polymers and methods of making them", US Patent 4,349, 386.

28. Davidovits, J., 1984, "Synthetic mineral polymer compound of the silicoaluminates family and preparation process", US Patent, 4, 472, 199.

29. Davidovits, J., 1988, "Geopolymers of the First Generation: SILIFACEProcess". In: Davidovits, J., Orlinski, J. (Eds.), Proceedings of the $1^{\text {st }}$ International Conference on Geopolymer '88, Vol. 1, Compiegne, France, 1-3 June, pp. 49-67.

30. Davidovits, J., 1991, "Geopolymers: Inorganic polymeric new materials", Journal of Thermal Analysis, Vol. 37, pp. 1633-1656.

31. Davidovits, J., 1994, "Geopolymers: Inorganic polymeric new materials", Journal of Materials Education, Vol. 16, pp. 91-139.

32. Davidovits, J., 1994, "Properties of Geopolymer Cements", Proceedings of $1^{\text {st }}$ international Conference on Alkaline Cements and Concretes, I, VIPOL Stock Company, Kiev, Ukraine, 131-149 pp.

33. Davidovits, J., 1994b, "Method for obtaining a geopolymeric binder allowing to stabilize, solidify and consolidate toxic or waste materials", US Patent 5,349,118.

34. Davidovits, J., 1999, "Geopolymeric reactions in the economic future of cements and concretes: world-wide mitigation of carbon dioxide emission", In: Davidovits, J., 
Davidovits, R., James, C. (Eds.), Proceedings of the 2nd International Conference on Geopolymer '99, Saint Qunentin, France, June 30-July 2, 111-121 pp.

35. Davidovits, J., 2002, "30 Years of Successes and Failures in Geopolymer Applications. Market Trends and Potential Breakthroughs.", Geopolymer 2002 Conference, October 28-29, 2002, Melbourne, Australia

36. Davidovits, J., Comrie, D.C., Paterson, J.H., Ritcey, D.J., 1990. "Geopolymeric concretes for environmental protection", Concrete International, Vol. 12, 30-39 pp.

37. Davidovits, J., 1983, "Geopolymer chemistry and properties", Proceedings of Geopolymer '88, Compiegne, France, 1-3, June 1988.

38. De Silva, P., Sagoe-Crenstil, K., Sirivivatnanon, V., 2007, "Kinetics of geopolymerization: role of $\mathrm{Al}_{2} \mathrm{O}_{3}$ and $\mathrm{SiO}_{2}{ }^{\prime \prime}$, Cem., Concr. Res., Vol. 37, $512-518$ pp.

39. Deja, J. and Antosiak, B., 2012, "Stopień zaawansowania reakcji popiołu lotnego w alkalicznie aktywowanych spoiwach popiołowych - Degree of progress of the fly ash reaction in alkali-activated fly-ash binders", Cement, Wapno, Beton / Stowarzyszenie Producentów Cementu i Wapna, ISSN 1425-8129. - 2012 R. 17/79 s. 67-76. Bibliogr. s. 76

40. Drud, A., CONOPT User Guide. ARKI Consulting and Development A/S, Bagsvaerd, Denmark. Available at: http://www.gams.com/dd/docs/solvers/conopt.pdf. Last accessed 14th July 2010.

41. Duxson, P., Fernandez-Jimenez, A., Provis, J.L., Lukey, G.C., Palomo, A., Van Deventer, J.S.J., 2007a, "Geopolymer technology: the current state of the art", Journal of Materials Science, Vol. 42, 2917-2933 pp.

42. Duxson, P., Lukey, G. C., Separovic, F., van Deventer, J. S. J., 2005, "Effect of alkali cations on aluminium incorporation in geopolymeric gels", Ind. Eng. Chem. Res., Vol. 44, 832-839 pp.

43. Duxson, P., Lukey, G.C., Van Deventer, J.S.J., Mallicoat, S.W., Kriven, W.M., 2005a, "Microstructural characterisation of metakaolin-based geopolymers", Ceramic Transactions, Vol. 165, 71-85 pp.

44. Duxson, P., Provis, J.L., Lukey, G.C., Mallicoat, S.W., Kriven, W.M., Van Deventer, J.S.J., 2005b, "Understanding the relationship between geopolymer composition, microstructure and mechanical properties", Colloids and Surfaces A - Physicochemical and Engineering Aspects, Vol. 269 (1-3), 47-58 pp.

45. Eisenhauer, J. G., 2003, "Regression through the Origin", Teaching Statistics, Vol. 25, No. 3, $76-80$ pp. 
46. Elvery R. H., 1973, "Estimating strength of concrete in structures", Current Practice Sheet 10, Concrete, Vol. 11, No. 7, 49-51 pp.

47. Famy, C., Brough, A. R., and Taylor, H. F. W., 2003, "The C-S-H gel of Portland cement mortars: Part I. The interpretation of energy-dispersive $\mathrm{X}$-ray microanalyses from scanning electron microscopy, with some observations on C-S-H, AFm and AFt phase compositions", Cement and Concrete Research, Vol. 23, pp. $1389-1398$.

48. Feng, X., Garboczi, E. J., Bentz, D. P., Stutzman, P. E., and Mason, T. O. , "Estimation of the Degree of Hydration of Blended Cement Pastes by a Scanning Electron Microscopy Point-Count Procedure", Cement and Concrete Research, Vol. 34, No. 10, 2004, pp. 1787 - 1793.

49. Fernandez-Jimenez, A. and Puertas, F., 1997, "Alkali-Activated Slag Cements: Kinetic Studies", Cement and Concrete Research, Vol. 27, No. 3, 359 - 368 pp.

50. Fernandez-Jimenez, A., and Palomo, A., 2003, "Characterisation of fly ashes. Potential reactivity as alkaline cements", Fuel, Vol. 82, Issue 18, December, 22592265 pp.

51. Fernandez-Jimenez, A., and Palomo, A., 2005, "Composition and microstructure of alkali activated fly ash binder: Effect of the activator", Cement and Concrete Research, Vol. 35, 1984 - 1992 pp.

52. Fernandez-Jimenez, A., Palomo, Criado, A., and M., 2005, "Microstructure development of alkali-activated fly ash cement. A descriptive model", Cem. Concr, . Res., Vol. 35, 1204 - 1209 pp.

53. Fernandez-Jimenez, A., Palomo, A., Sobrados, I., and Sanz, J., 2006, "The role played by the reactive alumina content in the alkaline activation of fly ashes", Microporous and Mesoporous Materials, Vol. 91, 111-119 pp.

54. Fernandez-Jimenez, A., de la Torre, A.G., Palomo , A., Lopez-Olmo, G., Alonso, M. M., Aranda, M.A.G., 2006, "Quantitative determination of phases in the alkaline activation of fly ash. Part II: Degree of reaction", Fuel, Vol. 85, 1960-1969 pp.

55. Fisher, R. A., 1926, "The arrangement of field experiments", Journal of the Ministry of Agriculture, Vol. 33, 504 pp.

56. Flaningen, E. M., Khatami, H., and Szymanski, H. A., 1971, "Moleculare Sieve Zeolite", Advan. Chem. Ser. 101, American Chemical Society, Washington D.C., 201 pp.

57. Gasteiger, H. A., Frederick, W. J., and Streisel, R. C., 1992, "Solubility of aluminosilicates in alkaline solutions and a thermodynamic equilibrium model", Ind. Eng. Chem. Res., Vol. 31, 1183-1190 pp. 
58. Glasser, L. S. D., and Harvey, G., 1984, "The gelation behavior of the aluminosilicate solutions containing $\mathrm{Na}^{+}, \mathrm{K}^{+}, \mathrm{Cs}^{+}$, and $\mathrm{Me}_{4} \mathrm{~N}^{+\prime}$, J. Chem. Soc., Chem. Commun., Vol. $13,1250-1252 \mathrm{pp}$.

59. Goretta, K.C., Nan Chen, Gutierrez-Mora, F., Routbort, J.L., Lukey, G.C., Van Deventer, J.S.J., 2004, "Solid-particle erosion of a geopolymer containing fly ash and blast-furnace slag", Wear 256 (7-8), 714- 719 pp.

60. Granizo, M. L. and Blanco, M. T., 1988, "Alkaline activation of metakaolin. An isothermal conduction calorimetry study", Journal of Thermal Analysis, Vol. 52, 957 965 pp.

61. Grutzeck, M.W., Siemer, D.D., 1997, "Zeolites synthesised from class F fly ash and sodium aluminate slurry", Journal of American Ceramic Society, Vol. 80, 2449-2458 pp.

62. Han, C. and Pyzik, A. J., 2011, "Geopolymer precursor dry mixture, package, processes and methods", United States Patent Application Publication, Pub No. US 2011/0132230 A1, June 2011.

63. Hardjito, D., \& Rangan, B. V., 2005, "Development and Properties of Low-Calcium Fly Ash-Based Geopolymer Concrete", Research Report GC1, Perth, Australia: Faculty of Engineering, Curtin University of Technology.

64. Hardjito, D., Wallah, S. E., \& Rangan, B. V., 2002a, "Research Into Engineering Properties of Geopolymer Concrete", Paper presented at the Geopolymer 2002 International Conference, Melbourne.

65. Hardjito, D., Wallah, S. E., \& Rangan, B. V., 2002b, "Study on Engineering Properties of Fly Ash-Based Geopolymer Concrete", Journal of the Australasian Ceramic Society, Vol. 38, No. 1, 44-47 pp.

66. Hardjito, D., Wallah, S. E., Sumajouw, D. M. J., \& Rangan, B. V., 2003, "Geopolymer Concrete: Turn Waste Into Environmentally Friendly Concrete", Paper presented at the International Conference on Recent Trends in Concrete Technology and Structures (INCONTEST), Coimbatore, India.

67. Hardjito, D., Wallah, S. E., Sumajouw, D. M. J., \& Rangan, B. V., 2004a, "Properties of Geopolymer Concrete with Fly Ash as Source Material: Effect of Mixture Composition", Paper presented at the Seventh CANMET/ACI International Conference on Recent Advances in Concrete Technology, Las Vegas, USA.

68. Hardjito, D., Wallah, S. E., Sumajouw, D. M. J., \& Rangan, B. V., 2004b, "On the Development of Fly Ash-Based Geopolymer Concrete", ACI Materials Journal, Vol. 101, No. 6, 467-472 pp. 
69. Hardjito, D., Wallah, S. E., Sumajouw, D. M. J., \& Rangan, B. V., 2005a, "Fly AshBased Geopolymer Concrete", Australian Journal of Structural Engineering, Vol. 6, No. 1, 77-86 pp.

70. Hardjito, D., Wallah, S. E., Sumajouw, D. M. J., \& Rangan, B. V., 2005b, "Introducing Fly Ash-Based Geopolymer Concrete: Manufacture and Engineering Properties", Paper presented at the Our World in Concrete and Structures International Conference, Singapore.

71. Hardjito, D., Wallah, S.E., Rangan, B.V., 2002, "Research into engineering properties of geopolymer concrete", In: Lukey, G.C. (Ed.), Proceedings of the International Conference on Geopolymers, Melbourne, Australia, 28-29 October (in CD-ROM).

72. Hermann, E., Kunze, C., Gatzweiler, R., Kiesig, G., Davidovits, J., 1999, "Solidification of various radioactive residues by geopolymere ${ }^{\circledR}$ with special emphasis on long-termstability, Part I: Laboratory investigations Part II: Pilot-scale experiment", In: Davidovits, J., Davidovits, R., James, C. (Eds.), Proceedings of the 2nd International Conference on Geopolymer '99, Saint Qunentin, France, June 30-July 2, 211-228 pp.

73. Huang, Q., Gardoni, P., and Hurlebaus, S., 2011, "Predicting Concrete Compressive Strength Using Ultrasonic Pulse Velocity and Rebound Number", ACI Materials Journal, Vol. 108, pp. $403-412$.

74. Ivanova, I., Aiello, R., Nagy, J.B., Crea, F., Derouane, E.G., Dumont, N., Nastro, A., Subotic, B., Testa, F., 1994, "Influence of cations on the physicochemical and structural properties of aluminosilicate gel precursors: II. Multinuclear magnetic resonance characterization", Microporous Materials, Vol. 3, 245-257 pp.

75. Kamhangrittirong, P., Suwanvitaya, P., Suwanvitaya, P., and Chindaprasirt, P., 2007, "Green binder technology development using fly ash based geopolymer", JSPS-DOST International Symposium on Environmental Engineering, Symposium on Harmonizing Infrastructure Development with the Environment, Phillipines, $7 \mathrm{pp}$.

76. Kar, A., 2010, "Prediction of Shrinkage of Concrete Containing Supplementary Cementitious Materials Using Microscale Characterizations and Composite Modeling", Masters' Degree Thesis submitted to West Virginia University, December, 2010.

77. Kar, A., Ray, I., Unnikrishnan, A., Davalos, J. F., 2012, "Estimation of C-S-H and Calcium Hydroxide for Cement Pastes Containing Slag and Silica Fume", Construction and Building Materials, Vol. 30, 505 - 515 pp.

78. Kar, A., 2010, "Prediction of Shrinkage of Concrete Containing Supplementary Cementitious Materials Using Microscale Characterizations and Composite Modeling", Masters' Degree Thesis Submitted to West Virginia University, USA, December 2010. 
79. Kar, A., Ray, I., Unnikrishnan, A., Davalos, J. F., 2012, "Microanalysis and optimization-based estimation of $\mathrm{C}$-SH contents of cementitious systems containing fly ash and silica fume", Cement and Concrete Composites, Vol. 34, 419 - 429 pp.

80. Komlos K., Popovics S., Niirnbergeroh T., Babd B. and Popovics J. S., 1996, "Ultrasonic Pulse Velocity Test of Concrete Properties as Specified in Various Standards", Cement and Concrete Composites, Vol. 18, 357-364 pp.

81. Komnitsas, K. and Zaharaki, D., 2007, "Geopolymerization: A review and prospects for the minerals industry", Minerals Engineering, Vol. 20, $1261-1277$ pp.

82. Krivenko, P., Kovalchuk, G., Kovalchuk, O., 2005, "Global Construction: Ultimate Concrete Opportunities", In: Proceedings of the International Congress, Dundee, Scotland, July 5-7.

83. Krivenko, P.V., Kovalchuk, G.Yu., 2002b, "Fly ash based zeolite cements. Innovations and developments in concrete materials and construction," In: Proceedings of the International Conference "Challenges of Concrete Construction", Dundee, Scotland, September 5-11, 123-132 pp.

84. Kumar, S., Kumar, R., Mehrotra, S. P., 2010, "Influence of granulated blast furnace slag on the reaction, structure and properties of fly ash based geopolymer", Journal of Material Science, Vol. 45, pp. 607-615

85. Kupwade-Patil, K and Allouche, E., 2011, "Effect of Alkali Silica Reaction (ASR) in Geopolymer Concrete", World of Coal Ash (WOCA) Conference, May 9 -12, Devnver, CO, USA

86. Lee, W. K. W. and van Deventer, J. S. J., 2002, "Effects of anions on the formation of aluminosilicate gel in geopolymers", Industrial \& Engineering Chemistry Research, Vol. 41, No. $18,4550-4558$, pp.

87. Leslie J. R. and Chessman W. J., 1949, "An ultrasonic method of studying deterioration and cracking in concrete structures", Journal of American Concrete Institute, Vol. 21, No. 1, pp. 17-35.

88. Liu, R., Wenshun, H., and Yonghon X., 2009, "Effect of Crumb Rumbler on the Mechanical Properties of Concrete", Journal of Building Materials, Vol. 12, No. 3, 341 $344 \mathrm{pp}$.

89. Lloyd, N. A. and Rangan, B. V., 2010, "Geopolymer Concrete with Fly Ash", Coventry University and The University of Wisconsin Milwaukee Centre for By-products Utilization Second International Conference on Sustainable Construction Materials and Technologies, June 28 - June 30, 2010, Università Politecnica delle Marche (UNIVPM), Ancona, Italy 
90. Lloyd, R. R., Provis, J. L., and van Deventer, J. S. J., 2009, "Microscopy and microanalysis of inorganic polymer cements. 2: The gel binder", J. Mater. Sci., Vol. 44, No. 2, $620-631$ pp.

91. Lloyd, R. R., Provis, J. L., and van Deventer, J. S. J., 2009, "Microscopy and microanalysis of inorganic polymer cements. 1: Remnant fly ash particles", J. Mater. Sci., Vol. 44, No. 2, 608 - 619 pp.

92. McDonald, David B. and Roper Harold, 1993, "Accuracy of Prediction Models for Shrinkage of Concrete", ACI Materials Journal, Vol. 90, No. 3, 265-272 pp.

93. Marfisi E., Burgoyne C. J., Amin M. H. G. and Hall L. D., 2005, "The use of MRI to observe the structure of concrete", Magazine of Concrete Research, Vol. 57, No. 2, 101-109 pp.

94. Mikuni, A., Komatsu, R., and Ikeda, K., 2007, "Dissolution properties of some fly ash fillers applying to geopolymeric materials in alkali solution", Journal of Materials Science, Vol. 42, No. 9, 2953-2957 pp.

95. Mindess, S. 2002, Concrete, Second Edition, Prentice Hall, Inc., New Jersey.

96. Mustafa Al Bakri, A. M, Kamarudin, H., Bnhussain, M., Khairul Nizar, I., Rafiza, A. R., and Zarina, Y., 2011, "Microstructure of different $\mathrm{NaOH}$ molarity of fly ash-based green polymeric cement", Journal of Engineering and Technology Research, Vol. 3, No. 2, 44-49 pp.

97. Muzek, M. N., Zelic, J., and Jozic, D., 2012, "Microstructural Characteristics of Geopolymers Based on Alkali-Activated Fly Ash", Chem. Biochem. Eng. Q., Vol. 26, No. 2, 89-95 pp.

98. Neville, A. M., 2007, Properties of Concrete, Fourth Edition, Pearson Education, New Delhi, India.

99. Nilsen, A. U. and Aitcin, P.-C., 1992, "Static modulus of elasticity of high-strength concrete from pulse velocity tests", Cement, Concrete and Aggregate, Vol. 14, No. 1, $64-66 \mathrm{pp}$.

100. Pacheco-Torgal , F., Castro-Gomes, J., and Jalali, S., 2007, "Investigations about the effect of aggregates on strength and microstructure of geopolymeric mine waste mud binders", Cement and Concrete Research, Vol. 37, pp. 933-941

101. Palomo, A. and Glasser, F. P., 1992, "Chemically-bonded cementitious materials based on metakaolin", British Ceramic Transactions and Journal, Vol. 91, 107 - 112 pp. 
102. Palomo, A. Fernández-Jiménez, A., Alonso, S., Sobrados, I., and Sanz, J. 2004a, "Alkaline Activation of Fly Ashes: NMR Study of the Reaction Products", Journal of the American Ceramic Society, Vol. 87, No. 6, 1141-1145 pp.

103. Palomo, A., Blanco-Varela, M. T., Granizo, M. L., Puertas, F., Vazquez, T., and Grutzeck, M. W., 1999, "Chemical stability of cementitious materials based on metakaolin", Cement and Concrete Research, Vol. 29, 997 - 1004 pp.

104. Panzera, T. H., Christoforo, A. L., Cota, F. P., Borges, P. H. R. and Bowen, C. R., 2011, "Ultrasonic Pulse Velocity Evaluation of Cementitious Materials", Advances in Composite Materials - Analysis of Natural and Man-Made Materials, Chapter 17, book edited by Pavla Těšnova, ISBN 978-953-307-449-8, Published: September 9, 2011 under CC BY-NC-SA 3.0 license, DOI: 10.5772/17167

105. Perera, D. S., Aly, Z., Vance, E. R., and Mizumo, M., 2005, "Immobilization of Pb in a geopolymer matrix", Journal of the American Ceramic Society, Vol. 88, 2586 - 2588 pp.

106. Phair, J.W., 2001. Compositional effects and microstructure of fly ash based geopolymers. PhD Thesis, Department of Chemical Engineering, University of Melbourne, Victoria, Australia

107. Popovics, S., 1973, "A Numerical Approach to the Complete Stress-Strain Curve of Concrete", Cement and Concrete Research, Vol. 3, 583-599 pp.

108. Provis, J.L., Lukey, G.C., Van Deventer, J.S.J., 2005, "Do geopolymers actually containnanocrystalline zeolite? A reexamination of existing results", Chem. Mater., Vol. 17, $3075-3085$ pp.

109. Provis, J. L. and van Deventer, J. S. J., 2009, Geopolymers: structure, processing, properties and industrial applications, Publisher: Oxford: Woodhead ; Boca Raton, FL : CRC Press, 2009.

110. Puertas, F., Santos, H., Palacios, M., and Martınez-Ramırez, S., 2005, "Polycarboxylate superplasticiser admixtures: Effect on hydration, microstructure and rheological behaviour in cement pastes, Advances in Cement Research, Vol. 17, No. 2, $77-89$ pp.

111. PUNDIT manual for use with the portable ultrasonic non-destructive digital indicating tester, 1992, MARK V, C. N. S. Electronics LTD, London.

112. Quillin, K., Dunster, A., and Abora, K., 2011, "Alkali-activated binder concretes in construction: an introduction to their benefits and properties and barriers to their use", BRE Information Paper IP 4/11, HIS BRE Press, Bracknell, 2011. Available from: www.brebookshop.com. 
113. Rahier, H., Van Mele, B., and Wasteils, 1996, "Low-temperature synthesized aluminosilicate glasses. 2. Rheological transformations during low-temperature cure and high-temperature properties of a model compound", Journal of Materials Science, Vol. 31, $80-85$ pp.

114. Rangan, B.V., 2008, "Low-Calcium, Fly-Ash-Based Geopolymer Concrete", Concrete Construction Engineering Handbook, Chapter 26, Edited by Edward G . Nawy, CRC Press 2008, Print ISBN: 978-0-8493-7492-0, eBook ISBN: 978-1-4200-0765-7, DOI: $10.1201 / 9781420007657 . c h 26$

115. Rangan, B.V., Hardjito, D., Wallah, S.E., Sumajouw, D.M.J., 2005, "Studies on fly ash-based geopolymer concrete." In: Davidovits, J. (Ed.), Proceedings of the World Congress Geopolymer, Saint Quentin, France, 28 June - 1 July, pp. 133-137.

116. Rees, C. A., 2007, "Mechanisms and kinetics of gel formation in geopolymers", Ph. D. Thesis submitted to the Department of Chemical and Biomolecular Engineering, University of Melbourne, March 2007.

117. Rees, C., Lukey, G. C., and Van Deventer, 2004, "The role of solid silicates on the formation of geopolymers derived from coal ash", International Symposium of Research Students on Material Science and Engineering, December 20-22, 2004, Chennai, India, Department of Metallurgical and Materials Engineering, Indian Institute of Technology Madras

118. Roode, M. and Hemmings, R. T., 1985, "Development of a unified theory for predicting the behavior of glassy waste products", CANMET (Canada) Contract Report No. ISQ83-00162, July 1985, cited in Davidovits, J., 2008, "Geopolymer Chemistry \& Applications", $2^{\text {nd }}$ Edition, June 2008, Institut Geopolymere, France

119. Rosenthal, R.E., 2008. GAMS - A user Guide. Gams Development Corporation, Washington D.C., USA.

120. Roy, D. M., 1999, "Alkali-activated cements Opportunities and challenges", Cement and Concrete Research, Vol. 29 pp. 249-254.

121. Sakulich, A. R., 2009, "Characterization of Environmentally-Friendly Alkali Activated Slag Cements and Ancient Building Materials", Ph. D. Thesis submitted to Drexel University, September 2009.

122. Sarker, P., 2008, "A constitutive model for fly ash-based geopolymer concrete", Architecture Civil Engineering Environment, No. 4, 113 - 120 pp.

123. Shi, C., Krivenko, P., and Roy, M., 2006, "Alkali-Activated Cements and Concretes", Taylor \& Francis, London and New York, 2006. 
124. Skvara, F., Kopecky, L., Nemecek, J., and Bittnar, Z., 2006, "Microstructure of geopolymer materials based on fly ash", Cermaics - Silikaty, Vol. 50, 208 - 215 pp.

125. Smilauer, V., Hlavacek, P., Skvara, F., Sulc, R., Kopecky, L., Nemecek, J., 2011, "Micromechanical multiscale model for alkali activation of fly ash and metakaolin", $J$. Mater. Sci., DOI 10.1007/s10853-011-5601-x.

126. Smith, A., Chotard, T., Gimet-Breart, N., Fargeot, D., 2002, "Correlation between hydration mechanism and ultrasonic measurements in an aluminous cement: effect of setting time and temperature on the early hydration", Journal of the European Ceramic Society, Vol. 22 1947-1958 pp.

127. Smith, J.W., Comrie, D.C., 1988. Geopolymeric building materials in third world countries. In: Davidovits, J., Orlinski, J. (Eds.), Proceedings of the 1st Int. Conf. Geopolymer '88, Vol. 1, Compiegne, France, 1-3 June 1988, pp. 89-92.

128. Sofi, M., Van Deventer, J.S.J., Mendis, P.A., Lukey, G.C., 2007, "Engineering properties of inorganic polymer concretes (IPCs)", Cement and Concrete Research, Vol. 37, 251-257 pp.

129. Stevenson, M. and Sagoe-Crentsil, K., 2005, "Relationships between composition, structure and strength of inorganic polymers. Part I - Metakaolin-derived inorganic polymers", Journal of Materials Science, Vol. 40, 2023 - 2036 pp.

130. Subaer, Van Riessen, A., 2007, "Thermo-mechanical and microstructural characterization of sodium-poly(sialate-siloxo) (Na-PSS) geopolymers", Journal of Materials Science, Vol. 42, 3117-3123 pp.

131. Sumajouw, D. M. J., Hardjito, D., Wallah, S. E., Rangan, B. V., 2007, "Fly ash-based geopolymer concrete: study of slender reinforced columns", Journal of Materials Science, Vol. 42, $3124-3130$ pp.

132. Talling, B. and Brandstetr, J., 1995,"Clinker-free Concrete Based on Alkali Activated Slag". In Sarkar, S. L. and Ghosh, S. N., 1995, Progress In Cement And Concrete: Mineral Admixtures in Cement and Concrete, Akademia Books International, New Delhi, India.

133. Taylor, H.F.W., 1990, Cement Chemistry, Academic Press London, UK.

134. Taylor, H.F.W., 1997, Cement Chemistry, 2nd Edition, Thomas Telford.

135. van Deventer, J. S. J., Provis, J. L., Duxson, P., and Lukey, G. C., 2007, "Reaction mechanisms in the geopolymeric conversion of inorganic waste to useful products", Journal of Hazardous Materials, Vol. A139, 506-513 pp. 
136. van Deventer, J., Duxson, P., and Provis, J. L., 2010, "Geopolymer concrete: a commercial reality", Proceedings of $6^{\text {th }}$ Global Slag Conference, Sydney, Australia, Paper 9, 6 pp., www.propubs.com.

137. Van Jaarsveld, J.G.S., 2000. "The physical and chemical characterisation of fly ash based geopolymers.", PhD Thesis, Department of Chemical Engineering, University of Melbourne, Australia.

138. Wallah, S. E. and Rangan, B. V., 2006, "Low-Calcium Fly Ash-Based Geopolymer Concrete: Long-Term Properties", Curtin University of Technology, Perth, Australia

139. Xu, H., 2001. Geopolymerisation of aluminosilicate minerals. PhD Thesis, Department of Chemical Engineering, University of Melbourne, Australia.

140. Yehia, S., Abudayyeh, O., Nabulsi, S., and Abdelqader, I., 2007, "Detection of Common Defects in Concrete Bridge Decks Using Nondestructive Evaluation Techniques", Journal of Bridge Engineering, ASCE, Vol. 12, 215 - 225 pp.

141. Yip, C. K. and van Deventer, J. S. J., 2003, "Microanalysis of calcium silicate hydrate gel formed within a geopolymeric binder", Journal of Materials Science, Vol. 38, 3851 - $3860 \mathrm{pp}$. 


\section{APPENDIX}




\section{A1. FTIR Spectra}

(a) $23^{\circ} \mathrm{C}$

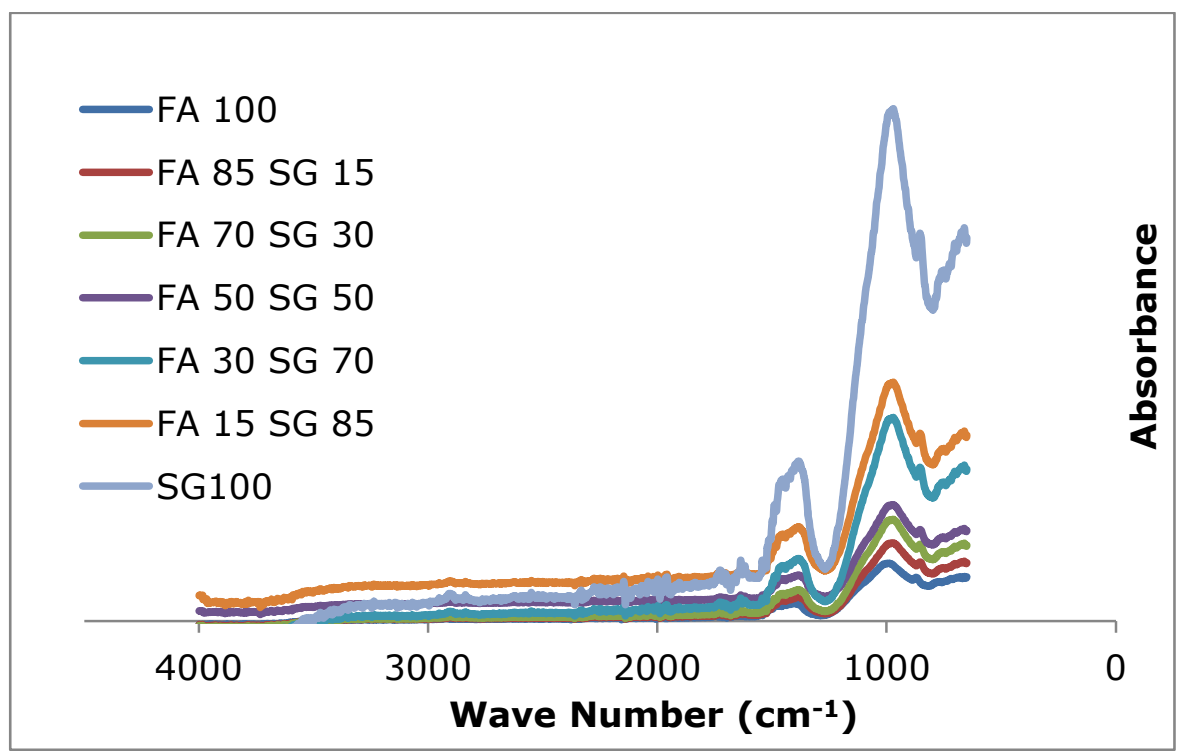

(b) $40^{\circ} \mathrm{C}$

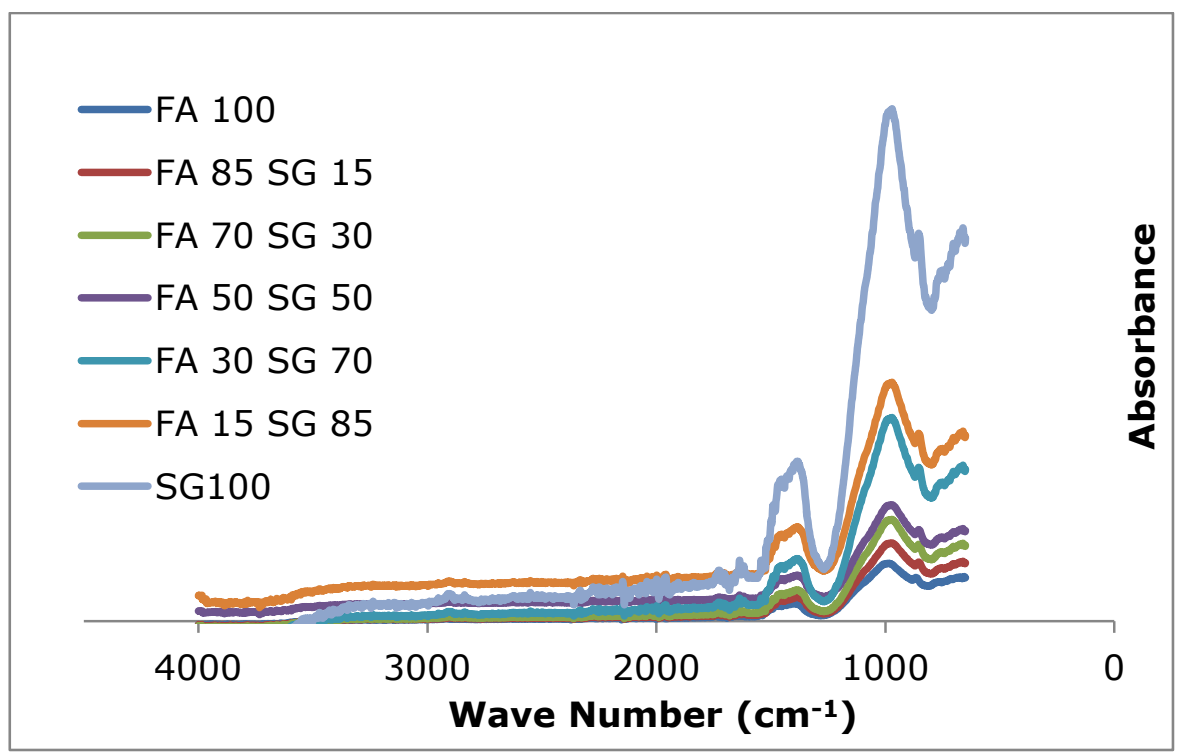


(c) $60^{\circ} \mathrm{C}$

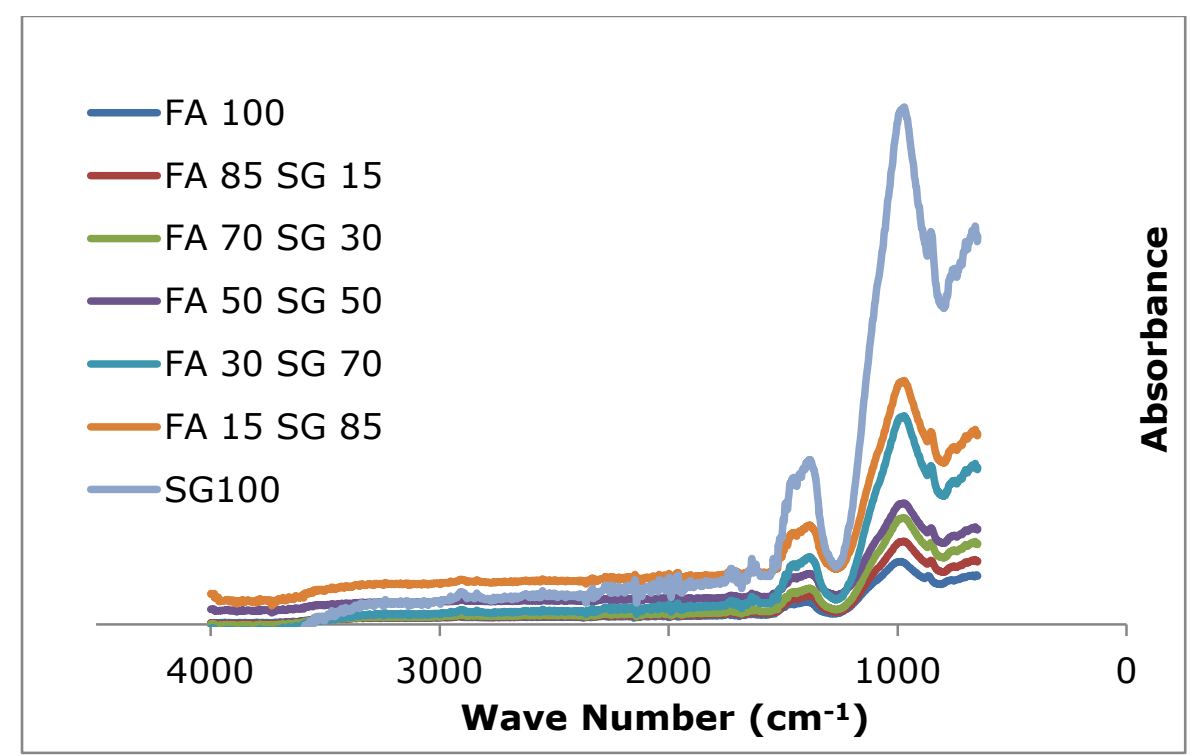




\section{A2. SEM Images}

\section{(a) $23^{\circ} \mathrm{C}$}

FA 85 SG 1528 d

FA 70 SG 30 28d
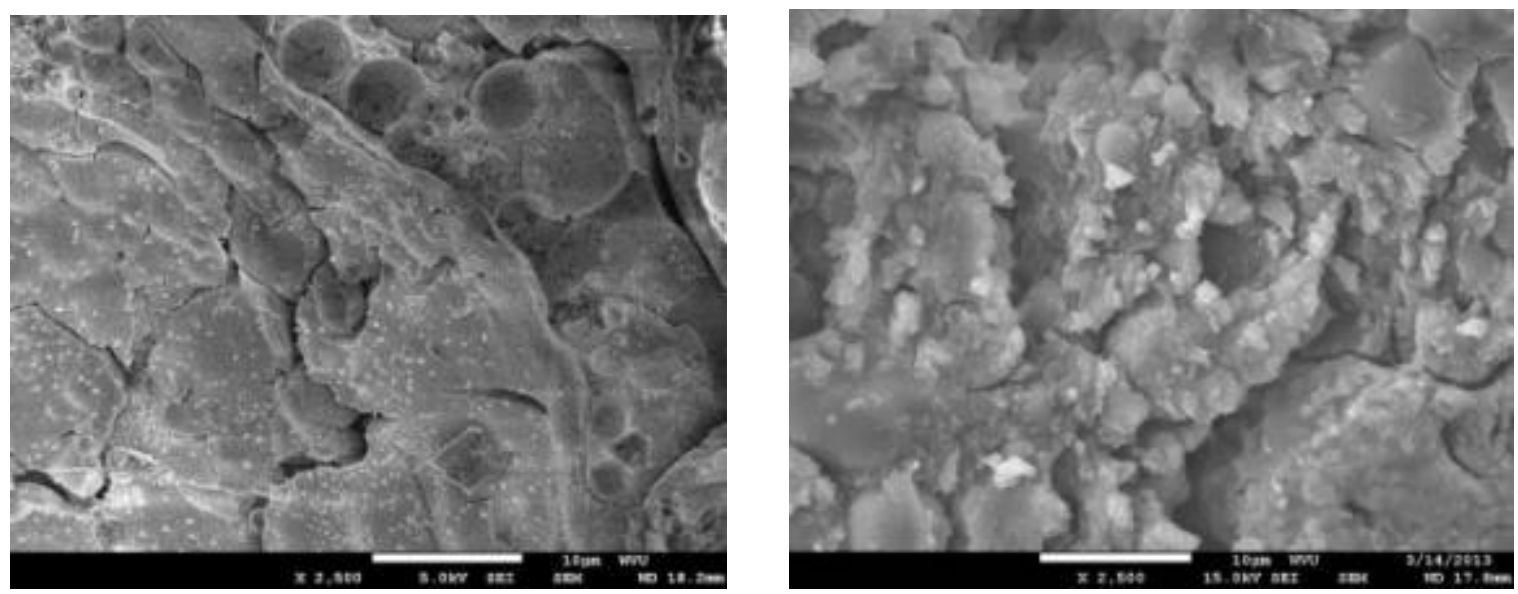

FA 50 SG 5028 d

FA 30 SG 7028 d
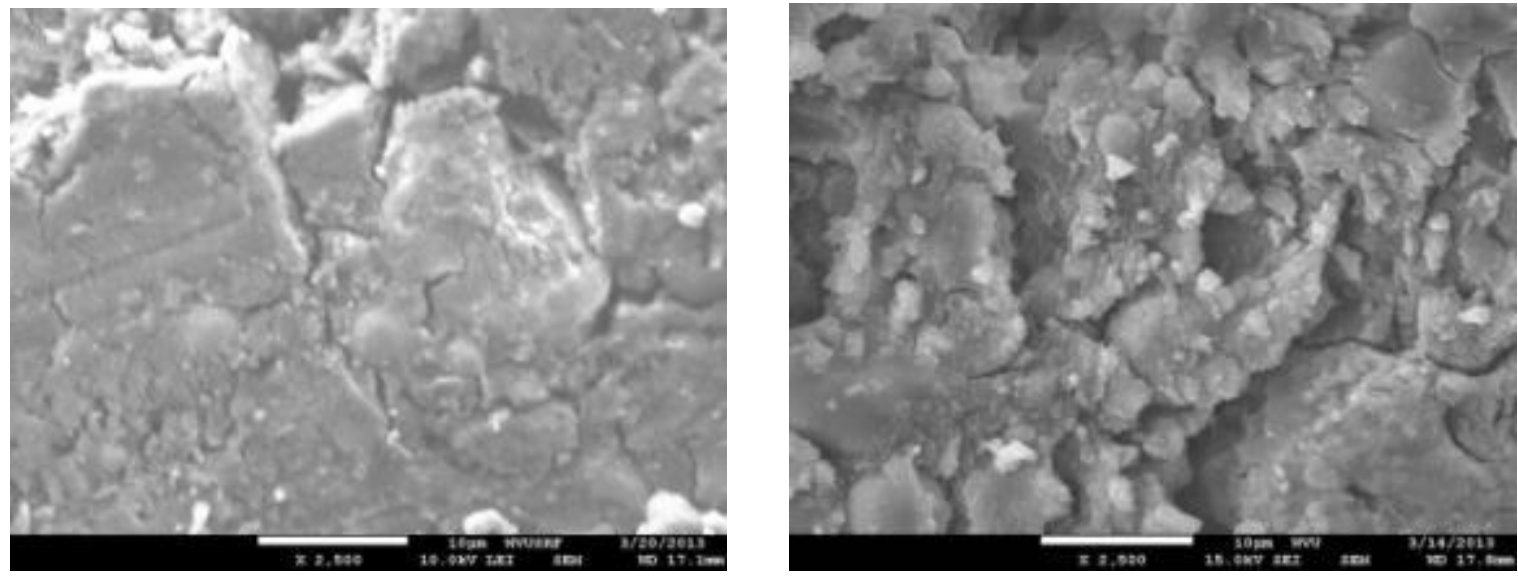

FA 15 SG $8528 d$

SG $10028 d$
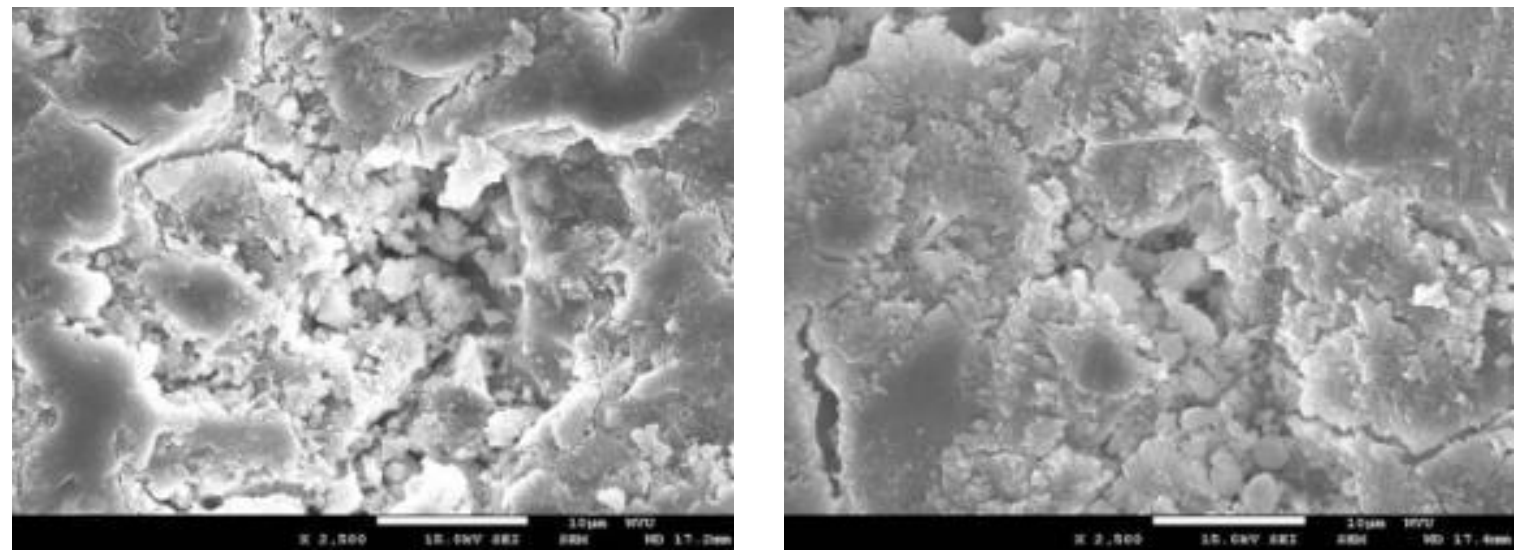


\section{(b) $40^{\circ} \mathrm{C}$}

FA 70 SG 30 28-d

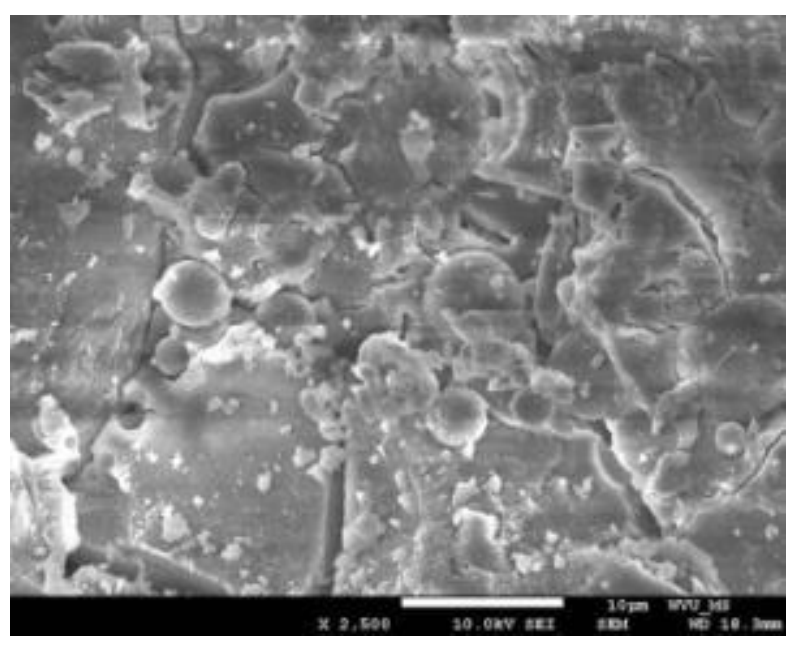

FA 30 SG 7028 d

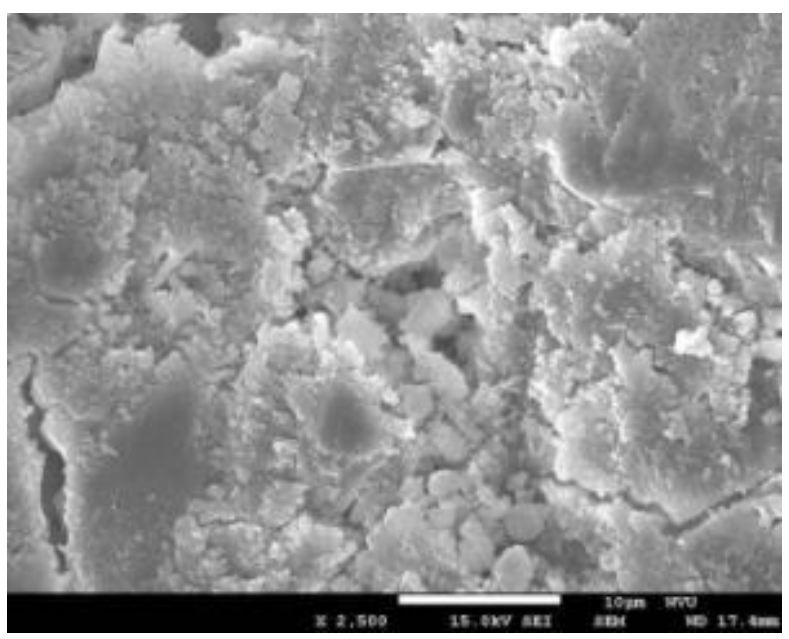

FA 15 SG $8528 d$

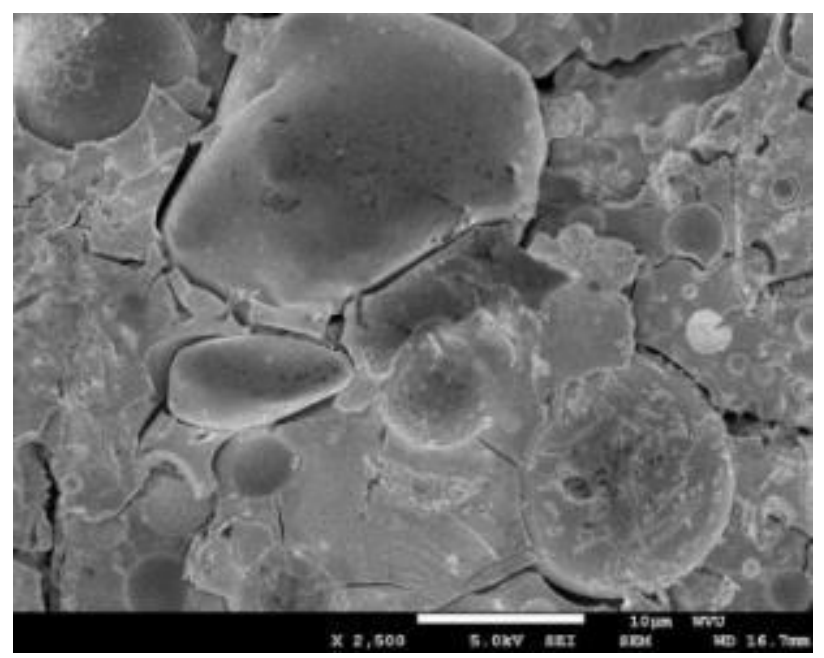




\section{(c) $60^{\circ} \mathrm{C}$}

FA 85 SG 1528 d

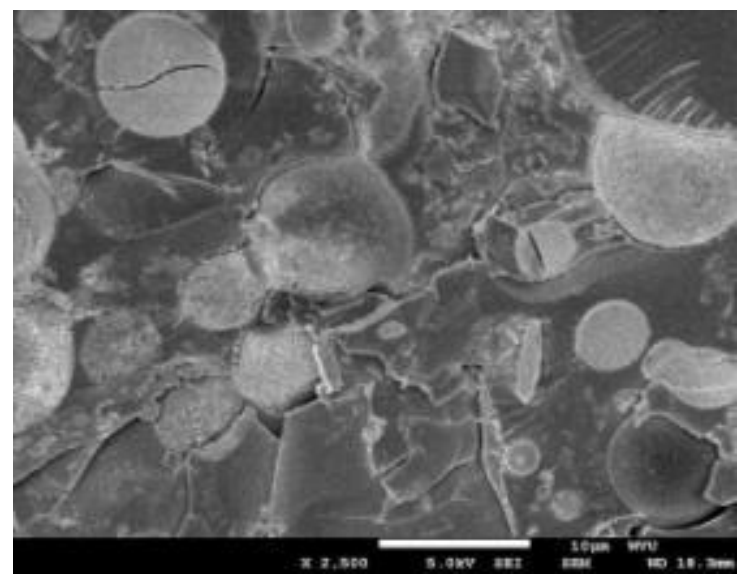

FA 70 SG 3028 d

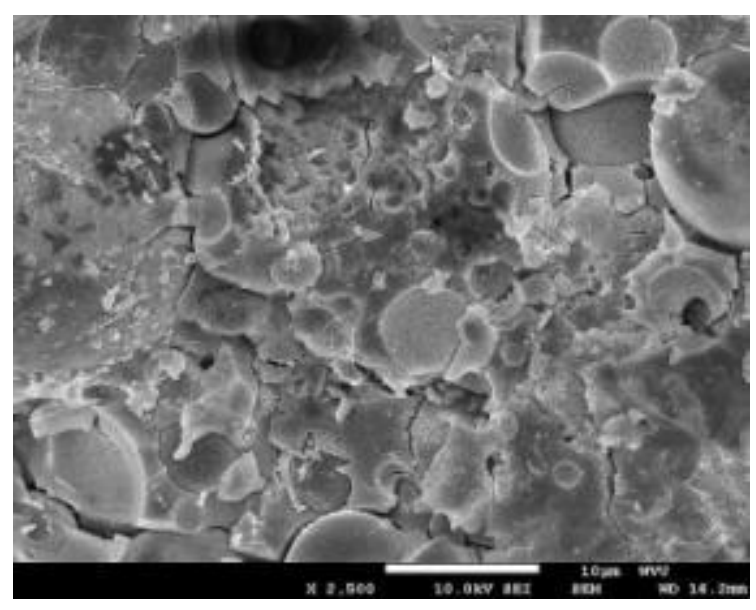

\section{FA 30 SG 7028 d}

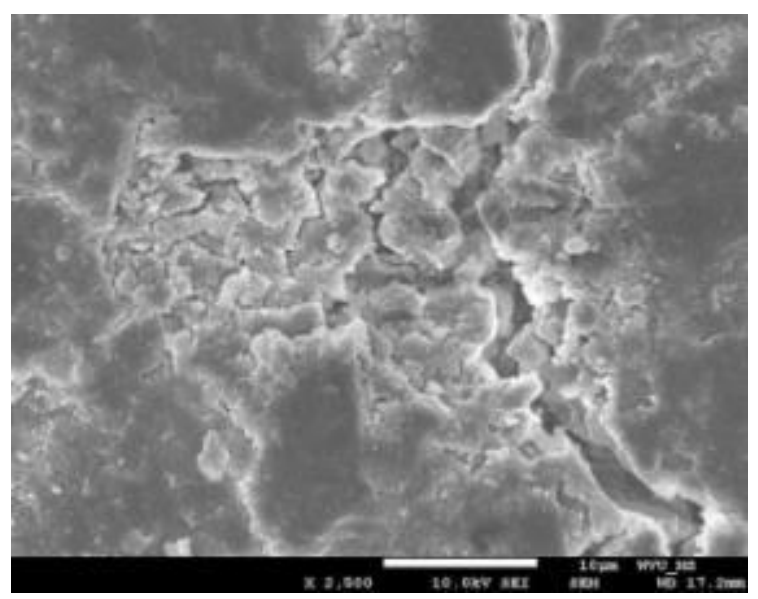

FA 50 SG 5028 d

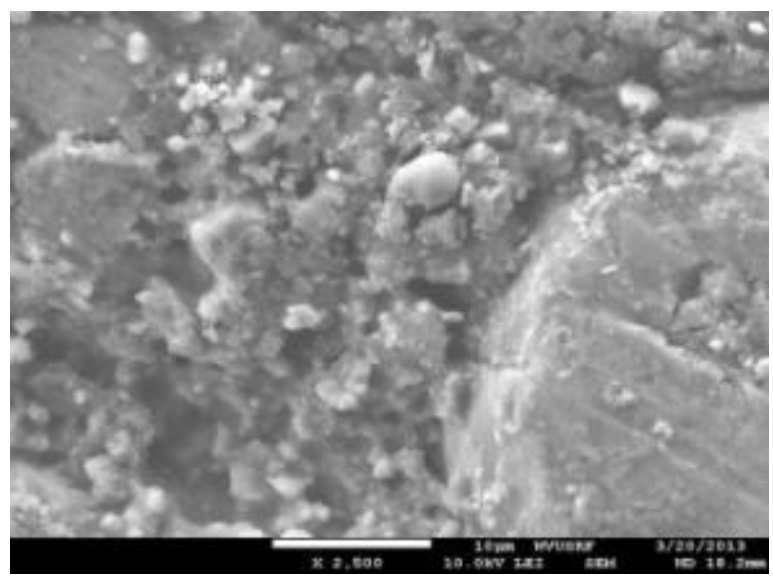

FA 15 SG $8528 d$

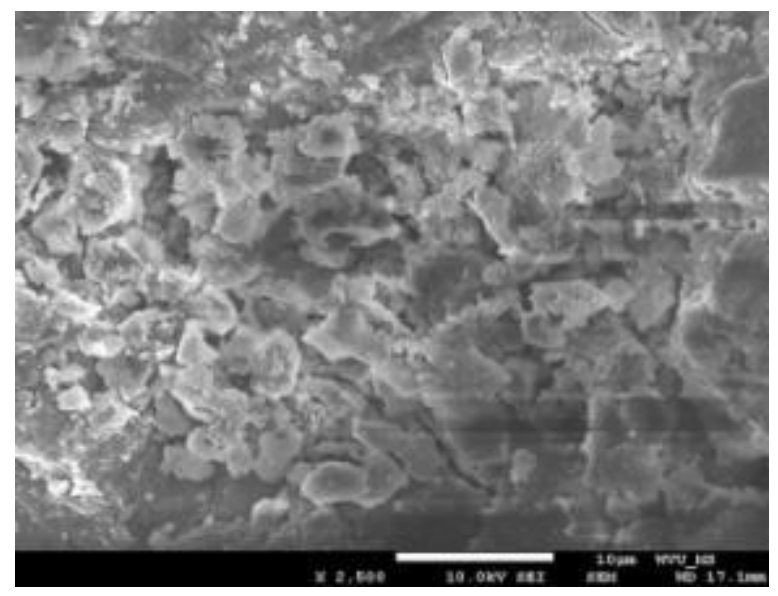

SG $10028 d$

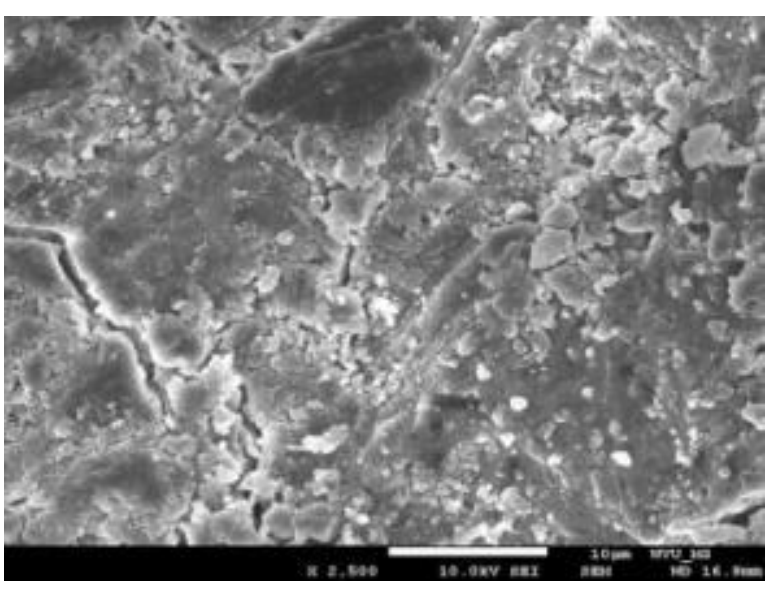


A3. 3D Plots of atomic Ratios of Si/Al, Na/Al, and Ca/Si for AAB

(a) $23^{\circ} \mathrm{C}$

FA 85 SG $1528 \mathrm{~d}$

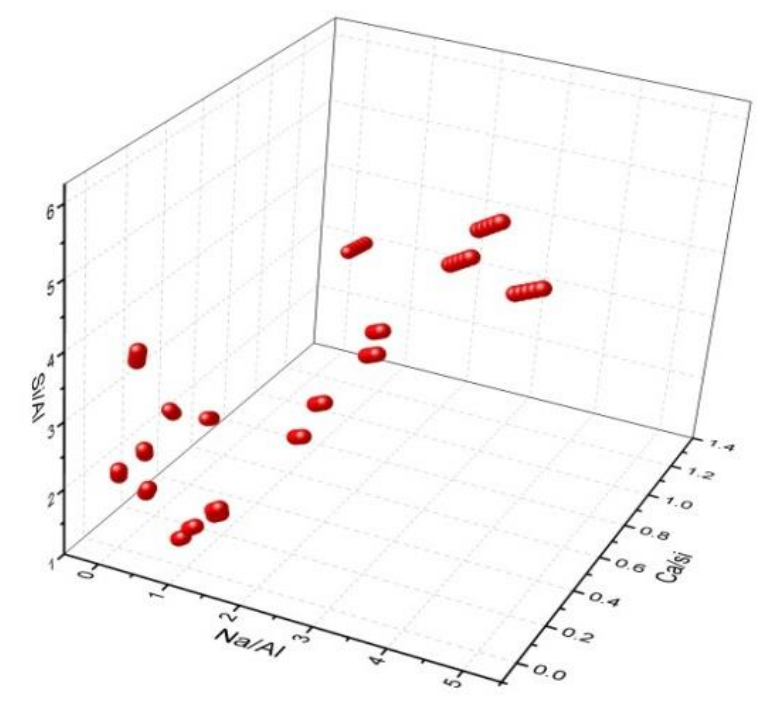

FA 50 SG $5028 \mathrm{~d}$

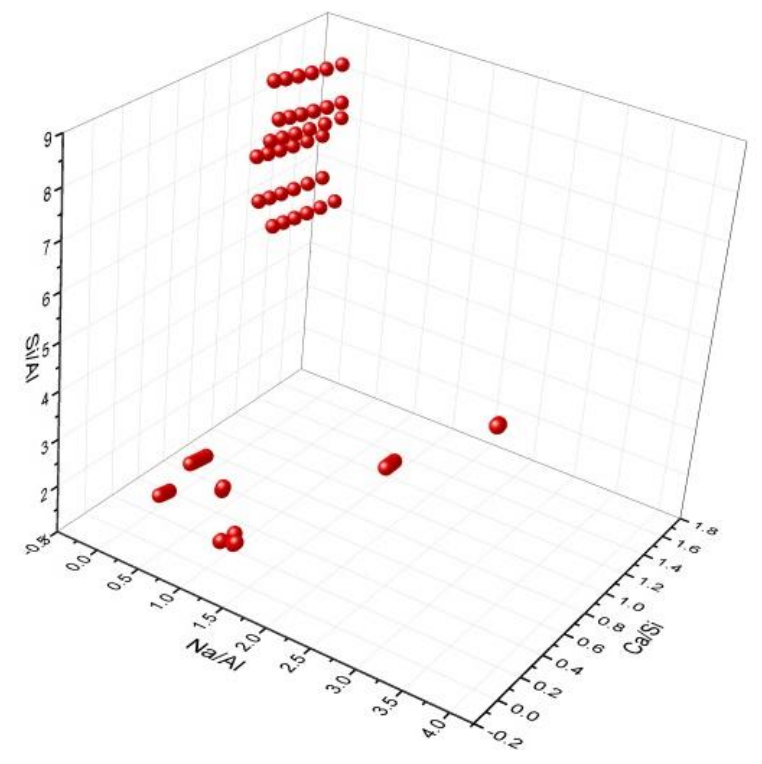

FA 70 SG $3028 d$

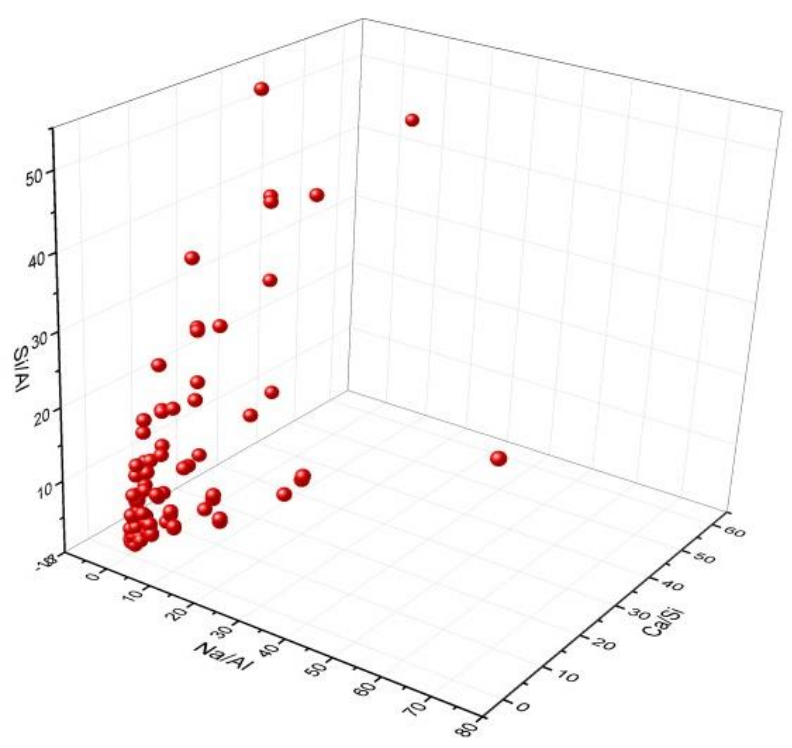

FA 30 SG 7028 d

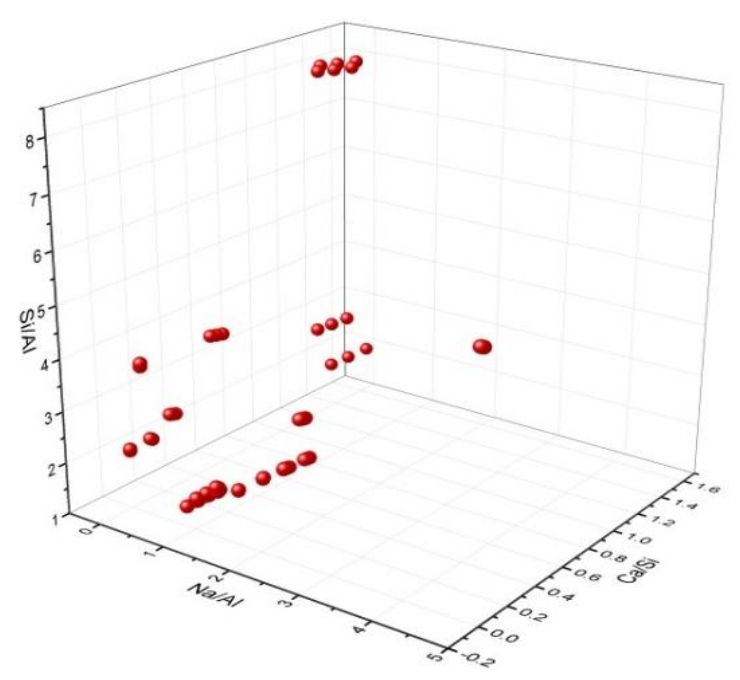


FA 15 SG 8528 d

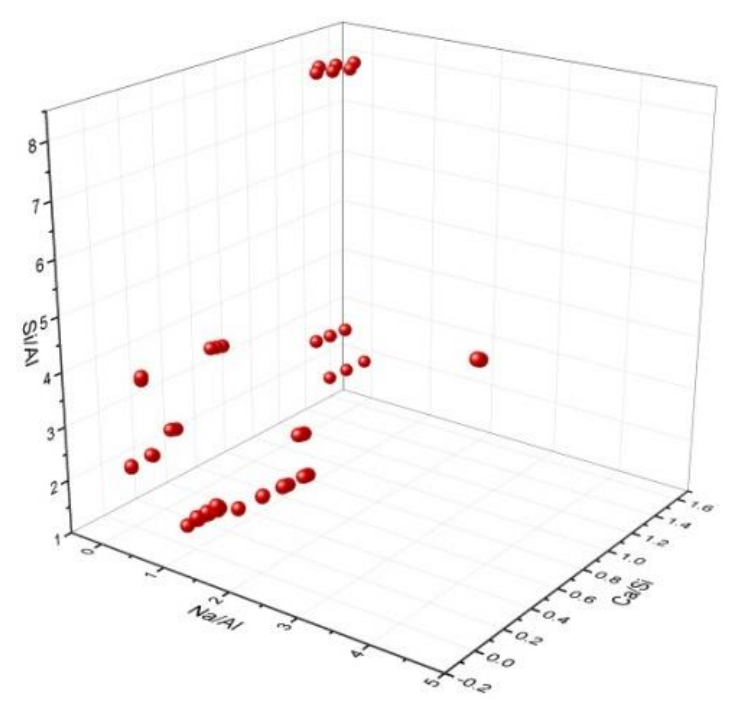

SG $10028 d$

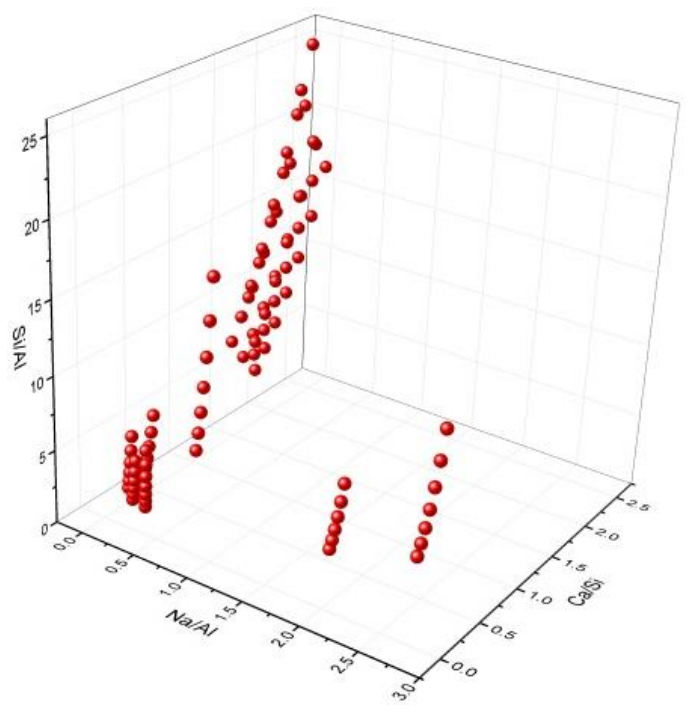


(b) $40^{\circ} \mathrm{C}$

\section{FA 85 SG $1528 d$}

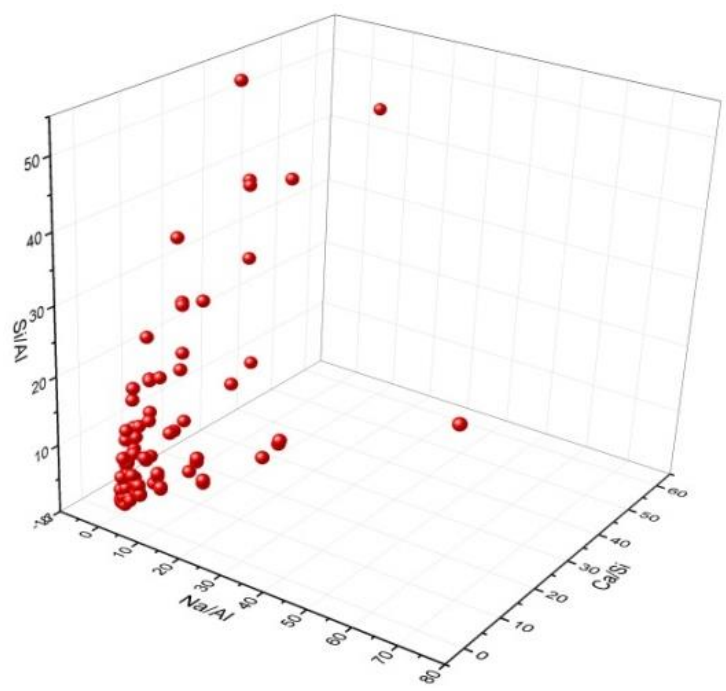

FA 30 SG 7028 d

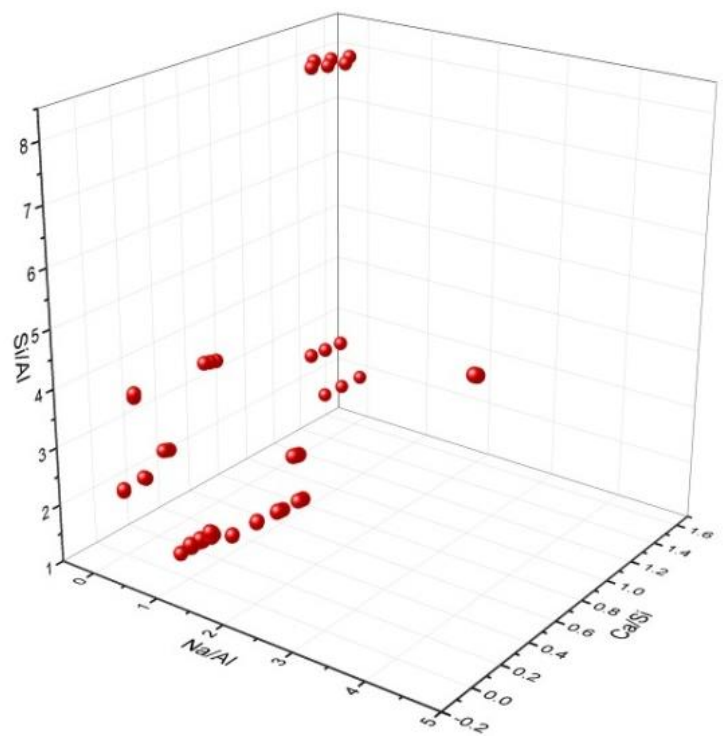

FA 70 SG 3028 d

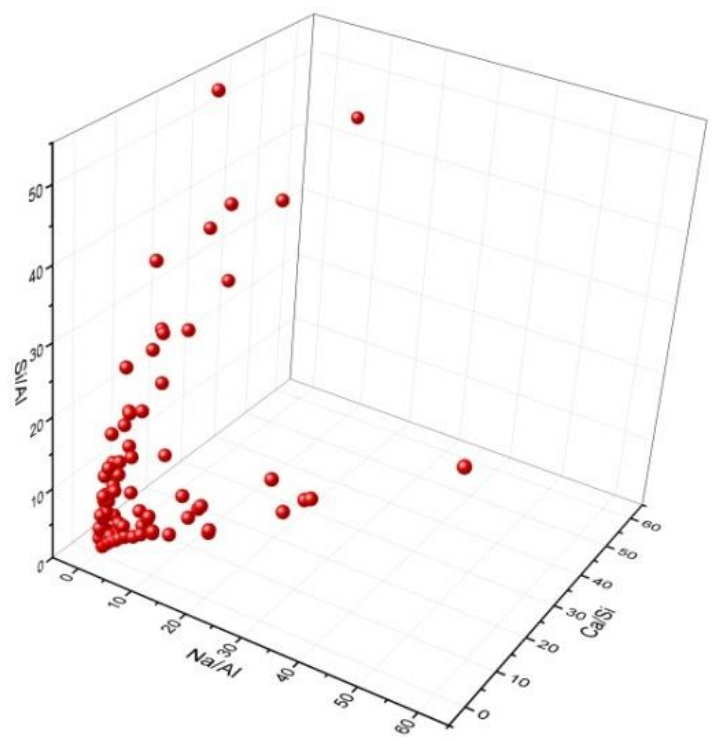

FA 15 SG $8528 d$

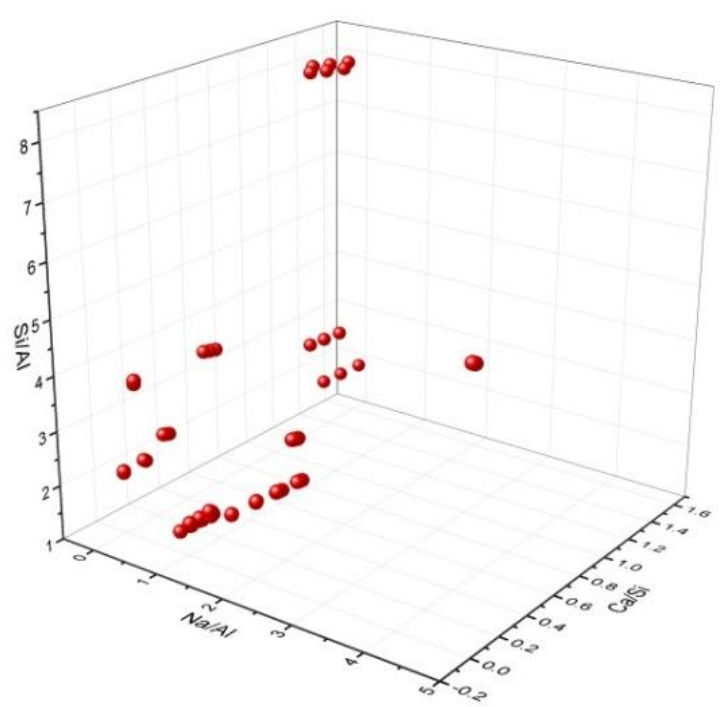


FA 50 SG 5028 d

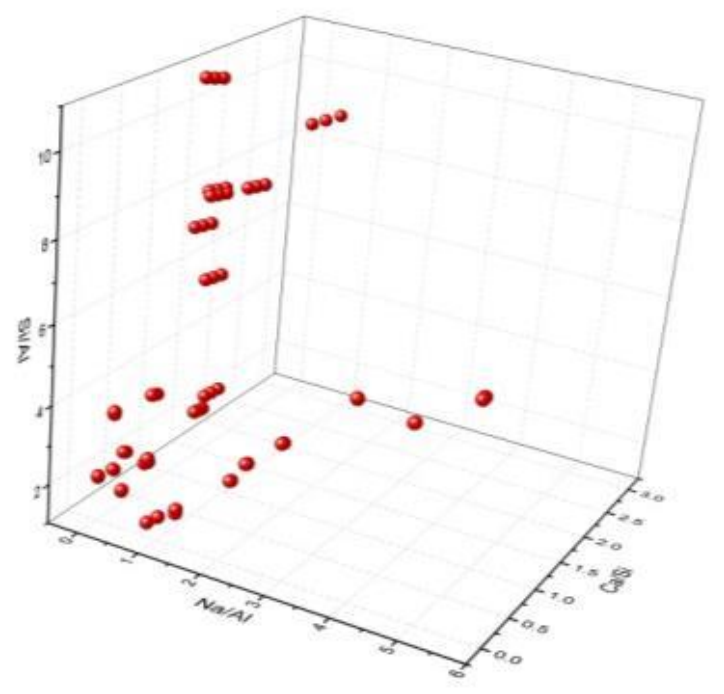

SG $10028 d$

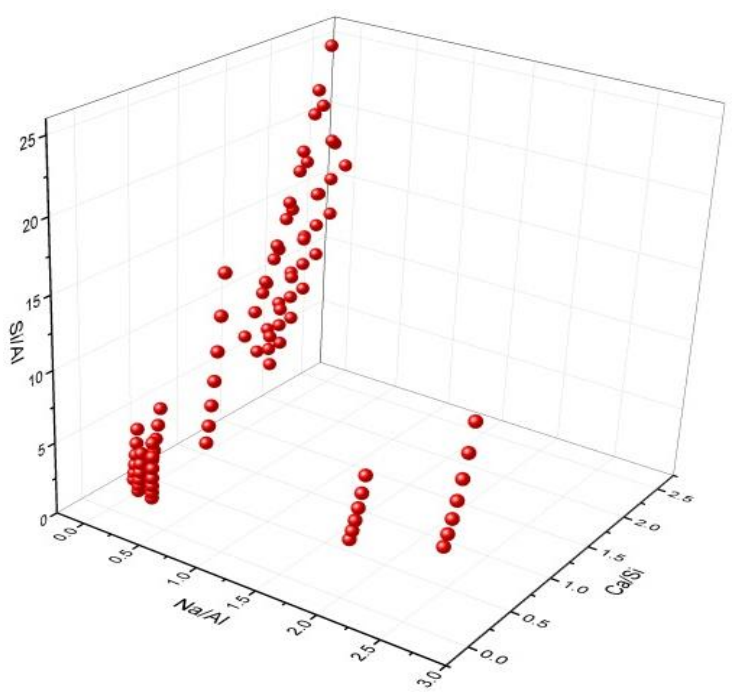


(c) $60^{\circ} \mathrm{C}$

FA 70 SG $3028 d$
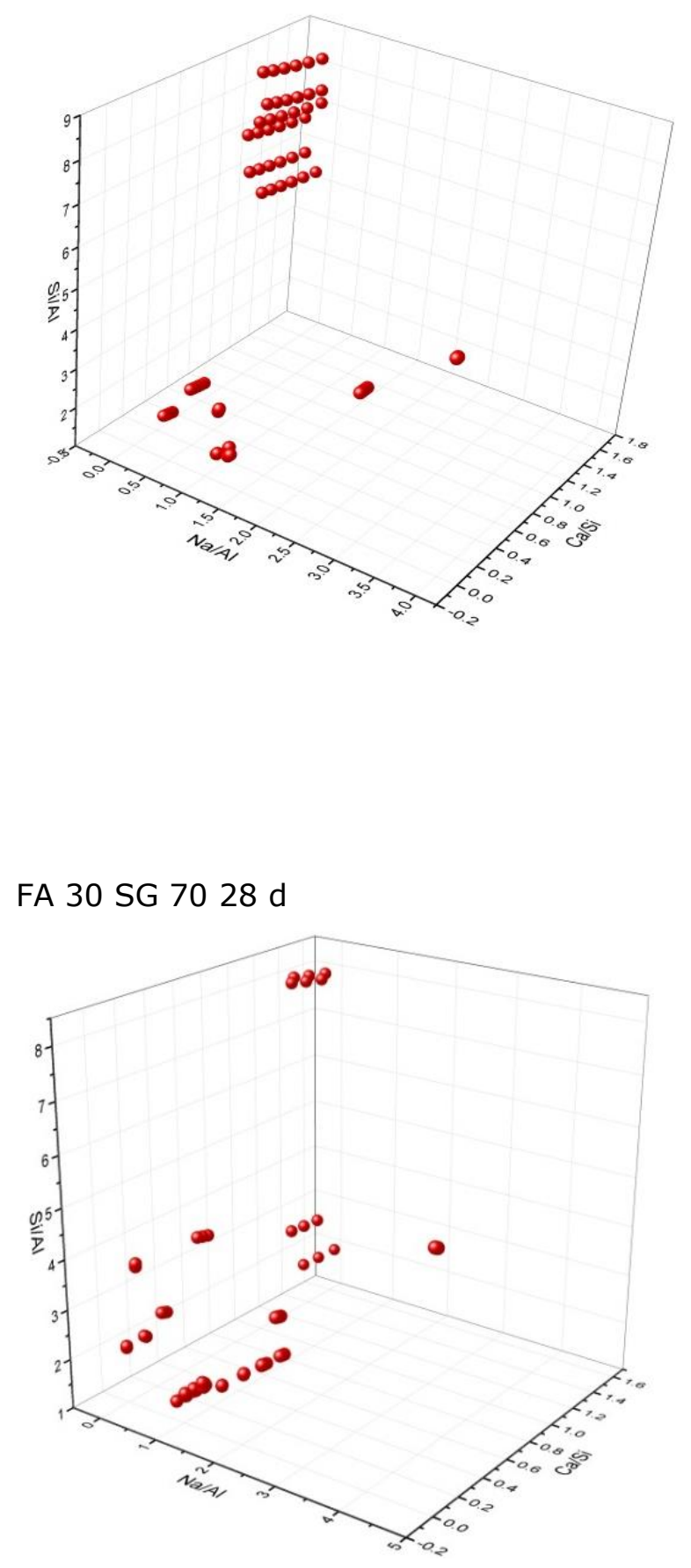

FA 70 SG $3028 d$

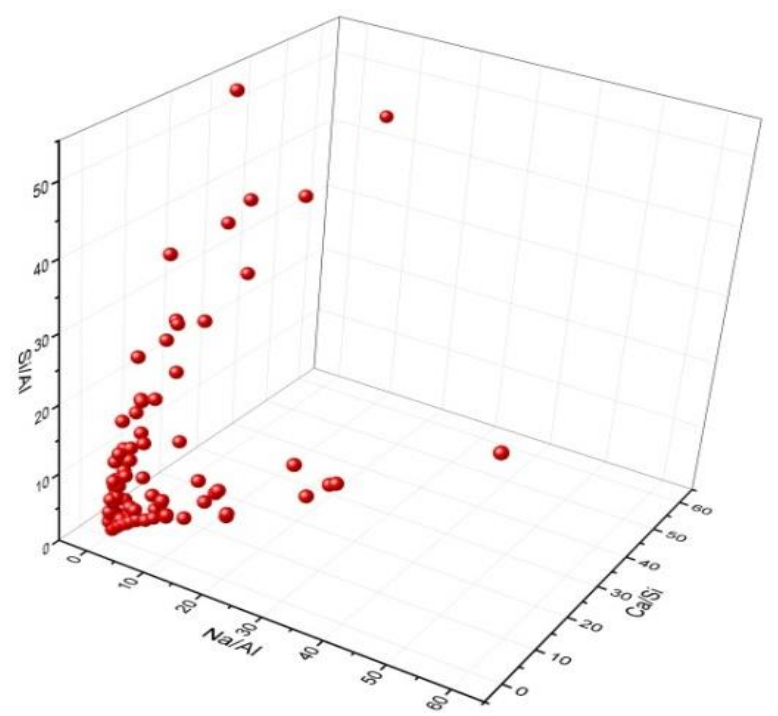

FA 15 SG $8528 d$

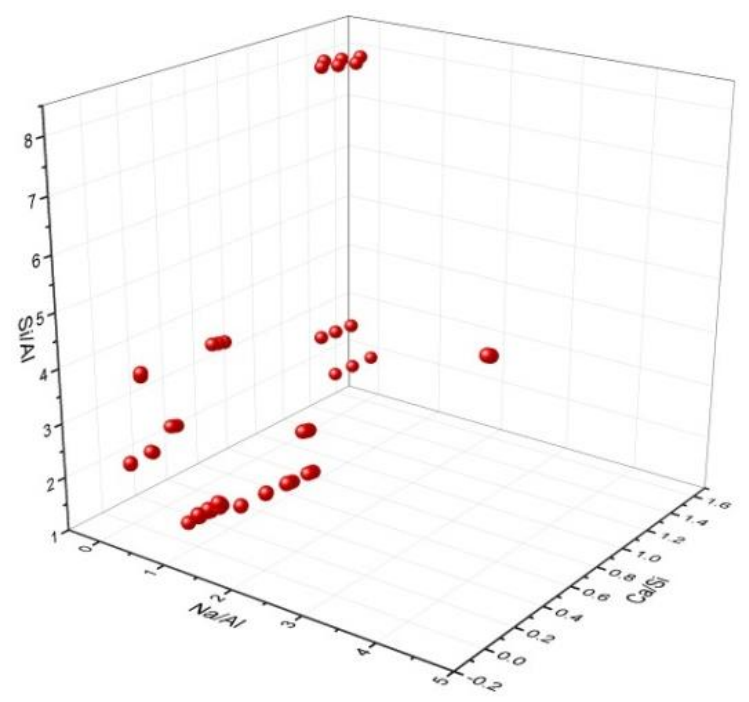


FA 50 SG 50 28d

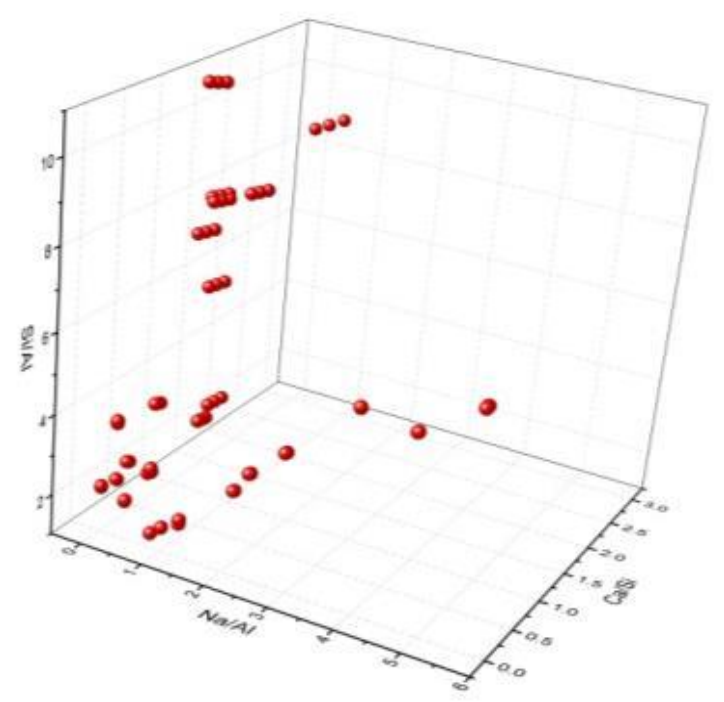

SG $10028 d$

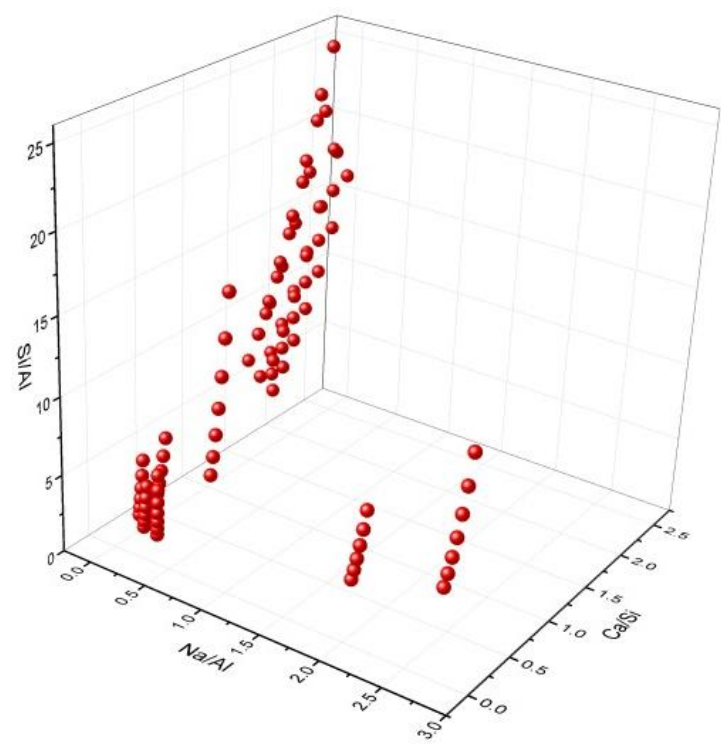




\section{A4. Isothermal Calorimetry Graphs}

\section{(a) $23^{\circ} \mathrm{C}$}

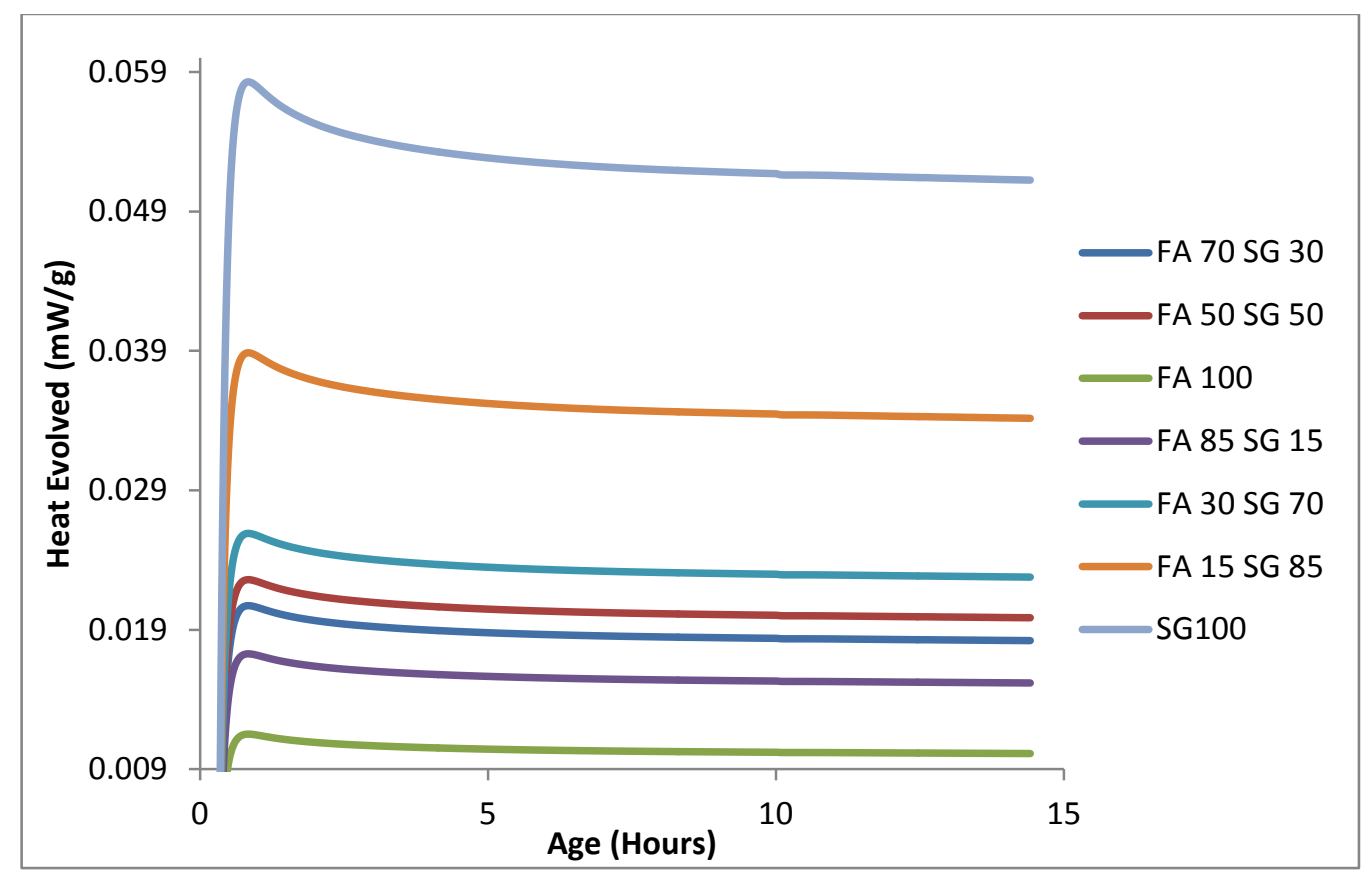

(b) $40^{\circ} \mathrm{C}$

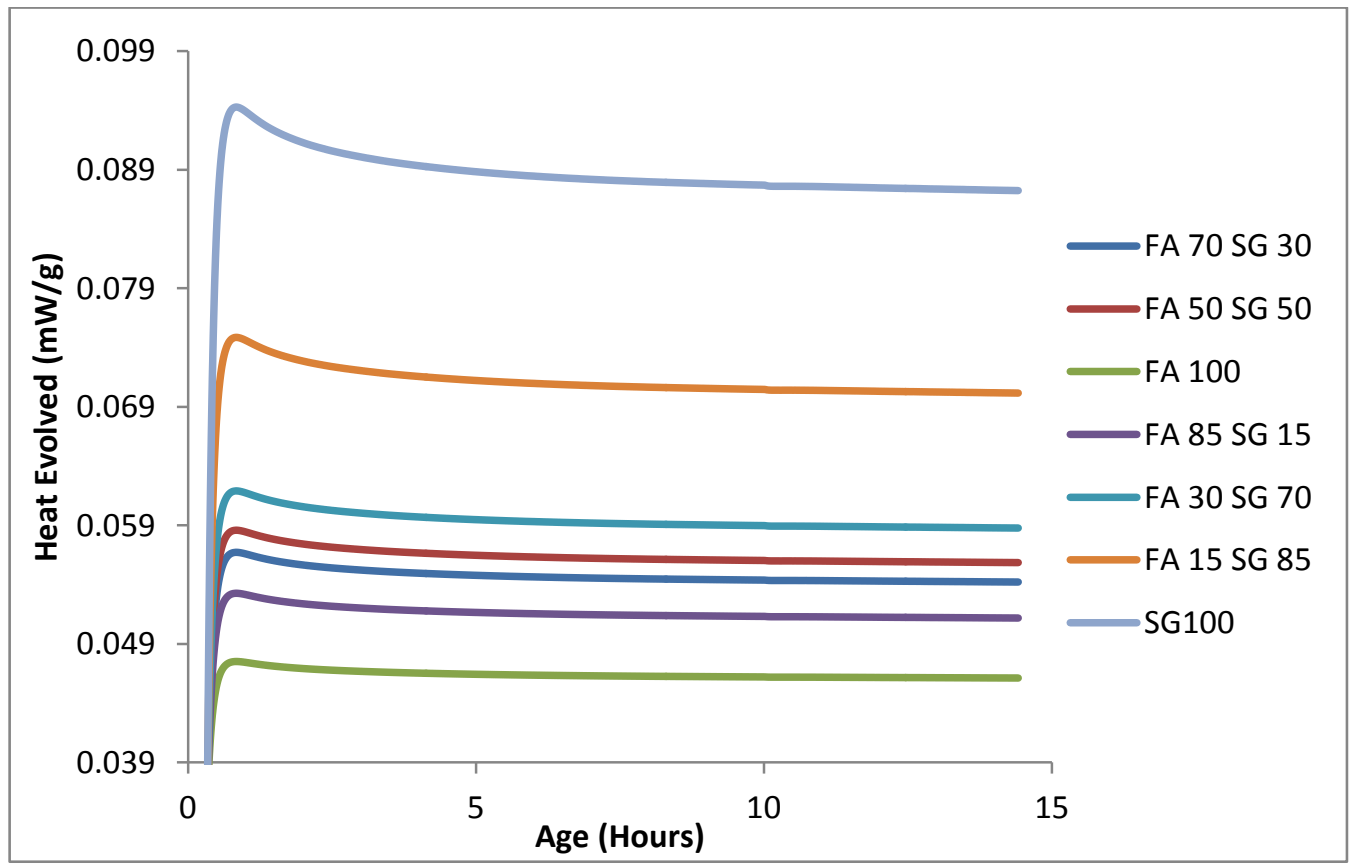


(c) $60^{\circ} \mathrm{C}$

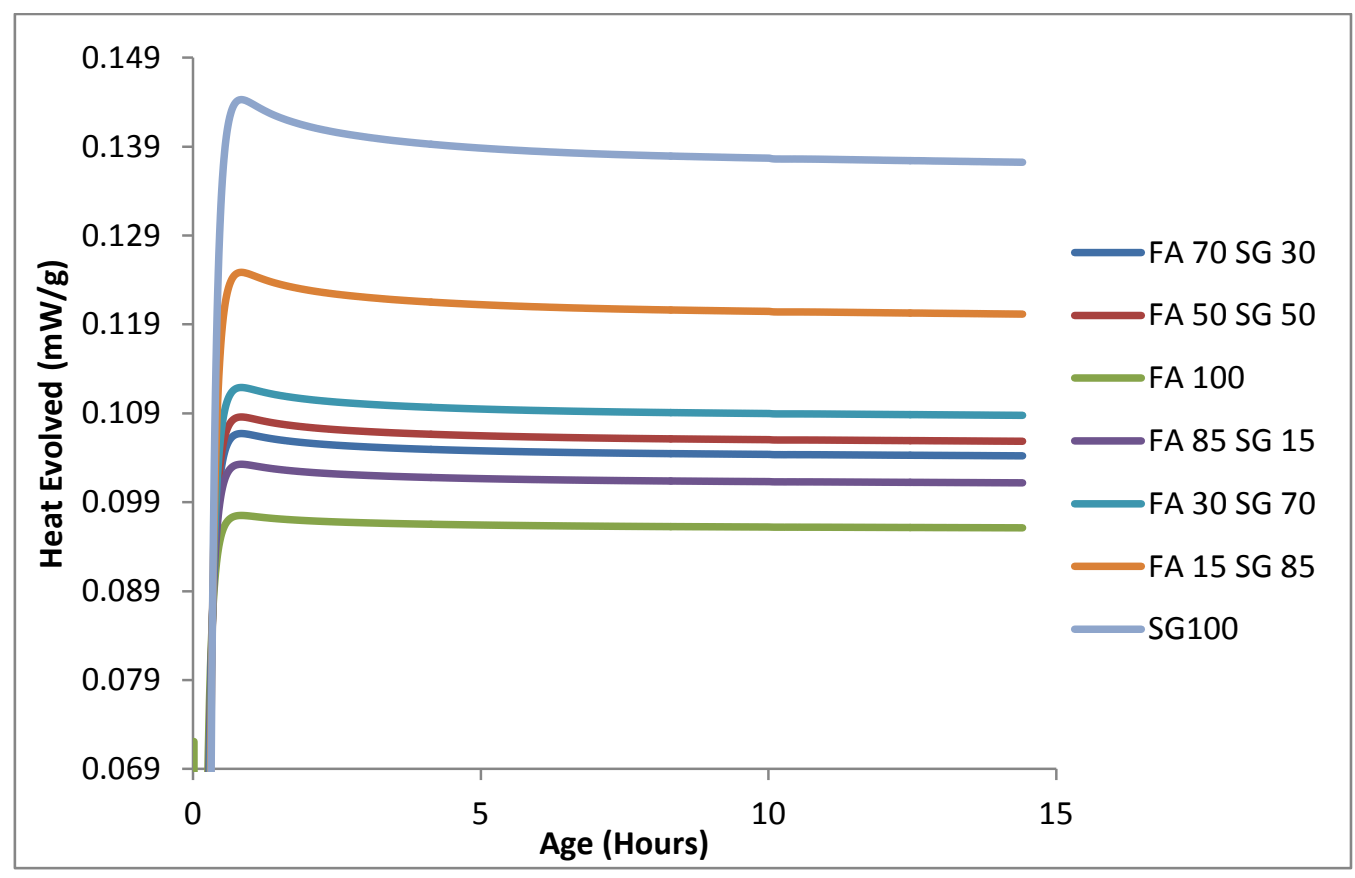




\section{A5. R-Codes}

\section{A5.1 Relation between $E_{c}$ and $v$}

(a) $23^{\circ} \mathrm{C}$

$<<>>=$

eupv<-read.csv("eupv23Irm.csv", header $=$ T)

attach(eupv)

head(eupv)

names(eupv)

eupv. Im $<-\operatorname{Im}($ e upvsq +0$)$

eupv. Imv $1<-\operatorname{Im}(\mathrm{e} \sim \mathrm{upv}+0)$

eupv.Imv $2<-\operatorname{Im}$ (e upv)

summary(eupv.Im)

summary(eupv.Imv1)

summary(eupv.Imv2)

@

(b) $60^{\circ} \mathrm{C}$

$<<>>=$

eupv<-read.csv("eupv60Irm.csv", header $=$ T)

attach(eupv)

head(eupv)

names(eupv)

eupv. Im $<-\operatorname{Im}($ e upvsq +0$)$

eupv. Imv $1<-\operatorname{Im}(\mathrm{e} \sim \mathrm{upv}+0)$

eupv.Imv $2<-\operatorname{Im}(\mathrm{e} \sim \mathrm{upv})$

summary(eupv.Im)

summary(eupv.Imv1)

summary(eupv.Imv2)

@

(c) All data

$<<>>=$

eupv<-read.csv("eupvalllrm.csv", header = T)

attach(eupv)

head(eupv)

names(eupv)

eupv. $\operatorname{Im}<-\operatorname{Im}($ e upvsq +0$)$

eupv.Imv $1<-\operatorname{Im}(\mathrm{e} \sim \mathrm{upv}+0)$

eupv. Imv $2<-\operatorname{Im}(\mathrm{e} \sim \mathrm{upv})$

summary(eupv.Im)

summary(eupv.Imv1)

summary(eupv.Imv2)

(a) 


\section{A5.2 Relation between $f_{c}{ }^{\prime}$ and $v$}

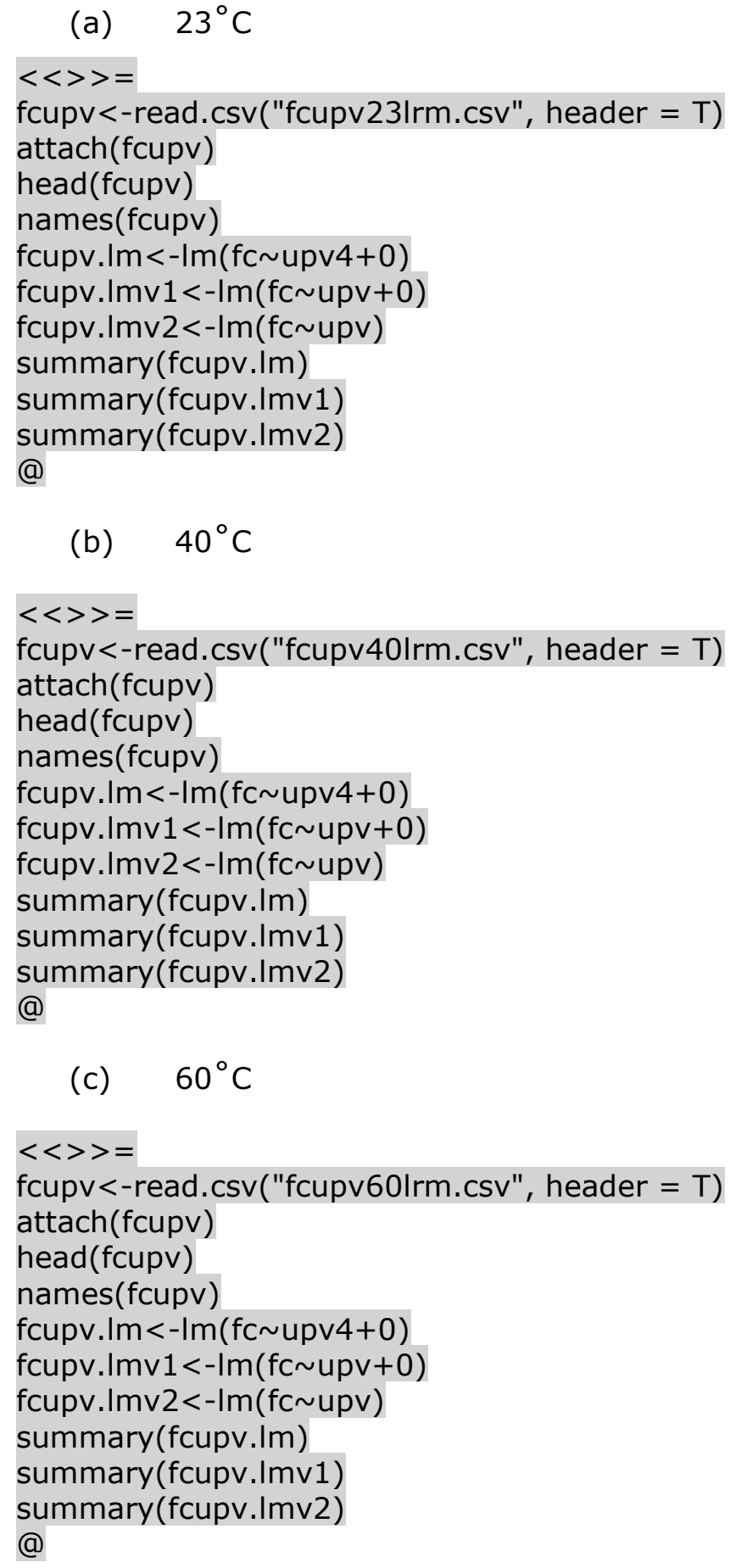




\section{A5.3 Correlation models between microscale and specimen level (with constant)}

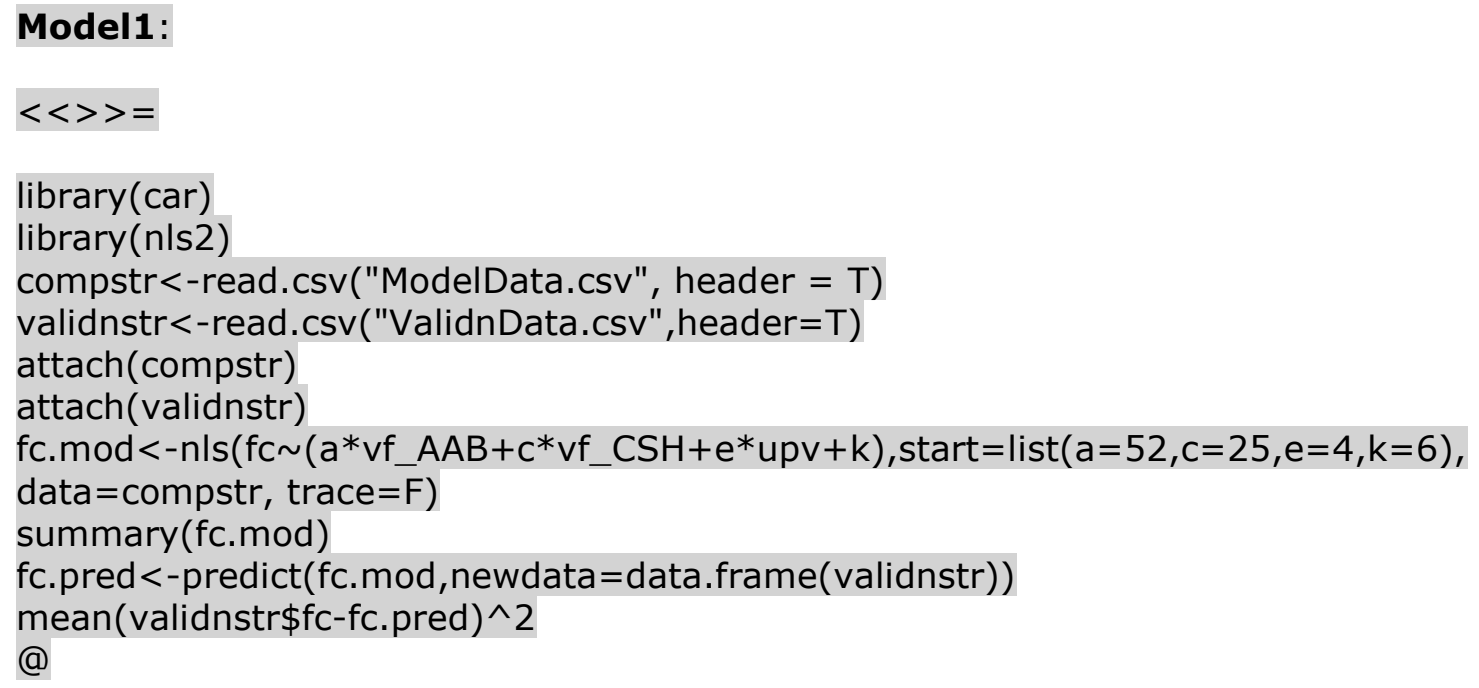

\section{Model 2:}

$<<>>=$

library(car)

library(nls2)

compstr<-read.csv("ModelData.csv", header = T)

validnstr<-read.csv("ValidnData.csv", header=T)

attach (compstr)

attach (validnstr)

fc. $\bmod <-n l s\left(f c \sim\left(a^{*} v f \_A A^{\wedge} 3+c^{*} v f \_C S H^{\wedge} 3+e^{*} u p v+k\right)\right.$, start=list $(a=50, c=25, e=7.1795$, $\mathrm{k}=5)$, data $=$ compstr, trace $=\mathrm{F})$

summary(fc.mod)

fc. pred <-predict(fc. mod, newdata=data.frame(validnstr))

mean(validnstr\$fc-fc.pred)^2

@

\section{Model3:}

$<<>=$

library(car)

library(nls2)

compstr<-read.csv("ModelData.csv", header $=\mathrm{T}$ )

validnstr<-read.csv("ValidnData.csv", header $=\mathrm{T}$ )

attach(compstr)

attach(validnstr)

$x<-u p v \wedge 4$

fc. $\bmod <-n l s\left(f c \sim\left(a * v f \_A A B+c * v f \_C S H+e^{*} x+k\right)\right.$, start $=\operatorname{list}(a=52, c=25, e=4, k=6)$,

data $=$ compstr, trace $=F)$

summary(fc.mod)

fc.pred <-predict(fc.mod, newdata=data.frame(validnstr))

mean(validnstr\$fc-fc.pred)^2

@ 


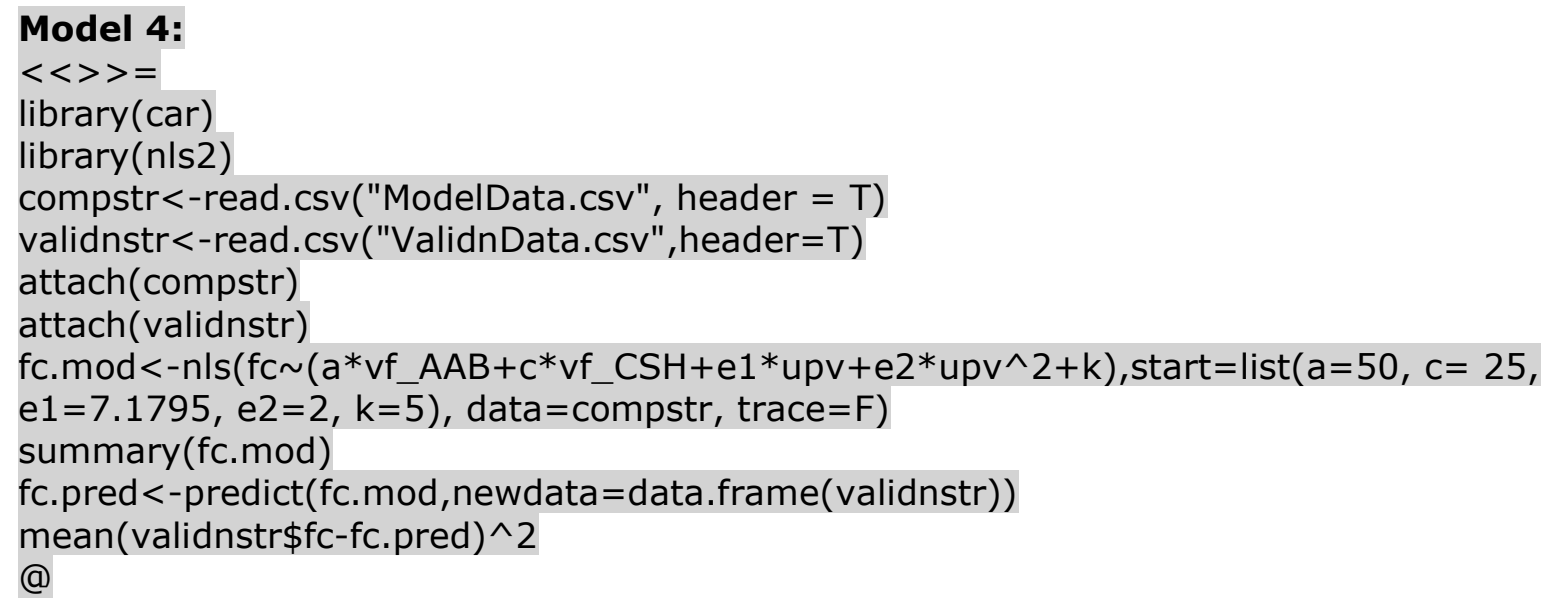

\section{Model 5:}

$<<>>=$

\section{Model 6:}

$<<>>=$

library(car)

library(nls2)

compstr<-read.csv("ModelData.csv", header = T)

attach(compstr)

$\operatorname{lnfc}<-\log (\mathrm{fc})$

Inv $1<$-ifelse (vf_AAB $\left.<=0,0, \log \left(v f \_A A B\right)\right)$

Inv $2<-$ ifelse(vf_CSH $\left.<=0,0, \log \left(v f \_C S H\right)\right)$

Inv $<-\log$ (upv)

fc. $\bmod <-n \mid s\left(\operatorname{Infc} \sim\left(a * \ln v 1+b * \ln v 2+e^{*} \ln v+k\right)\right.$, start=list $(a=2, b=3, e=2.5, k=5)$,

data $=$ compstr)

summary(fc.mod)

validnstr<-read.csv("ValidnData.csv", header=T)

attach(validnstr)

fc.pred<-predict(fc. mod, newdata=data.frame(validnstr))

mean(validnstr\$fc-fc.pred)^ 2

@ 


\section{Model 7:}

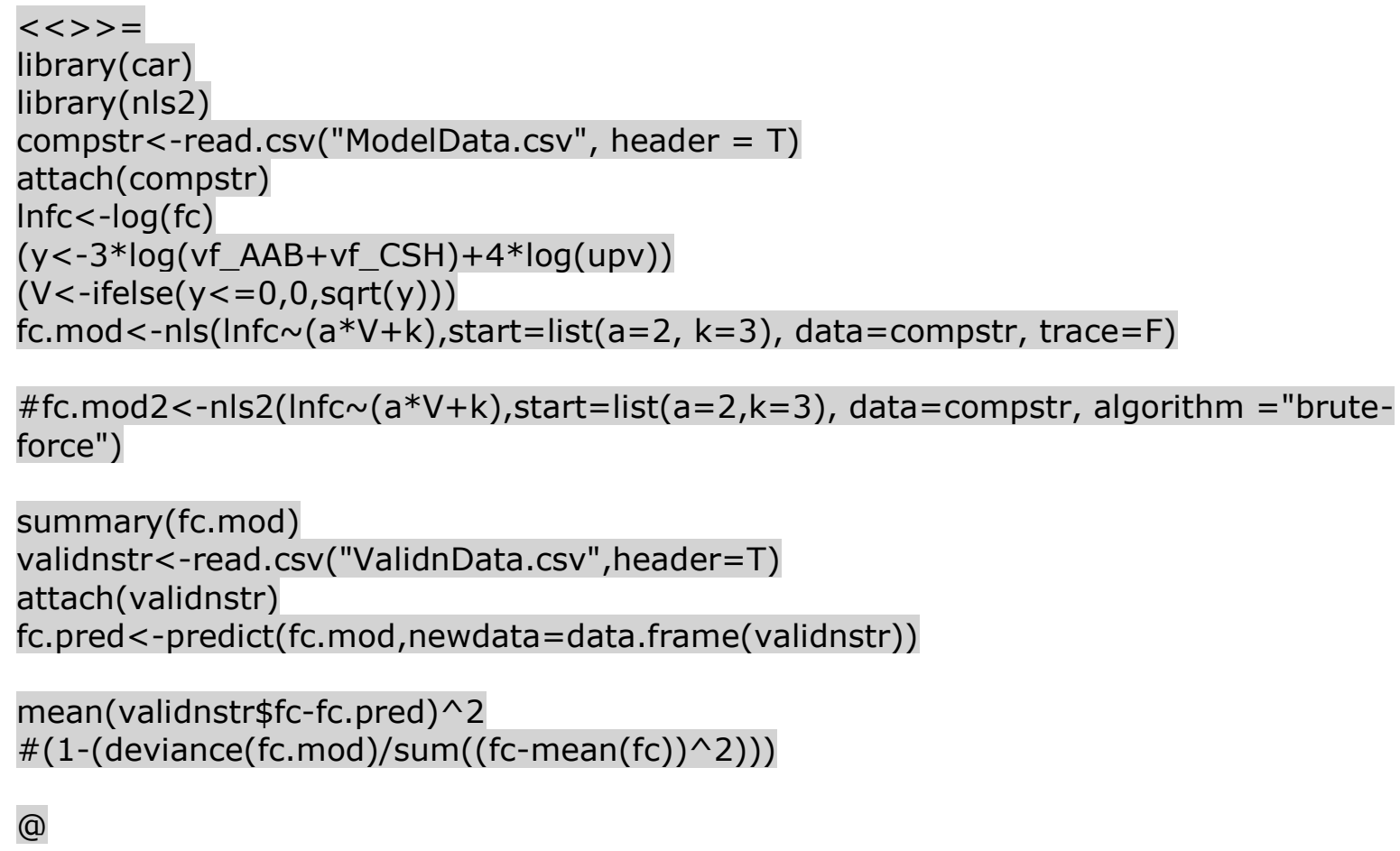




\section{A5.4 Correlation models between microscale and specimen level (without constant)}

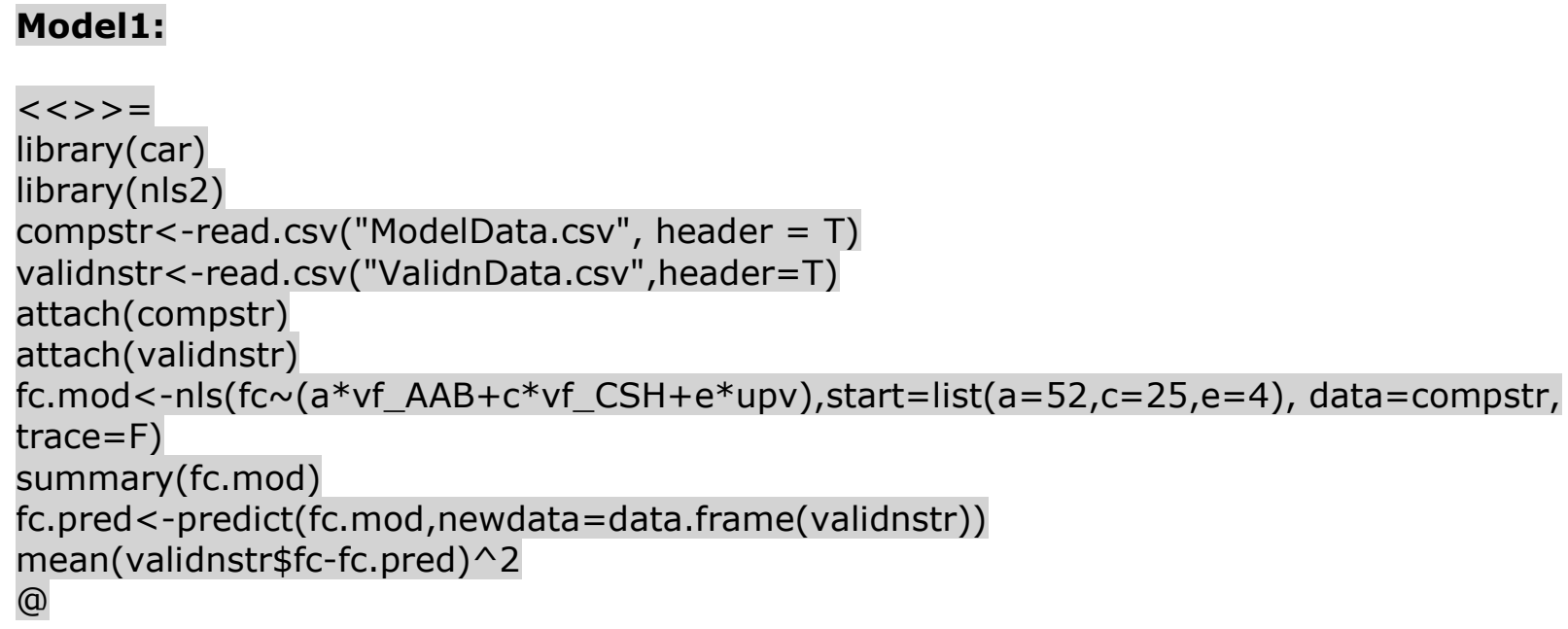

\section{Model 2:}

$<<>=$

library(car)

library(nls2)

compstr<-read.csv("ModelData.csv", header = T)

validnstr<-read.csv("ValidnData.csv", header=T)

attach(compstr)

attach(validnstr)

fc. $\bmod <-n l s\left(f c \sim\left(a * v f \_A A B \wedge 3+c^{*} v f \_C S H \wedge 3+e^{*} u p v\right)\right.$, start=list( $\left.a=50, c=25, e=7.1795\right)$, data $=$ compstr, trace $=F)$

summary(fc.mod)

fc. pred <-predict(fc. mod, newdata=data. frame(validnstr))

mean(validnstr\$fc-fc.pred)^2

(a)

\section{Model3:}

$<<>>=$

library(car)

library(nls2)

compstr<-read.csv("ModelData.csv", header $=\mathrm{T}$ )

validnstr<-read.csv("ValidnData.csv",header=T)

attach(compstr)

attach(validnstr)

$\mathrm{x}<-\mathrm{upv}^{\wedge} 4$

fc. $\bmod <-n l s\left(f c \sim\left(a * v f \_A A B+c^{*} v f \_C S H+e^{*} x\right)\right.$, start=list $(a=52, c=25, e=4)$, data $=$ compstr, trace $=F)$

summary(fc.mod)

fc.pred<-predict(fc.mod, newdata=data.frame(validnstr))

mean(validnstr\$fc-fc.pred)^2

@ 


\section{Model 4:}

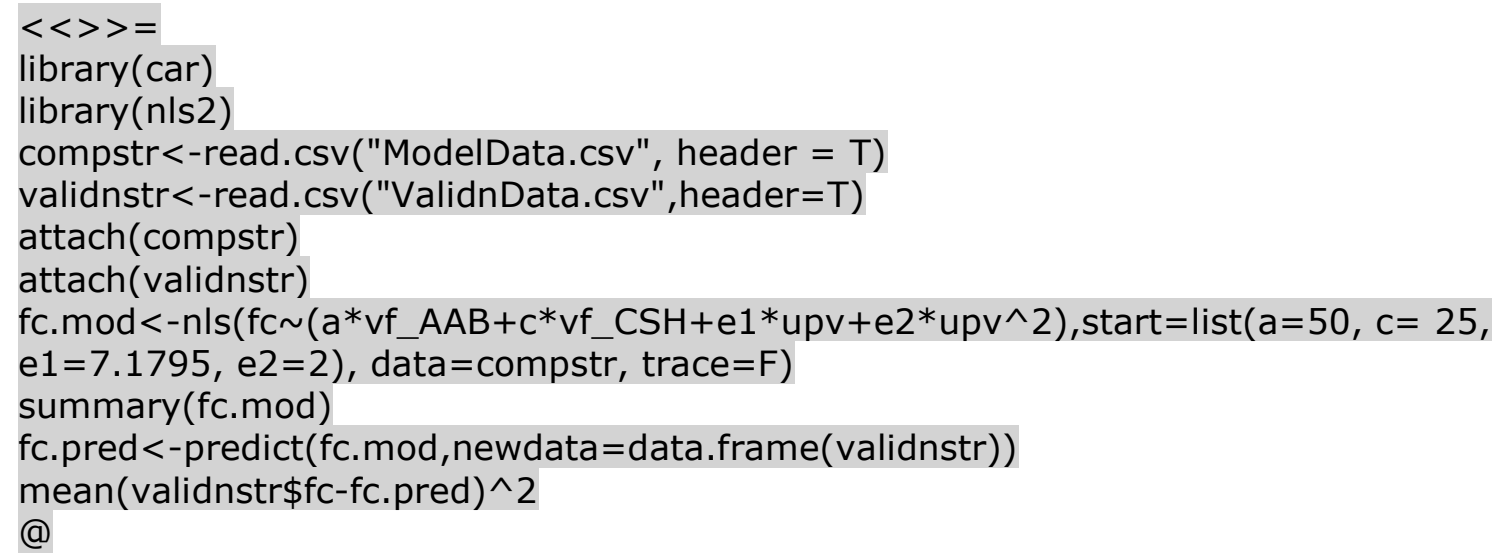

\section{Model 5:}

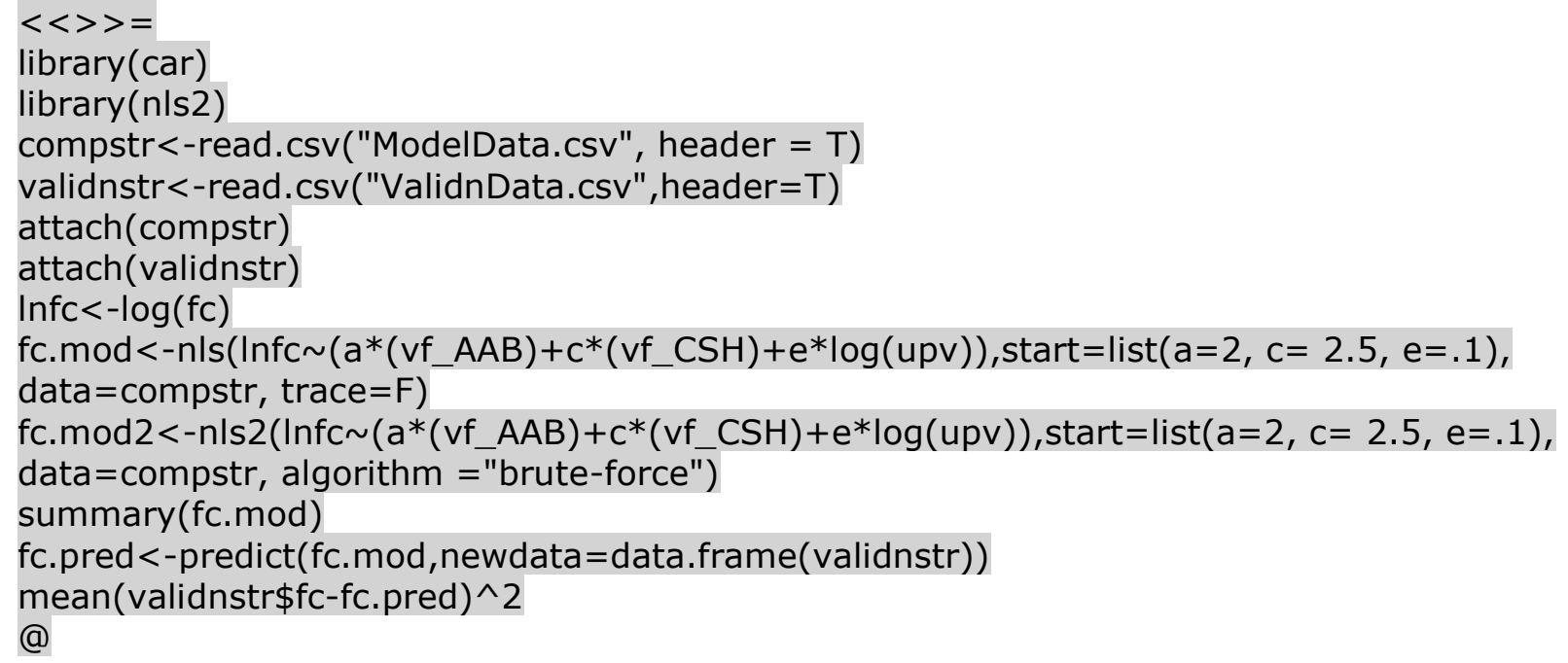

\section{Model 6:}

$<<>>=$ 


\section{Model 7:}

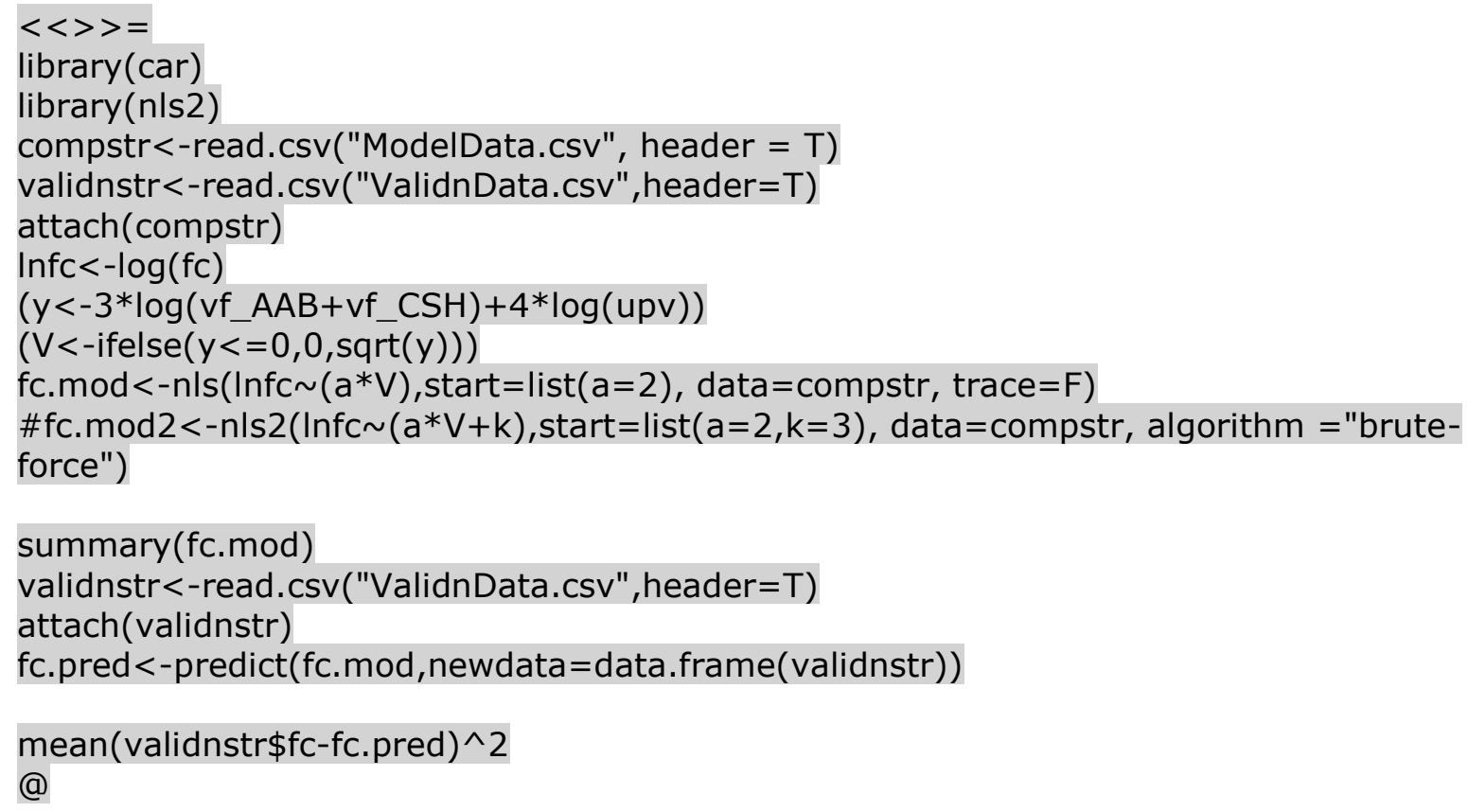

